\title{
Georg Stöger
}

\section{TRANSFORMATIONEN STÄDTISCHER UMWELT \\ Das Beispiel Linz, 1700 bis 1900}

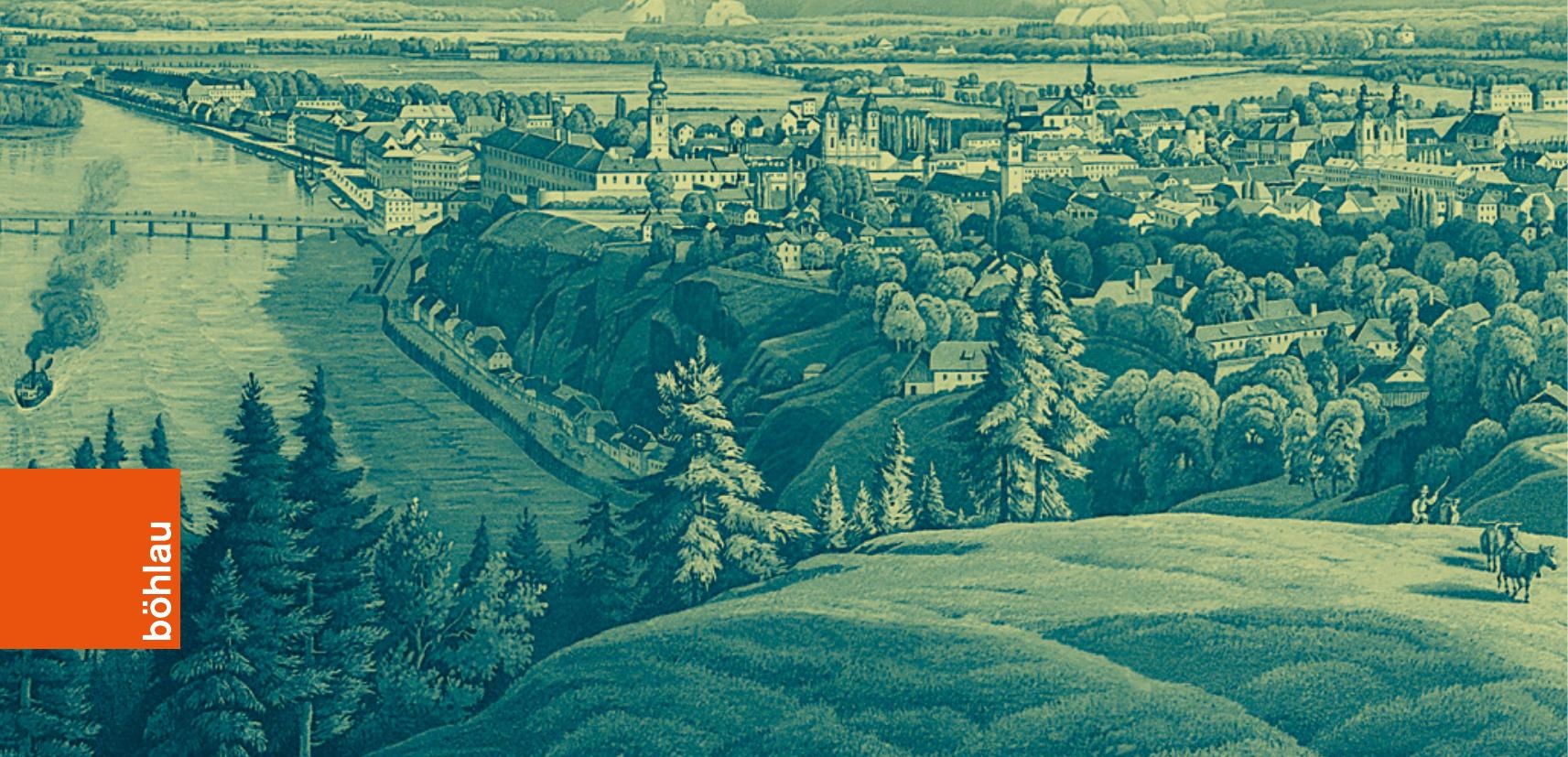


Publikation im Sinne der CC-Lizenz BY 4.0 
Publikation im Sinne der CC-Lizenz BY 4.0 
Georg Stöger

\section{Transformationen städtischer Umwelt}

Das Beispiel Linz, 1700 bis 1900

BÖHLAU VERLAG WIEN KÖLN WEIMAR 
Der Wissenschaftsfonds.

\section{Veröffentlicht mit der Unterstützung des Austrian Science Fund (FWF): PUB 728-G}

Open Access: Wo nicht anders festgehalten, ist diese Publikation lizenziert unter der Creative-CommonsLizenz Namensnennung 4.0; siehe http://creativecommons.org/licenses/by/4.o/

\section{(c)}

Die Publikation wurde einem anonymen, internationalen Peer-Review-Verfahren unterzogen

Bibliografische Information der Deutschen Nationalbibliothek:

Die Deutsche Nationalbibliothek verzeichnet diese Publikation in der Deutschen Nationalbibliografie; detaillierte bibliografische Daten sind im Internet über http://dnb.d-nb.de abrufbar.

Umschlagabbildung: Beda Weinmann, Panorama von Linz, um I 860 (Ausschnitt); Universitätsbibliothek Salzburg, Grafiksammlung G I I 7 IV.

(C) 202 I by Böhlau Verlag GmbH \& Co. KG, Wien Köln Weimar

Zeltgasse I, A-ro8o Wien, www.boehlau-verlag.com

Korrektorat: Anja Borkam, Jena

Satz: Michael Rauscher, Wien

Einbandgestaltung: Michael Haderer, Wien

Druck und Bindung: Prime Rate, Budapest

Gedruckt auf chlor- und säurefreiem Papier

Printed in the EU

Vandenhoeck \& Ruprecht Verlage | www.vandenhoeck-ruprecht-verlage.com

ISBN $978-3-205^{-2}$ I $233^{-I}$ 


\section{Inhalt}

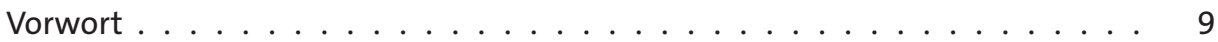

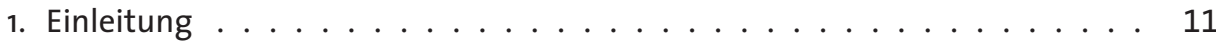

Zugänge: Stadt, Umwelt und Alltag . . . . . . . . . . . . . . . . . . . 17

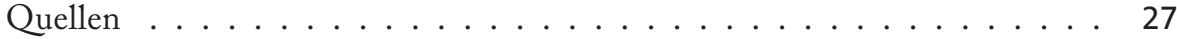

2. Kontexte: Linz 1700 bis $1900 \ldots \ldots$. . . . . . . . . . . . . . . 36

Naturräume ............................ 36

Wetter und Klima . . . . . . . . . . . . . . . . . . . . . . . . . . . . . . . . . . . . . 43

Grenzen der Stadt . . . . . . . . . . . . . . . . . . . 47

Regierende und Regierte . . . . . . . . . . . . . . . . . 50

Ausweitungen des Urbanen . . . . . . . . . . . . . . . . . . . . . . 68

3. Wasser .............................. 75

Praxis und Logik dezentraler Wasserversorgung . . . . . . . . . . . . . . . . . . 75

Differenzierungen von Wasser . . . . . . . . . . . . . . . 83

Kontinuität, Adaption und neue Bedürfnisse . . . . . . . . . . . . . . . . . 87

Netzwerklösung . . . . . . . . . . . . . . . . . . . . . . 94

4. Energie und Biomasse . . . . . . . . . . . . . . . . . 109

Omnipräsenz des Brennholzes . . . . . . . . . . . . . . . . . . . 109

Die langsame Transition zur fossilen Energie . . . . . . . . . . . . . . . 118

Pferde und Wasser: Erneuerbare Antriebsenergie . . . . . . . . . . . . . 123

Lebensmittel: Lokaler Bedarf und lokale Versorgung . . . . . . . . . . . . . 127

Dritter bis sechster »Kreis«: Lebensmittel aus dem Um- und Hinterland . . 137

Modifikationen der Lebensmittelversorgung . . . . . . . . . . . . . . . . . . 141

5. Zirkulationen und Output . . . . . . . . . . . . . . . . . . . . 145

Recycling-Mentalität und Praxis . . . . . . . . . . . . . . . . . . . . 145

Sekundäre Märkte in der Moderne . . . . . . . . . . . . . . . . . . . . . . 154

Abwasser und Fäkalien: Alltägliche Outputs . . . . . . . . . . . . . . . . . . . 160

Von der Senkgrube zur Kanalisation . . . . . . . . . . . . . . . . . . 167

Abfall und Emissionen: Moderne Probleme? . . . . . . . . . . . . . . . . . 181 
6. Fluviale und aquatische Räume . . . . . . . . . . . . . . . . . . 185

Stadt und Fluss . . . . . . . . . . . . . . . . . . . . 185

Von der fragilen zur stabilen Brücke . . . . . . . . . . . . . . . . . 192

Donau-Umbau . . . . . . . . . . . . . . . . . 196

Das Verschwinden der urbanen Gewässer . . . . . . . . . . . . . . . . 202

7. Geordnete und modifizierte Umwelt . . . . . . . . . . . . . . . . 205

Unsaubere und saubere Vormoderne . . . . . . . . . . . . . . . . . 205

Intermediäre Sauberkeit . . . . . . . . . . . . . . . . . . 210

U-Topie Garten und Park . . . . . . . . . . . . . . . . . . . . 216

Beleuchtung: Urbane Emanzipation von der Natur . . . . . . . . . . . . 226

8. Natur der Städter - Natur für Städter . . . . . . . . . . . . . . . . . 232

Irrationale und rationale Natur, untersuchte und gesammelte Natur . . . . . 232

Naturraum Um- und Hinterland . . . . . . . . . . . . . . . . . . . . . . . . 242

Verschönerung durch Natur . . . . . . . . . . . . . . . . . . . . 248

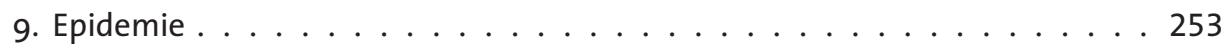

Die letzte Pest . . . . . . . . . . . . . . . . . . . 253

Epidemien und medizinische Infrastruktur: Konnex und Koevolution . . . . 257

Ferne und nahe Cholera . . . . . . . . . . . . . . . 263

10. Versorgungskrise . . . . . . . . . . . . . . . . . . . 274

Rekurrente Krisen type ancien . . . . . . . . . . . . . . . . . . . . 274

Das langsame Auslaufen der Versorgungskrisen . . . . . . . . . . . . . . . . 281

11. Naturgefahr . . . . . . . . . . . . . . . . . . . . . . . . . 290

Hochwasser zwischen Alltag und Extremereignis . . . . . . . . . . . . . . . 290

Absenz und Rückkehr des Hochwassers . . . . . . . . . . . . . . . . . . . . 298

Feuer als kollektives Risiko . . . . . . . . . . . . . . . . . . . . 304

Feuer als städtisch-bürgerliche Aufgabe . . . . . . . . . . . . . . 316

12. Logiken und Akteure des Existenten und des Wandels . . . . . . . . . . . . . 324

Literatur- und Quellenverzeichnis . . . . . . . . . . . . . . . . . . 332

Archivalien und ungedruckte Quellen . . . . . . . . . . . . . . . . 332

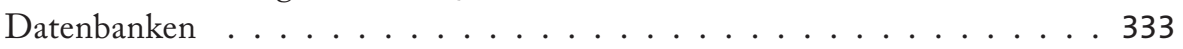

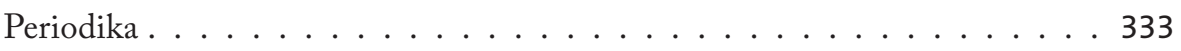

Gedruckte Quellen und Literatur . . . . . . . . . . . . . . . . 334 


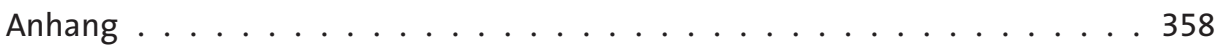

Verzeichnis der Tabellen und Grafiken . . . . . . . . . . . . . . 358

Abbildungsnachweis . . . . . . . . . . . . . . . . 359

Währungen und Maßeinheiten . . . . . . . . . . . . . . . . . . . 360

Hinweise zu den kartographischen Darstellungen . . . . . . . . . . . . . 362

Abkürzungen . . . . . . . . . . . . . . . . . . 364 
Publikation im Sinne der CC-Lizenz BY 4.0 


\section{Vorwort}

„Cesta poznáni je trnitá, jak zrno od plev oddělím?«"

Zuerst hat es nach einer eher kompakten Case Study zu einer überschaubaren Setting ausgesehen - wenn ich meinen Erinnerungen und Aufzeichnungen trauen kann, dann habe ich mit der Arbeit an diesem Thema im Frühjahr 2o I l begonnen. In dieser frühen Phase ermöglichte ein über ein Erwin-Schrödinger-Stipendium des Fonds zur Förderung der wissenschaftlichen Forschung (FWF) finanzierter Aufenthalt am Centre for Urban History der University of Leicester (absolviert im akademischen Jahr 20I2/20I3) ein intensiveres Literaturstudium und grundlegende Überlegungen, wofür ich dem FWF, Roey Sweet und Simon Gunn Dank schulde. Danach folgten mehrere Phasen der empirischen Arbeit und eine konzeptionelle Neuorientierung, die zwischen 20I4 und 20I7 durch Luisa Pichler-Baumgartner und ihre Dissertation zur Linzer Wasserinfrastruktur begleitet wurden. Luisa danke ich für reale und mentale Unterstützung, Ermahnungen und Anmerkungen zum Text.

Meine Anstellung am Fachbereich Geschichte der Universität Salzburg hat die Arbeit an diesem Projekt den nötigen Freiraum gegeben, unter den Auspizien einer gnadenlosen Deadline wurde der Text im Oktober 20 I 9 als Habilitationsschrift eingereicht und für die Drucklegung geringfügig überarbeitet. Der Gutachterin und den Gutachtern des Habilitationsverfahrens danke ich für die kritische Durchsicht und das ausführliche Feedback. Zahlreiche Anregungen und eine deutliche Reduktion von inhaltlichen und orthographischen Fehlern kamen von Martin Knoll, Norbert Ortmayr, Fredi Weiß, Fritz Mayrhofer, Severin Hohensinner und dem Kollektiv der Familie Stöger. Erich Lang hat mir die Daten zu Linz aus seiner demographischen Datenbank zur Verfügung gestellt, lektoriert hat Kordula Oberhauser - allen ganz herzlichen Dank: Solamen miseris socios habuisse malorum.

Meine Damen - Viktoria, Fanny, Elisa und Nelly - haben meine Texte und Überlegungen zwar nur selten konsumiert oder kommentiert, aber stets aus der Ferne kuratiert und goutiert. Tausend Dank: We ... hm ... you rock!

Dafür, dass ich nun gerade an diesem Thema gearbeitet habe und dass ich überhaupt ein second book schreiben konnte, ist Reinhold Reith verantwortlich. Ich danke ihm dafür herzlich, auch für die anderen gemeinsamen Projekte und Texte, kurz: für seine ungezählten Inputs. In Abwandlung zweier Polt'scher Dikta möchte ich dazu anmerken: Kollegialität ist die Relation von Wertschätzung, Gemütlichkeit und von Nicht-nurgerüchteweisem-Bescheidwissen.

I Štorm, Occultist, unpag. 
Publikation im Sinne der CC-Lizenz BY 4.0 


\section{Einleitung}

In der historischen Betrachtung europäischer Städte wird vielfach die zweite Hälfte des I 9. Jahrhunderts als eine Zäsur interpretiert: Industrialisierung und Urbanisierung führten zu unterschiedlichen sozialen wie auch infrastrukturellen Problemen, die bis ins beginnende 20. Jahrhundert weitgehend beseitigt wurden. Viele Umwelthistoriker/ innen, die sich seit den letzten drei Jahrzehnten auch städtischer Themen angenommen haben, teilen diese Annahme eines wesentlichen Umbruchs in den Jahrzehnten nach I 850 : In dieser Phase hätten sich »alte« Umweltprobleme intensiviert und zu neuen Formen von Verschmutzung und urbanen Transformationen geführt. Die Antworten auf diese Entwicklung seien vielerorts ähnlich gewesen und hätten in intensiven öffentlichen Bemühungen resultiert, neue institutionelle und technische Lösungen dieser Probleme zu schaffen, die zeitgenössisch als »Assanierung « (resp. »sanitation«) bezeichnet worden seien. ${ }^{1}$

Selten sind diese Transformationsprozesse in einer längerfristigen Perspektive betrachtet worden und kaum sind Fragen nach der Vorgeschichte, nach Wandel und Persistenz gestellt worden: Waren die Beziehungen zwischen den Stadtbewohnern/innen und ihrer Umwelt tatsächlich unberührt von der Vielzahl der Veränderungen, die rezente umwelthistorische Studien für die Frühe Neuzeit aufgezeigt haben? Hatte beispielsweise - die Ausdifferenzierung der vormodernen Verwaltungsstrukturen keine Auswirkungen auf die Art, wie die städtischen Administrationen mit der Umwelt umgingen? Welche »vormodernen « Lösungen und Arrangements waren noch in der sich "modernisierenden« Stadt anzutreffen? Nur in Einzelfällen sind Wechselwirkungen zwischen den einzelnen Bereichen städtischer Umwelt und deren Kausalitäten systematisch in den Blick genommen worden. Bestanden beispielsweise Zusammenhänge zwischen der Etablierung einer zentralisierten Wasserversorgung und gesundheitlichen Krisen, wie hingen städtische Grünräume und geänderte Naturwahrnehmungen zusammen, wie Energie und Landnutzung?

Im Hinblick auf diese umwelthistorischen Bereiche weiß man bislang wenig über mittlere und kleinere Städte, was erstaunlich ist, da diese eine spezifische Bedeutung für den Urbanisierungsprozess in Westeuropa besaßen. ${ }^{2}$ Divergierten Problemlagen und Lösungen mittlerer und kleinerer Städte von denen größerer Städte oder überwogen die Gemeinsamkeiten?

Die vorliegende Untersuchung betrachtet unterschiedliche Bereiche von urbaner Umwelt, verfolgt diese über den Zeitraum von I700 bis I 900 und bewegt sich damit

I Uekötter, Umweltgeschichte, r4f.; vgl. Lees/Lees, Cities, 283 und mit einem Blick auf größere Städte: Lenger, Metropolen, $27 \mathrm{f}$.

2 Clark, Cities, $226 f$. 
bewusst über die in der Forschung etablierten Zäsuren hinweg; als Fallbeispiel dafür fungiert die österreichische Mittelstadt Linz. Dieser Zeitraum ermöglicht es, Muster und Bedingungen von Kontinuität und Veränderung städtischer Umwelt während einer Übergangsphase zu rekonstruieren, die in neueren Arbeiten zwischen I750 und 1900 gesehen wird. ${ }^{3}$ Empirische Studien für diesen Periode haben gezeigt, dass - wenngleich das urbane Leben partiell noch durch einen vormodernen Pfad bestimmt war - signifikante Veränderungen stattfanden: Die expandierenden Städte wurden zunehmend durch das Bürgertum geprägt, das traditionelle System der urbanen Selbstverwaltung verlor an Bedeutung, während die staatliche Bürokratie auch auf städtischer Ebene expandierte und die Verwaltung professionalisierte. Die Aufklärung, wissenschaftliche Diskurse (vor allem Fragen der Medizin und Hygiene betreffend) und Verwaltungsreformen scheinen viele Aspekte der Stadtpolitik tangiert und die Wahrnehmung von Umweltproblemen und Natur beeinflusst zu haben. ${ }^{4}$ Insbesondere während der zweiten Hälfte des I 9. Jahrhunderts veränderte sich städtische Umwelt in einem sehr starken Maße: Flüsse wurden reguliert und öffentliche Parks etabliert, die Industrialisierung brachte neue Produktions- und Konsumptionsformen - und neue Umweltbelastungen - mit sich. Die Transportrevolution vereinfachte überregionale Transfers von Gütern und Personen, und die Errichtung neuer Ver- und Entsorgungssysteme führte zu einer Transformation und Substitution traditioneller Kreisläufe und Materialflüsse. Im Hinblick auf »natürliche Umwelten « ${ }^{5}$ bildeten die Jahre zwischen I700 und I900 die späte Phase einer Periode mit kälterem Klima, die als »Kleine Eiszeit« beschrieben worden ist. In Zentraleuropa folgten auf eine eher milde Phase zu Beginn des i 8. Jahrhunderts kältere Jahre zwischen I 730 und I 8 Io. Für die Landwirtschaft nachteilige klimatische Bedingungen führten zu Beginn der I 77oer Jahre zu einer gravierenden Subsistenzkrise in vielen Teilen Westeuropas. I8I6 kam es infolge eines Vulkanausbruchs in Indonesien - zu einem Jahr »ohne Sommer«. Die zweite Hälfte des I 9. Jahrhunderts ist - obgleich noch von Ausläufern der »Kleinen Eiszeit« beeinflusst - als Übergangsphase zum »warmen« 20. Jahrhundert interpretiert worden. ${ }^{6}$ Die epidemische Situation veränderte sich erheblich: Seit dem Beginn des I 8. Jahrhunderts verschwanden zunehmend ältere Epidemien (vor allem die Pest) und wurden durch neuere wie Pocken, Typhus, Tuberkulose und Cholera abgelöst - die Mortalität in den Städten blieb hoch. ${ }^{7}$

\footnotetext{
3 Vgl. Knoll, Luft.

4 Vgl. Clark, Cities; Moore/Rodger, Cities; Hamlin, Health.

5 Das Konzept der »natürlichen Umwelten« verfolgt die Mensch-Umwelt-Beziehungen in Bereichen, die kaum vom Menschen kontrolliert oder beeinflusst werden können, wie etwa das Klima (für die Zeit vor dem 20. Jahrhundert), Naturgefahren oder Epidemien - vgl. Reith, Umweltgeschichte, $8 \mathrm{f}$.

6 Reith, Umweltgeschichte, Iof.; vgl. die Überblicke in Pfister, Wetternachhersage, Mauelshagen, Klimageschichte u. White/Pfister/Mauelshagen, Handbook, 265-295 u. 309-315.

7 Reith, Umweltgeschichte, I9-24; Lees/Lees, Cities, $62 \mathrm{f}$.
} 
Nicht zuletzt will das Buch die weitgehend parallelen Forschungsrichtungen der Stadt- und Umweltgeschichte zusammenbringen: Für die Stadtgeschichte erlauben umwelthistorische Ansätze wichtige Kontextualisierungen, vice versa ist die Umweltgeschichte auf die Kultur, Sozial- und Wirtschaftsgeschichte angewiesen, um komplexere Sachverhalte zu verstehen - beispielsweise das Phänomen des Wiederverwertens von Materialien und Objekten, welches mit der städtischen Produktion und Konsumption, mit einer grundlegenden Mentalität des Sparens wie auch einer Ökonomie der labouring poor verbunden war. ${ }^{8}$ Somit kann die Verbindung von stadt- und umwelthistorischen Zugängen dazu beitragen, einen differenzierteren Blick auf vormoderne und moderne Städte zu werfen und Narrative zu hinterfragen.

Parallel zur Expansion der Umweltgeschichte im letzten Dezennium hat sich die Stadt als eigenes umwelthistorisches Feld etabliert. Das war anfänglich nicht ganz unumstritten: Wenn in der Umweltgeschichte der I 98 oer Jahre postuliert wurde, dass es um the role and place of nature in human life gehe und dabei nature als nonhuman world begriffen wurde, schloss dies einen Blick auf die Stadt im Rahmen der Umweltgeschichte aus. Gegen diese Sichtweise traten die US-amerikanischen Historiker Joel Tarr und Martin Melosi auf, die auf eine Betrachtung der städtischen Umwelt drängten und somit als Pioniere der urban environmental bistory gelten können. ${ }^{9}$ Beide beschäftigten sich vor allem mit Umweltbelastungen und der Implementierung technischer Infrastrukturen seit der Mitte des I 9. Jahrhunderts. ${ }^{10}$ Zahlreiche Texte der frühen städtischen Umweltgeschichte - auch im deutschsprachigen Raum - thematisierten städtische Umweltprobleme im Kontext der Industrialisierung und Urbanisierung und entwarfen dabei, wie es Martin Melosi bezeichnet hat, ein Szenario des Niedergangs, "stories of decline through human action ${ }^{11}{ }^{11}$ Es wurde das Einwirken des Menschen auf die Umwelt betrachtet, aber kaum Interaktionen. Einen zweiten Fokus der Forschung bildeten die Bereiche der städtischen Hygiene und die Etablierung der damit verbundenen technischen Infrastrukturen, die oft über ein lineares Modernisierungsnarrativ dargestellt wurden. ${ }^{12}$

Seit den frühen 2oooer Jahren ist die städtische Umweltgeschichte ein interdisziplinäres Themenfeld geworden - zu den Arbeiten aus der Geschichtswissenschaft kamen zahlreiche Beiträge aus der Ökologie, der Soziologie und der Geographie. Bei der Rekonstruktion urbaner Umwelt hatte bisher deutlich das Wasser im Mittelpunkt gestanden - begonnen bei der Frage der Wasserversorgung, was die Wassernutzung (als Trinkwasser, aber auch als Energiequelle und für andere Verwendungen in Haushalt und Gewerbe) und zudem die Abwasserentsorgung einschließt. Mit der Betrachtung

\footnotetext{
8 Stöger/Reith, Recycling.

9 Melosi, Place, 2-6; Schott, Resources, 2-4; Isenberg, Nature, XI-XVII.

ı Vor allem Melosi, America; Melosi, Garbage; Tarr, Search - vgl. auch Tarr, History.

I I Melosi, Humans, 3 u. 7 .

I 2 Melosi, Humans; Schott, Resources; Uekötter, Umweltgeschichte, I-6; Hamlin, Health, 332-337.
} 
von Flüssen und anderen Wasserwegen (Kanäle etc.) als anthropogene Umwelt erfuhr dieses Themenfeld jedoch eine Ausweitung. Andere Fokalpunkte der Forschung bilden die Energieversorgung, Materialflüsse, der Impact von Naturereignissen (z.B. Überschwemmungen, Stadtbrände bis hin zu klimatischen Extremen), die »künstliche« Umwelt (wie botanische oder zoologische Gärten, Parks und andere Grünflächen), Tiere oder Fragen der Landnutzung und der Stadt-Hinterland-Beziehungen. ${ }^{13}$ Insgesamt dominiert eine Betrachtung der letzten I 50 Jahre, besonders das 20. Jahrhundert ist mittlerweile relativ gut erforscht. Der Zeitraum I700- i 9oo hat eine unterschiedlich intensive Bearbeitung erfahren: Umweltaspekte des städtischen Lebens sind stärker für eine späte Phase, vor allem für die Zeit seit der Mitte des I9. Jahrhunderts, betrachtet worden. ${ }^{14} \mathrm{Im}$ umwelthistorischen Mainstream ist die Stadt deshalb noch nicht ganz angekommen: Selbst bei neueren und wegweisenden, also auch einflussreichen umwelthistorischen Studien, wie z. B. Mark Ciocs Eco-biography des Rheins, war die Stadt spürbar nicht im Blickwinkel der Schreibenden. ${ }^{15}$

In stadtgeschichtlichen Arbeiten finden sich zahlreiche Bezugnahmen auf Aspekte städtischer Umwelt für die Zeit des I 8. und I 9. Jahrhunderts - in vielen Fällen zeichnen sich dabei zwei grundlegende Narrative ab. Erstens: Die Zeit vor den I 85 oer Jahren sei eine eher statische Periode gewesen, die von prolongierten Umweltproblemen und mangelnden Ambitionen, diese zu lösen, geprägt war. ${ }^{16}$ Der ansonsten überaus reflektiert argumentierende Stadthistoriker Peter Clark charakterisiert die städtischen Aktivitäten in der Frühen Neuzeit als »relative failure and ineffectiveness. Arguably, councils were trying to do too much and the social, environmental, and other problems they experienced were beyond their capacity to handle. « ${ }^{17}$ Besonders die Bereiche der Hygiene und der Entsorgung sind oftmals in negativer und ziemlich drastischer Weise beschrieben worden, etwa wenn auf das Halten von Nutztieren in den Städten und das Deponieren von Fäkalien und Abfällen in den Straßen verwiesen worden ist. Bei näherer Betrachtung scheinen viele dieser Annahmen auf eine unreflektierte und selektive Verwendung normativer Quellen oder zeitgenössischer Literatur zurückzugehen. Vormoderne Ver- und Entsorgungssysteme waren sicherlich mit bedeutenden Problemen behaftet, wenn man aber die wenigen empirischen Studien berücksichtigt, die diese Thematiken genauer in den Blick genommen haben, entsteht ein etwas anderes Bild:

I3 Dieter Schott hat für die Frühe Neuzeit und das I9. Jahrhundert die bislang beste Synthese vorgelegt (Schott, Urbanisierung); probate Überblicke für den deutschsprachigen Raum auch in: Reith, Umweltgeschichte, 59-69 u. I 23- I 34; Rosseaux, Städte, 94- I I4; Winiwarter/Knoll, Umweltgeschichte, I77206; Uekötter, Umweltgeschichte; vgl. auch Bernhardt, Umweltprobleme; Massard-Guilbaud/Thorsheim, Cities u. Frioux, Crossroads.

I4 Vgl. Uekötter, Umweltgeschichte, I6-22; auch die umweltgeschichtlichen Themenhefte des »Journal of Urban History« (No. 3, I 994 und No. 33, 2007) behandelten mehrheitlich die Zeit ab den I $870 e r$ Jahren.

I5 Cioc, Rhine.

I6 Vgl. Clark, Cities, 204f. und Lees/Lees, Cities, ${ }_{28}{ }_{3} f$.

I7 Clark, Cities, 205. 
Oftmals ergriffen städtische Obrigkeiten und Institutionen, auch Individuen, umfangreiche Maßnahmen, um Ver- oder Entsorgungssysteme zu optimieren. Vor allem in urbanen Zentren ökonomisch prosperierender Regionen wurden technische Experten zur Errichtung von Wasserversorgungssystemen herangezogen. Diese Entwicklung resultierte mancherorts in sehr komplexen und teuren technischen Strukturen, die mitunter bis in die zweite Hälfte des I9. Jahrhunderts oder sogar bis ins 20. Jahrhundert genutzt wurden. ${ }^{18}$

Zweitens: Die Dauerkrise der städtischen Umwelt habe sich durch Urbanisierung und Stadtwachstum verschärft und sei erst durch die Hygienediskussion und die Choleraepidemien in den Blick gekommen und schließlich durch die Errichtung großtechnischer Infrastrukturen beseitigt worden. Unzweifelhaft führte die Urbanisierung zum Ende des I 8. und im beginnenden I 9. Jahrhundert zu einer »Verschärfung der Problemlagen « in den Städten, ${ }^{19}$ daraus ein lineares Modernisierungsnarrativ zu konstruieren, erscheint nicht sinnvoll. Es bestand bereits vor der industriellen Epoche eine "große Bandbreite an städtischen Umweltproblemen«, was Stadtbewohnern/innen durchaus bewusst war. ${ }^{20}$ Dies hat auch Peter Brimblecombe mit seinem Buch zur Londoner Luftverschmutzung unterstrichen, das in seiner Vielschichtigkeit und vor allem aufgrund des langen Untersuchungszeitraumes immer noch lesenswert ist. ${ }^{21}$ Selbst die Etablierung von Infrastrukturen folgte selten einem linearen Schema: Oft gab es Widerstände, meistens wegen der Frage der Finanzierung, es kam zu situativen Entscheidungen, die manchmal in Zwischenlösungen und in der Persistenz von alten Systemen/Praktiken resultierten. ${ }^{22}$ Wenn man die zunehmende Etablierung von öffentlichen Grünräumen als Zeichen für ein steigendes Naturbewusstsein der Stadtbewohner/innen deutet und dieses ex post als Vorläufer der ökologischen Bewegung des 20. Jahrhunderts sieht, dann erscheint hier ebenso ein differenzierter Blick notwendig: Viele Umweltprobleme wurden externalisiert und bis ins 20. Jahrhundert nach einer out-of-sight-out-of-mind-Logik behandelt, und das Streben nach mehr »Grün« in der Stadt war klar anthropozentrisch ausgerichtet. ${ }^{23}$

Die meisten Studien zur städtischen Umweltgeschichte behandeln einen bestimmten Bereich städtischer Umwelt - Arbeiten, die einen holistischen Ansatz verfolgen, sind hingegen selten: Richard Evans hat die Hamburger Cholera des späten r 9. Jahrhunderts in einer breiten sozial- und umwelthistorischen Perspektive untersucht, und Harold Platt hat die ökologische Transformation der Städte Manchester und Chicago

I 8 Reith, Umweltgeschichte I24- I 26; Radkau, Natur, I72 - I75; vgl. für Zürich: Suter, Wasser, Illi, Schîssgruob u. Sablonier, Wasser; für Wien: Haidvogl et al., Wasser.

I9 Winiwarter/Knoll, Umweltgeschichte, I9r.

20 Ebd., I86f.

2I Brimblecombe, Smoke; Cavert, Smoke.

22 Vgl. z.B. im Hinblick auf Wasserinfrastruktur: Evans, Tod u. Pichler-Baumgartner, Weg.

23 Frioux, Crossroads, $533 \mathrm{f}$. 
im I 9. Jahrhundert nachgezeichnet. ${ }^{24}$ Dazu kommen einige Sammelbände, die zwischen innovativen Case Studies (z.B. »Metropolitan Natures« zu Montreal), ${ }^{25}$ thematischen Überblicken ${ }^{26}$ und selektiven, lokalhistorischen Kompendien liegen. Für die Zeit vor dem i9. Jahrhundert fehlen Publikationen mit einem holistischen Ansatz fast vollständig: Während Christian Mathieu mit seinem Buch »Inselstadt Venedig. Umweltgeschichte eines Mythos in der Frühen Neuzeit« einen Fokus auf das die Stadt umgebende Wasser setzte, ist der Sammelband „Umwelt Stadt. Geschichte des Natur- und Lebensraumes Wien« eine zwar sehr umfang- und erkenntnisreiche, aber in manchen Bereichen etwas oberflächliche und insgesamt fragmentierte Zusammenschau verschiedener umwelthistorisch relevanter Themenfelder geblieben. ${ }^{27}$ Dennoch hat gerade »Umwelt Stadt« auf die Machbarkeit und den Mehrwert einer inhaltlich und zeitlich breiter angelegten Studie zur Umweltgeschichte eines konkreten Ortes verwiesen.

Es gibt bislang noch keinen umfangreicheren Text, der einen systemischen Zugang bei der Rekonstruktion der Umwelt einer konkreten Stadt verfolgt hätte, also dabei verschiedene umweltgeschichtliche Aspekte vernetzt betrachtet und dabei den Zeitraum I 700 bis I 900 in den Blick genommen hätte. Gerade eine zeitlich umfassendere Betrachtung erscheint notwendig: Martin Melosi hat betont, dass ein prozessualer Blick notwendig sei, um städtische Umwelt(en) als »ever-mutating systems« verstehen zu können. ${ }^{28}$ Erst eine längerfristige Perspektive ermöglicht es, Entwicklungspfade, Brüche sowie Aspekte der Persistenz zu rekonstruieren und damit die umfangreichen Veränderungen im urbanen Europa während des I 9. Jahrhunderts im Hinblick auf die städtische Umwelt besser erklären und kontextualisieren zu können.

Worauf kann das Buch in Bezug auf das gewählte Fallbeispiel Linz aufbauen? Es besteht insgesamt ein signifikanter Mangel an neueren geschichtswissenschaftlichen Studien zu Linz vor dem 20. Jahrhundert, vor allem für die vorindustrielle Zeit. Vorrangig sind populärwissenschaftliche Veröffentlichungen zu spezifischen Aspekten der Stadtgeschichte, besonders zu politischen und/oder konfessionellen Themen, vorhanden. ${ }^{29}$ Umweltgeschichtliche Bereiche sind nur selten behandelt worden: Luisa Pichler-Baumgartners Dissertation zur städtischen Wasserversorgung und Abwasserentsorgung während der zweiten Hälfte des r9. Jahrhunderts ${ }^{30}$ und die Master-

\footnotetext{
24 Evans, Tod; Platt, Shock.

25 Castonguay, Agriculture u. Dagenais, Source.

26 Vgl. Soens et al., Cities u. Isenberg, Nature.

27 Mathieu, Inselstadt; Brunner/Schneider, Umwelt; für Münster ist zudem der »Historische Umweltatlas« zu nennen (Historischer Umweltatlas Münster).

28 Melosi, Humans, Io; vgl. Hoffmann, Footprint.

29 Vgl. als Überblicke: Mayrhofer/Katzinger, Geschichte u. die Mappe zu Linz im »Österreichischen Städteatlas« (Mayrhofer, Linz).

30 Pichler-Baumgartner, Wege.
} 
arbeit von Maria Fuchs zu Materialflüssen nach Linz ${ }^{31}$ bilden diesbezüglich eine Ausnahme. Zudem sind Aspekte urbaner Umwelt von einer Studie zur städtischen Industrie gestreift $\mathrm{f}^{32}$ und von - mitunter durchaus reflektierten - Zeitschriftenartikeln aufgegriffen worden, die teilweise als Umweltgeschichte avant la lettre gesehen werden können. ${ }^{33}$ Auch Hanns Kreczis lexikalisches Kompendium "Linz. Stadt an der Donau«, das I 95 I erschien, weist einige Bezugspunkte zur Umweltgeschichte auf: So finden sich etwa Einträge zu »Überschwemmung « und »Grünanlagen « wie zu »Brunnen« und »Nachtkönigen«. ${ }^{34}$ Das Überblickswerk »Geschichte der Stadt Linz« (I 990) von Fritz Mayrhofer und Willibald Katzinger, das einen relativ konzisen und reflektierten Überblick gibt, spricht ebenso zahlreiche umwelthistorische Themen an. ${ }^{35}$ Der Umstand, dass umwelthistorisch relevante Aspekte von zahlreichen Publikationen berührt worden sind, hat - gemeinsam mit dem umfangreichen Bestand der edierten Quellen (vgl. unten) - auf die Möglichkeiten und die Sinnhaftigkeit der Bearbeitung dieses Exempels hingewiesen.

\section{Zugänge: Stadt, Umwelt und Alltag}

Um die Wechselwirkungen zwischen Mensch und Umwelt und deren Wandel für das Fallbeispiel Linz zu untersuchen, sollen folgende Fragen gestellt werden: ${ }^{36}$ Wie war die städtische Umwelt von Linz beschaffen, wie, wann und warum veränderte sie sich? Welche Akteure gestalteten diese Mensch-Umwelt-Beziehungen? Wie interagierten die Stadtbewohner/innen, politische Eliten und urbane Umwelt, wie begegneten sie dem »renewed encounter between the opportunities and constraints of the environment «? ${ }^{37}$ Wie wurde diese Akteurskonstellation durch politische, kulturelle und sozioökonomische Veränderungen, z.B. neue Naturwahrnehmungen oder den Wandel in den Wissenschaften, beeinflusst? Aus welchen Motiven handelten die Akteure? Aus Zwangslagen? Oder nutzte man (neue) Möglichkeiten? Wie wirkten natürliche Settings und Einflüsse (z.B. naturräumliche Bedingungen, Naturgefahren oder Epidemien) auf den urbanen Raum und deren Bewohner/innen? Wie veränderte der technologische, materielle und energetische Wandel die städtische Umwelt ${ }^{38} \mathrm{Zu}$ welchem Zeitpunkt wurden vormoderne Praktiken und Systeme (etwa der Ver- und Entsor-

3 I Fuchs, Produktion.

32 Lackner/Stadler, Fabriken.

33 Erschienen vor allem im »Historischen Jahrbuch der Stadt Linz«, den »Oberösterreichischen Heimatblättern« und dem »Naturkundlichen Jahrbuch der Stadt Linz«.

34 Kreczi, Linz, 5 f. u. 30 I-305.

35 Vgl. Mayrhofer/Katzinger, Geschichte, Bd. 2, 22, 44f., 57 f., 84 u. I37- I6o.

36 Melosi, Humans, I 3 ; Melosi, Place, 2-6; Schott, Resources, 2 - 4 .

37 Fougères, Water, 86.

38 Benton-Short/Short, Cities, 4I. 
gung) als unzureichend bzw. überholt erachtet? Wie erfolgte dieser infrastructural change, welche Modifikationen der städtischen Umwelt ergaben sich dadurch ${ }^{39}$ Wann und warum begannen sich Materialflüsse zu verändern und welche sozioökonomischen Auswirkungen hatte dies für die urbane sowie suburbane Bevölkerung? Können räumliche und soziale Aspekte städtischer Umwelt (z.B. spezifische Umweltbedingungen resp. praktiken an der urbanen Peripherie oder bei den städtischen labouring poor) identifiziert werden ? $^{40}$

Martin Melosi hat vorgeschlagen, eine Stadt und ihre Umwelt als natural system, als spezifisches Ökosystem, zu betrachten. ${ }^{41}$ Dadurch knüpft er an die Forderungen der Stadtökologie an, die Städte als Hybride aus komplexen physischen Strukturen und gesellschaftlichen Prozessen zu interpretieren. ${ }^{42}$ Städte bilden sehr spezifische Ökosysteme, da sie in der Regel dicht bevölkerte Zentren von Konsumption und Produktion sind. Zum einen weist diese Konstellation spezifische Vorteile auf, zum anderen verursacht sie Probleme, die oftmals eine umwelthistorische Dimension aufweisen. So haben z.B. Brände, Epidemien, Fragen der Hygiene oder Wetterextreme in ländlichen Gebieten andere Wirkungen als in städtischen Ballungsräumen. Zudem verändern Städte ihr physical environment in sehr starker Weise und weit über ihre eigentlichen Grenzen hinaus. ${ }^{43}$ Um nun in der Analyse Bereiche, die auch historisch stark verflochten waren, gemeinsam betrachten zu können, scheint ein systemischer Zugang notwendig. ${ }^{44}$ Bislang hat die städtische Umweltgeschichte jedoch dazu tendiert, sich einzelnen Umweltbereichen zuzuwenden, dabei aber selten nach parallelen Entwicklungen und Wechselwirkungen gefragt. Das ist nicht überraschend, denn ein systemischer Ansatz birgt in der Praxis einige Schwierigkeiten: Es ergibt sich die Notwendigkeit, sehr unterschiedliche theoretische und methodische Ansätze zu kombinieren, und auch im Hinblick auf die Quellen ist ein breiter Ansatz mit einem entsprechenden Mehraufwand verbunden, was sinnvollerweise nicht in einer bistoire totale, sondern in Schwerpunktsetzungen resultiert. Somit sollen die Wechselwirkungen zwischen Mensch und Umwelt und deren Transformation in drei Fokalpunkten beobachtet werden, die eine Bündelung ausgewählter Aspekte zu thematischen Clustern darstellen: erstens Materialflüsse/Metabolismus (Kap. 3 bis 5), zweitens Urbanisierung von Natur (Kap. 6 bis 8) und drittens sozionaturale Krisen (Kap. 9 bis I I). Alle diese Wechselwirkungen und deren Transformation manifestieren sich im Alltag, und sie lassen sich darin beobachten resp. analysieren.

39 Lees/Lees, Cities, r 88; Melosi, America, I 54f.; Schott, Urbanisierung, 280-282.

40 Vgl. Bernhardt, Umweltprobleme, 2 If. u. Pichler-Baumgartner, Weg.

4I Melosi, Place, 4; Melosi, Humans, ro.

42 Heynen/Kaika/Swyngedouw, Ecology; Douglas, Analysis.

43 Melosi, Place, 7- Io; Rosen/Tarr, Importance, $30 \mathrm{I}-307$ - vgl. dazu auch meine Überlegungen weiter unten.

44 Vgl. Barles/Knoll, Transitions; Melosi, Humans u. Schott, Resources. 
Ab den I970er Jahren haben englische Historiker/innen grundlegende Überlegungen zur Aussagekraft des Alltäglichen und zur Annäherung an das historische Alltagsleben vorgestellt, die im deutschen Sprachraum als "Alltagsgeschichte« vor allem von Alf Lüdtke vertreten worden sind. Man begann, Automatismen und "Top-down«Prozesse zu hinterfragen, und versuchte eine Annäherung an die alltägliche Handlungsmacht "der Vielen", wie es Lüdtke formuliert hat. ${ }^{45}$ "Aneignung" wurde in diesem Kontext ein zentraler, von Lüdtke geprägter Ansatzpunkt: Es gehe um die "Art und Weise, in der Chancen wie Zumutungen wahrgenommen und in Momente des eigenen Lebens umgeformt werden ${ }^{46}$ Damit grenzte man sich gegen die Vorstellungen der Strukturgeschichte ab und verwies u.a. auf die vielfältigen Ambiguitäten und Variationen in Modernisierungsprozessen. Aber weder wurde die Einbindung in übergeordnete Strukturen zurückgewiesen noch fand eine Konzentration auf isolierte Aspekte des Alltagslebens statt. Man fragte nach subjektiven Erfahrungen, deren Rekonstruktion mitunter durch mikrohistorische Ansätze versucht wurde. ${ }^{47}$ Interessanterweise sprach Lüdtke schon früh die Notwendigkeit an, im Rahmen der Alltagsgeschichte genauso »langfristige Zusammenhänge bzw. Veränderungen« zu bearbeiten, und schlug vor, nach "Reichweiten" von wissenschaftlich-elitären wie alltäglichen Wissensformen zu fragen. ${ }^{48}$

Obgleich diese Überlegungen vielfältige Anknüpfungspunkte für umwelthistorische Studien boten, sind sie interessanterweise in der Umweltgeschichte nicht rezipiert worden, zumindest nicht explizit. ${ }^{49}$ Impulse für eine Annäherung an die alltägliche historische Umwelt kommen auch aus der sozialen und politischen Ökologie und aus der Politikwissenschaft: Neben Konzepten wie dem Metabolismus und der Produktion von Natur (vgl. unten) ist hier die Frage nach dem Ablauf von Politikprozessen hilfreich. Der Geograph Erik Swyngedouw sieht Veränderungen von städtischer Umwelt eng an die Frage der Macht gebunden: Die »material conditions« in Städten wurden und werden ihm zufolge von Eliten gestaltet und kontrolliert, partiell »at the expense of marginalized populations«. Materielle (und ökologische) Veränderungsprozesse hätten also eine wesentliche soziale Dimension..$^{50}$ Überlegungen zur urban governance lieferten in diesem Kontext weitere Ansatzpunkte für das Verstehen politischer Prozesse in der Stadt. Diese Konzepte zweifelten an der Durchsetzungsfähigkeit - und Effizienz - zentraler Hierarchien (hier ging es vor allem um den postmodernen Nationalstaat) und sahen ein Nebeneinander resp. ein Zusammenwirken unterschiedlicher politischer Akteure auf verschiedenen Machtebenen. ${ }^{51}$ In Politikprozessen würden

45 Steege et al., History; vgl. Lüdtke, Einleitung.

46 Lüdtke, Alltagsgeschichte, 84 .

47 Lüdtke, Einleitung; Lüdtke, Alltagsgeschichte.

48 Lüdtke, Einleitung, 20; Lüdtke, Alltagsgeschichte, 87.

49 Wenngleich man einige Studien (z.B. Evans, Tod oder Collet, Katastrophe) durchaus so lesen könnte.

5o Heynen/Kaika/Swyngedouw, Ecology, 6 u. ebd., passim.

5 I Brenner, Governance, 447 . 
nichthierarchische Netzwerke und - mitunter situative - Kollaborationen einen erheblichen Einfluss ausüben, die in intermediäre, partiell informelle Bereiche zwischen Öffentlichkeit und Privatem hineinreichten. ${ }^{52}$ Somit lenkt die urban governance die Aufmerksamkeit auf nicht unmittelbar evidente Aspekte sozialer Interaktion in der Stadt.

Auch die Überlegungen des französischen Soziologen Henri Lefebvre zu Urbanisierung und städtischem Alltagsleben bieten - obgleich Lefebvre aus der Perspektive des Nachkriegsfrankreich auf die Vergangenheit blickte - einige interessante Ansätze, um die Transformation städtischer Umwelt zu rekonstruieren. ${ }^{53}$ Erstaunlicherweise wurden Lefebvres Texte zu städtischen Räumen in den Geschichtswissenschaften stärker rezipiert als die zum Alltag, obgleich die Alltagsgeschichte eine erhebliche Nähe zu marxistischen Ansätzen aufwies und Lefebvre schon Ende der I95oer Jahre - sich dabei auf Marc Bloch beziehend - eine Agenda der Alltagsgeschichte umrissen hatte: »Tatsachen ohne Prestige [i.e. das Alltägliche] waren tatsächlich wesentlich wichtiger und sind für uns, Historiker, aufklärender als sensationelle Ereignisse.« Man müsse »weg von den hervorragenden Ereignissen zur Gesamtheit der Alltagsereignisse [...,] weg vom Schein zur Realität «. ${ }^{54}$

In den Arbeiten von Lefebvre zur Entwicklung von Städten gibt es einen deutlichen Fokus auf die Industrialisierung, wobei sich insgesamt eine tendenziell negative Deutung der Industriestadt des 20. Jahrhunderts, besonders der saturierten Konsum- und Wohlstandsstadt in der Zeit des Nachkriegsfordismus abzeichnet, zudem ist Lefebvres Argumentation spürbar von der damaligen Diskussion um eine »Krise der Stadt« und seiner Hoffnung auf eine von urbanen Räumen ausgehende gesellschaftliche Revolution geprägt. ${ }^{55}$ Dennoch ist Lefebvre mit seinen Überlegungen nicht allzu weit von den zuvor angesprochenen Positionen der Alltagsgeschichte, der politischen Ökologie und der urban governance entfernt: Auch er sah in der Alltäglichkeit einen "Leitfaden«, um »Gesellschaft « - und hier könnte man die Umwelt hinzufügen - rekonstruieren zu können. ${ }^{56}$ Er hatte längerfristige Transformationsprozesse im Blick und identifizierte drei Ebenen von Akteuren in urbanen Prozessen, auch bei Veränderungen des Alltags: erstens eine »private Ebene«, die eine »Ebene der unmittelbaren, persönlichen und zwischenpersönlichen Beziehungen« zwischen Individuen und Gruppen - von Familie bis hin zu Korporationen - darstelle; zweitens eine »ferne Ordnung" großer und mächtiger Institutionen, z. B. von Nationalstaaten, die eine "ganz allgemeine, also ganz abstrakte« Macht auf städtische Räume ausübe; drittens eine gemischte Ebene (médiation), die zwischen diesen Ebenen liege und zugleich die »eigentlich« städtische

\footnotetext{
52 Einig et al., Governance, I-III.

53 Vgl. zum Kontext: Schmid, Stadt, I I 3 - I 69.

54 Lefebvre, Kritik, Bd. I, I4I u. I43.

55 Schmid, Stadt, I 25 - I 29 u. I 47.

56 Lefebvre, Alltagsleben, 46.
} 
Ebene sei, »Ideologie und Praxis zugleich«, und sich über »Straßen, Plätze, Alleen, öffentliche Gebäude« manifestiere. ${ }^{57}$ Diese drei Ebenen, »das Nahe oder Unmittelbare, das Urbane oder Vermittelnde und das Ferne oder Vermittelte $«{ }^{58}$ seien miteinander verknüpft, könnten sich überlagern, genauso aber auch in Konkurrenz zueinander stehen. ${ }^{59}$

Lefebvre ging ebenso von spezifischen Zeitformen des Alltags aus: Dabei sei die ursprüngliche, »zyklische« Zeit, die durch Repetitives geprägt sei (z.B. Tages- und Jahreszeiten und Ernten), durch die Industrialisierung weitgehend überformt worden. Nun bestimme eine »lineare «, kontinuierliche (von einem Nullpunkt weg) und diskontinuierliche (infolge einer beliebigen Zerteilung durch »zeitzerstückelnde Technik«) Zeit das menschliche Dasein, wenngleich beide Zeitformen in der Praxis weiterhin interagieren würden. ${ }^{60}$ Diese Zeitformen lassen sich auf die drei Fokalpunkte des vorliegenden Buches umlegen: Metabolismus und Materialflüsse waren repetitiv/zyklisch, die Urbanisierung von Natur verlief weitgehend kontinuierlich, wenn auch nicht zwingend linear und partiell beeinflusst von zyklischen Abläufen, ${ }^{61}$ und Krisen wirkten sowohl auf repetitive wie auf kontinuierliche Abläufe.

\section{Städtischer Metabolismus}

Die Betrachtung des Metabolismus bildet einen rezenten Fokus der Umweltgeschichte und mittlerweile gibt es auch einige Studien, die dies für städtische Settings und die Zeit vor 1900 angewandt haben. Unter Metabolismus kann man den "Stoffwechsel« einer Stadt verstehen: Dieser besteht aus den Ressourcen, die in die Stadt fließen und für die Reproduktion der Stadt lebenswichtig sind (Input), aus der Nutzung resp. Transformation dieser Materialien und Produkte in der Stadt und schließlich aus dem Output, welcher Produkte, aber genauso - als Umweltbelastungen - Abfälle, Abwässer oder Emissionen umfasst. ${ }^{62}$

Das Konzept des urbanen Metabolismus wurde erstmals in den I 960er Jahren entworfen, besonders einflussreich war das I98 I erschienene Buch von Stephen Boyden et al. zu Materialflüssen in Hongkong, das auch den Blick auf den Impact, den die Stadt auf ihre Umwelt ausübt, lenkte und auf das »Ressourcendefizit« einer Stadt hinwies. Städte sind in Bezug auf die Versorgung von außerstädtischen Gebieten abhängig und somit haben Städte nicht nur umliegende, sondern auch entferntere Gebiete

57 Lefebvre, Revolution, 86-89.

58 Schmid, Stadt, 165.

59 Lefebvre, Revolution, i 19.

6o Lefebvre, Kritik, Bd. 2, 55-57 u. Lefebvre, Kritik, Bd. 3, 6rf.

6I Lefebvre, Revolution, I3 3 u. 3 I.

62 Vgl. als Überblicke: Barles/Knoll, Transitions, Barles, Metabolism u. Reith, Umweltgeschichte, I 33 f. u. I 38 - I 40; vgl. als Fallstudien zu Paris und Wien: Barles, Approach u. Kim/Barles, Energy; Gierlinger, Food u. Gingrich/Haidvogl/Krausmann, Danube. 
in sozioökonomischer und ökologischer Hinsicht verändert. Der Zugriff der Stadt auf dieses »Hinterland « hat sich im Verlauf der Zeit erweitert, partiell verlagert und damit unterschiedliche Gebiete in unterschiedlicher Art und Weise betroffen. ${ }^{63}$

Der urbane Metabolismus ist dabei nicht nur als Denkfigur, sondern ebenso als analytisches Konzept zu verstehen, welches von der Forschung oft als material flow analysis in quantitativer Hinsicht bearbeitet wurde, wobei der Input/Output nach Masse resp. Energiemenge erfasst wurde. ${ }^{64}$ Derartige Zugänge bergen die Problematik, oft nur einen Zustand zu einem gewissen Zeitpunkt abzubilden oder auch einen Durchschnittswert resp. eine Summe für einen Zeitraum zu errechnen, wenngleich der urbane Metabolismus prozessualer und mitunter sehr volatiler Natur war. ${ }^{65}$ Darüber hinaus sind quantifizierende Ansätze für vormoderne Settings schwer umsetzbar, da Daten vor der zweiten Hälfte des i 9. Jahrhunderts lückenhaft und inkonsistent sind, was speziell bei der Betrachtung längerer Zeiträume erhebliche Probleme bereitet. ${ }^{66}$ Weniger häufig wurde eine qualitative Perspektive eingenommen, also nach der Beeinflussung des urbanen Metabolismus durch naturräumliche Voraussetzungen oder natürliche Bedingungen, durch die spezifische Funktion der Stadt, die städtische Verwaltungspraxis, durch Marktintegration und entwicklung, Konsummöglichkeiten, durch technische, infrastrukturelle oder soziokulturelle Veränderungen gefragt. ${ }^{67}$

Das Metabolismuskonzept ermöglicht es, Themen wie Wasser, Luft, Boden, die Zufuhr von und den Umgang mit Ressourcen, zudem den Zugriff der Stadt auf das Hinterland zu bündeln und dadurch »die Beziehungen zwischen Städten und ihrer Umwelt in einen Gesamtzusammenhang zu bringen «: ${ }^{68}$ Es können Wechselwirkungen, der urban outreach, divergierende oder gegensätzliche Entwicklungen, unintendierte Konsequenzen resp. die Externalisierung von Umweltproblemen in den Blick genommen werden. ${ }^{69}$ Es sind Fragen nach Akteuren und deren Logik möglich, auch danach, ob Aspekte des vormodernen Metabolismus nicht nur als automatische Reaktion auf eine pre-industrial economy of scarcity, sondern genauso als funktionelle Lösungen gewertet werden können. ${ }^{70}$ Zudem kann die Materialität als strukturierendes Element von Praktiken einbezogen werden, was Anknüpfungsmöglichkeiten an laufende Diskurse in der Frühneuzeitforschung sowie der Stadt- und Umweltgeschichte ermöglicht. ${ }^{71}$ Der Zugang über den urbanen Metabolismus kann auch helfen, Berei-

63 Barles/Knoll, Transitions; Schott, Urbanisierung, I7-20; Hoffmann, Footprint; Bai/Schandl, Ecology; vgl. Winiwarter/Knoll, Umweltgeschichte, I 94- 999.

64 Huang/Lee, Metabolism, 522-526; vgl. z. B. Kim/Barles, Energy.

65 Swyngedouw, Urbanization, 22.

66 Schott, Urbanisierung, I 9.

67 Bai/Schandl, Ecology, 30-34.

68 Schott, Urbanisierung, 20; vgl. Tarr, Metabolism; Schott, Resources, 9- I I .

69 Heynen/Kaika/Swyngedouw, Ecology, I 2 ; Hays, Role, 75 -80.

70 Schott, Resources, r 3 f.; vgl. Barles/Knoll, Transitions, $34-36$.

7 I Vgl. Weber, Urbanisierung u. den Überblick bei: Knoll, Bodenhaftung. 
che zu integrieren, die bislang noch wenig Aufmerksamkeit erfahren haben - etwa die Wiederverwendung oder Wiederverwertung von Produkten und Materialien. ${ }^{72}$

\section{Urbanisierung von Natur}

Der Geograph Erik Swyngedouw und die Urbanistin Maria Kaika haben darauf verwiesen, dass »socioenvironmental changes « in einer "continuous production of new snatures« « resultieren würden. ${ }^{73}$ Diese Umgestaltung von Natur, von Swyngedouw als urbanization of nature bezeichnet, wurde von soziokulturellen, ökonomischen und materiellen Settings beeinflusst und verlief nicht zwingend linear, sondern mitunter konfliktreich und widersprüchlich. ${ }^{74}$ Städtische Akteure modifizierten die lokale Geomorphologie durch Landnutzung, durch die Verlegung von Wasserläufen, das Ziehen von Gräben, das Abtragen von Vegetation oder durch die Entnahme von Material in Steinbrüchen, Lehm- und Sandgruben. Auch Flüsse und flussnahe Räume wurden durch Flussregulierungen, durch Besiedlung oder durch die Einleitung von Abwasser resp. durch das Ablagern von Abfällen erheblich verändert. ${ }^{75}$ Die anthropogene Modifikation von Flüssen konnte zu nichtintendierten Veränderungen des Strömungsverhaltens führen, die in Verlandungen und neuen Hochwassermustern resultierten. ${ }^{76}$

Städtische Bedürfnisse verursachten die Umgestaltung verschiedener Räume: Eine Verbesserung der Sauberkeit und Hygiene wurde über die Versiegelung des Bodens versucht, künstliche Beleuchtung wurde der nächtlichen Dunkelheit entgegengestellt, und städtische und stadtnahe Grünräume wurden für die Freizeitnutzung geschaffen und verändert. Mitunter wurden »Urbanitas« und Modernität über derartige Transformationsprozesse generiert und inszeniert. ${ }^{77}$ Hier kommt nochmals das Ausgreifen der Stadt auf das Umland, die Ausweitung der städtischen »ecological frontier « ${ }^{78}$ zum Tra- $^{-}$ gen, wobei aber - anders als beim Metabolismuskonzept - die Auseinandersetzung von Stadtbewohnern/innen mit Natur vor Ort betrachtet wird, also die »Bewunderung« und das »Studium «, zudem der Konsum von Natur und von Naturräumen im Hinterland. ${ }^{79}$

Henri Lefebvre hat im Rahmen seiner Überlegungen zur Stadt eine Typologie realer und imaginierter Orte entwickelt, die sich auch auf Bereiche urbanisierter Natur

72 Vgl. Strasser, Waste; Stöger, Märkte; Stöger/Reith, Recycling.

73 Swyngedouw/Kaika, Environment, 569.

74 Heynen/Kaika/Swyngedouw, Ecology; Swyngedouw, Urbanization; vgl. als aktuellen Überblick: Soens et al., Cities.

75 Douglas, Hydrology, I 56 - I62 ; Lübken, Cities, I 55 - I 59.

76 Cioc, Rhine, 35f.; Winiwarter/Schmid/Dressel, Danube; Hohensinner et al., Changes; vgl. Knoll/Lüb$\mathrm{ken} / \mathrm{Schott}$, Introduction, $5-7$.

77 Vgl. Schott, Modernität, 289 f.; Broich, London, I9; Lees /Hollen Lees, Europe; Reith, Umweltgeschichte, 60 u. 132 ; Janssens/Soens, Water, 94 u. ro3.

78 Swyngedouw, Urbanization, 36.

79 Uekötter, Umweltgeschichte, I 2 f. 
anwenden lässt: Gleiche Orte bezeichnet Lefebvre als »Isotopien«, in deutlichem Gegensatz dazu stünden »Heterotopien«, andere, auch divergierende Orte. Als »U-Topie« könne ein "Nicht-Ort, der keinen Ort hat und doch seinen Ort sucht«, bezeichnet werden, was Lefebvre nicht zwingend auf imaginiert Abstraktes beschränkte, sondern darunter genauso konzipierte Orte mit utopischen Elementen (z.B. Parks) verstand. ${ }^{80}$ Der vormoderne Stadtraum habe im Verlauf der urbanen Modernisierung seine heterotopische Prägung verloren, insbesondere die Technik, aber auch die Stadtplanung hätten auf eine Homogenisierung von Räumen abgezielt, also auf eine Schaffung von Isotopien. ${ }^{81}$ Lefebvres lineares Narrativ lädt zum Widerspruch ein, dies mindert aber nicht seinen Verdienst, den Blick auf Raumveränderungen infolge der Etablierung von Infrastrukturen oder neuer gesellschaftlicher Praktiken gelenkt zu haben.

Genauso relevant ist die Frage, welchen Einfluss konkrete Räume auf die städtische Umwelt und die mit ihnen verbundenen Praktiken ausübten. ${ }^{82}$ Über eine Analyse von historischen Stadtplänen wird versucht, die Nutzung und Transformation von konkreten Räumen zu rekonstruieren, und dabei nach räumlichen Lösungen, Veränderungen der Landnutzung resp. nach Pfaden und Determinanten räumlicher Entwicklung gefragt. ${ }^{83}$

\section{Sozionaturale Krisen}

Während die zwei vorangegangenen Bereiche mittel- und längerfristige Arrangements und Transformationen behandeln, werden im letzten Fokalpunkt kurzfristige Impacts der Umwelt auf die städtische Gesellschaft, die in sozionaturalen Krisen resultierten, in den Blick genommen. Zum einen ermöglichen temporäre Krisen, wie bereits die Alltagsgeschichte konstatiert hat, eine Annäherung an den Alltag, da die silent normality zusammenbreche und die Menge der Quellen deutlich anwachse. ${ }^{84}$ Zum anderen stellt sich die Frage nach dem "effect of the natural environment on city life « ${ }^{85}$ Somit geht es um die Auswirkungen von durch die Natur induzierten Krisen auf den städtischen Alltag, um den Umgang mit und das Lernen aus ihnen, was anhand von drei Szenarien - Epidemien, Versorgungskrisen und Naturgefahren - untersucht wird.

Krisen betrafen Stadtbewohner/innen in unterschiedlicher Intensität, die vor allem in räumlicher und sozialer Hinsicht divergierte. ${ }^{86}$ Deshalb ist in krisenbezogenen

\footnotetext{
8o Lefebvre, Revolution, 44 f. u. I 40.

8I Ebd., 47 u. I39.

82 Douglas, Analysis, I6f.; Heynen/Kaika/Swyngedouw, Ecology, 8; vgl. Steege et al., History, ${ }_{6} 6{ }_{3} f$.

83 Vgl. die räumliche Analyse verschiedener Umweltbereiche für Münster (Historischer Umweltatlas

Münster) und die Arbeiten zur Wiener Donau: Hohensinner et al., Changes u. Hohensinner et al., Steps.

84 Steege et al., History, 376; Lüdtke, Einleitung, I 2 ; Evans, Tod, 7 ro; vgl. zum Begriff: Collet, Katastrophe, 7 f. u. 34 f.

85 Tarr, History, 38.

86 Benton-Short/Short, Cities, I 23- I 25.
} 
Forschungsarbeiten neben der Beschäftigung mit den auslösenden Momenten und dem Ereignis an sich als systemischer Zugang das Konzept der Vulnerabilität vorgeschlagen worden, wobei Vulnerabilität als Wahrscheinlichkeit verstanden wird, mit der Menschen aufgrund bestimmter Ereignisse und Konstellationen Schaden nehmen. Dabei ist von einer historisch bedingten und sich verändernden Vulnerabilität auszugehen, die zudem durch Wahrnehmungen und Diskurse bestimmt sei. In der Forschung ist die Vulnerabilität meist über die Mortalität oder die Höhe von Schäden bemessen worden, seit den letzten Jahren fragt man aber zunehmend nach dem Handeln in Krisen. Dem Krisenereignis folgten gesellschaftliche Auswirkungen, wobei die Gesellschaft mit kurzfristiger Anpassung resp. langfristiger Adaption reagierte. Durch Adaption - d.h. durch präventives Handeln - konnten Gesellschaften eine höhere Resilienz gegen künftige Krisen erreichen. ${ }^{87}$

Die Betrachtung von Epidemien liegt an der Schnittstelle zwischen Medizin- und Umweltgeschichte: Neben Fragen nach Gesundheit und Krankheit, nach medizinischem Wissen und medizinischen Infrastrukturen stehen die nach der Rolle der städtischen Umwelt, denn Übertragungswege waren eng an spezifische Umweltbedingungen geknüpft, und Epidemien induzierten ebenso erhebliche Umweltveränderungen. Für das I 8. und I9. Jahrhundert handelt es sich um Pest- und Choleraepidemien, die im Hinblick auf die Impacts und die dagegen ergriffenen Maßnahmen untersucht werden. Häufig wurde hier ein lineares Narrativ mit - oft über die Passivform artikulierten - Automatismen entworfen, das ein »Besiegen« von Epidemien durch die Expansion von Wissen und Infrastrukturen sowie die Durchsetzung neuer Hygienestandards beschrieb. Dabei wurden zentrale Fragen nach Kausalitäten sowie nach Motiven, Strategien, Interessen und Macht von Akteuren, nach der räumlichen und sozialen Ungleichheit bei Krankheit und Tod selten gestellt. ${ }^{88}$

Bis ins I9. Jahrhundert traten regelmäßig klimatisch induzierte Versorgungskrisen auf: Eine spezifische Kombination von Temperatur- und Niederschlagsanomalien resp. Extremereignissen resultierte in Ernteausfällen, geringeren Erträgen oder einem geringeren Nährwert der Lebensmittel, was wiederum deren Preise ansteigen ließ. War die Ernährungsbasis Getreide von dieser Entwicklung betroffen, dann erschwerte sich für einzelne Bevölkerungsteile der Zugang zu Nahrungsmitteln, was in einer Hungersnot resultieren konnte. Diese hatte demographische und soziale Auswirkungen, die von Unterernährung, dem Sinken der Geburtenzahlen und einem Anstieg der Mortalität bis hin zu Abwanderung oder sozialen Unruhen reichen konnten. ${ }^{89}$ Derartige Versorgungskrisen sind nicht nur als Naturkatastrophen, sondern auch als ein Versagen von vulnerablen Systemen und als ein Produkt spezieller

87 Krämer, Vulnerabilität; Collet, Vulnerabilität; Collet, Katastrophe, 30-37 u. I4If.

88 Evans, Tod; Hamlin, Health, 8- I I ; vgl. Schott, Urbanisierung, 223-245.

89 Pfister/Brázdil, Vulnerability; Mauelshagen, Klimageschichte, 86f.; Krämer, Vulnerabilität; vgl. als Überblick: Reith, Umweltgeschichte, I 2 - I 5 u. 79 f. 
politischer und sozioökonomischer Konstellationen $\mathrm{zu}$ verstehen und $\mathrm{zu}$ analysieren. ${ }^{90}$

Zwei Naturgefahren, ${ }^{91}$ die in der vormodernen und sich modernisierenden Stadt omnipräsent waren und sich dementsprechend relativ gut beobachten lassen, sind Überschwemmungen und Brände. Wenn eine Stadt - wie Linz - an einem größeren Fluss lag, dann stellten Hochwasser und die damit verbundenen Auswirkungen eine periodisch wiederkehrende Erfahrung dar, die durch außergewöhnliche Extremereignisse durchbrochen wurde. Dabei ist Hochwasser als ein anthropogen definiertes Ereignis zu sehen: Natürliche Fluktuationen eines Flusses wurden zur Gefahr, wenn Menschen bzw. Besitz betroffen waren. ${ }^{92}$

Infolge der großen Anzahl von Feuernutzern, der dichten Bauweise und der Omnipräsenz brennbarer Materialien in der Stadt war das Brandrisiko in der Vormoderne relativ hoch. Auch andere Umweltkonstellationen, der Mangel an Löschwasser oder klimatische Faktoren (Trockenheit und Wind) begünstigten den Ausbruch von Bränden. Das Brandrisiko verringerte sich bis ins i 9. Jahrhundert erheblich - das Ausbleiben von Großbränden trotz steigender Bevölkerungszahlen hat die Forschung als fire gap bezeichnet und auf ein verändertes Risikobewusstsein und Risikomanagement verwiesen. Brände hatten auch sekundäre Wirkungen: Nach Großbränden ergaben sich für die Städte Möglichkeiten der Umgestaltung und erhebliche Veränderungen von umweltbezogenen Praktiken. ${ }^{93}$

\section{Begrenzungen}

Obgleich sich vergleichende Ansätze als probates Mittel der Geschichtswissenschaft (und besonders der Stadtgeschichte) erwiesen haben, ist dies in diesem Buch nicht intendiert: Die Umwelt eines städtischen Raumes ist als sehr spezifisch zu erachten (schon im Hinblick auf naturräumliche Gegebenheiten), somit würde ein vergleichender Ansatz - zumindest außerhalb eines größeren Projektverbundes - eine tiefergehende Analyse erschweren und wahrscheinlich in Oberflächlichkeit resultieren. Somit beschränkt sich das vorliegende Buch auf die Untersuchung eines Exempels.

Die Gründe für die Auswahl des Fallbeispiels Linz liegen einerseits in der relativ begrenzten Größe der Stadt, was es erlaubt, eine Analyse auf mittlerer Ebene durchzuführen, also etwa einzelne, konkrete Räume vertiefend zu bearbeiten, ausgewählte Individuen innerhalb des städtischen Raumes zu verorten und somit sozioökonomische mit ökologischen Aspekten zu verbinden. Andererseits ermöglicht das Exempel Linz, einen Blick auf eine Mittelstadt und ihre Umwelt zu werfen, worüber bislang

\footnotetext{
90 Mauelshagen, Klimageschichte, gof.

9I Im Sinne von environmental hazards - vgl. dazu die Diskussion in: Benton-Short/Short, Cities, I $22 \mathrm{f}$.

92 Brázdil/Kundzewicz/Benito, Hydrology; vgl. Mauelshagen, Klimageschichte, I 2 If. u. Cioc, Rhine, 33.

93 Garrioch, Fire; Mauelshagen, Klimageschichte, I24- r 30; Schott, Urbanisierung, I 78 - r 8 I u. $238 f$.
} 
wenig bekannt ist. Zudem handelt es sich bei Linz um eine Stadt, die durch die Donau geprägt ist, was wiederum Anknüpfungspunkte an gegenwärtige Forschungsdiskussionen zur Geschichte von Flüssen und deren Auswirkungen auf Ansiedlungen und zur Interaktion von Gesellschaften mit Flüssen bietet. ${ }^{94}$

Es ist nicht sinnvoll, die Betrachtung einer Stadt auf deren administrative (politische) Grenzen zu beschränken, da vormoderne und moderne Ballungsräume in eine Vielzahl von lokalen, regionalen und überregionalen Beziehungen eingebunden waren. ${ }^{95}$ William Cronon hat diese vielfältigen Wechselwirkungen zwischen Stadt und Hinterland, deren Implikationen und die Transformationen des urban-rural-system am Beispiel Chicagos im I9. Jahrhundert in seinem Buch "Nature's Metropolis« analysiert. ${ }^{96}$ Das vorliegende Buch wird - aufgrund konzeptioneller Überlegungen - jedoch nicht alle Vernetzungen der Stadt Linz mit ihrem Hinterland rekonstruieren, die Stadt-Hinterland-Beziehungen aber für ausgewählte thematische und zeitliche Bereiche untersuchen und auch die urbane Peripherie berücksichtigen. Der hauptsächliche Fokus wird auf der historischen inneren Stadt und den beiden Vorstädten liegen (vgl. Kap. 2. Kontexte: Linz I 700 bis I900). Die Wahl des Zeitraums I 700- I900 ergibt sich aus dem Versuch, die Veränderungen des I 9. Jahrhunderts in einen breiteren zeitlichen Kontext zu stellen und auch die erste Hälfte des I 8. Jahrhunderts, die mitunter noch zu einer Phase der "widespread urban stagnation « gerechnet wird, einzubeziehen. ${ }^{97}$

\section{Quellen}

Archivalien ehemaliger städtischer Behörden und Institutionen bilden die Basis zahlreicher stadthistorischer Untersuchungen für die Zeit vor ı 900, und sie sind auch ein Ausgangspunkt für die vorliegende Studie. Die Frage nach alltäglichen Praktiken impliziert jedoch die Berücksichtigung von Überlieferung abseits der »offiziellen« Politik und Verwaltung. Somit wurden auch Quellen einbezogen, die durch die städtische Umweltgeschichte bislang nur selten verwendet worden sind, wie etwa Rechnungsbücher, Ego-Dokumente oder Bildquellen.

Linz verfügt - und das kann zumindest für den österreichischen Raum als Alleinstellungsmerkmal gelten - mit den »Linzer Regesten« über ein sehr umfangreiches Kompendium an edierten schriftlichen Quellen für die Frühe Neuzeit. ${ }^{98}$ Die Regestenbände - nach meiner Zählung I 99 Bände - wurden ab I 952 bis in die I $990 e r$ Jahre

94 Vgl. als rezente Forschungsübersicht EdN, s.v. Flüsse; zudem Schott, Fluss; Knoll/Lübken/Schott, Introduction u. Gingrich/Haidvog1/Krausmann, Danube.

95 Winiwarter/Knoll, Umweltgeschichte, r 8of.

96 Cronon, Metropolis - vgl. auch die Überlegungen von Samuel Hays zum urbanen outreach: Hays, Role, 75-8o.

97 Clark, Cities, I 23.

98 Linzer Regesten (LR). 
veröffentlicht, um die im frühen I 9. Jahrhundert erfolgte Skartierung von städtischen Archivalien auszugleichen. Insgesamt erschienen mehrere zehntausend Seiten mit Regesten, die aus zahlreichen inländischen und ausländischen Archiven kompiliert wurden. Dabei wurden die umfangreichen Bestände der früheren Landstände genauso berücksichtigt wie grundherrschaftliche oder kirchliche Archive, es finden sich sogar Regesten zur »Linzer Zeitung«. Das Archiv der Stadt Linz wurde von den »Linzer Regesten« nicht erfasst, was zwar einer gewissen Logik folgt, aber ex post als eine etwas unglückliche Entscheidung erscheint. Interessanterweise sind die »Linzer Regesten« außerhalb der Lokalgeschichte noch nicht intensiver genutzt worden, obwohl sie einen ungewöhnlich einfachen Zugang zu einer breiten Quellenbasis ermöglichen und gleichzeitig eine wichtige Überblicksfunktion haben. Die Verwendbarkeit der Regesten divergiert: Teilweise sind Vollregesten vorhanden, die einzelne Bestände minutiös erschließen, meistens sind die Regesten aber eher knapp gehalten und manchmal wurde - etwa im Falle der Zeitungen und besonders bei seriellen Quellen (wie Rechnungsbüchern) - sehr selektiv gearbeitet, mitunter spürbar an Interessen der damaligen Bearbeiter/innen ausgerichtet.

Es ist die Frage, ob die Skartierungen der I 8 2oer Jahre (und vermutlich auch in der Folge) die Bestände im Archiv der Stadt Linz tatsächlich »zum großen Teil und planmäßig vernichtet« oder nur fragmentiert haben. ${ }^{99}$ Linz kann diesbezüglich wohl nicht als Ausnahmefall gewertet werden, aber tendenziell betraf dies besonders Archivalien, die aus umwelthistorischer Sicht relevant gewesen wären, da sie durch die Bürokratie des I 9. und frühen 20. Jahrhunderts oftmals als wenig bedeutend eingestuft wurden. Dennoch gibt es eine erhebliche Anzahl an Quellen im Archiv der Stadt Linz, die eine Annäherung an Aspekte urbaner Umwelt zulassen: Zumindest für das ausgehende r 8. und das I 9. Jahrhundert sind einige Bestände - wenngleich augenscheinlich lückenhaft - besonders zum Bauwesen und zur öffentlichen Sauberkeit vorhanden. ${ }^{100}$ Die Ratsprotokolle, eine zentrale Quelle der vormodernen Stadtgeschichte, sind erst ab dem Jahr I796 erhalten, ${ }^{101}$ ab I 876 sind neben den Ratsprotokollen gedruckte Rechenschaftsberichte des Gemeinderats verfügbar. ${ }^{102}$

Die Stadt als Akteur wird genauso in anderen Beständen sichtbar, besonders über die Interaktion mit den Landständen und der Landesregierung, deren Aktenmaterial vor allem für das I8. Jahrhundert umfangreich ist. Zudem waren die Stände und die Landesregierung politische Akteure im Stadtraum und als Immobilienbesitzer auch Unterhalter von Brunnen, einer Wasserleitung und eines Abwasserkanals. ${ }^{103}$

\footnotetext{
99 Kreczi, Linz, 233.

Ioo Vor allem die Bestände AStL, Altakten; ebd., Alte Registratur; ebd., Materienbestand.

Io r AStL, HS ro83ff. u. GRP - die Protokolle sind aber bis in die r 86oer Jahre hinein wenig ergiebig, da in der Regel nur die Beschlüsse notiert wurden.

I02 $\mathrm{RB}$ i $876 \mathrm{ff}$.

I03 Vor allem OÖLA, Landschaftsakten; ebd., Landschaftsakten, Alte Registratur - diese Bestände sind partiell von den »Linzer Regesten« erfasst worden.
} 
Die Arbeit mit Verwaltungsquellen beinhaltet sicherlich ein fundamentales Problem: Dysfunktionale Bereiche und Konflikte oder Anordnungen »von oben« dominierten den Verwaltungsalltag, was es erschwert, Normalität zu rekonstruieren. ${ }^{104}$ Somit erscheint bei der Frage nach dem Alltag eine Hinwendung zu anderen Beständen notwendig: Im Linzer Fall hat sich vor allem Material aus kirchlichen und herrschaftlichen Institutionen als ergiebig erwiesen. Als Beispiel kann der Quellenbestand der ehemaligen Herrschaft Weinberg fungieren: ${ }^{105}$ Durch die personelle Nähe zur Landesverwaltung finden sich zahlreiche Quellen zur Pestepidemie I7I3, die in Verbindung mit anderen Beständen eine überraschend »dichte« Beschreibung dieser Krise ermöglichen. Zudem verfügte die Herrschaft Weinberg über ein Linzer Herrschaftshaus (das Freihaus Thürheim), was über die Korrespondenz des Hausverwalters mit der Herrschaft einen Zugang zum städtischen Alltag gewährt. ${ }^{106}$

Rechnungsbücher liefern einen Zugang zu material flows, zur Verwendung von Ressourcen und zu anderen umweltbezogenen Praktiken: ${ }^{107}$ Zum einen stehen städtische Rechnungsbücher zur Verfügung - Gesamt- und Teilrechnungen (etwa des städtischen Bauamts oder Brunnenamts) $)^{108}$-, zum anderen Ausgabenrechnungen von Haushalten und anderen Institutionen. Auch hier besteht eine Zugriffsmöglichkeit auf die Alltagspraxis, da oftmals Ausgaben notiert wurden, die über andere Quellen kaum sichtbar werden. ${ }^{109}$ Für Linz handelt es sich um die Ausgabenrechnungen der Familie Thürheim, ${ }^{110}$ Vergleichbares gibt es für einzelne Klöster und Orden als Freihausbesitzer (Wilhering, Kremsmünster und der Deutsche Orden). Diese unterhielten oder etablierten Haushalte mit umfangreichen Ausgaben: Für die beiden Kremsmünsterer Häuser sind ab dem I6. Jahrhundert - fast lückenlos bis ins I9. Jahrhundert - Kammerei- und Rentsamtrechnungen überliefert, die als Sample auch von den "Linzer Regesten « erfasst wurden. ${ }^{111}$ Im Hinblick auf die Ausgabenrechnungen erfolgte einerseits die Auswertung der in den »Linzer Regesten« erfassten Rechnungen, andererseits eine Durchsicht ausgewählter Jahrgänge. ${ }^{112}$

\footnotetext{
I04 Vgl. Elisabeth Suters Überlegungen zu alltäglichen Wasserinfrastrukturen in Zürich: Suter, Wasser, 26. I05 OÖLA, Herrschaftsarchiv Weinberg - Regesten (bis zum Ende des I 8. Jahrhunderts) in LR BIIG $3-8$. Io6 An der heutigen Adresse Altstadt 30/Promenade 26 (Konskr.-No. 6r) - Kreczi, Häuserchronik, 24.

I07 Vgl. zum Potential: Rohr, Überschwemmungen u. Körner, Stadtzerstörung, Bd. I, I78.

Io8 AStL, Handschriften - die Rechnungen des Stadtkammeramts und des Bauamts sind relativ lückenlos überliefert.

Io9 Vgl. Reith et al., Haushalten.

I I O Ausgaben für Freihaus Thürheim: OÖLA, Herrschaftsarchiv Weinberg, Sch. 64Iff. - Regesten in LR BIIG8.

II I LR BVI 4 .

I 2 OÖLA, Herrschaftsarchiv Weinberg, Sch. 643 u. Sch. 66I - dabei handelt es sich um die Jahre I 7 IoI 723 U. I $770-$ I 774 .
} 
Ego-Dokumente, also Tagebücher, Chroniken und Briefe, sind bislang noch wenig durch die städtische Umweltgeschichte genutzt worden. ${ }^{113}$ Für Linz ist eine erstaunliche Anzahl von Chroniken vorhanden, die unerwartete Einblicke in Transformationsprozesse, aber auch in alltägliche Erfahrungen und Wahrnehmungen gewähren: Die »Sint-Chronik« verfasste der Archivar Leopold Joseph Sint (r674-1749) - als Sohn des Gründers der Wollzeugfabrik Teil des Linzer Establishments - vermutlich ab den I73oer Jahren, wobei sich Nachträge bis ins Jahr I 82 I finden. ${ }^{114}$ In den I $760 e r$ Jahren entstand die »Seyringer-Chronik«, die durch den Exjesuiten und Lehrer Ignaz Seyringer (gest. I777) zusammengestellt wurde und eine ausführliche Schilderung der Pest von I7I3/I7 I 4 enthält. ${ }^{115}$ Dazu kommen die Chroniken der Linzer Klöster (Kapuziner, Ursulinen, Karmeliter, Barmherzige Brüder, Minoriten), die ebenso meist aus dem I8. Jahrhundert stammen: Auch die Chronik der Urfahrer Kapuziner thematisiert die letzte Pestepidemie und ermöglicht dadurch eine Ergänzung und Kontrastierung der landesbehördlichen Überlieferung. Da das Urfahrer Kapuzinerkloster unmittelbar an der Donau lag, existiert zudem viel Material zu den Hochwasserereignissen des I 8. Jahrhunderts, besonders für die I740er und I75oer Jahre gibt es relativ lückenlose zeitgenössische Beschreibungen. ${ }^{116}$ Chronikale Aufzeichnungen sind auch für das I 9. Jahrhundert greifbar: Die »Geschichte von Linz«, die bis I 850 überblicksartig und danach bis Mitte der I 86oer Jahre wie eine Chronik angelegt ist, erschien über fast zwei Jahrzehnte (I867- I885) im »Geschäfts-, Haus- und Volks-Kalender [...] Der Oberösterreicher « und basiert vor allem auf Zeitungen und gedruckten Quellen. ${ }^{117}$ Der Verfasser der "Geschichte " war der in den I 8 Ioer Jahren geborene und I 870 gestorbene Buchhändler Josef Fink, ein Bruder des Linzer Bürgermeisters Vinzenz Fink. ${ }^{118}$

Eine interessante und für Linz singuläre Quelle bilden die Tagebücher von Franz de Paula Haslinger (I765-1833), der von I 806 bis zu seinem Tode in Linz lebte. ${ }^{119}$ Der Pfarrer und kirchliche Funktionär Haslinger notierte täglich das Wetter und wenngleich nur sehr kurz - andere Begebenheiten, besonders seine Beobachtungen

I 3 Allenfalls durch die Klimageschichte; vgl. als eine Ausnahme in einem anderen Themenfeld: Cockayne, Hubbub.

I 4 Ediert in LR E6; die in den I770er Jahren entstandene Abschrift (mit den erwähnten Nachträgen) befindet sich im AStL (HS 86I), daraus stammen im Folgenden auch alle direkten Zitate; vgl. zur Chronik: Ebner/Ebner/Weißengruber, Literatur, $92 \mathrm{f}$.

I 5 Ediert in LR E6.

ir6 LR Eia u. LR Eif.

I 7 Fink, Geschichte (= Sonderdruck aus dem Jahr I 885 mit eigener Paginierung); die letzten drei Teile (für den Zeitraum Juli I 862 bis Ende I866) erschienen nur in "Der Oberösterreicher" (Jahrgänge I $888_{3}$ I885); im Bestand OÖLA, Musealarchiv befinden sich das Manuskript (HS I78 u. I79) und die »Materialien« Finks ( $\mathrm{HS}_{5}$ I $)$. Entstanden ist das Werk Finks vermutlich zwischen den I $840 e r$ und I 86oer Jahren.

I 8 (Linzer) Tages-Post I 8. September I 870.

I 9 Stiftsbibliothek St. Florian, Handschriftensammlung, XI ${ }_{56}{ }_{5} \mathrm{~B}$ - zitiert in der Folge als $\mathrm{HTb}$ (unter Beifügung des entsprechenden Datums bzw. Abschnittes). 
zur Versorgungslage und zu Preisentwicklungen sind von wirtschafts, sozial- und umwelthistorischer Relevanz (vgl. Kap. ıо. Versorgungskrise). In den I 96oer Jahren wurden die Temperaturangaben und die kurzen täglichen Wetterbeschreibungen ediert, eine Auswertung unterblieb jedoch. ${ }^{120}$

Umfangreich ist auch die Korrespondenz von Adalbert Stifter, ${ }^{121}$ der seit 1845 einzelne Sommermonate in Urfahr verbrachte und dann ab I 848 als Beamter bis zu seinem Tod I 868 in Linz nahe der Donau lebte. ${ }^{122}$ Stifters Korrespondenz gewährt besonders für das Auftreten der Cholera in Linz I 865/r 866 Einblicke in Alltagspraktiken und Alltagswahrnehmungen. Aus bürgerlichen Haushalten des I 9. Jahrhunderts sind weitere Ego-Dokumente vorhanden: Ausführlicher sind die Erinnerungen von Emma Fossel, einer Tochter des Apothekers und Botanikers Carl Ehrlich, an ihre Kindheit im Linz der I 85 oer und I 86oer Jahre ${ }^{123}$ und ein biographischer resp. autobiographischer Text des Linzer Beamten Joseph v. Spaun, der zeitlich in die erste Hälfte des I 9. Jahrhunderts fällt. ${ }^{124}$ Andere Ego-Dokumente geben nur kürzere Episoden mit Linz-Bezug wieder: Karl Hirnschrodt, der der Sohn eines Linzer Webers und selbst zeitweilig in Linz Bäcker war, ${ }^{125}$ und der Schriftsteller Hermann Bahr ${ }^{126}$ haben Beschreibungen ihrer Kindheit und Jugend in den I 85 oer und I 86 oer resp. den I $870 e r$ Jahren hinterlassen, der Jurist und spätere Landesarchivar Ferdinand Krackowizer schilderte sein Ankommen in Linz im Mai I 868, ${ }^{127}$ und das Tagebuch des Wiener Mehlhändlers Gottfried Hartung berichtet über einen Linz-Besuch I 887 im Rahmen seiner Hochzeitsreise. ${ }^{128}$

Systematisch gesichtet und analysiert wurden die Kataster des späten I8. und frühen I9. Jahrhunderts, die zahlreiche Aspekte städtischer Umwelt tangieren und Rückschlüsse auf Flächennutzung, aber auch auf Alltagspraktiken und partiell auf Naturwahrnehmungen zulassen. ${ }^{129}$ Linz und die Vorstädte wurden durch das I 786 bis I 788 entstandene "Josephinische Lagebuch« erfasst, wobei die Vermessung der Parzellen

I 20 Haslinger, Tagebücher; vgl. zum Quellentypus: White/Pfister/Mauelshagen, Handbook, 53-58; EdN, s.v. Wettertagebuch u. Strömmer, Klima-Geschichte, 34-37.

I 2 I Stifter, PRA, Bde. I7-24; vgl. dazu Begemann/Giuriato, Stifter-Handbuch, I84- I 89.

I 22 Ebner/Ebner/Weißengruber, Literatur, 228 u. 23 I ; Haslinger, Ehrenbuch, I 24 ; Stifter, vgl. PRA, Bd. I 7, 299.

I 23 Es handelt sich dabei um eine von Emma Fossel um I 890 verfasste »Familien Chronick« (OÖLA, Nachlass Familien Dierzer v. Traunthal-Fossel, Sch. I) und um ein als »Mädchenjahre in Linz (I 855 77) « bezeichnetes Typoskript aus dem Jahr 1985 (Doku, Fossel). Das Typoskript bezieht sich teilweise auf die »Familien Chronick« und vermutlich auf ein weiteres - mir jedoch unbekanntes - Ego-Dokument von Emma Fossel.

I 24 Doku, Spaun; vgl. Depiny, Aufzeichnungen.

I25 Doku, Hirnschrodt.

I 26 Hermann-Bahr-Buch u. Bahr, Selbstbildnis.

I 27 Commenda, Linz, $236 f$.

I 28 Doku, Hartung.

I 29 Vgl. Gingrich/Haidvog1/Krausmann, Danube u. Miodunka, Longue Durée, 75-94. 
durch die Besitzer/innen selbst geschah. ${ }^{130}$ Differenzierter und wesentlich umfangreicher ist der "Franziszeische Kataster«, der in verschiedenen Arbeitsabschnitten I $825-$ I 827 , I 83 I - I 835 und I 842 angelegt wurde. ${ }^{131}$ Die Vermessungsarbeiten wurden bei diesem Kataster von Geometern und Militärangehörigen durchgeführt, die in den I 8 2oer Jahren auch das begleitende Kartenmaterial anfertigten. ${ }^{132}$ In den I $950 e r$ Jahren edierte der Linzer Lokalforscher und Landesbeamte Franz Xaver Bohdanowicz die Lagebücher und den Kataster für die ehemaligen Vorstädte und Vororte von Linz (also nicht für die Stadt Linz selbst), wobei Bohdanowicz auf mehreren tausend Seiten zusätzliche Informationen aus den Grundbüchern und anderen Quellen einfließen ließ. ${ }^{133}$ Zwar beinhalten die Kataster eine große Informationsmenge, es handelt sich aber - besonders tritt dies beim »Franziszeischen Kataster« zutage - um eine Quelle, die gezwungenermaßen abstrahiert, auf eine Standardisierung und eine Reduktion von Komplexität abzielt und mitunter - als Querschnitt zu einem bestimmten Zeitpunkt Stillstand suggeriert. ${ }^{134}$

Es hat sich insgesamt als schwierig erwiesen, zuverlässigere Zahlen zu Bereichen städtischer Umwelt zu erheben, etwa zur Flächennutzung, zu Materialtransfers oder zum Konsum: Für das I 8. Jahrhundert sind generell nur wenige und eher punktuelle Daten verfügbar, auch das umfangreiche Zahlenmaterial der Kataster ist - aufgrund von wechselnden Zählbezirken und unterschiedlichen Kategorien bzw. Vereinfachungen - nur schwer mit früheren und späteren Angaben zu vergleichen. Dennoch finden sich im Gefolge des »Franziszeischen Katasters» vermehrt lokale Statistiken und ab den I 83 oer Jahren setzen die staatlichen Statistiken ein. ${ }^{135}$ Aber auch mit der zunehmenden Datenfülle sind nicht zwingend konsistente Zahlen zu erwarten: Es finden sich Fehler, unklare Maße (besonders beim Brennholz) und wiederum neue Zählbezirke, zudem wurde die Stadt Linz in zahlreichen Fällen unter dem viel größeren Gebiet "Mühlkreis« subsumiert. ${ }^{136}$ Dennoch lässt sich auf dieser Basis ein Zugang zu mittel- und längerfristigen Transformationsprozessen gewinnen, die in anderen Quellen nicht evident werden.

Umfangreich ist der Bestand an anderen gedruckten Quellen, deren Zahl besonders in den letzten Jahrzehnten des I 8. Jahrhunderts und nochmals im Verlauf des I 9. Jahrhunderts deutlich anwuchs. Für Linz ist eine Zeitung, das »Lintzer Extract Blatl« zwar schon seit den I67oer Jahren belegt, regelmäßig erschien eine regionale Zeitung

I30 OÖLA, Josephinisches Lagebuch, HS r 90 - 192 (Linz Stadt, Obere und Untere Vorstadt); vgl. Bohdanowicz, Vorstädte, Bd. I, 9, ders., Vorstädte, Bd. 2, 35 u. LR Eıf, Reg. 448 (I 84 f.).

I3 I OÖLA, Franziszeischer Kataster, No. 534 (Linz Stadt, Obere und Untere Vorstadt) u. OÖLA, Franziszeischer Kataster, No. Iogo (Urfahr); Bohdanowicz, Vorstädte, Bd. I, 9 u. 467.

I32 Online zugänglich über Doris, Urmappe oder Mapire, Franziszeischer Kataster.

I33 Bohdanowicz, Vorstädte, ders., Urfahr, ders., Kleinmünchen.

I 34 Vgl. Scott, Seeing, 44-46.

I35 Vgl. zum I9. Jahrhundert: Fuchs, Produktion, $32-38$.

I36 Ebd., 34f. u. 54 f. 
aber erst ab den I75oer Jahren mit der »Linzer Zeitung «, die jedoch über mehrere Jahrzehnte die meisten Inhalte aus Nicht-Linzer Zeitungen übernahm und somit nur begrenzt das Linzer Alltagsleben dokumentierte. ${ }^{137}$ In die »Linzer Regesten« wurden einzelne Jahrgänge der »Linzer Zeitung « aus der zweiten Hälfte des I 8. Jahrhunderts relativ vollständig aufgenommen, ${ }^{138}$ die Auswahl für die Jahre I $800-$ I 840 war jedoch deutlich selektiver. ${ }^{139}$ Ergänzt wurde diese Sammlung von insgesamt mehreren zehntausend Zeitungsregesten mit der Durchsicht von ausgewählten Jahrgängen der »Linzer Zeitung « ${ }^{140}$ und Digitalisaten von Linzer Zeitungen aus dem Angebot »A N NO « der Österreichischen Nationalbibliothek. ${ }^{141}$ Dabei lieferten besonders die ab den r 86oer Jahren greifbaren Leser/innenbriefe eine interessante Zugangsmöglichkeit zu Wahrnehmungen von Sauberkeit und städtischer Repräsentativität.

Auch die Menge der zeitgenössischen Literatur expandierte deutlich im letzten Drittel des I 8. Jahrhunderts. ${ }^{142}$ Für Linz sind zwei interessante Satiren mit Lokalbezug hervorzuheben, die zwar als relativ typische Produkte der I 78 oer Jahre gelten können, aber dennoch spezifische Wahrnehmungen von städtischer Umwelt und Infrastrukturen widerspiegeln. Die I 783 anonym erschienene "Reise nach dem Kürbislande«, die polemische Kritik an Kirche und Verwaltung übt, ist verschiedenen Autoren zugeschrieben worden, wobei die neuere Forschung zum Linzer Wundarzt Franz Xaver Belotti tendiert. ${ }^{143}$ Die Satire »Die Gimpel Insel, oder der Stiefbruder des Linnäus« erschien im gleichen Jahr, ebenso ohne Nennung des Autors, was wenig überrascht, da »Die Gimpel Insel« ein ungleich böseres Spottbild entwirft. Eine mit Vögeln bevölkerte Insel fungiert als Allegorie auf Linz: Als ein Mensch dort strandet, wird er von einem aufgeklärten Star durch die Insel - die Stadt Linz - und ihre Missstände geführt. ${ }^{144}$ Es gebe in Linz "noch zu viele Vorurtheile und zu wenig Aufklärung«, entschuldigt sich der Star. ${ }^{145}$ Der Verfasser war wohl ein Linzer, dem die damalige Elite vertraut gewesen sein musste: Man hat als Autor den Landesrat Joseph Valentin Eybel angenommen, was, da Eybel und dessen Umfeld relativ unvorteilhaft dargestellt werden, zwar nicht als unmöglich, aber eher unwahrscheinlich erscheint. Immerhin scheint »Die Gimpel Insel« breit rezipiert worden zu sein - der Berliner Verleger und Publizist Friedrich Nicolai stellte das Bändchen in der »Allgemeinen deutschen Bib-

I 37 Ebner/Ebner/Weißengruber, Literatur, I 5 r ; vgl. LR E7a u. b, Xf.

I 38 I 758/59, I773, I776, I778-I786, I789/90, I796 u. I799-LR E7a u. b.

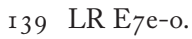

I 40 I 779/I 780, I 783/I 7 84, I 803/I 804, I 8 I 6/I 8 I 7, I 820 - I 823, I 828 , I 830 - I 832, I 845 - I 848 , I 855 /I 856 u. I $866 /$ I 867 .

I 4 I Zugänglich unter http://anno.onb.ac.at.

I 42 Vgl. Gugitz, Linz, 6 I -68 u. Haslinger, Ehrenbuch, 37.

I 43 Rabiosus, Reise, Bd. I u. 3; vgl. Ebner/Ebner/Weißengruber, Literatur, r69.

I 44 Gimpel Insel; vgl. Gugitz, Gimpelinsel, 3 I If. u. Ebner/Ebner/Weißengruber, Literatur, I69f.

I 45 Gimpel Insel, I42. 
liothek« vor und fügte hinzu, dass nicht nur er über den »Schlüssel« verfüge, der die einzelnen Vögel der Geschichte ihren realen Vorbildern zuwies. ${ }^{146}$

In diese Phase fiel auch die Entstehung der ersten topographischen Beschreibungen von Linz: I 787 erschien - möglicherweise auch eine Replik auf die etwas unverschämte »Gimpel Insel« - die »Skizze von Linz« des Beamten Heinrich Georg Hoff, einem Nicht-Linzer. ${ }^{147}$ I 8 I 2 veröffentlichte Gottlob Heinrich Heinse, ein Schriftsteller aus Gera, das handbuchartige "Linz und seine Umgebungen " ${ }^{148}$ und I 824 , I 837 und I 846 erschienen die umfang- und detailreichen Bände zur Topographie und Geschichte von Linz, die der ab 1822 in Linz tätige Beamte Benedikt Pillwein verfasst hatte. ${ }^{149}$ Pillweins Darstellungen, die teilweise von sehr hochwertigem Kartenmaterial begleitet wurden, sind als relativ akkurat zu werten, und sie wurden von Pillwein durchaus als Antwort auf die Fehler und Ungenauigkeiten früherer Stadt- und Reisebeschreibungen gesehen. ${ }^{150}$

Linz wurde auch in Reisebeschreibungen, deren Zahl ab dem Ende des r 8. Jahrhunderts spürbar anstieg, breiter Raum gewährt. Es sind zahlreiche Berichte - aus der ersten Hälfte des i 9. Jahrhunderts besonders von Reisenden auf der Donau - vorhanden, die aber Linz meist im Rahmen von Tagesaufenthalten besuchten. ${ }^{151} \mathrm{Ab}$ den I 86oer Jahren wurden kaum noch derartige Beschreibungen publiziert, dafür tauchten seit dieser Zeit die etwas nüchterneren Stadt- und Umgebungsführer auf. ${ }^{152}$

Gesichtet und ausgewertet wurden schließlich wissenschaftliche Abhandlungen und Gebrauchsliteratur mit Linz-Bezug, dies besonders für das I 9. Jahrhundert: Verwaltungsliteratur, Gesetzeskompendien und naturkundliche oder technische Literatur, z.B. die "Allgemeine Bauzeitung", die ab I 836 in Wien erschien und eine Annäherung an technisch-administrative Vorstellungen zulässt. ${ }^{153}$ Adressbücher, die ab den I 82 oer Jahren auch Berufsbezeichnungen enthalten, ermöglichen es, räumliche Aspekte von Umweltbelastungen bzw. problemen zu rekonstruieren. ${ }^{154}$

I46 Allgemeine deutsche Bibliothek 57 (1784), 597-60r.

I47 Hoff, Skizze; Ebner/Ebner/Weißengruber, Literatur, I66; der Wiener Franz Sartori bezeichnete Hoff I 8 I I als »mühsame[n] Verfasser der elenden Skizze« (Sartori, Reise, 409).

I 48 Heinse, Linz, I. Aufl.; eine zweite, in einigen Teilen erheblich divergierende Auflage erschien I 838 Heinse, Linz, 2. Aufl.; vgl. Haslinger, Ehrenbuch, 83.

I49 Pillwein, Beschreibung; Pillwein, Linz; Pillwein, Wegweiser.

I50 Mayrhofer/Katzinger, Geschichte, Bd. 2, 95; Haslinger, Ehrenbuch, roo; vgl. Pillwein, Beschreibung, 217.

I5 I Vgl. Király, Donau, 210-213; Gober, Linz, I5 If.; z.B. Risbeck, Briefe; Schultes, Donau-Fahrten; Koch, Reise.

I5 2 Haslinger, Ehrenbuch, I83- I85; z.B. Linz und seine Umgebung; Krackowizer, Landeshauptstadt; Zöhrer, Linz.

I 53 Beispielsweise De Luca, Landeskunde; Schrank/Moll, Briefe; Schreinzer, Methode.

I 54 Verzeichniß I825, Gewerbe-Adressen-Buch I853; vgl. die Beispiele in Historischer Umweltatlas Münster, Karten 13-16. 
An sonstiger - im Rahmen der Fragestellung verwendbarer - »schöner" Literatur scheint wenig vorhanden: Nur Adalbert Stifter hat in seinen Veröffentlichungen den Linzer Raum ausführlicher thematisiert, präsent ist vor allem das Hinterland, besonders das rund ıo Kilometer nördlich von Linz gelegene Kirchschlag, welches in den im Winter I865/ 866 entstandenen »Winterbriefen« breiten Raum einnimmt. ${ }^{155}$

Bildliche Quellen erscheinen überaus wichtig für eine umwelthistorische Betrachtung vormoderner und moderner Städte, vor allem für das I 8. und I9. Jahrhundert. Dennoch hat die städtische Umweltgeschichte Bilder eher illustrativ bzw. affirmativ und flankierend zu auf der Basis anderer Quellen gewonnenen Aussagen verwendet. ${ }^{156}$ Aber auch vonseiten der Visual History sind Fragen nach der historischen Dimension des Verhältnisses Mensch-Umwelt kaum gestellt worden. Nur wenige Studien haben bislang Bildquellen ins Zentrum der Analyse gestellt und deutlich gemacht, dass urbane Bildquellen - dazu seien auch Pläne und technische Skizzen gezählt ${ }^{157}-$ ein erhebliches Potential für die städtische Umweltgeschichte haben: Sie ermöglichen eine Verbindung bzw. ein Kontrastieren mit anderen - vorrangig schriftlichen - Quellen und sind eine wichtige Kontextualisierungsmöglichkeit. Sie erlauben es, Brüche, Ambivalenzen und heterogene Wahrnehmungen nachzuzeichnen, zudem eine Annäherung an - ansonsten nicht dokumentierte - Umweltveränderungen oder Inszenierungen städtischer Umwelt. ${ }^{158}$ Für Linz sind zahlreiche Stadtansichten und (ab den I 860er Jahren) Photographien vorhanden, dazu Pläne und Karten. ${ }^{159}$

I55 Erstveröffentlichung der "Winterbriefe« mit Namensnennung in der "Linzer Zeitung" von I.2. bis 24.4.I866 (Stifter, HKG 8/3, I05) - abgedruckt in: Stifter, HKG, Bd. 8/3, I99-228; vgl. dazu Begemann/Giuriato, Stifter-Handbuch, I 74- I 77 .

I56 Vgl. z. B. Schott, Urbanisierung; Evans, Tod; Platt, Shock.

I57 Zum Potential von Bauplänen für das Spätmittelalter und zur Frühen Neuzeit vgl. Fouquet, Bauen.

I 58 Knoll, Natur, I78-33 I ; Leidel/Franz, Flußlandschaften, 276-289; Dobraszczyk, Sewers, 349f.; Behringer, Topographie.

I59 Gesichtet und ausgewertet wurden die Bestände Nordico Stadtmuseum Linz, Grafik- u. Fotosammlung und OÖLA, Karten- und Plänesammlung (vgl. dazu: Schmidt, Linz u. Haslinger, Stadtplan, ıooII 2). 


\section{Kontexte: Linz 1700 bis 1900}

\section{Naturräume}

Für eine Stadt sind und waren die naturräumlichen Settings, d.h. die klimatischen Bedingungen, die Bodenverhältnisse und die hydrologische Situation prägend. ${ }^{1}$ William Cronon hat die Bedeutung der naturräumlichen Faktoren für den Aufstieg Chicagos zu einem überregionalen Zentrum betont: Einerseits gab es über Wasserwege eine gute Verbindung zu den Städten des Ostens, andererseits ermöglichte die Lage am Lake Michigan einen Zugang zu den nördlichen Wäldern, während die fruchtbaren Böden und klimatischen Bedingungen des Hinterlands günstige Voraussetzungen für die landwirtschaftliche Produktion boten. ${ }^{2}$ Vielfach finden sich Stadtgründungen an einem schiffbaren Gewässer, oft auch an Stellen, an denen Flussläufe überschritten werden konnten oder die zu breaks in transport - also etwa zum Umladen von Waren nötigten. ${ }^{3}$ Für die Genese von Linz war die Lage an der Donau entscheidend: Hier floss die Donau aus einem engen Durchbruchstal in eine Ebene hinaus, was einen einfacheren Flussübergang ermöglichte. Es kreuzten sich Handelswege aus dem Norden (Böhmen) und aus dem Süden resp. Südwesten, zudem mündete der Fluss Traun, der das Alpenvorland mit der Donau verband und besonders für den Holz- und Salztransport von erheblicher Relevanz war, nur 6 Kilometer südöstlich vom Stadtzentrum in die Donau. ${ }^{4}$ Die hohe Bedeutung der Donau prägte Linz auch in stadtmorphologischer Hinsicht - bis ins I 9. Jahrhundert blieb die Stadt deutlich auf die Donau hin ausgerichtet. $^{5}$

Die Stadt des I8. Jahrhunderts befand sich auf den Hügeln im Westen und auf der Ebene zur Donau hin, die Vorstädte schlossen im Westen, Süden und Osten an die Stadt an, im Norden bildete die Donau die Stadtgrenze. Eine stärkere vorstädtische Bebauung existierte schon in der Frühen Neuzeit entlang der Verkehrsachse »Landstraße« im Süden, die eine Verbindung zwischen der Donau und überregionalen Straßen herstellte, zudem bestand im Osten in der Nähe des Donauufers eine zweite, aber nicht sehr dichte vorstädtische Ansiedlung. ${ }^{6}$ Auf der gegenüberliegenden Seite der Donau lag die Ortschaft Urfahr, die - in funktionaler Hinsicht - eher als weitere Linzer Vorstadt zu sehen ist. Urfahr wies bis ins I 9. Jahrhundert eine überschaubare Größe auf, verfügte über einen Siedlungskern bei der Brücke und über eine dünne

\footnotetext{
Melosi, America, I 59 f.

Cronon, Metropolis, 33f., 6of., 72 f., 98 - Ioo. u. I 5 I - I 84.

Culver, Confluences, 554 f.; vgl. Schott, Fluss, I4I - I 43.

Mayrhofer, Linz, unpag.

Mayr, Reiseführer, 2 I -23.

6 Mayrhofer, Linz, unpag.
} 


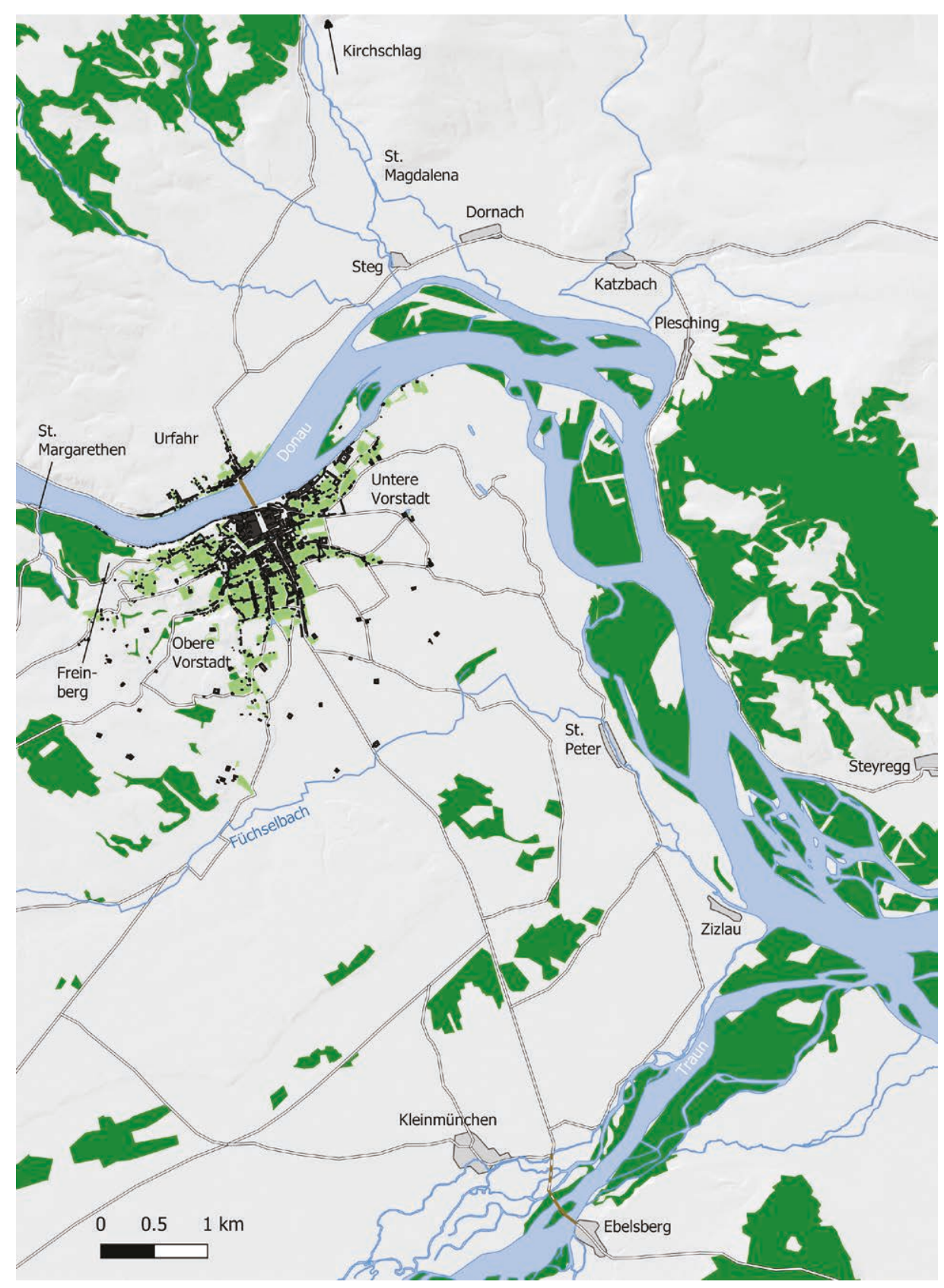

Abb. 1: Der Großraum von Linz zur Mitte der 182oer Jahre (vgl. dazu und zu den anderen Karten die Anmerkungen am Ende des Buches) 
Bebauung entlang der Ausfallsstraßen und ging dann bis zu den Abhängen des Mühlviertler Hochlandes in kleinere Ortschaften über (vgl. Abb. I). ${ }^{7}$

Im Süden und Südosten von Linz bestanden die beiden bereits stark ländlich geprägten und im I 8. Jahrhundert nur spärlich besiedelten Ortschaften Kleinmünchen, St. Peter und Zizlau, die sich bis zur Traun hin erstreckten. ${ }^{8}$ Im westlich von Linz gelegenen Donautal befanden sich die kleinen Ansiedlungen Kalvarienwänd und St. Margarethen. ${ }^{9}$

Die beiden Linzer Vorstädte erstreckten sich rund um den Stadtkern bis zur Donau und wurden - im Süden getrennt durch die Landstraße - als obere und untere Vorstadt bezeichnet. Hier fand bezeichnenderweise eine Bezugnahme auf eine Lage oberhalb bzw. unterhalb - im Sinne der Fließrichtung der Donau - der Landstraße statt (vgl. zu den Toponymen Abb. 6). Die Zusatznamen der Vorstädte charakterisieren die dort vorherrschenden Landschaftsformen: Die westlich gelegene Obere Vorstadt wurde als »Waldegg «, die östlich gelegene Untere Vorstadt als »Lustenau « bezeichnet. ${ }^{10}$ Die Obere Vorstadt wurde im »Josephinischen Lagebuch« der I 78oer als »Größtentheils Bergicht« beschrieben: Deren wesentlichste Erhebungen bilden - von Norden nach Süden - der Freinberg mit dem Schullerberg als seinem Ausläufer zur Stadt hin und der Bauern- resp. Froschberg, der mitunter als »Niederreither Berg« bezeichnet wurde. ${ }^{11}$ Die Untere Vorstadt war von der nahen Donau geprägt, überwiegend eben und teilweise Überschwemmungsgebiet und Auland. ${ }^{12}$ An der Donau lag das »Wörth« resp. »Werd«, wegen des dort bestandenen Spitalsbesitzes auch »Spittelau« genannt, das erst im Verlauf des r 8. Jahrhunderts stärker verbaut wurde. Lange Zeit befanden sich im Wörth vorstädtische Gärten und ab dem I7. Jahrhundert ein Manufakturbetrieb (meist als »Wollzeugfabrik« oder nur als »Fabrik« bezeichnet). Das Hochwasser von I 572 schuf in der dortigen Gegend einen neuen Donauarm - nach der Wollzeugfabrik später als »Fabrikarm« benannt - und trennte eine Insel ab, die zunächst als "Au«, dann mit der Nutzung als sommerliches Soldatenlager ab dem beginnenden I8. Jahrhundert als »Soldatenau« und später als »Straßerau« bezeichnet wurde. Der Fabrikarm verlandete ab den frühen I $870 e r$ Jahren und wurde I 889 bis I 892 verfüllt - somit bestand ab diesem Zeitpunkt keine Insel mehr. In dieser Gegend befand sich auch der Wasserlauf der Ludl, der angeblich ebenso als kleine Donauverzweigung durch das Hochwasser von I 572 entstanden war. Im I 8. und I 9. Jahrhundert hatte die Ludl bereits wenig Wasser, war partiell zugeschüttet und wurde in den I $890 e r$ Jahren kanalisiert (vgl. Kap. 6. Fluviale und aquatische Räume). Somit waren die Stadt und Vorstädte einerseits im Westen durch Hügel und deren Ausläufer bestimmt, anderer-

\footnotetext{
7 Vgl. Bohdanowicz, Urfahr; Bohdanowicz, Pöstlingberg; Bohdanowicz, Katzbach.

8 Vgl. Bohdanowicz, Kleinmünchen; Bohdanowicz, St. Peter.

9 Pillwein, Beschreibung, 2 I If.

Io Brosch, Flurnamen, 307.

I I OÖLA, Josephinisches Lagebuch, HS I9I (Linz Obere Vorstadt).

I 2 Ebd., HS I92 (Linz Untere Vorstadt).
} 


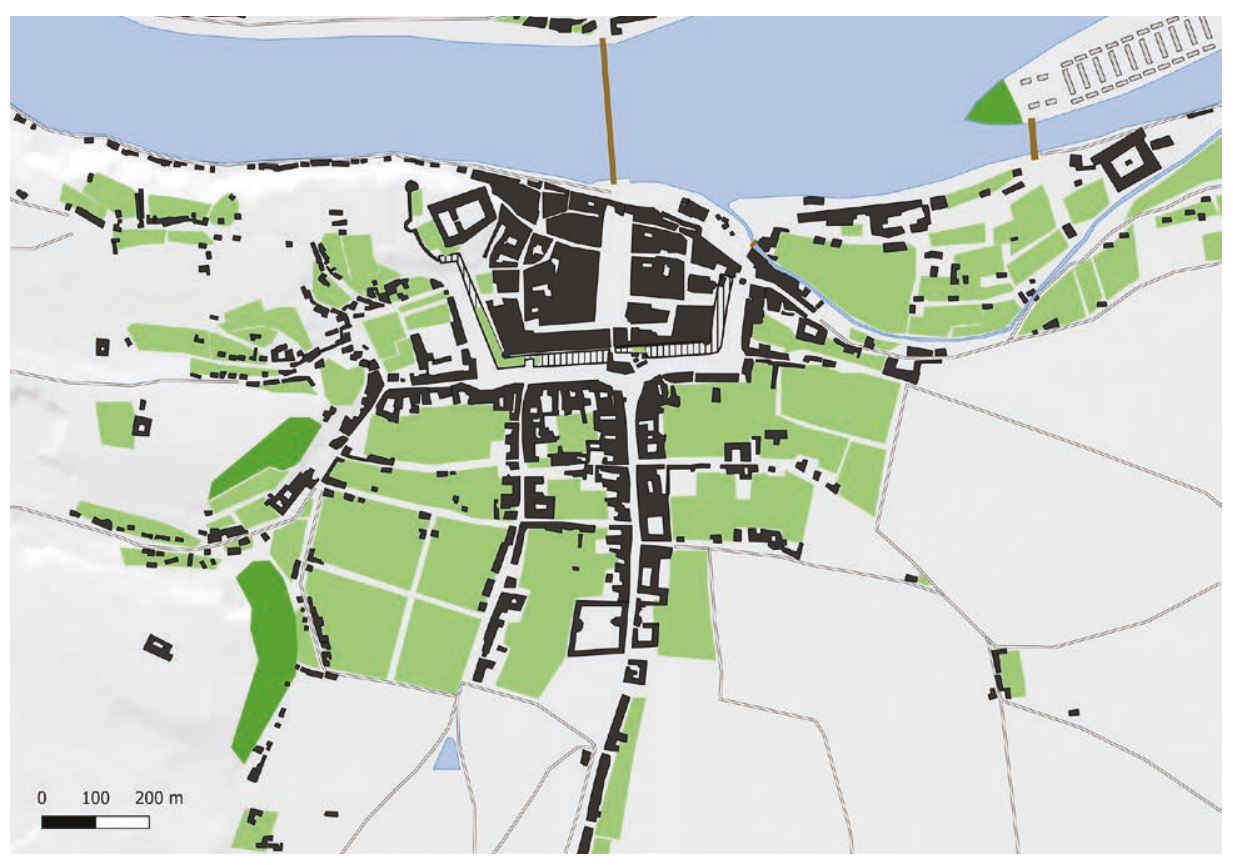

Abb. 2: Stadt und Vorstädte in den 1730 er Jahren

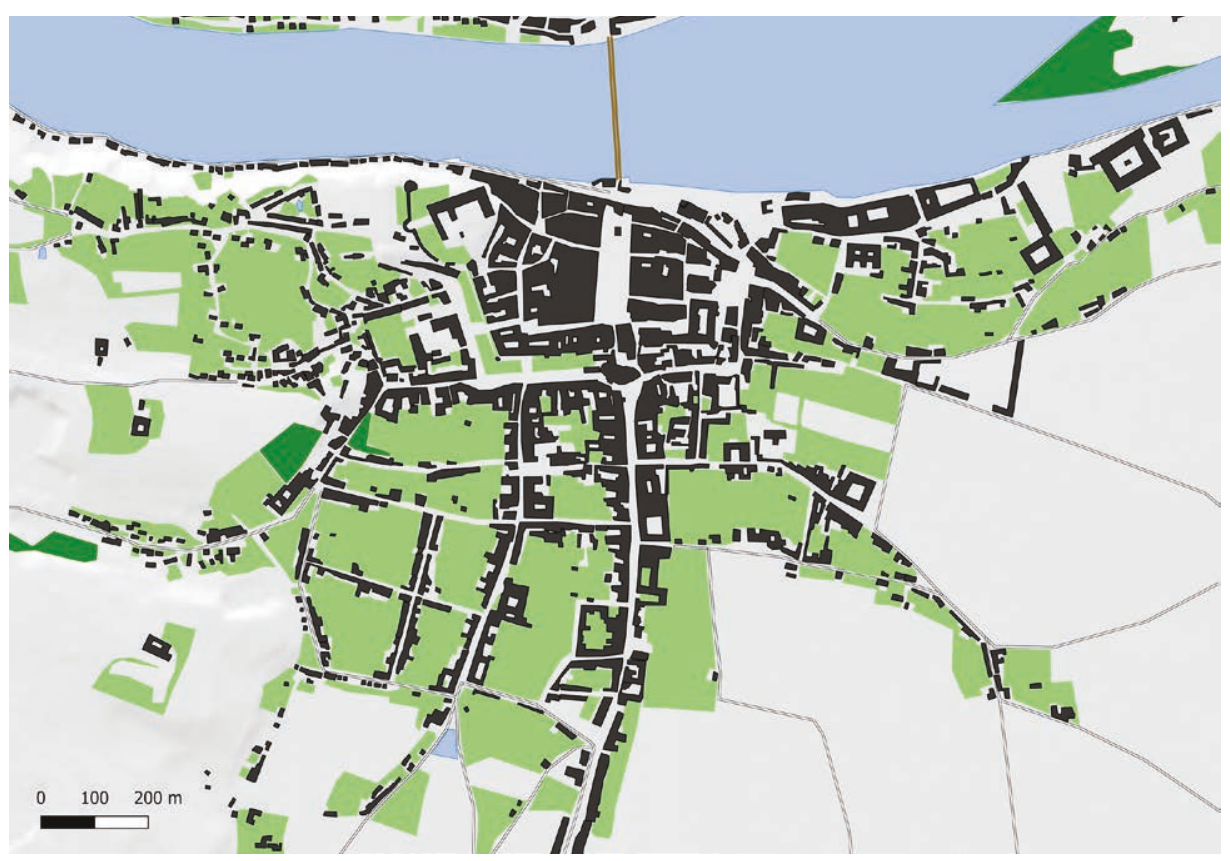

Abb. 3: Stadt und Vorstädte in den $1820 e r$ Jahren 


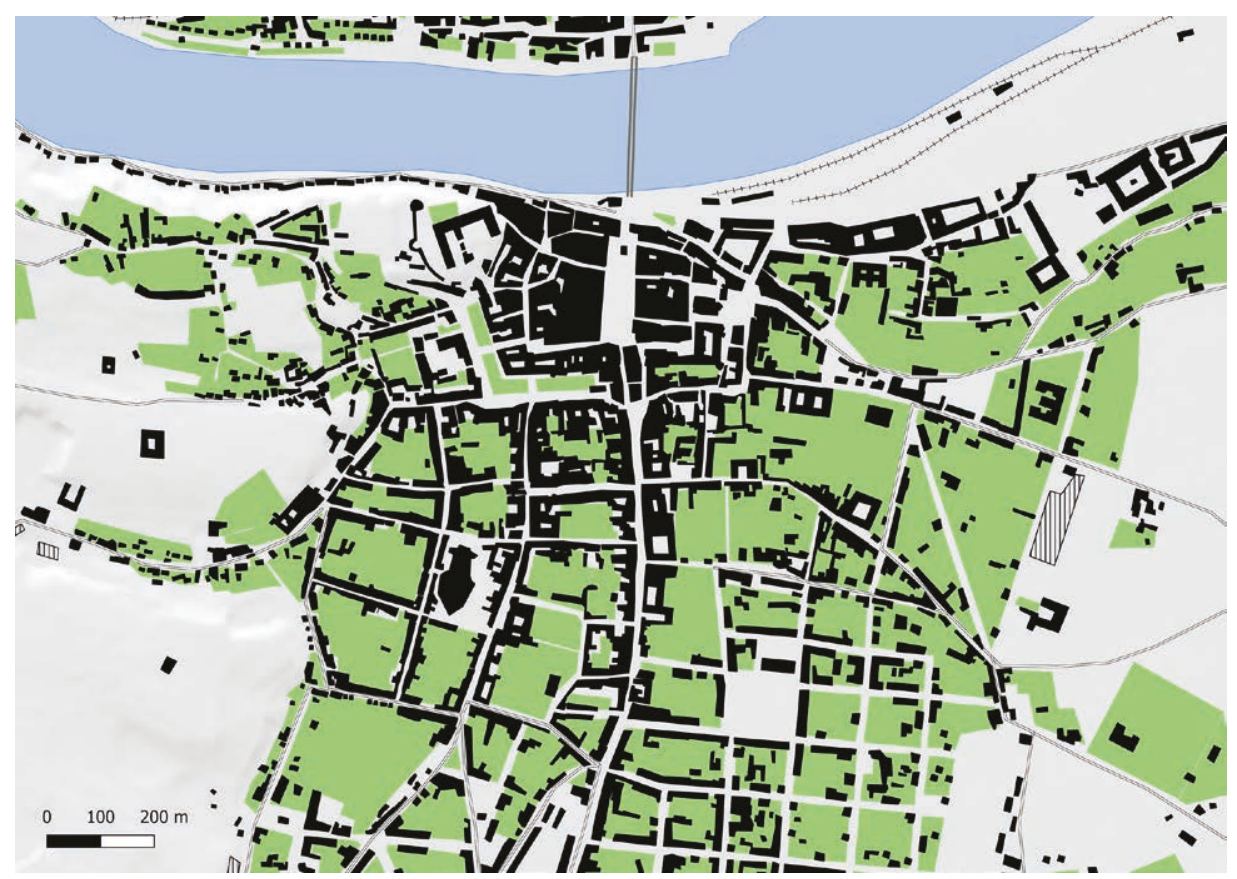

Abb. 4: Stadt und Vorstädte um 1900

seits war Linz zum größten Teil ein sehr flaches Gebiet, das nur wenige Meter oberhalb der Donau lag (vgl. Abb. I- 4 u. 7).

In geologischer Hinsicht lässt sich dieses Gebiet in drei Teile gliedern (vgl. Abb. 5): Im westlich gelegenen Hügelumland (Freinberg) ist granitähnliches Gestein (schiefriger Perlgneis) anzutreffen, das Teil der Böhmischen Masse ist und sich auf der Urfahrer Seite über den Pöstlingberg bis zum Katzbachgraben fortsetzt. Dazwischen bestehen kleinere, als »Linzer Sand« titulierte Sandeinlagerungen, die sich im Südwesten (Alharting und stadtnah am Bauernberg) und dann jenseits der Donau (Pöstlingberg, Gründberg, Plesching bis Steyregg) befinden. Die den Linzer Raum dominierende geologische Form stellen die Schotterterrassen dar: Die Hochterrassen umfassen den Schullerberg, den Bauernberg, das Harter Plateau (einige Kilometer südwestlich vom Stadtkern) und das Gebiet beim Ebelsberger Schloss jenseits der Traun, während die innere Stadt und die Vorstädte sich auf der flachen Niederterrasse befinden, an die die tieferen Austufen im Osten anschließen. ${ }^{13}$ Als Böden sind vor allem Braunerden anzutreffen: Auf der Böhmischen Masse liegt teilweise tiefgründige Braunerde (Pöstlingberg, Freinberg, St. Magdalena), die sich gut für die Acker- und Wiesennutzung eignet, aber auch seichtgründige, mit Steinen versetzte Braunerde, was eine landwirt-

I 3 Seelinger, Grundlagen, r6; Janik, Böden, 6-8; Schadler, Karte. 
Abb. 5: Geologie des Linzer Raumes.

Ohne Füllung: Schotter und Sande in Austufe; graue Schraffur : Schotter auf Niederterrasse; Graustufen bis schwarz in dieser Reihenfolge: Aufschwemmungen auf Niederterrasse, Lehm auf Hochterrasse, Löß auf Hochterrasse, Sand und Ton, Granit und Gneis.

Die topographische Situation entspricht dem Stand von um 1900. Die Darstellung basiert auf Mayrhofer, Donaustadt, 68f.; Janik, Böden u. Schadler, Karte.

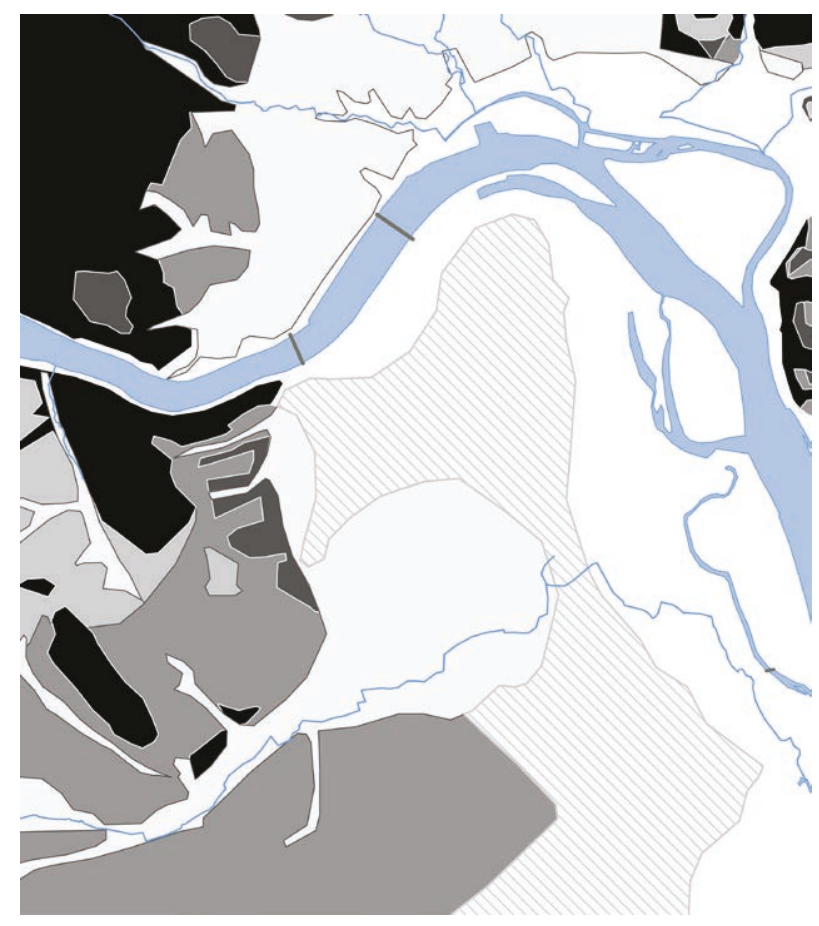

schaftliche Nutzung erschwert. Die höheren Terrassen sind von Braunerden sowie von Löß- und Lehmböden geprägt und stellen dadurch relativ gute Ackerböden dar. Auf der Niederterrasse im Stadtgebiet von Linz sind Braunerden auf Lößlehm weit verbreitet, mitunter auch Braunerden auf Schotter, die schlechtere Ackerböden, aber gute Gartenböden bilden. Die Böden der Austufe sind nur bedingt für den Garten- und Ackerbau geeignet, hier befanden sich zumeist lediglich Wiesen oder Auwald. ${ }^{14}$

Die Donau erreicht Linz nach einem engen Durchbruchstal, danach weitete sich vor den Regulierungen des i 9. Jahrhunderts - der Fluss erheblich aus und bildete ein breites Auengebiet, das bis in den Strudengau reichte. Das Kartenmaterial des »Franziszeischen Katasters« aus den I 8 2oer Jahren zeigt eine Breite, die zwischen rund 250 Metern bei der Linzer Donaubrücke und bis I, 5 Kilometern bei der Unteren Vorstadt lag (vgl. Abb. I). ${ }^{15}$ Aufgrund von Gefälle, Geschwindigkeit und Geschiebe ist die Donau in hydrologischer Hinsicht als Gebirgsfluss zu charakterisieren, der die Wasserführung des Inns widerspiegelte und erhebliche Dynamiken entwickeln konnte: In der Regel kam es ab Mai durch die Schneeschmelze zu Pegelanstiegen, die durch Niederschläge verstärkt in Hochwasser resultieren konnten; ab September sanken

I4 Seelinger, Grundlagen, 20; Janik, Böden, I I - 20.

I 5 Die Katastralpläne sind über Doris, Urmappe oder Mapire, Franziszeischer Kataster online zugänglich. 
wiederum der Pegel und die tägliche Abflussmenge. In der ersten Hälfte des 20. Jahrhunderts ( 1893 - I942) lag die tägliche Abflussmenge bei »Mittelwasser«, also bei normalen Pegelständen, bei durchschnittlich ca. I.500 Kubikmetern pro Sekunde, wobei als niedrigste tägliche Abflussmenge 29r Kubikmeter pro Sekunde (Jänner I 901) und als höchste 8.500 Kubikmeter pro Sekunde (beim Hochwasser im Herbst I 899) verzeichnet wurden. ${ }^{16}$ Diese Fluktuationen bedingten erhebliche Umlagerungsprozesse, die erst durch die Regulierungen des i 9. Jahrhunderts und die Kraftwerkserrichtungen des 20. Jahrhunderts verschwanden (vgl. Kap. 6. Fluviale und aquatische Räume). Die Donau war auch in Form des Grundwassers omnipräsent, das - wie ein Gutachten aus den I 88oer Jahren festhielt - im Linzer Stadtgebiet meist in einer Tiefe von I I bis I 3 Metern zu finden war. ${ }^{17}$

An anderen Gewässern war Linz relativ arm: Der Füchselbach, mitunter als »Hochgränz«, »Breitwies« oder »Grundbach« resp. »Grumbach« bezeichnet, bildete den größten Bach. Er floss aus der Leondinger Gegend südwestlich der Vorstädte über die Niederterrassen mäandernd nach St. Peter und mündete dort in die Donau. Der Füchselbach war zwar nur ein relativ kleiner Wasserlauf mit einer unregelmäßigen Wasserführung, er konnte aber kleinräumige Überflutungen auslösen und wurde - wohl auch deshalb - zu Beginn des 20. Jahrhunderts im damaligen Stadtgebiet kanalisiert und in gerader Linie zur Donau geführt. ${ }^{18}$ Der »Lamplwirtsteich « am Kapuzinerfeld südlich der Stadt bildete offenbar ein Aufnahmebecken für kleinere Wasserläufe, die vom westlich gelegenen Freinberg die Terrasse der Vorstadt erreichten. Seine Größe wurde in den I78oer Jahren mit 504 Quadratklaftern angegeben, was ungefähr r.80o Quadratmetern entspricht. Ab den I $840 e r$ Jahren wurde damit begonnen, den Teich zu verkleinern, in den r 86oer Jahren erfolgte die vollständige Zuschüttung. ${ }^{19}$ Lokalforscher meinen, mit dem »Schweinbach« einen weiteren kleinen Wasserlauf ausgemacht zu haben, der vom Schullertal über die Klamstraße in den Stadtgraben und weiter in die Donau verlief und dabei angeblich auch Mühlen betrieben haben soll. ${ }^{20}$ Dies ist für das I8. Jahrhundert nicht belegbar, bereits in Stadtansichten aus der Mitte des I7. Jahrhunderts sind weder ein derartiger Wasserlauf noch Mühlen sichtbar. ${ }^{21} \mathrm{Im}$ Nordwesten floss der Zaubertalbach, vom »Josephinischen Lagebuch« als »Wachtbergerbachl« bezeichnet, vom westlichen Abhang des Freinbergs nach St. Margarethen. ${ }^{22}$

I6 Neweklowsky, Donau, I 78f.; Jungwirth et al., Donau, 67.

I7 Schiedermayr, Sanitätsverhältnisse, 4.

I 8 Kreczi, Linz, 71 ; Gielge, Beschreibung, I 37; Bohdanowicz, Vorstädte, Bd. I, 36, 435 u. 442; vgl. OÖLA, Franziszeischer Kataster, No. 534 (Operat 2, Linz Obere Vorstadt, Katastralschätzungs-Elaborat, undat.).

I9 Berlinger, Lamplwirtsteich; Kreczi, Linz, 87.

20 Kreczi, Linz, 230; Mayrhofer, Donaustadt, 77f.; Mayrhofer/Katzinger, Geschichte, Bd. r, 69.

2 I Dass »kein Bach« in der Nähe sei, konstatiert auch ein Plan für ein Kanalisationsprojekt auf der Promenade aus dem Jahr I 800 - OÖLA, Karten- und Plänesammlung, VI/27.

22 Kreczi, Linz, 289. 
Abb. 6: Ausgewählte lokale Toponyme und Baulichkeiten

1 Kapuzinerkloster in Urfahr

2 Schloss

3 Untere Donaulände

4 Wasserkaserne

5 Wollzeugfabrik

6 Hauptplatz

7 Landhaus

8 Promenade (= Oberer Graben)

9 Schmiedtor

10 Kapuzinerkloster in Linz

11 Landstraße

12 Friedhof (bis 1786)

13 Lamplwirtsteich

14 Stockhof

15 Volksgarten

16 Bergschlössl

17 Friedhof (ab 1786)

Wiedergegeben ist die topographische Situation der $1820 e r$ Jahre, hellgrau die Bebauung um 1900

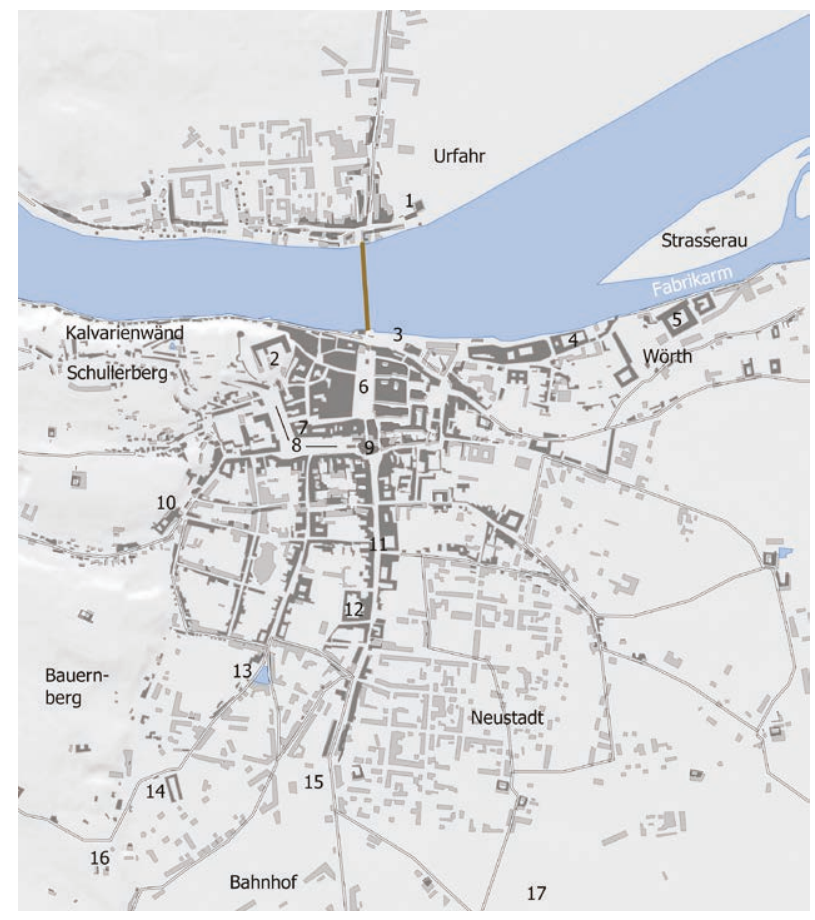

Südlich und südöstlich der Stadt bildete die Traun - wie bereits erwähnt ein wichtiger Transportweg aus dem Salzkammergut - ein weit verzweigtes Mündungsdelta in die Donau bei Zizlau, eine Brücke bestand bei Kleinmünchen (resp. Ebelsberg). ${ }^{23}$

\section{Wetter und Klima}

In klimatischer Hinsicht ist Linz dem Alpenvorland zuzurechnen, mit mäßig kalten Wintern und warmen Sommern, wobei das Stadtgebiet etwas höhere Temperaturen und tendenziell weniger Frost, auch seltenere Früh- und Spätfroste aufweist. Die Westwetterlage ist, typisch für das nördliche Alpenvorland, bestimmend, es dominieren die Windrichtungen West und Ost, im Falle von Linz sind Westwinde (und Südwestwinde) deutlich häufiger. Aufgrund der Donaunähe und der ausgeprägten Tallage treten im Linzer Raum vermehrt Nebel und dadurch auch Inversionswetterlagen auf, die über Tage fortdauern können. ${ }^{24}$ Der Linzer Raum zählt mit einer durchschnitt-

23 Brosch, Flurnamen, 325 .

24 Mayrhofer, Donaustadt, 79f.; Zotl, Geschichte, 6 u. I 7; vgl. Auer et al., Klimatographie, Bd. 2, 33, 78 f. u. 376 f.; dies., Klimatographie, Bd. 3, Karten I - I 7 u. 24. 
lichen Jahresniederschlagsmenge von 773 Millimetern (für die Periode r96 I - I 990) zu den niederschlagsärmeren Gegenden Oberösterreichs, wobei die Anzahl der Tage mit Niederschlag relativ gering und die der Gewittertage durchschnittlich ist, Hagelschläge und extreme Niederschlagsmengen aber nur selten auftreten. ${ }^{25}$

Interessanterweise wurde im »Josephinischen Lagebuch« der I 78 oer Jahre nur auf die kalten Nordwinde (»rauhe Luft«) verwiesen, für die Obere wie Untere Vorstadt auf häufigen Frost (»Reif») und im Falle der Oberen Vorstadt sogar auf einige Hagelschläge (»Schauer«). Für den benachbarten Ort Urfahr hielt man Ähnliches fest, zudem thematisierte man die "starke[n] Nebel«, die mit "der vorbeifließenden Donau« kausal verbunden wurden. ${ }^{26}$ Der vier Jahrzehnte später entstandene »Franziszeische Kataster« äußerte sich ausführlicher zu den »klimatischen Einwirkungen«: Für die Stadt Linz wurden »häufige[r] « Nebel, »schnelle Wechsel der Temperatur und heftige Windanfälle«, welche »wohl auch auf die Gesundheit der Stadtbewohner nachtheilig sind «, konstatiert. ${ }^{27}$ Obgleich die Obere Vorstadt unmittelbar an die innere Stadt anschloss, sah man die dortige Situation insgesamt positiver: Es bestehe kein Mangel »von freyer Einwirkung der Sonne und des Luftzuges«, zudem trete oftmals »sanfte[r] Regen « auf. ${ }^{28}$ Die höhere Anfälligkeit der Unteren Vorstadt für Frost und Hagel führte man, wie auch im Falle Urfahrs, auf die Nähe zur Donau zurück, ${ }^{29}$ wobei in Urfahr nur »die verderblichen Nebel etwas fühlbar nachtheilig« seien. Das "gemäßigte milde Klima«, die sonnige und luftige Lage, dazu die »öfteren fruchtbaren Regen« und die vor Wind geschützte Lage begünstige jedoch die »Wegetation der Pflanzen und ihre Erträglichkeit ungemein «. ${ }^{30}$ Adalbert Stifter, der am Linzer Donauufer wohnte, legte in den r 86oer Jahren vielfach Zeugnis von diesem "gräßliche[n] Nebel $a b,{ }^{31}$ der auch in seinen "Winterbriefen « aus dem so Kilometer nördlich von Linz und rund 600 Meter höher gelegenen Ort Kirchschlag breiten Raum einnahm. ${ }^{32}$ Der Nebel bewirkte nicht nur Temperaturunterschiede, sondern auch, wie Stifter Anfang I 866 in einem Brief an seine Frau betonte, dass - in diesem Fall Stifters - "leidende Nerven von naßkaltem Nebel auf das Widrigste berührt werden«. Er sei »seit Jahren auf die Donaunebel sehr böse« - in Kirchschlag gebe es eine andere Art von Nebel, der »nicht

25 Auer et al., Klimatographie, Bd. 2, 25 2-254, 26 I-263. u. 299-305; dies., Klimatographie, Bd. 3, Karten $25-37$.

26 OÖLA, Josephinisches Lagebuch, HS I 92 (Linz Untere Vorstadt); ebd., HS I 9 I (Linz Obere Vorstadt); Bohdanowicz, Urfahr, I 5 f.

27 OÖLA, Franziszeischer Kataster, No. 534 (Operat I u. 2, Braune Mappe, Linz-Stadt, Katastralschätzungs-Elaborat, I 8.1 2.1832).

28 Ebd. (Operat 2, Linz Obere Vorstadt, Katastralschätzungs-Elaborat, undat.).

29 Ebd. (Operat 2, Linz Untere Vorstadt, Beantwortung Fragen Gemeinde Lustenau, 25.I.I831).

30 Bohdanowicz, Urfahr, 24I.

3I Stifter, PRA, Bd. 2 I, 83; vgl. auch OÖLA, Musealarchiv HS 178 (Geschichte der Stadt Linz von Ignaz Fink, Bd. I, undat.), pag. 2.

32 Stifter, HKG, Bd. 8/3, 202-207. 
aus stinkenden Dünsten « bestehe. ${ }^{33}$ In den Topographien des frühen I 9. Jahrhunderts finden sich umfangreiche Erörterungen zum Thema Klima und Wetter: Beides sei "ziemlich gemäßigt«, wobei einmal - aufgrund der Nähe zum Hügelland und zur Donau - konstatiert wurde, dass es "nur wenige Gewitter « in der Stadt gebe, ${ }^{34}$ an anderen Stellen - wiederum aufgrund der Lage - wurde die Häufigkeit von Gewittern betont. ${ }^{35}$ Auch eine Publikation aus den I $870 e r$ Jahren sah den Linzer Raum zeitweilig von zahlreichen Niederschlägen und kalten Nordwestwinden betroffen, hielt aber insgesamt fest, dass das Klima ein "mildes und angenehmes« sei, wodurch »Fehlernten zu den größten Seltenheiten gehören « würden. ${ }^{36}$

Für die Rekonstruktion von klimatischen Bedingungen in Linz während des Betrachtungszeitraumes I 700 - I 900 gibt es eine von der Zentralanstalt für Meteorologie im Rahmen des "HistalP«-Projektes homogenisierte Temperaturreihe mit Monatswerten ab I 8 I 6 und eine Niederschlagsreihe ab i 852. ${ }^{37}$ Eine Annäherung an die Periode I700-I8I 5 für die Temperatur resp. I700-I85 I für den Niederschlag ist über den Datensatz einer Forschergruppe um Carlo Casty möglich, die Monatswerte für Temperatur und Niederschlag für einen Punkt nahe Linz errechnet hat. ${ }^{38}$ Dazu sind punktuelle Angaben in unterschiedlichen Quellen vorhanden: in Chroniken, Verwaltungsakten, aber auch bei Topographen des frühen I 9. Jahrhunderts. In Kombination ergibt sich somit die Möglichkeit, Extreme und negative Konstellationen zu rekonstruieren, diese genauer zu datieren und in der Analyse zu berücksichtigen (vgl. Tab. I).

Tab. 1: Temperaturextreme in narrativen Quellen und in Klimarekonstruktionen, $1700-1850$

\begin{tabular}{llll}
\hline $\begin{array}{l}\text { Zeitraum/ } \\
\text {-punkt }\end{array}$ & Temperatur & Quelle(n) & Klimarekonstruktion $^{\text {b }}$ \\
\hline $1708 / 1709$ & Kälte & $\begin{array}{l}\text { Pillwein, Wegweiser, 38; Lauscher et al., Witte- } \\
\text { rung, 30 } \\
\text { ebd. }\end{array}$ & C (12/1708-2/1709) \\
1713 & Kälte & Lauscher et al., Witterung, 30 & C (4,5 u. 11/1713) \\
$1715 / 1716$ & Kälte & Pillwein, Wegweiser, 38f.; Lauscher et al., Witte- & C (3/1720) \\
1720 & Kälte (W); $(12 / 1715,1,3$ u. 4/1716) \\
& Hitze (S) & rung, 30 & nicht bei C \\
1723 & Hitze (S) & Pillwein, Wegweiser, 39 & nicht bei C \\
1724 & Kälte (W) & Pillwein, Wegweiser, 38. &
\end{tabular}

33 Stifter, PRA, Bd. 21, I37f.

34 Heinse, Linz, r. Aufl., If.

35 Pillwein, Wegweiser, 48.

36 Foltz, Statistik, II u. IV.

37 HISTALP - vgl. zum Datensatz: Böhm et al., Webseite.

38 Casty et al., Temperature. Der Punkt liegt bei $48,25^{\circ}$ Nord und ${ }_{14}, 25^{\circ}$ Ost, also vertretbare 2 Kilometer südöstlich vom Linzer Stadtzentrum. 


\begin{tabular}{|c|c|c|c|}
\hline $\begin{array}{l}\text { Zeitraum/ } \\
\text {-punkt }\end{array}$ & Temperatur ${ }^{a}$ & Quelle(n) & Klimarekonstruktion ${ }^{b}$ \\
\hline 1728 & Kälte & LR E1g, Reg. 361; Pillwein, Wegweiser, 38 & C $(12 / 1728,1$ u. $3 / 1729)$ \\
\hline 1733 & Kälte (W) & Pillwein, Wegweiser, 38 & eventuell C (12/1732) \\
\hline $\begin{array}{l}10 / 1739 \text { bis } \\
3 / 1740\end{array}$ & Kälte & $\begin{array}{l}\text { LR E1a, Reg. 290; LR E1c, Reg. 2922; Pillwein, Weg- } \\
\text { weiser, 38; Lauscher et al., Witterung, } 30\end{array}$ & C (11/1739 u. $1-5 / 1740)$ \\
\hline $1741 / 1742$ & Kälte & Mayrhofer/Katzinger, Geschichte, Bd. 1, 388-392 & $C(3-5 / 1741,3-5$ u. $12 / 1742)$ \\
\hline $1743 / 1744$ & Kälte & $\begin{array}{l}\text { LR E1a, Reg. 356; LR E1a, Reg. } 362 \text {; Pillwein, Weg- } \\
\text { weiser, } 38 \text {; Lauscher et al., Witterung, } 30\end{array}$ & C (1 u. 4/1743, 1 u. $2 / 1744)$ \\
\hline 1748 & Kälte & Pillwein, Wegweiser, 38 & C ( $(2$ u. $3 / 1748)$ \\
\hline $1755 / 1756$ & Kälte & LR E1a, Reg. 463; LR E1a, Reg. 482 & C (1 u. $2 / 1755$ u. $1 / 1756)$ \\
\hline 1763 & Kälte & LR E6, 98; Pillwein, Wegweiser, 38 & $C(12 / 1762,1$ u. $3 / 1763)$ \\
\hline $1767 / 1768$ & Kälte & & C (1 u. $12 / 1767,1 / 1768)$ \\
\hline 1771 & Kälte & Pillwein, Wegweiser, 38 & $C(3,4$ u. $11 / 1771)$ \\
\hline 1776 & Kälte & Pillwein, Wegweiser, 38 & $C(1 / 1776)$ \\
\hline $1784-1786$ & Kälte & Pillwein, Wegweiser, 38 & $\begin{array}{l}\text { C }(12 / 1783,1,2 \text { u. } 12 / 1784 \\
2-4 / 1785,11 / 1786)\end{array}$ \\
\hline 1787 & Hitze & Pillwein, Wegweiser, 39 & $C(8 / 1787)$ \\
\hline $1788 / 1789$ & Kälte & Pillwein, Wegweiser, 38 & C (12/1788, 1 u. $3 / 1789)$ \\
\hline 1794 & Kälte & Pillwein, Wegweiser, 38 & C (12/1794 u. 1/1795) \\
\hline $1797-1799$ & Kälte & $\begin{array}{l}\text { LR E1b, Reg. 1951; LR E7a u. b, Reg. 1511; Pillwein, } \\
\text { Wegweiser, 38; Heinse, Linz, 1. Aufl., } 2\end{array}$ & C (12/1798, 1 u. 12/1799) \\
\hline 1800 & Kälte & & $C(3 / 1800)$ \\
\hline $1802 / 1803$ & Kälte & Pillwein, Wegweiser, 38 & C (1/1802, 1 u. $2 / 1803)$ \\
\hline $1806 / 1807$ & Hitze & Pillwein, Wegweiser, 39 & C (5/1806, 7 u. $8 / 1807)$ \\
\hline 1809 & Kälte & Pillwein, Wegweiser, 38 & $C(12 / 1808)$ \\
\hline 1811 & Kälte & & $\mathrm{H}(5-7 / 1811)$ \\
\hline 1811 & Hitze & Pillwein, Wegweiser, 39 & $C(5-7 / 1811)$ \\
\hline $1812 / 1813$ & Kälte & LR E7e-g, Reg. 1908; Pillwein, Wegweiser, 38 & $C(1,4$ u. $12 / 1812,1 / 1813)$ \\
\hline 1822 & Hitze & Pillwein, Wegweiser, 39 & $H(5$ u. $6 / 1822)$ \\
\hline 1823 & Kälte & & $H(1 / 1823)$ \\
\hline $1826 / 1827$ & Kälte & LR E7k, Reg. 7566; Pillwein, Wegweiser, 38 & $H(1$ u. 5/1826, 2 u. $11 / 1827)$ \\
\hline $1829 / 1830$ & Kälte & LR E7l, Reg. 8957; Pillwein, Wegweiser, 38 & $H(2$ u. $10-12 / 1829,1$ u. $2 / 1830)$ \\
\hline 1834 & Hitze & Pillwein, Wegweiser, 39 & $H(5-9 / 1834)$ \\
\hline 1835 & Kälte & & $\mathrm{H}(11$ u. 12/1835) \\
\hline 1838 & Kälte & Pillwein, Linz, Bd. 2, 29 & $\mathrm{H}(1 \mathrm{u} .2 / 1838)$ \\
\hline 1841 & Kälte & Pillwein, Linz, Bd. 2, 29 & $\mathrm{H}(12 / 1840$ u. $2 / 1841)$ \\
\hline 1842 & Kälte & & $H(1$ u. $2 / 1842)$ \\
\hline $1841 / 1842$ & Hitze & Pillwein, Linz, Bd. 2, 29 & $H(5 / 1841$ u. $8 / 1842)$ \\
\hline 1845 & Kälte & Pillwein, Linz, Bd. 2, 29 & $H(12 / 1844,2,3$ u. $5 / 1845)$ \\
\hline
\end{tabular}




\begin{tabular}{llll}
\hline $\begin{array}{l}\text { Zeitraum/ } \\
\text {-punkt }\end{array}$ & Temperatura & Quelle(n) & Klimarekonstruktion ${ }^{\text {b }}$ \\
\hline $1846 / 1847$ & Kälte & LR E1b, Reg. 2370 & H $(11$ u. 12/1846, 1, 3, 6 u. \\
& & $9 / 1847)$ \\
1848 & Kälte & H $(1 / 1848)$ \\
$1849 / 1850$ & Kälte & H $(11$ u. 12/1849,1 u. 3/1850) \\
\hline
\end{tabular}

a $\mathrm{W}=$ Winter $\mathrm{S}=$ Sommer

${ }^{b} \mathrm{C}=$ Casty et al., Temperature $; \mathrm{H}=$ HISTALP - jeweils mit Angabe der Monate

\section{Grenzen der Stadt}

Kern des Linzer Siedlungsbereiches war die bis ins i 9. Jahrhundert von der Stadtmauer umgebene innere Stadt mit dem Schlossberg und dem Hauptplatz. Dazu kam die vorstädtische Bebauung mit einer Verdichtung südlich der Stadt bei der Landstraße und östlich bei der Donau am Wasserlauf resp. Graben der Ludl (vgl. oben). Die beiden Vorstädte, die am Donauufer begannen und rund um die Stadt führten, wurden als »Obere« (westliche) bzw. »Untere« (östliche) Vorstadt bezeichnet, wobei die Landstraße die Grenze bildete. ${ }^{39}$ In administrativer und in politischer Hinsicht begrenzte bis ins r 9. Jahrhundert der Burgfried, der die Stadt und die Vorstädte umfasste, die Kommune. ${ }^{40}$

Diesen Burgfried hatte die Stadt vor allem seit dem I 7. Jahrhundert über den Erwerb von Grundherrschaften sukzessive erweitert: I707 waren der Schullerberg im Westen, I 709 die Gegend um den Stockhof im Süden und I 752 die Kalvarienwänd westlich der Stadt am Donauufer hinzugekommen. ${ }^{41}$ Diese waren aber nicht Teil des Stadtgebiets, sondern unterstanden lediglich dem Bürgermeisteramt. Der Stockhof und der dazugehörige umfangreiche Grundbesitz wurde um immerhin I $3.300 \mathrm{fl}$ angekauft, parzelliert und danach wieder mehrheitlich verkauft. ${ }^{42}$ Eine weitere Expansion erfolgte im I 9. Jahrhundert, die sich auch in der Situierung der Steuer- und Mauthäuser (Akzise- und Fleischkreuzer, später Linienämter) abzeichnete. ${ }^{43}$ Auch der Abriss der Befestigungsanlagen zu Beginn des I 9. Jahrhunderts bot eine Möglichkeit zur "Binnenkolonisation «. ${ }^{44}$

Dabei divergierten die »Grenzen« durchaus: Das »Josephinische Lagebuch» der I 780 or Jahre und auch der spätere »Franziszeische Kataster» hatten die Obere und Untere Vorstadt als Steuergemeinden (Katastralgemeinden) mit den Ortschaften Waldegg und Lustenau zusammengezogen, in politischer Hinsicht gehörten Letztere aber bis ins

39 Mayrhofer, Linz, unpag.

40 Sandgruber, Grenzen, 70.

4I Kreczi, Linz, 5 I ; Mayrhofer, Linz, unpag.; Pillwein, Linz, Bd. I, 22.

42 LR E6 (»Sint-Chronik«), 80-82.

43 Kreczi, Linz, 267; Mayrhofer/Katzinger, Geschichte, Bd. 2, 87 f.

44 Mayrhofer, Linz, unpag.; vgl. LR E7e-g, Reg. I 934 (47of.). 
I 9. Jahrhundert nicht zur Stadt Linz. ${ }^{45}$ Der Topograph und Beamte Benedikt Pillwein führte Mitte der I 83oer Jahre neben der inneren Stadt und den beiden Vorstädten noch eine »äußere « Vorstadt an, die aber von Pillwein abgesehen kein weiteres Mal auftaucht. ${ }^{46}$ Es handelt sich dabei wohl um das südlich der beiden Vorstädte an der Landstraße gelegene »Neuhäusl«. Erst nach der Aufhebung der Grundherrschaften I 848 wurden Stadt und Vorstädte zu einem einheitlichen politischen Raum: Bis dahin bestand in den sukzessive wachsenden Vorstädten eine Vielzahl an Grundobrigkeiten - das »Josephinische Lagebuch « gab für die Katastralgemeinde Obere Vorstadt über 40 an. ${ }^{47}$

Nach I 848 entstanden intensive Diskussionen um die Grenzen der Stadt: Im Kontext der allgemeinen Gemeindezusammenlegungen stand im Mai I 848 der Plan, eine »Ortsgemeinde Linz« mit der Stadt, den Vorstädten (samt Waldegg und Lustenau) und der Gemeinde St. Peter zu schaffen. Die Ortschaften Waldegg und Lustenau waren zunächst für eine Verbindung mit Linz, St. Peter jedoch dagegen, eine Entscheidung unterblieb und erst I85 I wurden durch die Landesbehörde zwei Gemeinden geschaffen : »Linz-Stadt« und »Linz-Landgemeinde» (die Vorstädte mit Waldegg und Lustenau), wobei Waldegg und Lustenau aber bereits wenige Jahre später wieder eigenständige Ortschaften wurden. ${ }^{48}$ Dennoch erweiterte sich die Stadt sukzessive: Im Südosten - begrenzt durch die Westbahntrasse und den »Südbahnhof« der Pferdeeisenbahn - boten die »Harrachfelder« Raum für einen neuen Stadtteil, der ab den frühen I86oer Jahren, durch die Stadt parzelliert, als »Neustadt« mit mehrgeschossigen Häusern bebaut und mit einem Marktplatz (dem heutigen Hessenplatz) versehen wurde. Zudem ergaben sich durch die Aufhebung des Bauverbotes bei den »Maximilianischen« Befestigungstürmen (vgl. unten) neue Möglichkeiten für eine zukünftige Stadtentwicklung. ${ }^{49}$

Um kleinere Flächen, das Bahnhofsareal und den Friedhof, wurde die Stadtgemeinde in den Jahren I 859 und I 869 erweitert, ${ }^{50} \mathrm{zu}$ einer signifikanten Vergrößerung des Stadtgebietes kam es aber erst mit der Eingemeindung von Waldegg und Lustenau im Jahr I 873. Die bereits bestehende Verbindung der Stadt mit den beiden Ortschaften in steuerlicher und gerichtlicher Hinsicht hatte immer wieder zu Unstimmigkeiten geführt und ab Mitte der I 86oer Jahre drängte der Linzer Gemeinderat auf eine Lösung. Über den Landtag wurde Ende 1872 nach längeren Diskussionen und gegen den Widerstand der Ortschaften die Eingemeindung beschlossen, welche ab März I 873

45 Sandgruber, Grenzen, $73 \mathrm{f}$.

46 Pillwein, Wegweiser, 53-55.

47 Laut Bohdanowicz wurden dabei dennoch einige Grundherrschaften vergessen - Bohdanowicz, Vorstädte, Bd. 2, 775-78I.

48 Altmüller, Eingemeindungen, I7 u. 2 If.; Mayrhofer/Katzinger, Geschichte, Bd. 2, I 39.

49 Doblhamer, Stadtplanung, 32; Mayrhofer/Katzinger, Geschichte, Bd. 2, I42; wenngleich diese Bauverbotszone meines Erachtens die städtische Entwicklung zu dieser Zeit noch kaum tangiert hatte - vgl. Hillbrand, Türme, I I 9, I 2 I u. I 77 u. Mayr, Reiseführer, 78.

50 Sandgruber, Grenzen, $73^{\mathrm{f}}$. 


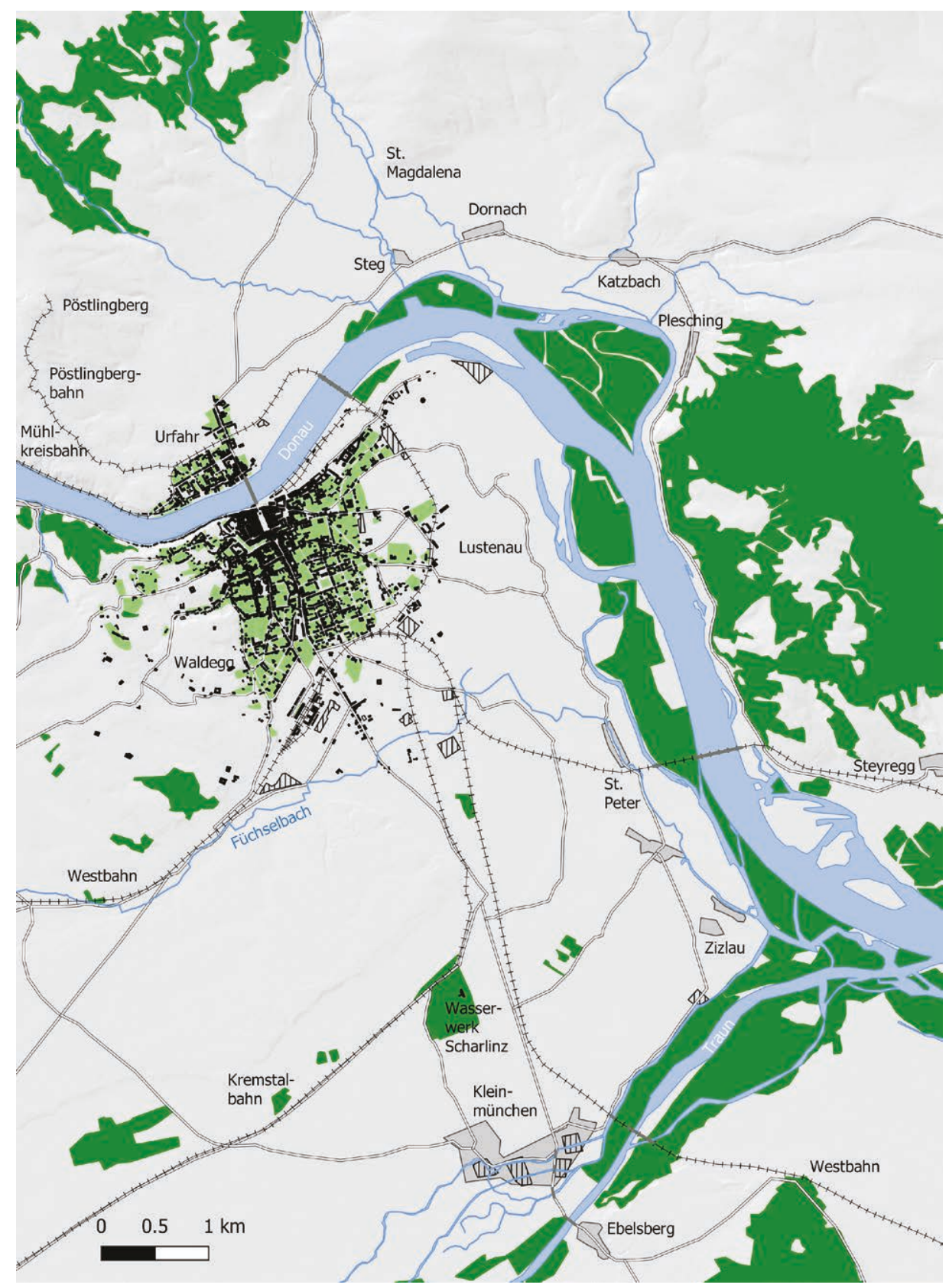

Abb. 7: Der Großraum von Linz um 1900 
wirksam wurde. ${ }^{51}$ Ein ausschlaggebendes Argument war die Tatsache der sich ohnehin vollziehenden städtischen Expansion, wie auch ein Linzer Gemeinderat betonte: "Nun sind wir aber [...] in der Neustadt bereits bis zur Eisenbahn hingekommen und können dort nicht erweitern«, da die dortigen Gründe von der Eisenbahn nicht verkauft würden. Mit der Erweiterung sei es möglich, »doch für eine gewisse Reihe von Jahren von 30, 40 oder 50 Jahren vorzusorgen.$^{52}$ Damit hatte sich die Stadtfläche im I 9. Jahrhundert mehr als verdreifacht und war von fast 6 Quadratkilometern (mit Vorstädten) auf r9,53 Quadratkilometer (ab I 873 mit Waldegg und Lustenau) angewachsen (vgl. Abb. 4 u. 7 ). ${ }^{53}$

Interessanterweise unterblieb zu dieser Zeit eine Eingemeindung der »Schwesterstadt«Urfahr am jenseitigen Donauufer, obwohl die Verbindungen mit Linz im I 9. Jahrhundert immer stärker wurden: Zunehmend stellte die Stadt Linz Infrastrukturen gegen Bezahlung zur Verfügung, was beispielsweise die Brücke oder die Straßenbeleuchtung betraf, genauso wurde das Projekt der Mühlkreisbahn, deren Endbahnhof sich auf Urfahrer Seite befand, in den I 88oer Jahren wesentlich von Linzer Seite getragen. In gewisser Weise nahm die enge Kooperation - auch im Hinblick auf die Stadtplanung - die kurz nach dem Ersten Weltkrieg vollzogene Eingemeindung Urfahrs vorweg. ${ }^{54}$

Mit der Expansion des Stadtgebiets wurde die Notwendigkeit einer allgemeinen Stadtplanung evident: Wenig überraschend bildeten die Planungen in Wien und anderen größeren Städten das Vorbild, aber erst in den I 88 oer Jahren kam es diesbezüglich zu umfangreicheren Diskussionen. Der I 887 vom Gemeinderat initiierte Planungswettbewerb für einen »Generalregulierungsplan« resultierte in einem sehr prototypischen Entwurf des späteren städtischen Baudirektors Josef Kempf, der vor allem Erweiterungen im Osten und Süden vorsah und der sich mit Ring- und Gürtelstraßen und Polygonplätzen augenscheinlich an den Wiener Planungen orientierte. ${ }^{55}$

\section{Regierende und Regierte}

\section{Stadtbewohner/innen}

Noch gegen Ende des I 8. Jahrhunderts bestand ein erstaunliches Nichtwissen über die Anzahl der Stadtbewohner/innen: „Die genau bestimmte Zahl der Häuser und Einwohner von Linz konnte ich nicht erfahren«, so ein Reisebericht aus den I 78 oer

5 I Altmüller, Eingemeindungen, 27-34; Mayrhofer/Katzinger, Geschichte, Bd. 2, I 39 .

52 Altmüller, Eingemeindungen, I 42f.; vgl. allgemein zu den Eingemeindungen: Lenger, Metropolen, I $79 f$.

53 Sandgruber, Grenzen, 76 ; die derzeitige Stadtfläche beträgt $96 \mathrm{~km}^{2}$.

54 Mayrhofer/Katzinger, Geschichte, Bd. 2, I 44 u. I64- I66; vgl. AStL, HS I 5 I (Oberkammeramt Empfang I 830 ), pag. 70 .

55 RB I885, I62-I64; Mayrhofer/Katzinger, Geschichte, Bd. 2, I 44; Kreczi, Linz, I 97; Mittmannsgruber, Stadtverwaltung, I 9 I ; vgl. Lenger, Metropolen, I 85 - I 87. 
Jahren, es seien »wohl gegen 20000 Einwohner $4 .{ }^{56}$ Der Berliner Publizist Friedrich Nicolai, der Linz in einem seiner Reiseberichte ausführlicher beschrieb, behalf sich mit Überschlagsrechnungen: 3.500 Haushalte zu 5 Personen würden plus Hof und Militär eine Einwohnerzahl von ca. 20.000 ergeben, eine Schätzung auf der Basis von in der »Linzer Zeitung" publizierten Todesanzeigen - ein monatlicher Durchschnitt von 48 Anzeigen mal 30 (angenommene Mortalität) - deute auf knapp über 17.00o Einwohner hin. ${ }^{57}$ Ähnlich verfuhr vermutlich Heinrich-Georg Hoff in den $1780 e r$ Jahren: Seine Schätzung der Einwohnerzahl (ohne Militär) auf ca. I6.500 entspricht der Zahl der Häuser - die über die Hausnummerierung damals schon bekannt war - mit dem Faktor 15 multipliziert. ${ }^{58}$ Es ist schwer zu beurteilen, wie zutreffend diese Überlegungen waren, für die Zeit vor den r8 roer Jahren bleibt man auf derartige Schätzungen angewiesen. Erst für die zweite Hälfte des I 9. Jahrhunderts sind zuverlässigere Zahlen greifbar, wenngleich die unterschiedlichen Zählmodi (im Hinblick auf »Fremde« oder die einbezogenen Stadteile) Vergleiche erschweren (vgl. Tab. 2). ${ }^{59}$

Rückschlüsse auf die städtische Mortalität lassen sich auf der Basis von Sterbezahlen, die von einem lokalen Projekt für alle oberösterreichischen Pfarren erhoben worden sind, ziehen. ${ }^{60}$ Für Linz waren die »Stadtpfarre« und ab der Pfarrreform I 784 die Pfarren der Unteren Vorstadt »St. Josef (später "Heilige Familie«) und der Oberen Vorstadt "St. Matthias« zuständig. ${ }^{61}$ Auf der Basis dieser Zahlen zeichnet sich folgende längerfristige Entwicklung ab: Im Zeitraum I 700 bis I 900 lag die Mortalität mehrheitlich bei 30 bis 40 Todesfällen pro r.ooo Einwohnern, ein generelles Anwachsen der Mortalität ist für die Zeit seit der zweiten Hälfte des I 8. Jahrhunderts zu konstatieren, wobei es zwischen I 770 und I 790 zu einem leichten Sinken der Mortalität kam. Es folgte in den I79oer Jahren und den ersten beiden Jahrzehnten des I9. Jahrhunderts ein erneuter Anstieg, an den sich eine Stagnationsphase zwischen I 820 und I 850 anschloss, danach stieg die Mortalität wiederum an und begann erst ab Mitte der I 8 7oer Jahre zu sinken (vgl. Grafiken I u. 2). ${ }^{62}$ Im Durchschnitt der Jahre I 865- I874, also noch in einer Phase mit relativ hoher Mortalität, lag Linz mit 36,3 Todesfällen je I.0oo Einwohnern ${ }^{63}$ zwar im österreichischen Vergleich über Wien $(3 \mathrm{I}, 7)$ und Inns-

56 Füssel, Tagbuch, $233 \mathrm{f}$.

57 Nicolai, Beschreibung, $522 \mathrm{f}$.

58 Hoff, Skizze, 16.

59 Klein, Ortslexikon.

6o Die Datenbank »Sterbefälle in Oberösterreich« ist als Web-App unter http://www.statistik-ooe.at/ verfügbar, im Folgenden wird sie als »Datenbank Sterbefälle« zitiert. Erich Lang danke ich herzlich für die Überlassung der Linzer Daten, deren Validität sich im Vergleich mit anderen Quellen zeigt - vgl. z.B. RB I 898, nach Seite 352; Tafeln zur Statistik 7 (I 834), Tafel 77 u. Tafeln zur Statistik I6 (I843), Tafel 52.

6I Sandgruber, Grenzen, 72.

62 Vgl. die durchaus vergleichbare Entwicklung in Wien: Weigl, Existenzsicherung, ${ }_{3}$ f. u. 79 u. Weigl, Wandel, r62-r 68.

63 Der mittels der Datenbank errechnete Wert liegt mit 44,6 jedoch deutlich höher (eigene Auswertung 
bruck $(26, \mathrm{I})$ aber deutlich unter Klagenfurt $(46,7) \cdot{ }^{64}$ Bis I 893 war der Wert für Linz auf 22,5, für Wien auf 22,9 und für Innsbruck auf 20 gesunken. ${ }^{65}$ Diese längerfristige Entwicklung deckt sich mit Befunden aus anderen west- und mitteleuropäischen Städten, im Hinblick auf die Sterbeziffern kann Linz als Stadt mit einer leicht überdurchschnittlichen Mortalität gelten. ${ }^{66}$

Tab. 2: Einwohnerzahlen für die Stadt Linz und die Vorstädte, 1700-1900

\begin{tabular}{llc}
\hline Zeitpunkt & Bezugsraum & Einwohnerzahl \\
\hline 1700 & Linz (Burgfrieden u. Vorstädte) $^{\mathrm{a}}$ & 11.500 \\
1750 & dito $^{\mathrm{b}}$ & 17.000 \\
1770 & dito $^{\mathrm{b}}$ & 20.000 \\
1800 & Linz plus Waldegg u. Lustenau $^{1}$ & 20.129 \\
1822 & Linz plus Vorstädte u. St. Peter & 20.803 \\
1837 & dito & 25.600 \\
1857 & Linz ("Stadt«) & 27.628 \\
1869 & Linz (ohne Urfahr) & 30.538 \\
1880 & Linz inkl. Lustenau u. Waldegg & 38.888 \\
1890 & dito & 44.995 \\
1900 & dito & 48.934 \\
\hline
\end{tabular}

Quelle: Datenbank Sterbefälle; Klein, Ortslexikon; Pillwein, Beschreibung, 62f.; Pillwein, Wegweiser, 59 f.; Tafeln zur Statistik NF 3, 1855-1857; Eichwalder, Wohnverhältnisse, 573; Statistischer Bericht 1882, Bd. 1, 23

a Schätzung auf Basis der Sterbefälle

b Schätzung auf Basis der Sterbefälle und der Anzahl der Häuser

Mortalitätsspitzen ergaben sich infolge von kriegerischen Ereignissen ${ }^{67}$ (I 74I - I 743, I762/I 763, I779, I 799, I 805/I 806, I 809/I 8 Io), ${ }^{68}$ von Versorgungskrisen (I 77 I/I 772) und von endemisch auftretenden Infektionskrankheiten (I852-I855, I873/1874, I878). Einen wesentlichen Anteil an der hohen Sterblichkeit, auch an den Spitzen,

basierend auf Datenbank Sterbefälle). Diese Diskrepanz erklärt sich wohl aus dem Nichtberücksichtigen der »fremden « Todesfälle - vgl. RB, I 898, nach Seite 352.

64 Statistische Monatschrift I (1875), I 83; vgl. Weigl, Existenzsicherung, $6{ }_{3} \mathrm{f}$.

65 Statistische Monatschrift 20 (1894), 93; zu berücksichtigen sind aber die erheblichen lokalen Unterschiede im Hinblick auf die Sterblichkeit, worauf Andreas Weigl für Wien verwiesen hat - vgl. Weigl, Wandel, i 77 f.

66 Clark, Cities, r6o u. 282f.; Evans, Tod, 240.

67 Da Linz eine wichtige Sammel- und Durchgangsstation für das Militär bildete, mussten kriegerische Auseinandersetzungen nicht zwingend vor Ort stattfinden, um in einer höheren Sterblichkeit der Zivilbevölkerung (infolge von Krankheiten) zu resultieren. Dies legen zumindest die Jahre 1762/ 1763 und I 799 nahe (vgl. zum Siebenjährigen Krieg: Pfister, Bevölkerungsgeschichte, 38 f.).

68 Vgl. zu den Ereignissen: Mayrhofer/Katzinger, Geschichte, Bd. I, 388 - 392 ; dies., Geschichte, Bd. 2, 5968. 


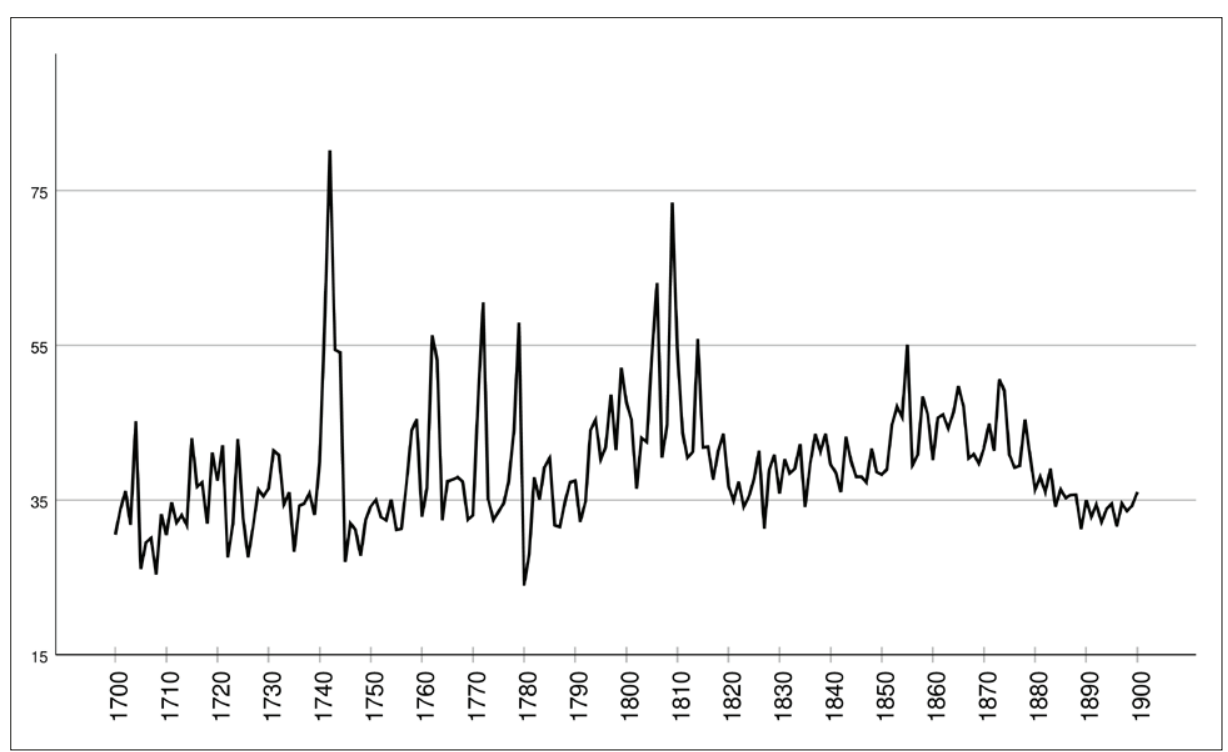

Grafik 1: Sterbefälle in Linz pro 1.00o Einwohner, 1700-1900. Quelle: Eigene Berechnung basierend auf Datenbank Sterbefälle

hatten die Säuglingssterblichkeit und die Kinderkrankheiten. ${ }^{69}$ Über die Entwicklung der Kinder- und Säuglingssterblichkeit in Linz ist kaum etwas bekannt, ebenso fehlt eine Ausdifferenzierung der Sterblichkeit nach Todesursachen, nach räumlichen oder sozialen Aspekten. In diesen Bereichen ist man auf wenige, eher punktuelle Angaben angewiesen: Der Topograph Benedikt Pillwein nahm eine interessante Auswertung von Sterbefällen in seine I 824 erschienene »Beschreibung der Provinzial-Hauptstadt Linz« auf. Dazu verwendete Pillwein die in der "Linzer Zeitung« zwischen I807 und I 816 - in einer Phase relativ hoher Mortalität - erschienenen Todesanzeigen der Stadtpfarre und der Pfarre Urfahr. Nach Pillweins Zählung lag der Anteil der Kinder unter sieben Jahren an den Todesfällen bei 40 bis 55 Prozent (vgl. Tab. 3). Dies war keineswegs unüblich und sollte sich erst langsam gegen Ende des i 9. Jahrhunderts verändern. ${ }^{70}$ Bei ca. einem Viertel der rund 7.000 im Krankenhaus der Barmherzigen Brüder zwischen I 757 und I850 verstorbenen Patienten (es handelte sich nur um Männer) wurde als Todesursache Tuberkulose angegeben, gefolgt von »Wassersucht« (als Erkrankung der inneren Organe zu verstehen) und weiteren unspezifischen Krankheiten. ${ }^{71}$ Für den Zeitraum I 873 bis I 880 stellte der Landessanitätsrat und Arzt Karl Schiedermayr Ähnliches fest: Die Mehrzahl der Todesfälle sei auf Tuberkulose

69 Clark, Cities, r6o; Zahlen für das r 9. Jahrhundert finden sich in: RB, I 898, nach Seite $35^{2}$.

70 Clark, Cities, 282 f.; Weigl, Existenzsicherung, 32-47.

7 I Losch et al., Tod, 3 If. 


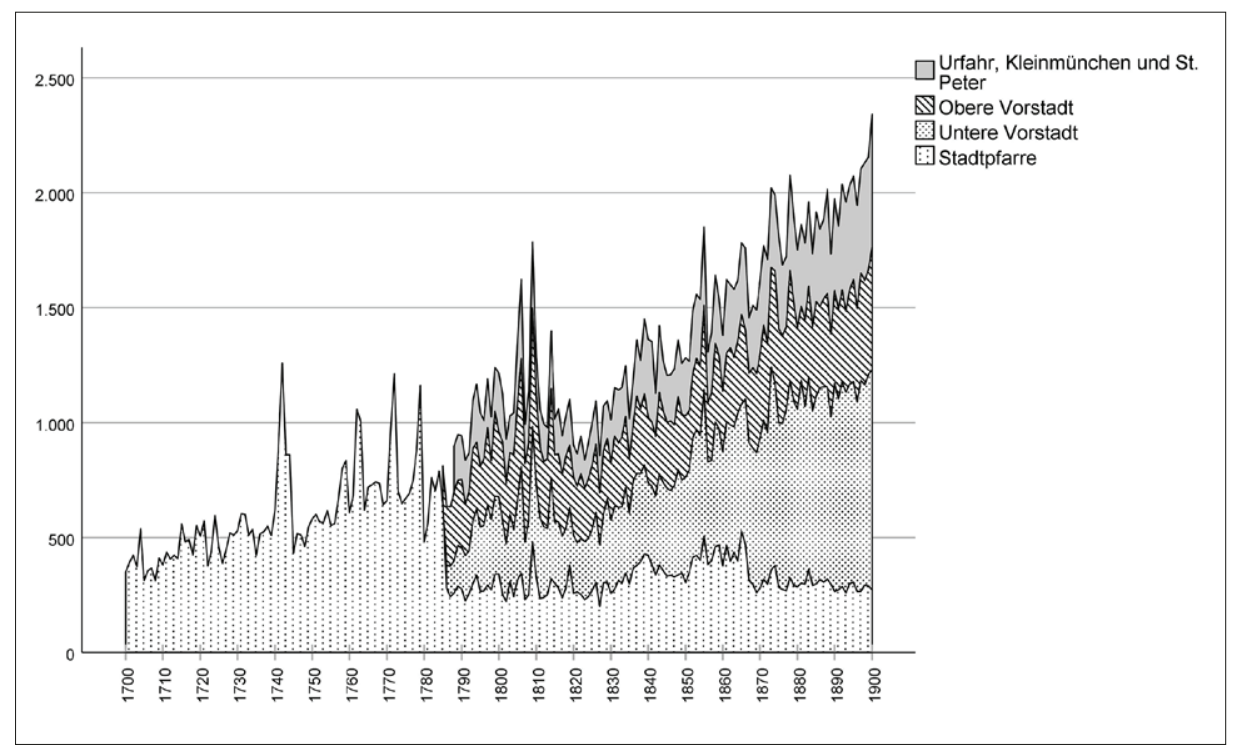

Grafik 2: Sterbefälle in Linz, Urfahr und Kleinmünchen, 1700-1900. Quelle: Eigene Berechnung basierend auf Datenbank Sterbefälle

(23, I Prozent) und andere Infektionskrankheiten zurückzuführen, wobei aber fast ein Drittel aller Todesfälle unter der Rubrik »Sonstige« verzeichnet wurde. ${ }^{72}$

Tab. 3: Kinder- und Säuglingssterblichkeit, 1807-1816

\begin{tabular}{lcccc}
\hline & $\begin{array}{c}\text { Todesfälle } \\
\text { Stadtpfarre }\end{array}$ & $\begin{array}{c}\text { Anteil der Kinder bis } \\
7 \text { Jahre }\end{array}$ & $\begin{array}{c}\text { Todesfälle } \\
\text { Pfarre Urfahr }\end{array}$ & $\begin{array}{c}\text { Anteil der Kinder bis } \\
\text { Jahre }\end{array}$ \\
\hline 1807 & 201 & $51,2 \%$ & 137 & $46,0 \%$ \\
1808 & 249 & $45,0 \%$ & 171 & $53,8 \%$ \\
1809 & 484 & $42,6 \%$ & 212 & $44,3 \%$ \\
1810 & 313 & $49,2 \%$ & 133 & $49,6 \%$ \\
1811 & 229 & $39,7 \%$ & 125 & $49,6 \%$ \\
1812 & 218 & $48,6 \%$ & 136 & $50,7 \%$ \\
1813 & 240 & $47,1 \%$ & 107 & $54,2 \%$ \\
1814 & 302 & $51,3 \%$ & 194 & $47,9 \%$ \\
1815 & 275 & $50,5 \%$ & 119 & $56,3 \%$ \\
1816 & 257 & $52,9 \%$ & 158 & $52,5 \%$ \\
\hline
\end{tabular}

Quelle: Eigene Berechnung auf der Basis Pillwein, Beschreibung, 64

72 Schiedermayr, Sanitätsverhältnisse, 40; vgl. Pichler-Baumgartner, Weg, I Io- I I 2. 
In sozialer Hinsicht ist bislang nicht sonderlich viel über die Linzer Bevölkerung des I 8. und I 9. Jahrhunderts bekannt: Es gibt wiederum nur einzelne Hinweise, die auf ein Bild hindeuten, das auch für andere Städte bekannt ist: Bis ins I 9. Jahrhundert hinein standen eine sehr kleine wohlhabende Elite und eine relativ kleine Mittelschicht einer großen Unterschicht gegenüber. ${ }^{73}$ Das Armutsproblem war noch zur Mitte des I 9. Jahrhunderts ungelöst, wie ein Linz-Besucher im Krisenjahr I 848 anmerkte: Er habe »viele Bettler« am Ostermarkt gesehen. ${ }^{74}$

Zumindest die längerfristige Entwicklung der Löhne und Verbrauchsausgaben ergo des Lebensstandards - lässt sich aufgrund der Pionierstudien von Roman Sandgruber besser abschätzen: Sandgruber hat eine Übersicht zu Oberösterreich im I8. und r 9. Jahrhundert vorgelegt, zudem gemeinsam mit Mühlpeck und Woitek Indices für Verbraucherpreise errechnet, darunter befindet sich auch ein Index für die Entwicklung der Linzer Preise für Ernährung und Getränke (Balken in Grafik 3; vgl. Tab. 4). ${ }^{75}$ Auf dieser Basis - ergänzt durch Hinweise aus den Quellen - lassen sich Teuerungsphasen, die partiell auch überregionalen Charakter hatten, relativ gut identifizieren, wenngleich die Informationen für das I 8. Jahrhundert punktuell und damit nur als vorläufige Annäherung zu sehen sind: Teuerungsphasen zeichnen sich für die ersten Jahre des I 8. Jahrhunderts $a b,{ }^{76}$ zudem für die I 740er, ${ }^{77}$ für die frühen I 77oer Jahre (diese Krise wird im Hauptteil der Arbeit ausführlicher behandelt - vgl. Kap. ıо Versorgungskrise), für die $1790 e r$ bis 18 roer Jahre, ${ }^{78}$ für die I $840 e r$ Jahre, ${ }^{79}$ für die Mitte der I 85 oer Jahre ${ }^{80}$ und für die r 86 oer Jahre. Extreme Teuerungsphasen scheint es in Linz ab den I 82 oer Jahren keine mehr gegeben $z u$ haben, sie wurden von einem allgemeinen Anstieg der Preise abgelöst, was die Unterschichten ungleich stärker betraf als Mittel- und Oberschichten. Roman Sandgruber hat für Oberösterreich im I 8. und r 9. Jahrhundert - verglichen mit anderen Teilen des heutigen Österreichs - einen relativ hohen Lebensstandard angenommen, wenngleich er auf die erheblichen

73 Awecker, Bevölkerung; Losch et al., Tod, 37f.; vgl. dazu Einschätzungen aus den Jahren I805 u. I 8 I I LR CIIIDI -3 , Reg. 223 (I 56 - I 59 ) u. Reg. 240 (I 72 f.).

74 Záloha, Tagebücher, I 27.

75 Sandgruber, Lebensstandard; Mühlpeck/Sandgruber/Woitek, Index, 676-679; vgl. dazu ebd., 655 u. $667-675$.

76 Vgl. die von den Ursulinen aufgezeichneten Getreidepreise: LR Eıb, Reg. I 370 (33); ebd., Reg. 1378 (34). Ein Archivverzeichnis aus den I730er Jahren nennt ähnliche Preise und konstatiert für das Jahr I70I "grosser Mangel« (LR BIA 4 , Reg. 4I9I).

$77 \mathrm{LR} \mathrm{CIIIC}_{3}$, Reg. 608 (256).

78 Wobei die Jahre I800-18 2 eine Phase konstant hoher Preise bildeten, was auch von der Chronik des Ursulinenklosters dokumentiert wurde: LR EIb, Reg. 20 I9 (I 34), ebd., Reg. 2084 (I 44); ebd., Reg. 2 I 28 (I 5 I); ebd., Reg. 2 I 32 (I 52 ); ebd., Reg. 2 I 76 (I58f.); ebd., Reg. 2236 (I67); ebd., Reg. 2255 (I69); vgl. LR BIV, Reg. 919 (359).

79 LR BVI 3 , Reg. I7I I (I06); Mayrhofer/Katzinger, Geschichte, Bd. 2, I04-ıo6; Mittmannsgruber, Stadtverwaltung, 137 .

80 LR BVI 3 , Reg. I732 (148). 


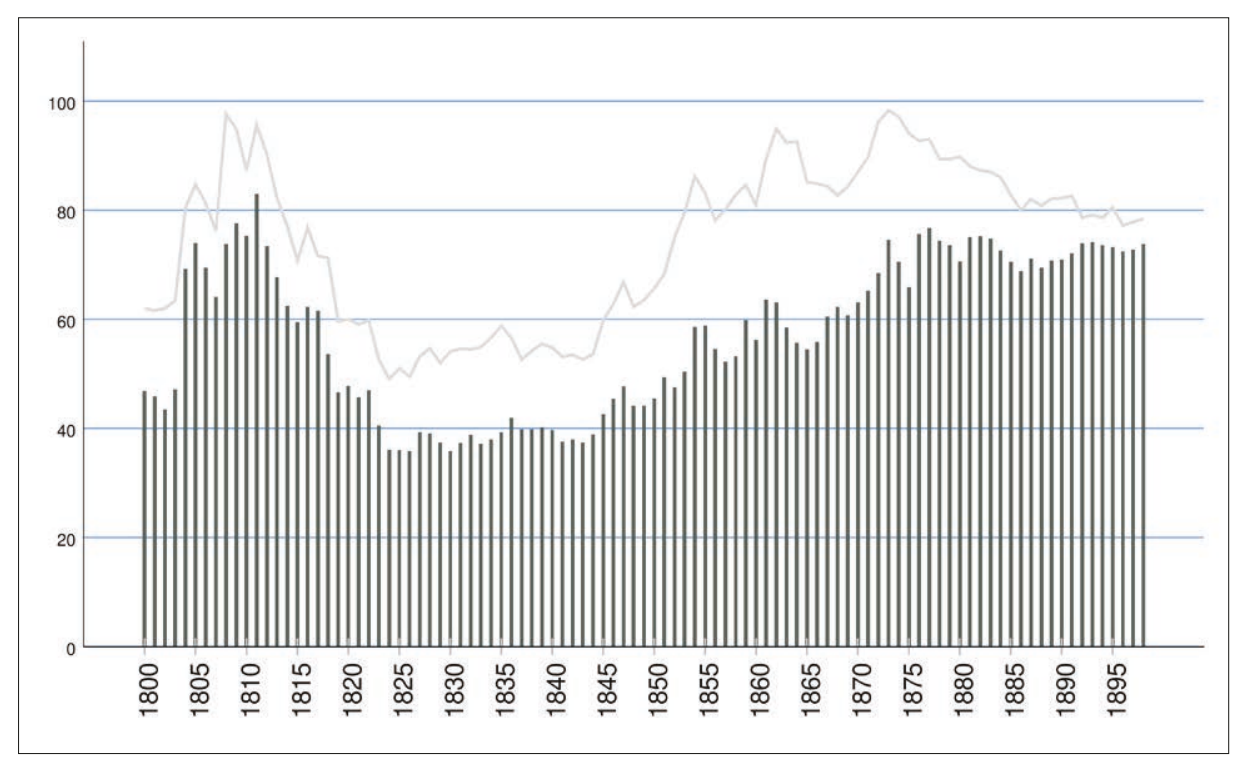

Grafik 3: Preisentwicklung für Ernährung und Getränke, 1800-1900 - Generalindex (Linie) und Linz (Balken). Quelle: Mühlpeck/Sandgruber/Woitek, Index, 676-679;1913 = 100

regionalen (und wohl auch sozialen) Unterschiede verwies. Dies könne auf eine gut entwickelte Landwirtschaft zurückgeführt werden, deren Erträge seit der Mitte des I8. Jahrhunderts anstiegen. Einen Indikator für den Lebensstandard sieht Sandgruber in der Veränderung des Fleischkonsums: Einem relativ hohen Verbrauch pro Kopf im Vormärz, der durch ein niedriges »Agrarpreisniveau « ermöglicht wurde, folgte mit dem Anstieg der Lebensmittelpreise ab den I 85 oer Jahren ein Sinken des Fleischkonsums, danach bis zur Jahrhundertwende wieder ein Anstieg. ${ }^{81}$ Für Linz sind Verbrauchsangaben ab den i 83 oer Jahren greifbar, die diesem Trend entsprechen (vgl. Tab. 4). Für die Unterschichten konstatiert Sandgruber eine insgesamt ungünstige Entwicklung im I8. und im I9. Jahrhundert, besonders ein Sinken der Reallöhne. Dennoch sind diese Annahmen, was Sandgruber auch betont, mit Vorsicht zu interpretieren: Wenn andere Produkte in den Warenkorb aufgenommen werden, dann ergeben sich geringere Lohnverluste, zudem sei der Taglohn real zumeist mit Zuzahlungen oder anderen Leistungen kombiniert gewesen. ${ }^{82}$

8I Sandgruber, Lebensstandard, 274-288.

82 Ebd., 289. 
Tab. 4: Linzer Taglöhne in Rindfleisch, 1700-1900

\begin{tabular}{lcccc}
\hline & \multicolumn{2}{c}{ Maurer- bzw. Zimmerergeselle } & \multicolumn{2}{c}{ Taglöhner } \\
in Geld & in Pf. Rindfleisch & in Geld & in Pf. Rindfleisch \\
\hline $1701-1710$ & $15 \mathrm{kr}$ & 4,60 & $10 \mathrm{kr}$ & 3,0 \\
$1741-1750$ & 15 bis $18 \mathrm{kr}$ & 4,10 & $12 \mathrm{kr}$ & 3,0 \\
$1791-1800$ & $20 \mathrm{kr}$ & 3,60 & $14 \mathrm{kr}$ & 2,5 \\
$1800-1810$ & $32 \mathrm{kr}$ & 4,00 & $20 \mathrm{kr}$ & 2,5 \\
$1821-1830$ & $24 \mathrm{kr} \mathrm{CM}$ & 5,60 & $15 \mathrm{kr} \mathrm{CM}$ & 3,5 \\
$1831-1840$ & 25 bis $30 \mathrm{kr} \mathrm{CM}$ & 5,00 & 15 bis $18 \mathrm{kr} \mathrm{CM}$ & 3,0 \\
$1841-1850$ & 30 bis $33 \mathrm{kr} \mathrm{CM}$ & 4,80 & 18 bis $20 \mathrm{kr} \mathrm{CM}$ & 2,9 \\
$1851-1860$ & 33 bis $40 \mathrm{kr} \mathrm{CM}$ & 3,70 & 20 bis $30 \mathrm{kr} \mathrm{CM}$ & 2,5 \\
$1861-1870$ & $80 \mathrm{kr} \mathrm{ÖW}$ & 3,45 & $60 \mathrm{kr} \mathrm{ÖW}$ & 2,6 \\
$1871-1880$ & $120 \mathrm{kr} \mathrm{ÖW}$ & 3,90 & $80 \mathrm{kr}$ ÖW & 2,6 \\
$1881-1890$ & - & - & $102 \mathrm{kr} \mathrm{ÖW}$ & 2,8 \\
$1891-1900$ & - & - & $110 \mathrm{kr}$ ÖW & 2,7 \\
\hline
\end{tabular}

Quelle: Sandgruber, Lebensstandard, 289

\section{Wirtschaftliche Entwicklung}

Roman Sandgruber hat Linz für die Zeit vor dem r9. Jahrhundert als Handelsstadt charakterisiert, "die keine spezielle gewerbliche Aktivität entwickelte u und erst im 20. Jahrhundert zur Industriestadt geworden sei. ${ }^{83} \mathrm{Im}$ I 8. Jahrhundert war Linz im Hinblick auf die wirtschaftliche Struktur durchaus vergleichbar mit anderen Mittelstädten, die an wichtigen Wasserstraßen lagen und überregional bedeutsame Märkte aufwiesen. Es gab zahlreiche Händler und mit dem Handel verbundene Berufe (Transportwesen), weiters Gewerbetreibende, die meist für den lokalen Bedarf arbeiteten, sowie an der Peripherie in der Landwirtschaft Tätige. ${ }^{84}$ Dazu kam die meist als Wollzeugfabrik bezeichnete Textilmanufaktur, die in den r67oer Jahren als Privatunternehmen an der östlichen Peripherie der Stadt am Donauufer gegründet und nach wiederholten finanziellen Problemen in den I 75 oer Jahren verstaatlicht wurde. Mehrheitlich beschäftigte die Manufaktur Arbeitskräfte im Verlag, direkt in der Fabrik waren um 1750 vermutlich ca. 500 Arbeiter/innen tätig. ${ }^{85}$

Bis in die erste Hälfte des r 9. Jahrhunderts blieb die städtische Wirtschaft von Handel, Kleingewerbe und Dienstleistung geprägt, wenngleich sich ab den I8zoer

83 Sandgruber, Grenzen, 6r.

84 Vgl. ein Verzeichnis von Gewerbetreibenden in Linz aus den I76oer Jahren - LR BIIG6, Reg. 3 I 44 (63f.).

85 Hofmann, Beiträge; Lackner/Stadler, Fabriken, 77-88. 
Jahren in Kleinmünchen an der Traun - einige Kilometer südlich der Stadt - zunehmend Textilproduzenten ansiedelten. Standortbestimmend waren dort die schon über Jahrhunderte genutzte Wasserkraft und wohl die günstigen Bedingungen im Hinblick auf Grundstückskosten und Arbeitskräfte (vgl. Kap. 4. Energie und Biomasse). Den Textilbetrieben folgten weitere Mühlbetriebe, was zu einer erheblichen Expansion der sehr ländlichen Gemeinde Kleinmünchen führte, die bis zum Ende des r 9. Jahrhunderts Vorstadtcharakter erhielt. ${ }^{86}$

Nachdem in den I77oer Jahren und nochmals zu Beginn des i 9. Jahrhunderts Pläne zur Errichtung eines Donau-Moldau-Kanals über Linz bestanden hatten, wurde ab den I 82 oer Jahren - inspiriert durch englische Vorbilder - mit Wiener Kapital eine Verbindung als Pferdeeisenbahn gebaut, die vor allem für den Salztransport zwischen dem Salzkammergut und Böhmen konzipiert war. Im Sommer I 832 wurde die Verbindung Linz-Budweis eröffnet und bis 1836 errichtete man durch die peripheren Stadtgebiete von Linz im Osten und Südosten eine Verlängerung nach Gmunden und eine Abzweigung zum Traunhafen bei Zizlau. ${ }^{87}$ Die Pferdeeisenbahn, retrospektiv tendenziell als failure und als vergebene Chance bewertet, transportierte erhebliche Mengen an Gütern und Personen, so beispielweise im August I 837 auf der Strecke Linz-Budweis (und retour) rund I 7 Tonnen Salz, 248 Klafter Brennholz, 5 Tonnen andere Güter und r.oo8 Personen. ${ }^{88}$ Augenscheinlich sind in Bezug auf die Stadt Linz die, wie es Roman Sandgruber bezeichnet hat, »erwarteten enormen industriellen Impulse durch die Pferdeeisenbahn nicht eingetreten, ${ }^{89}$ dennoch könnte man sie durchaus als sinnvolle Zwischenlösung, als Brückentechnologie interpretieren - immerhin war die Teilstrecke Linz-Lest bis in die frühen r $870 e r$ Jahre in Betrieb. ${ }^{90}$

Die Errichtung der "Maximilianischen« Festungsanlagen rund um Linz während der I 83oer Jahre resultierte in einem beschränkten Boom für die Bauwirtschaft: In der unmittelbaren Umgebung wurden I 2 Steinbrüche und I 4 Ziegeleien neu eröffnet, zeitweilig (183I) waren rund 3.700 Arbeiter beschäftigt, insgesamt verbaute man - für 26 Türme plus Batterien, Fort und Donautürme, die zwar 2 Millionen Gulden (CM) gekostet hatten, aber schon zum Ende der I 85 oer Jahre mehrheitlich außer Dienst gestellt wurden - u.a. I5 Millionen Ziegel, I 95.0oo Kubikmeter Steine und 6.I 88 Baumstämme. ${ }^{91} \mathrm{Ab}$ den $1840 e r$ Jahren entstand mit der Schiffswerft Ignaz Mayers, dem Neffen eines Linzer Schiffmeisters, ein weiterer Betrieb, der stetig expandierte und durch die Verwendung des neuen Werkstoffes Stahl bald überregionale Bedeutung erlangte. ${ }^{92}$ I 85 I

86 Sandgruber, Grenzen, 62; Lackner/Stadler, Fabriken, I04-147; Mayrhofer/Katzinger, Geschichte, Bd. 2, I89-I 9 I.

87 Oberegger, Weg, 247-252; Lackner/Stadler, Fabriken, I 5f.; Sima, Pferdeeisenbahn, 3 I -55.

$88 \mathrm{LZ}$, i 8.9.1 837 .

89 Sandgruber, Grenzen, 63.

90 Mayrhofer/Katzinger, Geschichte, Bd. 2, I 48.

9I Hillbrand, Türme, 77f., I I 4, I 28 u. I77.

92 Rafetseder, Verstaatlichung, 945-949. 
wurde die Wollzeugfabrik, die in den letzten Jahrzehnten nur noch Teppiche produziert hatte, aufgelassen und deren Räumlichkeiten in der Folge als Kaserne und Tabakfabrik genutzt, die ein staatliches Beschäftigungsprojekt mit rund tausend Arbeiter/innen bildete. ${ }^{93}$ Insgesamt zeichnet sich für das I 9. Jahrhundert eine wirtschaftliche Expansion $\mathrm{ab}$, die zunächst vermutlich vor allem auf Klein- und Mittelbetrieben basierte: Bestanden I 822 noch I.or 4 Gewerbeberechtigungen, so existierten I 847 bereits I.25 I Polizeigewerbe, 84I Kommerzialgewerbe und 76 »Handlungen«, I 859 2.533 Gewerbe und 74 »Handlungen« (vgl. auch Tab. 5). ${ }^{94}$

Tab. 5: Gewerbetreibende in Linz, 1822 und 1875

\begin{tabular}{lrr}
\hline Branchen & 1822 & 1875 \\
\hline Edelmetalle & 7 & 18 \\
Eisen, Kupfer, Zinn & 52 & 82 \\
Steine und Erden & 7 & 14 \\
Holz & 59 & 96 \\
Papier & 13 & 29 \\
Wolle, Seide & 110 & 96 \\
Leder & 139 & 182 \\
Verschiedene Grundstoffe & 225 & 169 \\
Nahrungs- u. Genussmittel & 139 & 298 \\
Gesundheitsdienst & 48 & 10 \\
Hausbau & 10 & 27 \\
Handelsgewerbe & 102 & 425 \\
Sonstige & 103 & 320 \\
Gesamt & 1.014 & 1.763 \\
\hline
\end{tabular}

Quelle: John/Stadler, Wirtschaftsraum, 130

Zwar gab es schon ab Ende der I 83oer Jahre regelmäßige Dampfschifffahrtsverbindungen von und nach Linz, für die städtische Wirtschaft wurde diese Verkehrsinnovation aber erst ab der Mitte des i 9. Jahrhunderts relevant. ${ }^{95}$ Ende der I 85 oer Jahre - im internationalen Vergleich "mit einiger Verzögerung ${ }^{96}{ }^{96}$ erreichte die Eisenbahn Linz: $\mathrm{Ab}$ Dezember 1858 bestand eine Verbindung mit Wien, ab September I 859 mit Lambach, ab August i 86o mit Salzburg und ab September i 86 I mit Passau. Dazu kamen ab den r 8 7oer Jahren weitere Nebenbahnen, die Linz mit dem nördlichen bzw. südlichen

93 Sandgruber, Grenzen, 62.

94 John/Stadler, Wirtschaftsraum, Io6- io9.

95 Neweklowsky, Donauschiffahrt, I 9of.; Fuchs, Produktion, 7of.

96 Lackner/Stadler, Fabriken, I 8. 
Hinterland verbanden. ${ }^{97}$ Der Eisenbahnanschluss war in Linz nicht mit erheblichen Wachstumsimpulsen verbunden, hatte aber dennoch einige wesentliche Auswirkungen für die Stadt: ${ }^{98}$ Zum einen entstanden mit der Eisenbahnwerkstätte beim Hauptbahnhof und der Lustenauer Lokomotivenfabrik ( $\mathrm{ab}$ I 880) zwei industrielle Großbetriebe, zum anderen wurde die Eisenbahn für betriebliche Neuansiedlungen standortprägend, $\mathrm{da}$ die industrielle Produktion meist an einen Eisenbahnanschluss gekoppelt war. ${ }^{99}$ Auch für die Stadtentwicklung war die Eisenbahn von Bedeutung: Die Trassenlegung führte zu einer Abtrennung der südlichen vorstädtischen Peripherie. ${ }^{100}$

In der zweiten Hälfte des I9. Jahrhunderts etablierte sich in Linz eine Nahrungsund Genussmittelindustrie, wobei die meisten Betriebe sich an der Peripherie im Osten und Süden der Stadt ansiedelten. Zu Großbetrieben wurden die Brauereien Poschacher und Hatschek und die Ersatzkaffeefabrik Franck. ${ }^{101}$ Infolge der Stadterweiterung durch die "Neustadt" seit den I 86oer und mit dem Kanalbau ab den I $870 e r$ Jahren entstanden aus einzelnen lokalen Ziegeleien in Urfahr und am Froschberg umfangreiche Betriebe. Die größte Ziegelei - im Besitz der „Oberösterreichischen Baugesellschaft « - erzeugte am Froschberg I 8733 und I 890 bereits 6, I Millionen Ziegel. ${ }^{102}$ Die Gründerkrise scheint die Linzer Wirtschaft nicht schwer getroffen zu haben: In den I 88oer Jahren setzte in Linz eine "Phase der Hochindustrialisierung « ein, die wenngleich auf einem eher niedrigen Niveau - bis in die Vorkriegszeit andauerte. ${ }^{103}$ In räumlicher Hinsicht blieb dieser Industrialisierungsprozess auf die östlichen und südlichen Randbereiche der Stadt beschränkt, die dünn besiedelt waren und in denen bereits gewerbliche Betriebe bestanden (vgl. die schraffierten Flächen in Abb. 7).

\section{Stadtpolitik}

$\mathrm{Zu}$ Beginn des I8. Jahrhunderts war Linz in politischer Hinsicht eine relativ typische Stadt: Innerhalb des Burgfrieds war die Stadt selbstverwaltet, sie verfügte über einen Stadtrat, einen Stadtrichter und einen Bürgermeister, die aus den städtischen Eliten, oft aus dem Handelsstand, stammten. Die Landstände waren ein weiterer wichtiger eigenständiger politischer Akteur, der aber im Verlauf des i 8. Jahrhunderts zunehmend an Macht verlor. Parallel dazu wurde der Staat zunehmend zu einem wichtigen lokalen Akteur, was sich besonders ab der Zeit Josephs II. intensivierte. ${ }^{104}$ Ein deutliches

\footnotetext{
97 Statistischer Bericht I 876, 633 u. 640; vgl. Mayrhofer/Katzinger, Geschichte, Bd. 2, I 48 - I 53.

98 Sandgruber, Grenzen, 63; vgl. allgemein: Rumpler/Urbanitsch, Habsburgermonarchie, Bd. 9, 57 If.

99 Lackner/Stadler, Fabriken, 353; Mayrhofer/Katzinger, Geschichte, Bd. 2, I 93 f.

roo Vgl. Lees/Hollen Lees, Cities, I4r.

Io I Sandgruber, Grenzen, 62f.; Lackner/Stadler, Fabriken, 335f. u. 59 If.

I02 Lackner/Stadler, Fabriken, 439-443 u. 709.

I03 John/Stadler, Wirtschaftsraum, I 3 I.

I04 Mayrhofer/Katzinger, Geschichte, Bd. I, 74-85, I65, 214-2 I6 u. ebd., Bd. 2, 8- I3 u. 4If.; vgl. zu Wien: Csendes/Opll, Wien, Bd. 2, $48-57$.
} 
Zeichen des staatlichen Zugriffs waren die erste "Seelenbeschreibung" und die damit verbundene Hausnummerierung (I 770/ I 77 I $)^{105}$ und die Katastralerhebungen des "Josephinischen Lagebuches« (I 786- I 788), die einerseits als Möglichkeit fungierten, alte Steuersysteme zu beseitigen und neue Abgabensysteme zu installieren, andererseits das begrenzte state knowledge über die lokale Topographie und Produktion erweiterten. ${ }^{106}$ Dazu kam, vor allem ab den $1780 e r$ Jahren, eine staatliche Ratschlags- und Reglementierungswelle, die Disziplinierung und Belehrung in Gesetzesform vorsah und bis in Detailbereiche ging, wie beispielsweise das Verbot, „Luftballons zwischen Häusern und Gärten« steigen zu lassen (I784), oder die Verordnung zu einem »Mittel wider den Hundbiß« (I785) illustrieren. ${ }^{107}$ Man fühle in Linz »überall«, so ein Bericht über einen Aufenthalt im Jahr I 780, daß man in einen militärischen Staat gekommen ist, der strenge auf Subordination hält«. ${ }^{108}$

Die Ausweitung der staatlichen Macht ging auch zu Lasten der städtischen Autonomie: Deutlich sichtbar wurde dies in der Magistratsreform des Jahres I784, die nach dem Vorbild der Wiener Reform die bisherige Stadtregierung entließ und "geprüfte« Bürgermeister resp. Magistratsräte (sechs, später acht) als Staatsbeamte einsetzte. Dazu wurden weitere staatliche Verwaltungs- und Exekutivbehörden in der Stadt etabliert. ${ }^{109}$ Ob damit auch eine Professionalisierung der städtischen Verwaltung verbunden war, ${ }^{110}$ ist auf der Basis des nicht sehr umfangreichen Forschungsstandes nicht zu beantworten. Vermutlich erleichterte sich dadurch der Politikprozess, da statt einem Stadtrat mit 30 Bürgern nun nur 6 resp. 8 Beamte und der Bürgermeister entscheiden mussten - somit war es zumindest in dieser Hinsicht eine "zweckmäßigere Einrichtung", wie es der Beamte Benedikt Pillwein in den I8 2oer Jahren bezeichnete. ${ }^{111}$ Zwischen I 784 und I 792 stellten Angehörige des Militärs den Bürgermeister, deren Verhältnis zur Landesregierung offensichtlich nicht friktionsfrei war. Danach folgten Zivilisten, die ihr Amt deutlich länger - bis I 848 - ausübten und vermutlich, da sie auch im Landtag aktiv waren, besser mit der Landesregierung kooperierten als ihre Vorgänger. ${ }^{112}$

Wenngleich die städtische Bürokratie weiter expandierte, veränderte sich in politischer Hinsicht im Vormärz nur wenig. ${ }^{113}$ Auch das Jahr I 848 blieb in Linz ohne größere Unruhen, wenn man von einzelnen Protesten gegen Lebensmittelteuerungen und

I05 LR BVI2, Reg. I 43 I (266f.); Pillwein, Linz, Bd. I, 223 ; Pillwein, Wegweiser, 30.

Io6 Scott, Seeing, $38 \mathrm{f}$.

I07 Luca, Landeskunde, Bd. 2, 4I 5 u. ders., Landeskunde, Bd. 3, 20-22; vgl. Reichert, Pest, 343.

Io8 Risbeck, Briefe, I 83.

I09 Mittmannsgruber, Stadtverwaltung, I05- I07; Mayrhofer/Katzinger, Geschichte, Bd. 2, 4I ; Pillwein, Beschreibung, I47; Heinse, Linz, I. Aufl., 23-25; vgl. dazu Csendes/Opll, Wien, Bd. 2, 8o-86 u. Clark, Cities, 2 I I.

I ro Vgl. Clark, Cities, ro9.

I I Pillwein, Beschreibung, I 47.

I 2 Mayrhofer/Katzinger, Geschichte, Bd. 2, 4I - 43 .

I I 3 Ebd., 86f.; Mittmannsgruber, Stadtverwaltung, I I 3 f. 
Verbrauchssteuern absieht. ${ }^{114}$ Im Gefolge von I 848 begann jedoch eine Neuverteilung der politischen Einflusssphären: Es kam zur (zeitweiligen) Gemeindeautonomie, zur Aufhebung der Grundobrigkeiten und der Ständevertretung. ${ }^{115}$ Dennoch scheint es - trotz der städtischen Emanzipationsrhetorik ${ }^{116}$ - keinen tiefen Bruch mit dem Vormärzsystem gegeben zu haben. Der Neoabsolutismus der i 85 oer Jahre schuf zwar wiederum neue Strukturen (u.a. eine »Gemeindeverwaltung« statt eines Magistrats), und er verstärkte den staatlichen Einfluss mit einer Beschränkung der Gemeindeautonomie - in personeller Hinsicht und damit wohl auch in der Herrschaftspraxis zeichneten sich aber Kontinuitäten ab. ${ }^{117}$

In dieser Phase gewannen middling groups, d.h. das Bürgertum, deutlich an politischer Bedeutung. ${ }^{118}$ Diese Entwicklung wurde durch das ungleiche Wahlrecht begünstigt: Bei den Gemeinderatswahlen im August I 850 waren von ca. 27.000 Einwohnern/innen weniger als r.6oo wahlberechtigt. ${ }^{119}$ Über dieses System konnten auch bürgerliche Aufsteiger und Zuzügler wichtige Positionen in der Stadtpolitik einnehmen, was im I 8. Jahrhundert seltener möglich gewesen war. Diese Newcomer verfügten über vielfältige Vernetzungen und Prägungen, die oft den lokalen Raum überschritten: Der Textilindustrielle Josef Dierzer (Bürgermeister I854- I856) hatte eine Kaufmannslehre in Triest absolviert und mehrere Englandreisen unternommen, er war Mitglied des Landtages, des Reichsrates, des Gewerbevereins und der Handelskammer und an der Gründung der »Allgemeinen Sparkasse « beteiligt. ${ }^{120}$ Carl Wiser (Bürgermeister I 873- I 885) war ein Wiener und seit I 835 in Linz als Jurist tätig; er war Gemeinderat sowie Abgeordneter im Landtag und im Reichsrat (resp. Reichstag). Wie Dierzer war er Mitglied des Gewerbevereins und ein Mitbegründer der Linzer Sparkasse. ${ }^{121}$ Bürgerliche Politik in der Stadt war auch stark mit dem Vereinswesen verbunden, das nach I 848 nicht nur in Linz boomte und einen überregionalen Austausch ermöglichte und intensivierte. ${ }^{122}$

Anfang der r 86oer Jahre kam der Neoabsolutismus in die Krise, was zu Gemeinderatswahlen führte und in einer Erneuerung der städtischen Autonomie resultierte. ${ }^{123}$ Damit begann die Phase des Liberalismus in der Stadtpolitik, die in Linz bis ins begin-

I 4 Mayrhofer/Katzinger, Geschichte, Bd. 2, I04- Io6; Mittmannsgruber, Stadtverwaltung, I I 6.

I 5 Mittmannsgruber, Stadtverwaltung, I04; Kreczi, Linz, 5 I ; Stauber, Ephemeriden, 97; vgl. Gemeindeordnung I 850 , LGB1. 261/1850.

I 6 Vgl. Fink, Geschichte, i 7 If.

I 7 Mayrhofer/Katzinger, Geschichte, Bd. 2, I I 2 ; Mittmannsgruber, Stadtverwaltung, I 2 of., I 28 u. I47I 5 ; ; vgl. zu Wien: Csendes/Opll, Wien, Bd. 3 , I 7 f.

I 8 Clark, Cities, I75f.

I 9 Mayrhofer/Katzinger, Geschichte, Bd. 2, I I 5 ; Tweraser, Gemeinderat, 294.

I 20 Lackner/Stadler, Fabriken, 477f. u. 48 I.

I 2 I Adam, Wiser, 260-307 u. 329 .

I 22 Kreczi, Linz, 265 ; Tweraser, Gemeinderat, 298; ders., Parteiensystem, rogf.; vgl. allgemein: Rumpler/ Urbanitsch, Habsburgermonarchie, Bd. 8, 239-272 u. 1030- I04I.

I 3 Mittmannsgruber, Stadtverwaltung, I68- I 74; vgl. Gemeindestatut Linz, LGB1. 7/ I867. 
nende 2o. Jahrhundert andauerte. Liberal sollte in diesem Kontext eher als »unpolitisch« und in Abgrenzung zu konservativ-klerikalen und später deutschnationalen Akteuren gesehen werden; in Linz war die liberale Stadtpolitik vor allem vom Besitz- und Bildungsbürgertum bestimmt. ${ }^{124}$ Die stadtgeschichtliche Forschung hat die liberale Verwaltung europäischer Städte - wohl mit Blick auf England - als von »limited action« und von »laissez-faire ideas « geprägt gesehen; ${ }^{125}$ für Linz muss dies eventuell differenzierter gesehen werden: Ab den I 86oer Jahren intensivierten sich die Bemühungen der Stadtpolitik, die drängenden Fragen der Stadt zu lösen, was vor allem infrastrukturelle (und weniger soziale) Bereiche betraf. Es kam zu einer Ausweitung und Ausdifferenzierung der städtischen Agenden, was auch eine Vergrößerung und Professionalisierung der Verwaltung verlangte. ${ }^{126}$ Bis ins ausgehende r 9. Jahrhundert wandelte sich die reaktive, situative Stadtverwaltung zu einer aktiven »Daseinsvorsorge «. ${ }^{127}$ Diese veränderten Ansprüche manifestierten sich ebenso im Bereich der Stadtplanung, die sich von Detailplanungen (wie Begradigungen und Verbreiterungen) und kleineren Parzellierungen entfernte ${ }^{128}$ und - in Anlehnung an die Planungen in anderen europäischen Städten ${ }^{129}$ auf die Umgestaltung resp. die Neuerrichtung ganzer Stadtteile und ihrer Straßennetze abzielte, was in Linz zum Ende der I88oer Jahre über einen "Stadtregulierungsplan« versucht, aber mangels städtischer Bautätigkeit nur partiell umgesetzt wurde. ${ }^{130}$

Ein Blick in den Linzer Gemeinderat des Jahres I 880 zeigt, dass die Stadtpolitik zu diesem Zeitpunkt immer noch für Aufsteiger und Zuzügler offenstand: Nur I6,5 Prozent der Gemeinderäte waren in Linz geboren worden (4I, 5 Prozent stammten aus Oberösterreich), und lediglich zwei der zwölf Akademiker gebürtige Linzer. Es dominierten freie akademische Berufe (v.a. Juristen) und Kaufleute, wenngleich mehr als die Hälfte der Gemeinderäte nur über einen Volksschulabschluss verfügte. Ein politisches Engagement musste man sich aber leisten können: Im Jahr I 880 bezog nur der Bürgermeister ein Gehalt, während die Gemeinderäte unentgeltlich tätig waren. ${ }^{131}$

\section{Das Geld der Stadt}

Ähnlich wie die politischen Rahmenbedingungen veränderten sich auch die finanziellen Möglichkeiten der Stadt Linz zwischen den Jahren I 700 und I 900 erheblich (vgl.

\footnotetext{
I 24 Mittmannsgruber, Stadtverwaltung; Mayrhofer/Katzinger, Geschichte, Bd. 2, I 26f. u. I37; Tweraser, Gemeinderat, 299; ders., Parteiensystem, ıo9f.; vgl. Rumpler/Urbanitsch, Habsburgermonarchie, Bd. 9, 564-566 u. Lenger, Metropolen, 288.

I 2 Clark, Cities, 336.

I 26 Lees/Hollen Lees, Cities, I 82 u. I 85 ; Lenger, Metropolen, I 53.

I 27 Vgl. Schott, Urbanisierung, 304; Lees /Hollen Lees, Europe, 473f.; Barles/Knoll, Transitions, 43.

I 8 Doblhamer, Stadtplanung, 26 u. $32 \mathrm{f}$.

I 29 Vor allem von Großstädten: vgl. Lenger, Metropolen, I 8 I - I 84.

I30 Doblhamer, Stadtplanung, 47-49.

I 3 I Tweraser, Gemeinderat, 295, 320-323 u. 328.
} 
Tab. 6: Städtische Ausgaben, 1700-1900

\begin{tabular}{|c|c|c|c|c|c|}
\hline & Ausgaben ${ }^{a}$ & Währung & in $\mathrm{gAg}^{\mathrm{b}}$ & $\begin{array}{c}\text { Veränderung } \\
\text { in \% (zu ...) }\end{array}$ & Quelle \\
\hline 1700 & $44.987,73$ & fl & 49,33 & & AStL, HS 63 (Kammeramtsrechnung 1700) \\
\hline 1713 & $76.806,20$ & fl & 74,50 & $+51(1700)$ & LR BIIG4, Reg. 2416 (206-10) \\
\hline 1720 & $107.431,97$ & fl & 96,76 & $+30(1713)$ & Ebd. \\
\hline 1740 & $82.631,62$ & fl & 69,46 & $-28(1720)$ & AStL, HS 69 (Kammeramtsrechnung 1740) \\
\hline 1750 & $31.287,67$ & fl & 21,55 & $-69(1740)$ & AStL, HS 70 (Kammeramtsrechnung 1750) \\
\hline 1772 & $84.644,27$ & fl & 49,50 & $+130(1750)$ & AStL, HS 92 (Kammeramtsrechnung 1772) \\
\hline 1790 & $46.113,85$ & fl & 26,97 & $-46(1772)$ & AStL, HS 111 (Kammeramtsrechnung 179o) \\
\hline 1800 & $46.070,58$ & fl & 23,30 & $-14(1790)$ & AStL, HS 121 (Kammeramtsrechnung 1800) \\
\hline 1816 & $129.163,77$ & flWW & 21,99 & $-6(1800)$ & AStL, HS 129 (Oberkammeramts Rechnung 1816) \\
\hline 1820 & $151.777,60$ & flWW & 25,85 & $+18(1816)$ & AStL, HS 133 (Kammeramtsrechnung 1820) \\
\hline 1830 & $74.870,32$ & $\mathrm{flCM}$ & 39,80 & $+54(1820)$ & AStL, HS 152 (Oberkammeramt Ausgaben 1830) \\
\hline 1840 & $114.174,23$ & $\mathrm{flCM}$ & 51,36 & $+29(1830)$ & AStL, HS 172 (Kammeramt Ausgaben 1840) \\
\hline 1849 & $144.414,63$ & $\mathrm{flCM}$ & 54,52 & $+29(1840)$ & AStL, HS 192 (Oberkammeramt Ausgaben 1849) \\
\hline 1860 & $216.020,20$ & flöW & 64,95 & $+19(1849)$ & AStL, HS 212 (Kammeramt Ausgaben 1860) \\
\hline 1870 & $228.600,17$ & flöW & 68,33 & $+5(1860)$ & AStL, HS 236 (Kammeramt Empfang 1870) \\
\hline 1880 & $529.166,87$ & flöW & 151,29 & $+121(1870)$ & RB 1880 \\
\hline 1890 & $618.873,00$ & fl ÖW & 171,57 & $+13(1880)$ & RB 1890 \\
\hline 1899 & $1.434 .304,50$ & flöW & 395,17 & $+130(1890)$ & RB 1899 \\
\hline
\end{tabular}

a Die Ausgaben des Jahres 1720 sind durch militärische Einquartierungen und Durchmärsche (über 30.000 fl) signifikant erhöht

${ }^{\mathrm{b}}$ Ausgaben in Gramm Silber pro Einwohner/in; diese Berechnung ist meine eigene und basiert auf meiner Schätzung der Einwohnerzahlen und den Annahmen von Pribram, Materialien, 77-84 u. Cvrcek, Wages

Tab. 6). Das i 8. Jahrhundert war von einem begrenzten Budgetrahmen geprägt: Die jährlichen Ausgaben der Stadt blieben meist unter $50.000 \mathrm{fl}$, da die Einnahmen aus Steuern, Zuschlägen und anderen Abgaben begrenzt waren. ${ }^{132}$ Dennoch lassen sich für diese Zeit städtische Bauprojekte mit erheblichen Ausgaben belegen: Die Stadt beteiligte sich in den I 7 I oer Jahren mit $7.500 \mathrm{fl}$ an der Errichtung der insgesamt über 29.000 fl teuren Dreifaltigkeitssäule, ${ }^{133}$ für die Erweiterung des städtischen Brauhauses wurden bis in die I720er Jahre angeblich I 9.000 fl ausgegeben. ${ }^{134}$ Dazu kamen finanzielle Belastungen durch Kontributionszahlungen im Gefolge der Türkenkriege. ${ }^{135}$

I32 Vgl. LR BIX 2 , Reg. 324 ( I 44- I 47).

I33 Pillwein, Beschreibung, 70; LR E6 (»Sint-Chronik«), 42; AStL, Altakten, Sch. I 46; Mayrhofer/Katzinger beziffern die Errichtungskosten hingegen auf 60.000 fl (Mayrhofer/Katzinger, Geschichte, Bd. I, 289 f.).

I34 Lackner/Stadler, Fabriken, 262; LR BIIG 4, Reg. 2397 (I 25 - I33).

I35 Stauber, Ephemeriden, 76-80. 
Deshalb war, selbst wenn diesbezüglich größere Ambitionen bestanden hätten, für andere städtische Baumaßnahmen und umfangreichere Investitionen relativ wenig Geld vorhanden. Die städtischen Rechnungen deuten sogar darauf hin, dass die Einnahmen des Bauamtes zumindest zeitweilig im I 8. Jahrhundert zur Querfinanzierung anderer Ausgaben verwendet wurden. ${ }^{136}$

Schon in der ersten Hälfte des I 8. Jahrhunderts war die Verschuldung der Stadt signifikant und wurde I7 I 3 auf 265.000 fl, in den I72oer Jahren bereits auf über 3 I 0.000 fl beziffert. ${ }^{137}$ Diese Schulden seien, so der Bürgermeister in einer Rechtfertigung gegenüber Landesregierung und Kaiserhof, vor allem aus »fremden Zumutungen« entstanden: Zu der hohen Steuerbelastung kamen die Einquartierungen des Militärs (für die letzten zehn Jahre auf über I 9.000 fl beziffert) und die Durchmärsche der Rekruten (mit Kosten für die Stadt während der letzten zehn Jahre von 63.500 fl), auch seien $7.000 \mathrm{fl}$ »Kontagionsunkosten« entstanden, womit man wohl das Auftreten der Pest von I7r3/I7r4 meinte. Zudem habe man das Stadtbräuhaus umgebaut, für dieses - aufgrund des günstigen Preises - I 2.000 Metzen Gerstenmalz (zu I Gulden) erkauft und Grundstücke zur Stadterweiterung (vgl. oben) erworben. ${ }^{138}$ Obgleich derartige Schulden nicht unüblich waren - auch andere Institutionen finanzierten regelmäßig größere Investitionen über Darlehen ${ }^{139}$ - und viele Schulden von Vermögenswerten aufgewogen wurden, scheinen Landesregierung und Kaiserhof auf einen rigiden Sparkurs gedrängt zu haben. ${ }^{140}$ I 733 waren die Schulden bereits auf $284.000 \mathrm{fl}$ gesunken $^{141}$ und auch in der Folge wurden erhebliche Teile der städtischen Einnahmen für die Schuldentilgung verwendet, was die Möglichkeit, Investitionen zu tätigen, beschränkte. Durch den Erbfolgekrieg ergaben sich neue Belastungen der städtischen Finanzen: I74I-I 743 wurden über 26.000 fl für einheimische und fremde Soldaten aufgewendet, dazu kamen Schäden an städtischem Besitz, und es reduzierten sich die städtischen Einnahmen durch temporäre Abgaben- und Steuerbefreiungen. ${ }^{142}$ Die zweite Hälfte des i 8. Jahrhunderts war ebenso von Schuldenrückzahlung und einer prinzipiellen Sparsamkeit geprägt: Die einzigen größeren städtischen Investitionsprojekte bildeten in den I 75 oer Jahren die Erweiterung der Wasserkaserne, die Linz von militärischen Einquartierungen befreien sollte, und der Ankauf der Kalvarienwänd. ${ }^{143}$

I 36 I 750 standen Ausgaben von 4.582 fl 39 kr Einnahmen von 8.485 fl. 30 kr gegenüber - AStL, HS 389 (Bauraittung I750), pag. I 37 u. I38.

I 37 LR CIIID $1-3$, Reg. I 57 (66-70); ebd., Reg. I6o (78-80).

I 38 LR BIIG 4 , Reg. 2397 (I 25 - I33); vgl. ebd., Reg. 2392 u. LR CIIIDI-3, Reg. I6 I (80-82).

I39 LR BVIII 2 , Reg. 890 (77f.).

I 40 LR BIIG 4 , Reg. 2400 (I33-I35); LR CIIIDI-3, Reg. I6 I (80-82); ebd., Reg. I64 (85-87).

I 4 I LR BIIG 5 , Reg. 2609 (57f.).

I 42 Awecker, Bevölkerung, I $97 \mathrm{f}$.

I43 Mayrhofer/Katzinger, Geschichte, Bd. I, 28 I; Kunstdenkmäler, Bd. 2, 74; Kreczi, Linz, I 23; für die zuvor sich in Staatsbesitz befindliche Grundherrschaft Kalvarienwänd hatte die Stadt fast 5.000 $\mathrm{fl}$ bezahlt - LR CIIIDI-3, Reg. I68 (93f.). 
Dennoch waren die Schulden der Stadt bis zur Mitte der I 78 oer Jahre erneut auf $400.000 \mathrm{fl}$ angestiegen, was Jahreszinsen in der Höhe von über I 5.000 fl verursachte. ${ }^{144}$ Dies waren immerhin rund ein Drittel der städtischen Ausgaben zu dieser Zeit.

Die Napoleonischen Kriege brachten erneut finanzielle Probleme für die Stadt: Schon die erste französische Besetzung (Dezember I 800 bis März I80 I) verursachte erhebliche Ausgaben für Verpflegungen und andere Bereiche, die die Stadt übernommen hatte, dazu kamen Requirierungen und Sachleistungen. Ähnliche Auswirkungen hatten die weiteren Besetzungen der Jahre I 805 und г 809/ 8 г $0 .{ }^{145}$ Bis in den Vormärz scheinen sich die städtischen Finanzen konsolidiert zu haben, was wohl auch auf die Einführung der Verzehrsteuer zurückzuführen ist, die ab I 829 die alten staatlichen Abgaben ersetzte und eine im europäischen Vergleich relativ hohe Steuer bildete, für die Stadt aber über den »Verzehrsteuerzuschlag« eine erhebliche und - im Verlauf des I9. Jahrhunderts - expandierende Einnahmequelle bot: ${ }^{146}$ I 830 stammte beispielsweise fast die Hälfte der städtischen Einnahmen aus dem Zuschlag. ${ }^{147}$

Interessant ist eine Übersicht für das Jahr I 834, die die Ausrichtung der städtischen Finanzpolitik in der ersten Hälfte des I 9. Jahrhunderts gut erkennen lässt: Einnahmen von 98.67 I fl (CM) standen Ausgaben von 98.46 I fl gegenüber, das »Aktiv-Vermögen« gab man mit $680.000 \mathrm{fl}$, die Schulden mit I $40.000 \mathrm{fl}$ an. ${ }^{148}$ Man zielte offensichtlich auf ein ausgeglichenes Budget ab und tendierte - das deuten zumindest die städtischen Rechnungsbücher an - immer noch zu einer generellen Sparsamkeit, was gleichzeitig größere infrastrukturelle Projekte ausschloss. ${ }^{149}$ Das Instrument des Kredites scheint in dieser Phase auf kleinere Anleihen beschränkt gewesen zu sein, ${ }^{150}$ wenngleich die Gemeindeordnung von I 850 bereits vorsah, dass ein Kredit, der ro.00o fl (CM) überstieg, mit der Zustimmung der Landesregierung abgeschlossen werden konnte. Wenn ein Darlehen oder eine Bürgschaft die Jahreseinnahmen der Gemeinde überstieg, dann war eine Genehmigung an die Verabschiedung eines eigenen Landesgesetzes gebunden. ${ }^{151}$

Mit dem Bevölkerungswachstum wuchsen die städtischen Einnahmen und Ausgaben bis ins ausgehende I 9. Jahrhundert weiter an. Immer noch stammte der Großteil der städtischen Einnahmen aus Zuschlägen auf staatliche Steuern und eigene Abga-

I44 LR CIIID I-3, Reg. I8o (I I6-II9); ebd., Reg. I84 (I39-I4I).

I 45 Mayrhofer/Katzinger, Geschichte, Bd. 2, 59 f., 63 u. $67 f$.

I 46 Sandgruber, Grenzen, 72 ; Mittmannsgruber, Stadtverwaltung, 207; Brunner/Schneider, Umwelt, 2 I 7.

I $4732.029 \mathrm{fl} \mathrm{I} 4 \mathrm{kr} \mathrm{CM}$ von $79.063 \mathrm{fl} 43 \mathrm{kr} \mathrm{CM}-\mathrm{AStL}, \mathrm{HS}$ I 5 ( Oberkammeramt Empfang I 830), pag. 57 u. I 54 .

I48 Tafeln zur Statistik 7 (I834), Tafel I 7.

I 49 Man vgl. die Voranschläge in den Rechnungsbüchern - z.B. AStL, HS I 5 I (Oberkammeramt Empfang I 830), pag. I93; vgl. zur städtischen Sparsamkeit in dieser Periode: Clark, Cities, 336; Lees/ Hollen Lees, Cities, roo.

I 50 Vgl. Fink, Geschichte, 70.

I 5 I Gemeindeordnung I 850, LGB1. 26r/I 850, 272f.; vgl. zu Wien: Csendes/Opll, Wien, Bd. 3, I36- I38. 
ben: Von den rund 357.000 fl (ÖW), die die Stadt Linz I 876 eingenommen hatte, stammten ca. I $2.000 \mathrm{fl}$ aus der Gemeindeumlage (ein Zuschlag auf diverse staatliche Steuern), ca. 58.000 $\mathrm{fl}$ aus dem Zuschlag auf die Verzehrungssteuer, ca. $40.000 \mathrm{fl}$ aus dem »Zinskreuzer« (ein Zuschlag auf Mietzins) und der Rest aus anderen Einnahmen, z.B. aus Vermietung und Verpachtung. ${ }^{152}$ Diese Einnahmen boten jedoch, so eine rezente Untersuchung der Linzer Finanzpolitik, nur »unzureichende finanzielle Handlungsmöglichkeiten «. ${ }^{153}$ Deshalb zielte die liberale Politik bis in die ausgehenden I 86oer Jahre auf private Investitionen und auf Kofinanzierungen (über den Markt und vor allem über den Staat) $a b,{ }^{154}$ danach rückte zunehmend die Finanzierung über am Kapitalmarkt aufgenommene Kredite ins Blickfeld der Stadtpolitik. Als im November I 870 im Linzer Gemeinderat das Budget des Folgejahres diskutiert wurde, verwies der Bürgermeister auf die Möglichkeit, infrastrukturelle Bauten über Kredite zu finanzieren, und betonte dabei, dass andere Städte - augenscheinlich dachte man hier vor allem an Wien - dies bereits getan hätten. ${ }^{155}$ Zur Aufnahme eines umfangreicheren Kredits kam es aber erst I 874 mit der »Millionenanleihe«, die man als notwendig "für die Hebung der städtischen Wohlfahrt, für das Aufblühen der Donaustadt« und »die Ausführung lange ersehnter Projekte« begründete. ${ }^{156}$ Finanziert wurde der Kredit, der ab I 875 in neun Jahresraten ausgezahlt wurde, über eine Erhöhung der Gemeindeumlagen und des Zinskreuzers. Die liberale Mehrheit im Gemeinderat betrachtete die langfristige Tilgung (über 50 Jahre) als gerechte Lösung, da eine direkte Finanzierung »die Steuerträger der Gegenwart allein und um desto höher « belasten werde. ${ }^{157}$ Den Kredit erhielt die Stadt von der »Allgemeinen Sparkasse«, die in Linz I 849 unter Beteiligung der städtischen Elite etabliert worden war, damit zahlreiche Überschneidungen zur Stadtpolitik aufwies und zum Zeitpunkt der ersten Anleihe bereits über Einlagen von angeblich I 4 Millionen Gulden (ÖW) verfügte. ${ }^{158}$ Interessanterweise hatte die Stadt noch in den I 85 oer Jahren weder von der »Allgemeinen Sparkasse « noch von der Nationalbank 300.000 fl (ÖW) als Darlehen für die Errichtung eines Gaswerks erhalten. Ab den beginnenden I87oer Jahren zeichnen sich für Linz steigende Ausgaben und ein steigendes Defizit deutlich $a b,{ }^{159}$ was auch für deutsche Großstädte als generelle Tendenz festgestellt worden ist. ${ }^{160}$

I 52 Mittmannsgruber, Stadtverwaltung, 2 I If.

I 53 Kitzmantel, Finanzpolitik, 2 I6.

I 54 Mayrhofer/Katzinger, Geschichte, Bd. 2, I 37 .

I 55 Pichler-Baumgartner, Weg, 37f.; Mittmannsgruber, Stadtverwaltung, 205; Kucera, Ausgaben, 49-55; vgl. zu städtischen Krediten: Lenger, Metropolen, 42-44; Schott, Urbanisierung, 270 u. 304.

I 56 Krackowizer, Landeshauptstadt, 2.

I 57 Eine ähnliche Argumentation findet sich beim ersten Wiener Darlehen I 866 - Pichler-Baumgartner, Weg, 37f.; vgl. Mittmannsgruber, Stadtverwaltung, 206.

I 8 Lackner/Stadler, Fabriken, 33-36 u. 49; Wacha, Sparkasse, 292f. u. 302; vgl. Commenda, Linz, 237.

I 59 Mittmannsgruber, Stadtverwaltung, 205.

I60 Lenger, Metropolen, I 56. 
Derartige Richtungsentscheidungen mussten auch politisch vertretbar sein: Die erste Linzer Anleihe war nicht unumstritten, wie Zeitungsberichte und andere Veröffentlichungen zeigen. Hauptkritikpunkte der Gegner bildeten einerseits die Prioritätensetzung bei den Investitionen, andererseits die Form der Finanzierung und Tilgung, die in einer Pfadabhängigkeit resultierte. ${ }^{161}$ Dass über die Aufnahme dieses Kredits mittelfristig aber Konsens bestand, legt die Aufnahme zweier weiterer Großkredite in den I $890 e r$ Jahren nahe: I 889/I 890 wurden 3 Millionen Gulden (u.a. zur Finanzierung der Wasserleitung, der Kremstalbahn, des Umschlagplatzes an der Donau und zur teilweisen Tilgung des ersten Darlehens) und I 897 2,5 Millionen Gulden (ÖW, u.a. für die Errichtung des Vorortekanals) aufgenommen. Auch dies war nicht unüblich für westeuropäische Städte zu dieser Zeit. ${ }^{162}$ Parallel dazu gab es aber immer noch Versuche, Infrastrukturen über private oder unternehmerische Investitionen zu etablieren: Ein Beispiel dafür ist die Tramway in Linz, deren Einrichtung, wie der Gemeinderat im Februar I 879 beschloss, »ohne irgend eine Belastung des Gemeindevermögens« erfolgen sollte. ${ }^{163}$

\section{Ausweitungen des Urbanen}

Die Vorstellungen und Ansprüche, was man - als Bewohner/in oder Besucher/in von einer Stadt erwartet, was eine »gute« Stadt ausmacht, wofür eine Stadt zuständig ist, änderten sich über den Betrachtungszeitraum hinweg erheblich. ${ }^{164}$ Dabei war die Stadt nicht nur »für sich« existent, sondern wurde genauso durch äußere Einflüsse, den Vergleich mit anderen Städten oder den Austausch von Ideen geprägt.

Linz war ein regionales Verwaltungszentrum, dessen Machtanspruch sich auch im Stadtbild manifestierte: Das mittelalterliche Schloss, der Hauptplatz und das im I6. Jahrhundert errichtete »Landhaus« bildeten in ihrer Situierung und Ausgestaltung repräsentative Räume, die nicht nur an die Stadtbewohner/innen adressiert waren. ${ }^{165}$ Infolge der Lage an der Donau war Linz immer schon zeitweiliger Aufenthalts- resp. Transitort für auswärtige Eliten - regelmäßig besuchten Angehörige des Kaiserhauses Linz, I 765 machten z. B. Maria Theresia und ihre Entourage mit 22 Schiffen in Linz Station. ${ }^{166}$ Diese Linz-Besuche nahmen bis ins beginnende r 9. Jahrhundert deutlich $\mathrm{zu}$, was vermutlich wesentliche Auswirkungen auf das Selbstbild der Stadt und die Erwartungen gegenüber derselben hatte. Illustriert wird dies durch die kaiserlichen

I6 I Altmüller, Eingemeindungen, I44; vgl. dazu eine zeitgenössische Publikation: Grubauer, Betrachtungen, 5 , IO- I 3 U. $24-26$.

I62 Pichler-Baumgartner, Weg, 37-40; Mittmannsgruber, Stadtverwaltung, I 89 u. 2 I 2.

I63 Statistischer Bericht I 882, Bd. 3, 7 1 .

I64 Vgl. zur good city: Lees/Hollen Lees, Europe, $475 \mathrm{f}$.

I65 Mayrhofer, Linz, unpag.; vgl. zur morphologischen Entwicklung des Hauptplatzes: Mayr, Reiseführer, 93-IOI.

I66 LR BVI2, Reg. I403 (259). 
Besuchsprogramme: i 820 und I 829 erlebte das Kaiserpaar nicht nur einen festlichen Empfang und eine dementsprechende Beleuchtung, es wurden auch städtische Infrastrukturen - vor allem die Spitäler, aber ebenso das städtische Schlachthaus - vorgeführt. ${ }^{167}$ Die Errichtung der Befestigungstürme in den I 82 oer und 3oer Jahren führte nicht nur zu regelmäßigen Aufenthalten des Erzherzogs Maximilian d'Este und anderen Mitgliedern des Kaiserhauses, die Befestigungsanlage brachte auch ausländische Eliten nach Linz, u.a. den russischen und den türkischen Botschafter, hohe französische und englische Militärs, sogar den bayerischen Kronprinzen. ${ }^{168}$ Da sich die Verkehrsanbindung deutlich verbessert hatte und Touristen/innen wie auch Angehörige des Kaiserhauses das Salzkammergut für sich entdeckten, stiegen ab der Mitte des I 9. Jahrhunderts die Linz-Besuche auswärtiger Eliten weiter an. ${ }^{169}$

Bereits in der zweiten Hälfte des I 8. Jahrhunderts war Linz intensiver in überregionale Personentransportnetze eingebunden: Ab I 754 gab es regelmäßige Verbindungen mit dem »Ordinarischiff", mit dem man Wien - statt in sechs bis sieben Tagen mit einem Schiffszug - mitunter in ein bis zwei Tagen erreichen konnte. In den I78oer Jahren gab es bereits zwei Verbindungen nach Wien pro Woche. ${ }^{170}$ Dazu expandierten auch die Personenverbindungen über Land: Seit I 807 bestanden tägliche Kutschenverbindungen zwischen Wien und Linz, die in den I 8 Ioer Jahren weiter nach Westen ausgedehnt wurden. Ab I 825 konnte man Wien in 24 Stunden mit der "wöchentlichen Eilfahrt« erreichen, die Verbindung zu weiteren Städten folgte bald, und ab den I $830 e r$ Jahren gab es sogar einen täglichen Eilwagen nach Wien. ${ }^{171}$ Eine deutliche Zäsur für das bürgerliche Reisen bedeutete die Dampfschifffahrt, die Linz ab dem Herbst I 837 mit Wien und ab dem Folgejahr mit den bayerischen Donaustädten verband. Zwar hatten »Sturm, anhaltender Regen, und ein ungewöhnlich hoher reißender Wasserstand « dazu geführt, dass die Jungfernfahrt von Wien nach Linz 53 Stunden dauerte, die Rückfahrt konnte aber in nur etwas über 9 Stunden absolviert werden. ${ }^{172}$ Bald gab es tägliche Dampfschiffverbindungen nach Wien, die nur ein Fünftel einer Postwagenfahrt kosteten und in der Regel zwischen sieben und acht Stunden dauerten: "Welche Kürze der Zeit!«, jubilierte man in einer Stadtbeschreibung. ${ }^{173}$ Gemeinsam mit der Pferdeeisenbahn machten die Dampfschiffverbindungen Linz zu einem Gateway für Touristen/innen, die ins Salzkammergut fuhren: ${ }^{174}{ }$ Im oberen Donauthale

I67 Fink, Geschichte, 33f. u. 40.

r68 Hillbrand, Türme, $48-50$ u. r66- I75.

I69 Fink, Geschichte, I 56 6f. u. I 92 - I 99; Der Oberösterreicher I 884, I 73, I76f. u. I 80; Der Oberösterreicher I 883 , I74; vgl. Schaller, Linz, I 49 f.

I70 Neweklowsky, Donauschiffahrt, I 87f.; Kreczi, Linz, 2 I 8f.; Hoff, Skizze, 94.

I7 I Fink, Geschichte, I I 5 ; Heinse, Linz, I. Aufl., 82; Murray, Handbook, I 25.

I72 LZ, 25.9.18 87 .

I73 Heinse, Linz, 2. Aufl., 67; Pillwein, Beschreibung, 308; Stifter, PRA, Bd. I7, 228; vgl. zum Diskurs: Király, Donau, ro3- ro5 u. I30-I37.

I74 Vgl. Wollstonecraft Shelley, Rambles, i9 u. 23. 
ist Linz, die Hauptstadt von Oberösterreich, recht eigentlich die Pforte, welche [...] hinanführt zu dem Mittel- und Hochgebirge des Salzkammergutes und in die Alpenregion Salzburgs, der sogenannten österreichischen Schweiz. « ${ }^{175}$

Die zwischenstädtische Vernetzung - und damit auch der zwischenstädtische Vergleich - intensivierte sich zudem mit der Expansion der Bild- und Druckpublizistik, was sich für die Zeit ab den I78oer Jahren und vor allem für die ersten Jahrzehnte des I 9. Jahrhunderts abzeichnet. Die zahlreichen Reiseberichte, Stadtbeschreibungen und Statistiken ermöglichten das Beobachten und Kommunizieren von Funktionalität oder Dysfunktionalität einer Stadt und definierten dadurch urbane Mindeststandards. Was machte im I 8. und frühen I 9. Jahrhundert eine funktionierende und damit repräsentative Stadt aus, die als »keine der letzten Hauptstädte der österr. Monarchie« gelten wollte ? $^{176}$ Meines Erachtens wurde dies wesentlich über die »Ordnung « des öffentlichen Raumes bestimmt, was wiederum sehr stark auf die Visualität abzielte. Dass Linz ein »schönes Ansehen ${ }^{177}$ habe, wurde oft mit wirtschaftlicher Prosperität verknüpft, ${ }^{178}$ häufiger noch mit der Frage der Gesundheit. ${ }^{179}$ Eine zentrale Bedeutung kam in dieser Hinsicht der Sauberkeit des Stadtraumes zu, die schon in Reiseberichten des frühen I 8. Jahrhunderts thematisiert wurde. ${ }^{180}$ Zudem wurden ab dem ausgehenden I 8. Jahrhundert öffentliche Räume für enlightened cultural activity (der bürgerlichen Schichten), Straßenpflasterung und Straßenbeleuchtung zu Gradmessern für die urbane Moderne, was sich auf den Einfluss großstädtischer Diskussionen und Entwicklungen zurückführen lässt. ${ }^{181}$ Die Feststellung in einer Satire aus den I 78 oer Jahren, dass die Straße an der Donau vor »zehn Jahren [...] eher einer Mistpfüze, als einer Landstrasse gleich gesehen« habe und die Pflasterung noch »verflucht schlecht« sei, ${ }^{182}$ traf damit bei den Linzer Eliten vermutlich wunde Punkte.

In den ersten Jahrzehnten des r 9. Jahrhunderts wurde das Fehlen von Pflaster in Teilen der Stadt wiederholt in Reiseberichten betont (oder das Vorhandensein gelobt), ${ }^{183}$ dazu kamen Hinweise auf visuelle Probleme der Stadt: Enge Passagen wurden ebenso moniert wie die Unebenheit des Hauptplatzes, ${ }^{184}$ der, wie das I 837 erschienene, in der englischsprachigen Welt breit rezipierte »Handbook for Travellers« festhielt, eigentlich ein »fine square« sei, aber »by throwing down the houses on the side nearest the ri-

I75 Koch, Reise, 2.

I 76 Krickel, Fußreise, I 88.

I77 Nicolai, Beschreibung, 496; Füssel, Tagbuch, 22 I.

I 8 Risbeck, Briefe, I 76.

I79 Richter, Reise, 7 .

I 80 Zum Bsp. beim Franzosen Casimir Freschot (Aufenthalt I 704) oder beim Niederländer Joannes van der Slype ( I 7 r 6) - vgl. Gugitz, Linz, 57 f.

I 8 I Clark, Cities, I 95 - i 97.

I 82 Gimpel Insel, ro4 u. I69.

I 83 Mader, Reise, I4.

I 84 Heinse, Linz, r. Aufl., I I u. I 4f.; Schultes, Donau-Fahrten, 84 f. u. 87 . 
ver« deutlich verbessert werden könne. ${ }^{185}$ Derartige visuelle Störungen wurden ab den I 8 2oer Jahren zunehmend beseitigt: Der städtische Raum an der Unteren Donaulände wurde neu gestaltet, hölzerne Lagergebäude (»Stadl«) abgerissen und man begann, auch die Stadtbefestigung in diesem Stadtteil abzutragen. Der Schmiedtorturm wurde I 828 abgerissen und ab I 836 reduzierte man die Anzahl der hölzernen Verkaufsstände in der Stadt. ${ }^{186}$ Bis in die I $840 e r$ Jahre hatten sich die Ansprüche ausgeweitet: Nun kamen Kanalbauten und "Annehmlichkeiten« im öffentlichen Raum (wie z.B. Sitzbänke) in den Blick, ${ }^{187}$ während man sich in einem Reisebericht aus den frühen I 84 oer Jahren erstaunt zeigte, dass "noch kein allgemeines Krankenhaus bestehe ${ }^{188}$

Ebenso symbolisierten neue Verkehrsinfrastrukturen die städtische Moderne, wie die spürbare Aufregung und Bewunderung in Reiseberichten und einzelnen Ego-Dokumenten nahelegt: ${ }^{189}$ Die Wiener Dampfschiffe hätten »sehr elegant[e]« Salons gehabt, hielt der Krumauer Ingenieur Josef Langweil anlässlich eines Linz-Besuchs zu Ostern I 848 in seinem Tagebuch fest. Nach einem Kanonenschuss und zwei Glockensignalen sei ein Schiff zuerst »in einem schönen Bogen« ein Stück flussaufwärts gefahren und dann der Donau flussabwärts gefolgt. »Dieser Anblick reißt zur Bewunderung über den menschlichen Erfindungsgeist hin. ${ }^{190}$ Eine überregionale Bühne betrat Linz mit dem Eisenbahnanschluss: Ab I86 r fanden - zunächst im städtischen »Volksgarten« (vgl. Kap. 7. Geordnete und modifizierte Umwelt) und maßgeblich durch die Stadt finanziert - »Volksfeste« statt, die an die Gewerbeausstellungen der I 84 oer Jahre anknüpften, dazu kamen weitere Großveranstaltungen mit überregionalem Einzugsbereich wie Sänger- und Turnerfeste. ${ }^{191}$

Meines Erachtens steigerten sich die Vernetzung und der Vergleich mit anderen Städten ab der Mitte des r 9. Jahrhunderts deutlich - Friedrich Lenger hat dies als "Städtekonkurrenz« bezeichnet. ${ }^{192}$ Einerseits bestand ein Spannungsfeld zwischen Metropole und Provinz, andererseits konkurrierten die kleineren und mittleren regionalen Zentren untereinander. Vernetzung und Vergleich manifestierten sich deutlich im politischen Diskurs: Bei den Diskussionen um die Aufnahme eines Großkredits im November I 870 verwies man explizit auf das Beispiel anderer Städte, ${ }^{193}$ im Dezember

\footnotetext{
I 85 Murray, Handbook, I 23.

I 86 Fink, Geschichte, I 22- I 24.

I 87 Pillwein, Linz, Bd. 2, 25 ; Koch, Reise, 36.

I 88 Kohl, Reise, 24.

I 89 Vgl. Gugitz, Linz, 48 u. Gober, Linz, r66f.

I 90 Záloha, Tagebücher, I 27 f.

I 9 I Lackner/Stadler, Fabriken, 29 u. 3 I ; Mayrhofer/Katzinger, Geschichte, Bd. 2, I 85 ; vgl. Fink, Geschichte, I I If.; Der Oberösterreicher I 883, I75- I 77; Der Oberösterreicher I 884, I 74; Commenda, Linz, 250.

I 92 Lenger, Metropolen, I7 I; vgl. dazu die Überlegungen von Hannes Stekl und Hans Heiss zur »Urbanität« von Mittel- und Kleinstädten: Rumpler/Urbanitsch, Habsburgermonarchie, Bd. 9, 563 f., 578 f. u. 6r4-6ig.

I93 Mittmannsgruber, Stadtverwaltung, 205.
} 
I 872 warnte ein Gemeinderat vor einem »Zurückbleiben der Entwiklung der Stadt Linz gegenüber anderen viel ungünstiger gelegenen und kleineren Städten«. ${ }^{194}$ Ähnlich argumentierte Bürgermeister Wiser I 875 im Gemeinderat: Wenn »man Linz zu einem zu scheuenden Aufenthalte machen wollte, wo die Ansiedlung gleichbedeutend mit Testamentmachen sei, [befinde] man sich auf dem besten Wege«. ${ }^{195}$ Die Volkszählungen und andere regelmäßige statistische Erhebungen brachten ab den späten I 86oer Jahren eine Fülle von Daten aus den unterschiedlichsten Lebensbereichen und ermöglichten damit überregionale Vergleiche, die besonders in den Hygienediskursen angewandt wurden. ${ }^{196}$

Verglichen wurde auch im Hinblick auf die Etablierung von städtischer Infrastruktur (vgl. Tab. 7), die ebenso zu zwischenstädtischem Austausch führte: Bei der Errichtung der Linzer Kanalisation wurde das Wiener Stadtbauamt mit einem Gutachten beauftragt, die Frage nach Erfahrungen mit unterschiedlichen Materialien ging nach Budapest, Zürich, Straßburg, Lyon und Bern. ${ }^{197}$ Vermutlich aus diesen Diskussionen heraus entstanden in Österreich ab den r 88oer Jahren Bemühungen, derartige Vernetzungen zu fördern. Im Wiener Gemeinderat gab es bereits I 882 den Plan, im Folgejahr in Wien eine »internationale Städte-Ausstellung in Verbindung mit einem internationalen Städtetag zu veranstalten«. Neben Kunst sollten auch die Themenbereiche Technik und Hygiene gezeigt werden, dabei strebte man eine »systematische Vorführung städtischer Einrichtungen aus der ganzen Welt « an. ${ }^{198}$ Wenngleich dieses Ausstellungsprojekt nicht umgesetzt wurde, begann mit dem »Städtetag« ab I 887 ein Versuch, die punktuelle Zusammenarbeit und Vernetzung von österreichischen Städten zu institutionalisieren. ${ }^{199}$

Tab. 7: Etablierung von städtischer Infrastruktur im 19. Jahrhundert

\begin{tabular}{lllll}
\hline & Linz & Wien & Graz & Salzburg \\
\hline zentrale Wasserversorgung & 1893 & 1873 & 1872 & 1875 \\
zentrale Kanalisation & $\mathrm{ab} 1876$ & $\mathrm{ab} 1831^{\mathrm{a}}$ & $1856^{\mathrm{b}}$ & $\mathrm{ab} 1854$ \\
Gaswerk & $1857^{\mathrm{c}}$ & $1828 / 34$ & 1845 & 1859 \\
Elektrizitätswerk & 1897 & 1889 & 1894 & 1887 \\
Pferdetramway & 1880 & 1865 & 1878 & \\
\hline
\end{tabular}

Quelle: Lackner/Stadler, Fabriken, 22f. u. 52-54; Brunner/Schneider, Umwelt, 157, 196-198 u. 262-264

a Expansionsphase aber erst mit Kanalkommission ab 1858

b als Tonnensystem mit Abfuhr

c Vertrag

I94 Pichler-Baumgartner, Weg, 37 f.

I95 Adam, Wiser, 313.

I 96 Vgl. Schiedermayr, Sanitätsverhältnisse, 6.

I 97 Adam, Wiser, 3 I 3 ; Pichler-Baumgartner, Weg, 78 -80; vgl. Lenger, Metropolen, I62f.

I 98 Wiener Stadt- und Landesarchiv, Hauptarchiv, A8/r.

I99 Kitzmantel, Finanzpolitik, 2 I 7. 
Mit neuen finanziellen und technologischen Möglichkeiten veränderten sich auch die Ansprüche an die Stadt. Von Landgemeinden erwarte man "ganz anderes« als von einer Stadt, gab ein Gemeinderat I 872 in der Diskussion um die bevorstehende Stadterweiterung zu bedenken: »Wenn einer [in der Stadt] ein Zinshaus baut, so wird er [...] eine bessere Straße fordern, er wird eine bessere Beleuchtung fordern, kurz er will jenes für sich in Anspruch nehmen, was eine Stadt bietet «. ${ }^{200}$ Auf die sich ändernde Erwartungshaltung verwies Bürgermeister Carl Wiser in seinem Vorwort zum ersten gedruckten Band des Rechenschaftsberichts des Linzer Gemeinderats: »Seit einem Menschenalter ist alles anders geworden, wie in Haus und Hof, in der Produktion und im Verkehr, so auch in der Gemeinde. An sie stellt der Bürger heute erhöhte Ansprüche in Folge der totalen Veränderung der Bedürfnisse, nicht minder der Sitten und Lebensgewohnheiten der Menschen. [...] Ein Gemeinwesen von einiger Bedeutung vermag sich keineswegs dem Wogendrange der Zeit zu entziehen. « ${ }^{201}$

Der mediale Diskurs dieser Zeit zeigt einerseits veränderte Ansprüche, andererseits finden sich ähnliche Monita, die schon im ausgehenden I 8. und frühen I 9. Jahrhundert anzutreffen waren. Zahlreiche Leserbriefe aus den Tageszeitungen der i 86oer Jahre beklagten die Ablagerung "von Mist und mannigfaltigem Unrath«, was nicht nur als gesundheitsgefährdend, sondern auch als visuelle Beeinträchtigung gesehen wurde. $^{202}$ I 870 erschien in einer Linzer Tageszeitung eine mehrteilige Serie, in der ein (realer?) Besucher seine Überlegungen auf »Wanderungen durch Linz« präsentierte: Er wolle zwar an eine »Provinzialstadt nicht die Ansprüche einer Weltstadt» stellen, dennoch aber die Obrigkeit auf »Uebelstände« in der Stadt hinweisen. Als Dysfunktionales identifizierte der Autor - über mehrere Folgen verteilt - die unvollständige Pflasterung, ${ }^{203}$ den Geruch, der aus einem Haus am Pfarrplatz »entgegenströmte «, ${ }^{204}$ die »sehr schwache Beleuchtung « und zu schmale Straßen. ${ }^{205}$ Ein zum Ende der I 880 oer Jahre erschienener Stadtführer entwarf wenig überraschend ein positiveres Gesamtbild: Man könne sich »hochbefriedigt fühlen im Hinblicke auf einen gewiss noch lange nicht abgeschlossenen Aufschwung, wie selbes [Linz] keinen solchen in den vielen Jahrhunderten seines Bestehens je erlebte! ${ }^{206}$ Überall sehe man »die nie ermüdende Arbeit des Umgestaltens und des Verschönerns, allerorts die frische Lust an vorsorglichem und folgenreichem Wirken [...] und aus dem Schutte, der für den Augenblick die zähen Anbeter des sguten Alten belästigt, steigt fortwährend `das bessere Neue empor zu Nutz und Zierde der Stadt«. ${ }^{207}$ Ähnliches konstatierte der

\footnotetext{
200 Altmüller, Eingemeindungen, I 43.

20I RB I 876-I 878 , IV.

202 Zum Bsp. LTP, i г.8. 866.

203 LTP, 2.2.1870.

204 LTP, 27.2.1870.

205 LTP, 6.2.1870.

206 Linz a./d. Donau, 8 I.

207 Ebd., $99 f$.
} 
Schriftsteller Adam Müller-Guttenbrunn, der in den I $870 e r$ Jahren als Telegraphist in Linz gearbeitet hatte, I 902 in seinem Tagebuch über einen Linz-Besuch: »Die Stadt entwickelt sich gegen die Donau hin ganz prächtig [...]. Jedenfalls ist in den letzten 22 Jahren [...] mehr geschaffen worden als vorher in Ioo Jahren. ${ }^{208}$ Trotz dieser beiden euphorischen Stimmen sollte nicht übersehen werden, dass viele Probleme der Stadt zur Jahrhundertwende noch ungelöst waren, da sie "private« und somit nur begrenzt sichtbare Bereiche betrafen. Vor allem die Wohnsituation blieb in Linz von »Wohnungsmangel und Überfüllung « gekennzeichnet. ${ }^{209}$

208 Haslinger, Ehrenbuch, I 82 (Zitat); vgl. zum Verfasser: ebd., I 78.

209 Eichwalder, Wohnverhältnisse, 569; vgl. GRP i 869, fol. 264a u. 264b u. RB I 898, 338. 


\section{Wasser}

\section{Praxis und Logik dezentraler Wasserversorgung}

Die Wasserversorgung bildete - wie es Elisabeth Suter für Zürich bezeichnet hat - den "Lebensnerv« einer vormodernen Stadt. ${ }^{1}$ Dass Wasser als zentrale und unentbehrliche Ressource empfunden wurde, spiegelt sich in Linz in den Beschreibungen wider, die bei Hausverkäufen die Vorzüge der Immobilie hervorhoben. Die in den I72oer Jahren entstandenen Beschreibungen des Stockhofes, eines bäuerlichen Anwesens an der Peripherie der Oberen Vorstadt, widmeten den umfangreichen Wasserinfrastrukturen breiten Raum: Es gebe im Garten ein "Pründl [...,] alwohin das springende Wasser durch bleyene gelegte Rohr" vom »Holzgrundt« oberhalb des Hofes »eingelaidet wierdet«. Dazu verfüge man auch im Gebäude über fließendes Wasser, das sogar den oberen Stock und die dortige Küche erreiche, »wormit man des Wasser Auf- und Abtragens über die Stiegen nicht vonnöth hat «. ${ }^{2}$ Zudem bestehe ein neu errichteter Ziehbrunnen mit »dem besten Traun waßer« und beim Pferdestall eine Schwemme mit Brunnenwasser. ${ }^{3}$

Derartige dezentrale Lösungen bestanden bereits seit Jahrhunderten und dominierten - wie in vielen anderen Städten ${ }^{4}$ - die Linzer Wasserversorgung bis ins I 9. Jahrhundert. In der Regel verfügten die Häuser über eigene Grundwasserbrunnen (Sodbrunnen), die sich im Hof oder im Garten, seltener im öffentlichen Raum befanden. ${ }^{5}$ Bei erhöhtem Wasserbedarf wurden mehrere Brunnen errichtet: Hinweise dazu gibt es für Gasthäuser, ${ }^{6}$ auch bei der Neuerrichtung der städtischen Kaserne (»Wasserkaserne «) waren sechs Brunnen vorgesehen, ${ }^{7}$ von denen aber offensichtlich nur drei tatsächlich gebaut wurden. ${ }^{8}$ Bei diesen Brunnen handelte es sich grundsätzlich um private, also nicht öffentlich zugängliche Infrastrukturen. Dennoch gab es Nutzungsgemeinschaften, die mitunter in Verträgen sichtbar sind: Bei einem Häusertausch in den I 75 oer Jahren verpflichtete sich z.B. der neue Besitzer dazu, die bisher bestehen-

I Suter, Wasser, 79 f.; vgl. als aktuellen Überblick: Janssens/Soens, Water.

2 LR CIIIHI - 3, Reg. 548 (373-379); vgl. OÖLA, Landschaftsakten, Sch. 443, D.XV.2/No. 56.

3 OÖLA, Landschaftsakten, Sch. 954, H.II/No. 2.

4 Vgl. z.B. Janssens/Soens, Water, 93 - го2 ; Tomory, Water; Gandy, Wasser; Tello/Ostos, Water, 350-352; Broich, London, 2f. u. 34-36; Bauer, Bauch, 56-64; Tarr, Search, 8; Ebner/Weigl, Wasser, 59; Hye, Geschichte, ${ }_{3}$ f.; Brunner/Schneider, Umwelt, I 88f.; Schott, Urbanisierung, Io9 - I I I.

5 LR BIAI, Reg. 499 (I64); LR BIIA42, Reg. 20060 (3); LR BVI2, Reg. I I 27 (6I -69); OÖLA, Landschaftsakten, Sch. 442, D.XV.2/No. 32 .

6 LR E 7 e-g, Reg. 953 (234f.).

7 LR BIIA40, Reg. I 9556 (8-13).

8 AStL, HS 409 (Bauraittung I770), pag. I I 5 . 
den Nutzungen des Brunnens nicht zu untersagen. ${ }^{9}$ Häufiger waren eine Nutzung gegen Entgelt oder das Teilen von Instandhaltungskosten, was teilweise sogar Eingang in die städtischen Grundbücher fand. ${ }^{10}$ Weitaus seltener in Linz waren Brunnen, die über Wasserleitungen aus Quellen versorgt wurden. Dies blieb meist auf Institutionen beschränkt: Das Linzer Schloss verfügte vermutlich schon im Mittelalter über eine Wasserleitung, die eine Quelle am nahen Freinberg fasste. Anfang des I7. Jahrhunderts errichtete man eine neue Quellfassung beim Jägermayr, eine Brunnstube (im "Dörfl«) und einen Wasserstollen, zudem erneuerte man die hölzerne Wasserleitung zum Schloss (vgl. Abb. 8 u. No. 2 in Abb. I7). ${ }^{11}$

$\mathrm{Ab}$ dem Ende des r6. Jahrhunderts hatte auch das neu erbaute Landhaus, das Versammlungsgebäude der oberösterreichischen Stände, eine eigene Wasserleitung, die ebenso aus einer Quelle am Freinberg (bei den Gehöften Jungbauer und Paulhaider) versorgt wurde und nach rund eineinhalb Kilometern als Endpunkt den repräsentativen Landhausbrunnen hatte (No. 3 in Abb. I7). ${ }^{12}$ Im Laufe der Zeit entstanden zumindest an dieser Wasserleitung private Anschlüsse, die einzelnen Angehörigen der Stände und dem oberhalb an der Wasserleitung gelegenen Kapuzinerkloster eingeräumt wurden. ${ }^{13}$ Auch manche Klöster verfügten über Quellwasserleitungen, z.B. das Karmelitinnenkloster, das vom Grund des Bergschlössls Wasser bezog. ${ }^{14}$ Eine Einleitung ins Haus war relativ selten und ist für die Vormoderne definitiv als »Luxus« zu erachten. ${ }^{15}$

Wenn Bewohner/innen nicht über einen Zugang zu Hausbrunnen oder Wasserleitungen verfügten, waren sie auf semiöffentliche und öffentliche Brunnen angewiesen. Angeblich nach einem Stadtbrand errichtete die Stadt Linz in den I $540 e r$ Jahren eine eigene Wasserleitung; zuvor war Wasser aus der Schlosswasserleitung in einen Brunnen am Hauptplatz geleitet worden. Westlich des Freinberges wurden in der Ortschaft St. Margarethen mehrere Quellen gefasst, deren Wasser mit Holzrohren der Donau entlang über ca. 3,5 Kilometer in die Stadt geleitet wurde. Für das I 7. Jahrhundert sind bereits zwei Brunnen am Hauptplatz belegbar, die den Endpunkt dieser Wasserleitung bildeten (No. I in Abb. I7). ${ }^{16}$ Dazu kamen weitere Grundwasserbrunnen im

9 OÖLA, Landschaftsakten, Sch. 576, E.XV.6/No. 47; vgl. Janssens/Soens, Water, 93- 96.

ro Vgl. Bohdanowicz, Vorstädte, Bd. 2, I 262, I 266, I 349 u. I 403f.; LR Eri, Reg. 56 I 3 (Iof.).

I I Kreczi, Linz, 225; Pillwein, Beschreibung, 276; Bohdanowicz, Vorstädte, Bd. 2, 656; vgl. zu den Salzburger Hofwasserleitungen: Ebner/Weigl, Wasser, 29-3 $\mathrm{I}$.

I 2 OÖLA, Landschaftsakten, Sch. 447, D.XV.3/No. 62; LR BIIA4I, Reg. 20054 (228); vgl. Kunstdenkmäler, Bd. I, 444-457; Pillwein, Beschreibung, 32; Stauber, Ephemeriden, I I ff.; Bohdanowicz, Vorstädte, Bd. 2, 605-607, r623 u. I656; vgl. zum Verlauf der Leitung: RB I 88 I, 84.

13 OÖLA, Landschaftsakten, Sch. 442, D.XV.2/No. I6; ebd., D.XV.2/No. 26; OÖLA, Herrschaftsarchiv Weinberg, Sch. 829; LR Era, Reg. I I05 (207); LR BIIA4I, Reg. 19949 ( I I6); vgl. zu Innsbruck: Hye, Geschichte, 76 .

I4 Awecker, Bergschlößl, I 87 f.

I5 Ebner/Weig1, Wasser, 53- 57 .

I6 Kreczi, Linz, 28f. u. 28of.; Pillwein, Beschreibung, 2 I I ; LR E6 (»Sint-Chronik«), 35, 87 u. I30; Bohda- 


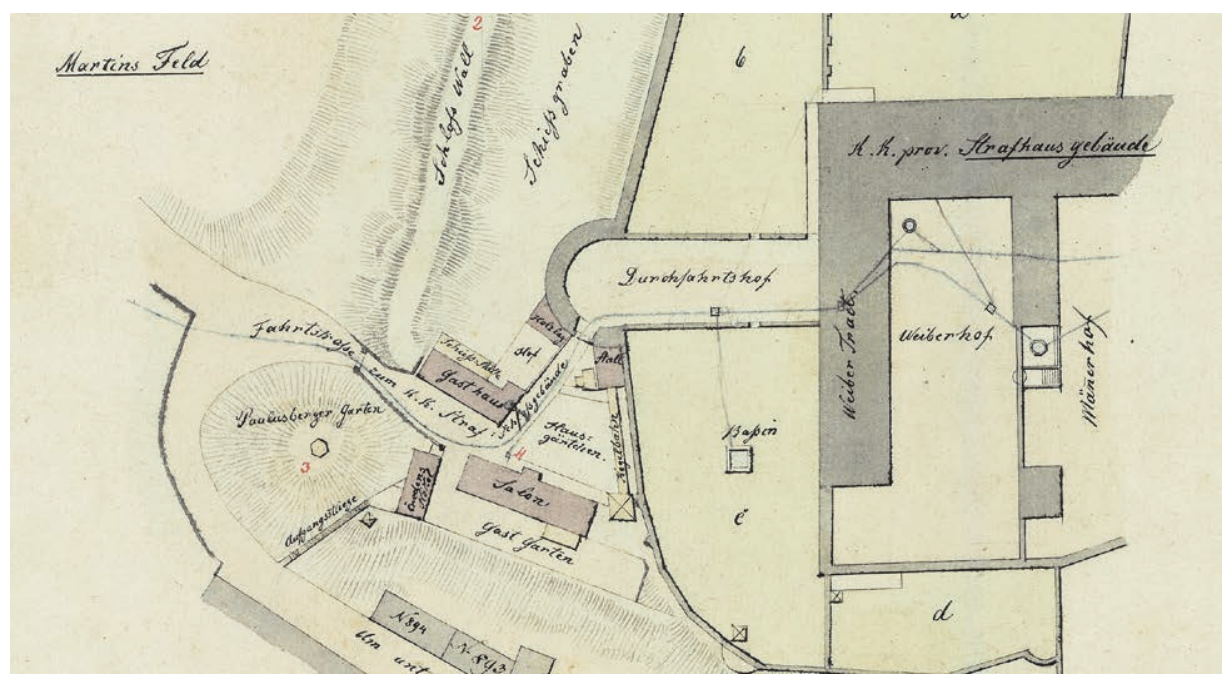

Abb. 8: Ein privilegierter Zugang zu Wasser - die Wasserleitung des Schlosses (Linie in der Bildmitte) mit Wasserbassin und Brunnen (Ausschnitt), 1848

öffentlichen Raum, die teilweise auch in den Stadtansichten aufscheinen: Die Vorzeichnung für den »Merian«-Stich von Linz, die in den I640er Jahren entstand, zeigt in der inneren Stadt neben den beiden Röhrenbrunnen auf dem Hauptplatz einen Grundwasserbrunnen, sowie Brunnen am Hofberg, beim Landhaus und am Pfarrplatz. Im Bereich der Vorstädte sind zwei Brunnen auf der Landstraße und einer am oberen Graben gegenüber dem Landhaustor sichtbar. ${ }^{17}$ Eine Ansicht der Belagerung im Winter I 74 I/I 742 (vgl. Abb. I 8) lässt - aus einer anderen Perspektive - die meisten der zuvor genannten Brunnen erkennen, zudem einen Brunnen am unteren Graben. ${ }^{18}$ Diese Standorte decken sich mit Hinweisen aus anderen Quellen: Die beiden "gemein-brün« auf der Landstraße erwähnt die »Sint-Chronik« aus dem I 8. Jahrhundert, und auch die meisten anderen Brunnen finden sich in einer tabellarischen Aufstellung des städtischen Magistrats aus den I 8 I oer Jahren. Hier sind neben den beiden Hauptplatzbrunnen insgesamt I 3 Brunnen verzeichnet, wobei 2 davon vermutlich an der städtischen Peripherie (»beim Gaderbauer« und »in der Kalkgrube«) lagen. ${ }^{19}$ Somit kann man für

nowicz, Vorstädte, Bd. 2, 80I ; AStL, Altakten, Sch. I7 I AStL, HS 859 (Kerschbaum, Chronologische Notizen, Teil 2, undat.), eingeklebt bei fol. 87; vgl. Gugitz, Linz, 58 u. AStL, HS 409 (Bauraittung 1770), unpag.; die Quellen befanden sich offenbar beim »Weber im Graben« und auf der »Mösbachwiese«.

I7 Schmidt, Linz, Tafel 8.

I 8 Abgedruckt in: Mayrhofer/Katzinger, Geschichte, Bd. I, 39of. - das Original befindet sich im Linzer Rathaus.

I9 AStL, HS 86r (»Chronologische Beschreibung«, I77oer Jahre), fol. 22b; AStL, HS 859 (Kerschbaum, Chronologische Notizen, Teil 2, undat.), eingeklebt bei fol. 87; vgl. zu den Standorten: Müller, Brunnen, $2 \mathrm{I}$. 
das i 8. Jahrhundert zwischen acht und elf von der Stadt unterhaltenen Brunnen annehmen, die die Bewohner/innen der inneren Stadt und der Vorstädte versorgten. Das ist eine relativ geringe Anzahl, die sich aber mit Befunden aus anderen Städten deckt und zeigt, dass der Stadt als Bereitsteller von Wasser - zumindest in dieser Zeit - eine beschränkte Rolle zukam. ${ }^{20}$ Als semiöffentliche Wasserentnahmestellen können solche gesehen werden, deren Nutzung zwar möglich war, worauf aber - im Gegensatz zu den von der Gemeinde unterhaltenen Brunnen - kein Anspruch bestand. Darunter fiel etwa der Brunnen im Hof des Linzer Landhauses, der von der landständischen Wasserleitung gespeist wurde. Auch konnte eine Nutzung beschränkt sein, wenn sich die Brunnen in Räumen befanden, zu denen ein Zugang während bestimmter Zeiten nicht möglich war. ${ }^{21}$ Dazu gab es die Möglichkeit, das Überwasser - also Wasser, das aus den Wasserleitungen ungenutzt abfloss - zu verwenden. Dafür konnte eine Bezahlung verlangt werden: Die städtischen Brunnenrechnungen dokumentierten kleinere Zahlungen einzelner Haushalte (in den I $720 e r$ Jahren meist $30 \mathrm{kr}$ oder I $\mathrm{fl}$ ), ${ }^{22}$ für die jedoch weitere Angaben fehlen ${ }^{23}$ - oder die Nutzung wurde einfach geduldet. ${ }^{24}$

Bei diesen Wasserinfrastrukturen handelte es sich um gewachsene Systeme mit einer spezifischen Logik, die durch wirtschaftliche, aber genauso durch technische und naturräumliche Aspekte bestimmt wurde. ${ }^{25}$ Wasserleitungen waren aufwändige Bauten, die eher dann angelegt wurden, wenn Grundwasserbrunnen nicht oder nur schwer möglich waren (wie etwa in den peripheren Gebieten auf der Hochterrasse), wenn sich eine Quelle in der Nähe befand oder wenn es darum ging, »repräsentatives« Wasser für Lauf- und Springbrunnen zu erhalten. Die Errichtung einer Wasserleitung, die weite Entfernungen überbrückte, war mit erheblichen Kosten und signifikanter Expertise verbunden: Es mussten Quellfassungen und Brunnstuben (Wasserbehälter) errichtet und die Rohrnetze gelegt werden. ${ }^{26}$ Zwar stellte man I 795 fest, dass bislang "nicht der geringste Plan« der ständischen Wasserleitung vorhanden gewesen sei $^{27}$ - dies sollte aber nicht als Beleg für die Primitivität eines technischen Systems gesehen werden. ${ }^{28}$

Neben den hohen Anfangsinvestitionen waren auch regelmäßige Kosten zu erwarten, die für Reparaturen und Adaptionen anfielen: Besonders die gebohrten Holz-

20 Vgl. für Wien und Graz: Brunner/Schneider, Umwelt, I 89 u. Macher, Hygienisierung, I 2.

2I Pillwein, Beschreibung, 32.

22 AStL, HS 485 (Brunnenrechnung I722), unpag.

23 Somit ist es unklar, ob es sich um Hausanschlüsse an die städtische Wasserleitung handelte oder nur für begünstigte Nutzung von Wasser (etwa für Fischkalter bei den Brunnen) bezahlt wurde - AStL, HS 5 or

(Brunnenrechnung I765), pag. 3I u. 35 .

24 AStL, HS 409 (Bauraittung 1770), pag. II 7.

25 Vgl. Janssens/Soens, Water, 92 - 102.

26 LR EIc, Reg. 276I (7If.); vgl. Suter, Wasser, 27-40.

27 LR BIIA4I, Reg. I9950 (I I6f.); der daraufhin angefertigte Plan befindet sich jedoch nicht in OÖLA, Karten- und Plänesammlung.

$28 \mathrm{Vgl}$. Jørgensen, Sanitation, 565. 
rohre mussten regelmäßig getauscht werden, da Lecks durch das Verfaulen und das Aufreißen bei zu hohem Wasserdruck oder bei Frost entstanden. ${ }^{29}$ Im überaus kalten Winter I709/17 I0 ${ }^{30}$ waren bei den Bleirohren zahlreiche Frostschäden aufgetreten und man hatte die defekten Stellen durch Holzrohre ersetzt. In den I 74oer Jahren beklagte man, dass die Holzrohre »nunmehr wider « anfangen würden zu faulen, zudem steige das Verstopfungsrisiko durch die sich in den Rohren befindlichen Wurzeln und Schwämme. ${ }^{31}$ Im Jahr I 8 I 6 mussten rund I 30 Meter Rohre der städtischen Wasserleitung (also vermutlich rund 4 Prozent der Gesamtlänge) ausgetauscht werden, was Ausgaben von $288 \mathrm{fl} 5 \mathrm{I} \mathrm{kr}$ für Arbeit und Material verursachte. ${ }^{32}$ Trotz derartiger Probleme und der aufwändigen Bearbeitung wurden Holzrohre, ${ }^{33}$ da sie billiger waren, bis ins I 9. Jahrhundert mehrheitlich für die Wasserleitungen verwendet, wenn man von kürzeren Abschnitten oder Hausleitungen mit Blei- und Kupferrohren absieht. ${ }^{34}$

Da die Rohre, um sie vor Frost zu schützen und fremden Besitz nicht übermäßig zu beeinträchtigen, meistens unter der Erde verlegt wurden, waren Defekte schwer zu lokalisieren und die Austauscharbeiten mit einem erheblichen Aufwand verbunden: Im Spätherbst I 7 I 6 hatte man für Reparaturen an der ständischen Wasserleitung "20 Gruben« ausheben müssen, ${ }^{35}$ und wiederholt finden sich Beschwerden betroffener Bauern, die Kompensation für die Erdarbeiten auf den von ihnen genutzten Flächen einforderten. Bereits I702 hatte ein Bauer i 8 fl erhalten, was zu dieser Zeit immerhin 9o Taglöhnen entsprach. ${ }^{36}$ Einem Bauern wurden als Entschädigung regelmäßige Fuhrdienste für die Landstände zugesprochen - angeblich bestand diese Praxis schon seit der Errichtung der ständischen Wasserleitung im späten I6. Jahrhundert, belegbar ist dies zumindest für das I 8. Jahrhundert. ${ }^{37} \mathrm{Z}$ wischenzeitlich wurde auch eine monetäre Entschädigung gewährt (jährlich I $6 \mathrm{fl}) .^{38}$

Zudem waren die Wassernutzungsrechte nicht frei ${ }^{39}$ Sie mussten durch die Grundobrigkeit eingeräumt werden und oftmals war dieser "Wasserdienst« mit jährlichen

29 Vgl. Suter, Wasser, 33-35 u. Hye, Geschichte, ro3.

30 Vgl. dazu Tabelle I u. Strömmer, Klima-Geschichte, I05- I07.

3I OÖLA, Landschaftsakten, Sch. 443, D.XV.2/No. 82.

32 AStL, HS 859 (Kerschbaum, Chronologische Notizen, Teil 2, undat.), eingeklebt bei fol. 87 .

33 So mussten die Baumstämme vor der Verwendung als Rohre im Wasser gelagert werden. Derartige »Rohrlacken" befanden sich z.B. Ende des I8. Jahrhunderts im Oberen Graben und Anfang des I 9. Jahrhunderts in St. Margarethen - LR BIIA4I, Reg. 9994 (I 5 If.); AStL, HS 436 (Bauamtsrechnung I 8I6), pag. II9.

34 LR Era, Reg. I054 (199); LR BIIG8, Reg. 4828 (57); OÖLA, Neuerwerbungen, HS 74 (»Bau-Rechnung" Kremsmünsterer Haus, I 804), pag. 243.

35 OÖLA, Landschaftsakten, Sch. 447 , D.XV.3/No. 62.

$36 \mathrm{LR} \mathrm{BIIG}_{3}$, Reg. 1685 (68); der Taglohn (I 2 kr) findet sich z. B. in: LR EIf, Reg. I 4I (53f.) oder LR BIV, Reg. I4I ( 53 f.).

37 OÖLA, Landschaftsakten, Sch. 447 , D.XV.3/No. 62.

38 Vgl. ebd.; LR BIIA4, Reg. 5 I06 (I 22); LR BIIA4I, Reg. 20002 (I68-I7I).

39 Vgl. zu Salzburg: Ebner/Weigl, Wasser, 29. 
Abgaben verbunden. ${ }^{40}$ Im frühen I8. Jahrhundert musste beispielsweise das Karmelitinnenkloster für die Quellnutzung jährlich I Gulden bezahlen, ${ }^{41}$ auch für die eingangs erwähnte Wasserleitung des Stockhofes musste eine jährliche Abgabe für den Wasserbezug an die Stadt entrichtet werden. ${ }^{42}$ Einen Anschluss an eine bestehende Wasserleitung herzustellen, war hingegen relativ günstig und technisch einfach, wenngleich dafür in der Regel eine Nutzungsgebühr durch die Betreiber der Leitung verlangt wurde (vgl. oben). ${ }^{43}$ Einen erheblichen Nachteil von Wasserleitungen bildeten neben den Kosten die jahreszeitlichen Schwankungen der Quellschüttung oder die variierende Qualität des Wassers, auch konnte in den Wintermonaten die Wasserversorgung unterbrochen sein (vgl. unten). ${ }^{44}$ Mitunter konnte - als Worst Case - eine Quelle versiegen, was offenbar zu Beginn des r 8. Jahrhunderts die ständische Wasserleitung betroffen hatte. ${ }^{45}$

Im Vergleich zu Wasserleitungen wiesen Grundwasserbrunnen erhebliche Vorteile auf: Die Errichtung von Brunnen war relativ einfach und deshalb Standard beim Hausneubau bis ins I9. Jahrhundert. Aufgrund dieser Alltäglichkeit bestand eine signifikante Expertise gewerblicher Akteure: Die Errichtung der Brunnen übernahmen meist Zimmerer und Maurer, die Brunnenmeister stellten Pumpen her und übernahmen die Instandhaltungsarbeiten. ${ }^{46}$ Im Hinblick auf die Kosten hatten die vormodernen Grundwasserbrunnen ebenso erhebliche Vorteile gegenüber den Wasserleitungen, denn teuer war lediglich deren Errichtung: I 7or bezahlten die Urfahrer Kapuziner für die Errichtung eines Brunnens in ihrem Kloster am Donauufer insgesamt $57 \mathrm{fl}$ $36 \mathrm{kr}^{47}$ Für den Brunnenbau in Linz war das oberflächennahe Grundwasser auf der Niederterrasse der Stadt günstig: Ein Gutachten aus den r 88 oer Jahren gab an, dass sich das Grundwasser meist in einer Tiefe von I I bis I 3 Metern befand. ${ }^{48}$ Dies deckt sich mit den spärlichen Befunden zur Tiefe von Linzer Brunnen, ${ }^{49}$ die I 8 I 6 in einem Verzeichnis erfassten I 3 städtische Brunnen hatten eine Tiefe zwischen 4 und 9 Klaftern, durchschnittlich 6 Klaftern, was ca. I I Metern entspricht. ${ }^{50}$ Auf den Hügeln (v.a. am Schullerberg) war die Errichtung von Brunnen deutlich aufwändiger: Ein in den I 8 I oer Jahren errichteter Brunnen im Bereich des ehemaligen Schlossgartens war

40 LR BIIA23, Reg. 16996 (6rf.); LR Ein, Reg. 5233 (I22).

4I Awecker, Bergschlößl, I87f.; OÖLA, Landschaftsakten, Sch. 443, D.XV.2/No. 7 I.

42 LR CIIIHI -3, Reg. 548 (373-379).

43 Vgl. dazu die Rechnungen des Thürheimer Freihauses, z.B. für I733 - LR BIIG 5, Reg. 2559 (36).

44 Vgl. Suter, Wasser, I 2.

$45 \mathrm{LR} \mathrm{BIIG}_{3}$, Reg. I 684 (67f.).

$46 \mathrm{LR} \mathrm{CIIIH}_{4}, 822-830$; vgl. Suter, Wasser, 57-78.

47 LR EIf, Reg. I4I (53f.).

48 Schiedermayr, Sanitätsverhältnisse, 4.

497 bzw. 8 Klafter (dies entspricht I 3 - I 5 Metern) - LR E7e-g, Reg. 822 (202f.); LR CIIIHI -3, Reg. 376 (229).

50 AStL, HS 859 (Kerschbaum, Chronologische Notizen, Teil 2, undat.), eingeklebt bei fol. 87 . 
I 4 Klafter (also über 26 Meter) tief bis in den Felsen geschlagen worden. ${ }^{51}$ Wenngleich dazu nur wenige Hinweise greifbar sind, so scheinen die Unterhaltskosten für Grundwasserbrunnen relativ gering gewesen zu sein: I 8 I 6 wurden für die I 3 städtischen Brunnen für Reparaturen und Reinigungen rund $270 \mathrm{fl}$ aufgewendet, wobei für 3 Brunnen keine Beträge verzeichnet wurden und die Kosten für die anderen Brunnen zwischen $2 \mathrm{fl} 45 \mathrm{kr}$ und $7 \mathrm{r}$ fl 23 lagen. ${ }^{52}$ I 808 setzten die Landstände in einem Vertrag mit einem Brunnmeister die jährlichen Reparaturausgaben auf $2 \mathrm{fl}$ pro Brunnen fest, wobei größere Arbeiten extra finanziert wurden. ${ }^{53}$ In einem Kaufvertrag aus dem Jahr I 804 wurde als jährliche Gebühr für die Nutzung eines Privatbrunnens bei der Promenade $2 \mathrm{fl} 30 \mathrm{kr}$ festgelegt, ${ }^{54}$ in den I 82 oer Jahren betrug das jährliche "Brunngeld « für ein nahegelegenes Haus nur $2 \mathrm{I} \mathrm{kr}$ und in den I 77oer Jahren für ein Haus am Schullerberg I $6 \mathrm{kr}^{55}$

Wasserinfrastrukturen scheinen auch nach einer Logik des Arbeitsaufwands ausgerichtet gewesen zu sein, also darauf abgezielt zu haben, das Wasser möglichst nahe an den Nutzern/innen verfügbar zu machen. Dies legt das Beispiel der Wollzeugfabrik nahe, die - obwohl sie unmittelbar am Donauufer gelegen war - zu Beginn des I 9. Jahrhunderts angeblich über insgesamt 28 Ziehbrunnen verfügte, was einerseits mit der Verfügbarkeit von Löschwasser im Bedarfsfall, andererseits aber eben auch mit logistischen Überlegungen zusammenhing. ${ }^{56}$ Ohnehin war, selbst wenn sich die Wasserentnahmestelle in unmittelbarer Nähe befand, die Arbeit des Wasserholens eine stetige und anstrengende Tätigkeit, die meist von häuslichem Gesinde oder von externen Arbeitskräften übernommen wurde und in den Linzer Quellen fast ausschließlich als Frauenarbeit auftaucht. ${ }^{57}$ Spürbar ist eine Logik der Redundanz: Zahlreiche Häuser wiesen zwei Brunnen auf, und Wasserleitungen wurden oft durch Grundwasserbrunnen ergänzt. Die Quellwasserbrunnen am Hauptplatz waren in der kalten Jahreszeit (vermutlich zwischen November und April) nicht benutzbar, da sie mit Stroh »eingemacht « wurden, ${ }^{58}$ was man später als »Winterdecken« bezeichnete. ${ }^{59} \mathrm{Da}$ sich diese Praxis auch für andere Röhrenbrunnen vermuten lässt, kann man davon ausgehen, dass die Wasserversorgung der Stadt in dieser Zeit wesentlich auf

\footnotetext{
5 I LZ/IB, I 5·7·18 I4.

52 AStL, HS 859 (Kerschbaum, Chronologische Notizen, Teil 2, undat.), eingeklebt bei fol. 87.

53 LR BIIA 35 , Reg. I 8948 (I83).

54 LR BIIK2, Reg. 672 (502).

55 Bohdanowicz, Vorstädte, Bd. 2, I 503.

56 Pillwein, Beschreibung, 283.

57 LR CIIIHI-3, Reg. I082 (7 I If.); LR BIV, Reg. 95 I (374f.); LAB, 28.r.I864; LVB, I8.2.187r ; ebd., I 2.5.I 872 ; die einzige männliche Ausnahme findet sich für einen Bäckerlehrling in den I 85 oer Jahren (Doku, Hirnschrodt, r6) - vgl. dazu Suter, Wasser, 97- гоo.

58 AStL, HS 5 о г (Brunnenrechnung I765), pag. 35 u. 38; AStL, HS 409 (Bauraittung r 770), pag. I I7 u. I 96 ; vgl. auch AStL, HS 2 I 2 (Kammeramt Ausgaben r 860), pag. 72.

59 AStL, HS 436 (Bauamtsrechnung i 8 i6), pag. I igf.
} 
den Grundwasserbrunnen basierte. Derartige doppelte Infrastrukturen wiesen zudem eine geringe Anfälligkeit für Störungen, etwa infolge von Trockenheit oder Überschwemmungen, auf.

Das Engagement der vormodernen Stadtverwaltungen im Bereich der Wasserinfrastrukturen divergierte in den einzelnen Städten offenbar erheblich: In Zürich scheint die Wasserversorgung eine zentrale Agenda der Stadtgemeinde gewesen zu sein, auch in Salzburg wurde - zumindest zeitweilig - erheblich in die städtischen Wassernetze investiert, in Wien und Linz blieben die städtischen Aktivitäten hingegen eher begrenzt. ${ }^{60}$ Im Falle von Linz kann die relativ einfach herzustellende Wasserversorgung über Grundwasserbrunnen eine mögliche Erklärung sein, zudem waren im I 8. Jahrhundert die finanziellen Möglichkeiten der Stadt beschränkt. Die Ausgaben des städtischen Brunnamtes fielen - verglichen mit anderen Budgetposten - sehr gering aus: In zehn Jahren (I7I3- I722) hatte man insgesamt I.330 fl $46 \mathrm{kr}$ ausgegeben, pro Jahr also durchschnittlich nur rund I $30 \mathrm{fl}$, während sich die jährlichen Gesamtausgaben zu dieser Zeit auf ca. 40 bis 50.000 fl beliefen (vgl. Kap. 2. Kontexte: Linz I 700 bis I900) und gleichzeitig die Einnahmen des Brunnamtes die Ausgaben teilweise deutlich überstiegen - für das Jahr I 7 I 3 verzeichnete man z. B. Einnahmen in der Höhe von $207 \mathrm{fl} 23 \mathrm{kr}^{61}$ Mit diesen geringen Ausgaben konnten nur Instandhaltungskosten abgedeckt werden, was auch ein Blick in die städtischen Brunnenrechnungen bestätigt, die für die I72oer bis in die I76oer Jahre vorhanden sind. ${ }^{62}$

Ein wichtiges Motiv für städtische Investitionen stellten die Röhrenbrunnen an zentralen Plätzen dar, die - wie es Dorothee Rippmann formuliert hat - als »visuelle Aushängeschilder einer Stadt«, als »städtisches und fürstliches (Eigen)Lob« fungierten. ${ }^{63}$ In Linz wurden die beiden Hauptplatzbrunnen in den I68oer Jahren zu repräsentativen Steinbrunnen umgestaltet und auch der »Planetenbrunnen« im Hof des Landhauses, der in den I 58 oer Jahren mit Steinen aus Salzburg und Mauthausen errichtet worden war, stellte nicht nur eine zweckmäßige Infrastruktur, sondern genauso eine demonstrative Zurschaustellung von Luxus und Macht dar. ${ }^{64}$ Ein vermutlich nicht weniger entscheidender Grund, ein basales städtisches Wassernetz zu errichten, war die Notwendigkeit, ausreichend Löschwasser verfügbar zu halten. ${ }^{65}$ Wenngleich die Obrigkeiten wiederholt darauf drängten, war der Zugang zu privaten Brunnen

6o Suter, Wasser, 79f.; Brunner/Schneider, Umwelt, r89; Ebner/Weigl, Wasser, $26-29$ u. 37-59; vgl. zu den Niederlanden: Janssens/Soens, Water, 93 - roo.

6I $\mathrm{LR} \mathrm{BIIG}_{4}$, Reg. 24I6 (I4I-2II).

62 Vgl. z.B. AStL, HS 485 (Brunnenrechnung I 722), unpag.

63 Schott, Urbanisierung, i 2 .

64 Gubitzer, Brunnenbaukunst, 5; Mayrhofer/Katzinger, Geschichte, Bd. I, I75f.; Stauber, Ephemeriden, II 6.

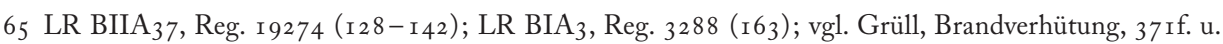
auch Kap. i r. Naturgefahr. 
im Brandfall nicht immer möglich ${ }^{66}$ und so basierte die Brandbekämpfung bis ins I 9. Jahrhundert weitgehend auf öffentlichen Wasserentnahmestellen.

\section{Differenzierungen von Wasser}

Wasser wurde nicht nur als Trinkwasser in der Stadt benötigt, sondern genauso als Brauchwasser. Dieter Schott hat darauf hingewiesen, dass sich für die Vormoderne eine »differenzierte Regulierung der Nutzung des knappen Gutes Wasser« abgezeichnet habe, wobei die Bedürfnisse der Haushalte deutlich über gewerblichen und anderen Nutzungen gestanden hätten, die mitunter auf alternative Bezugsquellen hätten ausweichen müssen. ${ }^{67}$ Für Linz ist diese Annahme zu bestätigen: Wenn Brauchwasser aus den Brunnen und Wasserleitungen entnommen wurde, handelte es sich oftmals um die Nutzung des Überwassers, ${ }^{68}$ vielfach gab es eigene Strukturen für den Bezug von Brauchwasser. Ställe und Gärten hatten oftmals eigene Grundwasserbrunnen (vgl. Abb. I I), ${ }^{69}$ auch größere Gewerbebetriebe - wie die Wollzeugfabrik - verfügten über ein eigenes Versorgungsnetz mit Brauchwasser: Das für die Wäschereien und Färbereien notwendige Wasser werde, so eine Beschreibung aus den I780er Jahren, "durch das ganze Gebäude an alle Orte, wo man desselben benöthiget ist, in bleyernen Röhren geführet « ${ }^{70}$ Mitunter gab es - tendenziell eher in größeren Institutionen wie Klöstern - eigene Brunnen für das Waschen der Wäsche. ${ }^{71}$ Vielfach nutzte man jedoch die Wasserläufe: Da im Linzer Stadtgebiet Bäche weitgehend fehlten, kam in Bezug auf das Brauchwasser der Donau eine erhebliche Bedeutung zu. An der Ludl, einem kleinen Seitenarm der Donau, der im I 8. Jahrhundert nur noch wenig Wasser führte, hatten sich zahlreiche Gewerbetreibende angesiedelt, die in ihrem Produktionsprozess auf Wasser angewiesen waren, wie Gerber und Färber. Diese räumliche Verdichtung manifestiert sich auch im Namen Lederergasse, der bereits vor dem I 8. Jahrhundert gebräuchlich war. ${ }^{72}$ Die Linzer Badehäuser waren ebenso teilweise an der Donau im Bereich der Kalvarienwänd - situiert und nutzten das Flusswasser. ${ }^{73}$ Die direkte Nutzung der Donau zum Baden scheint erst im frühen r 9. Jahrhundert an Bedeutung

66 OÖLA, Landschaftsakten, Sch. 446, D.XV.3/No. 57 ; vgl. Suter, Wasser, 83 u. Ebner/Weigl, Wasser, $48 f$.

67 Schott, Urbanisierung, i 16.

68 LR BIIG $_{3}$, Reg. 1504 (If.); OÖLA, Herrschaftsarchiv Weinberg, Sch. 829.

$69 \mathrm{LR} \mathrm{BVI}_{4}$, Reg. I 826 (252-254); LR BIIG8, Reg. 5278 (г26); LR EIc, Reg. 2936 (Iоrf.); LZ/IB, I 5.7.I8I4; LZ/ IB, I3.9.I 8 I 9 .

70 Füssel, Tagbuch, 223 f.

7I Etwa im Ursulinenkloster - vgl. LR Eıb, Reg. I4I 2 (38).

72 Neweklowsky, Donau, I 72 ; LR BIAI, Reg. 492 (I62); vgl. Mayrhofer/Katzinger, Geschichte, Bd. I, 69 u. Lackner/Stadler, Fabriken, 379.

73 Füssel, Tagbuch, 238 ; Pillwein, Wegweiser, I67; Bohdanowicz, Vorstädte, Bd. 2, 1574; LR E7e-g, Reg. 644 (I62f.). 
gewonnen zu haben: ${ }^{74}$ Durch die (erste) Polizeiordnung von I 786, die sich am Wiener Vorbild orientierte, war das Baden in der Donau - aufgrund von praktischen und moralischen Bedenken - noch verboten worden, ${ }^{75}$ im Sommer I 802 hatten die Landesregierung und der Magistrat, weil ohnehin gebadet werde und »es doch bei manchen Menschen die Reinlichkeit fordert, sich im fliessenden Wasser abzuwaschen«, einen Platz beim »Fischer im Gries« (d.h. fast 2 Kilometer flussabwärts vom Hauptplatz) ausgewählt, an dem für Männer unter Aufsicht und gegen Bezahlung das Baden nun doch erlaubt war. ${ }^{76}$

An der Donaulände bestand im i8. Jahrhundert eine Pferdeschwemme ${ }^{77}$ und Dienstbotinnen schöpften dort das Wasser für häusliche Zwecke aus der Donau. ${ }^{78}$ Zudem nutzte man das Donauwasser zur Frischhaltung von Speisefischen: Die Linzer Fischhändler verfügten über große Fischkalter, die sich offenbar in der Zizlau (nahe der Traunmündung) befanden. Das Inventar eines Fischhändlers aus dem Jahr I 750 listet 193 Pfund lebende Fische im Zizlauer Kalter auf, darunter Saiblinge, Forellen, Huchen, Rutten und Hechte. ${ }^{79}$ Zudem unterhielt die Stadt ein »Fischfloß« mit Fischkaltern in der Donau nahe der Brücke, das an Händler und vermutlich auch an Privatleute verpachtet war. ${ }^{80}$ Für Kühlzwecke gewann man Eis aus der Donau, das im Winter in die zahlreichen städtischen Eisgruben gebracht wurde. ${ }^{81}$ Erstaunlicherweise wurden die Eisgruben - wohl aus Kostengründen - manchmal mit Schnee gefüllt, in den I 72oer Jahren überlegte man hingegen, die ständische Eisgrube beim Landhaus mit importiertem Eis - deswegen war der Bauschreiber nach Salzburg, Laufen und Gmunden (!) gefahren - zu befüllen, was schlussendlich als zu teuer verworfen wurde. ${ }^{82}$

In der Donau wurde nur begrenzt Wäsche gewaschen, obgleich es - vermutlich bei der Brücke - ein von der Stadt unterhaltenes Waschfloß gab und ein Plan aus den I 8 Ioer Jahren ein »Wäscherhäusl« bei den Schotterbänken unterhalb der Strasserinsel zeigt. $^{83}$ Zudem wusch man die Erzeugnisse der Wollzeugfabrik vor dem Färben in der Donau aus, Ähnliches ist für die Linzer Gerber belegbar. ${ }^{84}$ Häufiger wurden für das Wäschewaschen aufgrund des kalkarmen Wassers die kleinen Wasserläufe nördlich der

74 Vgl. zu Salzburg und Wien: Ebner/Weigl, Wasser, 26 u. Brunner/Schneider, Umwelt, 248 u. 5 I 3 - 5 I 5.

75 Pfeisinger, Industrie, 26.

76 AStL, Altakten, Sch. I65; LR E7e-g, Reg. 227 (56); vgl. Kreczi, Linz, 23 I u. Fink, Geschichte, 7 I.

77 AStL, HS 86I (»Chronologische Beschreibung«, I770er Jahre), fol. 42 a.

78 Dokumentiert ist das über in den Tageszeitungen thematisierte Unglücksfälle: LAB, 28.I.I 864; LVB, I 8.2.187 I ; ebd., I 2.5.I 872 .

79 LR BIIB 1, Reg. Iо3 (9I-93), 30.5.I 750; vgl. LR BIIB2, Reg. 729 (г $24 f$ f.).

80 AStL, HS 389 (Bauraittung I750), pag. 84; vgl. Neweklowsky, Schiffahrt, Bd. $3,86$.

8I LR CIIIHI -3, Reg. 653 (469f.); ebd., Reg. 732 (535); LR BIIA24, Reg. 17178 (43f.).

82 LR BIIA4, Reg. 5533 (206).

83 AStL, HS 389 (Bauraittung I 750), »Holz Rechnung« (unpag.) u. AStL, HS 409 (Bauraittung I 770), pag. I 58 ; AStL, HS 434 (Baurechnung I795/I 796), pag. I 28 ; OÖLA, Karten- und Plänesammlung, XIV/7; vgl. Heinse, Linz, r. Aufl., 62.

84 LR CIIIG, Reg. I I 20 (29of.) u. ebd., Reg. I I 2 I (29I); AStL, Alte Registratur, Sch. I 44. 
Donau genutzt, was zur Etablierung von kleingewerblichen Strukturen führte, die in der Gegend von Gründberg, St. Magdalena und Katzbach teilweise bis ins 20. Jahrhundert bestanden. ${ }^{85}$

Diese Praktiken deuten auf eine Reflexion über die Eigenschaften des städtischen Wassers hin: Für die verschiedenen Nutzungen wählte man oftmals verschiedene Bezugsquellen. Flusswasser, das in anderen Städten als Trinkwasser verwendet wurde, ${ }^{86}$ trank man in Linz offenbar nicht, zumindest gibt es dafür keine Belege. Unklar ist, ob dies mit Überlegungen zur Wasserqualität zusammenhing; starke Vorbehalte gegen den Bezug von Trinkwasser aus der Donau wurden im I 9. Jahrhundert geäußert (vg1. unten). Möglicherweise hatte dies auch naturräumliche Gründe: Die starke Dynamik der Donau hätte die Errichtung von Wasserschöpfwerken zu einer - in finanzieller Hinsicht - unklugen Investition gemacht.

In den Quellen finden sich nur sehr wenige explizite Äußerungen zur Qualität von Wasser: Man habe nun eine neue Wasserleitung mit "gutem « Wasser, vermerkt die Hauschronik des Urfahrer Kapuzinerklosters $1747 .{ }^{87}$ Man habe im neu gegrabenen Brunnen »schmeckende[s] « Wasser vorgefunden, berichtete der Verwalter des in der Unteren Vorstadt gelegenen Deutschordenshauses im August I72I, nach dem Aufschöpfen sei der schlechte Geschmack weniger geworden. ${ }^{88}$ Neben dem Geschmack, dem Geruch und dem Aussehen (meist Klarheit) bildete auch die Temperatur des Wassers einen Qualitätsindikator: Der Ziehbrunnen eines an der südlichen Peripherie gelegenen Bauernhofes habe, so hieß es in einer Beschreibung aus dem Jahr I720, »beständig unnd frisches Wasser «. ${ }^{89}$ Häufiger sind implizite Hinweise zu einem vorhandenen Bewusstsein über die Qualität von Wasser: Es bestanden zahlreiche Vorschriften und Praktiken, die einer Verunreinigung des Wassers vorbeugen sollten, wie Brunnenordnungen, Wasserbehältnisse oder Abdeckungen an den Brunnen, dazu finden sich regelmäßige Ausgaben für das Reinigen von Brunnen. ${ }^{90}$ Eine Belastung des Grundwassers durch Sickerwässer wurde offenbar jedoch lange Zeit unterschätzt (vg1. Kap. 5. Zirkulationen und Output). ${ }^{91}$

Im i8. Jahrhundert verstärkte sich - nicht nur in Linz - der Diskurs zu Badekuren und Heilwasser. Dies betraf zwar eher mittlere und obere soziale Schichten, es sensibilisierte möglicherweise aber zunehmend für das Thema der Trinkwasserqua-

85 LR BIIB2, Reg. 507 (28), Ir.4.I767; Grünn, Wäschergewerbe, 58 I-589 u. 595; Bohdanowicz, Pöstlingberg, $22 \mathrm{If}$.

86 Vgl. Suter, Wasser, 4I - 50; Tomory, Water, 704 u. 707-7I 4.

87 LR Era, Reg. 425 (85).

88 LR CIIIHI -3 , Reg. 478 (3 I6f.).

89 Ebd., Reg. 41 5 (266f.).

90 AStL, HS 859 (Kerschbaum, Chronologische Notizen, Teil 2, undat.), eingeklebt bei fol. 87; LR CIIIC $_{3}$, Reg. 537 (226f.); AStL, HS 439 (Unterkammeramtsrechnung I 824), pag. 70; vgl. dazu Massard-Guilbaud, Einspruch, 79 f. u. Suter, Wasser 84-88.

9I Massard-Guilbaud, Einspruch, 80. 
lität und bot einen Rahmen für das Nachdenken über ideales und weniger ideales Wasser. ${ }^{92}$ Während sich für die erste Hälfte des i 8 . Jahrhunderts nur einzelne Hinweise auf Kuraufenthalte und den Bezug von Heilwasser finden, nahm ab den 175 oer Jahren das Interesse an diesem Bereich spürbar zu: $:^{93}$ Es wurden Mineralwasser in der »Linzer Zeitung" angeboten, ${ }^{94}$ die "Sint-Chronik« verwies auf eine Quelle von "sehr frisch[em] und heilsamen Wasser« am Kalvarienberg, ${ }^{95}$ Druckschriften und Annoncen kündigten bestehende und neu erschlossene regionale »Gesundbrunnen« an. ${ }^{96}$ Für Linz gewann in dieser Hinsicht der ca. Io Kilometer nördlich von Linz und 600 Meter höher gelegene Ort Kirchschlag an Bedeutung. Die I 753 gedruckte Publikation »Von der Beschaffenheit und Gebrauch Des Kirchschlager Baads« war eine Werbeschrift des Landschaftsarztes Johann Georg Mayer und ist vermutlich als Auftragsarbeit der starhembergischen Grundherrschaft zu sehen, was auch der Umstand unterstreicht, dass Mayer Hausarzt der Starhemberger war. In diesem Büchlein betonte Mayer nach einer "Approbation Medica« durch einen Linzer und einen Steyrer Arzt, dass das Kirchschlager Wasser seit mehr als 50 Jahren »viel tausend Menschen sowohl zur Cur als Praeservation nutzlich « gewesen sei. ${ }^{97}$ Unter den Fallgeschichten, die Mayer zitiert, finden sich auch Stadtbewohner/innen: „Eine Frau von Lintz / welche lange Zeit grosse Glieder-Schmerzen gelitten / ist gleich nach dem Baad davon befreyet worden “, ${ }^{98}$ ein Linzer, dessen Arm nach einem Schlaganfall gelähmt war, »ist mit dem gesund und starcken Arm zuruck gekommen «. ${ }^{99}$ An prominenter Stelle geht die Druckschrift auf die Frage der Wasserreinheit ein: Das Wasser der Kirchschlager Quelle sei »so rein«, dass es "scheinet / als wann es ein eigentlich lüfftiges solches Wasser wäre«. ${ }^{100}$ Mayer selbst habe das Wasser »sowol Medicè als Chymicè« untersucht, ${ }^{101}$ »ich habe das Wasser inspissirt / evaporirt / putrificirt / destillirt / multaque alis tentavi \& figula per Organa Vitrea, ich habe es pondirt gegen anderen gewogen / auch mit verschiedenen Sachen vermischet « und es »abrauchen lassen «. ${ }^{102}$ Schlussendlich sei nur ein "Häutlein« auf dem Wasser übrig geblieben, auch habe er als Inhaltsstoff »Vitriol« (Sulfat) entdeckt. ${ }^{103}$

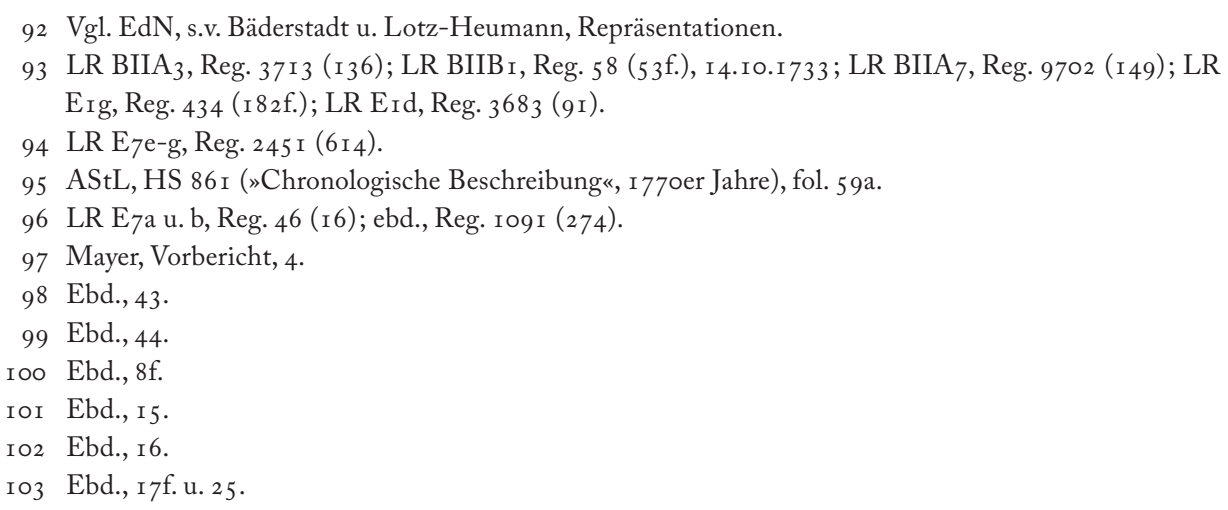




\section{Kontinuität, Adaption und neue Bedürfnisse}

Das Wasserversorgungssystem blieb bis zur Mitte des I 9. Jahrhunderts von erheblichen Kontinuitäten gekennzeichnet: ${ }^{104}$ Der Topograph Benedikt Pillwein zählte Mitte der I 83 oer Jahre I6 öffentliche Brunnen, also kaum mehr, als es vermutlich bereits im ausgehenden I 8. Jahrhundert gegeben hatte. ${ }^{105}$ Bestehende Nutzungen und Praktiken wurden fortgeschrieben, ${ }^{106}$ auch die Bauordnung für Linz und Salzburg aus dem Jahr I 846 sah die Errichtung von Hausbrunnen »in der Regel, und wo es möglich ist", bei Neubauten vor. ${ }^{107}$ Die wenigen Wasserleitungen scheinen sich kaum verändert zu haben: In einzelnen Fällen wurden - wie schon im i 8. Jahrhundert - Nutzungen des Überwassers genehmigt, ${ }^{108}$ signifikante Erneuerungen unterblieben jedoch, und die in den I 83oer und I 840er Jahren erfolgte grundbücherliche Eintragung des Rohrverlegungsrechtes für die ständische Wasserleitung deutet ebenso auf die intendierte Persistenz dieser Infrastruktur hin. ${ }^{109}$ Auch die Ausgaben der Stadt für die Wasserversorgung waren - anders als in anderen Bereichen - kaum angestiegen. I 849 hatte man für die Wasserinfrastruktur $489 \mathrm{fl}$ I $2 \mathrm{kr}$ ausgegeben, hingegen im gleichen Jahr für Säuberung und Beleuchtung der Stadt das mehr als I 8-Fache. ${ }^{110}$

Dennoch zeichnen sich Veränderungen ab: Einerseits reagierte man auf einen realen (oder befürchteten) Wassermangel in der Stadt, andererseits scheint die Frage nach der Qualität der Wasserversorgung an Bedeutung gewonnen zu haben. Ein Mangel konnte sich aus einer Vermehrung der Nutzer/innen ergeben, aber ebenso aufgrund neuer Praktiken entstehen: Die Feuerordnung aus dem Jahr I 808 forderte explizit ein, »die öffentliche Sprüngbrünne und Wasserbehälter nach Gelegenheit des Orts, und nach Erforderniß der umliegenden zahlreicheren, oder wichtigeren Gebäude zu vermehren " ${ }^{111}$ und auch das seit den frühen I 82 oer Jahren praktizierte Aufspritzen einzelner städtischer Straßen und Plätze während der Sommermonate (vgl. Kap. 7 . Geordnete und modifizierte Umwelt) erhöhte den realen - oder gefühlten - Bedarf an Wasser. ${ }^{112}$ Dass es durchaus neue Bedürfnisse im Hinblick auf das Wasser gab, zeigt das beim Landhaus nach dem Stadtbrand neu errichtete Freihaus in der Theatergasse: ${ }^{113}$

\footnotetext{
I04 Dies ist auch für Salzburg festgestellt worden - vgl. Ebner/Weigl, Wasser, 91 - 93.

I05 Pillwein, Wegweiser, I67.

Io6 AStL, HS I 52 (Oberkammeramt Ausgaben I 830), pag. 236.

I07 LZ, I 3.4. I 846 .

ro8 LR BIIA 36, Reg. I 8998 (23f.); AStL, Altakten, Sch. I 7 r ; GRP i 85o, fol. 2 I gb.

Io9 OÖLA, Landschaftsakten, Sch. 447, D.XV.3/No. 62.

I Io AStL, HS i 92 (Oberkammeramt Ausgaben r 849), pag. 624.

I I Feuer-Ordnung, 29.

I $2 \mathrm{LZ/IB,} \mathrm{I} \mathrm{2.4.} \mathrm{I} 822$.

I 3 Ehemaliges Freihaus Thürheim, I 800 abgebrannt, danach Kauf durch Khevenhüller, heute Altstadt 30 resp. Promenade 26 (Kreczi, Häuserchronik, 24); die Baurechnung und eine Hausbeschreibung finden sich in: OÖLA, Neuerwerbungen, HS 74 (»Bau-Rechnung« Kremsmünsterer Haus, I 804).
} 
Neben 62 Zimmern, I I Kaufmannsgewölben und 2 Pferdeställen wies das Haus auch eine demonstrative Wasserinfrastruktur auf, die, wie in der »Linzer Zeitung« betont wurde, der "gute[n] Errichtung der Brunnen« in Neapel ähnele. Das Haus verfügte über zwei Pumpbrunnen, wovon einer das Wasser bis zum letzten Stockwerke brachte, was »nebst dem Angenehmen auch den weitern Vortheil [... aufwies], daß an Zeit und Lohn der Dienstbothen gewonnen wird, und man im Augenblick frisches und wohlfeiles Wasser erhält«. ${ }^{114}$

Auch zur Qualität des städtischen Wassers finden sich in den ersten Jahrzehnten des i9. Jahrhunderts erstmals publizistische Überlegungen: Im Schloss gebe es, so Benedikt Pillwein in den I 82 oer Jahren, "das reinste und hellste Wasser «, ${ }^{115}$ ein Topograph der I 8 r oer Jahre hielt fest, dass das Wasser aus der ständischen Wasserleitung »einen widrigen Geschmack hat, aber ziemlich klar und hell ist «, ${ }^{116}$ wobei dieses Wasser etwas später aber auch als »ein Mineralwasser« bezeichnet wurde. ${ }^{117}$ Dazu intensivierte sich besonders ab den I $820 e r$ und I 83 oer Jahren der Diskurs zum Baden und zu mit Gesundheit verbundenem Wasser: Ab diesem Zeitpunkt finden sich in der »Linzer Zeitung« regelmäßig Anzeigen von Solebädern (im Salzkammergut), Heilquellen und Kuranstalten außerhalb von Linz, ${ }^{118}$ im nahen Kirchschlag scheint der Badebetrieb in den I 83 oer Jahren stark expandiert zu haben. ${ }^{119}$ In diesen Jahrzehnten gewann auch das Kaltwasserbaden in der Donau stark an Bedeutung: Aus der militärischen Schwimmschule beim »Fischer im Gries« (vgl. oben) entwickelte sich ein ziviler Badeplatz, der ab I 822 mit einem Badefloß als »Schwimmanstalt« durch die Landesregierung und später den Linzer Magistrat betrieben wurde. ${ }^{120}$ I 846 errichtete man dort - dem Vorbild anderer österreichischer Städte folgend - ein Bassin und Kabinen. ${ }^{121}$ Daneben gab es ein Badehaus, das in den I 830er Jahren interessanterweise auf den Betrieb »mit reinstem Quellwasser« verwies. ${ }^{122}$ An der östlichen Peripherie der Stadt, im Spitzfeld (Untere Vorstadt), etablierte ein Gastwirt zur gleichen Zeit eine "Trink-Kur-Anstalt«, deren »Gartenanlagen « auch zur »Körperbewegung « einluden. ${ }^{123}$

Am Schullerberg, einem an einem Ausläufer des Freinbergs gelegenen peripheren Teil der Oberen Vorstadt, konstatierte die Stadt Linz zuerst einen »Wassermangel«. In

I 4 LZ, 29.7.I 803; vgl. OÖLA, Neuerwerbungen, HS 74 (»Bau-Rechnung« Kremsmünsterer Haus, I 804), pag. 243, 292, 299-306.

II 5 Pillwein, Beschreibung, 276.

I 6 Gielge, Beschreibung, I36.

I 7 Schultes, Donau-Fahrten, i I I.

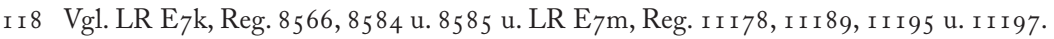

I 9 Leonhartsberger, Freizeiträume, Iо I- I03; Pfeffer, Kirchschlag, 3 If.

I 20 LZ/IB, 4.7.1817; ebd., 29.5.I820; ebd., 22.7.1822 ; Pillwein, Wegweiser, I67; Pillwein, Beschreibung, 3 I If.; Mayrhofer/Katzinger, Geschichte, Bd. 2, 85 ; vgl. zu Dresden und Wien: Butenschön, Geschichte, 277 u. Haidvogl et al., Wasser, $292-296$.

I 2 I Fink, Geschichte, I02; vgl. zu Graz: Allgemeine Bauzeitung 6 (I 84I), 5 I - 56.

I 22 LZ/IB, I7.4.I 835 ; Pillwein, Beschreibung, 3 I If.

I23 LZ/IB, 25.4.183I. 
einer Anzeige im Linzer »Intelligenzblatt« versprach man im Dezember I 828 eine Belohnung von $50 \mathrm{fl}(\mathrm{CM})$, was zu dieser Zeit ca. I6o Taglöhnen eines ungelernten Arbeiters entsprach, ${ }^{124}$ wenn eine »ergiebige Quelle« aufgefunden werde, deren Wasser man zu den Häusern auf dem Schullerberg leiten könne. ${ }^{125}$ Woher kam diese Empfindung eines Mangels? Der Schullerberg bildete eine wasserarme Gegend, in der zahlreiche Bewohner/innen das Wasser aus den in der Stadt gelegenen Brunnen holen mussten. Vermutlich hatte die zunehmende Bebauung des Schullerberges wesentlich dazu beigetragen, dass ein latenter zu einem manifesten Mangel geworden war, der auch als Bedrohung bei Bränden gesehen wurde. ${ }^{126}$ I 832 begannen die Planungen zur Fassung einer nahen Quelle, die mit Holzrohren zu einem öffentlichen Brunnen am »oberen neuen Weg“ geleitet werden sollte. ${ }^{127}$ Die Wasserleitung und der Brunnen waren ab dem Frühjahr I 833 in Betrieb, wobei es sich offenbar um keine sehr leistungsfähige Infrastruktur handelte: ${ }^{128}$ Wegen »des spärlichen Wasserzuflusses und zeitweiliger Versiegung « habe, so eine in den I86oer Jahren entstandene Linzer Chronik, diese Wasserleitung »dem Bedürfnisse nicht genügt «. ${ }^{129}$ Schon in den I 85 oer Jahren wurde deshalb ein Pumpbrunnen errichtet, der aber ebenso nur wenig Wasser, sporadisch sogar gar keines führte. Die hölzerne Wasserleitung wurde vermutlich nicht einmal zwei Jahrzehnte lang genutzt. ${ }^{130}$ Die Schullerberger Leitung steht für einen punktuellen Wandel, mit dem man kurzfristig auf Probleme oder Forderungen reagierte, städtisches (oder allgemein herrschaftliches) Engagement zeigte, aber gleichzeitig das bestehende System der Wasserversorgung nicht infrage stellte. Für Wien lässt sich zu dieser Zeit Ähnliches beobachten: Die durch Erzherzog Albert und Kaiser Ferdinand initiierten (und kofinanzierten) Wasserleitungen sollten ab i804 resp. I84I quantitative oder qualitative Defizite beseitigen, stellten aber nur Teillösungen dar. ${ }^{131}$ Den begrenzenden Faktor bildeten die Kosten: Bestehende Infrastrukturen konnten in der Regel nicht erweitert werden, da die Kapazität der genutzten Quellen und der Leitungssysteme begrenzt war, die Etablierung eines neuen zentralen Versorgungssystems war aus dem »normalen« Budget einer Stadt nicht zu finanzieren: Noch i 870 hatte die Stadt Linz für die Wasserversorgung nur $763 \mathrm{fl} 38 \mathrm{kr}$ ausgegeben. ${ }^{132}$

\footnotetext{
I 4 Vgl. Hillbrand, Türme, ıogf.

I $25 \mathrm{LZ} / \mathrm{IB}, 22 . \mathrm{I} 2 . \mathrm{I} 828$.

I 26 Den Konnex zwischen Feuersicherheit und Leitungserrichtung legen zumindest die Stadtratsprotokolle nahe - AStL, HS i rog (Stadtratsprotokoll i 828 ), fol. 5 a.

I 27 OÖLA, Karten- und Plänesammlung, VI/23.

I 28 AStL, Altakten, Sch. I7 I LR E7m, Reg. Io768 (I6 I 9); Pillwein, Wegweiser, r67.

I 29 Fink, Geschichte, I23.

I 30 OÖLA, Musealarchiv, HS 5 I (Materialien zur Geschichte der Stadt Linz von Ignaz Fink, undat.), pag. 672; AStL, HS 462 (Unterkameramts Contobuch pro I 848), pag. 84; Schreinzer, Methode, I I-I 3 ; vgl. AStL, HS I 29 (Sitzungsprotokolle des Gemeindeausschusses i 848), fol. 22 ra u. LVB, 30. I I. I 875.

I 3 I Vgl. Brunner/Schneider, Umwelt, I5 I u. I92f.; Meißl, Hochquellenleitungen, I 58 u. I6r; Stadler, Wasserversorgung, 38-40 u. 43-54; Weigl, Wandel, r 86f.; Birkner, Stadt, I 29.

I 32 AStL, HS 237 (Kammeramt Ausgaben i 870), pag. Io4f.
} 
Deutlich intensivierten sich die Diskurse zu den städtischen Wasserinfrastrukturen und zur Qualität des städtischen Wassers ab den r 840er Jahren: Auf der einen Seite diskutierten Techniker über die Umsetzbarkeit neuer zentraler Infrastrukturen und stellten bereits verwirklichte Projekte vor. I 840 wurden in der in Wien erschienenen "Allgemeinen Bauzeitung« die "Wasserleitungen zu Frankfurt am Main, Charenton, Paris und London« vorgestellt, wobei man einleitend betonte, dass es für »eine Stadt kaum ein größeres Bedürfniß als gutes und trinkbares Wasser« gebe, »sowohl in Rücksicht auf Reinlichkeit und Gesundheit, als auch in Bezug auf Gewerbe und Industrie «. ${ }^{133}$ In den Folgejahren wurden die Mitte der I 8 zoer Jahre errichtete New Yorker Wasserleitung und die Wasserversorgung in Udine beschrieben. ${ }^{134}$ I 843 erschien ein Bericht über die New Yorker Wasserleitung in der »Linzer Zeitung «, in dem darauf verwiesen wurde, dass derzeit auch in Marseille eine »ähnliche Leitung errichtet werde. ${ }^{135}$ Interessanterweise wurden in der "Allgemeinen Bauzeitung« erst wieder ab der Mitte der I 8 oer Jahre städtische Wasserversorgungssysteme thematisiert - dafür dann aber in zahlreichen Berichten. ${ }^{136}$

Parallel dazu zeichnet sich ein lokaler bürgerlicher Diskurs zur Qualität des Wassers ab. I 847 plädierte ein Artikel im in Linz erschienenen »Österreichischen Bürgerblatt für Verstand, Herz und gute Laune« für die Filtrierung von Trinkwasser: „Die Nothwendigkeit eines guten Wassers für jede Stadt liegt außer Zweifel, und doch ist ein reines und gutes Wasser sehr selten«. Das Wasser enthalte oft »eine Menge Kalksalze«, die man »mit geringen Kosten« über einen »Filtrirbrunnen« (ein Fass mit Schichten aus Sand und Knochenkohle) reinigen könne. ${ }^{137}$ Anfang der I 85 oer Jahre führte der Linzer Realschullehrer Edmund Schreinzer eine Trinkwasseruntersuchung durch, die wesentlich auf einem Aufsatz, der I 850 in den Sitzungsberichten der Wiener Akademie der Wissenschaften veröffentlicht worden war, basierte. ${ }^{138}$ Schreinzers »Härtebestimmung des Wassers« wurde I 854 im »Jahres-Bericht« seiner Schule veröffentlicht und damit vermutlich auch durch die lokale Elite rezipiert. ${ }^{139}$ Schreinzer ging von der Prämisse aus, dass die »harten Wässer sogar die besten Trinkwasser«, »vorzüglich tauglich und gesund« seien, und er wählte Wasserentnahmestellen, die

I33 Allgemeine Bauzeitung 5 (I840), 39-50; Zitat auf S. 39 .

I34 Allgemeine Bauzeitung 6 (I84I), 217-223; Allgemeine Bauzeitung 7 (I 842), 5 f.

I $35 \mathrm{LZ}, \mathrm{I} 7 \cdot 3 \cdot \mathrm{I} 843$.

I36 I 855 Berlin, I 856 Magdeburg, I 858 Liverpool, I86r London und I862 Paris - Allgemeine Bauzeitung 20 (I 855), 260-264; Allgemeine Bauzeitung 2I (I 856), 3 I 4f.; Allgemeine Bauzeitung 23 (I 858), 202; Allgemeine Bauzeitung 26 (I86I), 98f.; Allgemeine Bauzeitung 27 (I 862), 207-223; vgl. Schott, Urbanisierung, $266 \mathrm{u}$. Lenger, Metropolen, 39 .

I 37 ÖB, 8.I0.1 847 .

I 38 Es handelte sich dabei um Ignaz Moser, Ueber Th. Clark's Methode, die Härte des Wassers durch eine titrierte Seifenlösung zu ermitteln, in: Sitzungsberichte der kaiserlichen Akademie der Wissenschaften. Mathematisch-naturwissenschaftliche Classe 4 (I 850 ), 484-500; Clarks Untersuchungen erschienen I84I resp. I847/I 849 - vgl. ebd., 485.

I39 Schreinzer, Methode; vgl. Linz und seine Umgebung, 28 u. Stifter, HKG, Bd. 8/3, 22 I. 
er als für Linz »besonders« relevant einschätzte. Insgesamt waren dies I 3 Brunnen in oder vor der Stadt, dazu untersuchte Schreinzer das Wasser der Donau und der Traun, das er jeweils bei den Brücken entnommen hatte, zudem das Wasser der Kirchschlager Kurquelle. ${ }^{140}$ Schreinzer kam zu dem Ergebnis, dass die Grundwasserbrunnen »vorzügliches Trinkwasser enthalten, welche in westlicher Richtung der Stadt, in der Nähe des Frein- und Schullerberges liegen«, die Qualität in Richtung Osten abnehme, wenngleich das dortige Wasser »für industrielle Zwecke, so wie für den gewöhnlichen Haushalt als Koch- und Waschwasser ganz gut geeignet sein wird«. Weil sie über kalkhaltiges Wasser verfügten, schätzte Schreinzer die Hauptplatzbrunnen, den Grundwasserbrunnen beim Landhaus und einzelne Brunnen in der Altstadt als »die besten Trinkwässer«. Für das Wasser aus Kirchschlag konstatierte Schreinzer eine »besondere Reinheit«, positiv erschien ihm auch die niedrige Temperatur des Wassers, die sehr geringe Wasserhärte thematisierte Schreinzer hingegen nicht. ${ }^{141} \mathrm{Zu}$ den Proben der Donau und der Traun, für die eine relativ geringe Wasserhärte bestimmt wurde, gab Schreinzer kein explizites Urteil ab, merkte aber an, dass das Donauwasser "ziemlich trübe« gewesen und es vor der Untersuchung gefiltert worden sei, das Traunwasser hingegen »rein und klar ohne die geringste Trübung " gewesen sei. ${ }^{142}$ Der Geschmack bildete bei Schreinzer kein Kriterium.

Überlegungen zur Wasserqualität finden sich auch bei einem anderen Vertreter des damaligen Linzer Bildungsbürgertums: Für Adalbert Stifter wurde das Wasser besonders in dessen letzten Lebensjahren "zu einer Materie, mit der er sich geradezu obsessiv befasst[e]«, wie es Petra-Maria Dallinger - möglicherweise etwas zu dramatisch - formuliert hat. ${ }^{143}$ Bereits in der Korrespondenz der I 85 oer Jahre findet sich ein Nachdenken über Trinkwasser, was mit Stifters Sommeraufenthalten im - nahe der österreichischen Grenze gelegenen - bayerischen Ort Lackenhäuser und dem, wie Stifter es bezeichnete, dortigen »unaussprechlich herrlichem Wasser« zusammenhing. Stifter hob die »Klarheit und Durchsichtigkeit« des Wassers hervor und auch dessen Herkunft aus dem Wald („Waldwasser«) und Urgestein (»Granitlager«). ${ }^{144}$ Zwischen Wasser und Gesundheit sah Stifter eine kausale Verbindung, was nicht überrascht, wenn man die obigen Diskurse und die stetige Expansion von wasserbasierenden Kurbetrieben im Hinterland von Linz zu dieser Zeit betrachtet. ${ }^{145}$ Mit der Verschlechterung von Stifters Gesundheitszustand in den I86oer Jahren taucht das Wasser erneut und diesmal häufiger - in den Briefen auf. Im Juni I 864 schrieb Stifter, dass ihm sein Arzt geraten habe, »die heißeste Zeit in einer hochgelegenen nadelwaldartigen

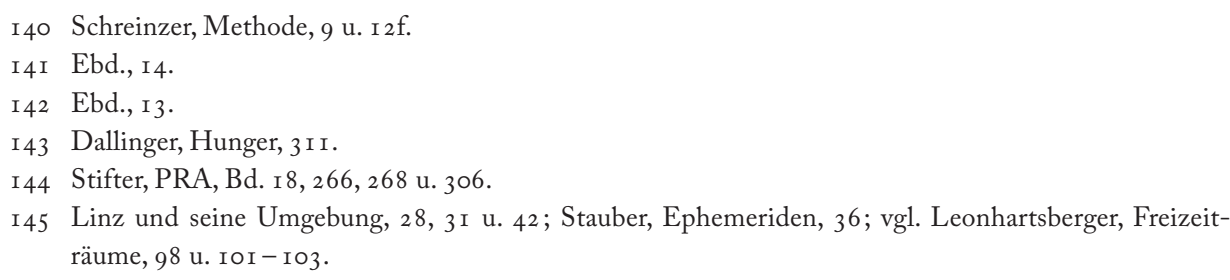


Gegend « zu verbringen, in der »herrliche Luft[,] das Wasser [... und der] Wald« seine Gesundheit verbessern würden. ${ }^{146}$ Ein Brief aus dem Frühjahr I 865 zeigt wiederum ein intensives Nachdenken (und eine empfundene Ungewissheit) über die Qualität von Wasser. Ein Linzer »Chemiker Apotheker« werde das Lackenhäuser Wasser untersuchen: "Ich hoffe, er wird in dem Wasser gar nichts finden, als nur das Wasser«. Gleichzeitig fungierte das städtische Wasser als Negativfolie: Als Stifter im Herbst I 864 nach Linz gekommen war, »ekelte es« ihn »vor dem hiesigen Wasser durch Wochen hindurch. Ich konnte es nur mit etwas Wein trinken. « ${ }^{147}$

Ab dem Herbst I 865 wurde Kirchschlag für Stifter zu einem wiederholten Aufenthalts- und Kurort, was einerseits mit persönlichen Verbindungen, andererseits mit den dortigen naturräumlichen Bedingungen und besonders mit dem Wasser zusammenhing. ${ }^{148}$ In zahlreichen Briefen dieser Zeit finden sich Lobeshymnen auf das Kirchschlager Wasser, etwa in einem Brief an seine Frau vom Oktober I 865: "Es ist unendlich lieblicher und kräftiger als das bei Rosenberger [in Lackenhäuser], es hat gar keinen Geschmack nach Süß oder Sauer «. ${ }^{149}$ Stifters Euphorie gipfelte in der Ankündigung, Wasser in einem Fass nach Linz zu schicken - was Stifter zumindest im Herbst/Winter I 865 und im Herbst des Folgejahres tatsächlich mehrfach tat (vgl. unten): »Trinke keinen anderen Tropfen. Dieses Wasser löst alle übeln Stoffe im Körper auf, und führt sie fort. ${ }^{150}$

Diese Überhöhung des nichtstädtischen (Kirchschlager) Wassers zeigt sich auch deutlich in den »Winterbriefen aus Kirchschlag", die im Winter I865/I866 entstanden und im Frühjahr I 866 in der "Linzer Zeitung « veröffentlicht wurden. ${ }^{151}$ In diesen Texten findet eine Reflexion über verschiedene Elemente, von Licht, Luft und Wasser bis hin zu Wärme und Elektrizität statt, neben praktischen Überlegungen (z.B. zu Vorteilen der Höhenlage im Hinblick auf die herbstlichen und winterlichen Talnebel) stehen aber ebenso vage Wortkaskaden zur Schönheit und Gesundheit des Ortes. Stifters Brief zum Wasser greift zahlreiche der bereits genannten Punkte auf, stellt nun aber einen expliziten Vergleich mit dem städtischen Wasser (in diesem Fall dem Linzer Wasser) her und lässt damit erkennen, dass Stifters Meinung nicht stark von den Einschätzungen anderer Zeitgenossen abwich: „Was thun wir? Wir graben in den meisten Fällen ein Loch in die Erde, und trinken das Wasser, das wir da finden.« Dies sei in den Bergen »und besonders im Granitboden« zulässig, in tieferen Lagen sei jedoch »ein solcher Brunnen wenig mehr, als ein Sumpf«. Wenn nun eine Stadt am Fluss oder "gar wie Linz« an zwei Flüssen gelegen sei, dann trinke man Flusswasser und dieses habe zwar »durch Seihung der Erde« Schwebstoffe verloren, die gelösten Stoffe

\footnotetext{
I46 Stifter, PRA, Bd. 20, I96f.; vgl. ebd., 2 I 7 u. Begemann/Giuriato, Stifter-Handbuch, I74-I77.

I47 Stifter, PRA, Bd. 20, 275.

I48 Pfeffer, Kirchschlag, $38-49$; vgl. Stifter, HKG 8/3, 359.

I49 Stifter, PRA, Bd. 21, 39.

I 5 O Ebd., 59; vgl. ebd., 97-99 u. Pfeffer, Kirchschlag, 43.

I 5 I Stifter, HKG, Bd. 8/3, I99-228; vgl. ebd., I05.
} 
(»pflanzliche oder thierische Ausscheidungen oder Verwesungsstoffe«) seien jedoch noch vorhanden: »Man kann aber denken, was ein Strom aus Städten und bewohnten Niederungen mit sich bringen mag. ${ }^{152}$ In großen Städten gelange »der menschliche und thierische Unrath in verschiedener Menge in der Erde", was wiederum die Brunnen $»$ mit Jauche durchsetzt ${ }^{153}$ Interessanterweise verwies Stifter auf die Untersuchung des Lehrers Schreinzers (wobei Stifter hartes Wasser als unsauber einstufte) und auf die Diskussionen zur Wiener Wasserversorgung und er betonte den städtischen Handlungsbedarf (»Dringlichkeit«) im Bezug auf die Wasserversorgung. ${ }^{154}$

Die Frage, welche allgemeinen Aussagen sich aus diesen spezifischen Wahrnehmungen ableiten lassen, wird man nicht wirklich beantworten können. Man darf aber das zeitgenössische Interesse an den »Winterbriefen« nicht unterschätzen, der Brief zum Wasser wurde immerhin im März I 866 unter dem Titel »Wasserfrage« in der Wiener »Neuen Freien Presse« abgedruckt. ${ }^{155}$ Aber auch im allgemeinen Diskurs dieser Zeit zeichnet sich immer häufiger eine Verbindung zwischen Krankheit und Wasser ab, was - in Bezug auf die Linzer Tageszeitungen - besonders ab der Mitte der I 86oer Jahre und im Kontext der Cholera festgestellt werden kann. Ab I 866 verknüpften mehrere Zeitungsartikel - dies war bei der Epidemie der I 85 oer Jahre noch unterblieben die Verbreitung der Cholera kausal mit der Frage des Trinkwassers. ${ }^{156}$ In einem Artikel in der »Linzer Tagespost« vom September I 866 wurde betont, dass der Münchner Hygieniker Max v. Pettenkofer »jetzt« eine mögliche Übertragung der Cholera über das Trinkwasser "zugibt ${ }^{157}$ Auch das praktische Handeln (vgl. Kap. 9. Epidemie) hatte die Wasserversorgung im Blick: Ende September wurden nach dem Auftreten von Cholerafällen mehrere Brunnen im Schullertal »kommissionell untersucht« und - da man dort »schlechtes Trinkwasser« vorgefunden habe - "versiegelt«. ${ }^{158}$ Wenig später forderte ein Linzer Apotheker in einem Leserbrief »anzuordnen«, täglich alle Brunnen zur gleichen Zeit eine Stunde lang abzuschöpfen, was nicht nur zu einer Durchspülung der Kanäle führe, sondern auch helfe, die Wasserqualität zu verbessern. ${ }^{159}$ Wenig überraschend bestärkte die heranrückende Cholera Stifter in seiner Ablehnung des Linzer Trinkwassers: Bereits im Juni I 866 - also noch vor dem Ausbruch der Cholera in Linz riet Stifter seiner Frau, »keinen Tropfen Linzerjauchenwasser « zu trinken, »koche auch nicht damit«, sie solle sich Wasser aus Kirchschlag schicken lassen. ${ }^{160}$

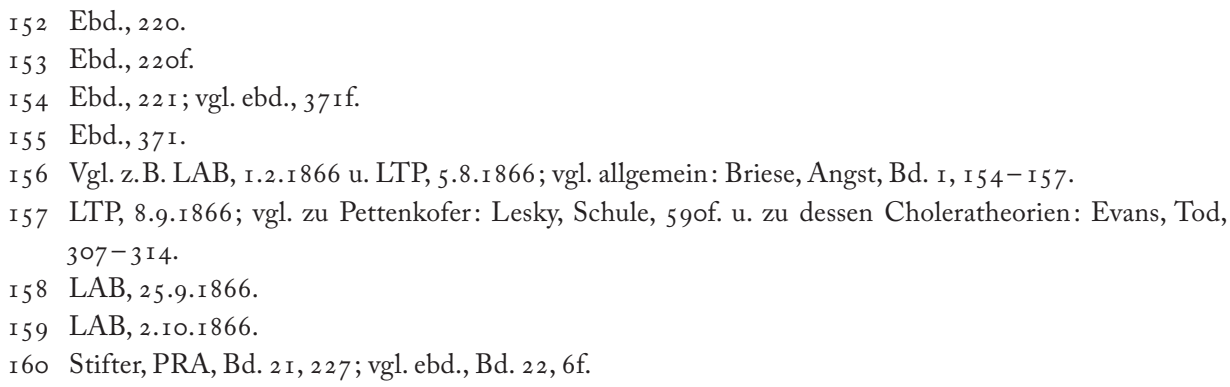




\section{Netzwerklösung}

Ambitionen zur Etablierung einer neuen Wasserversorgung gingen in den späten I 86oer Jahren von den bürgerlichen Eliten in Linz aus. Dies ist einer spezifischen Konstellation zuzuschreiben: Ab den i 85 oer Jahren gab es eine latente publizistische Diskussion zu Innovation im Bereich der modernen Wasserversorgung (vgl. oben), dazu hatten Städte, die zentrale Wasserinfrastrukturen bereits errichtet hatten resp. über eine Umsetzung diskutierten, Vorbildcharakter für andere Kommunen. Im Falle von Linz waren augenscheinlich die Diskurse und Aktivitäten in Wien von erheblicher Bedeutung - nicht nur, weil zahlreiche Mitglieder der politischen Elite aus Wien stammten oder über Verbindungen nach Wien verfügten (vgl. Kap. 2. Kontexte: Linz I700 bis I 900), sondern auch, weil in Wien Lösungswege aufgezeigt und erfolgreich umgesetzt wurden.

In den I 85 oer Jahren setzten in Wien intensivere Diskussionen über die Errichtung einer neuen, größeren Wasserleitung ein, da die bestehende Versorgung zunehmend mit Knappheiten und hygienischen Defiziten assoziiert wurde. I 853 bot - wie in vielen anderen Städten zu dieser Zeit - ein englisches Unternehmen die Errichtung eines umfangreichen Wasserversorgungssystems an, dazu wurden von verschiedenen lokalen Akteuren Projektvorschläge eingebracht, die eine Nutzung von Donauwasser (das bereits die Kaiser-Ferdinand-Wasserleitung der I 83oer/ I $840 e r$ verwendete) oder von Quellen bzw. kleinen Flussläufen im Hinterland vorsahen. Auf Initiative des Innenministeriums wurde I 858 mit Beteiligung der Akademie der Wissenschaften eine Kommission etabliert, die Vorschläge zur Modifizierung der Wiener Wasserversorgung erarbeiten sollte, und ab I 860 wurde die »Wasserfrage« auch im Wiener Gemeinderat intensiver diskutiert. ${ }^{161}$ Dort wurde im Dezember I 86 I beschlossen, in einer internationalen Ausschreibung Angebote darüber einzuholen, wie man die Stadt »in möglichst kurzer Zeit mit gutem Trink- und Nutzwasser « versorgen könne. ${ }^{162}$ Dies bildete den Auftakt für weitere Initiativen des Gemeinderates: Ab Mai I 862 beschäftigte sich ein »Specialcomité« der Stadterweiterungskommission mit der Wasserversorgung und im November I 862 beschloss der Gemeinderat, die Errichtung der Wasserleitung auf Kosten der Stadt umzusetzen. Dazu wurde eine eigene Kommission eingesetzt, die die mittlerweile eingereichten Vorschläge prüfen und die praktikabelste Lösung auswählen sollte. ${ }^{163}$

Im Juli I 864 entschloss man sich dafür, das Wasser aus dem 80 Kilometer entfernten Berggebiet der Rax und des Schneebergs zu beziehen, obwohl es die teuerste Variante war und sie sich ursprünglich nicht unter den eingereichten Vorschlägen be-

\footnotetext{
I6 I Csendes/Opll, Wien, Bd. 3, 75; Stadler, Wasserversorgung, 43-54 u. 95-97; vgl. Die [Wiener] Presse, 23.Io.1 853 u. Wiener Medizinische Wochenschrift. Hauptteil, Wien I 853, 73 I-734.

I62 Stadler, Wasserversorgung, 97f.; vgl. Meiß1, Hochquellenleitungen, r $62 \mathrm{f}$.

I63 Stadler, Wasserversorgung, I07- I I4.
} 
funden hatte. Diese Lösung war durch den Geologen Eduard Sueß erarbeitet worden, der der Gemeinderatskommission angehörte und dem später auch in der Linzer Wasserdiskussion eine erhebliche Rolle zukam. Eine der vorgesehenen Quellen, die »Kaiserquelle«, nutzte man bereits lange, ohnehin erachtete man das Wasser aus dem »Gebirge« als reiner und gesünder, aber auch finanzielle Überlegungen waren nicht unerheblich: Die Betriebskosten, so die Annahme, seien durch die Nutzung der Gravitationskraft insgesamt geringer als bei einem ständigen Pumpbetrieb. Zudem hatte sich die »Gesellschaft der Wiener Ärzte« für diese Variante ausgesprochen (vgl. Tab. 8). ${ }^{164}$

Tab. 8: Etablierung zentraler Wasserversorgung in Österreich

\begin{tabular}{|c|c|c|c|c|}
\hline & $\operatorname{Linz}$ & Wien & Graz & Salzburg \\
\hline $\begin{array}{l}\text { Diskussionsbeginn } \\
\text { im Gemeinderat }\end{array}$ & $10 / 1868$ & 1860 & $10 / 1867$ & $10 / 1865$ \\
\hline $\begin{array}{l}\text { Vertrag über } \\
\text { Errichtung resp. } \\
\text { Baubeginn }\end{array}$ & $\begin{array}{l}1871 \text { u. } 1881 \text { (aufge- } \\
\text { löste Verträge); } \\
1891 \text { (Baubeginn) }\end{array}$ & 1869 (Baubeginn) & 1869 (Vertrag) & 1874 (Baubeginn) \\
\hline Inbetriebnahme & 1893 & 1873 & 1872 & 1875 \\
\hline Wasserbezug & $\begin{array}{l}\text { Grundwasser aus } \\
\text { Kleinmünchen } \\
\text { (lokal) }\end{array}$ & $\begin{array}{l}\text { Quellwasser aus } \\
\text { dem Raxgebiet } \\
\text { (8o km entfernt) }\end{array}$ & $\begin{array}{l}\text { Grundwasserwerk } \\
\text { an der Mur (lokal) }\end{array}$ & $\begin{array}{l}\text { Quellwasser vom } \\
\text { Untersberg ( } 9 \mathrm{~km} \\
\text { entfernt) }\end{array}$ \\
\hline Finanzierung & Stadt (Kredit) & Stadt (Kredit) & Unternehmen & Stadt (Kredit) \\
\hline
\end{tabular}

Quelle: Pichler-Baumgartner, Wege, 43-45, 77, 102f. u. 238; Stadler, Wasserversorgung, 96f. u. 237; Brunner/Schneider, Umwelt, 196-198; Macher, Hygienisierung, 13f.; Ebner/Weigl, Wasser, 97-112

Während der I86oer Jahre begannen auch in anderen österreichischen Mittelstädten Debatten um eine Erneuerung der Wasserversorgung (vgl. Tab. 8): In Salzburg stießen eine Typhusepidemie, das damit verbundene Engagement eines Arztes und ein konstatierter Mangel an Löschwasser und vermutlich ebenso die Wiener Entscheidung den Diskussionsprozess im Gemeinderat an, ${ }^{165}$ der auch außerhalb von Salzburg - in Linz - rezipiert wurde. ${ }^{166}$ Einen weiteren Faktor für das Entstehen eines Diskurses zur Modernisierung der Wasserversorgung bildete der mittlerweile kaum noch umstrittene Konnex zwischen Wasser und Sauberkeit resp. Gesundheit, der sich durch den Choleraausbruch I 865/ I 866 verstärkt hatte. Als im Mai I 868 im Linzer Gemeinderat die Frage der Wasserversorgung diskutiert wurde, gab sich der Arzt Johann Heyss davon überzeugt, dass Linz »schlechtes Brunnenwasser« habe. ${ }^{167}$ Zudem erschien

\footnotetext{
I64 Brunner/Schneider, Umwelt, r 96f.; Meiß1, Hochquellenleitungen, I63.

I65 Ebner/Weigl, Wasser, 97- roo.

I66 LTP, 27.I.I 866 - vgl. Ebner/Weigl, Wasser, 95 - 100.

I67 GRP i 868, fol. I35a.
} 
die Finanzierung eines derartigen Projekts nicht mehr unmöglich: Einerseits konnten Großkredite aufgenommen werden - hier war wiederum Wien das Vorbild, das I 866 eine Anleihe über 25 Millionen Gulden aufgenommen hatte ${ }^{168}$-, andererseits konnten, wie andere Städte gezeigt hatten, Wasserleitungen durch Privatunternehmen errichtet und betrieben werden. Auch die politischen Faktoren waren günstig: Die Gemeindeautonomie der I 86oer Jahre hatte derartige Projekte angestoßen, die zunehmend als Positionierungsmöglichkeit gesehen wurden und dadurch Städte genauso unter Zugzwang brachte (vgl. Kap. 2. Kontexte: Linz I 700 bis I 900). ${ }^{169}$ Linz nehme »betreff seiner Sterblichkeit keinen günstigen Platz« ein, gab der Jurist Alois Bahr der Vater des Schriftstellers Hermann Bahr - r 868 im Gemeinderat zu bedenken. ${ }^{170}$ Schließlich ermöglichten erst die industriell gefertigten Eisenrohre, die massenhaft verfügbar und - verglichen mit Bleirohren - relativ günstig waren und einem höheren Druck standhielten, eine zentrale Wasserinfrastruktur. ${ }^{171}$

Dass es ab i 868 im Linzer Gemeinderat zu einer intensiveren Auseinandersetzung mit der Wasserfrage kam, ist als Nebenprodukt der Diskussionen um die Fäkalienund Abwasserentsorgung zu sehen (vgl. Kap. 5. Zirkulationen und Output). Im Jänner I 868 präsentierte das mit dieser Agenda betraute Komitee seinen Bericht: Man sei davon überzeugt, dass eine weitreichende »Verunreinigung des Brunnenwassers durch Einsikerung faulender Substanzen aus den Senkgruben oder Kanälen« erfolge. In Graz habe beim Auftreten der Cholera »verdorbenes Wasser sich rein und geruchlos» gezeigt, welches »den Hausbewohnern[,] die auf dessen Genuß angewiesen waren[,] so vollkommen gut und schmakhaft erschien, daß selbe die erwähnten Krankheiten eher allem Anderen, als ihrem Trinkwasser zuschreiben zu sollen glaubten«. ${ }^{172} \mathrm{Da}-$ raufhin beauftragte man die Realschule - und damit erneut Edmund Schreinzer mit »einer wissenschaftlichen Prüfung « des Linzer Wassers, ${ }^{173}$ deren Ergebnisse im März I 868 auch in einer Linzer Tageszeitung veröffentlicht wurden und damit eine breitere Öffentlichkeit erreichten. Auf der ersten Seite der Zeitung fanden sich Urteile über die Wasserqualität von 36 öffentlichen und privaten Brunnen, zudem von Donauwasser, wobei "mit dem relativ besten begonnen und mit dem schlechtesten geschlossen« wurde. In der Untersuchung, die auf einen Nachweis von "gelösten organischen Substanzen« (statt der Wasserhärte - vgl. oben) abgezielt hatte, habe sich gezeigt, »daß die meisten dieser Trinkwässer mehr organische Stoffe enthalten als mit der Gesundheit der Trinkenden verträglich ist «. ${ }^{174}$ Im Mai I 868 bestand im Gemeinderat Konsens darüber, dass durch das Fehlen eines umfangreichen Kanalsystems »der

i68 Kucera, Ausgaben, $49 \mathrm{f}$.

I69 Vgl. Dagenais, Source, Io5f.

I70 GRP i 868, fol. I36a.

I7 I Vgl. Suter, Wasser, $36 f$.

I72 GRP г 868, fol. Ioa; vgl. Linner, Salubritäts-Verhältnisse.

I73 GRP r868, fol. rib.

I74 LAB, I0.3.I 868. 
nachtheiligste Einfluß auf die gute Beschaffenheit des Brunnenwassers und dadurch in erster Linie auf die Gesundheits-Verhältnisse der Bewohner der Stadt genommen werde ${ }^{175}$ Dagegen sollte die vollständige Kanalisierung der Stadt helfen, zudem wurde als Ad-hoc-Maßnahme eine Brunneninspektion zur »beständigen sogfältigen Uiberwachung des Wasserzustandes in den Brunnen« etabliert und auch eine Kurzfassung des Linner-Gutachtens mit einer Auflage von I.500 Stück auf Gemeindekosten gedruckt und an »die hiesigen Hausbesitzer unentgeltlich abgegeben «. ${ }^{176}$ Damit - und mit dem Abdrucken von Auszügen des Gemeinderatsprotokolls in den Linzer Tageszeitungen - gab es spätestens ab diesem Zeitpunkt in Linz einen öffentlichen Diskurs zur Wasserfrage. ${ }^{177}$ Bereits im März I 868 hatte eine Zeitung bei der Benennung der drängendsten Fragen für die Zukunft der Stadt die »die Herstellung eines rationellen Kanalisationsystems und die Versorgung der Stadt mit gutem Trinkwasser« an zweiter Stelle angeführt. ${ }^{178} \mathrm{Im}$ Sommer und Herbst I 868 war der Gemeinderat - trotz eines Angebots des britischen Ingenieurs John Moore, eine Wasserleitung auf eigene Kosten zu errichten - jedoch eher mit der Diskussion der Kanalisation beschäftigt, erst im November I 868 führte eine Eingabe der Freiwilligen Feuerwehr, ${ }^{179}$ die einen zu erwartenden Mangel an Löschwasser bei Großbränden konstatierte, zu dem Beschluss, »endlich die lange schon ventillirte auch in anderer besonders sanitärer Beziehung wichtige Wasserangelegenheit in Angriff zu nehmen«. Im Blick hatte man aber offenbar keine umfangreiche Lösung nach Wiener Vorbild, sondern eher eine Nutzung von Quellen im Stadtgebiet. ${ }^{180}$ Die vom Gemeinderat eingesetzte Kommission legte im Dezember I 869 einen Bericht vor, der deutliche Bedenken hinsichtlich der Ergiebigkeit dieser Quellen äußerte und die Verwendung von Grundwasser als aussichtsreicher erachtete. ${ }^{181}$ Daran anschließend beschloss man - konsensual -, um die »Versorgung der ganzen Stadt mit guten [sic], für alle Bedürfnisse ausreichenden Wasser« sicherzustellen, Verhandlungen mit Moore aufzunehmen und gleichzeitig mit Anzeigen in »den technischen Fachblättern « nach weiteren Angeboten zu fragen. ${ }^{182}$ Es bestand also der Glaube, vielleicht der Wunsch, eine neue Wasserinfrastruktur über ein kommerzielles Unternehmen etablieren zu können. Was ex post als Desinteresse und Lavieren erscheint, sollte eher als Vorsichtigkeit verstanden werden: Infrastrukuren dieser Größe verursachten erhebliche Kosten, die legitimiert werden mussten, zudem gab

I75 GRP i 868, fol. I33b.

I76 Ebd., fol. I34b-I35a; Linner, Salubritäts-Verhältnisse; die Brunneninspektion war jedoch nur von 3.6. I 868 bis 28. Iо. I 869 tätig - Schiedermayr, Sanitätsverhältnisse, I 4.

I77 Vgl. etwa die Sitzung vom I 3.5.I 868 zur Wasserfrage - LTP, 24.5.I 868.

I78 LTP, I3·3.I 868 .

I79 Vgl. die Diskussion der »Wasserfrage« in Feuerwehrkreisen: Oesterreichische Feuerwehr-Zeitung, I.9. I 865 , unpag.

I 80 GRP i 869 , fol. 237b-238a u. 382b-383a; Pichler-Baumgartner, Wege, $43 \mathrm{f}$.

I 8 I GRP I 869, fol. 38 ra-382b.

I 82 Ebd., fol. $383 \mathrm{~b}-385 \mathrm{~b}$; Pichler-Baumgartner, Wege, 43 . 
es im Hinblick auf die technische Umsetzung - vor allem zu diesem Zeitpunkt - noch wenig Erfahrungswerte. ${ }^{183}$

Im April r 87 I schloss die Stadt Linz einen Vertrag mit dem Unternehmen "Pongratz und Moore« über die Errichtung einer Wasserleitung ab, deren Kosten das Unternehmen tragen musste, dem dafür aber das Betriebsrecht über 50 Jahre eingeräumt wurde. John Moore war ein englischer Ingenieur, der in den I 85 oer Jahren bei der Errichtung des Berliner Wasserwerks mitgewirkt hatte und ab I 870 gemeinsam mit dem Wiener Bauunternehmer Oskar Pongratz in Graz ein Grundwasserwerk errichtete. Das Unternehmen beabsichtigte, Grundwasser in der Welser Heide zu nutzen und in die Stadt zu leiten, scheiterte aber, und so wurde der Vertrag I 875 gelöst. ${ }^{184}$ Das Scheitern scheint sich schon zuvor abgezeichnet zu haben: Im November I 873 ordnete der Gemeinderat eine geologische Untersuchung der nächsten Umgebung von Linz an, um eine geeignete Wasserentnahmestelle zu finden. Dies übernahm im Folgejahr Eduard Sueß, der wenige Jahre zuvor die gleiche Frage für die Wiener Wasserversorgung gelöst hatte und in Linz eine Nutzung des Grundwassers nahe der Traun empfahl. Diese Ergebnisse übermittelte man im Mai I 874 Pongratz und Moore, wobei zu diesem Zeitpunkt bereits klar war, dass das Wasserleitungsprojekt »wohl in anderer Weise zur Ausführung kommen [werde] müssen «. ${ }^{185}$ I 876 war die Mehrheit des Gemeinderates davon überzeugt, die Errichtung der Wasserversorgung auf Kosten der Stadt durchzuführen: Man beauftragte den städtischen Ingenieur, nahe der Traun zwei Probebrunnen anzulegen, und die »Deutsche Wasserwerksgesellschaft « aus Frankfurt am Main, welche die städtische Wasserleitung in Salzburg geplant hatte und mit der der Gemeinderat bereits im Sommer I 874 Kontakt aufgenommen hatte, mit der Kostenschätzung für ein Wasserleitungsnetz, das das Grundwasser der Traun in Kleinmünchen mit Dampfkraft heben und in die Stadt leiten sollte. Im Oktober I 876 beschloss der Gemeinderat die Annahme des Projektvorschlags der »Wasserwerksgesellschaft «, der die Kosten mit rund 485.000 fl angab und eine Fertigstellung innerhalb der nächste zwei Jahre in Aussicht stellte. ${ }^{186}$

Mit der Entscheidung das Wasserversorgungsprojekt auf Kosten der Stadt zu finanzieren, kam es zu ersten Gegenstimmen, die als ein nach außen getragener Konflikt zwischen den Gemeinderatsfraktionen zu werten sind: Ab dem Ende des Jahres I 876 finden sich in den Tageszeitungen zahlreiche Beiträge, über die sich dieser Konflikt gut verfolgen lässt. Auf der Seite der Kritiker/innen meldeten sich der ehemalige Gemeinderat Karl Foltz - der sich stark für die Kanalisierung eingesetzt hatte - und der

I 83 Vgl. Melosi, America, 227.

I 84 Pichler-Baumgartner, Wege, 44; Heller, Wasserversorgung, 4; vgl. zu Moore: Allgemeine Bauzeitung 2I (I856), 3I4; vgl. zu den kommerziellen Wasserversorgern in London: Jenner, Monopoly; Van Lieshout, Droughts u. Tomory, Water.

I 85 Heller, Wasserversorgung, 5; GRP I 874, fol. r6ob u. fol. 207a-2 roa.

i 86 GRP r 874, fol. 335a; GRP r 875, fol. 248a u. $583 a-583$ b; Pichler-Baumgartner, Wege, 44f.; Heller, Wasserversorgung, 5 f.; RB I 876 - I878, 66 . 
Vorsitzende des Landessanitätsrats Josef Födinger zu Wort. ${ }^{187}$ Der »Privatier« Foltz verwies auf die hohen Kosten und auf die laufenden Kanalisierungsarbeiten, der Arzt Födinger gab sich überzeugt, dass zwischen dem Wasser und der "großen Sterblichkeit« kein Zusammenhang bestehe. Damit sind bereits die Hauptargumente der Kritiker benannt, die in den unterschiedlichsten, mehr oder weniger wortreichen Variationen während der nächsten beiden Jahre wiederkehrten: Die Wasserleitung sei ein "unwillkommener Fremdling, der uns das Wasser zu vertheuern droht, das wir bisher billig und bei Selbstbedienung umsonst haben konnten«, konnte man im Jänner I 877 auf der Titelseite des konservativen "Volksblatts« lesen. Im Februar 1877 lancierten die Gegner/innen der Wasserleitung eine Petition, in der eine Verschiebung der Umsetzung »bis nach vollendeter Canalisirung " und nachfolgender Wasseruntersuchung gefordert und die von etwas mehr als einem Viertel der Linzer Hausbesitzer/innen (460) unterschrieben wurde. ${ }^{188}$

Die Vorstellung, dass die Kanalisierung für die Verbesserung der Wasserqualität ausreichend sei, fand sich schon im Linner-Gutachten I868 (vgl. oben), zudem bestand in den I $870 e r$ Jahren eine Konkurrenz um Investitionen: Die I 874 aufgenommene »Millionen-Anleihe« sollte nicht nur die Kanalisation, sondern auch den Neubau des Schlachthauses, die Erweiterung des Volksgartens, Pflasterungen und andere städtische Investitionen finanzieren. ${ }^{189}$ Als Reaktion auf die Widerstände bemühte man sich um Rückhalt durch staatliche Stellen und ersuchte im Februar I877 um ein Gutachten des oberösterreichischen Landessanitätsrates, was dem Gemeinderat aufgrund des Sanitätsgesetzes aus dem Jahr I 870 möglich war. ${ }^{190}$ Dazu kam es zu weiteren Wasseruntersuchungen - zwischen I 877 und I 880 waren es vermutlich fünf ${ }^{191}-$, die Agenda der Wasserversorgung wurde aber erst wieder I 880 im Gemeinderat diskutiert, als das Prager Unternehmen »Corte \& Comp.[agnon]« anbot, die Errichtung und den Betrieb einer Wasserleitung durchzuführen. ${ }^{192}$

Auf dieses Angebot reagierten Gegner wie Befürworter, deren Argumentation sich kaum geändert hatte. Erneut starteten die Kritiker eine Petition, die nun jedoch fast doppelt so viele Unterschriften aufweisen konnte. ${ }^{193}$ In einem relativ sachlichen Vortrag umriss der Linzer Techniker Josef Seitz zu Beginn des Jahres I 88 I die Erfordernisse einer Wasserleitung und deren mögliche Optionen: Seitz nahm für Linz einen täglichen Pro-Kopf-Verbrauch von r30 Litern an, wobei 60 Liter auf den Haushalt,

I 87 Vgl. zu Folz und Födinger: Pichler-Baumgartner, Wege, 4I, 65, 72 u. rorf.

I 88 Pichler-Baumgartner, Wege, 72 f. u. 98 - ıoo; vgl. zu Widerständen in Wien: Brunner/Schneider, Umwelt, I 98.

I89 GRP I875, fol. 3b-7a; vgl. RB I876-1878, 59-64 u. Pichler-Baumgartner, Wege, 39.

I 90 Pichler-Baumgartner, Wege, 72 ; Schiedermayr, Sanitätsverhältnisse, I.

I9I Schiedermayr, Sanitätsverhältnisse, r6f.

I92 AStL, Altakten, Sch. I7 I Pichler-Baumgartner, Wege, 45 u. 78 ; Heller, Wasserversorgung, $6 \mathrm{f}$.

I93 Pichler-Baumgartner, Wege, 60-62 u. Ioo- I02; diese Unterschriftenliste ist als OÖLA, Musealarchiv, HS 43 I überliefert. 
20 auf die Industrie, 30 auf die Straßenreinigung und 20 auf den Rest (für Kanäle, Feuerlöschen und Wasserverluste) entfielen. Man müsse also (für 34.00o Einwohner) 4.420 Kubikmeter Wasser pro Tag bereitstellen. Dies sei mengenmäßig über Donauwasser relativ einfach zu bewerkstelligen, man müsse aber, da das Wasser »meist so verunreinigt [sei], theils durch das mitgeführte Geschiebe, theils durch die Abfallstoffe aus den am Strome und seinen Nebenflüssen oberhalb liegenden Orten«, aufwändige Filteranlagen errichten, die - wie man in Wien gesehen habe - sehr anfällig und teuer seien. Die Nutzung von Quellen der umliegenden Hügel sei aufgrund der begrenzten Kapazität nicht sinnvoll, eine bessere Option bilde das Grundwasser oder eine Fassung der Quellen im nördlich der Donau am Abhang des Mühlviertler Hochlandes gelegenen Haselgraben. Es bestünden dort viele Quellen, die ein »sehr gutes, weiches, schmackhaftes Wasser« aufwiesen, auch die höhere Lage sei wegen des Wasserdrucks ein Vorteil. Problematisch sei hingegen, dass dieses Wasser gewerblich genutzt werde den gewerblichen Bedarf bezifferte Seitz auf beachtliche 25.200 Kubikmeter pro Tag -, und das mache das Erkaufen von Wasserrechten resp. Ersatzlösungen notwendig. Insgesamt müsse man die Kosten für ein Wasserleitungsnetz mit 430.000-520.000 fl veranschlagen, wobei jährlich mit I I.00o-26.00o fl Betriebskosten zu rechnen sei. ${ }^{194}$

Im April r 88 I lag das - vom Gemeinderat bereits im Februar i 877 (!) angeforderte - Gutachten des Landessanitätsrates Schiedermayr vor, das deutliche Zusammenhänge zwischen der Trinkwasserversorgung und »dem Auftreten und Schwinden gewisser Krankheitsformen« konstatierte und die unzureichende Qualität des Linzer Brunnenwassers betonte. ${ }^{195}$ Schiedermayrs Argumentation war stark von den Überlegungen des Hygienikers Pettenkofer geprägt, der eine Belastung des Grundwassers durch eine Verunreinigung des Bodens annahm. Im Gutachten wurde eine Nutzung des Grundwassers im Gebiet der Traun als mögliche Variante erachtet, wenngleich Schiedermayr - einmal mehr ist hier das Vorbild Wien sichtbar - eine Quellwasserleitung befürwortete. ${ }^{196}$ Im April I88 I schloss der Gemeinderat einen Vertrag mit „Corte \& Comp.«ab, der die Errichtung einer Wasserleitung auf Kosten des Unternehmens und eine Verwendung von »Quellwasser« am linken Donauufer und den "Ausschluss« einer Nutzung von Grundwasser vorsah. Wiederum wurde, nachdem man keine geeignete Quelle gefunden hatte, im Sommer I 883 der Vertrag gelöst. ${ }^{197}$ Dass der Gemeinderat im Juli I 884 die Errichtung einer durch die Stadt finanzierten Wasserleitung ohne größere Widerstände beschloss, kann auf pragmatische Überlegungen und eine breitere politische Unterstützung zurückgeführt werden: I 883 wurde - nachdem ein Hochwasser zu Brunnenverunreinigungen und Typhusfällen geführt hatte - durch die Statthalterei (i.e. die Landesbehörde), das Militärkommando

\footnotetext{
I94 AStL, Altakten, Sch. I 7 I vgl. Pichler-Baumgartner, Wege, 24 of.

I 95 Schiedermayr, Sanitätsverhältnisse, 4 u. I 9.

I 96 Ebd., I3-I5, 20-23 u. 25.

I 97 RB I88 I, 7 If.; RB I 882, 86-89; Pichler-Baumgartner, Wege, 45; Heller, Wasserversorgung, rof.
} 
und den »Verein für Ärzte« eine Umsetzung des Wasserleitungsprojektes gefordert. ${ }^{198}$ Vermutlich waren mittlerweile die Begrenztheit und die Defizite der bestehenden Wasserversorgung deutlich geworden - vor allem im Vergleich mit anderen Städten. Diese Angst vor dem Verpassen der Moderne scheinen die Wasserleitungsbefürworter im Gemeinderat auch für ihre Zwecke genutzt zu haben: Man kann den Besuch der Berliner »Hygiene-Ausstellung« I 884 durch eine Abordnung des Gemeinderates wohl in diesem Kontext sehen. ${ }^{199}$

Parallel zur Diskussion um die »allgemeine Wasserleitung « waren zwei durch die Stadt finanzierte "provisorische Stadtteil-Wasserleitungen« errichtet worden: I875 eine Leitung auf den Schullerberg und I 886 eine Leitung, die St. Margarethen, die Kalvarienwänd und die Obere Donaulände versorgte. Der wasserarme Schullerberg hatte bereits in den I 83 oer Jahren eine Wasserleitung und einen öffentlichen Brunnen erhalten (vgl. oben), von denen zumindest der Brunnen noch in den I87oer Jahren in Betrieb war und erst 1879 aufgelassen wurde. ${ }^{200}$ Der Schullerberger Brunnen wurde auch vom Gutachten des Grazer Ingenieurs Rudolf Linner erwähnt, der die Qualität des Wassers als sehr schlecht beurteilte, da es »Auge, Nase und Mund beim Genusse derart beleidigte ${ }^{201}$ Seit den I 85 oer Jahren beklagten die Bewohner/innen des Schullerbergs wiederholt die Absenz von Wasser: r 855 beschied die Gemeinde, dass »die Kosten« einer neuen Wasserleitung »mit dem Nutzen [...] in keinem Verhältnisse stehen ${ }^{202}$ und zudem die Beitragsleistungen der Bewohner/innen deutlich übersteigen würden. I 86 I folgte ein weiterer Versuch, bei dem auch auf die Feuergefahr aufgrund des Wassermangels verwiesen wurde. Dazu wurde in der Eingabe mit Verteilungsgerechtigkeit argumentiert: Die anderen Stadtteile würden von neuer Infrastruktur wie der Gasbeleuchtung oder dem Volksgarten profitieren, der Schullerberg sei davon jedoch ausgeschlossen. ${ }^{203}$ Aber erst I 873 kam Bewegung in die Sache: Mehr als 40 Hausbesitzer/innen hatten gemeinsam mit der freiwilligen Feuerwehr eine neue Eingabe verfasst, in der man wiederum die zu geringe Wasserversorgung und die daraus resultierende Feuergefahr thematisierte und vorschlug, eine Leitung mit Donauwasser zu errichten. Bezugnehmend auf das damals noch laufende Leitungsprojekt des Unternehmens Pongratz und Moore betonte man erneut eine Benachteiligung gegenüber »den 3 flachen Linzer Stadttheilen«, schließlich bezahle man ebenso Steuern

I98 Pichler-Baumgartner, Wege, 45, 8 I, I05f. u. I I7; vgl. zur Überschwemmung im Jänner I 883: RB I 882 [sic], 77 .

I 99 Pichler-Baumgartner, Wege, 8 I ; vgl. zum Diffusionsprozess im deutschsprachigen Raum: Brown, Crisis.

200 AStL, HS 2 I2 (Kammeramt Ausgaben 1860), pag. 73; AStL, HS 237 (Kammeramt Ausgaben I870), pag 107-109; RB I879-1880, 82.

20 I Linner, Salubritäts-Verhältnisse, I 8 .

202 GRP I 855, fol. r 92 a.

203 OÖLA, Musealarchiv, HS 5 I (Materialien zur Geschichte der Stadt Linz von Ignaz Fink, undat.), pag. $670-674$. 
und Abgaben. ${ }^{204}$ Bürgermeister Wiser teilte diese Einschätzungen, verwies wortreich auf den großen Zeitaufwand und die »Beschwerlichkeit«, die mit dem Wasserbezug am Schullerberg - dem oftmaligem Wasserholen aus der Stadt - verbunden sei, und auf die latente Armut des Stadtteils, der zu diesem Zeitpunkt aus ca. ıoo Häusern mit r.80o Bewohner/innen bestand. Dass Wiser auch eine Gefährdung der Gesundheit konstatierte und Wassermangel mit Alkoholismus verband, ist wohl eher als Mittelschichtsangst vor dem social evil denn als argumentative Strategie zu sehen. ${ }^{205}$ Dennoch beschloss der Gemeinderat - wohl aufgrund der zu erwartenden Kosten - die Errichtung erst zu Beginn des Jahres 1875. In technischer Hinsicht handelte es sich um ein komplexeres Unterfangen, das durch den neu eingestellten städtischen Ingenieur, der bereits in Schweinfurt, Basel und Köln an Wasserleitungsprojekten mitgearbeitet hatte, geplant wurde. In der südlich des Schullerbergs gelegenen Sandstätte wurde eine Quelle gefasst, deren Wasser - täglich rund I.60o Hektoliter - man mit Dampfkraft in ein Reservoir pumpte und damit zuerst 6 - I883 bereits 2 I - öffentliche Brunnen versorgte (No. I in Abb. 9). Die Kosten der Struktur beliefen sich auf über 2 r.ooo fl und wurden aus der verfallenen Kaution des mittlerweile gescheiterten Wasserleitungsprojekts des Unternehmens Pongratz und Moore abgedeckt. ${ }^{206}$ Das große Fest anlässlich der Eröffnung der Wasserleitung im November I 875 lässt deutlich den symbolischen Charakter moderner Infrastrukturen und civic pride erkennen: "An den Häusern flatterten Fahnen und Blumen und Kränze schmückten die Wände«, ein »Triumphbogen wölbte sich über die Straße«, und der Bürgermeister trank aus einem »mit Blumen umkränzten Krystallbecher « Wasser aus der neuen Leitung. ${ }^{207} \mathrm{Zu}$ danken habe man nicht nur dem Bürgermeister und der Gemeindevertretung, heißt es in einem nach dem Festakt bei einem Imbiss vorgetragenen humoristischen Gedicht, sondern auch denen, die »so lang g'ren(n)t [sind] und habet bett'l't und bitt'[,] bis mir hirzt dö Brün(n) habn' in unserer Mitt'.« ${ }^{208}$

I 88 I bezeichnete man das Wasser der Leitung als ein »recht gutes«, das aber mit $20 \mathrm{kr}$ pro Kubikmeter »verhältnismäßig hohe Kosten« im laufenden Betrieb verursache. ${ }^{209}$ Schon vor der Errichtung der Leitung hatte es Ansuchen um Erweiterungen gegeben, denen man vonseiten des Gemeinderates zunächst ablehnend gegenüberstand. Bald nach der Inbetriebnahme wurden aber zahlreiche weitere öffentliche Brunnen und (gegen Bezahlung) Hauseinleitungen genehmigt, sodass sich I 890 die Zahl der Hauseinleitungen auf 45 und die der Brunnen auf 30 belief - das Versor-

\footnotetext{
204 Pichler-Baumgartner, Wege, I 24.

205 Adam, Wiser, 3 I 6.

206 Pichler-Baumgartner, Wege, I26- i 28 ; RB I879- I 880, 8of.; RB I883, 85.

207 LVB, 30. I I. I 875; vgl. Pichler-Baumgartner, Wege, $46-48$ u. I 25 f.; Adam, Wiser, 3 I 6-3 I 8.

208 Privatsammlung Paul Stöger, ohne Signatur, "Zur feierlichen Eröffnung der Wasserleitung am Schullerberge den 28. November I 875" (Abschrift 3.I 2.I 875).

209 AStL, Altakten, Sch. I 7 I ; vgl. Pichler-Baumgartner, Wege, 24 of.
} 
gungsgebiet erstreckte sich somit über die Innenstadt hinweg bis zum Donauufer und überstieg damit den Charakter einer »Teilleitung « deutlich. ${ }^{210}$

Analog dazu hatten im Dezember I 885 Hausbesitzer in St. Margarethen und entlang der Donau den Wassermangel vor Ort gegenüber dem Gemeinderat beklagt: Seitdem die städtische Wasserleitung, die von St. Margarethen aus die Hauptplatzbrunnen versorgt hatte, I 872 stillgelegt worden war und seither nur noch einen Brunnen in St. Margarethen versorgte, sei man darauf angewiesen, das Brauchwasser der Donau zu entnehmen, was aber im Winter kaum möglich sei. Die Errichtung von Brunnen sei keine Option, meist nütze man das Wasser, das über die Felsen abrinne, und erneut wurde das Argument der Ungleichbehandlung in die Diskussion eingebracht. Obgleich das städtische Bauamt von der Wiedererrichtung der Leitung abgeraten hatte - auf die Kosten und die ohnehin bald umgesetzte "allgemeine W Wasserleitung verweisend -, beschloss der Gemeinderat im Juli I 886 nach dem Gutachten eines Stadtarztes, der Handlungsbedarf konstatierte, die Umsetzung des Projekts. Ab November I 886 wurden ca. I.00o Bewohner/innen über vier Brunnen mit einer täglichen Wassermenge von bis zu 800 Hektolitern versorgt, was schlussendlich 7.400 $\mathrm{fl}$ kostete. Wie bei der Schullerberger Wasserleitung wurde auch dieses Leitungsnetz entsprechend zelebriert (»unablässige Fürsorge des Gemeinderathes allüberall«) und sukzessive erweitert, zudem stellte man - gegen Gebühr - einzelne Hauseinleitungen her. ${ }^{211}$

Als I 884 der Entschluss für die Errichtung der »Allgemeinen Wasserleitung « über eine Finanzierung durch die Stadt gefallen war, stand bereits fest, dass man Wasser aus dem Hinterland beziehen wollte. $\mathrm{Zu}$ dieser Zeit hatten schon zahlreiche Städte ihre Wasserversorgung überregional gelöst: Wien griff ab den r 86oer Jahren auf ein 8o Kilometer, Manchester ab den r $870 e r$ Jahren auf ein roo Kilometer entferntes Gebiet zurück. ${ }^{212}$ Dass man sich in Linz für den Bezug von Grundwasser nahe der Traun entschied, war Ausdruck einer gewissen Pragmatik: Nach zahlreichen Gutachten war mittlerweile klar, dass nahegelegene Quellen nicht genügend Wasser führten oder es bereits andere Nutzer vor Ort gab und dass eine Überleitung aus weiter entfernten Orten zu große Kosten verursachen würde, wie das Wiener Beispiel eindeutig bewiesen hatte. ${ }^{213}$ Noch während der Planungs- und Begutachtungsphase der "Allgemeinen Wasserleitung« erreichten den Gemeinderat zahlreiche »Anerbieten von Quellen«, die meist aus Orten des südlichen Alpenvorlandes kamen. Dass man diese Möglichkeiten nicht weiterverfolgte, hatte vermutlich vor allem finanzielle Gründe: Die Quellen lagen zwischen ${ }_{5}$ und 30 Kilometer von Linz entfernt. ${ }^{214}$ Damit blieb als Wasser-

\footnotetext{
2 Io Pichler-Baumgartner, Wege, I 28 - I33; vgl. den Leitungsplan I 892: ebd., I 32.

2 I I Ebd., 49f. u. I 44-I48; RB I 885, 2 I3-2 I 5 .

2 I 2 Brunner/Schneider, Umwelt, I98; Schott, Urbanisierung, 2 I 7.

2 I 3 Für den Bau der Wiener Wasserleitung wurde ein Kredit über 25 Millionen Gulden aufgenommen Stadler, Wasserversorgung, $30 \mathrm{r}$.

2 I 4 RB I886, I I3f.; RB I884, roo.
} 
bezugsquelle - nachdem Donauwasser mehrfach ausgeschlossen worden war - nur noch das lokale Grundwasser übrig, was bereits im Gutachten des Wiener Geologen Sueß empfohlen worden war. Aber auch hier entschied man sich für eine günstigere Variante: Die Brunnen wurden nicht - wie in einem Gutachten des Arztes Emmerich Stockhammer von I 887 vorgeschlagen - nahe der Traun (»Schörgenhub«) errichtet, sondern in "Scharlinz«, das rund 4 Kilometer von der Stadt entfernt war und unmittelbar an der Kremstalbahn lag, die für die Kohleversorgung der dampfbetriebenen Pumpanlage durchaus Relevanz hatte. Zudem war das dortige Gebiet kaum verbaut und relativ günstig zu erwerben (No. 2 in Abb. 9). ${ }^{215}$ Pragmatismus lässt auch das Gutachten von Stockhammer erkennen: Die Leitung könne später verlängert werden, wenn man wirklich Wasser aus »dem Hochgebirge« beziehen wolle. ${ }^{216}$

Im Planungsprozess der Wasserleitung waren lokale Akteure genauso wie externe Experten tätig: Auf die Errichtung von Probebrunnen folgte die Analyse des dort vorhandenen Wassers, dem schließlich alle Gutachter Unbedenklichkeit konstatierten. Dazu vernetzte sich die Stadt Linz mit anderen Kommunen, um Erfahrungen zu technischen Lösungen und den involvierten Unternehmen auszutauschen. ${ }^{217}$ Gleichrangig neben der Frage der Qualität stand die der Quantität, wobei man in dieser Hinsicht ebenso auf die Erfahrungswerte resp. Schätzungen anderer Städte zurückgriff. In Linz orientierte man sich schließlich an München, das einen Wasserbedarf von I 25 Litern pro Kopf und Tag angenommen hatte, wobei man rein rechnerisch gesehen bis zum Ende des I 9. Jahrhunderts weit unter diesem Wert blieb: I 893 wurden I 9 Liter und I 89862 Liter pro Kopf und Tag »bereitgestellt«. Zudem zielten die Linzer Planungen darauf ab, auch noch in 30 Jahren - bei angenommenen 77.000 Einwohner/innen - eine ausreichende Wassermenge zur Verfügung stellen zu können. ${ }^{218}$ Der materielle und energetische Wandel hatte sich bereits bei den beiden Teilwasserleitungen gezeigt: Die Schullerberger Leitung verfügte über eine mit einer Dampfmaschine betriebene Pumpe, und beide Leitungen nutzten mit Gusseisenrohren erstmals keine regionalen Materialien. ${ }^{219}$ Auch die "Allgemeine Wasserleitung « basierte auf fossiler Energie und auf Produkten des Industriesystems: Sie bestand aus Gusseisenrohren und verfügte über zwei Dampfpumpen (zu je 55 PS), ${ }^{220}$ die im Jahr I 896780 Tonnen Wolfsegger Braunkohle verbrauchten. ${ }^{221}$

$\mathrm{Ab}$ I 884 arbeitete man kontinuierlich an der Umsetzung der Wasserleitung: Nach dem Begutachtungsprozess wurden die Endplanungen erstellt, die Basis für ein länger dauerndes Genehmigungsverfahren waren. Mit der Erteilung der Errichtungs-

\footnotetext{
2 I 5 Pichler-Baumgartner, Wege, 76 u. 240.

$216 \mathrm{RB}$ I $887, \mathrm{I} 58$.

2 I7 Pichler-Baumgartner, Wege, 73-82; OÖLA, Musealarchiv, Sch. 4/No. 22; vgl. zu Salzburg: Ebner/

Weigl, Wasser, I07- I I 2 ; vgl. auch allgemein Lenger, Metropolen, I62f.

2 I 8 Pichler-Baumgartner, Wege, I75 u. I77; vgl. Heller, Wasserversorgung, $44 \mathrm{f}$.

2 I9 RB I879-1980, 80f.; RB I88I, 70.

220 Heller, Wasserversorgung, 48f. u. 55.

22 I RB I896, I 70; vgl. Jenner, Monopoly, 22 I.
} 
genehmigung Anfang r 89 I begann die eigentliche Bauphase, die Finanzierung über einen Kredit bildete nun kein Problem mehr. ${ }^{222}$ Wenig überraschend bildete die Fertigstellung der Wasserleitung im Mai I 893 ein Ereignis, das die Stadtverwaltung entsprechend inszenierte: Regionale Prominenz wurde mit einem »Separatzug" der Kremstalbahn nach Scharlinz gebracht, um - wie es Bürgermeister Wimhölzl formulierte - an diesem »Gedenktag « für die Stadt teilzunehmen, denn nun würde »die klare Flut reinen, kühlen Wassers unsere Stadt von einem Ende bis zum anderen durchströmen, allen Bewohnern gleich [...] der erfrischende Trunk die Erhaltung der Gesundheit und des Lebens«, dazu Brauchwasser und Löschwasser zugänglich gemacht. ${ }^{223}$ Auch in finanzieller Hinsicht zeichnete die Stadt bereits zwei Jahre später ein überaus positives Bild: Es sei zwar »mit der Wasserleitung kein Geschäft gemacht» worden, gleichzeitig habe sich »aber auch finanziell kein Schaden« ergeben, ohnehin »soll [...] die Wasserleitung kein gewinnbringendes Object sein, bedeute es doch schon einen Gewinn, daß eine Institution allerersten Ranges geschaffen wurde, welche in jeder Hinsicht entspreche und der Gemeinde zur Ehre gereiche, da sie auf die Wasserleitung stolz sein könne «. ${ }^{224}$ Interessanterweise entstand im Linzer Stadtzentrum - abgesehen von der I 894 erfolgten Aufstellung eines ehemaligen Hauptplatzbrunnens am Marktplatz (dem späteren Hessenplatz) 225 - kein demonstrativer Repräsentativbrunnen, wie etwa der als »Wasserkunst-Object« konzipierte »Hochstrahlbrunnen« am Schwarzenbergplatz in Wien. ${ }^{226}$ Vermutlich ist auch dies als Pragmatik und Ausdruck der Sparsamkeit zu werten, da ein mit gepumptem Grundwasser betriebener Springbrunnen Energie benötigte und damit laufende Kosten verursachte.

Relevant ist die Frage nach der Zugänglichkeit dieser neuen Infrastruktur, also ob tatsächlich »allen Bewohnern gleich« - wie der Bürgermeister bei der Eröffnung der Wasserleitung betont hatte - eine Nutzung ermöglicht wurde. In Wien hatte man in den I86oer Jahren angekündigt, die neue Wasserversorgung bis »in die äußersten Asyle der Armuth« zu führen, ex post lässt sich für Wien in sozialer Hinsicht jedoch keine Gleichverteilung feststellen. ${ }^{227}$ In Linz gab es - anders als bei der Kanalisation keine Anschlusspflicht, womit man möglicherweise auf die Kritik der r87oer und I $880 e r$ Jahre reagierte, aber dennoch lässt die Entwicklung des Netzes die Intention einer Vollversorgung erkennen. I 894 hatte man bereits die östliche Peripherie an der Donau erreicht und bis I 899 ein 55 Kilometer langes Leitungsnetz etabliert, das sogar einzelne Fabriken in den Vororten versorgte (vgl. Abb. 9). Verfügten r 893 30 Prozent der Häuser (inkl. der Vororte) über Anschlüsse, waren es I 898 schon 54 Prozent. Ver-

\footnotetext{
222 Pichler-Baumgartner, Wege, 76 u. 244; vgl. zu den verschiedenen Bauabschnitten: Heller, Wasserversorgung, $76-79$.

223 RB I 892, 307; vgl. Heller, Wasserversorgung, 79-82.

$224 \mathrm{LVB}, 6.9 .1895$; vgl. RB I 895, $203 \mathrm{f}$.

225 Kreczi, Linz, 29; RB I 895, 205.

226 Stadler, Wasserversorgung, 296.

227 Brunner/Schneider, Umwelt, 198 - 200.
} 
glichen mit Graz, wo ein Unternehmen eine Wasserleitung errichtet hatte, sei dies wie Luisa Pichler-Baumgartner festgestellt hat - eine rasche Expansion gewesen. ${ }^{228}$ Es sei auch kein Ausschluss der eingemeindeten Vororte festzustellen, man habe obwohl sich infolge der geringeren Besiedlungsdichte höhere Aufschließungskosten ergeben hätten - den Hausbesitzer/innen resp. Nutzer/innen keine höheren Kosten verrechnet und zudem wurde bei der Gestaltung der Tarife wiederholt die »Gerechtigkeit « betont. ${ }^{229}$ Bei einem genaueren Blick zeigen sich aber Grenzen der Gerechtigkeit, die vor allem finanzielle Gründe hatten: Die Landesbehörde hatte 1892 bei der Genehmigung der Benützungsbedingungen der Wasserleitung »Zum Zwecke einer reichlichen Benützung der Wasserleitung [...] die Aufstellung möglichst vieler öffentlicher (Auslauf)Brunnen, namentlich in den ärmeren Stadtheilen« vorgesehen, was jedoch vonseiten der Stadt - zumindest in der Planungsphase - nur begrenzt beachtet wurde: Die »Versorgung der Stadt Linz mit Wasser« solle, so das Wasserleitungskomitee I 893, "nicht durch die Abgabe des Wassers aus öffentlichen Brunnen[,] sondern durch den directen Anschluss der Häuser mittelst Privatleitungen an die allgemeine Wasserleitung [...] geschehen «. ${ }^{230}$ Auch im Hinblick auf den individuellen Zugang zu neuen Annehmlichkeiten, die mit den Wasseranschlüssen verbunden waren, wie etwa WCs oder Badezimmer, zeichnet sich mitunter sogar innerhalb der Häuser eine sehr ungleiche Verteilung ab. ${ }^{231}$ Somit bestand die alte Praxis, »das Bad in die Wohnung kommen« zu lassen, selbst in bürgerlichen Haushalten teilweise bis ins frühe 20 . Jahrhundert fort. ${ }^{232}$

Die Frage nach dem Weiternutzen der existenten Infrastrukturen ist schwer zu beantworten: Insgesamt lassen sich eine eher langsame Substitution der älteren Wasserinfrastrukturen und eine zumindest zeitweise Parallelität beobachten, wobei die verzögerte Umsetzung der "Allgemeinen Wasserleitung" in einem rascheren infrastrukturellen Wechsel resultiert zu haben scheint. Ende der i $870 e r$ Jahre waren noch I 9 öffentliche Brunnen (fast alles Pumpbrunnen) in Betrieb, darunter auch am Hauptplatz ein Grundwasserbrunnen, ${ }^{233}$ nachdem dort die 2 Röhrenbrunnen - in Antizipation der neuen Wasserleitung - bereits I 872 abgetragen worden waren. ${ }^{234}$ Die städtischen Brunnen wurden bis zur Errichtung der »Allgemeinen Wasserleitung" genutzt und bei Bedarf auch modernisiert: Am Marktplatz stattete man den dortigen Pump-

\footnotetext{
228 Pichler-Baumgartner, Wege, I 52 - I 59.

229 Ebd., I 88 u. I 97-200.

230 Ebd., I 7 I.

23 I Ebd., I6I-r64.

232 Puffer, Heimatstadt, I 74 f.

233 RB I876- I878, 67; vgl. AStL, HS 237 (Kammeramt Ausgaben r 870), pag 107- ro9.

234 Kreczi, Linz, 29 GRP г872, fol. i8ob u. i8 1a; RB г 895, 205; Müller, Brunnen, I4f. Ein Brunnen wurde I 979 wieder am Hauptplatz aufgestellt, der zweite befindet sich seit den I89oer Jahren am Hessenplatz.
} 


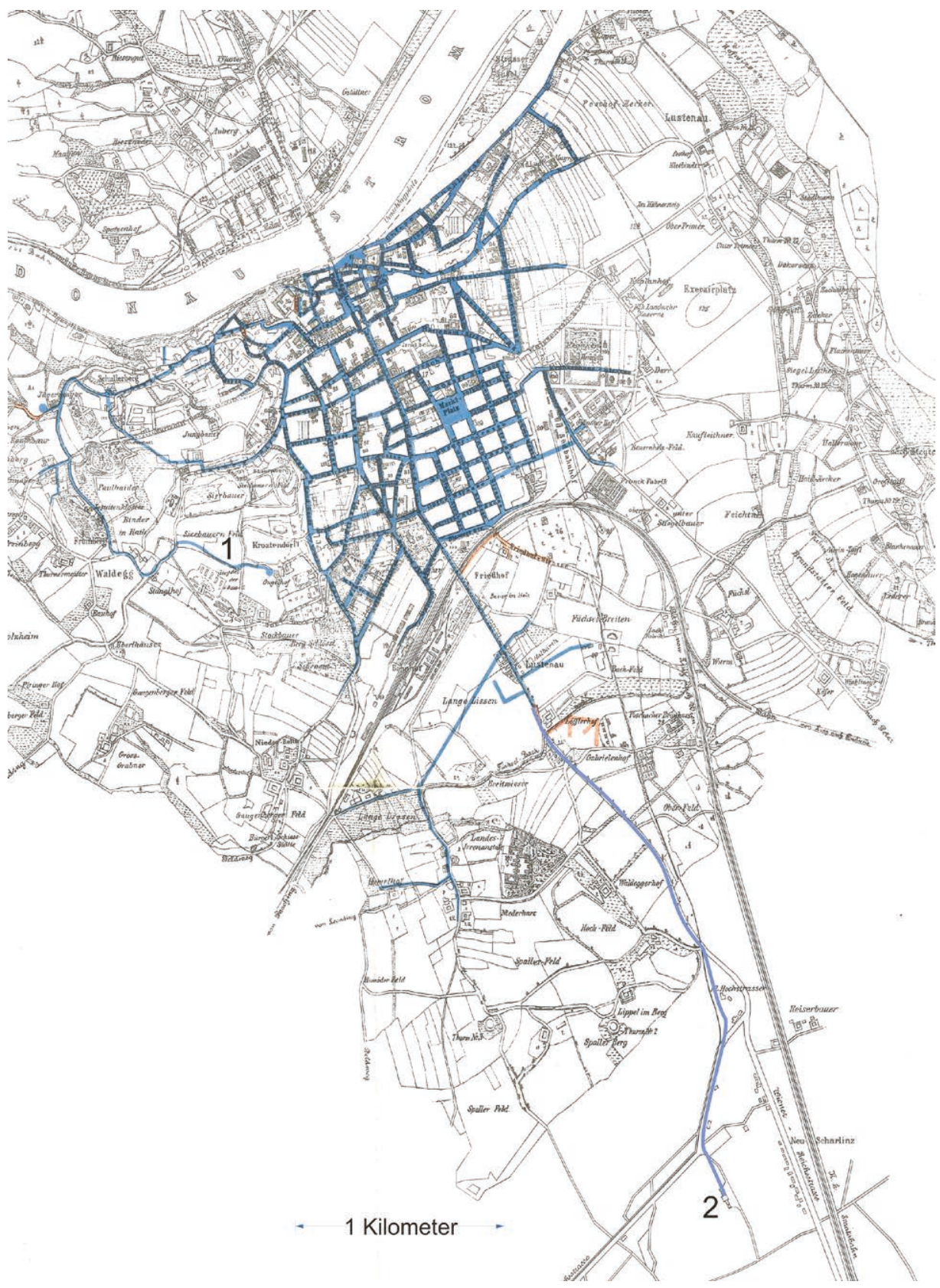

Abb. 9: Das Netz der "Allgemeinen Wasserleitung" - 1 bezeichnet die Schullerberger Wasserleitung, 2 das Wasserwerk in Scharlinz, 1899 
brunnen I 882 mit einem Benzinmotor aus. ${ }^{235}$ Aber bereits I 895 wurde angeordnet, die Pumpbrunnen am Hauptplatz und in der Pfarrgasse aufzulassen resp. an die Wasserleitung anzuschließen, auch die ab I 894 wiederum tätige städtische Brunneninspektion ist als Druckmittel für den Ersatz der alten Infrastrukturen zu sehen. ${ }^{236}$ Dabei variierten Druck und Geschwindigkeit des Infrastrukturwechsels durchaus: Während die Schullerberger Leitung I 893 mit der "Allgemeinen" Wasserleitung verbunden wurde, weil man das alte Reservoir am Schullerberg nutzte (No. I in Abb. 9), blieb die Margarethener Leitung bis I 902 bestehen. ${ }^{237}$ Schon die alte Schullerberger Leitung hatte eine Zeit lang neben der neuen Leitung bestanden: Als der Gemeinderat vor Eröffnung der neuen Leitung Hausbesitzer am Schullerberg befragte, gaben diese an, dass »die Beibehaltung der alten Wasserleitung als Reserve sehr wünschenwerth« sei, was dann auch der Gemeinderat unterstützte, zudem seien die »bestehende[n] Pumpbrunnen [... ] jedenfalls beizubehalten «. Die alte Leitung wurde erst I 879 aufgelassen. ${ }^{238}$ Wenngleich sich eine Persistenz der Brunnenerrichtung und nutzung - wenig überraschend - eher für die Peripherie abzeichnet, gibt es auch Beispiele für zentrumsnahe Stadtteile. Hinweise dazu finden sich im Kontext der Anschluss- und Wassertarifsdiskussionen, die gleichzeitig Logiken der Weiternutzung zeigen. I 894 argumentierte ein Hausbesitzer in der Schillerstraße, dass er nur Anschlüsse für die oberen Stockwerke herstellen lasse, während seine Mieter im Erdgeschoss auf den Hausbrunnen angewiesen blieben: »Mein seit vier Jahren bestehender Brunnen liefert ein sehr gutes Trinkwasser«, die Wasserleitung habe nur für die oberen Stockwerke eine »Bezugsbequemlichkeit«. »Ebenerdig wohnen Partheien, welchen es ohnedieß schwerfällt, den Jahreszins nebst den Zinskreuzern zu zahlen und bar welcher eine jede weitere Zinserhöhung ein vermehrtes Absparen vom Munde bedeutet. Wie kommen solche arme[n] Leute dazu, für Etwas Geld auszulegen, wofür sie gar nichts genießen? «239 Auch wurden Hausbrunnen offenbar situativ reaktiviert - etwa wenn die Wasserleitung eingefroren war, was, wie sich ein zu Beginn der I 88oer Jahre geborener Linzer erinnert, »oft« passiere. ${ }^{240}$ Die Reaktivierung des eigenen Hausbrunnens in der zentrumsnahen Herrengasse habe in drei Typhusfällen resultiert. ${ }^{241}$

\footnotetext{
$235 \mathrm{RB}$ I $882, \mathrm{I} 25$.

236 RB I 895, 205; RB I 898, 334 .

237 Pichler-Baumgartner, Wege, 153.

238 GRP I 875 , fol. 35 9b-36ob; RB I879- 1880, 82.

239 Pichler-Baumgartner, Wege, 164.

240 Puffer, Heimatstadt, 175.

24 I Ebd., I63.
} 


\section{Energie und Biomasse}

\section{Omnipräsenz des Brennholzes}

Holz war eine der entscheidenden Ressourcen der vormodernen Stadt: Einerseits war es als Bau- und Werkholz überaus relevant, andererseits blieb Holz bis in die zweite Hälfte des I 9. Jahrhunderts der wichtigste Primärenergieträger. ${ }^{1}$ Es ist nicht wirklich möglich, den Linzer Bedarf an Brennholz für das I 8. Jahrhundert abzuschätzen, da es nur punktuelle Hinweise in den Quellen gibt, die zudem selten erkennen lassen, auf welche Scheiterlänge sich die Klafterangabe bezog: In den I 75 oer Jahren schätzte das städtische Holzamt den Linzer Verbrauch auf rund 30.000 Klafter, auf den Holzplätzen an der Oberen und Unteren Donaulände hatten in den I 770 or Jahren insgesamt ca. r. 800 Klafter Holz Platz. ${ }^{2}$ Im I 9. Jahrhundert finden sich - ab den I 83 oer und I $840 e r$ Jahren - zwar erste zeitgenössische Statistiken, aber es ist fraglich, ob sie tatsächlich den städtischen Gesamtverbrauch abbilden. I834 wurde für rund ro.ooo Klafter Brennholz (der Klafter vermutlich mit 36-zölligen Scheitern gerechnet) Verzehrsteuer bezahlt, dazu wurden immerhin fast 300 Tonnen Holzkohle in der Stadt und den Vorstädten verbraucht (vgl. Tab. 9). In einer neueren Masterarbeit wird die r 834 konsumierte Menge an Brennmaterial mit 34.000 Tonnen angegeben, ${ }^{3}$ wobei nur für rund I 3.800 Tonnen Verzehrsteuer bezahlt wurde. ${ }^{4}$

Tab. 9: Holzeinfuhr nach Linz 1834 gemäß Verzehrsteuer

\begin{tabular}{lccc}
\hline & Menge & Preis pro Einheit in fl CM & Gesamtwert in fl CM \\
\hline Hartholz & 2.257 Klafter & 5 & 11.285 \\
Weichholz und »Büntelholz« & 7.874 Klafter & 3 & 23.622 \\
Holzkohle & 5.225 Zentner & 5 & 26.125 \\
\hline
\end{tabular}

Quelle: Tafeln zur Statistik 7 (1834), unpag.

I Reith, Umweltgeschichte, 67f., I04- I07 u. I I 5- I20; vgl. als neuere Überblicke: Charruadas/Deligne, Cities, Zumbrägel, Holzströme u. Kander/Malanima/Warde, Power, 56-6o.

2 AStL, Altakten, Sch. 52 ; vgl. zur Klafterproblematik: Mühlpeck/Sandgruber/Woitek, Index, 67 If. u. das Kap. Maßeinheiten und Währungen.

3 Dabei basiert diese Aussage offenbar auf den Verzehrsteuerdaten, woher der nicht unerhebliche Rest kommt, ist aber unklar - Fuchs, Produktion, 64.

4 Wenn man - den plausiblen Annahmen Roman Sandgrubers folgend - den Klafter 36-zölliges (d.h. 95 Zentimeter langes) Fichtenholz zu I,2 Tonnen und Buchenholz zu r,8 Tonnen rechnet - vgl. Kap. Währungen und Maßeinheiten. 
Aus den r 0.00o Klaftern Brennholz ergebe sich ein jährlicher Pro-Kopf-Verbrauch von rund einem halben Klafter Brennholz (dies auch die Annahme bei Sandgruber vgl. Tab. I3), was als ein zu geringer Wert erscheint: Im Frühjahr und im Sommer I 747 lieferte die Stadt Linz für die knapp über hundert in der Stadt anwesenden Offiziere täglich jeweils einen halben Klafter Brennholz, was über das Jahr gerechnet bereits eineinhalb Klafter pro Kopf ergeben hätte, ${ }^{5}$ und I 833 schätzte man für den »Franziszeischen Kataster« den Jahresbedarf für zehn Personen auf I 6 Klafter (40-zölliges) Weichholz. ${ }^{6}$ Brennholzdeputate deuten ebenso auf höhere Werte hin, wenngleich die Deputate nicht auf Einzelpersonen, sondern auf Haushalte abzielten: i 765 erhielt der Verwalter des Deutschordenshauses jährlich 3 Klafter hartes und 3 Klafter weiches Holz, ${ }^{7}{ }_{1} 830$ ein Krankenwärter jährlich 3 Klafter weiches und I Klafter hartes Holz, ${ }^{8}$ für die einzelnen Beschäftigten der Landstände sind Deputate verzeichnet, die im frühen I 8. Jahrhundert von 6 bis 60 Klaftern reichten, was vermutlich aber die Beheizung der Dienstorte mit einschloss. ${ }^{9}$ Angaben zu größeren Haushalten und Institutionen verdeutlichen die substantiellen Mengen an Brennholz, die städtische Nutzer/innen verbrauchten: In den Rechnungen des Deutschordenshauses verzeichnete man I 720 den Bezug von insgesamt fast 20 Klaftern Brennholz, ${ }^{10}$ das Kremsmünsterer Freihaus in der Herrenstraße verfügte über ein »doppeltes« Holzgewölbe, das 45 Klafter Holz fasste, ${ }^{11}$ und in den 173 oer Jahren waren rund 200 Klafter Holz im Garten des Ursulinenklosters gelagert. ${ }^{12}$ I 7 I 8 benötigten die Landstände für die Holzdeputate und das Heizen der Amtsräume $524 \mathrm{Klafter}^{13}$ und ${ }_{75} 6582 \mathrm{Klafter} \mathrm{Brennholz,}{ }^{14}$ für das Linzer Rathaus wurden in einem Jahr - zwischen November I 806 und Oktober I 807 I 6 Klafter Holz angekauft. ${ }^{15}$

Dabei war der häusliche Holzverbrauch »keine feststehende Größe«, wie Joachim Radkau angemerkt hat. ${ }^{16}$ Witterungsbedingt konnte die Heizperiode länger oder kürzer ausfallen, ${ }^{17}$ auch divergierten die individuellen Nutzungsusancen: Täglich sind 20 Öfen und die Küche zu heizen«, beklagte der Verwalter des Lambacher Stiftshauses die Einquartierung französischer Soldaten im Jänner I 80 I, »dabei lassen die Leute

\footnotetext{
5 LR BIIA40, Reg. I9694 (Io8f.).

6 Bohdanowicz, Vorstädte, Bd. 2, I802; in Klagenfurt wurden im I8. Jahrhundert eineinhalb bis zwei

Klafter pro Kopf angenommen - vgl. Johann, Holzversorgung, 84.

7 Dies explizit ohne Beheizung der allgemeinen Räume - LR CIIIHI -3, Reg. Io62 (699-70I).

8 LZ/AB, 4.I.I830; vgl. ähnliche Angaben: LZ/AB, I4.9.I8 8 u. LZ, 29.10.1842.

9 LR BIIA 44 , Reg. I 4380 (I 44); vgl. LR BIIA 24 , Reg. I 7 I I 9 (If.).

Io $\mathrm{LR} \mathrm{CIIIH}_{4}, 80 \mathrm{I}-822$.

II LR BVI2, Reg. I I 27 (6I-69).

I2 LR Eib, Reg. 1565 (58f.).

${ }_{3} 3$ LR BIIAr 4, Reg. I4380 (I44); vgl. LR BIIA23, Reg. I6950 (3 If.).

I4 LR BIIA24, Reg. I7II 9 (If.).

I5 AStL, HS i28 (Kammeramtsrechnung I 807), fol. 85 a u. 86a.

I6 Radkau, Rätsel, 59.

I7 Vgl. LR BIIA5, Reg. 6047 (38); LZ, I.2.I799.
} 
Türen und Fenster offen und die Zimmer müssen doch sehr warm sein «. ${ }^{18}$ Verbraucher/ innen, die für das Brennholz bezahlen oder darüber Rechenschaft ablegen mussten, waren üblicherweise eher auf einen sparsamen Umgang bedacht. Eine Sparmöglichkeit bildete die Verwendung von Winterfenstern oder von Sparöfen ${ }^{19}$ und das NichtHeizen einzelner Räume. ${ }^{20}$ Im Jänner r 808, so vermerkt die Chronik des Ursulinenklosters, hätten die Schwestern zur »Holzersparnis [...] wie im Vorjahr« die Näh- und Handarbeiten im Krankenzimmer durchgeführt, ${ }^{21}$ bereits 1802 hatte man im dortigen Kloster für das Wäschetrocknen einen »Sparherd« aufgestellt, »der viel weniger Holz braucht, als der bisherige « Ofen. ${ }^{22}$ Dafür ausschlaggebend waren augenscheinlich die zu Beginn des I 9. Jahrhunderts - im Kontext der allgemeinen Teuerung - angestiegenen Brennholzpreise.

In der Stadt und den Vorstädten von Linz gab es im I 8. Jahrhundert nur kleine Waldgebiete, auch verfügte die Stadtgemeinde nicht über eigenen Waldbesitz. Beim Kapuzinerkloster befand sich das »Wäldl«, das aber vermutlich nicht einmal den Eigenbedarf des Klosters abdecken konnte $:^{23}$ Für das "Josephinische Lagebuch « wurde I 788 der Ertrag des Kapuzinerwäldchens mit rund zweieinhalb Klaftern Weichholz pro Jahr angegeben, der gesamte Jahresertrag der Unteren Vorstadt mit i 85 Klaftern Weichholz. ${ }^{24}$ In der Oberen Vorstadt lagen kleinere Waldstücke an den abschüssigen Hängen des heutigen Froschbergs, die zu den dortigen Bauernhöfen und Gartenhäusern gehörten und genauso extensiv genutzt wurden. ${ }^{25}$ Weitere Waldflächen gab es am Freinberg, in den Augebieten und nördlich der Donau, doch selbst größere stadtnahe Bauernhöfe hatten in der Regel keinen eigenen Wald. Dieses sehr begrenzte Brennholzangebot vor Ort dokumentieren auch die Kataster der I 78 oer und I $820 e r$ Jahre (vgl. Tab. го u. I I).

Der »Franziszeische Kataster« vermaß nicht nur Flächen und schätzte Erträge ab, sondern er gewährt ebenso Einblicke in Praktiken der Waldnutzung. Auf den kleinen Waldflächen der Oberen Vorstadt wuchs Nadel- und kein Laubholz, vor allem Tannen und nur wenige Fichten und Föhren. Die »wenigen Waldungen« würden, so die Auskunft der Gemeinde, »mit äusserster Schonung « für den Eigenbedarf verwendet, dennoch seien alle Waldbesitzer auf den Zukauf von Brennholz angewiesen. Viehweide im Wald bestehe nicht, als »Kopfholz« nutze man die Weiden in den Gräben und bei

I8 LR BIV, Reg. 907 (354f.).

I9 Ebd., Reg. 528 ( 193-202); AStL, HS r 108 (Stadtratsprotokoll r 827), fol. 233b; vgl. OÖLA, Kartenund Plänesammlung, XII/70.

20 LZ/IB, 24.5.I839; vgl. Kander/Malanima/Warde, Power, ro If.

2I LR Erb, Reg. 2220 (I64).

22 Ebd., Reg. 2120 (149).

23 LR Eia, Reg. Ioor (I89).

24 LR Eıf, Reg. 448 (I84f.); Bohdanowicz, Vorstädte, Bd. I, 39.

25 Schrank/Moll, Briefe, 22. 
Tab. 10: Waldflächen in Linz und den Vorstädten, 1780er bis 1870er Jahre

\begin{tabular}{lccc}
\hline Nutzung & $\begin{array}{c}1780 e r \\
\text { ha }\end{array}$ & $\begin{array}{c}\text { 1830er/1842 } \\
\text { ha }\end{array}$ & ha \\
\hline Hochwälder $^{\text {t }}$ & & 52 & 1 \\
Niederwälder & 154 & 14 & 3 \\
Wiesen mit Holznutzung & & 1 & 3 \\
Hutweiden mit Holznutzung & & & 5 \\
in \% der Gesamtfläche & 9 & 4 & 1 \\
\hline
\end{tabular}

Quelle: Eigene Berechnung basierend auf OÖLA, Josephinisches Lagebuch, Linz Stadt HS 190; OÖLA, Josephinisches Lagebuch, Linz Obere Vorstadt HS 191; Bohdanowicz, Vorstädte, Bd. 1, 38f.; OÖLA, Franziszeischer Kataster, No. 534; Foltz, Statistik, 4 of.

a im Kataster für die Untere Vorstadt als Wald »1. Klasse " bezeichnet

b im Kataster für die Untere Vorstadt als Wald »2. Klasse«, im Lagebuch nur "Wald« verzeichnet

Tab. 11: Brennholzerträge im Linzer Raum (gerundet), 1780er und 1820er Jahre

\begin{tabular}{lcccc}
\hline & $\begin{array}{c}\text { 1780er hartes } \\
\text { Holz/Klafter }\end{array}$ & $\begin{array}{c}\text { 1780er weiches } \\
\text { Holz/Klafter }\end{array}$ & $\begin{array}{c}\text { 1820er hartes } \\
\text { Holz/Klafter }\end{array}$ & $\begin{array}{c}\text { 1820er weiches } \\
\text { Holz/Klafter }\end{array}$ \\
\hline Untere Vorstadt (St. Joseph) & - & 185 & - & 170 \\
Obere Vorstadt (St. Matthias) & 2 & 134 & 2 & 135 \\
St. Peter & & & 3 & 102 \\
Kleinmünchen & & & 3 & 99 \\
Leonding & & & 2 & 297 \\
\hline
\end{tabular}

Quelle: Bohdanowicz, Vorstädte, Bd. 1, 38; Bohdanowicz, Vorstädte, Bd. 2, 45f.; Pillwein, Beschreibung, 57

den Bächen, aber auch hier müsse das meiste zugekauft werden. ${ }^{26}$ Ähnliches wurde für die Untere Vorstadt festgestellt: Es gebe nur »zerstreute Fichten, Tan(n)en, und etwas Föhren«, dazu Auwald. Der Hausbedarf an Brennholz könne nicht über den Waldbesitz abgedeckt werden, zudem würden zur Gewinnung von Werk- und Bauholz nur wenige Bäume gefällt, »wie sie zu der vorgefallenen Hausreparatur nothdürftig sind «. Der Wald werde für einen möglichen Unglücksfall »geschont«, man entnehme jährlich pro Joch nur I Klafter Holz. Es gäbe keine Neupflanzungen, die Waldverjüngung werde »eigenem Selbstanflug überlassen «. ${ }^{27}$

Dennoch waren - wenn man sich die verfügbaren Daten ansieht (vgl. Tab. Io) - die Waldflächen im stadtnahen Raum innerhalb von roo Jahren deutlich kleiner gewor-

26 OÖLA, Franziszeischer Kataster, No. 534 (Operat 2, Linz Obere Vorstadt, Beantwortung Fragen Gemeinde Waldegg, I3.I.I83I).

27 Ebd. (Operat 2, Linz Untere Vorstadt, Beantwortung Fragen Gemeinde Lustenau, 25.r.r 831). 
den. Ex post wurde dafür vor allem das Militär verantwortlich gemacht: Das - wenngleich heute noch existierende - Kapuzinerwäldchen sei durch französische Soldaten »ruiniert « worden, ${ }^{28}$ auch am Pöstlingberg habe es aufgrund der französischen Schanzarbeiten Abholzungen gegeben, wodurch aber, wie in einer I 8 I 2 erschienenen Stadtbeschreibung pragmatisch festgestellt wurde, »die Aussicht freyer wurde«. ${ }^{29} \mathrm{Ab}-$ holzungen resultierten ebenso aus der Errichtung der »Maximilianischen« Befestigungstürme in den I 83oer Jahren, wobei es in diesem Fall primär um Flächen und nicht um die Gewinnung von Brennholz ging: ${ }^{30}$ Holz für das Brennen der Ziegel in den Linzer Ziegeleien bezog man aus Passau, Neuhaus und Gmunden, nur geringe Mengen kaufte man vor Ort bei Bauern ein, teilweise wurden Wolfsegger Braunkohle und Mauthausener Steinkohle genutzt. ${ }^{31}$ Auf andere punktuelle Abholzungen, die ebenso im Kontext der Umnutzung von Flächen gesehen werden sollten, deutet auch das Kartenmaterial des i 9. Jahrhunderts hin.

Die größten zusammenhängenden Waldgebiete im Umland der Stadt bestanden zu Beginn des r. Jahrhunderts nördlich der Donau, am Pfenningberg (östlich von Linz - vgl. Abb. I) und am westlich von Linz gelegenen Kürnberg. Der Kürnbergerwald wurde in den I 740er Jahren vom Stift Wilhering erworben und umfasste - in den I 8 2oer Jahren - rund I 2 Quadratkilometer. Aber auch dieses Holz trug vermutlich nichts zur Linzer Brennholzversorgung bei: Im Kürnbergerwald wurde der Großteil der jährlich geschlagenen rund r. ıoo Klafter Holz (840 Klafter) von lokalen Nutzern, der Rest wohl vom Kloster (und seinen Dependancen) selbst verbraucht, ${ }^{32}$ für Holzlieferungen aus den Wäldern am Pfenningberg gibt es keine Hinweise.

Linz war vermutlich weitgehend von überregionalem Holzbezug abhängig. Dafür lag Linz günstig: Mit der Donau und der Traun verfügte die Stadt über vergleichsweise preiswerte Transportwege für Brennholz, zudem gab es in beiden Fällen flussaufwärts waldreiche Gebiete. Dass Brennholzpreis zu einem erheblich Teil aus den Transportkosten bestand (wobei der Landtransport erheblich teurer war), zeigt ein Beispiel aus den I 73oer Jahren: Das Freihaus Kremsmünster bezog aus dem oberösterreichischen Alpenvorland (möglicherweise aus der Gegend nahe Scharnstein) sechs Flöße mit Buchenholz, wobei man vor Ort für die Flöße, die in Linz wohl ebenso zu Brennholz verarbeitet wurden, 2 fl und für die Ladung 2 I fl bezahlt hatte, der Wassertransport auf der Traun bis Zizlau und die Maut in Wels hatten i I fl $30 \mathrm{kr}$ gekostet, schließlich mussten noch I $8 \mathrm{kr}$ für den Wächter in Zizlau und I 2 fl für den Transfer von dort bis ins Linzer Freihaus bezahlt werden. ${ }^{33}$ Auf der Donau wurde das Brennholz mit Schiffen und Flößen befördert, z.B. mit den »Kehlheimer« Schiffen, die I 40 Klafter

28 LR EIf, Reg. 5 I 4 (205f.).

29 Heinse, Linz, I. Aufl., ro9; vgl. Pillwein, Beschreibung, 34I.

30 Fink, Geschichte, I 26.

3I Hillbrand, Türme, 80 .

32 LR BVIII 2 , Reg. 808 (38f.); LR BVIII 2 , Reg. 885 (73f.).

33 LR BVI2, Reg. I 228 ( I79); vgl. Neweklowsky, Schiffahrt, Bd. r, 6 6 4f. 
weiche oder I Io Klafter harte Scheiter fassten, ${ }^{34}$ ein städtischer Holzplatz, an dem das ankommende Holz angeboten werden musste, bestand an der Donaulände schon vor dem I 8. Jahrhundert. ${ }^{35}$ Haushaltsrechnungen aus der ersten Hälfte des I 8. Jahrhunderts deuten auf einen Bezug über die Donau hin, ${ }^{36}$ und sie verweisen gemeinsam mit anderen punktuellen Angaben regelmäßig auf das obere Mühlviertel und Bayern als Herkunftsregion des Brennholzes. ${ }^{37}$ Auch für die städtische Ziegelproduktion wurde in dieser Zeit offenbar Holz aus dem Mühlviertel verwendet. ${ }^{38}$ Seltener ist der Bezug aus dem südlichen Alpenvorland verzeichnet, wenngleich man von dort wiederholt Holzkohle ankaufte. ${ }^{39}$

Für die zweite Hälfte des i 8. Jahrhunderts und die erste Hälfte des i 9. Jahrhunderts scheinen ähnliche Holzbezugsgebiete auf, wobei ab den I 78 oer Jahren regelmäßig Brennholz aus dem Kobernaußerwald im Innviertel (das ab I 779 zu Österreich gehörte) erwähnt wurde. Das Holz aus dem staatseigenen Kobernaußerwald wurde auf der Mattig bis zum Holzplatz Hagenau (bei Braunau) getriftet und dann auf Inn und Donau mit Schiffen oder Flößen weiter flussabwärts gebracht. ${ }^{40}$ Dennoch kam ein erheblicher Teil des Brennholzes aus dem oberen Mühlviertel, einem »waldreiche[n], wilde[n] und romantische[n] Land «, das - wie in einem englischen Reisebericht aus den I 77oer Jahren eingeschätzt wurde - »den Einwohnern aber nichts liefert als Brennholz« ${ }^{41}$ Größere Waldgebiete im Mühlviertel wurden mit der Errichtung des Schwarzenberger Schwemmkanals ab dem Ende der i78oer Jahre erschlossen. Der Schwemmkanal stellte über die Große Mühl eine Verbindung mit der Donau her und damit - obwohl man vor allem an einen Absatz in Wien gedacht hatte - konnte auch Linz versorgt werden: Ab I795 existierte sogar ein eigener Holzverkaufsplatz der schwarzenbergischen Forstverwaltung an der Linzer Donaulände. ${ }^{42}$ Zeitungsanzeigen aus den r 83 oer Jahren erwähnen vor allem diese Holzbezugsregionen, dazu taucht in dieser Zeit auch Brennholz aus dem Bayerischen Wald (vor allem über die Ilz-Trift) auf. ${ }^{43}$

34 Donau in Oberösterreich, 3 I ; vgl. Neweklowsky, Schiffahrt, Bd. I, I 78 - I 80.

35 AStL, Altakten, Sch. 52; LR BIIA 37 , Reg. I 9274 (I 28 - I42); vgl. OÖLA, Josephinisches Lagebuch, HS $9_{2}$ (Linz Untere Vorstadt).

$36 \mathrm{LR} \mathrm{CIIIH}_{4}, 879-886$.

37 LR BIIG8, Reg. 563 I (176); LR BIIG8, Reg. 6020 (230); LR BIIB I, Reg. 67 (63-65); AStL, Altakten, Sch. 52 .

38 AStL, HS 389 (Bauraittung $175^{\circ}$ ), unpag.

39 LR BIIG8, Reg. 6I I5 (247); LR BIIG8, Reg. 6I 29 (249); LR BIIG8, Reg. 6I 3 I (250) .

40 AStL, HS 1087 (Stadtratsprotokoll I800), fol. 293a; LZ, 3.7.1786; LZ, 7.I 2.1807; LR BIIG7, Reg. 4468 (205f.); LR Eıb, Reg. 2 I 83 (г60); vgl. Statistischer Bericht I876, I39; Neweklowsky, Schiffahrt, Bd. 3, 546 u. 559 f. u. allgemein: Zumbrägel, Holzströme, 346-349.

4I Burney, Tagebuch, I4I.

42 Záloha, Geschichte, 257-264; Fuchs, Produktion, 78f.; Hoffmann/Meixner, Wirtschaftsgeschichte, Bd. I, 296; Neweklowsky, Schiffahrt, Bd. 3, 580-582.

$43 \mathrm{LZ/AB}, 27.4 .1832$; LZ/AB, 25.7.1834; LZ/AB, I5.4.I836; LZ/AB, Ir.8.1837; vgl. Neweklowsky, Schiffahrt, Bd. 3, 577 . 
Insgesamt scheint die Holzversorgung von Linz relativ problemlos funktioniert zu haben, reale Knappheiten gab es vermutlich selten und nur punktuell: Speziell die Kombination von Krise und verstärkter Nachfrage, etwa infolge eines kalten Winters, scheint im Auftreten derartiger Knappheiten resultiert zu haben, wie das Beispiel der Belagerung von Linz im Jänner I 742 nahelegt. ${ }^{44}$ Der Winter I794/I795, der im Dezember und Jänner überdurchschnittlich kalt war, ${ }^{45}$ habe, so ein ständischer Beamter, nicht nur in Teuerung, sondern in einem »außerordentlichen Brennholzmangel« resultiert, sodass »kein einziges Scheit mehr an der Lände« gewesen sei. Aber wenige Zeilen später folgt die Relativierung: Man habe doch noch Brennholz beziehen können (vgl. unten). ${ }^{46}$ Explizite Hinweise auf einen tatsächlichen Mangel sind in den Quellen insgesamt kaum anzutreffen - für Linz muss man wohl, wie das Joachim Radkau angenommen hat, unter Klagen über »Holzmangel« eher die Absenz von günstigen Preisen verstehen: ${ }^{47}$ Nun koste das "schlechteste« Brennholz bereits 30 Kreuzer pro Klafter, beklagte der Verwalter des Lambacher Stiftshauses I809 den "Mangel« an Brennholz. ${ }^{48}$ Auch als 1797 im Linzer Stadtrat der "Holzmangel« diskutiert wurde, ging es um die zu hohen Preise. ${ }^{49}$ Als Lösung etablierte man - wie in anderen Städten zu dieser Zeit ${ }^{50}$ - einen zusätzlichen »städtischen« Holzplatz bei der Donaulände (im »Fölsengarten«), wurde aber ansonsten nicht aktiv. ${ }^{51}$ Als Teil »staatlich-städtischer Armenpolitik « wird man das nicht bezeichnen können. ${ }^{52}$ Gegen das Vorhandensein einer latenten Knappheit spricht, dass die in Linz ansässigen Institutionen offenbar kein Problem hatten, umfangreichere Holzmengen anzukaufen, ${ }^{53}$ zudem sind gewerbliche Großverbraucher (wie Ziegelbrenner, die Wollzeugfabrik und die »k.k. Saliterey«) für das I8. wie das I 9. Jahrhundert in der unmittelbaren Umgebung der Stadt nachweisbar. $^{54}$

Die Holzversorgung von Linz vollzog sich über den Holzhandel, in dem vor allem Schiffmeister tätig waren und der - wie in anderen Städten - im I 8. und I 9. Jahrhun-

44 LR Eia, Reg. 298 (64).

45 Vgl. Tabelle I u. Strömmer, Klima-Geschichte, $239 \mathrm{f}$.

46 LR BIIA4I, Reg. I 9946 (Io9-I I 5).

47 Vgl. Radkau, Rätsel, 58 u. 6r ; Knoll, Wald, 206; vgl. zum Londoner fuel market: Cavert, Smoke, I I O - I 2 I.

48 LR BIV, Reg. 957 (376).

49 AStL, HS ro84 (Stadtratsprotokoll I797), fol. r43a.

50 Vgl. Knoll, Wald, 205-207; Johann, Holzversorgung, 91 u. 96-ı I ; Zumbrägel, Holzströme, 35 2f.; Sonnlechner/Winiwarter, Verbrauch, 72.

5 I AStL, HS ro84 (Stadtratsprotokoll i797), fol. r47b, r79a u. 2 г 3 a.

52 Freytag/Piereth, Holzversorgung, 4; vgl. Knoll, Wald, $201-207$.

53 Vgl. LZ/IB, 24.5.I8I6.

54 AStL, HS 399 (Bauraittung I760), unpag. (»Holz-Rechnung«); OÖLA, Franziszeischer Kataster, No. I09o (Operat I, Braune Mappe, Urfahr, Katastralschätzungs-Elaborat, undat.); ebd., No. 534 (Operat 2, Linz Untere Vorstadt, Katastralschätzungselaborat, undat.); der Jahresverbrauch der Wollzeugfabrik betrug gegen Ende des I 8. Jahrhunderts angeblich 3.000-4.000 Klafter (vgl. Pfeffer, Fabriksbau, 4I). 
dert nur punktuell reguliert war. ${ }^{55}$ Die Regulierungsversuche der lokalen Obrigkeit zielten im I 8. Jahrhundert vor allem auf das Festlegen von Höchstpreisen ab, was über Satzungen und einen Platzzwang sichergestellt werden sollte. ${ }^{56}$ Ein derartiger »Brennholzsatz«, der eine prinzipielle Preisbindung und ein Anbieten an der Donaulände vorsah und der durch städtische Bedienstete überwacht werden sollte, ist für Linz für die I67oer Jahre belegt. Gleichzeitig wurde hier jedoch den Verkäufern und Käufern explizit die Möglichkeit eingeräumt, sich vorab auf einen eigenen Preis zu einigen. ${ }^{57}$ In der Folge finden sich nur wenige Hinweise auf die Praxis dieses Holzmarktes: In den I 7 Ioer Jahren erachtete die Stadt Linz die Aufsicht über den Holzhandel vor Ort als relativ gering, man habe »kheinen ordinari Saz der Holz-Sorthen«, die Preise wurden also frei ausgehandelt. ${ }^{58}$ Eine vollständige Kontrolle war ohnehin kaum zu erreichen ${ }^{59}$ und bei den großen Mengen an Holz, die Linz aus dem Hinterland beziehen konnte, war dies weder notwendig noch intendiert. Die Konkurrenz um günstiges Brennholz scheint erst ab der Mitte des I 8. Jahrhunderts zugenommen zu haben: I763 kam es zu einem Konflikt mit der Stadt Wien, nachdem man einem Schiffmeister die »Passirung « von 500 Klaftern Brennholz, die wenige Kilometer oberhalb von Linz gelagert wurden und für Wien bestimmt waren, untersagt hatte. Der Linzer Magistrat argumentierte damit, dass Linz »selbsten bedärfftig" sei, was von der Gegenseite als Vorwand zurückgewiesen wurde. ${ }^{60}$ Schließlich verfügte ein kaiserliches Patent, dass der Verkauf von Holz nach Wien aus Wäldern oberhalb von Linz nur erlaubt sei, »wenn das Publikum in Linz damit hinlänglich versehen« sei. Von dieser Regelung explizit ausgenommen wurde Importholz (i.e. Holz aus Bayern und Passau) und Holz aus den Mühlviertler Schwemmen. Somit betraf die Ausnahme den Großteil des Brennholzes, das auf der Donau Linz passierte. ${ }^{61}$ Für die Praxis wird diese Regelung also keine größere Relevanz gehabt haben, zudem wurden in den I78oer Jahren mit kaiserlicher Verordnung die Holzsatzungen aufgehoben und man verkündete - begleitet von Klagen über den Holzmangel - eine "Freiheit des Holzhandels«. ${ }^{62}$

Als im Frühjahr r 795 der ständische Beamte über Maßnahmen gegen die Knappheit an Holz (oder an günstigem Holz) nachdachte (vgl. oben), plädierte er ausdrück-

55 Hoffmann/Meixner, Wirtschaftsgeschichte, Bd. I, I 77 f. - vgl. Schott, Energie, ${ }_{25}$ f. u. Radkau, Rätsel, 4446.

56 Vgl. zu Wien: Brunner/Schneider, Umwelt, I72.

57 LR BIIA 37 , Reg. 19274 ( 228 - I 42); LZ/IB, I6.3.I 82 I ; vgl. Hoffmann/Meixner, Wirtschaftsgeschichte, Bd. I, I $77 \mathrm{f}$.

$58 \mathrm{LR} \mathrm{BIIG}_{4}$, Reg. 22 I 5 (5f.).

59 Vgl. Radkau, Rätsel, 46 u. Brunner/Schneider, Umwelt, I 73.

6o Wiener Stadt- und Landesarchiv, Alte Registratur, A2 I69/1 763 u. ebd. A 3 I 75/1 763 - vgl. LR CIIIB, Reg. 257 (68).

6I Luca, Landeskunde, Bd. I, 285 ; vgl. LR BVIII 2, Reg. 969 (Io3).

62 LR E7a u. b, Reg. 894 (2 19-222); ebd., Reg. 828 (205); AStL, Altakten, Sch. 52 ; vgl. Luca, Landeskunde, Bd. 2, 423 . 
lich gegen eine Preisfestsetzung, da diese die Versorgung der Stadt gefährde. Sinnvoller sei es, den Zwischenhandel auszuschalten und durch die Landstände selbst einen »Holzverlag« zu etablieren, also den Ein- und Verkauf von Brennholz für die Stadtbevölkerung zu übernehmen. Dies erfordere ı $0.000 \mathrm{fl}$ und einen Holzlagerplatz nahe der Donau, wofür man einen entsprechenden, 3.500 Klafter Holz fassenden Grund bereits in Aussicht habe. Das Holz könne von Schwarzenberg und aus dem Kobernaußerwald bezogen werden, allein über Braunau könne man jährlich 2.000-3.000 Klafter Holz erhalten. Bereits im vorangegangenen Winter habe der Beamte selbst, da man ihn angesprochen hatte, eine »Aushilfe« organisiert, Holz angekauft und ohne Gewinn weiterverkauft. Die Stände griffen diesen Vorschlag aber nicht auf, man zweifelte daran, ob die avisierte Menge überhaupt angekauft werden könne, möglicherweise bildeten auch die relative Problemlosigkeit der Holzversorgung in normalen Jahren und das finanzielle Risiko Gründe für die ablehnende Haltung. ${ }^{63}$ Offenbar entwickelte man eine andere Lösung: Im Dezember I 796 wurde über die »Linzer Zeitung « verlautbart, dass die Stände eine Sammelbestellung für Brennholz organisieren würden, was eine interessante Vorwegnahme der Konsumvereine bildete, in der Praxis aber wohl nicht sehr intensiv betrieben wurde. ${ }^{64}$ Das prinzipielle Prozedere des Holzbezuges scheint sich nicht verändert zu haben: Die meisten Haushalte kauften ihr Holz über die Holzhändler - in der Stadt sind für die I 83oer Jahre sieben und für die I8 5 oer Jahre acht Handelsberechtigungen belegbar - und/oder auf den Holzplätzen, die sich bis in die I 84 oer Jahre an der Donaulände befanden (vgl. Abb. I 2) ${ }^{65}$

Es sollte in diesem Kontext nicht übersehen werden, dass die Linzer Brennholzversorgung mit umfangreichen Beschäftigungseffekten verbunden war: Einerseits wurden zahlreiche Arbeiter in der Waldwirtschaft und im Transportwesen (Trift wie Schiff- und Landtransporte) beschäftigt - Fuhrwerke des I 8. Jahrhunderts beförderten in der Regel nur I bis 2 Klafter Brennholz ${ }^{66}$-, andererseits boten vor Ort das Umund Ausladen des Holzes, das Hacken und schließlich das Einlagern und Schlichten des Holzes zahlreichen Tagelöhnern eine Verdienstmöglichkeit. ${ }^{67}$

$63 \mathrm{LR} \mathrm{BIIA}_{4}$ I, Reg. 19946 (I09-I I5).

64 LZ, I6.I2.1796.

65 Pillwein, Wegweiser, I 56 ; Gewerbe-Adressen-Buch I 853 ; LZ/IB, I6.3.I 82 I ; AStL, Altakten, Sch. 52 u. Sch. 172.

66 OÖLA, Landschaftsakten, Sch. 447, D.XV.3/No. 62; LR CIIIHi -3 , Reg. 725 (536f.).

$67 \mathrm{LR} \mathrm{CIIIH}_{4}$, 822-830; ebd., 879-886; ebd., 975-978; LR BIV, Reg. 940 (371); die Zahl der bei den drei Triften des Mühlviertels Beschäftigten wurde für die I87oer Jahre - also für eine Phase, in der die Trift bereits an Bedeutung verloren hatte - mit 2.600 angegeben (Statistischer Bericht 1876, I39); vg1. zu Wien: Zumbrägel, Holzströme, $358 \mathrm{f}$. 


\section{Die langsame Transition zur fossilen Energie}

In den I $830 e r$ und I $840 e r$ Jahren begann in Linz die Nutzung fossiler Energieträger. ${ }^{68}$ Versuche, das Holz zu substituieren, hatte es bereits im I 8. Jahrhundert gegeben: In den I76oer und I770er Jahren drängten landesherrschaftliche Verordnungen auf die Förderung und Nutzung von Torf und Kohle; in der »Linzer Zeitung" aus dem Jahr I77 I findet sich sogar eine Anzeige, die Lieferungen von Mühlviertler Torf nach Linz bewarb. ${ }^{69}$ Erneut wurde zu Beginn des I 9. Jahrhunderts von staatlicher Seite die Nutzung der oberösterreichischen Braunkohle propagiert: I 800 legte die Hofkammer den Linzer Militärbehörden wiederholt nahe, die »Behaitzung mit Kohlen so viel möglich einzuführen ${ }^{70}{ }^{70}$ Auf die häusliche und gewerbliche Energienutzung in Linz hatte dies noch keine umfangreicheren Auswirkungen, denn Angebot und Nachfrage dieser neuen Brennstoffe waren begrenzt: Im Jahr I 834 passierten erst 5 Tonnen Kohle die Verzehrsteuerlinie. ${ }^{71}$ Dies wären o, 25 Kilogramm Kohle pro Kopf, was deutlich unter dem Durchschnittsverbrauch in der Habsburgermonarchie zu diesem Zeitpunkt lag; in Wien wurden $183 \mathrm{I}$ bereits rund 1o Kilogramm verbraucht. ${ }^{72}$

Offenbar steigerte sich erst mit dem Beginn der Dampfschifffahrt die Nachfrage nach Kohle. Als im September I 837 das erste Dampfschiff Linz von Wien aus erreicht hatte, wurde die vor Ort bereitgehaltene Kohle - so war in einem zeitgenössischen Zeitungsbericht zu lesen - als »unbrauchbar" eingestuft und deshalb verwendete man auf der Rückfahrt Holz. ${ }^{73}$ Die für die Schifffahrt notwendige Steinkohle wurde ab I8 88 mit der Pferdeeisenbahn aus Böhmen nach Linz gebracht, I 840 transportierte die Pferdeeisenbahn bereits über 3.000 Tonnen Steinkohle, die aber vermutlich zum größten Teil nicht in Linz verbraucht wurden. ${ }^{74} \mathrm{Ab}$ den i $840 e r$ Jahren kam zudem Braunkohle aus dem Hausruckviertel in die Stadt: Die Braunkohlevorkommen bei Wolfsegg wurden schon seit den I 76oer Jahren genutzt, aber erst mit der Anbindung an die Pferdeeisenbahn und an die Eisenbahn (I 848/i 849 resp. i 854 und I 859/r 860) steigerte sich der überregionale Absatz. ${ }^{75}$ In den Linzer Quellen ist Kohle ab den I840er Jahren deutlich präsenter, besonders staatliche Stellen scheinen gezielt als Nachfrager aufgetreten zu sein. I843 hatte die Linzer Garnison die Lieferung von

68 Vgl. dazu allgemein Kander/Malanima/Warde, Power, 60-62 u. I3 I - I 38.

69 Luca, Landeskunde, Bd. I, 302f. u. 315 ; Luca, Landeskunde, Bd. 2, 55 ; vgl. Hoffmann/Meixner, Wirtschaftsgeschichte, Bd. I, 297-299.

70 LR CIIIG, Reg. I 436 (4IO); ebd., Reg. I447 (4I5).

7I Tafeln zur Statistik 7 (1834), unpag.

72 Schott, Urbanisierung, I75; Geschichte und Ergebnisse, I 33.

73 In der »Linzer Zeitung« ist einmal von »Steinkohlen«, dann wiederum von »Braunkohlen« die Rede, es handelte sich vermutlich um Letzteres - vgl. LZ, 25.9.1 837 u. LZ, 9. I0.1 837.

74 Tafeln zur Statistik I 7 (i 844), unpag.; vgl. Sima, Pferdeeisenbahn, I 2 of.

75 Starke, Kohlebergbau, 35-46 u. I 45- I60. 
272 Tonnen Stein- oder Braunkohle öffentlich ausgeschrieben, ${ }^{76}$ zwei Jahre später bezog man bereits "Wolfsegger Braunkohlen ${ }^{77}{ }^{77}$ Bis in die I 85 oer Jahre stieg der städtische Kohleverbrauch deutlich an: I853 wurde für rund 2.800 Tonnen Stein- und Braunkohle Verzehrsteuer bezahlt, das ergibt pro Kopf rund roo Kilogramm. ${ }^{78}$ Verglichen mit dem englischen Pro-Kopf-Verbrauch (für I 866) von I,8 Tonnen in London und 5,3 Tonnen in Manchester ist dies sehr wenig, es stellt aber eine erhebliche Steigerung des Verbrauches der I $830 e r$ Jahre dar. ${ }^{79}$

Immer noch wurden weitaus größere Mengen an Brennholz in Linz konsumiert - in einer Masterarbeit wurde der Linzer Brennholzverbrauch für I 850 auf ca. 27.00o Tonnen und für I 860 auf ca. 28.000 Tonnen geschätzt. ${ }^{80}$ Das langsame Sinken des Brennholzverbrauches (pro Kopf - vgl. Tab. I3) deckt sich mit der Entwicklung in Wien, die dort Mitte der I 840er Jahre einsetzte. ${ }^{81}$ Vorerst blieb das Angebot groß: Holz bildete eine häufige Gegenfracht der Pferdeeisenbahn aus Böhmen und dem Mühlviertel und machte Anfang der I $840 e r$ Jahre ca. I 5 Prozent der Gesamtfracht aus. ${ }^{82}$ Auf der Teilstrecke Budweis-Linz wurden I837 2.538 Klafter und I843 5.024 Klafter Brennholz befördert. ${ }^{83}$ Dies ist keine marginale Menge, wenn man bedenkt, dass große Holzschiffe zu dieser Zeit I Io-I40 Klafter Brennholz fassten. ${ }^{84}$ Doch der Transport von Brennholz sank seit den späten I 84 oer Jahren deutlich ab, I 856 wurden nur noch 1.802 Klafter Brennholz befördert. ${ }^{85}$ Wesentlich bedeutender war in dieser Zeit noch der Holztransport über die Donau: Allein im April I 849 wurden 10.6 I 6 Klafter Brennholz "auf der oberösterreichischen Donau «, d.h. in beide Richtungen, verschifft, ${ }^{86}$ bis in die späten I 86oer Jahre scheint die transportierte Holzmenge nicht abgenommen zu haben (vgl. Tab. I 2). Auch dass in den r 840er Jahren der städtische Holzplatz von der Donaulände weg flussabwärts zur Wollzeugfabrik verlegt wurde, ist nicht als Indiz für einen Bedeutungsverlust des Brennholzes zu werten, sondern ist eher Ausdruck der für diesen Raum bestehenden Umgestaltungsambitionen, zudem lag der Holzplatz nun außerhalb der Verzehrsteuerlinie. ${ }^{87}$ Noch in den I 86oer Jahren lukrierte die Stadt jährlich mit diesem Holzplatz Einnahmen von immerhin I.200 fl. ${ }^{88}$

$76 \mathrm{LZ}, \mathrm{I} 7 \cdot 7 \cdot 1843$.

$77 \mathrm{LZ}, 30.5 \cdot 1845$.

78 LAB, 25.7.I 855 ; vgl. Starke, Kohlebergbau, I I 4 - I I 8.

79 Schott, Urbanisierung, 209; in Wien wurden um r 880 rund 624 Kilogramm Kohle pro Kopf und Jahr verbraucht - vgl. Geschichte und Ergebnisse, I 33 .

80 Fuchs, Produktion, 64.

8I Brunner/Schneider, Umwelt, I 78; vgl. Krausmann, City u. Gingrich/Haidvog1/Krausmann, Danube.

82 Sima, Pferdeeisenbahn, I 20; Fuchs, Produktion, 9If.

83 Tafeln zur Statistik I 7 (I 844), unpag.

84 Donau in Oberösterreich, $3 \mathrm{I}$.

85 Fuchs, Produktion, 9rf.; ÖB, I9.I.I 857.

86 Donau in Oberösterreich, 32.

87 AStL, Altakten, Sch. I72; LZ, 2.6.1 843; Fink, Geschichte, 72.

88 LAB, 20.I.I 864. 
Tab. 12 : Über die Donau in Linz angekommenes Brennmaterial, 1849-1868

\begin{tabular}{lcccc}
\hline & & Brennholz & \multicolumn{2}{c}{ Braun- und Steinkohle } \\
& Tonnen & $\%^{\mathrm{a}}$ & Tonnen & $\%^{\mathrm{a}}$ \\
\hline 1849 & 22.829 & 27 & 297 & 0 \\
1854 & 20.308 & 28 & 602 & 1 \\
1858 & 23.538 & 35 & 1.061 & 2 \\
1864 & 21.005 & 41 & 1.026 & 2 \\
1868 & 25.303 & 42 & 1.836 & 3 \\
\hline
\end{tabular}

Quelle: Winckler, Übersicht, 52f.; eigene Umrechnung

a Prozent der Gesamtfracht (gerundet)

Tab. 13: Pro-Kopf-Verbrauch von Brennholz und Kohle in Linz, 1834-1905

\begin{tabular}{lcccr}
\hline & 1834 & 1850 & 1860 & 1905 \\
\hline Holz m $^{3}$ & 1,48 & 1,14 & 1,15 & 0,83 \\
Kohle kg & 0 & 8 & 114,70 & 537,10 \\
\hline
\end{tabular}

Quelle: Sandgruber, Lebensstandard, 288

Eine Transition zur fossilen Energie kann für Linz ab dem Ende der I 85 oer Jahre festgestellt werden (vgl. Tab. I3). Entscheidend dafür war die Anbindung an die Westbahn, die eine direkte und kostengünstige Verbindung zur Braunkohle im Hausruck herstellte. Bereits I 856 hatte man in einem - um Investoren werbenden - Bericht der "Wolfsegg-Traunthaler Kohlenwerks- und Eisenbahngesellschaft « betont, dass bereits jetzt der Betrieb auf die kommende Westbahn »vollkommen ausgerichtet « sei. Das einzige »Hinderniß der größeren Verbreitung der Kohle«, »die übermäßigen Frachtspesen«, würden mit der Anbindung an die Bahnstrecke deutlich sinken. ${ }^{89}$ Tatsächlich wurde die Eisenbahn schnell Transporteur und Großabnehmer der Hausrucker Kohle und davon profitierte offenbar auch das Kohleangebot in Linz. ${ }^{90}$ Der Übergang zur Kohle erfolgte in Linz deutlich langsamer als in Wien: Um I860 stammten in Linz I 5 Prozent der Energie aus Kohle, in Wien bereits ca. 3 I Prozent. Dies mag mit dem Umstand zusammenhängen, dass in Wien das Holz teurer und die dort verfügbare Kohle hochwertiger war. ${ }^{91}$

Auch die Dampfkraft - ein wesentlicher Kohleverbraucher - verbreitete sich in Linz nur zögerlich: Erste Verwendungen lassen sich ab i 840 in der Wollzeugfabrik

\footnotetext{
89 LZ, 28.2.1 856.

90 Fuchs, Produktion, I04- Io8.

9I Ebd., I I3- I I 5 ; vgl. zu Paris: Kim/Barles, Energy, 30of. u. 304f.
} 
und ab I 857 in der Schiffswerft feststellen, aber noch 1863 verzeichnete man erst 5 Dampfmaschinen in Linz und 3 weitere in Urfahr, bis zum Beginn der I 88 oer Jahre war deren Zahl hingegen auf über 50 angestiegen. ${ }^{92}$ Der erste Großverbraucher von Kohle in Linz war das Gaswerk, das von einem Triester Unternehmen an der östlichen Peripherie der Stadt errichtet wurde (vgl. Kap. 7. Geordnete und modifizierte Umwelt). Das Gaswerk produzierte seit I 858 Leuchtgas, wofür man zunächst noch Brennholz verwendet hatte. Erst im Sommer I 865 erfolgte der Umstieg auf Kohle, bis zum Ende der I $870 e r$ Jahre war der Jahresverbrauch auf 2.370 Tonnen Steinkohle und 8г 6 Tonnen Koks angestiegen. ${ }^{93}$ Die Erzeugung von Elektrizität war ebenso an die Kohle gebunden: In den I 88 oer Jahren existierten bereits kleinere elektrische Beleuchtungsanlagen, die an Dampfmaschinen angeschlossen waren (beim Bahnhof, in der Tabakfabrik und in der Spinnerei Zizlau), und ab I 897 gab es an der nordöstlichen Peripherie der Stadt eine eigene »Elektrische Central Station«, die für den Antrieb der Straßenbahn und der Pöstlingbergbahn errichtet worden war (vgl. unten), aber auch Strom an Privatabnehmer lieferte. ${ }^{94}$

Diese Transitionsphase war von einem langsamen Sinken des Brennholzangebotes begleitet: I 875 wurden durch die Mühlviertler Holztriften noch insgesamt 44.000 Klafter transportiert, dazu kamen weitere Triften in Oberösterreich, vor allem auf der Mattig (vgl. oben). ${ }^{95}$ Bis zum Ende des r 9. Jahrhunderts gingen die Brennholzlieferungen aber kontinuierlich zurück, die Trift auf der Großen Mühl, die für Linz relevant gewesen war, wurde 1900 verlegt und am Ende des Ersten Weltkriegs gänzlich eingestellt. ${ }^{96}$ Brennholz kam in der zweiten Hälfte des I 9. Jahrhunderts auch aus Bayern, oder es wurde mit der Eisenbahn transportiert - ab I 888 verfügte das Mühlviertel mit der Mühlkreisbahn über eine Anbindung an Urfahr. ${ }^{97}$ In den letzten Jahrzehnten des i 9. Jahrhunderts stellte eindeutig die Eisenbahn die energetische Basis der Stadt Linz sicher: I 895 verzeichnete das »kk. Bahnbetriebsamt Linz« 238.284 Tonnen an angekommener Fracht, darunter befanden sich 28.503 Tonnen Steinkohle und 64.984 Tonnen Braunkohle. ${ }^{98}$ Vergleichsweise gering war zu dieser Zeit der Beitrag der Donau zur Energieversorgung der Stadt: I 895 waren in Linz nur 204 Tonnen Holz (vermutlich ist darunter nur Brennholz zu verstehen) und 5.557 Tonnen Kohle angekommen. ${ }^{99}$

92 Dampfmaschinen, I5; Statistischer Bericht I 882, Bd. 2, 298-30 I.

93 Fuchs, Produktion, ro9; Pfeffer, Fabriksbau, 42; Otruba/Kropf, Industrietopographie, ro8f.; Imhof, Gaswerk, 58 u. 6r ; Lackner/Stadler, Fabriken, 54, 469, 489 u. 523; Statistischer Bericht I 882, Bd. 2, 275.

94 Lackner/Stadler, Fabriken, 430; Rafetseder, Variationen, 422-426; Kreuzer, Stadtumbau, 522 f. u. 530 ; vgl. Mayrhofer/Katzinger, Geschichte, Bd. 2, I54, I 59 u. 2 Io; vgl. RB I891, 250 u. RB I 900 , I35.

95 Statistischer Bericht I 876, I 39 u. I48.

96 Záloha, Geschichte, 257-269; Neweklowsky, Schiffahrt, Bd. 3, 582.

97 Fuchs, Produktion, 89 u. 98f.; Lackner/Stadler, Fabriken, 2 I.

$98 \mathrm{RB}$ I 895, I 23.

99 Ebd., I 9. 
Ein noch langsamerer Übergang vom Holz zur fossilen Energie ist im Haushaltsbereich anzunehmen, da errechnete Durchschnittswerte (»pro Kopf «) durch die expandierende Kohlenutzung in Gewerbe und Transportwesen deutlich verzerrt werden. Somit muss ein sinkender Pro-Kopf-Verbrauch von Brennholz - wie er in Wien bereits für die Zeit zwischen I 830 und I 860 konstatiert wurde ${ }^{100}$ - nicht zwingend auf einen Rückgang in den Haushalten hindeuten. ${ }^{101}$ Insgesamt zeichnet sich für manche Bereiche eine Parallelität der beiden Energieträger für die zweite Hälfte des i 9. Jahrhunderts ab, ohnehin benötigte man auch bei Kohlebeheizung erhebliche Mengen an »Unterzündholz«: ${ }^{102}$ In Linz gab es I 890 noch I 6 Holzhändler (wobei dies auch Werk- und Bauholz einschloss), aber nur 5 Kohlehändler. ${ }^{103}$ Möglicherweise war die Entscheidung für einen der beiden Energieträger auch situativ und an den jeweiligen Preisen ausgerichtet. I 854 sei - so ein Linzer Zeitungsartikel - im Vergleich zum Vorjahr fast um die Hälfte weniger Kohle verbraucht worden, weil »die Holzpreise niedrig «, die Kohlepreise hingegen "ziemlich geschraubt fest blieben «. ${ }^{104}$ In den letzten drei Jahrzehnten des i 9. Jahrhunderts scheinen sich die Preise für Brennholz und Kohle reduziert zu haben, wobei sich die Steinkohle deutlich stärker verbilligte (vgl. Tab. I4).

Tab. 14: Preisentwicklung von Brennholz und Kohle in Linz, 1876-1899

\begin{tabular}{|c|c|c|c|c|c|c|}
\hline & 1876 & 1881 & 1890 & 1895 & 1899 & $1876-99$ \\
\hline $\begin{array}{l}1 \mathrm{~m}^{3} \text { Brennholz, hart, } \\
\text { ungeschwemmt }\end{array}$ & $6 \mathrm{fl} 52 \mathrm{kra}^{\mathrm{a}}$ & $6 \mathrm{fla}^{\mathrm{a}}$ & $6 \mathrm{fl}$ & $5 \mathrm{fl} 62,5 \mathrm{kr}$ & $5 \mathrm{fl} 60 \mathrm{kr}$ & $-14 \%$ \\
\hline $\begin{array}{l}1 \mathrm{~m}^{3} \text { Brennholz weich, } \\
\text { ungeschwemmt }\end{array}$ & $5 \mathrm{fl} 50 \mathrm{kr}^{\mathrm{a}}$ & $5 \mathrm{fl}^{\mathrm{b}}$ & $5 \mathrm{fl}$ & $4 \mathrm{fl} 25 \mathrm{kr}$ & $4 \mathrm{fl} 75 \mathrm{kr}$ & $-14 \%$ \\
\hline 100 kg Braunkohle & $86 \mathrm{kr}$ & 94 & $80 \mathrm{kr}$ & $84,5 \mathrm{kr}$ & $1 \mathrm{fl} 8 \mathrm{kr}$ & $+26 \%$ \\
\hline 100 kg Steinkohle & $1 \mathrm{fl} 96 \mathrm{kr}$ & $1 \mathrm{fl} 80 \mathrm{kr}$ & $1 \mathrm{fl} 70 \mathrm{kr}$ & $1 \mathrm{fl} 50 \mathrm{kr}$ & $1 \mathrm{fl} 50 \mathrm{kr}$ & $-23 \%$ \\
\hline Quelle & $\begin{array}{l}\text { RB 1876- } \\
1878,35 \mathrm{f}\end{array}$ & $\begin{array}{l}\text { RB 1881, } \\
42 f .\end{array}$ & $\begin{array}{c}\text { RB 189o, } \\
75-78\end{array}$ & $\begin{array}{c}\text { RB 1895, } \\
82-85\end{array}$ & $\begin{array}{c}\text { RB 1899, } \\
84-87\end{array}$ & \\
\hline
\end{tabular}

a 100 Stück "Bündelholz"

b $1 \mathrm{~m}^{3}$ »Bündelholz«

Auch der öffentliche und semiöffentliche Bezug von Brennmaterial zeigt das Nebeneinander von Holz und Kohle im Heizungsbereich: Für den Winter I 864/ I 865 erwarb man für die städtischen Gebäude und Schulen 222 Klafter ( I 8-zölliges) weiches, sowie

\footnotetext{
Ioo Brunner/Schneider, Umwelt, I42f.

Iо I Auf dieser Basis sollte auch keine »Verarmung« der Bevölkerung angenommen werden, wie dies in aktuellen Studien mitunter zu lesen ist: vgl. Fuchs, Produktion, I 2 u. Gingrich/Haidvogl/Krausmann, Danube, 287 .

I02 LR CIIIG, Reg. 2 I 99 (733).

I03 RB I 890, 84-86.

IO4 LAB, $25 \cdot 7 \cdot 1855$.
} 
6 Klafter ( 1 8-zölliges) und 34 Klafter (36-zölliges) hartes Holz und zudem I68 Tonnen Braunkohle. ${ }^{105}$ I 860 kaufte man für eine Linzer Schule 32 Tonnen Braunkohle und 5 I Klafter (г 8-zölliges) Holz, fürs das Rathaus fast 39 Tonnen Braunkohle und 28 Klafter Holz. ${ }^{106}$ I 885 gab man den jährlichen Bedarf für die Beheizung des Glashauses im Volksgarten mit 4 Kubikmetern Buchenholz und I,5 Tonnen Braunkohle an. ${ }^{107}$ Noch in den I $870 e r$ Jahren bezog der Hausmeister des Kremsmünsterer Stiftshauses als Deputat 6 Klafter Holz. ${ }^{108}$

\section{Pferde und Wasser: Erneuerbare Antriebsenergie}

Wenngleich tierische Antriebsenergie in der vormodernen und sich modernisierenden Stadt omnipräsent war, gibt es dafür nur wenige und relativ verstreute Hinweise in den Quellen - besonders für das I 8. Jahrhundert. ${ }^{109}$ Zentral waren Pferde, die als Reit- und Zugtiere fungierten und eine, wie Harold Platt dies mit Blick auf Chicago bezeichnet hat, »horse infrastructure« bildeten: ${ }^{110}$ Die repräsentativen Linzer Freihäuser verfügten über teilweise sehr umfangreiche Pferdeställe, ${ }^{111}$ einzelne Institutionen unterhielten selbst Pferde als Zugtiere ${ }^{112}$ und ab den I $720 e r$ Jahren - vermutlich bis ins frühe r 9. Jahrhundert - nutzte man in der Wollzeugfabrik Pferde als Antriebsquelle für eine Mangel, eine Walke und später Spinnmaschinen. ${ }^{113}$ Erst der »Franziszeische Kataster« der I 83oer Jahre gewährt einen Einblick in die städtische und stadtnahe Nutzung von Pferden: Damals gab es in der Stadt und den Vorstädten rund 500 Pferde (vgl. Tab. I 5), angeblich vor allem »mittelstarken böhmischen Schlages ${ }^{114}$ bei "größeren Wirtschaften « seien, so der Kataster für die Obere Vorstadt, meist 6 Pferde anzutreffen. ${ }^{115}$ Pferde wurden nicht nur für den innerstädtischen Transport und die stadtnahe Landwirtschaft genutzt, sondern sie waren auch wichtiger Bestandteil der überregionalen Versorgung über Land und Wasser. ${ }^{116}$ Das

\footnotetext{
I05 LAB, 22.7.1864.

Io6 AStL, HS 2 I 2 (Kammeramt Ausgaben I860), pag. I 5 U. 5 I.

I07 RB I885, ro9.

I08 $\mathrm{LR} \mathrm{BVI}_{3}$, Reg. 1745 (I53f.).

Io9 Vgl. für US-amerikanische Städte im ausgehenden I 9. Jahrhundert Tarr, Search, 323-328 u. allgemein Kander/Malanima/Warde, Power, 50-52.

I I Platt, Shock, $253 \mathrm{f}$.

I I I LR BVI 2 , Reg. I I 27 (6I-69); ebd. Reg. I 245 (I 86); ebd., Reg. I 394 (256).

I 2 AStL, Altakten, Sch. 42 ; OÖLA, Landschaftsakten, Sch. 447, D.XV.3/No. 62.

I 3 LR CIIIF I u. 2, Reg. 323 (i62) u. ebd., Reg. 375 (20of.); Pfeffer, Fabriksbau, 37 u. 42 ; vgl. Pillwein, Beschreibung, 286 u. 288.

I 4 OÖLA, Franziszeischer Kataster, No. 534 (Operat I u. 2, Braune Mappe, Linz-Stadt, Katastralschätzungs-Elaborat, I 8.1 2.1832).

I 5 Ebd. (Operat 2, Linz Obere Vorstadt, Katastralschätzungs-Elaborat, undat.).

I 6 Reith, Umweltgeschichte, i 6 ; EdN, s.v. Treidlerei; vgl. Neweklowsky, Schiffahrt, Bd. I, 296-3I 5 .
} 
Inventar eines Linzer Schiffmeisters aus dem Jahr I 767 erfasste ro Zugpferde $;{ }^{117}$ für die zwei Schiffzüge, die I 772 rund 300 Tonnen oberungarisches Getreide in die Stadt transportierten, benötigte ein Linzer Schiffmeister insgesamt 92 Pferde. ${ }^{118}$ Daneben bestand eine Vielzahl kleinerer Schiffzüge: ${ }^{119}$ I 8 Pferde hätten einen Schiffszug aus Budapest in zwei Monaten bis nach Linz »heraufgeschleppt«, so ein Reisebericht aus den I 8 2oer Jahren. ${ }^{120}$

Bei der Pferdeeisenbahn, die ab den s 83oer Jahren Budweis über Linz und Wels mit dem Salzkammergut verband, setzte man erneut auf die Antriebskraft des Pferdes. Dazu kam ab r 879 die innerstädtische Pferdetramway, die vom Hauptbahnhof in die Innenstadt und später bis zum Mühlkreisbahnhof in Urfahr führte. Sie wurde bis zur Elektrifizierung I 897 (vgl. oben) mit Pferden betrieben - für I 880 ist deren Zahl mit 22 bis 26 angegeben. ${ }^{121}$ Insgesamt stieg im I 9. Jahrhundert die Anzahl der Pferde in der Stadt und in den Vororten resp. Vorstädten dem Bevölkerungswachstum entsprechend an, wenngleich die verfügbaren Zahlen nicht ganz konsistent erscheinen (vgl. Tab. I 5).

Tab. 15: Pferde in Linz, 1831-1900

\begin{tabular}{lcc}
\hline & Pferde & Militärpferde \\
\hline 1831 & 472 & \\
1834 & 523 & \\
1843 & $391^{a}$ & \\
$1845 / 1846$ & 522 & \\
1869 & $332^{\mathrm{a}}$ & \\
1883 & 597 & 234 \\
1890 & 730 & 338 \\
1900 & 820 & \\
\hline
\end{tabular}

Quelle: OÖLA, Franziszeischer Kataster, No. 534; Tafeln zur Statistik 16 (1843), Tafel 52; Tafeln zur Statistik 18/19 (1845-1846), Tafel 15; Statistischer Bericht 1876, 103; RB 1883, 74; RB 1890, 311

a diese Zahlen sind vermutlich zu niedrig angesetzt

I 7 LR BIIB 2, Reg. $520(32-35)$.

I I 8 Neweklowsky, Getreidetransport, 347; vgl. Neweklowsky, Schiffahrt, Bd. 3, 587 .

I 9 Donau in Oberösterreich, 3of.; Neweklowsky, Donauschiffahrt, I82f.; Hohensinner, Fahrzeuge, i IoI I 4 .

I 20 Kyselak, Skizzen, 407 .

I2 I Mayrhofer/Katzinger, Geschichte, Bd. 2, I54; Leonhartsberger, Freizeiträume, 87f.; Statistischer Bericht I 882 , Bd. 2, 7 I. 


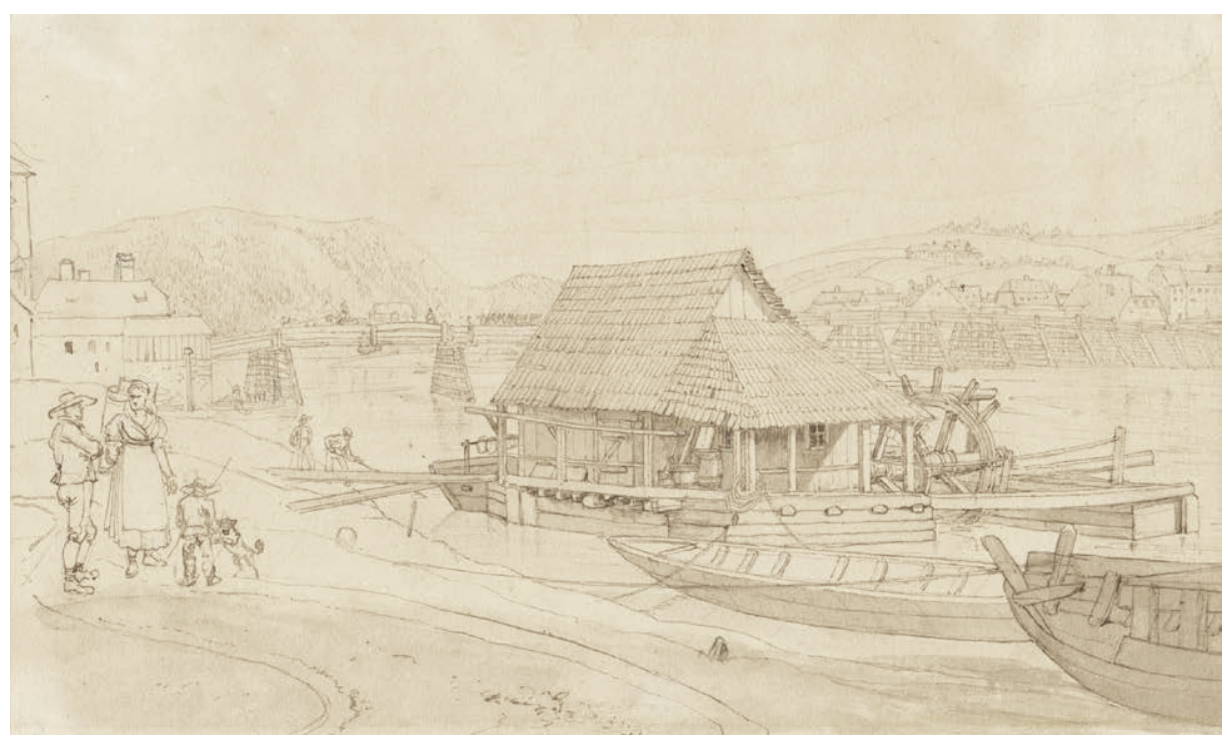

Abb. 10: Die Schiffmühle in der Winterposition an der Linzer Donaulände, 1815

Über die Quellen besser zu erfassen ist die Nutzung der Wasserkraft. ${ }^{122}$ Im Stadtgebiet von Linz gab es im I8. und I9. Jahrhundert keine dafür verwendbaren Wasserläufe und auch die Donau wurde nur zeitweilig für den Antrieb von Mühlen genutzt. Die Flussdynamik erlaubte - wie in Wien ${ }^{123}$ - nur Schiffmühlen, die von den 158 oer Jahren bis ins I 9. Jahrhundert nachweisbar sind (vgl. Abb. Io u. I 2). Auf Linzer Seite war die Schiffmühle, wenn sie in Betrieb war, an die Brücke angehängt. Die in städtischem Besitz stehende Mühle diente ursprünglich zum Mahlen des Getreides für das Bürgerspital, später erzeugte die Mühle Malzschrot für das Stadtbräuhaus. Das Fremdmahlen war untersagt, wurde aber dennoch teilweise im I 8. Jahrhundert praktiziert. ${ }^{124}$ Zwischenzeitlich - um I700 und im I9. Jahrhundert - bestand auf Urfahrer Seite eine zweite Schiffmühle. ${ }^{125}$ Die Schiffmühlen waren überaus anfällig für Hochwasser bzw. Eisstöße, und somit ist es vielleicht kein Zufall, dass man 1787 - ein Jahr nach dem katastrophalen Sommerhochwasser (vgl. Kap. I I. Naturgefahr) - über die Auflassung der Schiffmühle nachdachte. ${ }^{126}$ Vermutlich verfügten die Linzer Schiffmühlen über maximal zwei Mahlgänge, ${ }^{127}$ sie hatten somit nur eine begrenzte Kapazität und

I 2 Kander/Malanima/Warde, Power, 64-67; Reith, Umweltgeschichte, I I6 - i I 8; EdN, s.v. Wasserkraft; vgl. zu Wien Haidvogl et al., Wasser, 240-248.

I 23 Brunner/Schneider, Umwelt, 58, 3 I 8 u. 325 .

I 24 Neweklowsky, Schiffmühlen, 53f.; LR BIAI, Reg. 573 (I 8 If.).

I 5 Neweklowsky, Schiffmühlen, 55 f.; LR BIA 5 , Reg. 6500 (I 9I); vgl. Kyselak, Skizzen, 4 O7.

I 26 Rafetseder, Variationen, 376; AStL, Altakten, Sch. 52.

I 27 Heinse, Linz, I. Aufl., 2 I. 
sind als Nischenlösung zu betrachten. Die stadteigene Mühle an der Donaubrücke bestand bis 1 826, die Schiffmühle an der Urfahrwänd bis 1908. ${ }^{128}$ Nach »mehrjährigen schlimmen Erfahrungen« hätten die Brauhauspächter die Schiffmühle »freywillig« aufgelassen und »dafür eine neue Roßmühle zum Malzbrechen« errichtet, so eine Einschätzung der Verwaltung der Wollzeugfabrik wenige Jahre später. ${ }^{129}$ Bezugnehmend auf einen Kanalbau in Laibach überlegte die Verwaltung der Wollzeugfabrik in den I770er Jahren, Wasserkraft für den Antrieb von Spinnmaschinen zu nutzen. Projektiert wurde eine Ableitung der Donau, die aber angesichts der zu erwartenden Kosten (und Probleme) nicht umgesetzt wurde, die Spinnmaschinen versah man schließlich mit einem Pferdeantrieb. ${ }^{130}$

Relevanter waren die zahlreichen Mühlen im Linzer Hinterland: An den Bächen nördlich der Donau gab es viele kleinere Betriebe, die die Wasserkraft teilweise bis ins 20. Jahrhundert nutzten. ${ }^{131}$ Der »Franziszeische Kataster« verzeichnete am Höllmühlbach zwei Mühlen (fünf Gänge) und ein Sägewerk, am Katzbach drei Mühlen (fünf Gänge), am Haselbach eine Hammerschmiede (zwei Hämmer), vier Mühlen (elf Gänge) und zwei Sägewerke. ${ }^{132}$ Ein zweiter Schwerpunkt der Wasserkraftnutzung befand sich an der Traun. Der Fluss und das dortige Gebiet eigneten sich gut für Mühlen: Die Traun fror nur selten zu, man konnte bestehende Verzweigungen der Traun nutzen oder künstliche Ableitungen anlegen, die im flachen Gebiet relativ einfach herzustellen waren. Belegbar sind Wasserbauten in Kleinmünchen durch Grundabtretungen und Servituten für das I 8. Jahrhundert, die dortigen Mühlen sind vermutlich aber älter. ${ }^{133}$ In der Regel scheint das Linzer Getreide in den Kleinmünchner Mühlen (Jauker, Steinbrückl, Weidinger, Schernegger- und Schörgenhubermühle) oder in den jenseits der Traun in Ebelsberg gelegenen Mühlen (Markt- und Aumühle) gemahlen worden zu sein. Dazu gibt es zahlreiche Hinweise in Inventaren und anderen städtischen Dokumenten. ${ }^{134} \mathrm{Ab}$ den I $720 e r$ Jahren nutzte die Wollzeugfabrik einen Teil der Steinbrücklmühle als Walke, im »Josephinischen Lagebuch« scheint ein eigenes kleines Gebäude bei der Mühle als "Walk von der k.k. Fabrik in Linz« auf. ${ }^{135}$ I 8 I I kaufte die Wollzeugfabrik die bisher gepachtete Steinbrücklmühle an und man überlegte wiederum (vgl. oben), dort Spinnmaschinen mit Wasserkraft zu betreiben. Auch diesmal verhinderten die hohen Kosten eine Umsetzung, gebaut wurden aber

I 28 Neweklowsky, Donau, 2 I6; Fink, Geschichte, 70.

I 29 LR CIIIFI u. 2, Reg. 666 (328-330).

I30 Ebd., Reg. I4I (62); ebd., Reg. I 56 (69f.); ebd., Reg. 375 (20of.); vgl. Pfeffer, Fabriksbau, 42.

I3 I Lackner/Stadler, Fabriken, Ioo.

I32 Bohdanowicz, Pöstlingberg, 22 If.; Bohdanowicz, Katzbach, 25 I u. 262.

I33 Lackner/Stadler, Fabriken, I03 u. I 7 I.

I34 LR BIX 2 , Reg. 199 (9of.); LR BIIB I, Reg. I5 I (I 2 of.); LR BIIB2, Reg. 707 (I I 5f.); ebd., Reg. 735 (I 27); ebd., Reg. 757 ( ( 36 ); LR BIIB 3 , Reg. I 422 (I 82 f.); ebd., Reg. I 765 (I oof.); Bohdanowicz, Vorstädte, Bd. 2, 816; Bohdanowicz, Kleinmünchen, 8 - 10; vgl. Lackner/Stadler, Fabriken, $358 \mathrm{f}$.

I 35 Pfeffer, Fabriksbau, 38 ; Bohdanowicz, Kleinmünchen, 9; vgl. LR CIIIF I u. 2, Reg. 254 (I 24- I 26). 
mehrere durch Wasserkraft betriebene Arbeitsmaschinen (u.a. eine Walke und eine Farbholzschneidemaschine), drei der insgesamt fünf Mahlgänge der Steinbrücklmühle verpachtete man als Getreidemühle. ${ }^{136}$ Dem Beispiel der Wollzeugfabrik folgten ab den I 8 zoer Jahren Baumwollspinnereien und webereien, die sich an den Kleinmünchner Mühlbächen ansiedelten und partiell alte Getreidemühlen umnutzten. ${ }^{137}$ Andere Getreidemühlen wurden ab dem Ende der I83oer Jahre modernisiert und mit neuen Verarbeitungs- und Antriebstechnologien ausgestattet. Das Beispiel der »Kunstmühle Löwenfeld \& Hofmann« zeigt die Persistenz der Wasserkraftnutzung im Kohlezeitalter: Ab I 854 entstand - basierend auf einem alten Mühlbetrieb - ein Großbetrieb, in dem I 860 bereits I 3.450 Metzen Weizen und 44.000 Metzen Roggen (d.h. rund 7.700 Tonnen Getreide) verarbeitet wurden. ${ }^{138}$ Angetrieben wurde die Mühle durch zwei Wasserturbinen mit I 50 PS, was deutlich über der Leistung der damals in Linz verwendeten Dampfmaschinen (um I 880 meist unter io PS, maximal 30 bis 40 PS) lag. ${ }^{139}$ Noch in den I 8 7oer Jahren scheinen Kleinmünchner Wasserkraftnutzer ihre Kapazitäten deutlich erweitert zu haben. ${ }^{140}$

\section{Lebensmittel: Lokaler Bedarf und lokale Versorgung}

Ähnlich wie beim Brennholz gibt es für den Verbrauch von Lebensmitteln in Linz ebenso nur Zahlen aus dem i 9. Jahrhundert, die anfänglich aus Abgaben (Verzehrsteuer) und später aus zeitgenössischen Erhebungen stammen (vgl. Tab. I6). Bereits in den späten I 97oer Jahren hat Roman Sandgruber eine Verbrauchsschätzung für Oberösterreich und partiell auch Linz vorgenommen (vgl. Tab. I7). Für das I 9. Jahrhundert konstatiert Sandgruber einen Rückgang des städtischen Getreidekonsums, einen relativ hohen Fleischkonsum für den Vormärz, der danach - mit dem Anstieg der Preise - wieder zurückging und später erneut anstieg. ${ }^{141}$ Die Durchschnittswerte überdecken die enormen Unterschiede der Ernährungssituation in den verschiedenen sozialen Schichten und Milieus: Sandgruber hat - basierend auf einer zeitgenössischen Berechnung - für I 875 einen jährlichen Fleischkonsum von I 43,8 Kilogramm in der Oberschicht, von I I 4,8 Kilogramm in der Mittelschicht und von 45,3 Kilogramm für

I36 LR CIIIF I u. 2, Reg. 254 (I 24-I26); ebd., Reg. 3 I9 (I6of.); ebd., Reg. 503 (279); vgl. Pfeffer, Fabriksbau, 42 ; Pillwein, Beschreibung, 286; LZ/IB, 28.4.I 820.

I37 Bohdanowicz, Kleinmünchen, 336 u. 348; Lackner/Stadler, Fabriken, Io3- Io6 u. I I7f.; vgl. Mayrhofer/Katzinger, Geschichte, Bd. 2, I89-i 9I ; vgl. LR CIIIF I u. 2, Reg. 806 (375f.) u. ebd., Reg. 8 I6 (379f.).

I 38 Lackner/Stadler, Fabriken, 345 f. u. 352; Otruba/Kropf, Industrietopographie, I 05 .

I 39 Statistischer Bericht I872, I78; Statistischer Bericht I 882, Bd. 2, 298-30I u. 308f.

I 40 Allgemeine Bauzeitung 65 (I 900), 49.

I 4 I Sandgruber, Lebensstandard, 287. 
Arbeiter/innen oder Dienstleister/innen angenommen. ${ }^{142}$ Für Linz gab der »Franziszeische Kataster« den jährlichen Fleischkonsum von erwachsenen landwirtschaftlichen Arbeitskräften mit I79,3 Kilogramm (davon I62,4 Kilogramm Rindfleisch) an und den Getreidekonsum mit 33 I, I Kilogramm (davon Weizen I 2,9 Kilogramm), was für diese Zeit - die frühen I 8 zoer Jahre - eine sehr große Menge darstellt, an der man durchaus Zweifel äußern kann (vgl. Tab. I7). ${ }^{143}$ Für das I 8. Jahrhundert lässt sich der Pro-Kopf-Verbrauch schwerer abschätzen: Aus den I $720 e r$ Jahren ist eine Aufstellung über die Lebensmittelkosten eines stadtnahen Bauernhofes überliefert, die sogar Mengenangaben enthält. Für die sechs (offenbar erwachsenen) Arbeitskräfte veranschlagte man jährlich 30 Metzen Roggen, 9 Metzen Gerste und 3 Metzen Weizen, dazu wöchentlich 7 Pfund Rindfleisch und 3,5 Pfund Getreidebrei. ${ }^{144}$ Dies wären durchschnittlich pro Person - wobei auch hier in der Praxis keine Gleichverteilung anzunehmen ist - jährlich ca. I62 Kilogramm Roggen, 44 Kilogramm Gerste, I7 Kilogramm Weizen, I7 Kilogramm Haferbrei und 34 Kilogramm Fleisch. Dies liegt nahe an anderen für das I 8. und I 9. Jahrhundert errechneten und geschätzten Werten. ${ }^{145}$ Wenn man nun für das i 8. Jahrhundert den Pro-Kopf-Verbrauch von Getreide mit 220 Kilogramm und für das I9. Jahrhundert mit I 80 Kilogramm annimmt, dann benötigte Linz in der ersten Hälfte des I 8. Jahrhunderts jährlich zwischen 2.500 und 3.000 Tonnen Getreide für den menschlichen Verbrauch und hundert Jahre später rund 5.000 Tonnen.

Dazu kamen signifikante Mengen für die Nutztiere in der Stadt und in den Vorstädten: I7 9 kaufte die Linzer Dependance des Deutschen Ordens 600 Metzen Hafer (i.e. rund I4 Tonnen) an. ${ }^{146}$ Wenn man davon ausgeht, dass ein Pferd täglich 3,5 Kilogramm Hafer benötigte, ${ }^{147}$ dann bedeutete dies für 500 Pferde eine Gesamtmenge von jährlich rund 640 Tonnen Hafer. Dies passt relativ gut zu den Angaben, die für die Anzahl der Pferde und für die Einfuhr von Hafer greifbar sind: I 834 wurde für 696 Tonnen Hafer Verzehrsteuer bezahlt und I 853 für 777 Tonnen. ${ }^{148}$

Die Versorgung der Stadt mit Lebensmitteln erfolgte nur teilweise über die Eigenproduktion, der größte Teil wurde - wie in anderen Städten - über Lebensmittelgewerbe und handel bezogen. ${ }^{149}$ Die städtische Obrigkeit verhielt sich dabei in der Regel relativ passiv, bis ins I 9. Jahrhundert bestanden lediglich Höchstpreisfestsetzungen und ein gewisser Marktzwang, wobei Linz nicht über einen eigenen

\footnotetext{
I 42 Ebd., 280.

I 43 Ebd., $285 \mathrm{f}$.

I44 LR CIIIHI-3, Reg. 46 I (299-302); vgl. zu den Gewichtseinheiten das Kap. Maßeinheiten und Währungen.

I 45 Vgl. Sandgruber, Anfänge, I 35 .

I 46 LR CIIIHi -3, Reg. 292 (I6 If.).

I47 So eine Angabe aus den I 740er Jahren: LR BIIA40, Reg. I 9606 (57).

I 48 Tafeln zur Statistik 7 (I834), unpag.; LAB, 2 5.7.I 855 .

I 49 Vgl. Reith, Umweltgeschichte, 25, 66 u. I 29f.; Gierlinger, Food.
} 
Tab. 16: Einfuhr von Lebensmitteln gemäß Verzehrsteuer, $1830 e r$ und 1850er Jahre

\begin{tabular}{|c|c|c|c|c|}
\hline \multirow[b]{2}{*}{ Kategorie } & \multicolumn{2}{|c|}{$1834 / 1836$} & \multicolumn{2}{|c|}{1853} \\
\hline & Menge & $\begin{array}{l}\text { kg pro } \\
\text { Kopf }\end{array}$ & Menge & $\begin{array}{l}\text { kg pro } \\
\text { Kopf }\end{array}$ \\
\hline $\begin{array}{l}\text { "Mehl aus Getreide, Kartoffeln und Hülsenfrüchten, Gries, gerollte } \\
\text { Gerste, Habergrütze« (1853 "aller Arten«) }\end{array}$ & $4.569^{a}$ & 188 & $5.222^{\mathrm{a}}$ & 192 \\
\hline Gemüse & $332^{\mathrm{a}}$ & 14 & $69^{a}$ & 2,54 \\
\hline Obst & $601^{a}$ & 25 & $456^{\mathrm{a}}$ & 17 \\
\hline Ochsen, Kühe, Kälber & $10.027^{b}$ & & $20.418^{b}$ & \\
\hline Schweine (1853 über 35 Pfund) & $798^{b}$ & & $1.885^{\mathrm{b}}$ & \\
\hline Schafe (1853 inkl. Ziegen) & $2.706^{b}$ & & $2.020^{\mathrm{b}}$ & \\
\hline Lämmer (1853 Lämmer, Kitze und Ferkel) & $1.919^{b}$ & & $2.788^{b}$ & \\
\hline Fleisch (1853 "Fleisch und Würste») & $441^{a}$ & 18 & $495^{a}$ & 18 \\
\hline Federvieh & & & $13.574^{a}$ & \\
\hline
\end{tabular}

Quelle: Eigene Berechnung basierend auf Tafeln zur Statistik 7 (1834), unpag.; LZ, 23.1.1837; LAB, 25.7.1855

a Tonnen (gerundet)

b Stück

Tab. 17: Linzer Fleisch- und Getreidekonsum pro Kopf, 1834-1905

\begin{tabular}{lrrrrr}
\hline & 1834 & 1850 & 1860 & 1900 & 1905 \\
\hline Fleisch kg & 85 & 62,1 & 70,0 & 86,7 & 77,6 \\
Getreide kg & 183 & 181,0 & 178,9 & - & 89,0 \\
\hline
\end{tabular}

Quelle: Sandgruber, Lebensstandard, 288

Getreidemarkt verfügte (vgl. auch Kap. Io. Versorgungskrise). ${ }^{150}$ Für Linz ergibt sich im Hinblick auf die Lebensmittelversorgung ein Bild, das partiell an die Überlegungen von Johann Heinrich v. Thünen zu Grunderträgen erinnert (erstmals I 826 publiziert in "Der isolirte Staat«) ${ }^{151}$ Idealtypisch sei die Stadt, so Thünen, von verschiedenen Versorgungsregionen umgeben, die zentral von der Frage des Transports abhingen. Nahe der Stadt (im ersten »Kreis«) produziere man schwer zu transportierende Frischprodukte (Gemüse, Milch) in intensiver Landwirtschaft, die daran anschließenden Zonen dienten der Produktion von Holz und Getreide, noch weiter

I 50 Vgl. LR BIIA 37 , Reg. I 9274 (I 28 - I42); LR E7a u. b, Reg. I074 (270); OÖLA, Franziszeischer Kataster, No. 534 (Operat I u. 2, Braune Mappe, Linz-Stadt, Katastralschätzungs-Elaborat, I 8. I 2.I 832); ebd. (Operat 2, Linz Untere Vorstadt, Beantwortung Fragen Gemeinde Lustenau, 25.I.I83 I).

I 5 I Thünen, Staat. 
entfernt gebe es extensive Weidewirtschaft. ${ }^{152}$ Thünen betrachtete sein Modell explizit als Modellannahme und betonte, dass - da die Städte nicht voneinander isoliert seien und Flüsse als Transportmittel die Settings erheblich veränderten - die Realität komplexer sei. ${ }^{153}$ Dies zeigt sich auch für Linz: Thünens »zweiter Kreis« (Forstwirtschaft) lag für Linz in der Regel weiter entfernt als der dritte bis fünfte »Kreis« (verschiedene Formen des Ackerbaus), wenngleich der Getreidebezug - im Hinblick auf die Entfernung - durchaus dem sechsten Kreis (extensive Viehzucht) nahekommen konnte. Hier liegt das hauptsächliche Defizit des Thünen'schen Modells: Unberücksichtigt blieben Dynamiken (die Auswirkungen resp. Wechselwirkungen kurzfristiger Impacts wie langfristiger Veränderungen) und geo- und hydromorphologische Spezifika der konkreten Orte. ${ }^{154}$

Die innere Stadt verfügte, wie Pläne aus dem r 8. Jahrhundert zeigen, kaum über Flächen, die zur Nahrungsmittelversorgung beitrugen: Das "Josephinische Lagebuch» erfasste in den I 780er Jahren Gartenflächen von nur rund 6.00o Quadratmetern (d.h. ca. 5 Prozent der Gesamtfläche), die jedoch eher als Ziergärten zu sehen sind. ${ }^{155}$ Die Stadt »consumirt ihre wenigen Garten Produkte selbst«, gab der 50 Jahre später entstandene »Franziszeische Kataster « an. ${ }^{156}$ Über dieses Katasterwerk ist ein Einblick in die innerstädtischen Gärten möglich, deren Fläche nun - nach der Abtragung der Stadtmauer - mit ca. I8.000 Quadratmetern angegeben wurde. Dort wurden Gemüse, Salate, Kohl und »Grünzeug« angebaut, dazu gab es »veredelte Obstgattungen«. Die Gärten erhielten »kräftigste Düngung« und »bestmöglichste Pflege«, die Qualität der Erzeugnisse sei als gut zu erachten, und diese fanden, sofern es nicht der Eigenversorgung diente, »in loco der Stadt selbst jederzeit den besten Absatz und Kaufmannswerth «. ${ }^{157}$ Weitaus umfangreichere landwirtschaftliche Flächen bestanden in den Vorstädten, besonders südwestlich und südöstlich der inneren Stadt, wo der für die Gartenwirtschaft gut geeignete und ertragreiche Boden der Niederterrasse intensiv genutzt wurde. ${ }^{158}$ Viele Toponyme verweisen für diese Gegend auf eine frühere landwirtschaftliche Nutzung, z. B. Baumgärten (untere Promenade), Spittelwiese (Herrengasse) oder Weingarten und Kapuzinerfeldgasse (Kapuzinerviertel). ${ }^{159}$ Zudem befanden sich größere Gartenanlagen östlich der inneren Stadt zwischen dem Ludlgraben und der Donau. Die Gärten lagen in den Vorstädten meist unmittelbar bei den

I 52 Vgl. Cronon, Metropolis, 48-52; Barles/Knoll, Transitions, 33f. u. EdN, s.v. Thünensche Ringe.

I 53 Thünen, Staat, If.

I54 Vgl. Castonguay, Agriculture, i $87 \mathrm{f}$.

I 55 OÖLA, Josephinisches Lagebuch, HS 190 (Linz Stadt).

I56 OÖLA, Franziszeischer Kataster, No. 534 (Operat I u. 2, Braune Mappe, Linz-Stadt, Preisberichtigungsprotokoll, 7.I 2.183I).

I 57 Ebd. (Operat I u. 2, Braune Mappe, Linz-Stadt, Katastralschätzungs-Elaborat, I 8.I 2.I 832).

I 58 OÖLA, Josephinisches Lagebuch, HS I9I (Linz Obere Vorstadt); vgl. zur urbanen und suburbanen Landwirtschaft: Soens, Agriculture, I3-28 u. Miodunka, Longue Durée, 75-94.

I59 Pfeffer, Naturfreude, 205; vgl. OÖLA, Karten- und Plänesammlung, V/8 (Stadtplan, I78I). 
Häusern, ein Zwölftel der Gartenfläche nutze man - so die Angabe für die Obere Vorstadt im »Franziszeischen Kataster« - als Krautäcker, also für den Anbau von Kartoffeln und Kraut, "größtentheils« habe man zudem Obstbäume, die Ernte werde selbst verbraucht oder in der Stadt verkauft. ${ }^{160}$ Von den etwas über 500 Häusern der Oberen Vorstadt verfügten nur I 40 über keinen eigenen Garten. ${ }^{161}$ Auch wenn die Kataster bei den Gartenflächen keine Erntemengen auswiesen, ${ }^{162}$ kann man davon ausgehen, dass deren Produktivität relativ hoch war: Im »Franziszeischen Kataster « schätzte man der Reinertrag von Gärten der »I. Klasse«, die vor allem dem »Küchengewächsbau« dienten, auf das mehr als Zweieinhalbfache von Äckern » I. Klasse«, selbst die Gartenklasse mit dem geringsten Reinertrag lag um den Faktor I,4 resp. 2,25 höher als die ertragreichsten Ackerflächen. ${ }^{163}$

Tab. 18: Landwirtschaftlich genutzte Flächen in Linz, 1780er bis 1870er Jahre

\begin{tabular}{|c|c|c|c|c|c|c|}
\hline Nutzung & 178 oer ha & $1830 e r$ ha & $1870 e r$ ha & 178 oer \% & $1830 e r \%$ & 1870 er \% \\
\hline Äcker & 997 & 1.068 & 1.026 & 56 & 60 & 58 \\
\hline Äcker mit Obstbäumen & & 3 & 5 & & 0 & 0 \\
\hline kleine Gärtena & & 63 & & & 4 & \\
\hline Gärten & 188 & 95 & 148 & 11 & 5 & 8 \\
\hline Wiesen & 143 & 149 & 147 & 8 & 8 & 8 \\
\hline Wiesen mit Obstbäumen & & 11 & 30 & & 1 & 2 \\
\hline Wiesen mit Holznutzen & & 1 & 3 & & 0 & 0 \\
\hline Hutweiden & & 19 & 25 & & 1 & 1 \\
\hline Hutweiden mit Holznutzen & & & 5 & & & 0 \\
\hline Gesamtfläche ${ }^{b}$ & 1.772 & 1.771 & 1.769 & 100 & 100 & 100 \\
\hline
\end{tabular}

Quelle: Eigene Berechnung basierend auf OÖLA, Josephinisches Lagebuch, Linz Stadt HS 190; OÖLA, Josephinisches Lagebuch, Linz Obere Vorstadt HS 191; Bohdanowicz, Vorstädte, Bd. 1, 38f.; OÖLA, Franziszeischer Kataster, No. 534; Foltz, Statistik, 4 of.

a in der Stadt wurden nur über 400 Quadratklafter (ca. 1.400 Quadratmeter) große Flächen erfasst

b Stadt und Vorstädte

Eine Aufstellung aus den I 78oer Jahren deutet auf die Relevanz der Gärten für Nutzer/innen vor Ort hin: Dem Hausmeister des Lambacher Freihauses wurde als Ausgleich für geringen Barlohn neben freier Unterkunft und anderen Sachleistungen auch

I6o OÖLA, Franziszeischer Kataster, No. 534 (Operat 2, Linz Obere Vorstadt, Beantwortung Fragen Gemeinde Waldegg, I3.r.I83 I); ebd. (Operat 2, Linz Obere Vorstadt, Katastralschätzungs-Elaborat, undat.).

I6 I Bohdanowicz, Vorstädte, Bd. 2, 63 .

I62 Der Output der Gärten wurde als Wiese (Heu und Grünfutter) geschätzt.

I63 OÖLA, Franziszeischer Kataster, No. 534 (Operat I, Braune Mappe, Linz Untere Vorstadt) u. ebd. (Operat 2, Linz Obere Vorstadt). 
die (Mit)Nutzung des Hausgartens eingeräumt. In den I $780 e r$ Jahren wurde diese Gartennutzung auf jährlich 30 fl geschätzt, während der Jahreslohn des Hausmeisters zu dieser Zeit 50 fl betrug. ${ }^{164}$

Die Kataster und andere Quellen zeigen die Nutzung kleinster Flächen: Das Bürgerspital verfügte über ein Grasnutzungs- und Viehweiderecht am Stadtgraben, dort bestanden zudem kleine (offenbar gepachtete) Gärten. ${ }^{165}$ Viele Handwerker beim Schmiedtor hatten einen kleinen Garten oder einen Arbeits- resp. Lagerplatz im Stadtgraben. ${ }^{166}$ Neben den Ziergärten vor dem Landhaustor gab es bis in die I77oer Jahre auch einen Nutzgarten, der dem landständischen Personal wohl als Lohnbestandteil zur Nutzung überlassen wurde. ${ }^{167}$ Diese kleinen Flächen - ein Haus östlich der Landstraße verfügte laut »Franziszeischem Kataster« über einen Gemüsegarten mit 250 Quadratmetern - bildeten vermutlich typische »Kuchlgärten« (also Gemüse- und Kräutergärten), die Teile des Eigenbedarfs abdeckten. ${ }^{168}$ Dazu gab es in den Vorstädten eine Vielzahl mittlerer und größerer Gärten, die in den Stadtplänen und Stadtansichten des I8. Jahrhunderts deutlich zu erkennen sind - besonders auf dem westlich der Landstraße gelegenen früheren Kapuzinerfeld befand sich bis ins I9. Jahrhundert eine relativ geschlossene Gartenlandschaft, die östlich der Landstraße über ein kleineres Pendant verfügte. ${ }^{169}$ Das in der Herrengasse gelegene spätere "Kremsmünsterer Haus ${ }^{170}$ verfügte I7 I9 über einen Garten mit rund 3.500 Quadratmetern Fläche. ${ }^{171}$ In der Bethlehemgasse befand sich ein ca. I.30o Quadratmeter großer Garten, ${ }^{172}$ in dem, wie I72 I festgehalten wurde, »Biern, Öpfel, Pfersich« und Marillenbäume sowie Weinreben gepflanzt waren. Der Gemüsegarten war »in 4en Stücken abgetheillet« und wurde zum Anbau von »Spargl und anderes Kuchel Kreutlwerch « genutzt. ${ }^{173}$

In der Regel unterhielten Klöster, Freihäuser und andere Institutionen sehr große Gärten: Das »Josephinische Lagebuch« gab für die Obere Vorstadt die Gartenfläche des Schlosses mit 2,4 Hektar an, die Gärten des Kapuzinerklosters - bestehend aus »Sakristeigarten«, »Refektorigarten«, "Kräutlgarten«, »Kreitlgarten«, »Feigengartel« und »Baumgarten« - waren I, I Hektar groß. ${ }^{174}$ Östlich der Landstraße befanden sich die umfangreichen Gartenanlagen der Elisabethinen, der Ursulinen, der Jesui-

\footnotetext{
I64 LR BIV, Reg. 780 (3 II); ebd., Reg. 573 (217-2 I9).

I65 AStL, HS 86I (»Chronologische Beschreibung«, I77oer Jahre), fol. $32 \mathrm{~b}$.

I66 Bohdanowicz, Vorstädte, Bd. I, 59-73.

I67 LR BIIG6, Reg. 3554 (2 I4).

I68 Bohdanowicz, Vorstädte, Bd. I, 634; LZ, I 9.4.I 805 ; LZ, 30.6.1 806.

I69 AStL, HS 86 (»Chronologische Beschreibung«, I77oer Jahre), fol. 3 I a u. 3 I b.

I70 Ab I784 »Bischofshof« (Konskr.-No. 573, heute Herrenstraße I9) - Kreczi, Häuserchronik, 299.

I7 I LR BVI2, Reg. I I 27 (6I-69).

I72 Konskr.-No. 438 (heute Bethlehemstraße 26) - Kreczi, Häuserchronik, 243.

I73 LR CIIIHI -3 , Reg. 447 (288-290).

I74 Bohdanowicz, Vorstädte, Bd. 2, 67; LR Eıf, Reg. 448 (I 84 f.).
} 


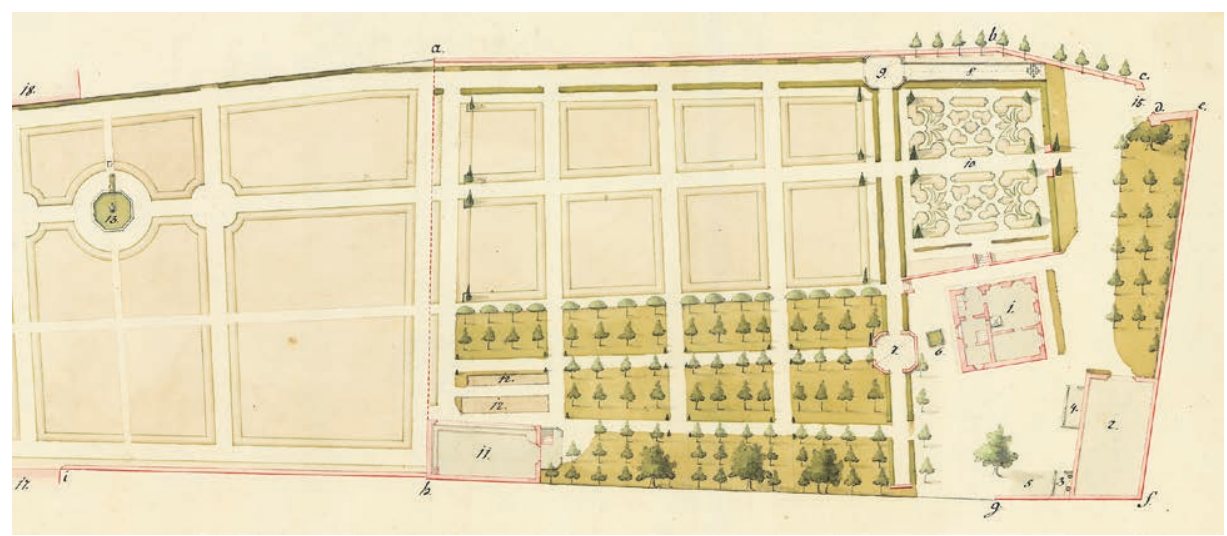

Abb. 11: Bürgerliche Gartenanlage bei der Wasserkaserne, 1775 (Ausschnitt) - links Wasserturm und Springbrunnen, rechts unten ein Stadel mit Schweinestall, "Mistgrube» und Abtritt

ten, des Nordischen Stiftes und des Deutschen Ordens. ${ }^{175}$ Zahlreiche wohlhabende Stadtbewohner/innen besaßen am Rand der Vorstädte Gartenanlagen, die meist eine Kombination aus Ziergärten (vgl. Kap. 7. Geordnete und modifizierte Umwelt) und Nutzgärten waren. Das Nebeneinander von Zier- und Nutzgarten zeigt ein in den I 770er Jahren entstandener Plan eines rund 6.60o Quadratmeter großen Gartens, der bei der Wasserkaserne lag. Als Besitzer wird der Apotheker Joseph Franz Weber genannt, der als Bürgermeister (zwischen I 778 und I784) Teil der städtischen Elite war. ${ }^{176}$ Der Plan bildet auch die Infrastruktur derartiger Großgärten ab (wobei unklar ist, wie viel davon tatsächlich in der Realität bestand): Gartenhaus, Holzstadel, Brunnen, Mistgrube und Schweinestall (vgl. Abb. I I). Verlassenschaften des I 8. Jahrhunderts dokumentieren die suburbanen Gärten vermögender Stadtbürger: Ein Stadtrat besaß zwei Gärten beim Ludlgraben, in der Nähe gehörten einem landständischen Beamten umfangreiche Flächen, ein Bäcker und eine Handelsfrau hinterließen nicht nur Stadthäuser, sondern auch vorstädtischen Gartenbesitz. ${ }^{177}$ Analog dazu nutzte das neben dem Landhaus und unmittelbar an der Stadtmauer gelegene Minoritenkloster nicht nur den ca. I 7o Quadratmeter großen Garten vor dem Refektorium, sondern es verfügte ebenso über ein Gartengrundstück am nahen Schullerberg. ${ }^{178}$

I75 Bohdanowicz, Vorstädte, Bd. I, 58 If., 6 6 5 f. u. 634f.; LR CIIIC 4 , Reg. 826 (356); LR CIIIH I -3, Reg. 595 (423f.); OÖLA, Josephinisches Lagebuch, HS 192 (Linz Untere Vorstadt); vgl. zum Garten des Deutschen Ordens: Wacha, Obstgarten.

I76 Abbgebildet ist der Plan auch in Mayrhofer/Katzinger, Geschichte, Bd. I, 332, wobei er hier dem Vorbesitzer, dem Apotheker Justus Pfaller, zugeschrieben wird (vgl. dazu Kreczi, Häuserchronik, I69).

I 77 LR BIIB I, Reg. 388 (2 I 4); ebd., Reg. 5 I (49f.); LR BIIA 3 O, Reg. I 8492 (I49- I69); LR BIIA 3 I, Reg. I 85 I 2 (36-62); vgl. Pfeffer, Naturfreude, $205 \mathrm{f}$.

I78 LR Erg, Reg. 346 (I46); ebd., Reg. 444 (I87); ebd., Reg. 449 (I89- I93). 
Nur partiell sind Einblicke in die Gärtenwirtschaft möglich. Einerseits machen Ausgabenrechnungen die Bepflanzung privater Gärten sichtbar, andererseits gibt es auch Informationen für einige Klöstergärten. Die Patrizierfamilie Thürheim, die seit dem I 7. Jahrhundert ein Freihaus neben dem Landhaus besaß, ${ }^{179}$ tätigte zahlreiche Ausgaben für den Unterhalt ihrer Gartenanlagen. Vermutlich handelte es sich dabei um den I 7 Io erworbenen Garten an der Promenade. ${ }^{180}$ I 7 I 4 kaufte man I.ooo Stöcke Spargel, »Braunschweiger Kohlsamen« und Samen für Spinat, Karfiol, Kraut, Rettich, Kohlrabi, Sellerie, Zwiebel, Knoblauch und Gewürze (Petersilie und Majoran), I7 I 9 bezog man I 2 Marillenbäume, I 2 Pfirsichbäume und 36 Weinstöcke aus Bozen, I72 I erneut die gleiche Anzahl an Marillen- und Pfirsichbäumen und Weinstöcken, wobei nicht eindeutig festgestellt werden kann, ob alles nur für den Linzer Garten bestimmt war, wenngleich es dort »welsche« Bäume gab. ${ }^{181}$ Im umfangreichen Garten des Ursulinenklosters wurden - was man in der Hauschronik für die I 780 er und I 79oer Jahre relativ detailliert vermerkte - Kräuter, Kraut, Kohl, Rüben, Karfiol, Salat, Sellerie, sogar Artischocken und Spargel angebaut, an Obst fanden sich Äpfel, Melonen, Marillen, Pfirsiche und Feigen. ${ }^{182}$ Die Chronik des Urfahrer Kapuzinerklosters dokumentiert ständige Investitionen in den Garten, die auch den Anbau von Obst und Gemüse betrafen: I746 hatte man eine »Verbesserung « des Gartens vorgenommen, I760 wurde die 1733 erfolgte Pflanzung von Weinreben aufgegeben (die man durch Buchen ersetzte), zudem erneuerte und erweiterte man mehrfach den Obstbaumbestand (Äpfel, Birnen, Marillen und Zwetschken). ${ }^{183}$ Der Garten des Linzer Kapuzinerklosters war zwar relativ groß (vgl. oben), er scheint jedoch wenig intensiv oder vorrangig als Ziergarten genutzt worden zu sein: I 740 wurde der Garten neu gestaltet, für einen Ersatz der I 74I abgefrorenen Weinstöcke wollte man aber offenbar längere Zeit kein Geld aufwenden. ${ }^{184}$ I 8 I 2 gab das Kloster an, keine Einnahmen aus dem Garten zu erzielen, er diene nur dem Eigenbedarf, ${ }^{185}$ und als das Kloster r 824 einen Teil des Gartens für die Errichtung der Taubstummenanstalt abtrat, stellte man fest, dass es sich dabei lediglich um ein »mittelmäßige[s] Gartengrundstück« mit wenigen Beeten und »mittelmäßige[n] Obstbäume[n] « handle, das zudem schwierig zu bewässern sei. ${ }^{186}$

In Summe trugen die Gärten vermutlich bis ins i 9. Jahrhundert wesentlich zur Ernährung von Linz bei - darauf deutet auch die niedrige Menge von Gemüse und

\footnotetext{
I79 Heute Altstadt 30 resp. Promenade 26 - Kreczi, Häuserchronik, 24.

I 80 Heute Promenade 9 (Kreczi, Häuserchronik, 290); vgl. LR BIIG8, Reg. 54I4 (I 46).

I8 I LR BIIG8, Reg. 5036 (89); ebd., Reg. 505 I (9 If.); ebd., Reg. 5 I 97 (I I 4); ebd., Reg. 53 I6 (I 32); ebd., Reg. 5760 (193).

I82 LR Eıb, Reg. I505 (50); ebd., Reg. I 804 (Iоo); ebd., Reg. I 836 (Iо5f.); Reg. I 843 (Iо6f.).

I 83 LR Eг (I08).

I84 Ebd., Reg. Iо03 (190); ebd., Reg. Iог6 (192).

I8 5 LR EIf, Reg. 5 I4 (205f.).

I86 Ebd., Reg. 556 (2 18f.).
} 
Obst hin, für die Verzehrsteuer bezahlt wurde (vgl. Tab. I6). Größere Gärten konnten eine Verdienstmöglichkeit bieten: I 72 I hatte man die Einnahmen, die man aus einem ca. I.300 Quadratmeter großen Garten lukrieren könne, auf jährlich 40 fl für Gemüse und Kräuter und 50 fl für Obst geschätzt, was den Jahresverdienst eines Taglöhners überstieg. ${ }^{187}$ Für den umfangreichen - und intensiv genutzten - Garten des Ursulinenklosters verzeichnete man I788 Einnahmen von 2 Io fl 6 kr I 2 d, hingegen Ausgaben (für Handwerker, Taglöhner und Dünger) von nur 68 fl I 8 kr. Spürbar stolz errechnete die Buchführerin der Ursulinen einen Reinertrag von I 50 fl jährlich für die letzten 20 Jahre, was als »Jahreszinsen« bezeichnet wurde und damit auf ein Verständnis des Gartens als Investitions- und Erwerbsobjekt hindeutet. ${ }^{188}$ Diese Strategie scheint auch funktioniert zu haben: In den I 79oer Jahren übertrafen die Einnahmen die Ausgaben und Investitionen zumindest um das Doppelte, meist um das Dreifache. ${ }^{189}$

Die "fruchtbarsten Feldern und schattenreichsten Meyerhöfe«, so liest man in einer Reisebeschreibung aus den I 78 oer Jahren, schlossen an die Bebauung und die Gärten der Vorstädte an. ${ }^{190}$ Auch diese Bauernhöfe verfügten über Hausgärten : I 722 wurden in einer Beschreibung des am südlichen Ende der Vorstädte gelegenen Stockhofes ein »Blumbgärtl« mit »Zwerg Baumben und Weinreben« und ein »Kuchlgartten« erwähnt, zudem ein um den Hof angelegter »Baumbgartten« mit Obstbäumen und Grasnutzung. ${ }^{191}$ Die Äcker profitierten von den ertragreichen Böden der Hoch- und Niederterrassen, die der bayerische Botaniker Franz de Paula Schrank als »vortreffliches Erdreich« einschätzte, lediglich weiter südlich sei alles nur »noch ein unermeßlicher Schutt kleiner Kiesel«. ${ }^{192}$ Der »Franziszeische Kataster der I 83oer Jahre differenzierte deutlicher: In der Oberen Vorstadt wurden die Felder auf der Gug1, am Spallerhof und bei Niedernreith als sehr ertragreich eingestuft, die überwiegend für den Anbau von Getreide genutzt wurden. Eine schlechtere Eignung des Bodens und geringere Erträge wurden - aufgrund der Donaunähe - für die östlichen und nordöstlichen Teile der Unteren Vorstadt konstatiert, aber dennoch dominierte auch hier die Ackernutzung, besonders der Anbau von Getreide. Als Haupterzeugnisse werden im Kataster Weizen, Roggen, Gerste und Hafer genannt, zudem Klee, »etwas« Wicken, als »Nebenbau« Kartoffel und Kraut, als »Nachbau« Rüben und »KühfutterGetreide«. Der Kartoffelanbau war noch begrenzt und wurde nur auf ein Vierzigstel der Fläche geschätzt. Die Fruchtfolge bildete in beiden Vorstädten die Regel, Brachen waren die Ausnahme. Gärten und Äcker wurden intensiv bewirtschaftet und größtenteils auch regelmäßig gedüngt: Man entnehme den Dünger "größtentheils«

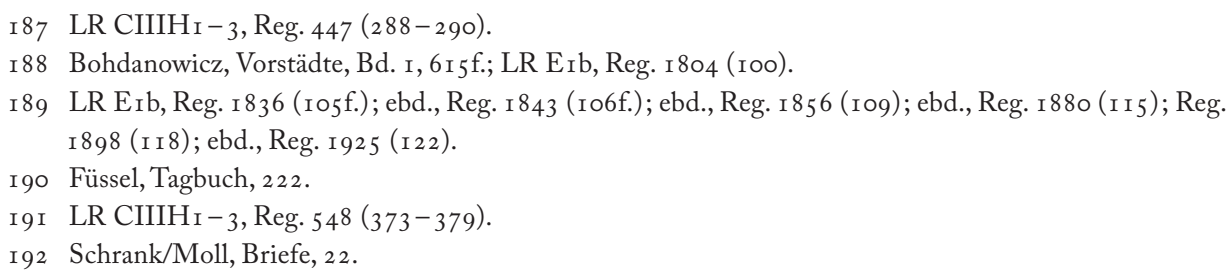


aus eigenem Betrieb, beziehe das »Fehlende« aus Linz, zudem verwende man etwas Mergel (»Schlier«) und Gips aus dem Umland, wobei die Gemeinde Lustenau angab, Gips aus Salzburg anzukaufen. In der Oberen Vorstadt düngte man die Äcker alle vier Jahre, in der Unteren Vorstadt die Äcker mit Brache alle drei Jahre und ohne Brache alle zwei Jahre. Roggen und Hafer wurden meist selbst verbraucht, das überschüssige Getreide verkaufte man in der Vorstadt oder direkt an die Linzer Bäcker und Greißler. ${ }^{193}$ Wenn man die Ernteerträge - die jedoch als zeitgenössische Schätzung zu erachten sind - betrachtet (vgl. Tab. I9), dann wird deutlich, dass in den Vorstädten und im Nahbereich der Stadt signifikante Mengen an Getreide produziert wurden, wenngleich dies zum Ende des I 8. Jahrhunderts zur Versorgung der lokalen Bevölkerung nicht ausgereicht hätte.

Tab. 19: Ernteerträge im Linzer Raum (gerundet), Ende der 1780er Jahre

\begin{tabular}{lcccccc}
\hline & $\begin{array}{c}\text { Weizen } \\
\text { Metzen }\end{array}$ & $\begin{array}{c}\text { Weizen } \\
\text { Tonnen }\end{array}$ & $\begin{array}{c}\text { Roggen } \\
\text { Metzen }\end{array}$ & $\begin{array}{c}\text { Roggen } \\
\text { Tonnen }\end{array}$ & $\begin{array}{c}\text { Hafer } \\
\text { Metzen }\end{array}$ & $\begin{array}{c}\text { Hafer } \\
\text { Tonnen }\end{array}$ \\
\hline Stadt Linz & - & - & - & - & - & - \\
Untere Vorstadt (St. Joseph) & 1.081 & 49,86 & 3.373 & 145,21 & 2.647 & 73,26 \\
Obere Vorstadt (St. Matthias) & 917 & 42,30 & 2.954 & 127,17 & 2.705 & 74,86 \\
St. Peter & 254 & 11,72 & 2.027 & 87,26 & & \\
Kleinmünchen & 441 & 20,34 & 3.688 & 158,77 & & \\
Leonding & 2.117 & 97,65 & 6.511 & 280,30 & & \\
Summe & & 221,87 & & 798,71 & & \\
\hline
\end{tabular}

Quelle: Eigene Berechnungen basierend auf Pillwein, Beschreibung, 57, Bohdanowicz, Vorstädte, Bd. 1, 38 u. Bohdanowicz, Vorstädte, Bd. 2, 45. Pillweins in den 1820er Jahren für den »Kommisariatsbezirk « angegebene Zahlen stammen offensichtlich aus dem 50 Jahre zuvor entstandenen "Josephinischen Lagebuch".

Anders als beim Getreide waren für die Fleischversorgung der Stadt die vorstädtischen Bauernhöfe vermutlich nur begrenzt relevant: Ein 1778 erstelltes Inventar für den relativ großen Gugelhof listet nur 8 Kühe, 2 Kälber, 4 Schweine und 6 Hennen auf, das Inventar eines Schiffmeisters, der über umfangreichen landwirtschaftlichen Besitz verfügte, dokumentiert ebenso nur 9 Rinder, 6 Kälber und einige Ziegen sowie - was der peripheren Lage im Auengebiet geschuldet ist - 40 Schafe und 35 Lämmer. ${ }^{194}$ Die Angaben im »Franziszeischen Kataster« zum Viehbesitz divergieren erheblich, was

I93 OÖLA, Franziszeischer Kataster, No. 534 (Operat 2, Linz Obere Vorstadt, Katastralschätzungs-Elaborat, undat.); ebd. (Operat 2, Linz Obere Vorstadt, Protokoll Klassifikation, 8.7.I 83 I); ebd. (Operat 2, Linz Obere Vorstadt, Beantwortung Fragen Gemeinde Waldegg, I 3. I. I 83 I); ebd. (Operat I, Braune Mappe, Linz Untere Vorstadt, Einlage des allgemeinen Katasters, undat.); ebd. (Operat 2, Linz Untere Vorstadt, Beantwortung Fragen Gemeinde Lustenau, 25.I.I 83 I); vgl. zum Gipsdünger: Neweklowsky, Schiffahrt, Bd. 3, 78 .

I 94 LR BIIB $_{3}$, Reg. 94I (If.); LR BIIB 2 , Reg. 520 (32-35). 
möglicherweise Schlachtungen zuzuschreiben ist: Für die Obere Vorstadt wurden 202 resp. 390 Kühe, I 56 resp. 259 Schweine und 76 resp. 243 Schafe angegeben, für die Untere Vorstadt 2 I 9 resp. 295 Kühe, 60 resp. 74 Jungrinder, I 30 resp. 239 Schafe, 239 resp. 357 Schweine und 80 Ziegen. Insgesamt wurde festgestellt, dass bei "größeren Wirtschaften« Io bis I 2 Kühe, 4 bis 6 Jungrinder, I 5 bis 30 Schafe und I 2 bis 20 Schweine anzutreffen seien. ${ }^{195}$ Der Tierbesitz von nichtbäuerlichen Haushalten zur Selbstversorgung ist kaum sichtbar: Im Ursulinenkloster wurde I 740 die Kuhhaltung aus Kostengründen aufgegeben, die Schweine blieben aber. ${ }^{196}$ In den I 73oer Jahren kritisierte ein Rechnungsprüfer die Haltung einer Kuh im Linzer Waisenhaus als unwirtschaftlich - man kaufe ohnehin Milch und Butter an. Zu dieser Zeit gab es dort auch Schweine, angeblich hatte der Verwalter - widerrechtlich, wie betont wurde sechs eigene Schafe ins Waisenhaus mitgebracht. ${ }^{197}$ Vereinzelt dokumentieren Inventare - häufig bei Bäckern - den Besitz von Schweinen; ${ }^{198}$ der Beitrag dieses Kleinbesitzes zur städtischen Ernährung ist aber nicht abzuschätzen.

Infolge der Lage an Donau und Traun waren im Linzer Raum auch Fischer tätig, die jedoch nur geringe Mengen an Fisch für den städtischen Bedarf bereitstellten: Durch den Magistrat Linz wurde das Fischereirecht, das von Margarethen bis zur Donauinsel reichte, im frühen I 9. Jahrhundert nur an einen Pächter und um einen geringen Betrag (jährlich 8 fl CM) vergeben, auch das "Josephinische Lagebuch« notierte für die Donau in St. Peter und an der Traun nur eine Handvoll Fischer mit geringen Erträgen. ${ }^{199}$

\section{Dritter bis sechster »Kreis«: Lebensmittel aus dem Um- und Hinterland}

Die meisten Lebensmittel wurden außerhalb der Stadt und der Vorstädte produziert, wobei die Herkunftsregionen nach Produkten und zudem nach Preisen variierten. Ein großer Teil der Lebensmittel kam aus dem Umland, das ebenso durch Ackerwirtschaft und Obstanbau geprägt war. Schon in der zweiten Hälfte des I 8 . Jahrhunderts war

I 95 OÖLA, Franziszeischer Kataster, No. 534 (Operat 2, Linz Obere Vorstadt, Katastralschätzungs-Elaborat, undat.); ebd. (Operat 2, Linz Obere Vorstadt, Beantwortung Fragen Gemeinde Waldegg, I3.I. I 83I); ebd. (Operat 2, Linz Untere Vorstadt, Katastralschätzungselaborat, undat.); ebd. (Operat 2, Linz Untere Vorstadt, Beantwortung Fragen Gemeinde Lustenau, 25.I.I83I).

I 96 LR Erb, Reg. I6r6 (65).

I 97 LR BIIG 5 , Reg. 2559 (5 I); ebd., LR BIIG 5 , Reg. 2630 (67f.).

I 8 Vgl. LR BIIB 2, Reg. 509 (29); LR BIIB 3 , Reg. I 422 (I 82 f.).

I99 AStL, Altakten, Sch. 3 I ; AStL, HS I 108 (Stadtratsprotokoll I 827), fol. 5 2a; AStL, HS I5 I (Oberkammeramt Empfang I 830), pag. I 5 ; Bohdanowicz, St. Peter, I96f.; Fangzahlen für das I 9. Jahrhundert sind mir nicht bekannt, die geringen Pachtzahlungen sprechen aber nicht für sehr hohe Erträge (vgl. AStL, HS i 9 I [Oberkammeramt Empfang i 85o], pag. 75 u. AStL, HS 236 [Kammeramt Empfang I 870], pag. 43); für I 904 wurde ein Fang von nur rund I I Tonnen im »Linzer Donaurevier« angegeben - Jungwirth et al., Donau, I 83 . 
die Landwirtschaft im oberösterreichischen Zentralraum relativ hoch entwickelt, vor allem beim Weizenanbau gab es in dieser Zeit signifikante Zuwächse, auch der Verzicht auf die Brache und die Expansion des Kleeanbaus - beides Kennzeichen für die Agrarmodernisierung - setzte sich früher als in anderen Teilen Österreichs durch. ${ }^{200}$ Für die letzten Jahrzehnte des r 8. Jahrhunderts kann man bereits bei Getreide von einer (rechnerischen) Überproduktion in normalen Erntejahren ausgehen (vgl. Tab. 20).

Tab. 20: Erzeugung und Verbrauch von Getreide pro Kopf/Jahr in Oberösterreich, 1770er Jahre bis 1910

\begin{tabular}{lccc}
\hline & Erzeugung Getreide in kg & davon Weizen in kg & geschätzter Verbrauch in kg \\
\hline 1785 & 318 & 42 & $240-260$ (für 1771) \\
1830 & 352 & 62 & \\
1870 & 373 & 71 & $200-215$ (für 1880) \\
1910 & 399 & 80 & \\
\hline
\end{tabular}

Quelle: Sandgruber, Lebensstandard, 279

Getreide wurde aber genauso überregional bezogen: Welchen Anteil die Versorgung aus weiter entfernten Gebieten ausmachte, ist für das I 8. Jahrhundert nur schwer abschätzbar - es ist hier auch von einem erheblich divergierenden Bedarf auszugehen. Für das I 8. Jahrhundert ist als häufige Gegenfracht der Salzfuhren böhmisches Getreide belegbar, das, über Linz transportiert, wohl für das Salzkammergut bestimmt war. ${ }^{201}$ Wie für Brennholz und andere Materialien bildete die Donau auch für Getreide einen relativ günstigen Transportweg, der im Verlauf des i 8. Jahrhunderts vermutlich erheblich an Bedeutung gewann. Tendenziell wird diese überregionale Versorgung in Krisen sichtbar: I7 I 3 kauften die Landstände 550 Mut Roggen und 200 Mut Hafer (also über 700 Tonnen Getreide) in Ungarn an, um die Versorgung Oberösterreichs sicherzustellen und die Preise niedrig zu halten. ${ }^{202}$ I 723 bezog man, weil die regionale Ernte »so wenig geriet«, Getreide aus Bayern und Niederösterreich, wobei darunter eher allgemein Süddeutschland und eventuell auch Oberungarn zu verstehen sind. Aus Bayern kamen insgesamt i 8 I Mut Weizen, I4 Mut Roggen, 24 Mut Gerste und 55 Mut Hafer, der überwiegende Teil des Getreides - 7 I 7 Mut Weizen, I.057 Mut Roggen und 22 Mut Hafer - wurde donauaufwärts nach Linz gebracht. ${ }^{203}$ Insgesamt waren dies ca. 2. Ioo Tonnen Getreide, was ausgereicht hätte, um die Stadt Linz für ein

200 Sandgruber, Lebensstandard, 275-277; Hoffmann/Meixner, Wirtschaftsgeschichte, Bd. I, 264 u. 290.

20 I Awecker, Bruckamt, I 9o; vgl. LR BIIA40, Reg. I9684 (I03).

202 Kumpfmüller, Hungersnot, Ior - ro6; OÖLA, Landschaftsakten, Sch. 930, G.XXIII.2/No. 40.

203 LR BIIG 4 , Reg. 2344 (7 If.); ebd., Reg. 234I (69); vgl. für die I 740er Jahre: LR CIIA, Reg. 625 (I $79 f$.). 
Jahr zu versorgen (vgl. oben). ${ }^{204}$ Auch in der Versorgungskrise der I 77oer Jahre wurde Getreide in großen Mengen aus Ungarn importiert (vgl. Kap. Io. Versorgungskrise). ${ }^{205}$

Aber nicht nur in Krisenzeiten bezog man große Mengen an Lebensmitteln aus entfernteren Gebieten: Einem Linzbesucher fiel zu Beginn des I9. Jahrhunderts die »Menge kleiner Kähne« mit »Holz, Kohlen, Getraide, und vorzüglich Gemüse aus dem Innviertl« auf, ${ }^{206}$ das »Josephinische Lagebuch « betonte für die Gemeinde Urfahr, dass die Lebensmittelproduktion vor Ort »nicht hinlänglich« sei - »das Abgängige wird auf der Donau heraufgebracht ${ }^{207}$ Beim Getreide scheint der überregionale Bezug vor allem der Transport über Wasser - in der zweiten Hälfte des I8. Jahrhunderts an Bedeutung gewonnen zu haben. ${ }^{208}$ Größere Lieferungen auf der Donau wurden im I 8 . und frühen I9. Jahrhundert direkt über die Schiffmeister abgewickelt, die nicht nur als Transporteure, sondern offenbar auch als Händler tätig waren. I 804 nahm die Linzer Faktorei der Innerberger Gewerkschaft mit einem Linzer Schiffmeister Kontakt auf, um Getreide anzukaufen: Dieser bot 3.000 Metzen (also rund 130 Tonnen) ungarischen Roggen an, die schon donauaufwärts unterwegs waren, weitere 6.00o Metzen könnten nachgeliefert werden. ${ }^{209}$ Bereits für das I 7. Jahrhundert sind große Schiffzüge belegbar, die vermutlich bis zu I 30 Tonnen transportieren konnten, dazu kam eine Vielzahl an kleineren Schiffen. ${ }^{210}$ Die Transportkapazitäten der Linzer und Urfahrer Schiffmeister in der Stadt (offenbar fünf Gewerbe im ausgehenden I 8. Jahrhundert) waren jedenfalls beachtlich: In den $1780 e r$ Jahren brachte ein Schiffmeister angeblich jährlich 40.00o Zentner Kupfer und »einige« I.ooo Zentner Eisenwaren - also zumindest 2.300 Tonnen - donauaufwärts. ${ }^{211}$

Auch der städtische Fleischkonsum basierte wahrscheinlich größtenteils auf überregionalen Importen. Um I750 lag die Fleischproduktion in Oberösterreich unter 30 Kilogramm pro Kopf und Jahr, I 850 bei 40 Kilogramm und I 875 (wie auch I 9 ro) bei 49 Kilogramm, was deutlich unter dem Pro-Kopf-Verbrauch lag (vgl. Tab. 17). ${ }^{212}$ Noch zur Mitte des 19. Jahrhunderts gab es in Oberösterreich keine ausgeprägte Schweinehaltung; man bezog "Läuferschweine«, vielfach aus Ungarn und Serbien. ${ }^{213}$ Das Rindfleisch kam vermutlich ebenso überwiegend aus Ungarn: Dafür lag Linz

\footnotetext{
204 Wenn man Mut zu 30 Metzen rechnet und 23-35 Kilogramm pro Metzen annimmt - vgl. Kap. Währungen und Maßeinheiten.

205 Vgl. Kumpfmüller, Hungersnot, ro7- г 20 u. Neweklowsky, Getreidetransport, 344-347.

206 Mader, Reise, 24.

207 Bohdanowicz, Urfahr, I8; eine Marktordnung aus dem Jahr I 8 I 9 erwähnt »Schiffe mit Gemüse, Grünzeig und Obst« an der Oberen Donaulände (OÖLA, Musealarchiv, Sch. 4/No. 2 I).

208 Albrecht, Need, 8- I 2.

209 LR CIIB, Reg. I 988 (522).

2 Io Donau in Oberösterreich, 3of.; Neweklowsky, Donauschiffahrt, I 82f.; Pillich, Donaureise, $502 f$.

2 I I Hoff, Skizze, 93.

2 I 2 Sandgruber, Lebensstandard, 279.

2 I 3 Hoffmann, Bauernland, 376.
} 
relativ günstig, da eine Transitroute des internationalen Ochsenhandels, der vor allem Süddeutschland versorgte, nahe Linz verlief. ${ }^{214}$ I 723 und I724 wurde für insgesamt 5.895 ungarische Ochsen in Linz Maut bezahlt, ${ }^{215}$ wobei ein großer Teil davon Linz wieder verlassen haben wird. Dennoch unterstreichen einzelne Hinweise aus dem I 8. Jahrhundert, dass die ungarischen Ochsen auch für den lokalen Konsum eine erhebliche Bedeutung hatten. ${ }^{216}$

Bei spezifischen Produkten weitete sich das Hinterland erheblich aus: Fisch bezog man vor allem aus Böhmen, auch wenn der Straßentransport relativ aufwändig war. Böhmische Fische, vor allem Karpfen, wurden über Linz bis nach Salzburg, Wien oder in die Steiermark transportiert. ${ }^{217}$ Den Bezug aus Böhmen dokumentieren Inventare von Linzer Fischhändlern, die mit erheblichen Mengen von lebenden Fischen handelten: In einem Inventar aus dem Jahr I 750 wurden fast 400 Kilogramm Karpfen erfasst, in einem Inventar aus dem Jahr ${ }_{1772}$ über 400 Kilogramm Karpfen. ${ }^{218} \mathrm{Im}$ Winter I 788 war in einem Linzer Gasthaus ein ungarischer Fischhändler verstorben, der offenbar mit einem Schlitten unterwegs gewesen war und der - wenn man dafür das aufgefundene Bargeld als Indikator nimmt ( $92 \mathrm{fl} 2 \mathrm{I} \mathrm{kr}$ ) - bereits eine erhebliche Warenmenge veräußert hatte. ${ }^{219}$ Beim Bezug von hochpreisigen Lebens- und Genussmitteln wurden - wenig überraschend - große Distanzen überwunden: Wein kam aus Südtirol und Niederösterreich, ${ }^{220}$ für den Deutschen Orden wird sogar der Bezug von Rheinwein erwähnt. ${ }^{221}$ Die Linzer Patrizierfamilie Thürheim erwarb schon im beginnenden I 8. Jahrhundert regelmäßig größere Mengen an Südfrüchten, so etwa im Jahr I 700 über I 50 Limonen und fast ıoo Pomeranzen. ${ }^{222}$ Dazu kaufte der Thürheim'sche Haushalt Kakao, Kaffee und Tee, ${ }^{223}$ I 726 sogar »neue isländische Fische« und »neue flämische Heringe «. ${ }^{224}$ Die Ausgabenrechnungen der Linzer Stiftshäuser deuten darauf hin, dass ähnliche Lebensmittelimporte in der Oberschicht keine Ausnahme, sondern eher die Regel bildeten. ${ }^{25}$

2 I 4 Hoffmann/Meixner, Wirtschaftsgeschichte, Bd. I, 439; Silló-Menzel, Oxenweg, 22f. u. 74-77; vgl. EdN, s.v. Ochsenhandel u. Westermann, Forschungsaufgaben, $267 \mathrm{f}$.; in einem Plan aus dem frühen I9. Jahrhundert ist die »Ochsen Strasse« südlich von Linz verzeichnet: OÖLA, Karten- und Plänesammlung, V/I I.

2 I 5 LR BIIA2 1 , Reg. I6152 (73).

216 LR BIIA6, Reg. 7485 (36); ebd., Reg. 8075 (I34); LR CIIA, Reg. $55^{2}$ (I58).

2 I 7 Wacha, Fische, 72, 89 u. 9 I -96.

2 I 8 LR BIIB I, Reg. Iо3 (9 I-93); LR BIIB2, Reg. 729 (г 24f.).

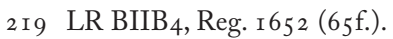

220 LR BIA 5 , Reg. 667 ( 208); LR CIIIC 3 , Reg. 36 (i I); LR BIIBI, Reg. 96 (83f.).

22 I LR CIIIHI -3 , Reg. 302 (I72).

222 LR BIIG8, Reg. 4729 (36); ebd., Reg. 474I (39f.).

223 Ebd., Reg. 4956 (77); vgl. ebd., Reg. 4950 u. ebd., Reg. 5095.

224 Ebd., Reg. 549I (I57).

225 LR BIV, Reg. 373 (I3 If.); ebd., Reg. 546 (208); LR BX2 u. 3, Reg. I 9 I 8 (706-709). 


\section{Modifikationen der Lebensmittelversorgung}

Bereits in den I76oer Jahren war in Linz als merkantiles Projekt der Landstände und des Kaiserhofes eine »Agricultur-Societät« gegründet worden, von der eine Modernisierung der Landwirtschaft ausgehen sollte. Diese Gründung blieb aber offenbar ohne umfangreiche Aktivitäten, erst mit der Etablierung einer Lehrkanzel für Landwirtschaft am Linzer Lyzeum i 808 setzten sich die Modernisierungsdiskurse fort. Damit verbunden war I8 10 der Ankauf eines »Musterhofes« in der Linzer Vorstadt, der einerseits für den praktischen Unterricht gedacht war, andererseits als Vorbild für moderne landwirtschaftliche Bewirtschaftungsmethoden (v.a. Propagierung der Fruchtfolge und des Kartoffelanbaus) fungieren sollte. ${ }^{226}$ Dieser Betrieb (der ehemalige Taschlbauer) war am südlichen Rand der Vorstädte gelegen und kam mit über 32 Joch Äckern und Gärten, zwei Pferden, zwei Ochsen, rund zehn Kühen (ohne Jungvieh), zehn Schweinen und hundert Hühnern einem Großbetrieb gleich. ${ }^{227}$ Die I 825 erfolgte Auflassung und Versteigerung des Musterhofes lässt sich als ein Hinweis auf die mangelnde Strahlkraft derartiger Projekte zu dieser Zeit lesen - bereits vor dem Ankauf waren die Landstände skeptisch gewesen und hatten darauf verwiesen, dass die Landwirtschaft vor Ort ohnehin ein »Vorbild « sei. ${ }^{228}$ Mit der Gründung des »k.k. Landwirthschafts-Vereins für Oberösterreich« und den landwirtschaftlichen Ausstellungen und Vorführungen im Volksgarten betrat die Agrarmodernisierungsdiskussion um die Mitte des I9. Jahrhunderts wieder eine städtische Bühne. ${ }^{229}$ Wenn man die Erntemengen betrachtet (vgl. Tab. 20), scheint der Reformdiskurs nicht zu großen Veränderungen in der Landwirtschaft des Umlandes geführt zu haben. Roman Sandgruber hat für den oberösterreichischen Pflanzenbau in der zweiten Hälfte des I 9. Jahrhunderts eine Phase der Stagnation konstatiert, den er vor allem auf die ungarische Konkurrenz beim Getreideanbau zurückführt. ${ }^{230}$ Der Großraum von Linz blieb aber trotz »der Umwälzungen, welche der moderne Cerealienverkehr hervorgerufen hat « - gemeint sind hier die umfangreichen ungarischen Weizenimporte -, vom Ackerbau geprägt. ${ }^{231}$

Relevanter waren Verluste lokaler Produktionsflächen infolge von Überbauung und Umnutzung. ${ }^{232}$ Fast jede Erweiterung der Stadt betraf landwirtschaftlich genutzte Flä-

226 LR BIIA $_{3}$ 8, Reg. I93 I I (78-83); Pillwein, Beschreibung, 227f.; Stauber, Ephemeriden, 37 I - 375; vgl. Hoffmann/Meixner, Wirtschaftsgeschichte, Bd. I, 29I u. Rumpler/Urbanitsch, Habsburgermonarchie, Bd. 8, 22 f.

227 Pillwein, Beschreibung, 227 f.; Heinse, Linz, r. Aufl., 33.

228 LZ/AB, 3.I.I825; LR BIIA4I, Reg. 19887 (66f.); Fink, Geschichte, 83.

229 Pillwein, Linz, Bd. 2, 26; Stauber, Ephemeriden, 374f.; Der Oberösterreicher I 884, I73f.; Statistischer Bericht I 876, XXI; vgl. Mayrhofer, Donaustadt, I 53.

230 Sandgruber, Lebensstandard, 277.

23 I Foltz, Statistik, 79; Linz a./d. Donau, ro (Zitat).

232 Vgl. zu Wien: Brunner/Schneider, Umwelt, 42. 
chen: In den I 7 Ioer Jahren war der ehemalige Garten des kaiserlichen Beamten Michael Anton v. Engel - der selbst auf Äckern entstanden war - parzelliert und teilweise überbaut worden, ${ }^{233}$ die Elisabethinen erwarben 1745 ein vorstädtisches Gartengrundstück, das eigentlich schon I 7 I 4 bebaut werden hätte sollen. ${ }^{234}$ Der Vergleich von Stadtplänen des beginnenden I 8. Jahrhunderts mit solchen aus der zweiten Hälfte des I 9. Jahrhunderts zeigt ein deutliches Zurückweichen der Ackerflächen rund um die Stadt: Der Bahnhof und die umfangreiche dazugehörende Infrastruktur wurden ebenso wie die "Neustadt« auf Äckergründen errichtet (vgl. Kap. 2. Kontexte: Linz I 7oo bis I 9oo). ${ }^{235}$

Auch in Bezug auf die Versorgung aus dem Hinterland sind erhebliche Veränderungen anzunehmen, die mit Veränderungen des Angebots und der Nachfrage zusammenhingen. ${ }^{236}$ Auf der Nachfrageseite lässt sich für das I 9. Jahrhundert ein Übergang zum Weizen und hier - aufgrund der besseren Qualität - ein Bedeutungsgewinn des ungarischen Getreides feststellen. ${ }^{237} \mathrm{Ab}$ der Mitte des i 9. Jahrhunderts gewann die Kartoffel an Bedeutung für die Ernährung, ${ }^{238}$ auch der Fleischkonsum stieg an (vgl. oben), wobei nun zunehmend Schweinefleisch konsumiert wurde. ${ }^{239}$ Auf der Angebotsseite standen eine deutliche Expansion der Weizenproduktion in Oberungarn und im Banat ${ }^{240}$ und die Verbesserung der Transportsituation - zuerst auf der Donau und dann zur Donau hin (vgl. Kap. 6. Fluviale und aquatische Räume) ${ }^{241}$ Gewaltige Mengen an Getreide und anderen Lebensmitteln passierten und erreichten Linz über die Donau (vgl. Tab. 2 I ) : ${ }^{242}$ "Die Fracht ist billig, die Gebühren, welche zur Erhaltung der Leinpfade (Treppelwege) in gutem Stande bestehen, sind gering «, konstatierte man in einem Reisebericht aus den I $840 e r$ Jahren, zudem habe das Transportwesen »durch die Einführung der eisernen Frachtschiffe eine sehr bedeutende Beschleunigung « erfahren. ${ }^{243}$ In der Linzer Schiffswerft wurden ab den I 840er Jahren eiserne Frachtschiffe gebaut, die eine Kapazität von rund 120 Tonnen aufwiesen, ${ }^{244}$ zum Ende der I $880 e r$

233 AStL, HS 86r (»Chronologische Beschreibung«, I 77oer Jahre), fol. 3 ra u. 3 Ib; LR BVI2, Reg. Ior6 (6-I 5); LR BIX 2 , Reg. 324 (I 44-I47).

234 Ardelt, Elisabethinen, Iorf.

235 Vgl. z.B. OÖLA, Karten- und Plänesammlung, V/3 (»Eigendtlicher GrundtRiß der Haubtstatt Lintz«, undat. [r 73 oer Jahre]) u. Österreichische Nationalbibliothek, Kartensammlung, K III ro 834 (Plan der Landeshauptstadt Linz, I898).

236 Vgl. zu Montreal: Castonguay, Agriculture, I 92 - I 94 u. 2ogf.

237 Vgl. zu Wien: Albrecht, Need, 7 f., ro u. I $2 f$.

238 Dies widerspiegelt sich in den Linzer Zeitungen für die Zeit seit Mitte der I 83oer Jahre; vgl. zu Wien: Albrecht, Need, $6 f$.

239 Sandgruber, Lebensstandard, 287.

240 Albrecht, Need, Io- 2.

24I Gierlinger et al., Feeding, 228; Albrecht, Need, rof.

242 Donau in Oberösterreich, 32f.; vgl. AStL, HS I 29 (Sitzungsprotokolle des Gemeindeausschusses I 848$)$, fol. 75 a u. I 42 b.

243 Koch, Reise, $27 \mathrm{f}$.

244 Rafetseder, Verstaatlichung, 948; Neweklowsky, Donauschiffahrt, I 85. 
Jahre konnte ein »Normalschlepp« bis zu 650 Tonnen transportieren. ${ }^{245}$ I 895 waren auf der Donau rund I5.Ioo Tonnen »Frucht« nach Linz gekommen ${ }^{246}$ - wenn man einen Pro-Kopf-Verbrauch von roo Kilogramm annimmt (vgl. oben), dann benötigte die Stadtbevölkerung zu dieser Zeit jährlich nur rund 5.00o Tonnen Getreide. Einen erheblichen - und stetig steigenden - Beitrag zur städtischen Lebensmittelversorgung leistete die Eisenbahn. ${ }^{247}$ Die Westbahn hatte I 864 insgesamt über I 20.000 Tonnen Getreide transportiert, ${ }^{248}$ I 895 waren in Linz mit der Eisenbahn 8.569 Tonnen Getreide angekommen, I0.653 Tonnen wurden abgeschickt, beim Nutzvieh wurden vor allem Schweine bezogen: Den 28.797 angekommenen Schweinen standen nur 2.r 99 abgeschickte Schweine gegenüber. ${ }^{249}$

Tab. 21: Über die Donau in Linz angekommene Lebensmittel, 1849-1868

\begin{tabular}{lcccccc}
\hline & $\begin{array}{c}\text { Getreide- und Hülsenfrüchte } \\
\text { to }\end{array}$ & \multicolumn{2}{c}{ \% } & to & $\%^{\mathrm{a}}$ & \multicolumn{2}{c}{ Gemüse und Obst } \\
\hline 1849 & 34.068 & 40 & 1.577 & 2 & 1.061 & $\%^{\mathrm{a}}$ \\
1854 & 5.360 & 7 & 1.927 & 3 & 1.781 & 2 \\
1858 & 7.992 & 12 & 807 & 1 & 931 & 1 \\
1864 & 12.025 & 24 & 470 & 1 & 562 & 1 \\
1868 & 17.432 & 29 & 57 & 0 & 587 & 1 \\
\hline
\end{tabular}

Quelle: Eigene Berechnung basierend auf Winckler, Übersicht, $52 f$.

a \% der Gesamtfracht (gerundet)

Da die zeitgenössischen Statistiken eher an Mengen interessiert waren und zunehmend nur noch die Kategorie »Oberösterreich « verwendet wurde, sind nur allgemeine Aussagen zum Linzer Lebensmittelhinterland der zweiten Hälfte des I 9. Jahrhunderts möglich: Das in Linz konsumierte Getreide scheint sowohl regionaler als auch überregionaler Herkunft gewesen zu sein, neben ungarischem Getreide sind ebenso Importe aus Bayern (und Exporte dorthin) anzunehmen. ${ }^{250}$ Infolge des Deutsch-Französischen Krieges (1870/I871) seien die Mehlpreise angestiegen, deshalb hätten die Linzer Bäcker »Mehl aus Amerika und Ägypten« verwendet, erinnert sich Karl Hirnschrodt, der ab I 869 eine Bäckerei in Urfahr besaß. Die auf dessen Betrieb lastende Hypothek deutet auf weitere Bezugsquellen hin: Hirnschrodt hatte bei Mehlhändlern und der

245 Donau in Oberösterreich, 8 I ; vgl. Neweklowsky, Schiffahrt, Bd. 2, 6o-63.

246 RB I 895, I 9 .

247 Vgl. Schott, Urbanisierung, 2 I 5 f. u. Cronon, Metropolis, 67-8o.

248 Hoffmann/Meixner, Wirtschaftsgeschichte, Bd. 2, 92 ; Fuchs, Produktion, 73-76.

249 RB I 895, I 24 u. I 26.

250 Marx, Ende, $505 \mathrm{f}$. 
"Kunstmühle Concordia in Ungarn « Schulden. ${ }^{251}$ Linz diente ebenso als Umschlagsplatz für Getreide: Als I 878 in Linz - wohl dem Wiener und Budapester Vorbild folgend - eine »Frucht- und Mehlbörse « etabliert wurde, ${ }^{252}$ betonte man, dass die »Exportgeschäfte nach Deutschland [...] in Weizen und Gerste in manchem Jahrgange [...] bedeutend « seien. ${ }^{253}$ Für I 895 lässt sich feststellen, dass immerhin die Hälfte des in Linz mit der Eisenbahn angekommenen Getreides »regionaler« (nicht weiter spezifizierter) Herkunft war. ${ }^{254}$ Hinweise auf die Herkunft der Kartoffeln, die meist allgemein unter »Feldfrüchten« subsumiert wurden, finden sich spärlicher und erst im Kontext der Teuerungen und der Kartoffelkrankheit der I 8 4oer Jahre: Es zeichnet sich vor allem ein lokaler und regionaler Bezug ab, wobei diesbezüglich vielfach das Innviertel genannt wurde. ${ }^{255}$ Bis zur Mitte des I 9. Jahrhunderts kamen die Schweine angeblich überwiegend aus Ungarn und Serbien, bis die Schweinepest zu einer Verringerung der Importe und zum Beginn einer regionalen Schweinezucht führte. ${ }^{256}$

Gleichzeitig gab es erhebliche Kontinuitäten in der Lebensmittelversorgung: Der Anteil der städtischen Gartenfläche war zumindest bis in die I $870 e r$ Jahre stabil (vgl. Tab. I 8), speziell in den Vorstädten und in peripheren Lagen blieben die Hausgärten bis ins 20. Jahrhundert erhalten. ${ }^{257}$ Auch die landwirtschaftlichen Betriebe in den Vorstädten und im Umland der Stadt blieben für den Bezug von Frischwaren von Relevanz. ${ }^{258}$ Die städtische Nutztierhaltung, besonders von Schweinen und Hühnern, scheint ebenso nur langsam abgenommen zu haben: Für das letzte Jahrzehnt des I9. Jahrhunderts sind einzelne Zählungen überliefert, die aufgrund von Hygienebedenken erfolgten: ${ }^{259}$ I 889 erfasste man in 257 Linzer Häusern 254 Ställe mit 980 Schweinen und I 89320 r Häuser mit 205 Ställen und 787 Schweinen. ${ }^{260}$ Die Zahlen sind wohl eher als Minimalwerte zu verstehen, denn für I 890 zählte man als »häusliche Nutztiere« der Stadt noch I.858 Schweine, ${ }^{261}$ I 895 I.050 ${ }^{262}$ und I 900 I.375. ${ }^{263}$

\footnotetext{
25 I Doku, Hirnschrodt, 7 I u. 94.

252 LTP, 8.7.I 873; ebd., I I.7.I 878; vgl. Mayrhofer, Donaustadt, I 52.

253 LTP, I 5.4.1 877.

$254 \mathrm{RB}$ I895, I 24.

255 Marx, Ende, 370 u. 506.

256 Hoffmann, Bauernland, 377-379.

257 Vgl. OÖLA, Karten- und Plänesammlung, V/43 (Plan Linz und Urfahr, 1903).

258 Vgl. Sandgruber, Grenzen, 64; Födermayr, Pflug, 8f. (mit Dank an Norbert Ortmayr für diesen Hinweis); Doku, Fossel, 7 u. г 3 ; Puffer, Heimatstadt, r68f.

259 Restriktivere Auflagen gegen die Haltung von Schweinen im Stadtgebiet gab es ab r89 - vgl. RB I $898,33 \mathrm{I}$.

260 RB I 892, 206; in der mit der Volkszählung I 869 verbundenen Erfassung der Nutztiere wurden für die Stadt Linz 593 Schweine angegeben (Statistischer Bericht I876, I03).

26I RB I890, 3II.

$262 \mathrm{RB}$ I895, 229.

$263 \mathrm{RB}$ 1900, 344 .
} 


\section{Zirkulationen und Output}

\section{Recycling-Mentalität und Praxis}

In der vormodernen und sich modernisierenden Stadt zirkulierten Materialien und Objekte, die ausgebessert, weiterverwendet, umgenutzt oder wiederverwertet wurden. ${ }^{1}$ Es lässt sich als Grundzug ein sorgsamer und sparsamer Umgang mit den Dingen konstatieren - ein "stewardship of objects« und eine ausgeprägte »Recycling-Mentalität«, wie es Susan Strasser und Christian Pfister bezeichnet haben. ${ }^{2}$ Die Unsicherheit des alltäglichen Lebens bildete für weite Teile der städtischen Bevölkerung in der Vormoderne eine konstante Erfahrung: Zu latenter Knappheit, unzureichenden Familieneinkommen und einer nur rudimentären Armenversorgung kam eine Vielzahl existenzbedrohender Faktoren wie z. B. wirtschaftliche Misslagen, Kriege oder klimatische Extreme. Dies resultierte in einem Repertoire an »household strategies for survival«, ${ }^{3}$ was bestimmte Erwerbsstrategien und auch den sparsamen und bewahrenden Umgang mit Dingen und Materialien miteinschloss.

Kleidung bildete bis ins i9. Jahrhundert einen wesentlichen Ausgabenfaktor von Haushalten: Musterrechnungen des ausgehenden i 8. und beginnenden I 9. Jahrhunderts nahmen (inkl. der Wäsche und Ausbesserungsarbeiten) zumindest ein Viertel bis ein Drittel für einen bescheidenen Mittelschichtshaushalt an. ${ }^{4}$ In den I 7 I oer Jahren wurde in Linz der Preis eines neu angefertigten klösterlichen »Habits « mit I 5 Gulden angegeben $;^{5}$ dafür hätte ein Taglöhner 75 Tage arbeiten müssen. ${ }^{6}$ Selbst das einfache, "abgetragene« Leinenhemd in einem Inventar aus den I77oer Jahren (Schätzpreis I Gulden) entsprach fünf Taglöhnen eines ungelernten Arbeiters. ${ }^{7}$ Die Preise für Kleidung scheinen sich bis ins beginnende i 9. Jahrhundert nicht wesentlich verändert zu haben - verglichen mit damaligen Taglöhnen kommt man auf ein ähnliches Verhältnis. Preisbildend waren dabei vor allem die Stoffe. ${ }^{8}$ I 735 wurden dem Stift Lambach bei der Anfertigung von Trauerkleidung durch einen Linzer Schneidermeister für die Stoffe 240 fl 26 kr und für die Arbeit r 4 fl ro kr in Rechnung gestellt. ${ }^{9}$ Somit konn-

I $\mathrm{Zu}$ diesen Themenfeldern habe ich mich bereits ausführlicher geäußert - vgl. Stöger, Konsumieren; Stöger, Märkte; Stöger, Re-use u. Stöger, Sustainability.

2 Vgl. Strasser, Waste, 2 I -67; Pfister et al., Syndrom, 26.

3 Vgl. Fontaine/Schlumbohm, Household.

4 Sandgruber, Anfänge, I I 4- I I 8, 308-3 I I, 3 I 7f. u. 323f.; Stöger, Markets, 2 I I - 2 I 3.

5 LR Eia, Reg. I 27 (3 If.).

6 LR BIIA2 3, Reg. I6949 (28-3i); vgl. zu anderen Preisen: ebd., Reg. I 7089 (I 46).

7 Ebd., Reg. I $8604(64-74)$.

8 Vgl. Fennetaux, Economics, I $26 f$.

9 LR BIV, Reg. $55^{2}$ (2 I of.). 
ten Alltagsgegenstände nach ihrer Erstnutzung einen erheblichen Wert behalten, was bei den in Verlassenschaftsabhandlungen angegebenen Schätzpreisen sichtbar wird. ${ }^{10}$ Im Inventar eines im November I 7 I 3 verstorbenen Landhaustürwächters wurde ein Livreerock auf $6 \mathrm{fl}$, einer auf ıo $\mathrm{fl}$ und ein Paar Hosen auf $4 \mathrm{fl}$ geschätzt - dies hätte ausgereicht, um den ausständigen "Zimmerzins « für eineinviertel Jahre zu bezahlen. ${ }^{11}$ Ein Linzer Bauschreiber hinterließ I 770 unter anderem einen Rock um I 2 fl, eine »alte« Weste um I fl $30 \mathrm{kr}$, ein »altes Sommerkleid« um I fl $30 \mathrm{kr}$, einen »bessere[n]« Rock und einen »alte[n] « Mantel zu je $5 \mathrm{fl}$, zwölf »abgetragene Hemden« zu I fl, ein "sauberes« Bett mit Wäsche um 20 fl und Weiteres um I 8 fl. Gemessen an den Löhnen der labouring poor ${ }^{12}$ verkörperten diese Gegenstände erhebliche Werte. Teilweise erfolgte bewusst eine Investition in Gegenstände als Strategie, denn die meisten Dinge darunter kann man auch Kleidung rechnen - waren wertbeständig und relativ einfach zu verkaufen. ${ }^{13}$ Die von einer Dienstmagd I78 I hinterlassene Kleidung wurde auf einen Wert von I 20 fl $24 \mathrm{kr}$ geschätzt, was ungefähr die Hälfte des Gesamtbesitzes ausmachte. ${ }^{14}$ Hier überstieg der Kleidungsbesitz klar die Menge des Verwend- und »Konsumierbaren«.

Praktiken des Wiederverwertens und Weiterverwendens sind tendenziell nur bedingt sichtbar - für diese Bereiche bieten Inventare und Ausgabenrechnungen eine Annäherungsmöglichkeit. ${ }^{15}$ Das Aufbewahren von alten Gegenständen und Materialien, teilweise sogar deren Horten, findet sich auch in wohlhabenderen Haushalten und in Institutionen. Das Inventar einer I754 verstorbenen Gastwirtin erfasst in einem Nebenzimmer sechs »schlechte ordinari Sessel«, ${ }^{16}$ ein Bestandsinventar des Lambacher Stiftshauses aus dem Jahr I693 dokumentiert zahlreiche »alte« Bettrahmen in peripheren Räumen, dazu einen Kasten mit Messingresten. ${ }^{17}$ Ein landständischer Beamter hinterließ I 7 I 5 nicht nur r.649 fl 48 kr Bargeld, sondern auch »zwei Pinkel zusammengebunden mit allerlei altem Weißzeug und Leingewand «, eine »schwarze alte Truhe mit allerhand alten Flecken und Fetzen« und im Kellergewölbe eine weitere Truhe mit neuem und altem Eisen. ${ }^{18}$ Unter dem - auf rund 30.000 fl geschätzten Vermögen eines Stadtrates befanden sich I73 I auch 5 Zentner altes Eisen. ${ }^{19}$ Derartiges ist weniger als Ausdruck zwanghafter Sparsamkeit, sondern als allägliche Praxis

\footnotetext{
Io Die dem realen Wert der Dinge oft nahekamen - vgl. Stöger, Märkte, ${ }_{2}$ f.

II LR BIIA29, Reg. I 8409 (194- I96).

I 2 Io $\mathrm{fl}$ als Jahreslohn einer Dienstbotin (LR BIIA 33 , Reg. I 8604 [64-74]) resp. I 5 kr als Taglohn einer

Näherin (LR BIIA24, Reg. I7243 [90- IOI]).

I3 Stöger, Märkte, 2ogf.

I4 LR BIIB 3 , Reg. I I 46 (9o).

I5 Vgl. Stöger/Reith, Tobakier.

i6 LR BIIBI, Reg. I44 (I I5-Ii 8).

I7 LR BIV, Reg. 34I (I02-II6).

I8 LR BIIA 30 , Reg. I $8428(2 \mathrm{I}-35)$.

I9 Ebd., Reg. I 8492 (I $49-$ I69).
} 
zu verstehen: Altmaterial wurde zu Ausbesserungsarbeiten verwendet und konnte direkt als Bezahlung für Dienstleistungen dienen. ${ }^{20}$

Dem Wert der Gegenstände entsprechend bemühte man sich »um eine möglichst lange Gebrauchsdauer« der Dinge, was eine entsprechende Pflege und Ausbesserungsarbeiten implizierte. ${ }^{21} \mathrm{Ob}$ und wie man etwas reparierte (oder reparieren ließ), war dabei durchaus eine situative Entscheidung, die sich an einem Abwägen von Kosten und Nutzen orientierte, aber auch mit individuellen Einschätzungen und Wertzuschreibungen zusammenhing. ${ }^{22}$ Anlässlich der Reparatur einer Kirchentür I797 gaben die Linzer Landstände zu bedenken, dass eine Ausführung mit Hartholz zwar doppelt so teuer sei wie eine Türe aus weichem Holz, dafür halte diese aber - im Vergleich mit den »vielleicht sieben Jahren« Lebensdauer der billigeren Variante - länger als 30 Jahre. Schließlich entschied man sich für die dauerhaftere Lösung. ${ }^{23}$

Begünstigt wurden außerhäusliche Reparaturen und Umarbeitungen durch den meist hohen Materialwert und vergleichsweise niedrige Arbeitslöhne. ${ }^{24}$ Das Reparieren war auch in wohlhabenden Haushalten anzutreffen, wie die Ausgabenbücher der Patrizierfamilie Thürheim zeigen: In drei Monaten des Jahres I7oo wurde ein Büchsenmacher für Reparaturen und Wartungsarbeiten an Pistolen und einer Flinte bezahlt, ein Kupferschmied für Ausbesserungen an Kochkesseln und am Leibstuhl, ein Taschner für die Reparatur eines Sessels und ein Tischler für Reparaturen an verschiedenen Einrichtungsgegenständen. ${ }^{25}$ Regelmäßig wurden in diesem Haushalt auch Kleidungsstücke und Schuhe von außerhäuslichen Dienstleistern/innen »außgebässert«, »zurechtgemacht« oder »dopelt «. ${ }^{26}$ Für das städtische Handwerk war das Reparieren ein wichtiger Erwerbsbereich, der aber vergleichsweise wenig Spuren in den Quellen hinterlassen hat. ${ }^{27}$ Es finden sich Hinweise in Handwerkerinventaren ${ }^{28}$ und - vor allem für das I 9. Jahrhundert - in den Linzer Zeitungen: I 82 I wurde eine "Pfannenflickerbehausung « versteigert, ${ }^{29}$ I 822 vergab das Militär Flickarbeiten der

20 LR BIIG8, Reg. 52 10 (I 16); LR BIIA 31, Reg. I85 I2 (36-62); vgl. OÖLA, Herrschaftsarchiv Weinberg, Sch. 643 u. Sch. 66r.

2I Sandgruber, Anfänge, 3 I 6.

22 Vgl. Stöger, Konsumieren; vgl. die zahlreichen Beispiele in OÖLA, Herrschaftsarchiv Weinberg, Sch. 643 u. Sch. 66r.

23 LR BIIA4I, Reg. 19835 (33).

24 Vgl. EdN, s.v. Reparatur u. Stöger, Sustainability, I48.

25 LR BIIG8, Reg. 4726 (37); ebd., Reg. 4730 (38); ebd., Reg. 4732 (38); ebd., Reg. 4733 (38).

26 Ebd., Reg. 5045 (9I); ebd., Reg. 5 109 (ro2); ebd., Reg. 546I (I53); ebd., Reg. 5599 (I72); ebd., Reg. 5740 (I II); ebd., Reg. 5962 (222); OÖLA, Herrschaftsarchiv Weinberg, Sch. 643.

27 Vgl. Stöger, Sustainability, I48.

28 LR BIIB I, Reg. 74 (7 If.).

29 LZ/AB, 29.6.I 82 I (im Schullertal, Konskr.-No. 988). 
Bettwäsche per Versteigerung ${ }^{30}$ und I 839 bot ein »Reparateur [...] auf der Durchreise« die Ausbesserung von Glas- und Porzellangeschirr an. ${ }^{31}$

Am Ende der Lebensdauer von Gegenständen wurde das Material genutzt - in den Haushalten und auch außerhalb davon: Vormoderne Menschen seien, so Donald Woodward, "notorious recyclers « gewesen. ${ }^{32}$ Impetus waren die in vielen Bereichen hohen Materialpreise und die teilweise nur begrenzt verfügbaren neuen Materialien. Wenig überraschend war das Wiederverwerten besonders bei Altmetallen sehr ausgeprägt: Inventare Linzer Metallhandwerker dokumentieren einen umfangreichen Altmetallbesitz. ${ }^{33}$ Als man 1788 den Kirchturm des Ursulinenklosters renovierte, verbrauchte man 3 Zentner und I7 Pfund neues Kupfer, vom alten Kupfer wurden 64 Pfund wiederverwendet, die Kupferreste (»Abschnittkupfer») verkaufte man an einen Schmied. ${ }^{34}$ Drei Kupferschmiedmeister und zwei jüdische Händler suchten im Jahr I 800 darum an, das beim Stadtbrand geschmolzene Kupfer des Landhausturmes ankaufen zu können. Schließlich entschlossen sich die Landstände - »nach langen Beratungen« - dazu, das Kupfer nicht zu verkaufen, sondern von einem Steyrer Kupferschmied umgießen zu lassen und es beim Wiederaufbau des Turmes zu verwenden. ${ }^{35}$

Bis ins I 9. Jahrhundert basierte die Papierproduktion auf Recycling: Neben Altpapier wurden vor allem Textilreste (Lumpen) - im österreichischen (und Linzer) Raum allgemein als »Hadern« oder »Strazzen« bezeichnet - verwendet. Im Linzer Raum gab es vermutlich nur einzelne kleine Papiermühlen, ein Betrieb ist für das I6. Jahrhundert in St. Magdalena jenseits der Donau belegbar. Vielleicht ist dieser Standort mit der ab dem frühen I 9. Jahrhundert öfters erwähnten Mühle im nahegelegenen Steg ident, in der in den I 82 oer Jahren große Teile des städtischen Archivs skartiert wurden. ${ }^{36}$ Angeblich wurden damals "neun Zehntel aller Handschriften [...] an den Papiermüller von Steg verkauft, der pro Zentner fünf Gulden bezahlte« (vgl. unten). ${ }^{37}$ Zumindest in den I 83 oer Jahren bestanden noch zwei kleinere Betriebe flussaufwärts in St. Margarethen und Ottensheim, wahrscheinlich gingen die Linzer Lumpen aber hauptsächlich in die größeren Betriebe des oberösterreichischen Alpenvorlandes. ${ }^{38}$ Lumpen waren kein Abfall, sondern ein begehrter Rohstoff, dessen Sammlung eine

\footnotetext{
30 LZ/IB, 29.3. I 822 - was auch das Waschen mit einschloss.

3 I LZ/IB, 27.9.1839.

32 Vgl. Woodward, Swords, I 90; Stöger/Reith, Recycling u. zum I9. Jahrhundert: Strasser, Waste, 53-67.

33 LR BIIB I, Reg. I55 (г 22f.); ebd., Reg. 359 (207); LR BIIB2, Reg. 483 (2 If.); LR BIIB4, Reg. I699 (8г); ebd., Reg. I795 (i го).

34 LR Eib, Reg. 1797 (99).

35 Awecker, Brand, 38 ; LR BIIA4I, Reg. $200{ }_{2} 2$ (I 83).

36 Thiel, Papiererzeugung, I I 9 ; Lackner/Stadler, Fabriken, Iorf.

37 Ebner/Ebner/Weißengruber, Literatur, 92; das erscheint im Hinblick auf den genannten Preis und auf vergleichbare Aktionen in dieser Zeit durchaus plausibel - vgl. LZ/AB, 30.4.I 824.

38 LZ/IB, I4.3.1828; Heinse, Linz, 2. Aufl., 92; Bohdanowicz, Vorstädte, Bd. 2, I519; vgl. LZ/IB, 21.I0.I83 I und für eine spätere Zeit: Statistischer Bericht I876, 568 f.
} 
Verdienstmöglichkeit bot. Im I8. Jahrhundert war die Lumpensammlung in den österreichischen Ländern noch an bestimmte Papiermühlen gebunden, vielfach wurde der Export verboten (und dennoch praktiziert). In den I 78 oer Jahren kam es zu Liberalisierungen: Zuerst wurde die Lumpensammlung freigegeben, dann folgte auch eine Aufhebung des Exportverbotes. ${ }^{39}$ Das Sammeln von Lumpen war oftmals eine Tätigkeit der städtischen labouring poor und tendenziell eine informelle Beschäftigung, die somit nur schwer sichtbar zu machen ist. ${ }^{40}$ Für Linz sind in den Adressverzeichnis-

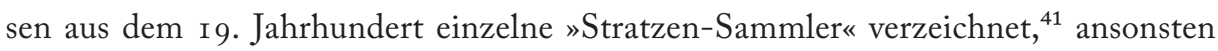
traten Sammler/innen nicht in Erscheinung, erst für die zweite Hälfte des I9. Jahrhunderts gibt es Zahlen zu den Linzer Lumpenhändlern (vgl. unten). Nicht nur in der Papierproduktion verwendete man Lumpen: Im Haushalt nutzte man Textilreste zum Putzen und in anderen Bereichen, in Kriegszeiten waren Leinenlumpen als Verbandsmaterial überaus gefragt, ${ }^{42}$ im November 1805 stellten sogar die Nonnen des Ursulinenklosters gemeinsam mit Soldaten derartige »Charpien « her. ${ }^{43}$

Genauso wurde Baumaterial wiederverwendet: Dies betraf das Bauholz, ${ }^{44}$ vor allem aber Ziegel und Steine, die man - je nach Erhaltungszustand - gleich wieder verbaute, für Gartenmauern oder zerkleinert als Anschüttung nutzte. ${ }^{45}$ Besonders nach dem Stadtbrand des Jahres I 800 wurden zahlreiche Baumaterialien wiederverwendet: ${ }^{46}$ Ohnehin scheint beim Wiederaufbau die Nachfrage nach (neuen oder alten) Ziegeln das lokale Angebot überstiegen zu haben. ${ }^{47}$ Dass beim Wiederverwerten Kosten und Nutzen deutlich abgewogen wurden, zeigt der Abbruch des baufälligen Schmiedtorturms I 828: Zunächst hatte die Stadt als Eigentümer versucht, den Turm (zum Abriss) zu versteigern; der Ausrufpreis ( roo fl CM) war offenbar zu hoch angesetzt, schließlich musste man einem Maurermeister $300 \mathrm{fl}(\mathrm{CM})$ für den Abriss bezahlen. Mit dem Schutt wurde der - damals bereits skeptisch beäugte - Ludlgraben weiter zugeschüttet (vgl. unten). ${ }^{48}$

Auch bei städtischen Institutionen lässt sich eine ausgeprägte Recycling-Mentalität erkennen. In den Rechnungen des städtischen Bauamts taucht das Wiederverwenden und Wiederverwerten regelmäßig auf: Im Rechnungsbuch des Jahres I750 wurde

39 Thiel, Papiererzeugung, I 46; vgl. Luca, Landeskunde, Bd. 2, 43 I ; Luca, Landeskunde, Bd. 3, 20; Handbuch, Bd. 9, 234.

40 Vgl. Stöger, Re-use, I62- I65.

4I Vgl. Verzeichniß I 825 u. Gewerbe-Adressen-Buch I 853.

42 LR E7a u. b, Reg. I573 (389); LZ, 2.6.1809; LR Erb, Reg. 2026 (I36); ebd., Reg. 204I (I38).

43 LR Erb, Reg. 2 I 64 (I 57 ).

44 LR CIIIHI -3 , Reg. 265 (I 48 ); ebd., Reg. 409 (259f.).

45 OÖLA, Landschaftsakten, Sch. 446, D.XV.3/No. 53; LR BIIG8, Reg. 5266 (I 25); ebd. Reg. 54I 4 (I 46); LR CIIIHI -3 , Reg. 25 I (I 4 I).

46 Awecker, Brand, 35 .

47 Vgl. LR BIIA4 1 , Reg. 20019 (I92f.).

48 AStL, Altakten, Sch. 79 u. Sch. 80; LZ/IB, 3 I.3.I 828; Straßmayr, Schmiedtor, I 37; Fink, Geschichte, I 22 . 
der Verbrauch von Schindeln in zwei Rubriken (»alte« und »neue«) eingeteilt, für die »außdökung deren Rin(n)en im Rath-Hauß« benötigte man I.500 alte und 200 neue Schindel, für das Rathausdach 2.000 alte und 2.500 neue Schindel. Ebenso verzeichnete man die Wiederverwendung von Nägeln : Für das Soldatenhaus am Hofberg wurden 6.000 alte und I r.000 neue Schindelnägel verbraucht. ${ }^{49}$ I 8 I 6 beschäftigte das städtische Bauamt drei Tage lang zwei Taglöhner (pro Tag je I fl), die »aus dem alten Holz Nägl gezogen und gericht « hatten. ${ }^{50}$ Zum Einwintern der zwei Hauptplatzbrunnen kaufte man I770 eine geringere Menge Stroh, "weil d(e)s alte noch villes brauchpar gewössen «. ${ }^{51}$

Bei der Donaubrücke fiel regelmäßig Altholz an, das - wie es bereits eine Instruktion aus den I 69oer Jahren vorsah - als Brennholz »zerscheittert « und zu Gunsten der Stadt verkauft wurde. Bei der Verpachtung der Brücke I 760 räumte man den Pächtern u.a. als Deputat 6 Klafter Altholz ein, I775 wurden laut Brückenrechnung aus »altem Bruckholz« ro4 Klafter weiches Brennholz gewonnen. ${ }^{52}$ Verglichen mit den Einnahmen aus den Brückengebühren war der Erlös aus dem Recycling zwar begrenzt (vgl. Tab. 22), das stellte aber dennoch diese Praxis nicht infrage. Hinweise zu dieser Form des Holzrecyclings finden sich auch in anderen Bereichen: Im Inventar eines Linzer Schiffmeisters aus den I76oer Jahren schätzte man altes Arbeitsgerät als Brennholz, ${ }^{53}$ in den I73oer Jahren wurden die Kosten der Umbauarbeiten im jesuitischen Schulhaus teilweise über den Verkauf des Abfallholzes abgedeckt. ${ }^{54}$

Tab. 22: Ausgewählte Einnahmen und Ausgaben des städtischen Brückenamtes, 1713 und 1716

\begin{tabular}{llr}
\hline 1713 & Gesamteinnahmen des Brückenamtes & $3.003 \mathrm{fl} 23 \mathrm{kr}$ \\
1713 & Einnahmen aus dem Verkauf von altem Holz & $18 \mathrm{fl} 19 \mathrm{kr}$ \\
1716 & Einnahmen aus dem Verkauf von altem Eisen & $17 \mathrm{fl} 9 \mathrm{kr}$ \\
\hline
\end{tabular}

Quelle: LR BIIG4, Reg. 2416 (141-211)

Größere Mengen an Altmaterialien wurden über Versteigerungen angeboten, die in größerer Zahl seit dem Beginn des i 9. Jahrhunderts in lokalen und überregionalen Zeitungen angekündigt wurden. ${ }^{55}$ Diese Ankündigungen lassen Einblicke in Märkte und Praktiken des Recyclings zu: Regelmäßig versteigerten der Magistrat und die Lan-

49 AStL, HS 389 (Bauraittung I750), unpag.

50 AStL, HS 436 (Bauamtsrechnung I 816), pag. I37.

5 I AStL, HS 409 (Bauraittung I770), pag. I I 7 u. I 96.

52 Awecker, Bruckamt, I82, I 98 u. 205; AStL, Altakten, Sch. 44.

53 LR BIIB 2, Reg. 520 (32-35).

$54 \mathrm{LR} \mathrm{CIIIC}_{3}$, Reg. 502 (2I3).

55 LR BIIA4I, Reg. I 9925 (95); vgl. z.B. LZ/IB, I6.4.I 824 u. ebd., I7.4.I 835. 
desbehörden in Linz Bauholz (z.B. Schindel oder ganze Dachstühle), ${ }^{56}$ Altpapier und Altmetall, ${ }^{57}$ aber auch Fenster ${ }^{58}$ und sogar alte Boote (»Pletten zum Eisbrechen $)^{59}$ I 842 bot das Linzer Arbeitshaus »altes unbrauchbares, jedoch theilweise zu Brennholz noch verwendbares Stafetten-Gehölz, bestehend aus abgefaulten Säulen, Riegeln und Latten « zur Versteigerung an. ${ }^{60}$ Das »k.k. Militär-Haupt-Betten-Magazin« nutzte regelmäßig Versteigerungen, um Alttextilien (»Betten-Hadern und Säckflecke«) zu verkaufen. ${ }^{61}$ Genauso finden sich Anzeigen, die den Ankauf von Altmaterial in Aussicht stellten: Ein Schriftgießer und Buchdrucker war an altem Blei und Zinn interessiert, die Linzer Tabakniederlage an Altpapier. ${ }^{62}$

Im Alltagsleben des i 8. Jahrhunderts war die Zirkulation des Gebrauchten omnipräsent: Gegenstände wurden innerhalb der Haushalte weitergegeben, an Kinder und an das Gesinde, mitunter als Teil der Lohnzahlung. Auch außerhalb der Haushalte zirkulierten die Dinge, als Geschenke oder als Spende bis hin zum Tausch oder Verkauf. ${ }^{63}$ Oftmals waren bei den Transfers von Gebrauchtwaren professionelle Akteure eingebunden. In den meisten Städten bestanden eigene Marktplätze für Gebrauchtes, in Wien als »Tandelmärkte« bezeichnet, und Gebrauchtwarenhändler/innen verkauften in Läden und an Ständen oder als Hausierer/innen. ${ }^{64}$ Genauso gab es Verkaufsvermittler/innen, die fremdes Eigentum übernahmen und es gegen eine (fixe oder anteilige) Provision verkauften. ${ }^{65}$

Die dürftigen Hinweise aus dem i 8. Jahrhundert deuten auf mehrere formelle Linzer Gebrauchtwarenhändler (d.h. Inhaber einer besteuerten und weitergebbaren Gewerbeberechtigung) hin, möglicherweise waren dies - inklusive Urfahr - drei bis vier Händler. ${ }^{66}$ Aus den I740er Jahren ist das Inventar eines Tandlers überliefert, ${ }^{67}$ in den I75oer Jahren bezahlte ein Tandler eine jährliche Gebühr für seinen - sich vermutlich am Urfahrer Brückenkopf befindenden (vgl. Abb. I2) - Verkaufsstand an das Brückenamt, ${ }^{68}$ und die in dieser Zeit entstandene "Theresianische Rustikalfassion « erfasste einen »behausten« Tandler, also einen Händler mit Bürgerrecht, in der Beth-

56 LZ/AB, I I.I.1822; ebd., 26.9.1836.

57 LZ/IB, I3.3.I8I 8 ; ebd., 22.4.I822; ebd., 28.10.183 I.

$58 \mathrm{LZ} / \mathrm{AB}$, I $4.9 \cdot 1827$.

$59 \mathrm{LZ} / \mathrm{AB}, 6.7 \cdot 1827$.

60 LZ, 28.2.1 842 .

6I Vgl. z.B. LZ/IB, 29.3.I822; ebd., 26.4.I830; ebd., 8.4.I836.

$62 \mathrm{LZ} / \mathrm{IB}, 30.1 .1835$; LZ/IB, I3.3.1840.

63 LR BIIA 30 , Reg. I84I8 (I).

64 Vgl. dazu ausführlich: Stöger, Märkte, 44f., 49-79, 209f. u. Lemire, Clothing, I 47- I 49.

65 Vgl. Stöger, Märkte, I 4 I - I 46.

66 Dies würde auch zu den Zahlen des offiziellen Gebrauchtwarenhandels in Wien und Salzburg passen:

Stöger, Märkte, I 54- I6o (dort finden sich auch Überlegungen zu den Problemen des Quantifizierens).

67 LR BIIBI, Reg. 76 (72f.).

68 Awecker, Bruckamt, I93. 
lehemstraße. ${ }^{69}$ Vereinzelt finden sich seit dem ausgehenden i 8. Jahrhundert Anzeigen von Tandlern in den Linzer Zeitungen, ${ }^{70}$ der gut informierte Linzer Beamte und Topograph Benedikt Pillwein zählte in den I 83oer Jahren vier Tandlergewerbe. ${ }^{71}$

Diese gering erscheinenden Zahlen sollten nicht darüber hinwegtäuschen, dass vermutlich eine weitaus größere Anzahl von Akteuren im Linzer Gebrauchtwarenhandel tätig war. Der Gebrauchtwarenhandel blieb bis ins r 9. Jahrhundert in den meisten mittleren und kleinen österreichischen Städten unreguliert, er bot somit eine - temporäre oder mittel- und langfristige - Erwerbsmöglichkeit für die labouring poor, auch für Angehörige ethnischer oder sozialer Minoritäten. ${ }^{72}$ Aufenthaltsbeschränkungen und Niederlassungsverbote für Juden und Jüdinnen - die anderenorts häufig im Gebrauchtwarenhandel und in der Pfandleihe tätig waren - wurden in Linz erst im Verlauf des I 9. Jahrhunderts aufgehoben; dies beschränkte zusammen mit anderen Hindernissen die Teilnahme am Detailhandel vor Ort. ${ }^{73}$ Vielleicht hatten aber jüdische Händler, die die Linzer Jahrmärkte besuchten, auch gebrauchte Objekte in ihrem Sortiment: I 705 bot man eine umfangreiche Welser Verlassenschaft, offenbar vor allem Schmuck, jüdischen Jahrmarktshändlern an, ${ }^{74}$ und I 720 überlegte man, ob Prager resp. böhmische Juden auf dem Jahrmarkt alte Kleidung anbieten dürften. ${ }^{75}$ In einem I 784 erschienenen »Lustspiel«, das den Linzer »Bartholomämarkt« als Szenerie wählte, hat ein jüdischer Altkleiderhändler einen kurzen Auftritt: Der Händler agiert ambulant, fragt danach, ob es »was zu handeln« gebe, und kommt so mit einem Protagonisten des Stücks ins Gespräch, der ein Kleidungsstück für seinen Dienstherrn verkaufen will. Nach längeren Diskussionen über den Preis und einer kurzen Beschimpfung (»Da verdammter Jud!«) wechseln Objekte (ein Rock und silberne Hemdknöpfe) und Geld ( $7 \mathrm{fl}$ ) den Besitzer. ${ }^{76}$ Trotz der lebensnah erscheinenden Beschreibung und der Angabe, dass der Händler "gleich vorm Wasserthor, neben den Fleischbänken « zu finden sei, ${ }^{77}$ sollte die Darstellung als fiktiv gelesen werden - vergleichbare Straßenhandelsszenen (oft mit jüdischer Beteiligung) sind in zahlreichen Texten dieser Zeit greifbar. ${ }^{78}$

Es sind insgesamt nur sporadische Einblicke in die Handelstätigkeit möglich: Vor allem ist der Handel mit gebrauchter Kleidung anzunehmen und - als zweiter Bereich - mit Möbeln, zudem liehen die Tandler/innen auf Pfänder und vermieteten

69 Awecker, Bevölkerung, 20I, 209 U. 23 I.

70 LR E7a u. b, Reg. 854 (2 I I); LZ, 28.5.1802; LZ/IB, I 2.2.1 838.

7I Pillwein, Wegweiser, I55.

72 Vgl. zu den umfangreichen informellen Bereichen, zur Absenz von Regulierung und zu Minoritäten im städtischen Gebrauchtwarenhandel: Stöger, Märkte, 79- I33 u. I75- I8 I.

73 I 849 resp. I 867 - vgl. John, Bevölkerung, I 32 f. u. Marckhgott, Mitbürger, 285 f.

$74 \mathrm{LR} \mathrm{BVII}_{4}$ u. 5, Reg. 2805 (962).

75 LR BIIG $_{4}$, Reg. 2273 ( 38 ).

76 Bartholomämarkt, $22-25$.

77 Ebd., 26.

78 Vgl. Stöger, Märkte, 237-24I. 


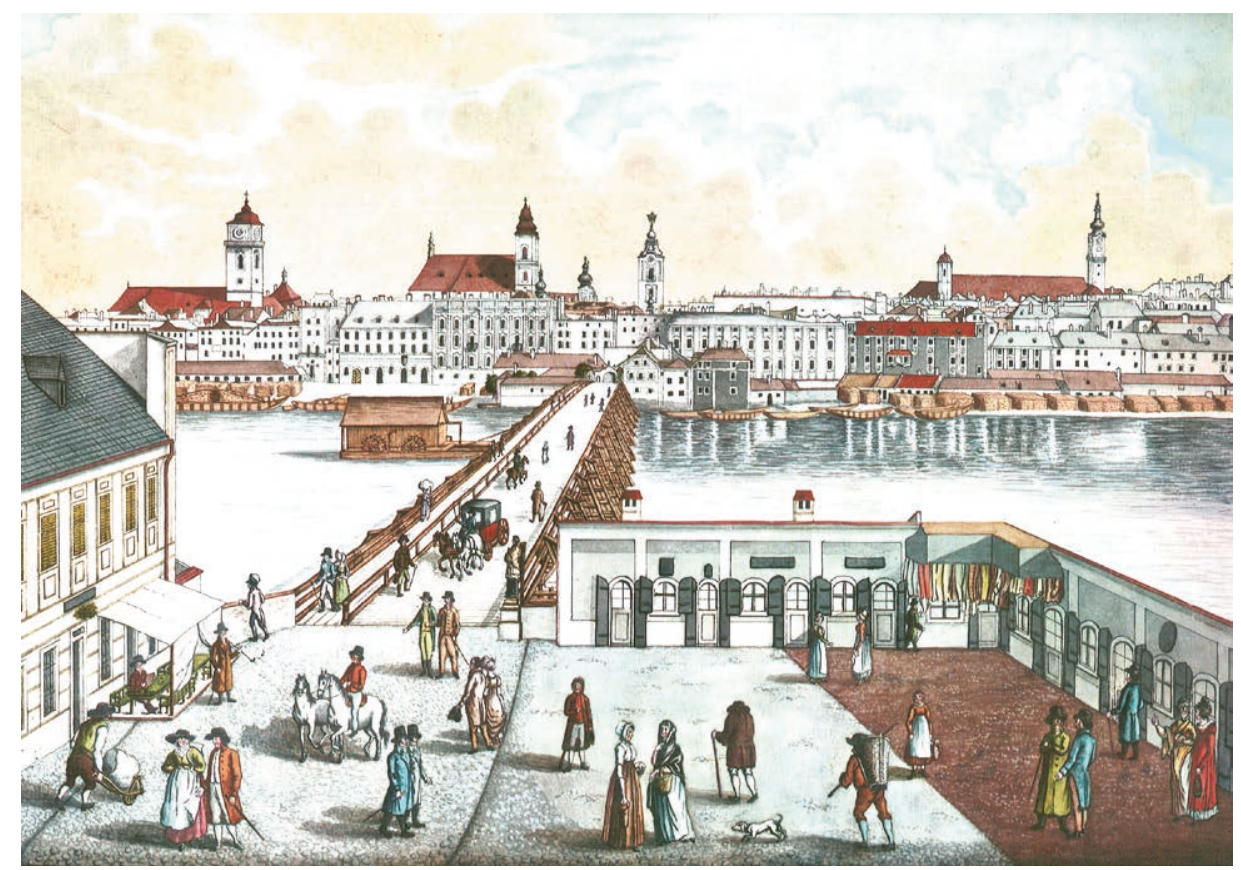

Abb. 12: Das Urfahrer Platzl - rechts der Bildmitte ist der Tandlerladen zu erkennen, im Hintergrund (an der Oberen und Unteren Donaulände) Brennholzstapel, 1820

Gegenstände. Das bereits erwähnte Inventar eines Tandlers aus den I740er Jahren erfasste neben dem eher bescheidenen persönlichen Besitz nur versetzte Gegenstände. Es waren hauptsächlich Kleidungsstücke und andere Textilien, dazu einige höherwertige Objekte und drei Uhren, die ein Uhrmacher belehnt hatte. ${ }^{79}$ In den Zeitungen finden sich Hinweise auf den Verleih von Gegenständen: Der Laden im »StadtTändlerhause« in der Altstadt ${ }^{80}$ verlieh Faschingsmasken und Möbel, verfügte aber offenbar auch über ein umfangreiches Lager an Gebrauchtwaren. ${ }^{81}$ Nach dem Tod der Gewerbeinhaberin wurde die Mischung aus Verkaufs- und Verleihbetrieb fortgeführt: Alle »Gattungen von Zimmer Einrichtungen als noch wenig gebrauchte« könnten, so eine Zeitungsanzeige aus dem Jahr I 837, »um die billigsten Preise sowohl ausgeliehen als verkauft werden«. Zudem würde man »alle Gattungen Effecten einkaufe[n] und austausche[n] «(vgl. auch Abb. I 3). ${ }^{82}$

Dazu zirkulierten Gegenstände über Versteigerungen und die Pfandleihe: In mittelgroßen Städten wie Linz fanden zumindest wöchentlich private Versteigerungen

79 LR BIIBi, Reg. 76 (72f.).

80 Heute Altstadt 8 (Konskr.-No. 76) - Kreczi, Häuserchronik, 32 f.

8I LZ, 29.I.I810; ebd., 3.I.I817; ebd., 25.I2.1837; ebd., 28.12.1835; ebd., 29.I.I836.

$82 \mathrm{LZ} / \mathrm{IB}, 27 \cdot 3 \cdot 1837$. 
statt. ${ }^{83}$ Diese boten meist Besitztümer aus Verlassenschaften an, genauso wurden Gegenstände aufgrund von Geldbedarf oder »einer Abreise wegen« versteigert. ${ }^{84}$ In Linz war im I8. Jahrhundert - anders als in zahlreichen Städten des deutschsprachigen Raumes $^{85}$ - kein öffentliches (städtisches) Leihhaus etabliert worden und es gab auch keine offiziell berechtigten Pfandleiher. Die Lücke wurde offensichtlich - neben einem Engagement von Gebrauchtwarenhändlern/innen in diesem Bereich - von informellen Leiher/innen ausgefüllt, deren Tätigkeit in Inventaren und Zeitungen dokumentiert ist: Ein I723 verstorbener Hafner hatte Silberknöpfe und Silbergeschirr bei einem Schreiber versetzt, ${ }^{86}$ das Inventar eines Stadtrichters aus dem Jahr I 7 I 9 listet verpfändete Gegenstände (v.a. Schmuck) im Wert von über I.ooo Gulden auf, ${ }^{87}$ eine vermögende, I742 verstorbene Witwe gewährte nicht nur den Landständen einen erheblichen Kredit, sondern lieh auch auf Pfänder. ${ }^{88}$

\section{Sekundäre Märkte in der Moderne}

Im Verlauf des r 9. Jahrhunderts nahm der relative Preis vieler Materialien und Dinge ab, während die Reallöhne (wenngleich langsam) anstiegen, dazu weitete sich die world of goods aus, und damit veränderten sich auch die sekundären Märkte. ${ }^{89}$ Der Preisverfall zeigte sich besonders bei der Kleidung (vgl. Tab. 23), einem Hauptartikel des Gebrauchtwarenhandels, obwohl Gebrauchtkleidung in den Unterschichten nur langsam an Relevanz verlor. ${ }^{90}$ Mit der Hygienediskussion kam es bei Kleidung jedoch zu steigenden Vorbehalten gegenüber dem Konsum von Gebrauchtem. ${ }^{91}$ Als man während des Preußisch-Österreichischen Krieges über die »Linzer Zeitung« zur Abgabe von Verbandsmaterial aufgerufen wurde, bezog sich dies - anders als noch zu Beginn des i9. Jahrhunderts - explizit auf "Cardien-Abfall« und "Spinnabfall«, nichtgebrauchte Textilreste. ${ }^{92}$ In den r 8 7oer Jahren bezeichnete der Hygieniker Max v. Pettenkofer - anlässlich der Cholera - selbst die Schränke, in denen die eigenen (benutzten) Textilien aufbewahrt wurden, als "wahre Herde der Miasmen«. ${ }^{93}$ Die Zei-

\footnotetext{
83 Vgl. Stöger, Märkte, 44-46.

84 LZ/IB, I4.I I.I 834 (Zitat); vgl. z.B. LZ, 3.5.I779; ebd., I0.7.I80 I ; LZ/IB, I I.8.I 820; ebd., 20.7.I840.

85 Vgl. Stöger, Märkte, $222 \mathrm{f}$.

$86 \mathrm{LR} \mathrm{BVI}_{2}$, Reg. I 150 (77-80).

87 LR BIIBI, Reg. 46 (4I-45).

88 Ebd., Reg. 62 (59-62); vgl. ebd., Reg. 68 (65); weitere Beispiele in: LZ/IB, 20.3. 8 I 8 u. ebd., I 7. Io. 1828.

89 Stöger/Reith, Recycling, 272 u. 278.

90 Lemire, Clothing; Ginsburg, Rags, I27- I29; vgl. zum nur langsam sinkenden Kleidungsaufwand in städtischen Unterschichten: Sandgruber, Anfänge, $323 \mathrm{f}$.

9I Vgl. Charpy, Scope, I 44f.

92 LZ/AB, I.4.I 856; vgl. Doku, Fossel, I6.

93 LTP, 23.8.1 873 .
} 
Abb. 13: Zeitungsanzeige eines Linzer Tandlers, 1842

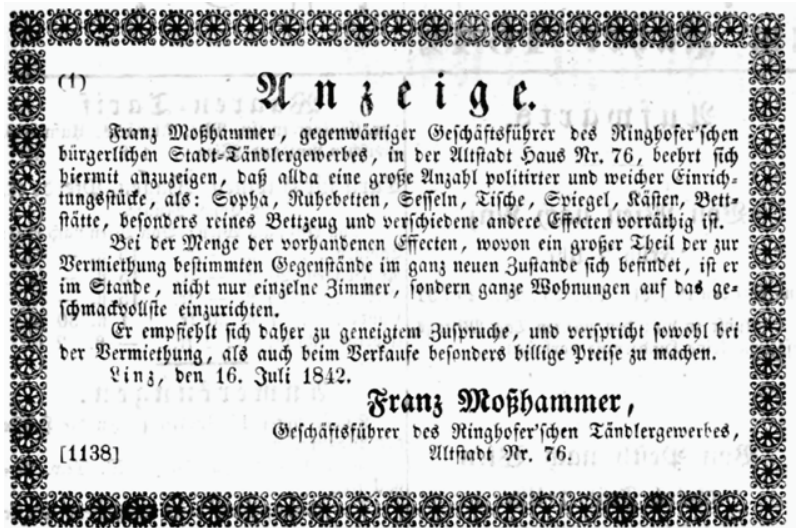

tungsanzeige eines Linzer Tandlers aus den I 840er Jahren lässt einerseits eine Spezialisierung auf Einrichtungsgegenstände und deren Vermietung erkennen, andererseits betonte der Tandler die Neuwertigkeit der Gegenstände und den Umstand, dass es sich um »besonders reines Bettzeug « handle (vgl. Abb. I3). ${ }^{94}$

Tab. 23: Preise für ein einfaches neues Leinenhemd, 1865-1894

\begin{tabular}{lccl}
\hline & Preis in fl öW & in Taglöhnen & Quelle \\
\hline 1865 & 1,75 & 2,9 & LAB, 27.2.1865 \\
1877 & 2,00 & 2,5 & LVB, 18.4.1877 \\
1885 & 2,00 & 2,0 & LTP, 29.11.1885 \\
1894 & 2,00 & 1,7 & LTP, 13.6.1894 \\
\hline
\end{tabular}

a die Taglöhne beziehen sich auf Tab. 4

Dennoch ist ein Fortdauern der Recycling-Mentalität, die nun zunehmend die ökonomische Notwendigkeit überschritt, festzustellen. Für den Haushaltsbereich sind diesbezügliche Befunde aber relativ spärlich : Lediglich in der Korrespondenz von Adalbert Stifter werden das Umfärben von Kleidung und das Wiederverwerten von Stoffresten durch eine "Wollreißerin thematisiert. $^{95}$ Besser erkennbar ist die Persistenz von Recyclingpraktiken bei städtischen Institutionen: Noch in den I87oer Jahren bot z.B. das Strafhaus »200 Ctr. altes Liegestroh, sowie Strazzen, alte Kotzen, alte Schuhe, Eisen etc. « zur Versteigerung an, ${ }^{96}$ und in der Einnahmenrechnung der Stadt Linz findet sich eine eigene Kategorie »Materialien und Requisiten alte«: Dort verzeichnete

94 Vgl. auch: AStL, HS I 29 (Sitzungsprotokolle des Gemeindeausschusses I 848), fol. 255 a u. 255 b.

95 Stifter, PRA, Bd. r 9, 25 I u. 272 f.; ebd., Bd. 20, I5; vgl. Doku, Fossel, r3.

96 LVB, I3.I2.I 874 ; vgl. ebd., I 4.6.1883. 
man für das Jahr i 850 u.a. den Verkauf eines alten Schreibtisches und Aktenschranks (wodurch 6 fl erlöst wurden), ${ }^{97}$ I 870 Einnahmen in der Höhe von $85 \mathrm{fl} 75 \mathrm{kr}$ durch den Verkauf von ${ }_{2} 4$ Zentner "Skartpapier « an die Papiermühle in Steg. ${ }^{98}$

Zeitungsberichte aus den letzten Jahrzehnten des i 9. Jahrhunderts deuten ebenso auf Kontinuitäten des Wiederverwertens hin: 1882 findet sich ein Hinweis auf "Burschen, welche sich größtentheils mit Aussuchen des unter der Donaubrücke abgelagerten Kehrichts beschäftigen «, ${ }^{99}$ I 876 konstatierte man, dass Altmaterialsammler, da sie »Waaren zum Umtausche bei sich [...] führen « würden, als Hausierer tätig seien. ${ }^{100}$ Tendenziell ist hier eher delinquentes oder deviantes Verhalten greifbar, das aber dennoch Einblicke in Praktiken des Recyclings zulässt: I 868 wurden zwei Taglöhner aus Urfahr verhaftet, die »einem hiesigen Hadern-Magazin [...] vollkommen gute Schiffsseile, welche auf kleine Stücke zerhackt waren «, angeboten hatten, ${ }^{101}$ I 870 fand man bei einem 75 jährigen Hadernsammler 206 Pfund Kupfer, das dieser gemeinsam mit Komplizen aus einer Baumwollspinnerei gestohlen hatte, ${ }^{102}$ ein anderer Sammler hatte - Ende der I 88 oer Jahre $\rightarrow$ Kupferspäne im Werte von mehr als $30 \mathrm{fl}$ « unterschlagen, die er bei der Suche »nach Abfällen von Essen« bei der Bahnhofswerkstätte gefunden hatte. ${ }^{103}$ Gleichzeitig zeichnen sich Negativwahrnehmungen ab, die im Kontext des Hygienediskurses zu sehen sind. In einem Leserbrief aus den s $870 e r$ Jahren wurden Beeinträchtigungen durch ein innerstädtisches Lumpenlager beanstandet: Jeden »zweiten oder dritten Tag“ komme »ein großer Lastwagen des Papierfabrikanten in Steg in der Morgenstunde angefahren und es werden die in diesem Hause, respektive Magazine gesammelten Ueberreste der alten Kleidungsstücke und Wäschsorten, Knochen und sonstigen Gegenstände durch volle 2-3 Stunden aufgeladen«. Es entstehe dabei nicht nur Staub, sondern auch "pestilenzische[r] Geruch «, deshalb könne die »so nothwendige, erfrischende Luft in der Morgenstunde « nicht mehr genossen werden. ${ }^{104}$ Bereits einige Jahre zuvor hatte ein Leserbriefschreiber aus der Vorstadt sich über Ähnliches beklagt: Es würden "fortwährend Hadern unverpackt von Wägen vor dem Hausthore abgeladen, welche einen solchen Staub verursachen, daß in Folge dieser sich ausbreitenden höchst ungesunden Miasmen« die Fenster geschlossen bleiben müssten. ${ }^{105}$ Schließlich - zu Beginn der I $890 e r$ Jahre - sah man die Entfernung der »Hadern- und Knochenmagazine aus der Stadt« als Ausdruck »ernsten Streben[s] [...] nach gründlicher Assanierung «. ${ }^{106}$

\footnotetext{
97 AStL, HS r9i (Oberkammeramt Empfang 1850), pag. 72.

98 AStL, HS 236 (Kammeramt Empfang 1 870), pag. 43.

99 LVB, II.I.I 882.

Iо० LTP, 27.8.1876.

IOI LTP, 27.5.I 868 .

IO2 LVB, 23.II.I 870.

I03 LTP, I 3.I 2.I 889 .

I04 LTP, г 8.6.1875.

I05 LTP, 29.II.I872.

I06 RB I892, I99.
} 
Tab. 24: Akteure auf sekundären Märkten in Oberösterreich und Linz, 1859-1900

\begin{tabular}{lcccccccc}
\hline & 1859 & 1864 & 1870 & 1875 & 1880 & 1890 & 1895 & 1900 \\
\hline Lumpenhändler Ö̈ & 12 & 16 & 15 & 14 & & & & \\
Lumpenhändler Linz & & & & $4 / 5$ & 6 & 3 & $3^{b}$ & \\
Knochenhändler Linz & & & & 12 & 10 & $1 / 1^{c}$ & $1^{c}$ & $1^{c}$ \\
Pfannenflicker OÖ & 26 & 12 & 9 & 3 & & & & \\
Tandler OÖ & 48 & 63 & 77 & 77 & & & & \\
Tandler und Trödler Linz & $7^{\text {a }}$ & & & 17 & 17 & 18 & 20 & 21 \\
Kleiderhandel malte« Linz & & & & 1 & & & & \\
Kleiderhandel malte u. neue« Linz & & & & 1 & & & & \\
\hline
\end{tabular}

Quelle: Gewerbe-Adressen-Buch 1853; RB 1876-1878, 40f.; Statistischer Bericht 1876, 176f., 18of. u. 195f.; Statistischer Bericht 1882, Bd. 2, 14; RB 1890, 84-86; RB 1895, 94; RB 1900, 102

a Tandler/Trödler im Gewerbe-Adressen-Buch 1853

b "Stoffrestenverkauf"

${ }^{\mathrm{c}}$ Knochensammler

Während das Reparieren für die alltägliche Konsumption zunehmend an Bedeutung verlor, ist das Bild für das Recycling in Gewerbe und Industrie uneinheitlicher: Gesunkene Materialkosten und gestiegene Arbeitskosten machten das Recycling einzelner Materialien zwar unrentabel, infolge gesunkener Transportkosten, neuer technischer Verfahren und der gesteigerten Produktion ergaben sich aber auch neue Möglichkeiten des Wiederverwertens und damit Märkte für Altmaterialien. ${ }^{107} \mathrm{Im}$ Bereich der Papierproduktion blieb das Recycling bis ins ausgehende I9. Jahrhundert relevant: In den I 870er Jahren beschäftigten selbst die oberösterreichischen Großbetriebe "Hadernkocher" und "Hadernsortirer«, bei den kleineren, handwerklichen Papiermühlen standen zu dieser Zeit den jährlich verwendeten 2.550 Tonnen Stroh und 2.500 Tonnen Holz noch 3.400 Tonnen Lumpen gegenüber. ${ }^{108}$ Ende der I 860er Jahre begründete man die hohen Papierpreise mit einem »Mangel an Lumpen«, der auf ausbleibende Lieferungen aus Ungarn zurückgeführt wurde, wohl aber auch mit dem in dieser Zeit prosperierenden internationalen Lumpenhandel zusammenhing. ${ }^{109} \mathrm{In}$ den I $870 e r$ Jahren garantierte eine Anzeige in einer Linzer Zeitung den Ankauf von »alle[n] Strazzen und Knochen zu guten Preisen « ${ }^{110}$ und regelmäßig finden sich in dieser Zeit auch die Marktpreise für Lumpen, die deutlich machen, dass selbst Stoffresten ein bestimmter Wert zugemessen wurde (vgl. Abb. I4). ${ }^{111}$ In den r 88 oer Jahren stellte

I07 Vgl. Stöger/Reith, Recycling, 278-284.

I08 Statistischer Bericht I 876, 568 f.

Io9 LTP, 8.I.I 868 ; vgl. Strasser, Waste 85 f.

I IO LTP, 5.7.1874.

I I Vgl. z.B. LVB, 28.1.1871 ; ebd., 26.r.I878. 
die Papiermühle in Steg, die damals ein vergleichsweise kleiner Betrieb ohne Maschinenausstattung war, aus jährlich 20 Tonnen Papierabfällen und so Tonnen Lumpen Karton und Packpapier her. ${ }^{112}$

Die Anzahl der Gewerbeberechtigungen deutet für das Wiederverwenden und Wiederverwerten in manchen Bereichen auf einen Bedeutungsverlust (Lumpen- und Knochenhändler, Pfannenflicker), in anderen Bereichen (Tandler/Trödler) auf eine Persistenz hin (vgl. Tab. 24). Für I 875 lassen sich in Linz I 7 Gebrauchtwarenhändler/innen feststellen, denen 80 Schneidermeister gegenüberstanden. Während die Schneider pro Kopf 6 fl jährliche Erwerbssteuer entrichteten, bezahlten die Gebrauchtwarenhändler/ innen immerhin etwas über 7 fl. ${ }^{113}$ Nachdem I 849 Aufenthaltsbeschränkungen für Juden und Jüdinnen aufgehoben worden waren, finden sich für die Folgezeit Hinweise auf »Trödlerjuden«, die in Linz als Hausierer tätig waren oder Altkleidung aufkauften. Im 1866 durch den Linzer Bethausvorstand angelegten »Verzeichnis der im PolizeiBezirke Linz wohnhaften lsraeliten« scheinen zwar 20 Hausierer und eine Vielzahl von Händler/innen, aber nur ein Tandler auf. ${ }^{114}$ Regelmäßig wurden Tandler/innen in den Linzer Tageszeitungen erwähnt, wobei Transfers und Handelsformen auftauchen, die bereits über Jahrhunderte praktiziert wurden: In den I 86oer Jahren z.B. stahlen zwei Handwerksgesellen einen Rock aus den vor einem Tandlerladen »hängenden Effekten« und "vertauschten« diesen bei einem anderen Tandler "gegen mehrere andere Kleidungsstücke«, ${ }^{115}$ eine Dienstbotin wurde verhaftet, als sie versuchte, die in einem Gasthaus gestohlene Bettwäsche einem Tandler zu verkaufen, ${ }^{116}$ und in Urfahr übergab ein Tandler zwei bayerische Deserteure, die Zivilkleidung ankaufen wollten, den Behörden. ${ }^{117}$ Als im Verlauf des r 9. Jahrhunderts die Bedeutung des Gebrauchtwarenhandels für den alltäglichen Konsum abnahm, wandten sich Händler/innen dem Neuwarenhandel zu oder spezialisierten sich in Nischen wie etwa dem Antiquitätenhandel. ${ }^{118}$ Das Beispiel Adalbert Stifters illustriert diesen Wandel: Schon Anfang der I 84 oer Jahre hatte Stifter den Wiener Tandelmarkt als vormodernes Relikt beschrieben, als einen "poetische[n] Clubb aller alten, verschollenen und verblichenen Dinge«, der bald verschwinden werde. ${ }^{119}$ Er "gehöre zu den fleißigen Besuchern des Tandelmarktes« und "ging oft mit einem unschätzbaren, erhandelten Preisstücke von dannen, welches die Meinen zu Hause in die größte Verlegenheit brachte, was damit anzu-

\footnotetext{
I 2 Statistischer Bericht I 882, Bd. 2, 2 I 9 .

I 3 Statistischer Bericht I876, I96 u. 6r 4.

I I Marckhgott, Mitbürger, 286f. u. 293-295.

I 5 LTP, 2 I.5. I 869 .

I 6 LTP, 5.I.I867.

I 7 LTP, I 5.I I.I 866; vgl. zu den korrespondierenden Beispielen aus dem vormodernen Gebrauchtwarenhandel: Stöger, Märkte, I 42 - I 53, I 83 u. 243.

I 8 Vgl. Charpy, Scope, I $46 f$.

I 9 Stifter, HKG, Bd. 8/3, I03.
} 

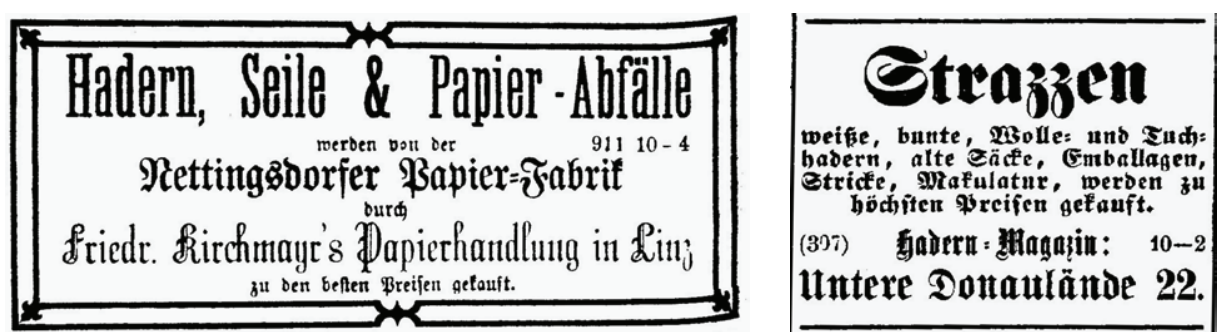

Abb. 14: Lokale und überregionale Märkte für Altmaterialien, 1877 (links) und 1880 (rechts)

fangen sei«. ${ }^{120}$ Stifters Affinität zu den alten Dingen manifestierte sich auch in seiner Linzer Zeit: Während eines Kirchschlagaufenthaltes in den r 86oer Jahren überlegte Stifter den Ankauf eines alten Kastens, der, so Stifter, zusammen mit anderen Möbeln in der Wohnung, »schon eine hübsche Erl[enholz]geräthschaft« ergeben könne. Die eigenen Sachen könne man »verkaufen oder vertauschen«, dazu solle Amalie Stifter »einen Tandler [...] kommen lassen « und ihn fragen, »was er [...] gäbe «. ${ }^{121}$ Sie habe noch »keinen Tändler kommen lassen«, so wenig später die Antwort der Frau aus Linz, sie wolle sich von den zwei Kästen nicht trennen, weil sie Erinnerungsstücke seien. ${ }^{122}$

Der Bereich der Pfandleihe scheint im I 9. Jahrhundert noch nicht an Bedeutung verloren zu haben: In Linz wurde I 849 eine Pfandleihanstalt - deren Etablierung seit dem ausgehenden I 8. Jahrhundert wiederholt diskutiert worden war ${ }^{123}$ - gemeinsam mit der »Allgemeinen Sparkasse« gegründet. Analog zu den Usancen in anderen Städten (vermutlich waren hier Salzburg und Wien die Vorbilder) belehnte man die verpfändeten Gegenstände mit bis zu zwei Dritteln ihres Schätzwertes, ausgeschlossen waren sperrige und schwierig aufzubewahrende Gegenstände (Pelze, Möbel, Bilder und Bücher), auch war verständlicherweise eine Belehnung von militärischer Ausrüstung oder von Schuldscheinen und Anleihen nicht möglich. Der Mindestbetrag zum Versetzen war I Gulden (CM), die Rückzahlung der Leihsumme (plus 9 Prozent Zinsen und die Schätzgebühr) war jederzeit möglich, nach spätestens einem Jahr und sechs Wochen verfielen die Pfänder und wurden versteigert. ${ }^{124}$ Explizit sah man die Leihanstalt als karitative Gründung, als - wie es eine Festschrift aus den I $870 e r$ Jahren formulierte - einen »Rettungsanker in drängender Noth« und nahm Verluste in Kauf, die auch bald nach der Gründung eintraten: Schon im ersten Jahrzehnt sollen es über 5.000 fl gewesen sein, die durch die Gewinne der »Allgemeinen Sparkasse« abgedeckt wurden. Direkt von der Stadt betrieben wurde die Pfandleihanstalt aber erst ab den

\footnotetext{
I 20 Ebd., IOI U. I04.

I 2 I Stifter, PRA, Bd. 2 I, I I 3; vgl.e., Bd. I 8, 56 u. Dallinger, Hunger, 307.

I 2 Ebd., Bd. 24, 93.

I 3 LR CIIID I-3, Reg. I72 (ro5-ro8) u. ebd., Reg. I84 (I39-I4I); zu den I840er Jahren vgl. Marx, Ende, I 49.

I 24 Wacha, Sparkasse, 293-295.
} 
I 9 Ioer Jahren. ${ }^{125}$ Die Anzahl der versetzten Gegenstände und die hohe Auslöserate (vgl. Tab. 25) deuten auf eine erhebliche Relevanz der Pfandleihe für die Alltagsökonomie dieser Zeit hin.

Tab. 25: Pfandleihanstalt der »Allgemeinen Sparkasse« in Linz, 1849-1875

\begin{tabular}{lccc}
\hline & versetzte Gegenstände & Wert in fl (ab 1859 ÖW) & ausgelöste Gegenstände \\
\hline $1849^{\mathrm{a}}$ & 184 & 1.345 & 9 \\
1855 & 13.978 & 57.194 & 13.354 \\
1860 & 12.017 & 44.502 & 11.495 \\
1865 & 17.757 & 74.520 & 16.937 \\
1870 & 10.454 & 55.644 & 11.006 \\
1875 & 25.119 & 96.326 & 25.887 \\
$1849-75$ & 479.700 & & \\
\hline
\end{tabular}

Quelle: Statistischer Bericht 1876, 699

a nur Dezember

\section{Abwasser und Fäkalien: Alltägliche Outputs}

Im städtischen Stoffwechsel fielen auch unerwünschte resp. problematische Materialien an: Wasser aus Niederschlägen musste in der oberflächenversiegelten Stadt abgeleitet werden, dazu kam in den Haushalten und im Gewerbe genutztes - aber nicht verbrauchtes - Wasser. ${ }^{126}$ Kontinuierlich produzierten Bewohner/innen und Nutztiere Ausscheidungen, die in einer verdichteten Siedlungsform wie der Stadt in beträchtlichen Mengen anfielen und nach Lösungen verlangten. ${ }^{127} \mathrm{Im}$ I 8. Jahrhundert waren diese Lösungen und die damit verbundenen alltäglichen Praktiken bereits Jahrhunderte alt und vergleichbar mit denen der Wasserversorgung, wenngleich deutlich zwischen Abwasser (häuslich/gewerblich), Über- und Regenwasser sowie Fäkalien unterschieden wurde, die man aber - in der Entsorgung - partiell dennoch gemeinsam behandelte. Grundlegend war eine private Verantwortung, die meist in dezentraler Infrastruktur resultierte: In der Regel leitete man Regenwasser, das genutzte Wasser (oder das Überwasser aus den Wasserleitungen) in Wassergräben, Gerinne und Sickergruben oder ließ es in Gärten, auf Wiesen und Feldern versickern. ${ }^{128}$ Besonders die Ableitung von Regenwasser bildete ein Problem, da große Wassermengen punktuell

\footnotetext{
I 25 Ebd., 296-300 (Zitat ebd., 296); vgl. Rafetseder, Variationen, $452 \mathrm{f}$.

I 6 Vgl. Douglas, Hydrology, I 48 - I 50 u. Benton-Short/Short, Cities, 6-8.

I 27 Schott, Urbanisierung, I 7 .

I 28 LR E6 (»Sint- Chronik«), 8o-82; LR Eıa, Reg. Io29 (I 94); vgl. zu Frankfurt: Bauer, Bauch, 72-89 u. zu England: Cockayne, Hubbub, I 43 f.
} 
anfallen konnten, aber auch die Wasserleitungen produzierten ständig Abwasser, da dauernd Wasser floss. Das an der Stadtmauer gelegene Landhaus leitete offenbar das Regenwasser und das Überwasser der eigenen Wasserleitung in den Stadtgraben ein. ${ }^{129}$ Wenn Einleitungen fremden Grund tangierten, dann war dies an die Zustimmung des Besitzers gebunden. Wie konfliktreich dies sein konnte, ist für das I 8. Jahrhundert nicht abzuschätzen, da Stadtratspro+tokolle und städtische Akten für diese Zeit nicht überliefert sind. Zumindest ein Konflikt ist andernorts aktenkundig geworden: I7 I I war der Magistrat Linz gegen die Überleitung von Wasser aus dem Karmeliterkonvent in einen Wassergraben auf dem Kapuzinerfeld aufgetreten, was schließlich in wechselseitigen Beleidigungen und der Verhaftung eines Klosterdieners resultierte. ${ }^{130}$ I 7 I 6 erhielt das neben dem Landhaus gelegene Minoritenkloster durch den Magistrat die Erlaubnis, das Überwasser durch die Stadtmauer in den Stadtgraben einzuleiten. ${ }^{131}$ Unklar ist, ob der Stadtgraben damals über eine direkte Verbindung mit der Donau verfügte - da das Gerinne der Ludl, die mit der Donau verbunden war, vom Ende des Stadtgrabens nur rund 50 bis 60 Meter entfernt lag, ist dies durchaus vorstellbar, Belege dafür gibt es jedoch keine. ${ }^{132}$ Zumindest im letzten Drittel des I 8. Jahrhunderts wurden Abwässer im Stadtgraben entsorgt, aber wohl nur aus einzelnen Häusern : 1773 beklagte der ständische Syndikus gegenüber der Stadt Linz den »unleidentliche[n] Geschmache" (Gestank) und verlangte eine Lösung, die offenbar in Form von Senkgruben erfolgte, deren Errichtungskosten den Hausbesitzern verrechnet wurden. ${ }^{133}$ Als in den I79oer Jahren der Besitzer eines am Beginn des oberen Grabens gelegenen Gasthauses einen »Ausfluß von seinen Priveten und vom Brunnwasser in seine ganz unhal[ $t$ ]bare Mistkrippe und durch selbe in den ständi(schen) Grabengarten« anlegen hatte lassen, wurde dies mit dem Hinweis untersagt, dass bereits die Baubewilligung im Jahr I 784 an die Anlage einer Senkgrube und die Ableitung des Abwassers nin die dortige Wasserrunzen oder Rinnsal« gebunden worden sei. ${ }^{134}$

Bei gewerblichen Abwässern gab es häufig eine räumliche Lösung: Man nutzte zur Entsorgung zumeist direkt Wasserläufe, was oftmals Fleischhauer, Gerber und Färber

I 29 LR BIIG 3 , Reg. I 537 (I 7 ).

I30 LR Eih, Reg. 5 I 94 (I08); vgl. LR BVI2, Reg. IоI6 (6- I5).

I3 I LR Eıg, Reg. 33 I (I4I); LR BIIG 3, Reg. I537 (I7); vgl. zur Entsorgung über die Stadtgräben in Frankfurt: Bauer, Bauch, 82-84 u. 97-99 u. für Münster: Historischer Umweltatlas Münster, 26 u. 30.

I32 Auch die Stadtansichten des späten I7. und frühen I 8. Jahrhunderts (Schmidt, Linz, Tafeln 8, I 2 u. I 7 ) und der Knittel-Plan aus den I73oer Jahren (OÖLA, Karten- und Plänesammlung, V/3) zeigen keine oberirdische Verbindung.

I33 OÖLA, Landschaftsakten, Alte Registratur, Sch. 84, D.XIV.2/No. I 96; ebd., Sch. 90, D.XV.2/No. 3; ebd., Sch. 96, D.XV/3, No. Io $1 \frac{1}{2}$; der Plan eines Landschaftsingenieurs aus dem Jahr i 800 konstatierte für den Stadtgraben »mehrere Senkgruben«, die man aber nicht erfasst habe, »weil man ihre Lage nicht finden konnte[,] indem alles uberschwemmet ist« (OÖLA, Karten- und Plänesammlung, VI/26); auch I 80I war der Grabenabschnitt zwischen Minoritenkloster und Schmiedtor angeblich »voll des Unraths« (OÖLA, Landschaftsakten, Alte Registratur, Sch. 96, D.XV/3, No. 2 I/I I).

OÖLA, Landschaftsakten, Alte Registratur, Sch. 92, D.XV.2/No. I35. 
betraf und für zahlreiche Städte belegbar ist. ${ }^{135}$ In Linz diente die Ludl »denen Lederern zur Abspuell- oder Abluedlung «, ${ }^{136}$ so die "Sint-Chronik« - tatsächlich befand (und befindet) sich dort die Lederergasse. In dieser Gasse und entlang der Ludl gab es zahlreiche Abwasser produzierende Gewerbe: Ein Adressverzeichnis aus dem Jahr I 825 listet insgesamt sieben Fleischhauer, fünf Gerber und drei Färber auf. ${ }^{137}$

Mit menschlichen und tierischen Ausscheidungen ging man meist anders um. ${ }^{138}$ Menschliche Ausscheidungen wurden in »Leibstühlen«, "pots de chambre» und "Nachtgeschirren« gesammelt, die durch Linzer Inventare und Haushaltsrechnungen vielfach dokumentiert sind. ${ }^{139}$ Dazu verfügten die Häuser über »Aborte« (auch als »Abtritte« oder »Privets« bezeichnet), die direkt (oder über eine hölzerne Zuleitung) mit einer Senkgrube verbunden oder mit Behältern versehen waren. ${ }^{140}$ Meist befanden sich die Aborte in abgelegenen Gebäudeteilen, im Hofraum oder in Nebentrakten: Gemäß einer Beschreibung des späteren Kremsmünsterer Freihauses ${ }^{141}$ aus den I 7 Ioer Jahren befanden sich die zwei Aborte »im Gang [...] gegen den Hoff in einen Winkhl ${ }^{142}$ Der vorstädtische Stockhof verfügte in den I 74oer Jahren über einen Abort im Erdgeschoss und einen im Hof, dazu über zwei Aborte im ersten Stock. ${ }^{143}$ Viele Aborte scheinen - was aufgrund der Geruchsbelästigung verständlich ist, aber gleichzeitig wenig benutzerfreundlich war - eher am Rande eines Hofes situiert worden zu sein. ${ }^{144}$ Auffällig ist die relativ geringe Anzahl der Aborte: Bei den Planungen zur Errichtung der Wasserkaserne, die für bis zu I.30o Menschen Platz bieten sollte, waren nur sechs »loca« vorgesehen, die aber immerhin "gut « verteilt sein sollten. ${ }^{145}$

Dass Fäkalien in »Reichen« - das heißt in Lücken zwischen den Häusern - gesammelt und »einmal im Jahr « durch Taglöhner in der Donau entsorgt wurden, ${ }^{146}$ ist für das I 8. Jahrhundert nicht belegbar. Für unmittelbar am Fluss gelegene Gebäude, von denen es in Linz aber nur wenige gab, ist ein Einbringen direkt in die Donau anzunehmen, wie z.B. für die Wasserkaserne auf der Donaulände, deren Senkgruben mit

I 35 Vgl. Illi, Schîssgruob, 24 u. 55; Brunner/Schneider, Umwelt, 285; Reith, Umweltgeschichte, 58 u. Schott, Urbanisierung, I 20.

I36 AStL, HS 86I (»Chronologische Beschreibung«, I77oer Jahre), fol. 42b.

I 37 Dabei handelt es sich um die Konskriptionsnummern 249, 253-260, 325, 344, 347 U. 356-359 (Verzeichniß I 825).

I38 Vgl. die Beispiele bei Illi, Schîssgruob, I 8; Bauer, Bauch, 72 -80; Schott, Urbanisierung, I I 7 .

I39 LR BIIA 30, Reg. I 8428 (2 I - 35); LR BIIG8, Reg. 49 I (7I); ebd., Reg. 6067 (237); LR BIV, Reg. 34I (IO2-I I6); LR CIIIHI -3, Reg. 396 (25 of.).

I 4 O LR BIV, Reg. 738 (285); vgl. Schott, Urbanisierung, I I 7.

I4I Heute Herrenstraße i 9 (Konskr.-No. 573) - Kreczi, Häuserchronik, 299.

I42 LR BVI2, Reg. I I 27 (6I-69).

I43 Ebd., Reg. I 278 (204-206).

I44 Ebd., Reg. Ior6 (6- I5); LR CIIIHI -3, Reg. 383 (233f.); ebd., Reg. 894 (622f.).

I 45 LR BIIA40, Reg. 19556 (8- I3).

I46 Mayrhofer/Katzinger, Geschichte, Bd. I, 227; vgl. für Frankfurt Bauer, Bauch, 72 2f. 
der Donau verbunden waren. ${ }^{147}$ Auch auf der Strasserinsel bestanden im Soldatenlager Aborte »hinten hinaus auf das Wasser«. ${ }^{148}$ Es gibt für das I 8. Jahrhundert keine Bauoder Situationspläne von Kanälen in der Stadt, auch die beiden Stadtpläne der I $730 e r$ und I78oer Jahre zeigen keine derartigen Infrastrukturen. Aus den verstreuten Belegen zeichnet sich jedoch ab, dass neben offenen und gedeckten Rinnen (»Rinnsale«, „Wasserschläuche«) sowie kurzen Kanälen einen städtischen Sammelkanal (»Stadt Schlauch«, später auch als »Hauptkanal« bezeichnet) gab, der wahrscheinlich vom Landhaus über den oberen Graben, durch das Schmiedtor und über den Dom- und Pfarrplatz in die Donau mündete. Die gemeinsame Zuständigkeit von Stadt und Landständen deutet darauf hin, dass der Sammelkanal in engem Zusammenhang mit dem Landhaus stand und - wie die ständische Wasserleitung - eher als semiöffentliche Infrastruktur zu sehen ist. ${ }^{149}$ Die relative Absenz von Kanälen überrascht nicht, wenn man bedenkt, dass die Errichtung und Erhaltung von Kanälen teuer war und aufgrund der mangelnden Durchspülung häufige Verstopfungen zu erwarten waren. Zudem wies Linz im Hinblick auf die Entwässerung eine relativ schwierige Topographie auf: Man konnte kein natürliches Gerinne als Entsorger nutzen und da sich der Großteil der Ansiedlung auf der flachen Niederterrasse befand, war die Herstellung eines stärkeren Gefälles schwierig und mit einem erheblichen Aufwand verbunden. Die Rinnen wurden für Regenwasser und genutztes Wasser (resp. Überwasser) verwendet, während eine Einleitung von Fäkalien nicht vorgesehen war. Aber auch der Sammelkanal diente offenbar vor allem der Entwässerung, ein direkter Anschluss und die Nutzung zur Fäkalienentsorgung waren lediglich für ausgewählte Nutzer möglich. ${ }^{150}$ I 760 verzeichnete man in der städtischen Baurechnung Einnahmen aus fünf Häusern, die bereits nahe der Donau (in der unteren Badgasse) lagen und die »ihre S:V: Schlauch bey der Hörl-Binderis(chen) Behausung in dem Gmainer Stadt Schlauch eingezäpft haben «. ${ }^{151}$

Standardlösung zur Sammlung der Fäkalien (und auch für andere Abwässer) waren Senkgruben, die in den Höfen gegraben und seitlich ausgemauert wurden. ${ }^{152}$ Es sind

I 47 AStL, HS 409 (Bauraittung I 770), unpag.; vgl. LR BIIA40, Reg. I9556 (8- I3).

I48 LR BIIA 4, Reg. 5485 ( ( 96); LR CIIIG, Reg. I 20 (29of.); vgl. dazu den Plan in Mayrhofer/Katzinger, Geschichte, Bd. I, 279.

I 49 LR BIIA 24 , Reg. I7269 ( ( 26); OÖLA, Landschaftsakten, Sch. 442, D.XV.2/No. 32; ebd., Sch. 448, D.XV.3/No. I 26; AStL, HS 399 (Bauraittung I760), unpag.; OÖLA, Josephinisches Lagebuch, HS I 9 I (Linz Obere Vorstadt); OÖLA, Karten- und Plänesammlung, VI/27 u. ebd., VI/28.

I50 LR BIIG 4 , Reg. 24I6 (I4I-2II); OÖLA, Landschaftsakten, Sch. 448, D.XV.3/No. I 26; OÖLA, Landschaftsakten, Alte Registratur, Sch. 92, D.XV.2/No. I35; OÖLA, Neuerwerbungen, HS 74 (»Bau-Rechnung« Kremsmünsterer Haus, I 804), pag. 30rf.; vgl. OÖLA, Karten- und Plänesammlung, $\mathrm{VI} / 27$.

I 5 I Es wurden jeweils 30 kr bezahlt - AStL, HS 399 (Bauraittung I 760), pag. I 9 ; beim erwähnten Binderhaus handelte es sich vermutlich um die Konskr.-No. 227 (heute Adlergasse I5) - Kreczi, Häuserchronik, roif.

I 52 Vgl. z.B.: LR CIIIHI -3, Reg. 386 (235); LR BVI2, Reg. Ior6 (6- I5): LR BIIA 5, Reg. 7275 (253); 
nur wenige Angaben zur Ausgestaltung der Senkgruben vorhanden: In den I79oer Jahren projektierte man für das Theater an der Promenade zwei Senkgruben, die rund 6 Meter tief waren (und ein Fassungsvermögen von je ca. 5,7 Kubikmeter aufwiesen), für ein nahes Gasthaus wurde die Errichtung einer »ordentliche[n] « Senkgrube mit einer Tiefe von 7,6 Meter und einem Fassungsvermögen von 75 Kubikmeter gefordert. ${ }^{153}$ Offensichtlich wurden, wobei dies eher in peripheren Lagen und bei größeren Grundstücken der Fall war, mitunter neue Senkgruben angelegt ${ }^{154}$ - in einem Nachbarschaftsstreit um eine geruchsintensive und latent überlaufende Senkgrube verwies man jedoch darauf, dass die Grube in dieser Form bereits seit der Bebauung des Grundstückes (was damals bereits hundert Jahre zurücklag) existierte. ${ }^{155}$ Insgesamt gewinnt man den Eindruck, dass in die Abwasserinfrastrukturen des I 8. Jahrhunderts nicht viel Geld investiert wurde, auch deren Pflege, wenngleich diese teilweise - wie bei Brunnen und Wasserleitungen - vertraglich vorgesehen war, ${ }^{156}$ scheint nicht sehr intensiv gewesen zu sein und wurde eher anlassorientiert (d.h. bei Nichtfunktionieren) vorgenommen. ${ }^{157} \mathrm{Als}$ es in den I79oer Jahren erneut zu Problemen mit Fäkaleinleitungen in den Stadtgraben gekommen war, begnügten sich die Stadt und die Landstände damit, den Verursachern derartige Praktiken zu verbieten und - auf deren Kosten - Reparatur- und Reinigungsarbeiten durchzuführen. ${ }^{158}$ Ähnlich agierte man I 797: Nachdem eine Verstopfung in einem »Schlauch«, der einige Häuser am Hofberg mit der Donau verband, aufgetreten war, organisierte das Stadtbauamt »alsogleich« eine Räumung des Kanals und stellte die Kosten den Hausbesitzern in Rechnung. Zuletzt sei der Kanal I 788 geräumt worden, hielt die "Augenscheins Kom(m)ission« fest. ${ }^{159}$

Die Kanalräumungen, die Entleerung der Senkgruben und die Reinigung der häuslichen Zuleitungen (etwas missverständlich auch als "Schläuche« bezeichnet) wurden von Dienstleistern übernommen, die in Linz - wie in anderen Städten - „Nachtkönige « oder "Nachtarbeiter« genannt wurden. Sie tauchen in den Rechnungsbüchern der Stadt und den Ausgabebüchern anderer Institutionen regelmäßig auf. ${ }^{160}$ Die Frage nach der Häufigkeit von Senkgrubenentleerungen ist kaum zu beantworten, da sich die konkreten Zeit-

OÖLA, Landschaftsakten, Sch. 576, E.XV.6/No. 47 ; OÖLA, Landschaftsakten, Alte Registratur, Sch. 85, D.XV/No. 29.

I53 OÖLA, Landschaftsakten, Sch. 448, D.XV.3/No. I I 8; OÖLA, Landschaftsakten, Alte Registratur, Sch. 92 , D.XV.2/No. 135 ; vgl. zu Frankfurt: Bauer, Bauch, 78 f.

I 54 OÖLA, Landschaftsakten, Sch. 443, D.XV.2/No. 56; LR Erb, Reg. I 9 I I ( ( 20 ).

I 55 LR CIIIHI -3 , Reg. 894 (622f.).

I56 AStL, HS 86 I („Chronologische Beschreibung«, I77oer Jahre), fol. 32b; OÖLA, Landschaftsakten, Sch. 442 , D.XV.2/No. 32 .

I57 AStL, HS 436 (Bauamtsrechnung I8I6), pag. I23; OÖLA, Landschaftsakten, Alte Registratur, Sch. 85 , D.XV/No. 29.

I 58 Ö̈LA, Landschaftsakten, Alte Registratur, Sch. 95, D.XV.2/No. 27 I.

I59 AStL, HS ro84 (Stadtratsprotokoll I797), fol. r 5 ob.

I6o Vgl. z.B. LR BIIG8, Reg. 5298 ( ( 29); LR BIIG 3 , Reg. I 504 (If.); AStL, HS 389 (Bauraittung I 750), I04; vgl. Schott, Urbanisierung, i 7 f. 
Tab. 26: Zahlungen der Stadt Linz an den »Nachtarbeiter« Paul Wallinger, 1816

\begin{tabular}{|c|c|c|c|}
\hline Zeitpunkt & & Betrag & pag. \\
\hline 20. Jänner & Senkgrube "Kirchstetter oder Recrouten Haus« (2 Nächte) & $22 \mathrm{fl}$ & 85 \\
\hline 30. Jänner & Senkgrube Landgericht & $11 \mathrm{fl}$ & 79 \\
\hline 10. Februar & Senkgrube unteres Wassertor "oder Neubau " & $11 \mathrm{fl}$ & 96 \\
\hline 11. März & Senkgrube Pfarrschule St. Matthias (2 Nächte) & $22 \mathrm{fl}$ & 61 \\
\hline 30. März & Senkgrube "Gerhauser Haus« (4 Nächte) & $44 \mathrm{fl}$ & 88 \\
\hline 6. April & Senkgrube "Kirchstetter oder Recrouten Haus» (2 Nächte) & $22 \mathrm{fl}$ & 85 \\
\hline 27. Juli & Landgericht & $12 \mathrm{fl}$ & 80 \\
\hline 27. Juli & Senkgrube unteres Wassertor "oder Neubau« & $12 \mathrm{fl}$ & 96 \\
\hline 28. September & Senkgrube »Gerhauser Haus» (4 Nächte) & $60 \mathrm{fl}$ & 95 \\
\hline 28. September & Senkgrube "Kirchstetter oder Recrouten Haus» (5 Nächte) & $45 \mathrm{fl}$ & 86 \\
\hline 19. Oktober & Senkgrube Stadtwaagschule & $15 \mathrm{fl}$ & 58 \\
\hline 16. November & Senkgrube "Kirchstetter oder Sam(m)elhaus" & $11 \mathrm{fl}$ & 84 \\
\hline 30. November & »Nachtarbeit« Rathaus & $5 \mathrm{fl}$ & 74 \\
\hline 16. Dezember & Senkgrube "Fölsen Stockl« & $11 \mathrm{fl}$ & 91 \\
\hline \multirow[t]{2}{*}{ undatiert } & für »Raumung des Schlauches beim Lamplwirth" & $4 \mathrm{fl} 30 \mathrm{kr}$ & 116 \\
\hline & Summe & $307 \mathrm{fl} 30 \mathrm{kr}$ & \\
\hline
\end{tabular}

Quelle: AStL, HS 436 (Bauamtsrechnung 1816)

punkte aufgrund der häufig üblichen Sammelrechnungen nur selten abzeichnen, ohnehin war die Notwendigkeit mit der Anzahl der Nutzer/innen und der Dimensionierung der Senkgruben verbunden. Entleerungen fanden - wenig überraschend - anlassbezogen statt (was auch in manchen Mietverträgen vorgeschrieben war), ${ }^{161}$ d.h. mehrfach pro Jahr bis alle paar Jahre. ${ }^{162}$ Im Hinblick auf die Dienstleister ist eine erstaunliche Persistenz festzustellen: Im I 8. Jahrhundert sind in den städtischen Rechnungen fast ausschließlich die Namen Wimmer (auch Wimber), Peyrböck (auch Payrbäk oder Peyrbak), Joseph Mayr und später Paul Wallinger als Namen verzeichnet. ${ }^{163}$ Dabei konnten einzelne Akteure nicht unerhebliche Summen lukrieren, was vielleicht auch den zynischen Namensteil „König« erklärt (vgl. Tab. 26). Mitglieder der Familie Wallinger blieben auch im I 9. Jahrhundert als Senkgruben- bzw. Kanalräumer tätig, und Franz Wallinger schaffte es im letzten Drittel des Jahrhunderts immerhin in den Gemeinderat (vgl. unten). ${ }^{164}$

I6 I Dass »die heimbliche gemächer und Sinkgrueben geseubert und geraumbet« werden sollen - OÖLA, Landschaftsakten, Sch. 442, D.XV.2/No. 32 .

I62 LR BVI2, Reg. I 98 (I 22- I67); Ebd., Reg. I 253 ( I 90); vgl. Bauer, Bauch, $78 f$.

I63 LR BIIG8, Reg. 5482 ( 156 ); AStL, HS 389 (Bauraittung I 750), ro4; AStL, HS 399 (Bauraittung I 760), pag. 78, 8of. u. Ioo; AStL, HS 4I9 (Baurechnung I780), pag. Iо3 u. I I 2 ; AStL, HS 434 (Baurechnung I795/I796), pag. 76; OÖLA, Landschaftsakten, Sch. 583 , E.XV.8/No. 55 .

I64 Verzeichniß I 825 u. Gewerbe-Adressen-Buch I 853; GRP I 867, fol. I 4 I a u. I 4 Ib; vgl. RB I 879- I 880, 4. 
Ob die Fäkalien in der Landwirtschaft genutzt oder in der Donau entsorgt wurden, lässt sich nur schwer abschätzen. ${ }^{165}$ Die soziale und räumliche Verortung einzelner Dienstleister würde eine Verwendung in Landwirtschaft und Gartenbau nahelegen: Unter den Akteuren findet sich zumindest ein vorstädtischer Bauer, ${ }^{166}$ das im Schullertal ansässige Nachtarbeiterehepaar war als »Kräutler» - d.h. als Kräutergärtner und verkäufer - tätig, ${ }^{167}$ auch befand sich das »Nachtkönig-Haus « ${ }^{168}$ am Rande der Vorstadt in einer ausgeprägten Gartenlandschaft. ${ }^{169}$ Ein Nachbar des letztgenannten Hauses war der bereits erwähnte "Nachtarbeiter « Paul Wallinger. ${ }^{170}$ Es finden sich ebenso einzelne Hinweise bei den Befreiungen von der Brückenmaut: So suchte etwa ein Bäcker in der Altstadt an, seine »sehr viele[n] Dung- und Trankfuhren« in sein »Höfel« bei Urfahr gegen eine jährliche Zahlung zu gestatten, um Ähnliches supplizierte I 724 ein Steuereinnehmer. ${ }^{171}$ Aber diese »Dungfuhren« können sich genauso auf Stallmist und andere Abfälle bezogen haben: 1767 kaufte man im Schloss Pferdemist für die »Mistbeete « an, ${ }^{172}$ im Garten des Deutschordenshauses wurde in den I72oer Jahren zur Düngung der Weichsel- und Kirschbäume »Kämpelmacher-Mist« - wohl Hornreste - verwendet, zudem bezog man »alten abgefaulten« Kuhmist. ${ }^{173}$ Die »benachbarten Bauern [...] haben die heimlichen Gemächer in der Stadt gemiethet und führen diesen kostbaren Dünger auf ihre Gründe, den man anderwärts aus nichtigen, und zum Theile lächerlichen Ursachen in vorbeyfliessende Wasser leitet«, konstatierte hingegen der bayerische Botaniker Franz de Paula Schrank in den I 78 oer Jahren. ${ }^{174}$ Eine derartige Praxis erwähnt das zur gleichen Zeit entstandene "Josephinische Lagebuch« nicht: Zwar gebe es viel »Dung« in der Stadt, dessen Verwendung sei aber »mit schweren Kosten« verbunden - man meinte hier wohl den Transport -, welche »die wenigsten bestreitt(e)n « könnten oder wollten. ${ }^{175}$

Im rund 50 Jahre später erstellten »Franziszeischen Kataster« tauchen für die Vororte und Vorstädte ähnliche Angaben auf, wobei nun vermehrt auf den Ankauf von

I65 Vgl. Schott, Urbanisierung, I I 8; Bauer, Bauch, I 50- I 56 ; Tarr, Search, 293-9.

I66 Simon Reiserbaur am Taschlbauernhof - AStL, HS 434 (Baurechnung I795/I796), pag. 88.

I67 Auf eine eigene Produktion deutet der ca. I.300 Quadratmeter große Garten hin - vgl. Bohdanowicz, Vorstädte, Bd. 2, 690 .

I68 LZ, I4.5.I804; heute Wurmstraße I6 (Konskr.-No. 67I); I73 I - I770er Jahre im Besitz von Joseph Mayr, I77I ist die »Kräutlerin« Eva Peyrböckerin verzeichnet - vgl. Kreczi, Häuserchronik, $349 f$.

I69 Bohdanowicz, Vorstädte, Bd. 2, 209.

I70 Heute Hopfengasse 25 (Konskr.-No. 67I) - Kreczi, Häuserchronik, 349; vgl. Verzeichniß I 825 u. Gewerbe-Adressen-Buch I 853 .

I7 I Awecker, Bruckamt, I88f.

I72 LR BIIG8, Reg. 6I 24 (248).

I73 LR CIIIHI -3, Reg. 64I (459f.); $\mathrm{LR} \mathrm{CIIIH}_{4}, 866-869$ u. 886-893.

I74 Schrank/Moll, Briefe, 22.

I75 OÖLA, Josephinisches Lagebuch, HS I9I (Linz Obere Vorstadt); fast gleichlautend ist die Einschätzung für die Untere Vorstadt - OÖLA, Josephinisches Lagebuch, HS I92 (Linz Untere Vorstadt). 
Dünger verwiesen wurde. ${ }^{176}$ Es werde »eine große Quantität Dünger um einen wohlfeilen Preis aus der nahen Hauptstadt angekauft und beygeführt«, gab man in Bezug auf die Obere Vorstadt an, ${ }^{177}$ wobei die Beifügung, dass man den Dünger »auch durch Tausch gegen Streuhstroh bekomme, ${ }^{178}$ eher auf Stallmist denn menschliche Fäkalien hindeutet. Explizit wird im »Franziszeischen Kataster« an keiner Stelle die landwirtschaftliche Nutzung menschlicher Fäkalien thematisiert, selbst für die Stadt wird nur die Nutzung von Pferdemist, der »an die benachbahrten Landwirte oder Grundbesitzer verkauft« werde, erwähnt. ${ }^{179}$ Tatsächlich fand sich in den Quellen nur ein konkreter Hinweis auf eine derartige Praxis, ${ }^{180}$ deshalb sollte man diesbezüglich bei Verallgemeinerungen vorsichtig sein, wie auch die in der zweiten Hälfte des r 9. Jahrhunderts geführten Diskussionen zeigen (vgl. unten). ${ }^{181}$

\section{Von der Senkgrube zur Kanalisation}

Aufgrund der Vorstellung von krankmachenden »Miasmen« bestand über das I 9. Jahrhundert hinaus ein tendenzielles Misstrauen gegenüber Feuchtigkeit und Ausdünstungen. ${ }^{182}$ Somit wurde vielfach schlechter Geruch zu einem Indikator für Dysfunktionales und für mögliche Gesundheitsgefährdungen. ${ }^{183}$ Viele Lösungen zielten auf eine Vermeidung von Gestank ab: Senkgruben wurden abseits der Häuser errichtet, abgedeckt und in der Nacht geleert, auch versah man Aborte mit Luftrohren, die schlechte Gerüche ableiten sollten. ${ }^{184}$ Das nicht unproblematische Nebeneinander von Senkgruben und Brunnen wurde vor der Mitte des i 9. Jahrhunderts kaum thematisiert. ${ }^{185}$ Nur in einem beim Landhaus gelegenen Patrizierhaus entschloss man

I76 Vgl. Bohdanowicz, Pöstlingberg, 229 u. Bohdanowicz, St. Peter, $228 \mathrm{f}$.

I77 OÖLA, Franziszeischer Kataster, No. 534 (Operat 2, Linz Obere Vorstadt, Katastralschätzungs-Elaborat, undat.); ebd. (Operat 2, Linz Obere Vorstadt, Beantwortung Fragen Gemeinde Waldegg, I 3.I. I 83 I).

I78 OÖLA, Franziszeischer Kataster, No. 534 (Operat 2, Linz Untere Vorstadt, Beantwortung Fragen Gemeinde Lustenau, 25.I.I83I).

I79 OÖLA, Franziszeischer Kataster, No. 534 (Operat I u. 2, Braune Mappe, Linz-Stadt, Katastralschätzungs-Elaborat, I8.12.1832).

I80 Im September 1789 verwendete ein Bauer den Inhalt der Senkgrube in der Ursulinenschule, die ein »Nachtkönig" gemeinsam mit einem Taglöhner ausgeschöpft hatte, als Dünger für sein Feld - LR Eıb, Reg. I8I5 (IO2).

I 8 I Vgl. zu Fäkalien als economic good im vormodernen Japan: Hanley, Sanitation, 9- I2; zudem Barles, Approach, 34-37 (Paris) u. Gray, Sewage, 28 I u. 288-303 (Berlin).

I 82 Vgl. EdN, s.v. Miasmen; Kiple, Disease, I4 u. I8f.; Leven, Ratten, I8-22; Reith, Umweltgeschichte, 95- I03.

I 83 AStL, Altakten, Sch. I72; LR CIIIHI -3 , Reg. 894 (62 2f.).

I 84 LR CIIIHI -3 , Reg. 409 (259f.); LR BIIA40, Reg. I 9592 (44-46); OÖLA, Landschaftsakten, Sch. 443 , D.XV.2/No. 56.

I 85 OÖLA, Landschaftsakten, Sch. 443, D.XV.2/No. 56; vgl. dazu Schott, Urbanisierung, I I 8f. 
sich, als es nach dem Stadtbrand von I 800 wiederaufgebaut wurde, die alten Brunnen »mitten im Hoff» zu ersetzen, »weilen die abtrits Canaäle, vorbeyfließen, und durchschwitzen, wodurch das Wasser immer ungenusbahr gewesen «. ${ }^{186}$ Meistens sah man, wenngleich viele Senkgruben in Linz als Sickergruben angelegt waren, die oft bis zum Grundwasser gegraben wurden, ${ }^{187}$ jedoch eher im Verschlammen der Gruben und im dadurch bedingten Überlaufen ein Problem. ${ }^{188}$

Veränderungen dieser Abwasserlösungen waren deutlich anlassbezogen: Als nach dem Großbrand im Sommer I 800 der Stadtgraben aufgefüllt wurde (vgl. Kap. 7. Geordnete und modifizierte Umwelt), ergab sich in Bezug auf die Abwasserentsorgung Handlungsbedarf. Vonseiten der Landstände, die durch den Besitz des Landhauses Anrainer waren, wurde ein Konzept für die Errichtung eines neuen Kanals vom Landhaus über Promenade und Pfarrplatz zur Donau erarbeitet, das aber an bereits angesprochenen Problemen - den Kosten und der mangelnden Durchspülung - vorerst scheiterte (vgl. Abb. I 5) ${ }^{189}$ Man beschränkte sich - wie zehn Jahre später festgestellt wurde - auf das tägliche (!) »Ausschöpfen der Pfützen, und das nächtliche Räumen und Wegführen des Unraths «. ${ }^{190}$ Dieser Planung (und späteren) ${ }^{191}$ merkt man bereits eine erhebliche technische Expertise an: Es wurden umfangreiche Niveaumessungen und Berechnungen durchgeführt, die die Ingenieure der Landesbehörden übernommen hatten. ${ }^{192}$ Im Herbst I 809 wurde das Kanalprojekt schließlich unter französischer Herrschaft gebaut, was ex post in der etwas irreführenden Zuschreibung »Franzosenkanal« resultierte. ${ }^{193}$ Auch dieser Kanal stellte die Lösung eines konkreten Problems dar, man handelte also reaktiv: Der »Unrath« der Kollegienkaserne am Unteren Graben sollte in die Donau geleitet werden und damit »die in den halbverschütteten Stadtgraben die Luft verpestenden Pfützen ausgetroknet « werden. Die Errichtung des Kanals, der wiederum eine Mischung aus einer »öffentliche[n] Anstalt « und einer privaten Infrastruktur bildete, kostete schließlich fast 6.000 fl. ${ }^{194}$

Danach scheint es im Bereich der Abwasserkanäle keine umfangreicheren Erweiterungen gegeben zu haben, erst zu Beginn der I 8 2oer Jahre, in einer Phase abklingen-

I 86 OÖLA, Neuerwerbungen, HS 74 (»Bau-Rechnung« Kremsmünsterer Haus, I 804), pag. 242.

I 87 Vgl. ebd., pag. 30r ; LR CIIIH I-3, Reg. 4I I (262); ebd., Reg. 470 (309f.).

I88 OÖLA, Landschaftsakten, Alte Registratur, Sch. 95, D.XV.2/No. 27 I.

I 89 OÖLA, Landschaftsakten, Alte Registratur, Sch. 84, D.XIV.2/No. 205 ; ebd., Sch. 98 , D.XV.3/No. 79; OÖLA, Karten- und Plänesammlung, VI/27.

I90 OÖLA, Landschaftsakten, Alte Registratur, Sch. 84, D.XIV.2/No. 205.

I9 I Vgl. z.B. OÖLA, Karten- und Plänesammlung, VI/20.

192 Grüll, Ingenieure; Stauber, Ephemeriden, 7 u. 9.

I93 AStL, Altakten, Sch. I3; vgl. Mayrhofer/Katzinger, Geschichte, Bd. 2, 67 u. OÖLA, Karten- und Plänesammlung, $\mathrm{VI} / 28$.

I94 AStL, Altakten, Sch. I3; OÖLA, Landschaftsakten, Alte Registratur, Sch. 84, D.XIV.2/No. 205; die Stadt finanzierte offenbar nur einen Bruchteil der Kosten, die zudem über drei Jahre abgezahlt wurden. 


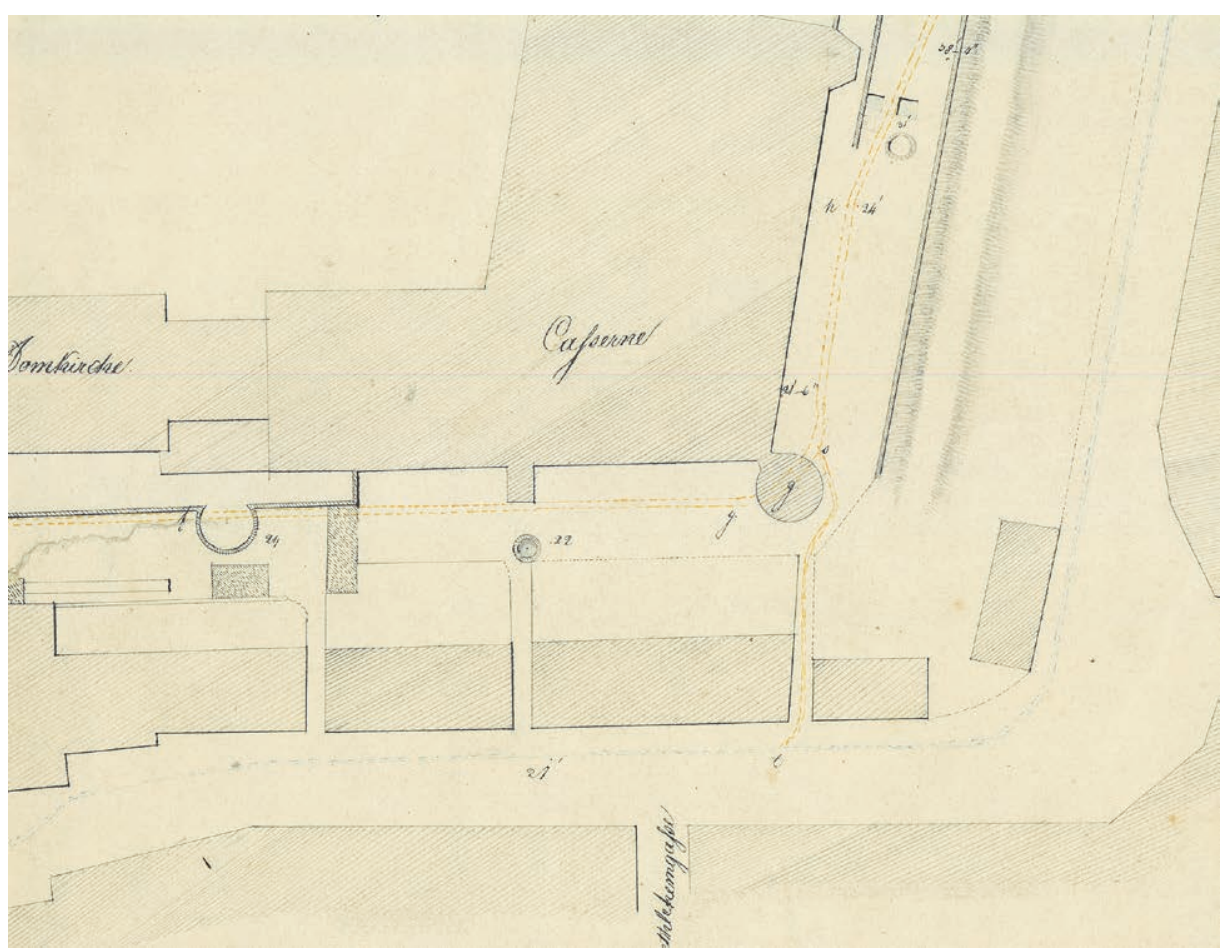

Abb. 15: Plan eines nicht umgesetzten Kanalisationsprojektes im Stadtgraben, 1800 (Ausschnitt) - die dickere strichlierte Linie in der Bildmitte zeigt den geplanten Kanal, die strichlierte Linie im unteren und rechten Bildteil ein bestehendes gedecktes Rinnsal

der Krisen, sinkender Preise und anderer Bemühungen um städtische Sauberkeit (vgl. Kap. 7. Geordnete und modifizierte Umwelt), setzten erneut diesbezügliche Ambitionen ein. $\mathrm{Zu}$ dieser Zeit bestand immer noch eine »Cloake« im Stadtgraben, die, wie ein Kreisamtsdekret I 820 feststellte, zu »üblen Ausdünstung[en]« führe und somit beseitigt werden sollte. Dieser Aufforderung folgten Planungen des Magistrats, der die Errichtungskosten auf 4.600 fl schätzte. Es wurde versucht, für diesen Kanalbau - auch dies war Teil der Kreisamtsanordnung - Zahlungen von den Besitzern der angeschlossenen Häuser einzuheben, wobei aber explizit von »freywilligen Beträge[n] « ausgegangen wurde. Das war insgesamt nur mäßig erfolgreich: Kosten von rund $4.000 \mathrm{fl}$ standen als Einnahmen nur 885 fl gegenüber, die von (vermutlich 30) Hausbesitzern bezahlt wurden. ${ }^{195}$ Der Errichtung dieses Kanals folgten in den nächsten Jahrzehnten zahlreiche weitere Bauten (vgl. Tab. 27): Euphorisch - und zu diesem Zeitpunkt durchaus verfrüht - verkündete der Beamte Benedikt Pillwein in seiner I 824 erschienenen »Beschreibung der Provinzial-Hauptstadt Linz«, dass Kanäle »indeß beinahe in

I95 AStL, Altakten, Sch. I72. 
allen gangbaren Gassen und Plätzen zur Fortschaffung des Unraths [...] in die Donau angebracht sind «. ${ }^{196}$

Tab. 27: Kanalbauten in Linz, 1821-1840

\begin{tabular}{llr}
\hline $\begin{array}{l}\text { Zeitpunkt/ } \\
\text { raum }\end{array}$ & Ort und Art des Kanals & $\begin{array}{c}\text { Kosten in fl } \\
\text { (gerundet) }\end{array}$ \\
\hline $1821 / 1822$ & Landhaus über Unteren Graben in Donau (Hauptkanal) & 4.000 \\
$1827-1831$ & Erweiterung zu Theater und oberer Promenade (Hauptkanal) & \\
$1835 / 1836$ & Erweiterung Klammgasse bis Hirschgasse (Hauptkanal), »Nebenkanal « bis Jung- & über 8.000 \\
& bauerngasse und durch den Weingarten bis zur Kapuzinergasse & \\
1836 & unterer Graben durch Landstraße bis nach Neuhäusel (Hauptkanal) & 1.500 \\
1839 & Neuhäusel durch Langgasse bis Ausgang Herrengasse (Seitenkanal) & 5.000 \\
$1840 / 1841$ & $\begin{array}{l}\text { Kapuzinergasse (Erweiterung des Kanals, gepflastertes Rinnsal); Landstraße und } \\
\text { Herrengasse durch die Spittelwiese (Verbindungskanal), städtisches Waaghaus bis }\end{array}$ & \\
& $\begin{array}{l}\text { Klostergasse und durch die Hahnengasse und Hofgasse auf den Hauptplatz (Kanal); } \\
\text { dieser »schon früher mit Hauptkanal vom Schmiedtor bis zur Donau verbunden }\end{array}$ & \\
\hline
\end{tabular}

Quelle: AStL, Altakten, Sch. 172 u. 173; AStL, HS 1103 (Stadtratsprotokoll 1822), fol. 17b; Fink, Geschichte, 123; Pillwein, Wegweiser, 168; LZ/IB, 26.9.1828; LZ/AB, 29.4.1831; LZ/AB, 31.5.1839, 299 f.

Diese Kanalprojekte gingen in Linz eindeutig von den Landesbehörden aus, die bereits in den I77oer Jahren im Nahbereich der ihnen zugehörigen Gebäude als lokale Umgestalter aufgetreten waren (vgl. Kap. 7. Geordnete und modifizierte Umwelt) und sich auch zu Beginn des 19. Jahrhunderts an den Planungen beteiligten resp. neue Kanalbauten einforderten. ${ }^{197}$ Die Grundlagen für die Kanalbauten der I82oer und I83oer Jahre wurden ausnahmslos durch die Ingenieure der Landesbehörden erarbeitet, was zahlreiche Pläne dokumentieren. ${ }^{198}$ Das Interesse der Landesbehörden an neuen Formen der Fäkalentsorgung zeigt auch die Existenz eines »beweglichgeruchlosen Senkgrubenapparates« im Landhaus, was vermutlich ein Fassentsorgungssystem darstellte und möglicherweise 1825 erworben wurde. ${ }^{199}$ Zudem wurden die Kanalbauten erst durch die finanzielle Unterstützung der Stadt durch die Landesbehörden möglich: I834 gewährten diese für die Kanalbauten ein Darlehen in der Höhe von $20.000 \mathrm{fl}(\mathrm{CM})$, wobei Zinsen von 4 Prozent und eine jährliche Tilgung von r.ooo fl vorgesehen waren. ${ }^{200}$ Aus dem normalen städtischen Budget I830 verzeichnete man Ausgaben in Höhe von $74.870 \mathrm{fl}$ - hätte man diese Projekte nicht umsetzen können, auch die »Beiträge« zur Kanalerrichtung, die man von den

I96 Pillwein, Beschreibung, 309 .

I97 Vgl. AStL, HS i 102 (Stadtratsprotokoll i 82 I), fol. ro8b u. 220a; AStL, HS r ro8 (Stadtratsprotokoll I827), fol. I75a, 275 a u. 275 b.

I98 Vgl. z.B. OÖLA, Karten- und Plänesammlung, VI/49.

I99 LZ/AB, I8.4.I825; ebd., 28.10.1831; ebd., 7.9.1832.

200 OÖLA, Landschaftsakten, Sch. 2 I 4, B.III. I 7 /No. 170. 
betroffenen Hausbesitzern einhob, bildeten nur einen relativ kleinen Zuschuss zur Finanzierung der Kanalbauten. ${ }^{201}$ Zentral erscheint die Verbindung der Kanalbauten mit einer allgemeinen visuellen Neuordnung des Stadtbildes in dieser Zeit, die auf allgemeine Sauberkeitsbestrebungen und eine bauliche "Regulierung« von Straßen und Plätzen abzielte, was vor allem Pflasterungen aber auch die Errichtung von Wasserrinnen und Kanälen betraf. ${ }^{202}$

Die Veränderungen, die sich infolgedessen bei der Fäkal- und Abwasserentsorgung ergaben, werden in den Stadtkammerrechnungen evident: Wurden in den I 8 2oer Jahren noch Ausgaben für Senkgrubenräumungen verzeichnet, so verschwanden diese weitgehend bis in die I $840 e r$ Jahre. ${ }^{203}$ Zwar lagen die meisten von der Stadt unterhaltenen Gebäude relativ zentral; vielleicht zeigt sich hier aber auch die Ambition, vor allem diese Gebäude zuerst an die Kanäle anzubinden. Den Erweiterungen der I 8 2oer und I83oer Jahre folgte ein sukzessiver, jedoch deutlich kleinerer Teilausbau, ${ }^{204}$ im Jahrzehnt vor der Errichtung der zentralen Kanalisation wurde die Zahl der Senkgruben im Stadtgebiet - bei einer Häuserzahl von rund I.400- I.500 - mit 850 (I 869) resp. 682 (1873) angegeben. ${ }^{205}$ Somit behielt die Senkgrube ihre zentrale Rolle im Abwassersystem der Stadt und führte, wie Baupläne dokumentieren, teilweise eine Koexistenz mit den Kanälen: Das Lazarett im Wörth ${ }^{206}$ verfügte in den I 840er Jahren für einen Abort über eine Senkgrube, ein anderer war an einen »Canal«, der wohl in die nahe Ludl führte, angeschlossen (vgl. Abb. I6). ${ }^{207}$

Der Grazer Ingenieur Rudolf Linner, der I 868 im Auftrag des Gemeinderats ein Gutachten erstellte (vgl. unten), beschrieb die Situation vor der Errichtung des zentralen Kanalisationssystems. Zwar kann Linner nicht als neutraler Beobachter gelten, aber dessen Berichte ermöglichen einen Einblick in die damals in Linz bestehenden Abwasserlösungen: Neben Kanälen waren die Senkgruben omnipräsent, deren Seitenwände und Sohlen Linner als "ganz und gar durchlässig« einschätzte, dazu kamen zahlreiche Sickergruben (»Versitzgruben«) für Regen- und Brauchwasser, die teilweise mit den Überläufen der Senkgruben verbunden waren. ${ }^{208}$ Am Schullerberg fielen Linner - er besuchte Linz im Frühjahr I $868^{209}$ - mehrere Sammelgruben für tierische Jau-

\footnotetext{
20 I 1850 wurden z.B. in der Pumpenmachergasse von den Hausbesitzern zwischen 2 und 20 fl (im Durchschnitt io fl) eingehoben - AStL, HS i 9 I (Oberkammeramt Empfang I 850), pag. I 32.

202 LZ/IB, I 5.9.1826; LZ/AB, I 7.9.1827; OÖLA, Karten- und Plänesammlung, VI/64.

203 Vgl. z.B. AStL, HS 439 (Unterkammeramtsrechnung I 824), pag. 2 I-35 u. AStL, HS 462 (Unterkameramts Contobuch pro I 848 ), pag. 2 I -70.

204 Vgl. z.B. LAB, I 5.2.I 865 u. GRP I 867, fol. 2 I 4a, 2 I 4 b, 25 Ib, 252 a u. 302 a.

205 GRP I 869, fol. 3 I 7a; Pichler-Baumgartner, Wege, 36.

206 Früher Pestlazarett, zum damaligen Zeitpunkt Gebär- und Findelanstalt, heute Lederergasse 33 (Konskr.-No. 366) - Kreczi, Häuserchronik, ı 93.

207 Vgl. auch OÖLA, Karten- und Plänesammlung, VII/ I 8.

208 Linner, Salubritäts-Verhältnisse, I 2 - I 4 u. 20; vgl. z.B. AStL, Altakten, Sch. 83.

209 LAB, I6.3.I 868.
} 

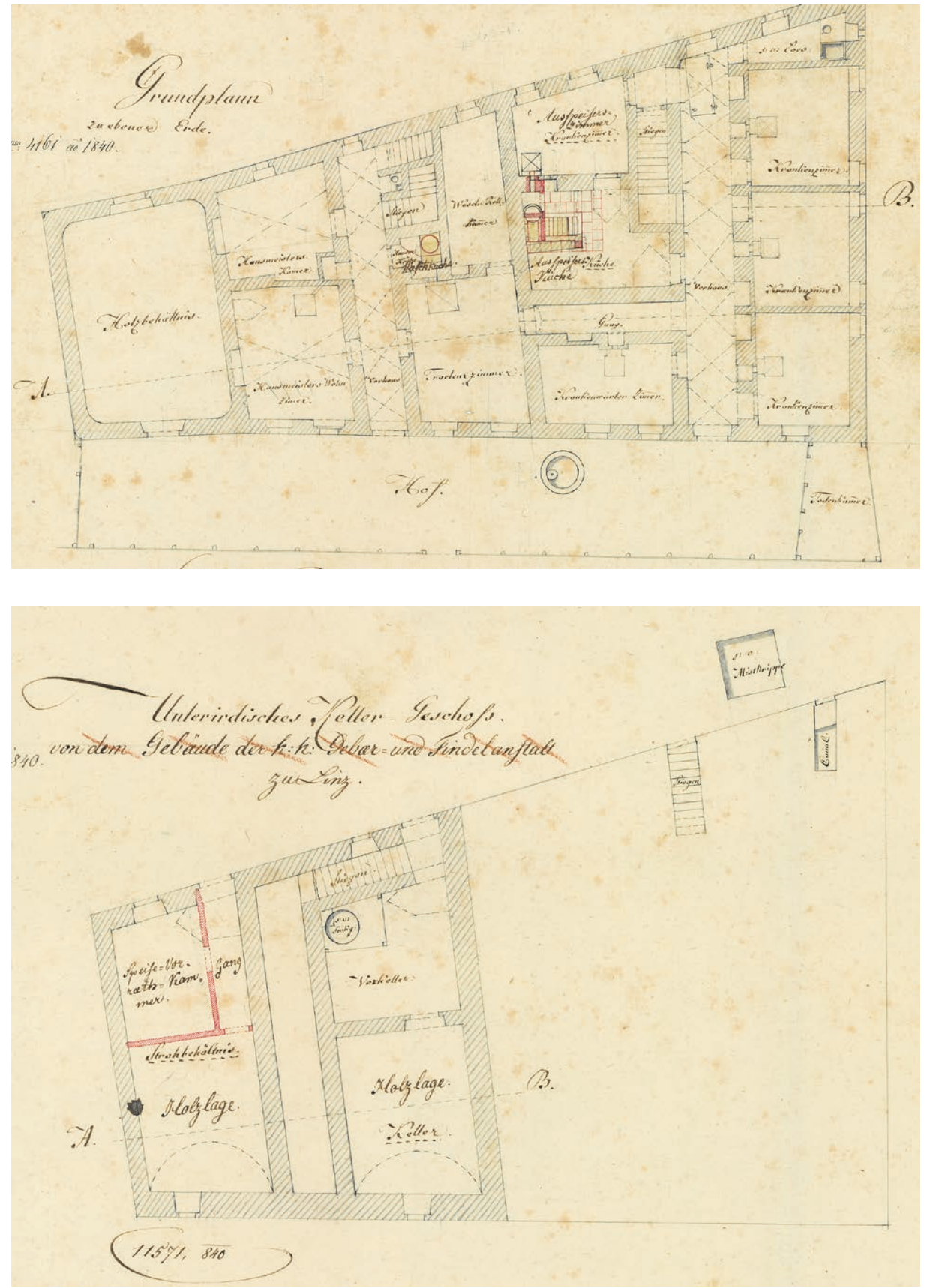

Abb. 16: Duale Abwasserlösung des Lazaretts im Wörth - oben das Erdgeschoss mit den Aborten, unten der Keller mit Kanal und Senkgrube (Ausschnitte), 1840 
che (»Adelgruben«) und am Harrachfeld eine große »Straßenwasser-Sammelgrube« ins Auge. ${ }^{210}$

Parallel zur Errichtung der Kanalbauten des Vormärz fanden umfangreiche Diskussionen zu städtischer Hygiene und der damit verbundenen Infrastruktur statt. Nachdem im Frühsommer I 837 in Wien zehn Schüler der Theresianischen Akademie an einer Magen-Darm-Erkrankung gestorben waren, wurde eine Untersuchungskommission eingerichtet, deren Bericht in zahlreichen Zeitungen, auch in der "Linzer Zeitung «, veröffentlicht wurde: Als Ursache des Krankheitsausbruches identifizierte man »eine Art animalischer Vergiftung des Brunnenwassers«, die infolge von »Communicationen des Unraths-Canals mit diesem Hofbrunnen« und von den »mephistischen Dünsten« des Fassabortsystems aufgetreten seien. Es habe sich um »Localursachen« gehandelt, die nicht zu erkennen gewesen seien und deshalb, so die entschuldigende Beifügung, »bisher keinen Anlaß« zum Einschreiten der zuständigen Behörden gegeben hatten. ${ }^{211}$ Derartige Berichte widerspiegeln das latente Misstrauen gegenüber den städtischen Abwässern und den damit verbundenen Gerüchen, zudem hatten der Anstieg der Bevölkerung und die Siedlungsverdichtung vermutlich die Probleme der Fäkalentsorgung im Alltag evidenter werden lassen. ${ }^{212}$ Auch der technische Diskurs zur Abwasserentsorgung, der international geführt und lokal rezipiert wurde, intensivierte sich während der I 83 oer und I $840 e r$ Jahre: Schon in der ersten Ausgabe der Wiener "Allgemeinen Bauzeitung« finden sich eine »Beschreibung eines sehr einfachen Mittels, den üblen Geruch der Abtritte zu beseitigen«, und ein Vorstellen der »englischen [...] Waterklosets«. ${ }^{213}$

Dazu kamen die Diskussionen und Baumaßnahmen in anderen Städten: Zahlreiche Impulse gingen von England aus, wo man in den I 84 oer Jahren - besonders für London - die Errichtung eines zentralen Kanalisationssystems intensiv und öffentlich diskutierte, wenngleich die Londoner Kanalisation erst ab dem Ende der I 85 oer Jahre gebaut wurde. ${ }^{214}$ Nach einem Großbrand errichtete die Stadt Hamburg ab den I 84 oer Jahren ein umfangreiches zentrales Wasserversorgungs- und Kanalisationssystem, ${ }^{215}$ im österreichischen Raum etablierten Städte wie Graz und Salzburg in den I 85 oer

2 Io Linner, Salubritäts-Verhältnisse, I 7 u. 32 ; bei der »Straßenwasser-Sammelgrube« handelte es sich offenbar um eine von der Stadt unterhaltene Infrastruktur - vgl. GRP i 870, fol. 6ra u. 6rb.

2 I I LZ, I7.7.I 837; dieser Beitrag wurde weitgehend aus der "Wiener Zeitung« übernommen - vgl. Wiener Zeitung, 26.6. I 837 .

2 I 2 In den I 83oer Jahren fielen in Linz täglich - wenn man eine Menge von rund I, 3 Kilogramm pro Kopf annimmt - mehr als 30 Tonnen menschliche Fäkalien an: vgl. Gierlinger et al., Feeding, 229 u. Schott, Urbanisierung, I 7 .

2 I3 Allgemeine Bauzeitung I (I836), 97-99 u. 2 I I-2 I6; dass die »Bauzeitung « auch in Linz rezipiert wurde, legen die heutigen Bibliotheksbestände vor Ort nahe.

2 I 4 Halliday, Stink, 46- Io I; vgl. Schott, Urbanisierung, 226-234.

2 I 5 Evans, Tod, I 8of.; vgl. Schott, Urbanisierung, 238f. u. Gray, Sewage, 283. 
Jahren neue Lösungen für die Fäkalienentsorgung, ${ }^{216}$ ein maßgebliches Vorbild für Linz war - wie bei der Wasserversorgung - jedoch die Stadt Wien. Dort bestand zwar für die innere Stadt im beginnenden I 8. Jahrhundert schon ein umfangreicheres Kanalsystem, aber erst ab i 83 I errichtete man (noch vor dem Ausbruch der Cholera und im Rahmen von Arbeitsbeschaffungsmaßnahmen) einen ersten »HauptunrathsCanal« am rechten Wienufer. Daran anschließend entstanden weitere Sammelkanäle, teilweise unter Verwendung der Stadtbäche. ${ }^{217}$ Im Hinblick auf die Kanalisierung zelebrierte man Wien in der "Allgemeinen Bauzeitung" zur Mitte der I 840er Jahre bereits als »Muster«, das »allen großen Städten [...] vorleuchten dürfte« ${ }^{218}$ Damit veränderten sich zunehmend die Ansprüche an eine moderne Stadt - gerade bei der Kanalisation scheint die Städtekonkurrenz stärker als beim Wasser gewesen zu sein. ${ }^{219}$ Wenn also ein Wiener Reisebericht I84I verkündete, dass die Linzer »keine Kanäl habn «, ${ }^{220}$ dann stellte dies - obwohl in satirischer Absicht geäußert - die Urbanität der Stadt infrage. Dazu kamen staatliche Impulse: Die Bauordnung für Linz und Salzburg aus dem Jahr I 846 erlaubte bei Neubauten nur noch eine Errichtung von Senkgruben, wenn kein Kanal vorhanden war, ${ }^{221}$ und I 850 betonte die Gemeindeordnung explizit die Zuständigkeit der Stadt »für Erhaltung und Reinigung der Hauptabzugskanäle«. ${ }^{222}$

Wesentlich beeinflusste die Cholera das Hinterfragen der existenten Abwassersysteme (vgl. Kap. 9. Epidemie): Für England und größere deutschsprachige Städte (darunter auch Wien) lässt sich das bereits für die I 83 oer und I $840 e r$ Jahre konstatieren, ${ }^{223}$ in Linz geschah dies deutlich später. Der Bericht des Linzer Stadtarztes Adam Haller zum schweren Choleraausbruch des Jahres I 855 stellte zwar beim Haus, in dem die ersten Choleraerkrankungen aufgetreten waren, "Gebrechen [...] in sanitätspolizeylicher Beziehung « fest, sie seien aber nicht als unmittelbare Ursache der Krankheit zu sehen, da die dortigen Zustände (ohne Cholerafall) »seit Jahren « geherrscht hätten. ${ }^{224}$ Deutlich intensivierte sich die Diskussion über städtische Abwasserlösungen nach der Choleraepidemie der I 85 oer Jahre in der "Allgemeinen Bauzeitung «:225 I 857 beschrieb man dort den Zustand der »öffentliche[n] Reinlichkeit in den Städten« relativ

2 I 6 Macher, Hygienisierung, I $2 \mathrm{f}$.

2 I 7 Brunner/Schneider, Umwelt, 262-264; Birkner, Stadt, 85-89; Weigl, Wandel, I 84f.; vgl. LZ, I6.9. I83i.

2 I 8 Allgemeine Bauzeitung 9 (I844), I37-I40, hier I37.

2 I 9 Vgl. Pillwein, Beschreibung, 309; Pillwein, Wegweiser, I68; Pillwein, Linz, Bd. 2, 25; Koch, Reise, 36.

220 Reiseabentheuer, I 24.

22 I LZ, I3.4.I846.

222 Gemeindeordnung I 850, LGBl. 26 I/ I 850, 274.

223 Schott, Urbanisierung, 223-233; Weigl, Wandel, I 85.

224 OÖLA, Archiv der Statthalterei, Präsidium, Sch. 369.

225 Allgemeine Bauzeitung 22 (I 857), 205-209; Allgemeine Bauzeitung 23 (I858), I56f; Allgemeine Bauzeitung 24 (I859), 77-8I; Allgemeine Bauzeitung 25 (I860), 5f.; Allgemeine Bauzeitung 26 (г861), 98-104; Allgemeine Bauzeitung 27 (1862), Iо1-105; vgl. zur bildlichen Inszenierung in London: Dobraszczyk, Sewers, 354-358. 
drastisch - obgleich sich die Stadtverwaltungen ständig "mit Verbesserungen und Verschönerungen« und mit der Versorgung »der Bevölkerung mit Luft, Wasser und Licht« beschäftigen würden, sei dennoch die »verdorbene Luft« in den Städten aufgrund der »Abfälle« aus Gewerbe und Haushalten und der »Ausdünstungen« von Senkgruben und Kanälen omnipräsent. ${ }^{226}$

In der Choleradiskussion der I 86oer Jahre nahm die Frage des städtischen Umgangs mit Fäkalien bereits breiten Raum ein: Im Sommer I 865 brachte die Linzer "TagesPost « eine Serie von Aufmacherartikeln zur Cholera, die auch mehrere ausführlichere Beiträge zur »Kloakenfrage « inkludierte. ${ }^{227}$ Darin griff man wesentlich auf die Argumentation des Münchner Hygienikers Max v. Pettenkofer und der englischen Assanierer zurück: Menschliche und tierische Exkremente würden den Boden und somit die Brunnen verunreinigen, dadurch Typhus und andere Infektionskrankheiten verursachen. Es seien menschlich verursachte Epidemien, es liege somit auch »in der Macht des Menschen « und - hier kann man ergänzen - in der Verantwortung der Stadtverwaltung, diese zu beseitigen. ${ }^{228}$ Wenn man täglich 3 Pfund Exkremente pro Einwohner annehme und mit einem Pferdewagen rund 20 Zentner wegbringen könne, dann sehe man - da die notwendige Zahl der Fuhren nie erreicht werde -, "wie viel in der Stadt zurückbleibt« ${ }^{229}$ Nach der Cholera I 866 erschien ein Zusammenhang zwischen Epidemie und "mangelhafte[r] Desinficirung der Unrathscanäle in Verbindung mit schlechter Beschaffenheit des Trinkwassers« wohl den meisten Stadtbewohner/innen als plausibel. ${ }^{230}$ Adalbert Stifter teilte diese Ansicht, wie er seiner Frau im Sommer I 866 mitteilte: Die Cholera werde »fast gewiß« durch die »Entleerungen« der Kranken übertragen, »durch die Unrathskanäle einer Stadt« und sie würde von dort »in die Lüfte der Straßen und Wohnungen hauchen «. ${ }^{231}$

I 867 diskutierte man im Gemeinderat bereits eine umfangreiche Erweiterung des städtischen Kanalnetzes, wobei aber die Wahrscheinlichkeit einer Finanzierung als "nicht günstig“ eingeschätzt wurde. ${ }^{232}$ Überraschend war das vermutlich nicht: Dass die Kosten hoch und nicht aus dem normalen Budget $\mathrm{zu}$ finanzieren sein würden, hatten die Wiener Kanalbauten eindrucksvoll unterstrichen. ${ }^{233}$ Auf diesen latenten Diskussionsprozess traf im Herbst I 867 eine Aufforderung der Landesregierung, einen Bericht zur »Verwerthung des Kloakeninhalts« in Linz zu verfassen. ${ }^{234}$ Dabei

226 Allgemeine Bauzeitung 22 (1857), 205.

227 LTP, I 5.8.1865; ebd., I8.8.1865, ebd., 24.8.1865; ebd., 30.8.1865; ebd., I.9.1865; vgl. auch: ebd., 9.3.1 865 .

228 LTP, 18.8.1 865; ebd., 30.8.1865; ebd., I.9.1865; vgl. zu Pettenkofer: Schott, Urbanisierung, 24 of.

229 LTP, r.9.1 865.

230 LTP, 6.10.1866.

23I Stifter, PRA, Bd. 21, 273.

232 GRP I 867 , fol. 25 rb u. 252 a.

233 Allgemeine Bauzeitung 9 (I 844), I40; vgl. zu London: Schott, Urbanisierung, 236.

234 GRP i 867, fol. 3 r 8a; vgl. Pichler-Baumgartner, Wege, $40-42$. 
handelte es sich um eine Anfrage, die aus Preußen kam und über das Handelsministerium an die Landwirtschaftsgesellschaften und Provinzregierungen weitergereicht wurde: Anknüpfend an die damals laufenden Diskussionen über die Nutzung von Fäkalien als Dünger in der Landwirtschaft, versuchte man, Informationen über Erfahrungen und Praktiken in verschiedenen mitteleuropäischen Städten zu sammeln. ${ }^{235}$ Interessanterweise entwickelte diese Anfrage mittelfristig eine erhebliche Dynamik zunächst etablierte der Gemeinderat ein Komitee, das die bestehende Fäkalentsorgung und die Option der Düngernutzung evaluieren sollte. ${ }^{236}$ Damit entwickelte sich - was in anderen Städten damals begann oder bereits stattgefunden hatte ${ }^{237}$ - in Linz die Stadtverwaltung zu einem entscheidenden Akteur, der aktiv auf eine Neuregelung der Fäkal- und Abwasserentsorgung hinarbeitete.

Im Jänner I 868 wies das Komitee in drastischen Worten auf die »Mängel« der derzeitigen Fäkalentsorgung hin, konstatierte einen kausalen Zusammenhang zwischen durch Abwässer verunreinigtem Trinkwasser und dem Ausbruch epidemischer Krankheiten und plädierte dafür, das »bestehende Sistem [...] aufzugeben, und ein entsprechenderes an deren Stelle zu setzen «. ${ }^{238}$ Der Gemeinderat ließ einen Niveauplan der Stadt herstellen, Wasseruntersuchungen durchführen (vgl. Kap. 3. Wasser) und beauftragte den Grazer Ingenieur Rudolf Linner mit einem Gutachten zum Linzer Abwasserentsorgungssystem. ${ }^{239}$ Linner argumentierte ähnlich wie der Gemeinderat: Er nahm eine Verunreinigung des Trinkwassers durch Abwässer über Boden und Luft an, bewertete die Sickergruben (»Versitzgruben«) als »ein Unikum an Sanitätswidrigkeit« und sah die Stadt allgemein von krankmachenden Gasen und »Ausdünstungen« betroffen. ${ }^{240}$ Linners Gutachten wurde als gemeindefinanziertes Druckwerk publiziert und an alle Linzer Hausbesitzer verteilt, zudem auszugsweise - im Rahmen der Berichterstattung über die Gemeinderatssitzungen - in den Zeitungen veröffentlicht. ${ }^{241}$ Linners Empfehlung zielte darauf - wie bereits in Graz praktiziert -, die Fäkalien in Fässern zu sammeln und diese über einen städtischen Dienst regelmäßig zu leeren (»Fass-Abort-System «). Dies sei schnell und günstig umzusetzen. ${ }^{242}$ Eine kostengünstige Lösung war im Gemeinderat konsensfähig und zunächst versuchte man, das Fass-Abort-System im Volksgartensalon probeweise einzusetzen, was aber offenbar unterblieb. Nur die Landesregierung und einzelne Haushalte scheinen die Fass-Ab-

\footnotetext{
235 Wochenblatt der k.k. Gesellschaft der Aerzte in Wien 43 (г867), 370-371, hier 370; vgl. PichlerBaumgartner, Wege, 65.

236 GRP I 867 , fol. 329 a.

237 Pichler-Baumgartner, Wege, 4 of. u. 64; vgl. zu US-amerikanischen Städten: Melosi, America, r68.

238 GRP i 868 , fol. $9 a-$ i r b.

239 AStL, Alte Registratur, Sch. I75; GRP I 868, fol. I 33 a.

240 Linner, Salubritäts-Verhältnisse, 32.

24I LTP, 24.5.I 868.

242 Linner, Salubritäts-Verhältnisse, 23 f. u. 28 f.
} 
ort-Lösung tatsächlich umgesetzt zu haben. ${ }^{243}$ Im September I 869 verwarf man »der vielfachen Schwierigkeiten wegen« eine verpflichtende Einführung des Fass-AbortSystems für die ganze Stadt ${ }^{244}$ - was man sich unter diesen Problemen vorstellen kann, zeigen die Diskussionen aus dem folgenden Jahrzehnt: Nur »mit Mühe« habe man für eine Linzer Schule einen Bauern zur Entleerung der Fässer gefunden, ${ }^{245}$ I 878 machte eine Eingabe von Bauern aus der Umgebung von Linz deutlich, dass man an »Stall- und Hofmist « und nicht »Kloakendünger « interessiert sei, ${ }^{246}$ und auch die Wiener Gutachter rieten I 872/I 873 aus ähnlichen Gründen vom Fass-Abort-System ab. ${ }^{247}$ Dass der Senkgruben- und Kanalräumer Franz Wallinger I 873 einen Mangel an "Ablagerungs-Plätzen« konstatierte - Wallinger wurde daraufhin vom Gemeinderat als Entsorgungsweg die Donau nahegelegt -, deutet ebenso auf ein Nichtverwenden von Fäkalien in der lokalen Landwirtschaft hin. ${ }^{248}$

In Linz war die Umwandlung von Stadtbächen in Abwasserkanäle (wie es z.B. in Wien praktiziert wurde) nicht möglich, es verblieb nur die Errichtung eines Schwemmkanalsystems. Nach dem grundsätzlichen Beschluss des Gemeinderates im Herbst I 869, »die Kanalisierung der Stadt Linz nach dem zwekmässigsten System« durchzuführen, ${ }^{249}$ folgten Vermessungsarbeiten, Gutachten, Berichte, Ausschreibungen und weitere Planungen, die schließlich im Herbst I 873 abgeschlossen wurden. ${ }^{250}$ Anders als bei der Wasserleitung wurde am Kanalprojekt zu diesem Zeitpunkt kaum Kritik geäußert, lediglich die Art der Finanzierung führte zu einer kurzen öffentlichen Debatte. $^{251}$ Über die Modernisierung des städtischen Abwasserentsorgungssystems bestand also offenbar weitgehender Konsens, obwohl eine Anschlusspflicht vorgesehen wurde. ${ }^{252}$ Wesentlichen Anteil daran hatten die stetigen Diskussionen der I 86oer und I $870 e r$ Jahre über die Gesundheitsgefährdung durch die existenten Abwasserlösungen - evident wurde dies erneut mit dem Heranziehen der Cholera im Herbst I 872 , der man wiederum mit der »Disinfizierung sämmtlicher Aborte, Senkgruben und Kanäle« begegnete. ${ }^{253}$ Möglicherweise trug auch der Umstand, dass mit der »Oberösterreichischen Baugesellschaft« ein Unternehmen mit zahlreichen Verbindungen zu lokalen Institutionen und Eliten tätig wurde, zu diesem Konsens bei. ${ }^{254}$ Errichtet wurde

243 GRP r 868, fol. 3 rob; vgl. GRP r 869, fol. I 4b- i 5b; Pichler-Baumgartner, Wege, 66.

244 GRP i 869, fol. 266b.

245 Pichler-Baumgartner, Wege, 66.

246 LVB, 3.3.1878.

247 Pichler-Baumgartner, Wege, 67.

248 GRP r 873, fol. 27 ra.

249 GRP I 869, fol. 3 I 3 b-3 I 8 b.

250 GRP I 87o, fol. 266a-27ob; GRP I 874, fol. 3b-4b; GRP 1875, fol. 2 I 4b-2 2 Ib; Pichler-Baumgartner, Wege, 4If.; RB I 876 - i 878, $73-77$.

25 I Pichler-Baumgartner, Wege, 92 ; vgl. dazu die zeitgenössische Druckschrift Grubauer, Betrachtungen.

252 Pichler-Baumgartner, Wege, 93-96.

253 GRP I 872 , fol. 299 b u. $300 a$.

254 Pichler-Baumgartner, Wege, 42 ; Lackner/Stadler, Fabriken, $444 \mathrm{f}$. 
das Kanalsystem ab I 876, wobei man viele bereits bestehende Kanäle - darunter auch den »Franzosenkanal« - weiterverwendete bzw. adaptierte. Da es noch keine leistungsfähige Wasserleitung gab, wurde ein Reservoir (»Spülgalerie«) in der Kapuzinerstraße errichtet, das mit dem Überwasser eines nahen Brunnens das periodische Durchspülen ermöglichte. ${ }^{255}$ Der Zeitpunkt der Umsetzung eines Schwemmkanalsystems ist im österreichischen wie auch im internationalen Vergleich als früh zu erachten. ${ }^{256}$ Bis zur Mitte der I 88oer Jahre wurden weite Teile der inneren Stadt und der Vorstädte an das Kanalsystem angeschlossen (vgl. Abb. I 7). ${ }^{257}$

Danach erfolgte eine Erweiterung in verschiedenen Phasen, wobei die dünn besiedelten Vororte erst kurz vor der Jahrhundertwende an das Kanalisationssystem angeschlossen wurden. Ab Anfang der I 89 oer Jahre waren die ersten öffentlichen »Bedürfnisanstalten und Pissoirs « in der Stadt errichtet worden und I 90 I wies das städtische Kanalnetz bereits eine Länge von 43 Kilometer auf. ${ }^{258}$ Die zunehmende Verlandung des Fabrikarms (vgl. Kap. 6. Fluviale und aquatische Räume) und auch die verhältnismäßig kleinen Hochwasserereignisse von I 885 und I889 führten I 890 zur Entscheidung, einen Sammelkanal zu errichten, der die Abwässer weiter vom Stadtzentrum entfernt in die Donau leitete. Einen zweiten Entlastungskanal - und einen Kanal für die Vororte - bildete der »Hauptsammelkanal«, der ab I 897 angelegt wurde und im Augebiet der Zizlau in die Donau mündete. ${ }^{259}$

Dass alle Kanäle die Abwässer ohne vorherige Reinigung in die Donau einbrachten, nahm man kaum als Problem wahr. Begünstigt wurde diese Praxis durch den Umstand, dass die Donau bei Linz ein relativ großer Fluss war und es viele Kilometer flussabwärts nur wenige und kleine, direkt am Ufer gelegene Ansiedlungen gab, zudem nutzte man das Wasser der Donau kaum (vgl. Kap. 3. Wasser). Ohnehin war der Glaube an die Selbstreinigungskraft größerer Flüsse zu dieser Zeit noch unerschütterlich: In den I $870 e r$ Jahren sah das Wiener Stadtbauamt in seinem Gutachten zu den Linzer Kanalbauplänen kein Problem in der ungeklärten Einleitung der Abwässer. Es sei eine übliche und sinnvolle Praxis, aufgrund der "großen Wassermassen« habe man »kein Besorgniß wegen [einer] Verderbung des Wassers«. Der »natürliche Ablagerungsort der Unrathsstoffe«, beschied der Gemeinderat im August I 873 dem Kanalräumer und Senkgrubenentleerer Wallinger auf eine Anfrage hin, sei »die Donau«. ${ }^{260}$ Auch in einer Bauverhandlung des Hauptsammelkanals gab man sich I 898 davon überzeugt, dass

255 RB I 876- I878, 73-77; Pichler-Baumgartner, Wege, 4If. u. 94 f.

256 Pichler-Baumgartner, Wege, 43.

257 Mayrhofer/Katzinger, Geschichte, Bd. 2, I 55 f.

258 Pichler-Baumgartner, Wege, 216-227; RB 1892, 233f.; in Wien gab es derartige Infrastrukturen schon ab der Mitte des I9. Jahrhunderts - vgl. Brunner/Schneider, Umwelt, 257.

259 Pichler-Baumgartner, Wege, 216 u. 254-257.

260 Ebd., 25 I; vgl. zu England und Frankreich: Schott, Urbanisierung, 236f.; Goddard/Sheail, Reform, 93-99 u. Barles, Umwelt, 6rf.; vgl. die etwas vorsichtigere Einschätzung in der »Allgemeinen Bauzeitung«: Allgemeine Bauzeitung 30 (I 865), $220 f$. 


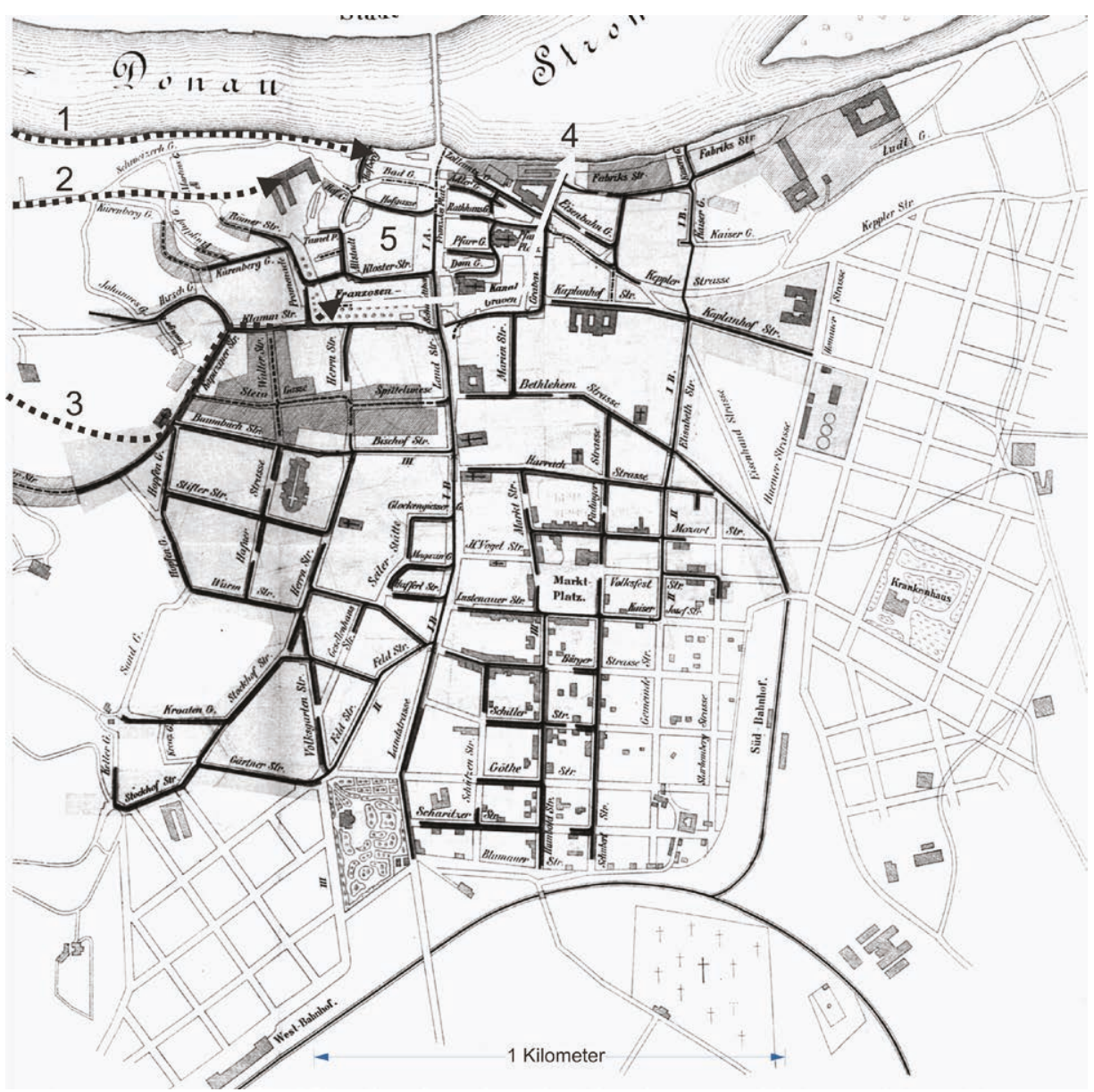

Abb. 17: Bestehende und geplante Kanäle in Linz, 1881 - zudem eingezeichnet sind die Wasserleitungen aus St. Margarethen (1), ins Schloss (2) und ins Landhaus (3)

»den an der Donau stromabwärts befindlichen Ortschaften [...] keine Gefahr durch die Einleitung des Kanalinhaltes« drohe, »weil ja das Wasserquantum der Donau ein so riesiges und das Gerinne ein ziemlich rasches ist«. Tatsächlich erhob der unmittelbare Anrainer, die Gemeinde Steyregg, keinen Einspruch. ${ }^{261}$

Als Problem sah man lediglich ein Nichtfunktionieren der gewohnten Entsorgungswege: Im Sommer r 865 beklagte ein Leserbriefschreiber, dass sich im Fabrikarm »durch die letzten Hochwässer ein sehr ansehnlicher Schlammhaufe gebildet [habe], der den Abfluß des nebenan ausmündenden Unrathskanales in die Donau geradezu

26I Pichler-Baumgartner, Wege, 258. 
unmöglich macht «. ${ }^{262}$ Mit der neuen Kanalisation und der fortschreitenden Verlandung des Fabrikarms traten ab der zweiten Hälfte des i9. Jahrhunderts offenbar größere Probleme bei der Einleitung der Fäkalien in die Donau auf. ${ }^{263}$ Siegmund Taussig, ein Ingenieur der Wiener Donauregulierungskommission, konstatierte 1883 in einem Gutachten, dass der Fabrikarm mittlerweile »mehr einer großen Pfütze als einem Donauarme« ähnle, und verwies auf die »schädlichen Ausdünstungen der [...] gährenden und auf den zu Tage tretenden Schotterbänken trocknenden Fäcalmassen «. ${ }^{264}$ I 886 beschloss der Gemeinderat die Zuschüttung des Fabrikarms, was ab Herbst i 889 nach längeren Diskussionen über Finanzierung und konkrete Ausgestaltung umgesetzt wurde. Dadurch ergab sich Handlungsbedarf für die Hauptkanalarme, die bei der Unteren Donaulände und der Wasserkaserne in den Fluss mündeten. Dennoch wurden die Fäkalien weiterhin in den zeitweilig kaum noch Wasser führenden Fabrikarm eingeleitet, bis im Frühsommer I 890 durch die Stadtverwaltung ein neuer Sammelkanal errichtet wurde, der nun unter der (ehemaligen) Strasserinsel direkt in die Donau mündete. Damit - und mit einem zwischenzeitlich erfolgten Hochwasser - scheint sich die Situation verbessert zu haben. ${ }^{265}$

In Bezug auf die Abwasser- und Fäkalentsorgung lässt sich eine partielle Persistenz von vormodernen Systemen und Praktiken feststellen, die aber in den letzten Jahrzehnten des r 9. Jahrhunderts zunehmend infrage gestellt wurden. ${ }^{266}$ Ein Beispiel bildet eine Gerberei, die sich in der Kaisergasse (und damit nahe der historischen Gerberansiedlung in der Lederergasse) befand. Der Betrieb wurde bis in die I86oer Jahre erweitert und verfügte über ein zusätzliches Gebäude an der Unteren Donaulände, das in der Nähe eines anderen Ledererzeugers lag. I 874 verunreinigte das Lohwasser des Betriebes einen Nachbarbrunnen, was zu verschärften Auflagen führte, I 878 wurde schließlich der Anschluss an die Kanalisation hergestellt. ${ }^{267}$ An der urbanen Peripherie waren die Kontinuitäten ausgeprägter: Da der Anschluss von dünner besiedelten Gebieten an die Kanalisation spät erfolgte, bestanden dort weiterhin Sicker- und Senkgruben, die auch bei Neubauten errichtet wurden. ${ }^{268}$ Aber hier ist ebenso eine zunehmende städtische Kontrolle über ehemals private Zuständigkeiten erkennbar: Ab der Mitte der I 88 oer Jahre gab es regelmäßige - offenbar flächendeckende - Kontrollen der Abwasserinfrastrukturen durch städtische Bedienstete, die auch die Zwangsentleerung von Senkgruben anordnen konnten, und I 894 legte man fest, dass die Entleerung von Senkgruben im Stadtgebiet nur noch über den (kostenpflichtigen) städtischen

262 LTP, 22.6.1865.

263 RB I881, I02; RB I889, I 59.

264 Pichler-Baumgartner, Wege, 252.

265 RB I 890, 206f.; der Sammelkanal war schon mehrere Jahre zuvor diskutiert worden: vgl. RB I 887, I03.

266 Vgl. Illi, Schîssgruob, 73-75 u. Brunner/Schneider, Umwelt, I 52.

267 Lackner/Stadler, Fabriken, 38 I ; vgl. zum Betrieb: Statistischer Bericht I 882, Bd. 2, I74.

268 Schiedermayr, Sanitätsverhältnisse, I 3 ; Lengauer, Massenwohnbau, I 5 I - I 53 ; vgl. RB I 882, 3 of. u. RB I 887, I 75 . 
Dienst erfolgen dürfe. ${ }^{269}$ Zwar merkte die Gemeindeverwaltung wenige Jahre später an, dass »die Befolgung dieser Anordnung viel zu wünschen übrig« lasse, ${ }^{270}$ dennoch scheint die Stadt die Entleerungen zum größten Teil übernommen zu haben. ${ }^{271}$

\section{Abfall und Emissionen: Moderne Probleme?}

Neben Fäkalien und Abwässern produzierten Haushalte und Gewerbe auch Emissionen und andere Abfallstoffe. Für diese Bereiche und die damit verbundenen Praktiken finden sich für die Zeit vor dem letzten Drittel des i 9. Jahrhunderts nur wenige Hinweise in den Quellen. Dieser Umstand ist nicht unbedingt einem absenten Problembewusstsein, sondern eher einem geringen Problemdruck zuzuschreiben: Das omnipräsente Wiederverwerten und Weiternutzen minimierte Abfälle, und Emissionen waren eine alltägliche Erfahrung, die alternativlos erschien.

Noch im ausgehenden I9. Jahrhundert bestand der häusliche Abfall größtenteils aus »Kehricht«, vegetabilen Resten und Asche. ${ }^{272}$ Der Abfall in und an der Donau bei der Linzer Brücke sei, so ein Leserbrief I 880, »ein Chaos von allen nur erdenklichen Abfallstoffen von zerrissenem Kartenpapier an bis zu den schwersten Ofenkacheln, vom verrostetem kleinen Blechsieb bis zur gebrochenen Dachrinne und vom I/8 Liter Ciment hinauf bis zu einem mit Steinen oder Ziegeltrümmern gefüllten Spritzkruge « ${ }^{273}$ Meist wurden die häuslichen Abfälle vor Ort oder an der urbanen Peripherie zur Anschüttung oder zum Befüllen von Gruben und Gräben verwendet. ${ }^{274}$ In den I69oer Jahren habe man, so eine Chronik aus der ersten Hälfte des I 8. Jahrhunderts, beim Gerinne der »Luedl und mehr anderer Orten hölzerne Kreuz« aufgestellt, wo »allerhand Unrat und Unflat« deponiert werden sollte. ${ }^{275}$ Vegetabile Reste wurden in Gärten und in der Landwirtschaft als Dünger verwendet ${ }^{276}$ und konnten auch von stadtnahen Bauern »als Gegenfuhr « für die in die Stadt gebrachten Lebensmittel mitgenommen werden. ${ }^{277}$ Es ist ebenso (wie beim Abwasser) eine häufige Entsorgung über die Donau anzunehmen: Bereits die "Fürkaufsordnung" aus dem ausgehenden I 7. Jahrhundert sah vor, dass konfiszierte Waren und das beim Verkauf von Kleintieren

269 Vgl. RB I 884, I I I RB I 887, I73f.; RB I 888, 206; RB I890, 2 I 7; AStL, Materienbestand, Sch. 2 I 3.

$270 \mathrm{RB}$ I 898,33 .

27 I RB I900, 227.

272 Illi, Schîssgruob, I 8; Stöger/Reith, Recycling, 282; vgl. EdN, s.v. Abfall.

273 LVB, I 5.2.1880.

274 OÖLA, Landschaftsakten, Sch. 583, E.XV.8/No. 51/3; OÖLA, Landschaftsakten, Alte Registratur, Sch. 96, D.XV.3/No. 2 I/4; vgl. Schott, Urbanisierung, I $20-$ I 23.

275 AStL, HS 86r („Chronologische Beschreibung«, I 77oer Jahre), fol. 42a.

276 AStL, HS ro87 (Stadtratsprotokoll r 800), fol. 239b; vgl. zu Wien: Brunner/Schneider, Umwelt, 276.

$277 \mathrm{LVB}, 3 \cdot 3 \cdot 1878$. 
benutzte Stroh in die Donau geworfen werden müsse. ${ }^{278}$ Die bis in die I $830 e r$ Jahre an der Oberen und Unteren Donaulände bestehenden Fleischbänke und Schlachthäuser deuten auch auf eine Entsorgung über die Donau hin. ${ }^{279}$ Für die r86oer bis r $880 e r$ Jahre dokumentieren zahlreiche Zeitungsmeldungen das Einwerfen von Abfall in die Donau als alltägliche Praxis. ${ }^{280}$ In einem Leserbrief aus dem Jahr I 880 wurde vermutet, dass die Lagerung von städtischem Abfall bei der früheren Wollzeugfabrik ebenso auf eine spätere Entsorgung über die Donau abziele: „Man scheint sich da auf Mutter Natur zu verlassen, jedes Frühjahr ein Hochwasser erwartend, damit die Uferbewohner von den $[. .$.$] Abfallstoffen [. .$.$] verschont werden«. { }^{281}$

Martin Melosi hat für US-amerikanische Städte festgestellt, dass der häusliche Abfall vor den I89oer Jahren eher als »nuisance« denn als »serious threat« wahrgenommen worden sei, dementsprechend seien die meisten kommunalen Maßnahmen reaktiv gewesen. ${ }^{282}$ Auch in Linz sah man I 865 die Ansammlungen von Abfällen und Kehricht bei der Linzer Donaubrücke und vor der Collegienkaserne eher als visuelle Beeinträchtigungen, ${ }^{283}$ erst das I 882 erfolgte Auftreten der Statthalterei gegen die (eigentlich schon seit I874 verbotene) Abfallentsorgung in die Donau - den Anlass dafür bildete hier jedoch wiederum die Verlandung im Fabrikarm - führte zu einem Engagement der Stadt in diesem Bereich. ${ }^{284}$ Man überlegte, einen eigenen städtischen Kehrichtwagen anzuschaffen, der »zu bestimmten Stunden« die häuslichen Abfälle sammeln und »an einem geeigneten Platze« ablagern solle. Hauptproblem bildete die Abdeckung der mit $2.000 \mathrm{fl}$ angenommenen Kosten - schließlich bot ein bereits für die Stadt tätiger Fuhrunternehmer einen Wagen samt Arbeiter um die Hälfte dieses Betrages an und erhielt den Zuschlag. ${ }^{285}$ Die Stadtverwaltung entschied sich dafür, den Hausbesitzern die Kehrichtabfuhr als freiwillige Dienstleistung anzubieten, für die jährlich - je nach Mietwert - zwischen 2 und 6 fl bezahlt werden mussten. Die Abfuhr bezog sich nur auf "gewöhnliche[n] Kehricht und Hausmist, [...] Asche, trockene Küchenabfälle, Thon und Glasscherben u.s.w.«; Bauschutt, Schotter oder tierische Exkremente wurden explizit ausgeschlossen. ${ }^{286}$ Kaum 20 Jahre später beurteilte man diese Praxis als unzureichend: Die verschiedenen, oft offenen Behälter würden die Verbreitung von »Unsauberkeit«, »Ungeziefer« und »Krankheitsstoffe $[n]$ « begünstigen, zudem sei die Staubbelastung bei der Ent-

\footnotetext{
278 LR BIIA 37 , Reg. I 9274 (I28-I42).

279 Kreczi, Linz, 62 u. 220 - vgl. auch Kap. 7. Geordnete und modifizierte Umwelt.

280 LTP, I I.4.I865; ebd., 9.I I.I867; ebd., 24.8.I87 I; ebd., 26.I I.I887; LVB, 20.3.I88 I; ebd., I I.I.I 882 u. ebd., I 7.I I.I 887 .

28 I LVB, I 5.2.I 880 .

282 Melosi, America, 43 u. 223.

283 LTP, 28.6.I865; ebd., 3 I.Io.I 865.

$284 \mathrm{LVB}, \mathrm{I} 3 \cdot 5 \cdot \mathrm{I} 882$.

285 LTP, I 9.2.I 882; LVB, 4.5.I882; ebd., I3.5.I882; ebd., 27.I.I 883.

286 LVB, 6.2.I883; AStL, Alte Registratur, Sch. I44.
} 
leerung erheblich. Eine Änderung des Abfuhrdienstes, der offenbar aus vier Arbeitern bestand, ${ }^{287}$ unterblieb jedoch. ${ }^{288}$ Zur Entsorgung von städtischen Abfällen dienten weiterhin periphere Orte: ${ }^{289}$ Der städtische Abdecker verfügte über einen »Verschar[r]platz«, der sich zunächst in einer Schottergrube in Scharlinz befand und in den I89oer Jahren - aufgrund der Nähe zu den Grundwasserbrunnen der städtischen Wasserleitung - in ein entfernteres Augebiet verlegt wurde. ${ }^{290}$ Häusliche Abfälle und Kehricht deponierte man ebenso im Augebiet südöstlich der Stadt, wo einzelne Altarme der Donau aufgefüllt wurden. ${ }^{291}$

Im Hinblick auf die Emissionen zeichnen sich für Linz nur teilweise räumliche Lösungen ab, die jedoch eher auf eine Reduktion der Brandgefahr denn der Geruchsbelästigung abzielten (vgl. Kap. I I. Naturgefahr). ${ }^{292}$ Zahlreiche Schmiede hatten sich wohl schon im späten Mittelalter - vor dem Schmiedtor angesiedelt, ${ }^{293}$ was aber im I 8. Jahrhundert keine periphere Lage mehr darstellte. Im Donautal, an der Straße nach St. Margarethen, gab es zahlreiche Bäckerhäuser, ${ }^{294}$ ansonsten finden sich - durch Adressverzeichnisse aus der ersten Hälfte des r 9. Jahrhunderts dokumentiert - auch zahlreiche Rauch emittierende Gewerbetreibende in dichter bebauten Stadt- und Vorstadtteilen. ${ }^{295}$ Es gibt kaum Hinweise auf Beschwerden wegen gewerblichem Rauch aus dem I 8. Jahrhundert, ${ }^{296}$ was vielleicht mit den omnipräsenten Emissionen durch den alltäglichen Hausbrand zu erklären ist: Linz gleiche »einem Walde von Schornsteinen «, so ein Besucher des frühen r 9. Jahrhunderts. ${ }^{297}$ Wie beim Abfall wurden Emissionen noch im ausgehenden I 9. Jahrhundert eher als Beeinträchtigung denn als Gesundheitsgefahr und dementsprechend kaum als drängendes Problem wahrgenommen. ${ }^{298}$ In Linz blieb die Belastung durch gewerbliche und industrielle Emissionen insgesamt begrenzt: Die wenigen Rauch emittierenden Betriebe befanden sich an der urbanen Peripherie im Osten und Südosten und aufgrund der häufigen Westwetterlage wird nur wenig Rauch die Stadt erreicht haben. ${ }^{299}$ Eine Ausweisung von Gewerbegebieten unterblieb in Linz im I9. Jahrhundert, die Neuansiedlung von Betrieben

$287 \mathrm{RB}$ I 900, 280.

288 RB I 899, 345; RB I 898, 33 I.

289 Vgl. zu Wien Brunner/Schneider, Umwelt, 277; zudem zu anderen europäischen Städten: Stöger/ Reith, Recycling, 280-283 u. Lenger, Metropolen, I 70.

290 GRP I 869, fol. 22a-22b; RB I 895, 228.

29I RB I898, 33 I ; vgl. Hausmülldeponie Hollaberergraben, 2 f.

292 Vgl. als Klassiker zu London: Brimblecombe, Smoke, 39-56 u. den Forschungsüberblick in: Cavert, Smoke, 5-7.

293 Mayrhofer/Katzinger, Geschichte, Bd. I, 69.

294 Bohdanowicz, Vorstädte, Bd. 2, I 556.

295 Verzeichniß I 825 u. Gewerbe-Adressen-Buch I 853.

296 LR BVI2, Reg. I I 27 (6I-69); vgl. zu London im I 7. u. I 8. Jahrhundert: Cavert, Smoke, 6I - 79.

297 Mader, Reise, 26.

298 Vgl. Brimblecombe, Smoke, го3 - I 19; Massard-Guilbaud, Einspruch, 75 - 79 u. Melosi, America, 39.

299 Vgl. Lackner/Stadler, Fabriken, r 99f., 270-273, 335f., 398, 405, 429, 494 u. $55^{8}$. 
erfolgte - wie auch in anderen Städten ${ }^{300}$ - über individuelle Genehmigungsverfahren. Selbst dem neuen Gaswerk, einem zukünftigen, kontinuierlichen Luftbelaster, wies man keinen Standort zu - dieser solle »nach eigenem Ermeßen« vom Betreiber selbst gewählt werden. ${ }^{301}$

Die zeitgenössischen Bewertungen der Linzer Luft divergierten: Wenn man »an den heitersten Tagen« von Kirchschlag aus nach Linz herabblicke, so Adalbert Stifter in seinen zur Mitte der I 86oer Jahre entstandenen »Winterbriefen«, dann sehe man »die Ausdünstungen der Niederungen und insbesondere die Ausdünstungen der Menschen, Thiere, Schornsteine, Unrathkanäle und anderer Dinger der Stadt« als »einen schmutzig blauen Schleier schweben «. ${ }^{302}$ Ein 1887 in einer Linzer Tageszeitung erschienener Kommentar sah hingegen »im Innern der Stadt eine ziemlich athembare Atmosphäre«, von den in Städten wie London, Prag oder Wien herrschenden Luftbelastungen sei man weit entfernt, wenngleich der Wind manchmal »die Rauchmassen der Hatschek'schen Brauerei gegen Osten wälzt « und der Kohlenrauch aus dem Hausbrand »mehr und mehr fühlbar« werde, der »besonders in der Gegend des Bahnhofs, in der Kapuzinerstraße und in solchen Gassen lästig [ist], in welchen sich niedrige Häuser mit niedrigen Schornsteinen befinden «. ${ }^{303}$ Mit der Expansion der Stadt in die Peripherie intensivierte sich aber die Belastung: „Der Rauch der verschiedenen in der Stadt liegenden Fabriken verpestet oft die Luft«, wurde im Rechenschaftsbericht des Gemeinderates I 894 festgestellt, der »Pechgeruch« der Brauerei Hatschek mache »oft den Spaziergang auf den Freinberg unmöglich«. Bei Großbetrieben werde, so die kritische Beifügung, "schweigend alles geduldet«. ${ }^{304}$ Man sah den Handlungsbedarf aber aufseiten der Unternehmen: Es sollten hohe Schornsteine errichtet werden, damit "nicht einer alles, sondern viele etwas bekommen «. ${ }^{305}$ Die Stadtpolitik blieb weiterhin passiv - lapidar vermeldete der Rechenschaftsbericht des Gemeinderates für das Jahr I 900 »keine nennenswerten Fortschritte Rauchbelästigung «. ${ }^{306}$ Eine Lösung blieb somit, wie in anderen Städten zu dieser Zeit, "avoiding the city«. ${ }^{307}$

\footnotetext{
300 Vgl. Brunner/Schneider, Umwelt, 45; Uekötter, Umweltgeschichte, I gf.; Guillerme, Geschichte, 42 f.; Brüggemeier, Umweltprobleme, I 50 - I 52.

30 I AStL, Altakten, Sch. I92.

302 Stifter, HKG, Bd. 8/3, 202.

303 LTP, г 2.6.1 887.

304 LVB, 6.9.1895.

305 RB I 898, 332 (Hervorhebungen im Original).

$306 \mathrm{RB}$ 1900, 420.

307 Vgl. Cavert, Smoke, 224-23r.
} 


\section{Fluviale und aquatische Räume}

\section{Stadt und Fluss}

Das große Gemälde der Belagerung von Linz I74I/I 742 ${ }^{1}$ zeigt eine Besiedlung, die abgesehen von einigen Häusern zwischen Donau und Ludl - weitgehend mit der Niederterrasse endet. Dahinter, also östlich und südöstlich der Stadt, in Lustenau, St. Peter und Zizlau, sind umfangreiche, landwirtschaftlich genutzte Flächen zu sehen, vor allem Äcker, die dann in Wiesen und Augebiete übergehen (vgl. Abb. I8). Auf Karten des späten I 8. und beginnenden I9. Jahrhunderts, die das Gebiet der floodplains erstmals detailreicher abbildeten, lässt sich Ähnliches feststellen: Es finden sich nur einzelne Bauernhöfe, deren Grundstücke in ihrer Nutzung deutlich an regelmäßige Überflutungen angepasst waren. ${ }^{2}$ Die Kataster erfassten extensiv genutzte Auwälder und Wiesen nahe der Donau und dokumentierten auch Risiken und Strategien des Lebens nahe einem großen Fluss. Nach den Überschwemmungen des Sommers I 786 (vgl. Kap. I I. Naturgefahr) mussten für das »Josephinische Lagebuch«u.a. zwei Wiesenparzellen an der Donau nachgemessen werden, da mehr als 300 Quadratklafter »durch das grosse Wasser abgerissen « worden waren. ${ }^{3}$ Der unmittelbar an der Donau gelegene »Fischer im Gries« beanstandete - mit Erfolg - die Ertragsschätzung des Katasters, weil »das wenige, was er hat, dem Bruch [Abbruch des Ufers] unterliegt und die Überschwemmung vieles hinweggerissen und das übrige also mit Schid [Geschiebe] und Sand überschwemmt worden, daß mehrere Jahre nicht hinreichen[,] eine Nutzung zu erzielen«. Tatsächlich lag der - über drei Jahre geschätzte - Getreideertrag des »Fischer im Gries« pro Hektar nur bei der Hälfte des benachbarten, etwas südlich gelegenen Posthofes, dessen Hektarerträge durchaus mit dem donaufernen »Oberen Lehenbauer« nahe der Landstraße vergleichbar waren. ${ }^{4}$ Für die Untere Vorstadt sind im »Josephinischen Lagebuch« zahlreiche weitere Überschwemmungsschäden vermerkt, die aber eher Wiesen betrafen und in der Regel nicht zu einer Reduktion der Ertragsschätzung führten, da man von »ausserordentlichen Wassergüsse[n] « und nicht von ständigen Beeinträchtigungen ausging. ${ }^{5}$ Weiter hielt man fest, dass dieser Teil von Linz unter »der Ergießung

I Abgedruckt in: Schmidt, Linz, Tafel 34 u. Mayrhofer/Katzinger, Geschichte, Bd. I, 39of. - das Original befindet sich im Linzer Rathaus (Nordico Stadtmuseum Linz, Inv.-No. G 38 I).

2 Dabei handelt es sich um die Militärkarten der I 77oer Jahre, die Katasterpläne aus den I 82 oer Jahren (Mapire, Franziszeischer Kataster) und OÖLA, Karten- und Plänesammlung, V/I I (»Die nächsten Spazierfahrten und Spaziergänge in der Gegend von Linz«, I 807).

3 Bohdanowicz, Vorstädte, Bd. I, 3 I 4; zur Koexistenz vgl. Winiwarter/Schmid/Dressel, Looking u. Reith, Umweltgeschichte, 27-29.

4 Bohdanowicz, Vorstädte, Bd. I, 3 I6f., 340 u. 395.

5 Ebd., 288, 293-297 u. 357. 
der Donau zu leiden« habe, drei Gründe seien von Uferabbrüchen betroffen (»Bruch«), eine Parzelle »unterliegt dem Wasser«, einzelne Grundstücke seien »voller Sand« und deshalb nicht nutzbar. ${ }^{6}$ Auch für das südlich gelegene St. Peter konstatierte man häufige Überschwemmungen und Böden, die in Donaunähe »schottrig, voller Stein und schlecht« seien. Die Verdienste aus der Landwirtschaft seien somit begrenzt, viele Bewohner/innen auf einen Nebenerwerb als Schiffer oder auf den Verkauf von »Kräuterwerch « in Linz angewiesen. ${ }^{7}$ In der Gemeinde Katzbach nördlich der Donau könne man zwar »meistens gut [e] « Produkte ernten, »nur werden solche durch die alljährliche Donauüberschwemmung entweder sehr schlecht oder ganz unbrauchbar «. ${ }^{8}$ Weitgehend analoge Einschätzungen finden sich im »Franziszeischen Kataster«, wenngleich wie durch die Gemeinde Lustenau - bereits auf einzelne, nicht näher beschriebene Maßnahmen von »Privaten « gegen Hochwasserereignisse hingewiesen wurde. ${ }^{9}$ Die Gemeinde Urfahr beurteilte die Nähe zur Donau indes ambivalent: Äcker und Wiesen würden durch Überschwemmungen beeinträchtigt, »andererseits« sei das »Niederlassen fruchtbarer Bestandtheile des Wasserschwalles« vor allem für die Obstgärten wichtig. ${ }^{10}$

Auf Linzer Seite lagen nur wenige Gebäude direkt an der Donau und der tiefer gelegene, donaunahe Vorstadtbereich (»Wörth«) blieb bis zur Mitte des I 9. Jahrhunderts dünn besiedelt, was man durchaus als Hinweis auf ein vorhandenes Risikobewusstsein sehen kann: Wiederholt, so eine Chronik aus der Mitte des I 8. Jahrhunderts, seien an der Donaulände »ein und andere Grundstück von der Donau wekgeriss(en) worden «. ${ }^{11}$ Neben den Schiffmeisterhäusern und einigen weiteren, eher kleineren Häusern befanden sich - was in logistischer Hinsicht Sinn ergibt - nur das Stadtbräuhaus, die Wasserkaserne und die Wollzeugfabrik unmittelbar am Ufer. ${ }^{12}$ Das Hochwasser vom August I 8I 5, das kleiner als die Überschwemmungen von I 786 und I 787 blieb, aber durchaus als mittelschweres und nichtalltägliches Ereignis einzuschätzen ist (vgl. Kap. I I. Naturgefahr), zeigt die Vulnerabilität des Wohnens und der Landwirtschaft nahe der Donau: Das Hochwasser verursachte erhebliche Schäden in diesem Bereich der Unteren Vorstadt und in den südlich gelegenen Gemeinden Zizlau und St. Peter. ${ }^{13}$ Im Wörth an der Ludl wurden Gärten und Häuser überschwemmt, bei manchen Häusern war der »Brun eingestürzt«, bei anderen der Keller »eingegangen«. Zahlreiche Bauernhöfe hatten die Ernte auf den Feldern und eingelagerte Lebensmittel verloren,

6 OÖLA, Josephinisches Lagebuch, HS I92 (Linz Untere Vorstadt).

7 Bohdanowicz, St. Peter, 9 f.

8 Bohdanowicz, Katzbach, 8.

9 OÖLA, Franziszeischer Kataster, No. 534 (Operat 2, Linz Untere Vorstadt, Beantwortung Fragen Gemeinde Lustenau, 25.I.I83I).

ıo OÖLA, Franziszeischer Kataster, No. ıоgo (Operat I, Braune Mappe, Urfahr, KatastralschätzungsElaborat, undat.).

II AStL, HS 86I ("Chronologische Beschreibung«, I 770er Jahre), fol. $36 \mathrm{a}$.

I 2 Vgl. Kreczi, Häuserchronik, I 7 I - I 82 u. Verzeichniß I 825 (Konskr.-No. 262-274 u. 33 I-334).

I3 Donau in Oberösterreich, 22-25; vgl. zum Hochwasser: LZ/IB, I4 8. I 8 I 5. 


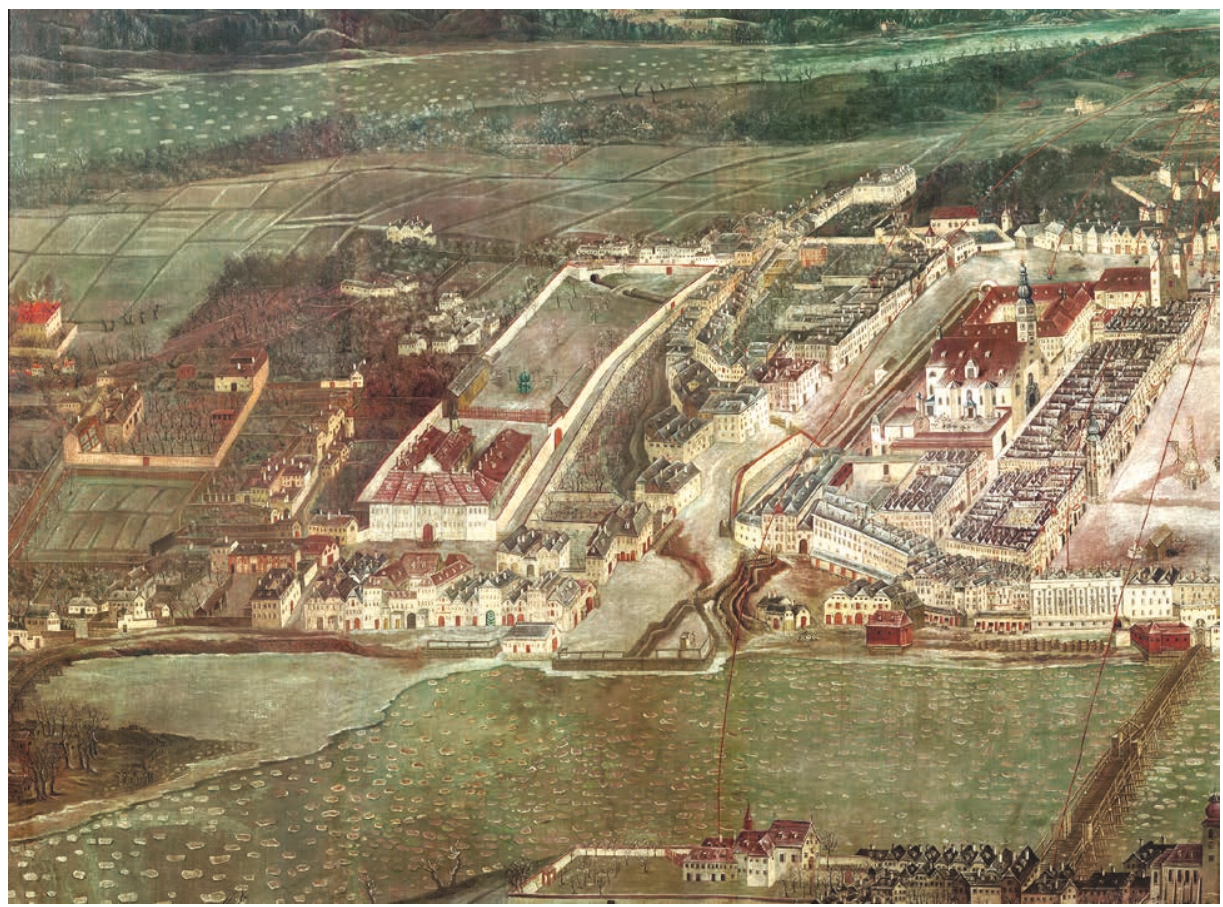

Abb. 18: Ansicht von Linz, 1742 (Ausschnitt) - in der linken Bildhälfte die Untere Vorstadt mit Wörth und Donauinsel, in der Bildmitte die Abzweigung der Ludl, im Vordergrund Urfahr, rechts Hauptplatz und Donaubrücke

insgesamt stellte der Magistrat Linz Schäden in der Höhe von $44.840 \mathrm{fl}$ fest, die in den individuellen Fällen zwischen ro und über 3.000 fl lagen. ${ }^{14}$

Einige Kilometer flussabwärts der Donaubrücke befanden sich zahlreiche Schotterbänke und ephemere Inseln, die offenbar kaum genutzt wurden und im »Josephinischen Lagebuch « eher als Schifffahrtshindernisse beschrieben wurden. ${ }^{15}$ Eine größere Insel war beim Hochwasser 1572 durch die Abtrennung des Ufers im Wörth (Untere Vorstadt) entstanden, die im I 8. Jahrhundert meist als »Spittelau« oder »Soldatenau « bezeichnet wurde und bis ins beginnende I 9. Jahrhundert im Besitz des Bürgerspitals resp. der Stadt war (vgl. Abb. 2, 6, I 8 u. 23). ${ }^{16}$ Zumindest ab I 7 I 5 - vielleicht schon früher - wurde die Insel als Lagerort („Campement«) für die Sommerdurchzüge von Soldaten genutzt. ${ }^{17}$ Zunächst war dies vom zuständigen Militärkommandanten aufgrund der Überflutungsgefahr abgelehnt worden, wobei man interessanterweise auch den zurückbleibenden Schlamm als Gesundheitsrisiko interpretierte. Dass es dennoch

\footnotetext{
I 4 AStL, Altakten, Sch. I 90.

I 5 Neweklowsky, Donau, I73.

I6 Ebd., I72; Mayrhofer/Katzinger, Geschichte, Bd. I, 279; ebd., Bd. 2, I46.

I 7 OÖLA, Landschaftsakten, Sch. 443, D.XV.2/No. 7 I.
} 
zur Errichtung eines Lagerplatzes für vermutlich 600-700 Soldaten kam, hängt mit den offensichtlichen Vorteilen für beide Seiten - die Stadt Linz wie das Militär resp. den Staat - zusammen: Die Insel lag in logistischer Hinsicht optimal, sie konnte etwa beim Ausbruch von Seuchen oder im Kriegsfall - gut kontrolliert und isoliert werden, gleichzeitig bildete das Insellager eine relativ kostengünstige Lösung. Gegen eine jährliche Zahlung verpflichtete sich die Stadt zur Errichtung der Baracken und einer Schiffbrücke, die im Herbst wieder abgebaut und eingelagert wurden. Dieses Soldatenlager ist bis in die I78oer Jahre belegbar, zeitweilig gab es auch eine fixe Holzbrücke, die die Insel mit dem Ufer bei der Wollzeugfabrik verband und die vermutlich bis zu den großen Hochwasserereignissen des Jahres I 786 bestand. ${ }^{18}$

Wenngleich die Insel regelmäßig von Überschwemmungen betroffen war und einen temporären Aufenthaltsort von mehreren hundert Soldaten bildete, ist dennoch eine landwirtschaftliche Nutzung belegt. Für die I72oer und I 73oer Jahre sind Entschädigungszahlungen dokumentiert, die den Pächtern auf der Insel - in den I 73oer Jahren wird das große Gehöft des Lenzlbauern genannt - für nicht eingebrachtes Heu und Grünfutter gewährt wurden. ${ }^{19}$ Das »Josephinische Lagebuch « der I 78 oer Jahre verzeichnete als Besitzer der »Soldaten-Au« die Stadt Linz (4,6 Hektar) und einen Linzer Fleischhauer ( 1,3 Hektar), für beide wurden als Erzeugnisse Grünfutter und Heu angegeben, wobei der Fleischhauer darauf verwies, dass er aufgrund der Überschwemmung erhebliche Ernteverluste gehabt habe. ${ }^{20}$ Im April 1789 bezeichnete die Wiener Hofkammer die Insel als einen »fast öden Grund «, ${ }^{21}$ aber dennoch scheint die landwirtschaftliche Nutzung anders als die militärische - fortgedauert zu haben. Als Besitzerin der Insel nennt der »Franziszeische Kataster« Magdalena Strasser, die vermutlich als Obsthändlerin nahe der Insel im Wörth wohnte und auf die sich die im I 9. Jahrhundert gebräuchlichen Bezeichnungen »Strasserau « und »Strasserinsel« zurückführen lassen. Interessanterweise zeigen der Kataster und das dazugehörige Kartenmaterial (die »Urmappe«) eine intensivere Nutzung als im I8. Jahrhundert: Es wurden 4, I Hektar Wiesen und Obstbäume, 7,7 Hektar auwaldartiger Bewuchs (»Stangenholz« und »Jungmais«), sogar ein Gemüsegarten mit 450 Quadratmetern und Äcker mit einer Fläche von I, 2 Hektar erfasst. Dazu gab es ein kleines Wohn- und Wirtschaftsgebäude auf der Insel. ${ }^{22}$ Auch ein Stadtplan

I8 LR BIIA 35, Reg. I890 (I 23); LR BIIA39, Reg. I 9457 (I2 I); LR BIIA40, Reg. I97 I I (I I6f.); ebd.,

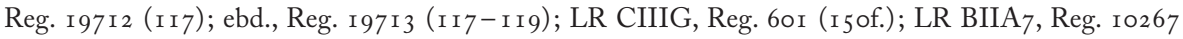
(233); Gimpel Insel, ro7; Awecker, Bruckamt, I 93f. u. 204; es haben sich zwei Baupläne der "Aubrücke» aus den r77oer Jahren erhalten: Österreichisches Staatsarchiv, Finanz- und Hofkammerarchiv, Sonderbestände, Sammlungen und Selekte, Karten- und Plansammlung, G 045/I u. 2.

I9 LR BIIA4, Reg. 5296 (I6I); ebd., Reg. 5299 (I6I); ebd., Reg. 5409 (I82); ebd., Reg. 566I (230); LR BIIA 5 , Reg. 6053 (39); ebd., Reg. 6955 (196).

20 Bohdanowicz, Vorstädte, Bd. I, 330 u. 35 of.

2I LR CIIIDi-3, Reg. I93 (i44f.).

22 Bohdanowicz, Vorstädte, Bd. I, 756f.; vgl. Verzeichniß I 825 (Konskr.-No. 334 u. I I 4I); Kreczi, Häuserchronik, I73; Mapire, Franziszeischer Kataster. 


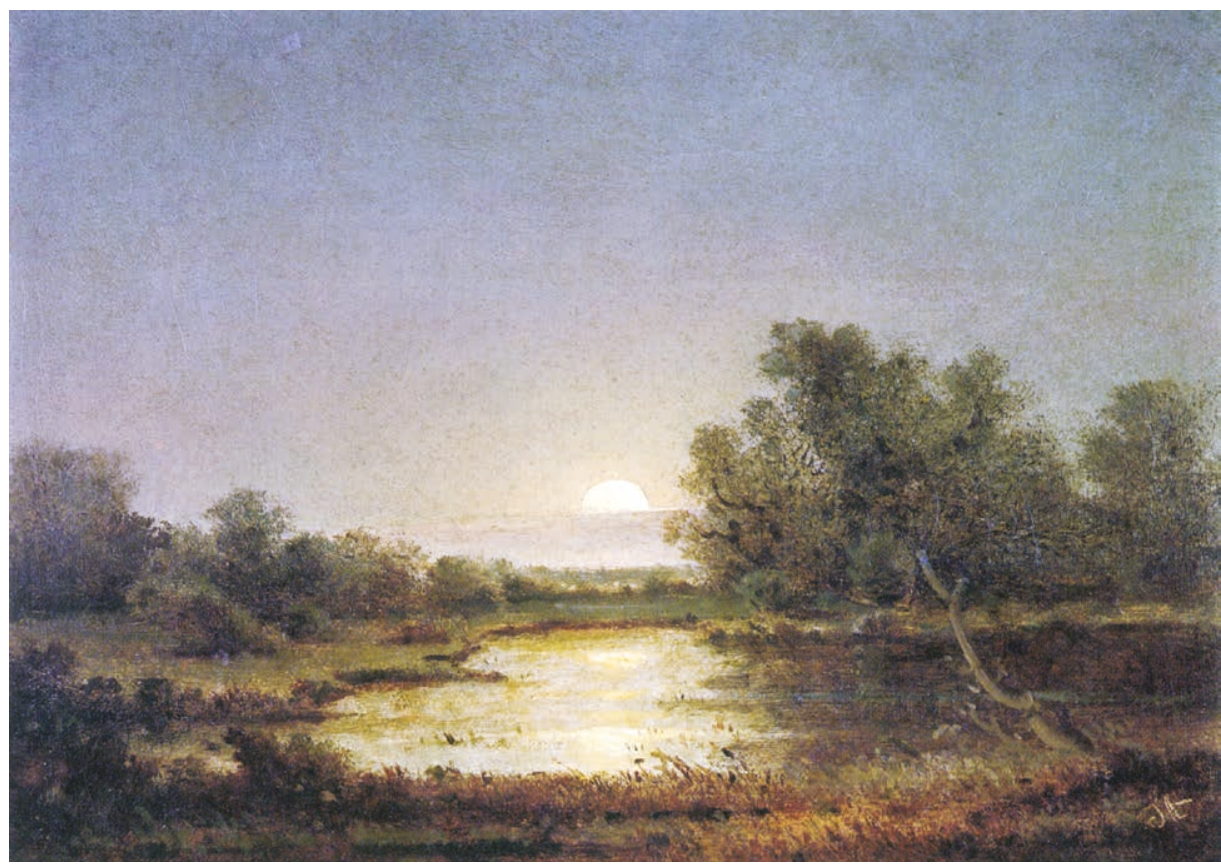

Abb. 19: Adalbert Stifter, Die Strasserau bei Linz, um 1850

aus den I 86oer Jahren zeigt die Äcker, Wiesen und das Gebäude, ${ }^{23}$ das - vermutlich ab den I $840 e r$ Jahren - als Gasthaus betrieben wurde und über einen Steg, später mit einem Fährdienst erreicht werden konnte. ${ }^{24}$

Die "grünende Strasserinsel« und deren "poetischer Baumschmuck" - wie es ein zeitgenössischer Stadtführer umschrieb - entwickelten sich in der zweiten Hälfte des I 9. Jahrhunderts zu einem beliebten Naherholungsgebiet, das mit der Zuschüttung des Donauarmes und der Errichtung des »Umschlagplatzes« in den I $890 e r$ Jahren (vgl. unten) den Inselcharakter verlor. Dennoch überlebte das dortige Gasthaus sogar die großen Überschwemmungen der I $890 e r$ Jahre und bestand bis ins 20. Jahrhundert. ${ }^{25}$ Im Gegensatz zu dieser vielfältigen Nutzung zeigt Adalbert Stifters um I 850 entstandenes Bild die Strasserau als ein menschenleeres und unbewirtschaftetes Augebiet, was somit nur einem Aspekt dieses fluvialen Raumes Rechnung trägt (vgl. Abb. I 9). ${ }^{26}$

23 Österreichische Nationalbibliothek, Kartensammlung, AB 52 A 3 (Stadtplan, I 863).

24 Fink, Geschichte, I 28 ; Gewerbe-Adressen-Buch I 853, Konskr.-No. I I 4 i vgl. Commenda, Linz, 238 u. LTP, 20. I. I 870.

25 Zöhrer, Linz, 25 (Zitat); LTP, I3.I 2.ı 877; ebd., I 2.6.1 887 u. Linz a./d. Donau, ı 4; vgl. LTP, 3.8.I 897 u. ebd., 20.2.1898.

26 Angemerkt sei, dass es sich um ein »von fremder Hand vollendet[es]« und bezeichnetes Bild handelt vgl. Schultes, Stifter, 282 u. 297. 
Veränderungen des fluvialen Raumes ergaben sich nicht nur durch Hochwasser, sondern auch durch Wasserbauten. Regulierungsarbeiten im Linzer Stadtgebiet sind für das I 7. und frühe I 8. Jahrhundert belegt: Eine Chronik aus den I73oer Jahren datiert die Errichtung einer »neue[n] Schlacht« an der Donau bei der Einmündung des kleinen Seitenarmes der Ludl auf das Jahr I663. I706 und I 707 habe man die »Luedl abermahl etwas tieffer gegraben, und d(as) Wasser alsdann von der Donau hineingeleitet, und widerum ein Brückl darüber errichtet «. ${ }^{27}$ Beide Baumaßnahmen, die wohl auf die Erhaltung der Ludl abzielten und auch dem Uferschutz in diesem Bereich dienten, wurden von der Stadt finanziert und ausgeführt. Wiederholt verzeichnen die städtischen Baurechnungen Ausgaben für Wasserbauten, wie z. B. im Jahr I 750 für die Ausbesserung einer "Schlacht« bei der Wasserkaserne. ${ }^{28}$ Auch beim Wasserbau bestand eine private Zuständigkeit: ${ }^{29}$ Die Stadt wurde nur aktiv, wenn ihr zugehörige Bauten oder Räume betroffen waren - wie bei der Brücke, der Donaulände oder eben der Wasserkaserne. Aufgrund der hohen Kosten blieben Wasserbauten klein und punktuell und sie zielten primär auf den Uferschutz ab. So suchte etwa ein Schiffmeister in den I72oer Jahren beim Urfahrer Kapuzinerkloster um Erlaubnis an, bei der Klostermauer am Donauufer alte, mit Steinen beschwerte Boote versenken zu dürfen, um eine auch im Winter verwendbare Anlegestelle zu schaffen. ${ }^{30}$ Die unmittelbar am Donauarm gelegene und damit relativ exponierte Wollzeugfabrik errichtete in den I 77oer Jahren Uferschutzmauern, davor hatte vermutlich nur eine Verbauung aus Holz bestanden. ${ }^{31}$ Hinweise auf Bauten zum Hochwasserschutz finden sich für das I 8. Jahrhundert nur vereinzelt: Nach einer Beschädigung der Militärbaracken auf der Donauinsel durch ein Hochwasser in den I 73oer Jahren überlegten die Landstände als zuständige Behörde, ein »doppeltes Sporrenschlächt« am Anfang der Insel zu errichten. Trotzdem die Kosten auf I.290 fl geschätzt wurden, stimmte man diesem Vorhaben zu - die tatsächliche Umsetzung ist aber nicht belegt, ${ }^{32}$ wenngleich ein Plan aus den frühen I78oer Jahren einen (nicht näher bezeichneten) Blockwurf aus Steinen am Beginn der Insel andeutet. ${ }^{33}$ Die Erhöhung der zwei Wassertore und der Donaulände, die von der Stadt in den I77oer Jahren vorgenommen wurde, erfolgte angeblich auch aus Überle-

27 AStL, HS 86r (»Chronologische Beschreibung«, I 77oer Jahre), fol. 42a; vgl. Neweklowsky, Schiffahrt, Bd. I, I $38 \mathrm{f}$.

28 AStL, HS 389 (Bauraittung 1750 ), unpag.

29 Vgl. Rohr, Naturereignisse, 354-357.

30 LR Eia, Reg. 2 I 8 (48f.); vgl. Neweklowsky, Schiffahrt, Bd. 3, 36 u. Leidel/Franz, Flußlandschaften, I I 3 f.

3I Gielge, Beschreibung, I67; Pillwein, Beschreibung, 286; OÖLA, Karten- und Plänesammlung, XIV/5 (Uferverbauung bei Wollzeugfabrik, I8 I6).

32 LR BIIAI 4 , Reg. I 4380 (I 44).

33 Der Plan ist undatiert, enstand aber vermutlich um die Jahre $\mathrm{I}_{7} 83 / \mathrm{I} 78_{4}-$ Österreichisches Staatsarchiv, Finanz- und Hofkammerarchiv, Sonderbestände, Sammlungen und Selekte, Karten- und Plansammlung, $\mathrm{F}-370 / 3$. 
gungen des Hochwasserschutzes, ${ }^{34}$ vermutlich ging es aber ebenso um eine Nivellierung und Ausweitung des Raumes, wie I 800 , als Teile des Bauschutts vom Stadtbrand für eine zusätzliche Anschüttung der Donaulände verwendet wurden. ${ }^{35}$

$\mathrm{Zu}$ diesen Anrainerbauten kamen Baumaßnahmen der staatlichen Behörden, die auf die Schifffahrt abzielten, also Hindernisse in der Donau beseitigen und eine Fahrrinne schaffen oder erhalten sollten. An und in der Donau erfolgten in Niederösterreich und im Wiener Raum ab dem I6. Jahrhundert punktuelle Wasserbaumaßnahmen, die vor allem Problembereiche wie den Greiner Struden oder die Donauübergänge und arme im Wiener Raum betrafen. ${ }^{36}$ In Oberösterreich wurde in den I $720 e r$ Jahren der »Neubruch«, ein Schifffahrtshindernis nahe der niederösterreichischen Grenze bei Spielberg, reguliert, auch an den Strudenregulierungen waren die oberösterreichischen Stände beteiligt, ${ }^{37}$ für die I $760 e r$ Jahre gibt es Hinweise auf kleinere Wasserbauten bei Linz, Urfahr, Aschach und Engelhartszell, ${ }^{38} \mathrm{zu}$ umfangreicheren Wasserbauprojekten kam es aber erst ab den I 77oer Jahren. ${ }^{39}$ Diese gingen von merkantilen Überlegungen des Staates zur Förderung des Wassertransportes aus, was über eine Verbesserung der Fahrrinnen und der Uferbegleitwege (meist als »Treppelweg« oder »Hufschlag« bezeichnet), die für das Flussaufwärtsziehen der Schiffzüge benötigt wurden, erreicht werden sollte. ${ }^{40}$ Baumaßnahmen waren auch aufgrund der »stark erhöhten Umlagerungsdynamik« der Donau im i 8. Jahrhundert, die zu breiteren Hauptarmen und neuen Verzweigungen führte, notwendig. ${ }^{41}$ In einem I 8 I 8 entstandenen Reisebericht wird ein derartiger Schiffszug bei Aschach beschrieben: Der »sehr langsam« vorankommende Salztransport bestand aus einem »Hohenau«-Schiff und zwei weiteren Schiffen (»Nebenbei«), die mit Seilen, die über drei leere Boote liefen, von insgesamt 26 Pferden gezogen wurden. Teilweise befanden sich die Pferde beim Ziehen »über ıoo Schritte« weit vom Ufer entfernt, wobei - da "die Donau alle Jahre die Tiefe ihres Bettes verändert« - ein Reiter vorab die Wassertiefe sondierte und den weiteren Weg festlegte. Aber auch die Treppelwege, so die Beifügung des Verfassers, seien nicht ohne Gefahr zu benutzen, da sie manchmal unterspült waren und unter der Last der Pferde einbrachen. ${ }^{42}$

34 AStL, HS 86I (»Chronologische Beschreibung«, I 770er Jahre), fol. 6oa.

35 OÖLA, Landschaftsakten, Alte Registratur, Sch. 96, D.XV.3/No. 21/4; AStL, HS ro87 (Stadtratsprotokoll, r 80o), fol. 265 a; vgl. Awecker, Brand, 34 .

36 Jungwirth et al., Donau, I 33 u. I37; Haidvogl et al., Wasser, 74-79.

37 Grüll, Ingenieure, 47; Stauber, Ephemeriden, 246.

38 Österreichisches Staatsarchiv, Finanz- und Hofkammerarchiv, Sonderbestände, Sammlungen und Selekte, Karten- und Plansammlung, F-365/I-4.

39 Stauber, Ephemeriden, 247-252; vgl. dazu auch das Projekt einer Kanalverbindung zwischen der Moldau und der Donau über Linz, das der ständische Baudirektor 1773 vorgelegt hatte (Sima, Pferdeeisenbahn, $3 \mathrm{I}-35$ ).

40 Veichtlbauer, Strombaukunst, 6rf.; LR BIIA38, Reg. 19320 (89); vgl. EdN, s.v. Treidlerei.

4I Jungwirth et al., Donau, I 43.

42 Martens, Reise, I 23f.; vgl. Neweklowsky, Schiffahrt, Bd. I, I79f. u. 296-3I 5 ; Leidel/Franz, Flußlandschaften, $65-67$. 
Die staatlich induzierten und finanzierten Wasserbauprojekte, im Verständnis von Lefebvre Auswirkungen einer fernen Ordnung (vgl. Kap. I), erreichten den Linzer Raum in den frühen I780er Jahren und wurden vor Ort wesentlich durch die landständischen Ingenieure ausgearbeitet. ${ }^{43} \mathrm{Da}$ in Linz schon I 708 eine Ingenieurschule etabliert worden war, hatten die Landstände zu diesem Zeitpunkt bereits eine erhebliche Expertise aufbauen können, die durch die erhaltenen Pläne dokumentiert wird. ${ }^{44}$ An einzelnen Uferabschnitten wurden Steinmauern und hölzerne Schlachten errichtet, die - wie Pläne insinuieren - vorrangig den auf der Linzer Seite verlaufenden Treppelweg schützen sollten. ${ }^{45}$ In dieser Phase begann auch - wohl vor allem aus Kostengründen - die verstärkte Verwendung von Weidenruten im Wasserbau (»Faschinen«), ${ }^{46}$ was durch die einfache Verfügbarkeit von Weiden in Donaunähe begünstigt wurde. ${ }^{47}$ Insgesamt blieben derartige Baumaßnahmen im Linzer Raum bis in die I 8 roer Jahre eher punktueller Natur oder sie reagierten auf Schäden oder auf Verlandungen der Fahrrinne. ${ }^{48}$ Charakteristisch für diese Periode sei, so die Einschätzung von Wasserbauingenieuren ıoo Jahre später, eine »immer >defensive< Bauführung « gewesen. ${ }^{49}$

\section{Von der fragilen zur stabilen Brücke}

Die Interaktionen zwischen Stadtbevölkerung und Fluss werden auch anhand der Donaubrücke sichtbar. ${ }^{50}$ Für die Aufrechterhaltung des städtischen Alltagslebens und des überregionalen Handels war die Brücke ein zentrales Bauwerk, deren »Mangel«, wie im Frühjahr I743 nach einer kriegsbedingten Unterbrechung des Überganges, deutlich zu spüren war. ${ }^{51}$ Eine rund 270 Meter $^{52}$ lange Holzbrücke, die Linz mit Urfahr verband, bestand vermutlich seit den I 490er Jahren und blieb bis ins I 9. Jahrhundert eine der wenigen ständigen Donaubrücken im österreichischen Raum. Ein kaiserli-

43 Vgl. zu Bayern: Leidel/Franz, Flußlandschaften, 297-3 13.

44 Grüll, Ingenieure, 43-46; Stauber, Ephemeriden, 5-9; vgl. LR BVII 4 u. 5, Reg. 4I85 (I 325 ) u. LR $\mathrm{BIIA}_{7}$, Reg. 10056 (202).

45 Vgl. Österreichisches Staatsarchiv, Finanz- und Hofkammerarchiv, Sonderbestände, Sammlungen und Selekte, Karten- und Plansammlung, F-370/I (Wasserbauten bei Linz, I783); vgl. Allgemeine Bauzeitung 27 (1 862), 83-93, hier $84 \mathrm{u}$. Donau in Oberösterreich, 36 .

46 Veichtlbauer, Strombaukunst, 58-60; vgl. Leidel/Franz, Flußlandschaften, 50-52.

47 Luca, Landeskunde, Bd. 3, 257; Bohdanowicz, St. Peter, 232; vgl. Allgemeine Bauzeitung 27 (I 862), 83-93, hier 84 u. LZ/IB, 27.I.I 8 I 7 .

48 Vgl. z.B. OÖLA, Karten- und Plänesammlung, XIV/7; ebd., VI/28; ebd., XIV/6.

49 Donau in Oberösterreich, 36.

50 Vgl. zur Welser Traunbrücke: Rohr, Überschwemmungen, 28 I - 284.

5 I LR BIIA6, Reg. 75 I 7 (44).

52 Für die I 8 I oer und I 82 oer Jahre wurde die Länge mit I 44 Klaftern angegeben: vgl. Heinse, Linz, r. Aufl. I 3 u. Pillwein, Beschreibung, $67 f$. 
ches Privileg berechtigte die Stadt Linz zur Errichtung und Erhaltung der Brücke sowie zur Einhebung von Benutzungsgeldern für Personen, Fuhrwerke und Waren (»Bruckgeld«). ${ }^{53}$ Diese Zahlungen - im I 8. Jahrhundert vermutlich I Pfennig für Fußgänger ${ }^{54}$ - bildeten einen latenten Konflikt zwischen der Stadt und Urfahr: Erst ${ }_{6} 68$ kam es zu einem Vergleich, der die Urfahrer vom Bruckgeld befreite, dafür aber zur Erhaltung des »Bollwerk[s] an der Brucken« auf Urfahrer Seite verpflichtete. Wegen der durch Linz gewährten finanziellen Unterstützung während der Pest musste ab I 7 I 4 erneut das Bruckgeld bezahlt werden, was I 753 aufgehoben wurde. ${ }^{55}$ Dass Linz auf die Einhebung von Nutzungsgebühren bestand, erklärt sich aus den signifikanten Ausgaben für die Erhaltung der Brücke. Vielfach konnten diese Ausgaben nicht über die Bruckgelder abgedeckt werden: Im Rechnungsjahr I 757 standen z. B. Einnahmen von $3.339 \mathrm{fl} 48 \mathrm{kr}$ Ausgaben von über $4.000 \mathrm{fl}$ gegenüber. ${ }^{56}$ I 760 verpachtete die Stadt Linz die Einhebung der Benutzungsgelder, die Erhaltung der Brücke blieb aber städtische Aufgabe und dadurch die Brücke ein Verlustgeschäft. ${ }^{57}$ Mit der Neuverpachtung I 766 versuchte die Stadt, das finanzielle Risiko der Brückenerhaltung auf den Pächter abzuwälzen, was erstaunlicherweise funktionierte. Auf Druck des Staates wurde dieser Vertrag jedoch Ende I775 beendet und das Bruckgeld durch das k.k. Mautamt eingehoben, die Erhaltung der Brücke fiel wiederum - gegen Bezahlung - der Stadt zu. Im Frühjahr 1776 führte ein Konflikt über die Finanzierung der Wiedererrichtung der Brücke zu einer Übernahme der Brücke durch den Staat. ${ }^{58}$

Anfällig war die hölzerne Brücke vor allem für Eisstöße, was die Chronik des in Urfahr unmittelbar an der Donau gelegenen Kapuzinerklosters eindrucksvoll dokumentiert: Zwischen den Jahren I735 bis I76 I wurde die Brücke r6-mal durch Eisstöße unterbrochen, im Schnitt also fast jährlich, wobei in einzelnen Jahren auch Schäden durch Hochwasser dazukamen. ${ }^{59}$ I 736 zerstörte ein Eisstoß im Jänner Teile der Brücke, Ende Juli führte ein Hochwasser wiederum zu einer mehrwöchigen Unterbrechung der Brücke, Ähnliches ist für das Jahr I 738 verzeichnet. ${ }^{60}$ Teilweise wurde die Brücke fast vollständig zerstört, wie z.B. in den Jahren I740, I745 und I747. ${ }^{61}$ Es bestand nur ein begrenztes Repertoire an Präventivmaßnahmen: Zum Schutz der Brücke konnten »Eispflüge« an die Brückenpfeiler angebracht oder Brückenteile abge-

53 Rohr, Naturereignisse, 205f.; LR BIAr, Reg. 546 (I 76).

54 Wobei Juden »von alters her gebräuchlich, doppeltes Bruckgeld« bezahlen mussten - vgl. AStL, Altakten, Sch. 44 u. LR CIIIF i u. 2, Reg. I i6 (46-50).

55 LR E6 (»Seyringer-Chronik«), 96.

56 Awecker, Bruckamt, I 89f. u. I92; LR BIIA 3 , Reg. 3806 (I 54 f.).

57 Awecker, Bruckamt, I98f.; LR E6 (»Seyringer-Chronik«), 96.

58 Awecker, Bruckamt, I99f., 203f. u. 207-209.; Heinse, Linz, r. Aufl., I3f.

59 Neweklowsky, Donau, I94f.; vgl. dazu LR Era.

6o LR Era, Reg. I7r (40); ebd., Reg. I73 (4of.); ebd., Reg. 228 (53); ebd., Reg. 229 (54).

6I Ebd., Reg. 290 (6I); ebd., Reg. 365 (76); ebd., Reg. 409 (83); vgl. auch den Plan für den Neubau nach dem Eisstoß des Jahres i 830 : OÖLA, Karten- und Plänesammlung, XIV/r 9. 
tragen bzw. Holz für etwaige Reparaturen bereitgehalten werden. ${ }^{62}$ Dennoch kann die Holzbrücke durchaus als eine an Erfordernisse und natürliche Settings angepasste Lösung interpretiert werden: Bei Bedarf - wie etwa I764 "zur sicheren Durchfahrt« der kaiserlichen Regenten, bei der Pest I 7 I 3 oder bei kriegerischen Auseinandersetzungen - konnte die Brücke relativ einfach unterbrochen werden, darüber hinaus ermöglichte die Holzkonstruktion rasche Reparaturen und war für den Fuhrwerksverkehr und (nach Adaptionen) sogar für die Pferdeeisenbahn ausreichend (vgl. Abb. ıо, I 2 u. 20). ${ }^{63}$ Erst ab den späten I 83oer Jahren trat ein Defizit der bestehenden Brückenform verstärkt zutage: Dampfschiffe konnten die Brücke nicht passieren, aber auch bei anderen Schiffen verhinderten hohe Wasserstände die Durchfahrt. Die Brücke »verursachet der Schifffahrt sehr bedeutende Erschwernisse und Gefahren«, so die Einschätzung des oberösterreichischen Landesbaudirektors Josef Baumgartner I 86 I . ${ }^{64}$

Wiederholt wurde in den I84oer und I 85 oer Jahren die Errichtung einer neuen, eisernen Brücke diskutiert - augenscheinlich waren hier die damals entstehenden Kettenbrücken in Prag und Budapest Vorbilder; eine Umsetzung scheiterte aber an der Finanzierungsfrage. ${ }^{65}$ Erst als im Mai 1868 ein Schlepper mit der Brücke kollidierte und einen teilweisen Einsturz mit mehreren Toten verursachte, entschloss man sich zur Errichtung einer Eisenbrücke. I870- I872 wurden die Eisenelemente in Paris gefertigt; insgesamt kostete die Brücke fast ı 00.000 fl, von denen die Stadt Linz 30.000 und die Gemeinde Urfahr 10.000 fl übernahmen. ${ }^{66}$ Die neue Brücke unterschied sich in materieller und konzeptioneller Hinsicht deutlich vom über Jahrhunderte bestehenden Vorläufermodell und war damit ein städtisches Prestigeprojekt, mit dem man sich vom Fluss emanzipieren konnte: Es sei die »einzige stabile [Straßen] Brücke zwischen Passau und Krems«, betonte ein Landtagsabgeordneter noch in den I 8 9oer Jahren. ${ }^{67}$ Trotzdem war die Linzer Eisenbrücke - ungeachtet der erheblichen Kosten - eine pragmatische und eher kleindimensionierte Lösung, die bald an ihre Kapazitätsgrenzen stieß. ${ }^{68}$

Wenngleich die Errichtung einer zweiten, stadtnahen Donaubrücke - anlässlich der Bahnverbindung zwischen Linz und Budweis - bereits I 867 diskutiert worden war, ${ }^{69}$

62 Awecker, Bruckamt, 205; LZ, 30. I. I 809; vgl. Rohr, Naturereignisse, 368-370.

63 LR E6 (»Seyringer-Chronik«), 98; LR BIIG 3 , Reg. 2 I27 (I9of.); LR CIIIFI u. 2, Reg. 2 I 5 (Io6); Aschauer, Eisenbahnbrücke, 163 .

64 Allgemeine Bauzeitung 27 (1862), 83-93.

65 Aschauer, Eisenbahnbrücke, r64; vgl. z. B. OÖLA, Musealarchiv, Sch. 4/No. 3 I ; AStL, HS I I 28 (Stadtratsprotokoll I 847), fol. ro8b u. ÖB, 4.4.I 854; vgl. zu Wien Haidvogl et al., Wasser, 359.

66 Mayrhofer/Katzinger, Geschichte, Bd. 2, I 4rf.; Kreczi, Linz, 44; Commenda, Linz, 236; Linz a./d. Donau, I03.

67 RB I 895, I43; zu dieser Zeit bestanden aber bereits Eisenbahnbrücken bei Steyregg und Mauthausen (vgl. Aschauer, Eisenbahnbrücke, r64 u. Streitt/Schiller/Stadler, Eisenbahnbrücke, Ior).

68 RB I 895, I 43.

69 GRP i 867, fol. I78a u. 179a; vgl. LZ, 5.5.1867. 


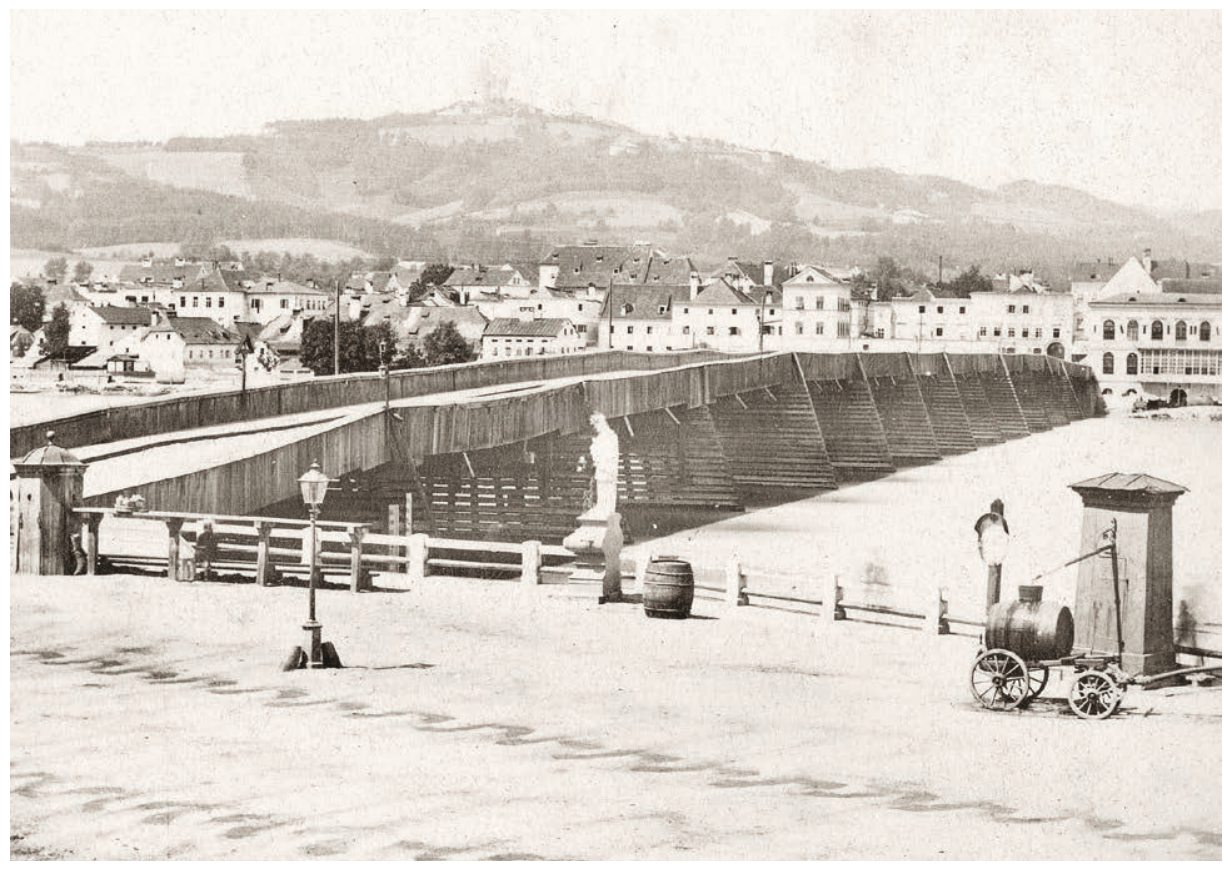

Abb. 20: Die hölzerne Donaubrücke um 1865 - rechts ist ein Pumpbrunnen, im Vordergrund eine kürzlich erfolgte Straßenbespritzung zu sehen

wurde dieses Projekt erst wieder zum Ende der i 88 oer Jahre aufgegriffen. ${ }^{70}$ Dahinter standen praktische Überlegungen: I 888 wurde die Mühlkreisbahn auf Urfahrer Seite fertiggestellt, die mit einer Brücke direkt - also ohne das Umladen der Güter - an die Westbahn angebunden werden konnte, auch sah man die zweite Brücke als Entlastung der bestehenden Brücke und als ideale Ergänzung des geplanten Umschlagplatzes (vgl. unten). Zudem werde Linz, so die Stadtverwaltung I 895, "gegenüber anderen Städten gänzlich concurrenzunfähig“, genauso real sei die Gefahr, dass Urfahr mit einem Westbahnanschluss am linken Ufer (bei Steyregg) Linz umgehe. ${ }^{71}$ Wie bei anderen Linzer Großprojekten dieser Zeit verhinderten nun die Kosten nicht mehr eine Umsetzung: Die kombinierte Straßen- und Eisenbahnbrücke wurde mehrheitlich vom Staat finanziert und zwischen I 897 und I 900 errichtet (vgl. Abb. 22). ${ }^{72}$

70 Streitt/Schiller/Stadler, Eisenbahnbrücke, I I - I 9; AStL, Materienbestand, Sch. 3 I I.

7I RB I 895, I36-i45; AStL, Materienbestand, Sch. 3 Io.

72 RB I 895, I 42 u. I45; Allgemeine Bauzeitung 68 (I 903), 69-75; Streitt/Schiller/Stadler, Eisenbahnbrücke, 25 f. u. 37; vgl. zur Materialität der Brücke: ebd., 32-35 u. 46-5 I. In den 20 ioer Jahren wurde die Brücke als irreparabel deklariert und 2016 - trotz lokaler Proteste - abgerissen. 


\section{Donau-Umbau}

$\mathrm{Zu}$ Beginn des r 9. Jahrhunderts wurden umfangreichere Regulierungen der Donau immer wieder diskutiert, aber erst nach den Napoleonischen Kriegen begonnen. Zunächst erfolgte eine Kartierung der Donau und ab den r 8 2oer Jahren kam es zu größeren Wasserbauarbeiten wie z.B. in Oberösterreich die Durchstiche bei Au und Wallsee (Ardagger) und bei der Traunmündung. Erneut war der Staat der zentrale Impuls- und Geldgeber. ${ }^{73}$ Deutlich spürte man auch in Linz das Engagement des Staates: Ab den I8 2oer Jahren gab es "Donau-Strom-Polizei-Vorschriften«, eine "Strom-AufsichtsAnstalt«, ${ }^{74}$ und seit I82 I wurden für Linz tägliche Pegelstände notiert. ${ }^{75}$ Baumaßnahmen im Linzer Raum betrafen wiederum die Treppelwege, die neu angelegt oder verbessert wurden und zudem mit steinernen Uferschutzbauten gegen Erosion abgesichert wurden. ${ }^{76}$ Bis zur Errichtung eines Treppelweges unter der Brücke hindurch, der zur Mitte der I 83oer Jahre erfolgte, mussten die Pferde der Schiffszüge zwischen den Häusern an der Brücke und dem Haupttor durchgeführt werden. ${ }^{77}$ In den I 82 oer und I 8 zoer Jahren errichtete man auf Urfahrer Seite einen nicht durchgängigen Uferschutz aus Bruchsteinen, ${ }^{78}$ auf Linzer Seite steinerne Uferschutzmauern, die erhebliche Kosten verursachten: Für die etwas über 300 Meter lange Uferbefestigung der Unteren Donaulände wurden fast i 8.000 fl (CM) aufgewandt. ${ }^{79}$ In der Regel versteigerte die Landesbaudirektion solche Wasserbauten (was auch bei anderen Baumaßnahmen wie Pflasterungen, beim Bezug von Lebensmitteln oder Brennmaterial üblich war), zudem wurden »Uferschutz« und »Uferbepflanzung « - in diesem Fall bei Zizlau -verpachtet. ${ }^{80}$ Diese Bauphase dauerte bis in die I $840 e r$ Jahre, blieb aber auf einzelne Bereiche begrenzt und griff - abgesehen von den erwähnten Durchstichen - kaum in die Hydrologie des Flusses ein. ${ }^{81}$

In Oberösterreich und auch im Linzer Raum bildeten, wie rückblickend zu Beginn des 20. Jahrhunderts festgestellt wurde, erst die Jahre I 850 bis I 869 den »Beginn einer systemgemäß durchgeführten Regulierungsaktion zur Behebung der mißlichsten Schifffahrtshindernisse« (vgl. Tab. 28 u. Abb. 22) ${ }^{82}$ Diese Wasserbauten waren erneut

73 Jungwirth et al., Donau, I54-r 56; Veichtlbauer, Strombaukunst, 64-67; Király, Donau, 57-6r ; vgl. LZ/AB, 24.6.1822; ebd., 20.9.1824; ebd., 8.9.1826.

74 Pillwein, Wegweiser, I63. $_{3}$.

75 Rosenauer, Donau, 86; vgl. OÖLA, Karten- und Plänesammlung, XIV/ı I (Hochwassermarkierungen und Uferverbauung auf der Unteren Donaulände, I 825 ).

76 Neweklowsky, Donauschiffahrt, ı88; Neweklowsky, Donau, 197; Fink, Geschichte, I 16; vgl. LZ/AB, I 4.9.I $82 \mathrm{I}$.

77 Neweklowsky, Donau, I98; Pillwein, Wegweiser, 6r.

78 LZ/AB, 28.1 I.I 825 ; Bohdanowicz, Katzbach, 250.

79 LZ/AB, I7.10.1 836, 508f.; vgl. OÖLA, Karten- und Plänesammlung, XIV/I 2 u. I 4.

80 LZ/AB, I 4.4.I826; ebd., 27.2.1829.

8г OÖLA, Karten- und Plänesammlung, VI/ I 8 .

82 Donau in Oberösterreich, 36; vgl. zum Diskurs: Király, Donau, $82-98$. 
staatlich induziert, und sie trafen vor Ort - zumindest in Linz - auf weitgehend kongruente Vorstellungen im Hinblick auf den Donau-Umbau. Im Vordergrund stand wiederum die Ambition, die Donau als Transportweg zu optimieren, die Bedrohung durch Hochwasser zu reduzieren (vgl. Kap. I I. Naturgefahr) und - mit einem geraden Flussverlauf - Land zu gewinnen. Ein nicht unerwünschter Nebeneffekt war die Schaffung von Arbeitsplätzen. ${ }^{83} \mathrm{Zu}$ den Intentionen und der Durchführung dieser Wasserbauphase veröffentlichte der damalige oberösterreichische Landesbaudirektor Josef Baumgartner in der »Allgemeinen Bauzeitung « I 862 einen umfangreichen Bericht. Interessanterweise wies Baumgartner den Auen eine wichtige lokale Funktion "für die Beschaffenheit des Stromes und Sicherheit der Anwohner« zu: Somit müssten die Regulierungen auf »die fernere Erhaltung dieses natürlichen Schutzmittels» abzielen. Ein anderer Teil der Flusslandschaft wurde negativer wahrgenommen: Die "Zersplitterung in viele Rinnsale « erschwere die Schifffahrt und erhöhe das Risiko von Eisstößen und damit verbundenen Überschwemmungen. ${ }^{84}$ Deshalb sollten die Regulierungen - nun mit Parallel- statt Querbauten - auf »ein einziges Rinnsal« mit einer »Normalbreite von I 80 Klaftern« hinarbeiten und dadurch »den Strom aus seiner Verwilderung in einen geregelten Zustand [...] versetzen«. Dennoch erachtete Baumgartner Begradigungen, was als Ideal früherer Flussregulierungen gegolten hatte, aufgrund der hohen Fließgeschwindigkeit als problematisch und zudem als unnötig teuer. ${ }^{85}$ An vielen Stellen betonte Baumgartner die Zweckmäßigkeit und - wenngleich die aufgewendeten Summen gewaltig waren ${ }^{86}$ - die Sparsamkeit der Regulierungsarbeiten. ${ }^{87}$ Profitieren würde vom Donau-Umbau nicht nur der Wassertransport, sondern auch die Anwohner infolge der gestiegenen Hochwassersicherheit. ${ }^{88}$

Im Linzer Raum fanden umfangreichere Regulierungsarbeiten zwar deutlich später statt als z.B. am Rhein, wo man in den späten I 8 Ioer Jahren begonnen hatte (und was spürbar den Donau-Umbau inspirierte), ${ }^{89}$ im Wiener Raum setzte ein systematischer Wasserbau hingegen erst in den r 86oer Jahren ein. ${ }^{90}$ Der Flussumbau hatte gravierende Auswirkungen auf die Flusslandschaften und veränderte, wie eine neuere Studie annimmt, die Morphologie der Donaulandschaft stärker »als die Errichtung der vielen Kraftwerke im 20. Jahrhundert «. ${ }^{91}$ Und dieser »Fortschritt« hatte auch un-

83 Jungwirth et al., Donau, I 59 u. I62; Neweklowsky, Donau, I99f.; ähnlich die Motive bei den Rheinregulierungen: vgl. Cioc, Rhine, 56 u. 75 .

84 Allgemeine Bauzeitung 27 (I 862), 83-93, hier 83 .

85 Ebd., 85 u. 9r; vgl. Cioc, Rhine, 38 f. u. 52-54.

86 Im Vergleich zum Eisenbahnbau war der Donau-Umbau pro Kilometer angeblich doppelt so teuer Jungwirth et al., Donau, I67; vgl. Statistischer Bericht I 882, Bd. 2, 73 f.

87 Allgemeine Bauzeitung 27 (I862), 83-93, hier 85f. u. 9 I.

88 Ebd., 91 u. 93.

89 Cioc, Rhine, $52-63$.

90 Jungwirth et al., Donau, I63; Hohensinner et al., Changes, I6 I- I63; Haidvogl et al., Wasser, $90-98$.

9I Jungwirth et al., Donau, 36. 
intendierte Konsequenzen. ${ }^{92}$ In seinem Artikel wies Landesbaudirektor Baumgartner - und hier wird das Vorbild des Rheins erneut deutlich ${ }^{93}$ - im Hinblick auf frühere Regulierungsbauten auf "manche, ja sogar viele Fehlgriffe hin. ${ }^{94}$ Die aufgetretenen Probleme schrieb man in Linz vor allem der neu errichteten Eisenbrücke zu. ${ }^{95}$ Bei der Regulierung der I 85 oer Jahre hatte man den Donauarm (»Fabrikarm«) erhalten, da die dort ansässigen gewerblichen Betriebe (die frühere Wollzeug- und nunmehrige Tabakfabrik, die Schiffswerft und eine Dampfsäge) auf den Zugang zur Donau angewiesen waren. ${ }^{96}$ Die Verlandung des Fabrikarmes war aber offenbar ein längerfristiger Prozess: Bereits Ende der I 77oer Jahre konnte dieser »oft trockenen Fußes überschritten ${ }^{\prime}$ werden, ${ }^{97}$ auch in einer Topographie aus den I 8 roer Jahren wurde Ähnliches festgestellt ${ }^{98}$ und in den I 79oer Jahren hatte die Wollzeugfabrik Baggerungen »in der Mitte des Donau Armes« - vermutlich, um die nötige Tiefe des Wasserweges zu erhalten - vornehmen lassen. ${ }^{99}$

Tab. 28: Donauregulierungen im Linzer Raum, 1850-1860

\begin{tabular}{lll}
\hline 1850 & linkes Ufer & "Lichtlackenauwerk (außerhalb von Linz) \\
$1850 / 1858$ & linkes Ufer & Pleschinger Graben bis »Panglmayr « \\
$1850 / 1851$ u. 1853 & linkes Ufer & Griesau bis Furter Graben \\
1851 & rechtes Ufer & Raigerau (unterhalb Weikerlwerk) \\
1852 & rechtes Ufer & Untere Donaulände, Auflassung des »Linzer Umschlagplatzes " \\
1852 & rechtes Ufer & Grieslerau (heute "Welser Mühlbach «) bis alte Traunmündung \\
$1852 / 1854$ & rechtes Ufer & Panglmayrau (anknüpfend an Bau von 1843) \\
1854 & rechtes Ufer & bei Brücke (ergänzend zu Bauten von 1832/33) \\
$1854 / 1856$ u. 1860 & rechtes Ufer & Schiffswerft bis Pleschinger Au \\
1855 & rechtes Ufer & untere Panglmayrau (heute bei Steyreggerbrücke) \\
$1856 / 1858$ & rechtes Ufer & Weiklerau, dort auch späterer »Floßhafen « \\
$1856-1859$ & linkes Ufer & Uferverbauung bei Urfahr (Brücke) \\
1857 & linkes Ufer & "Mitterauwerk« (heute Winterhafen) \\
1859 & rechtes Ufer & Zizlau \\
\hline
\end{tabular}

Quelle: Neweklowsky, Donau, 202-204

92 Donau in Oberösterreich, 44.

93 Cioc, Rhine, 69-71.

94 Allgemeine Bauzeitung 27 (1862), 83-93, hier 9I.

95 Wobei es sich aber genauso um erste Anzeichen einer Sohlevertiefung gehandelt haben könnte - vgl. Neweklowsky, Donau, I 75 f. u. Jungwirth et al., Donau, I 7 of.

96 Donau in Oberösterreich, 52 ; Allgemeine Bauzeitung 27 (I862), 83-93, hier 86; vgl. Lackner/Stadler, Fabriken, 353 u. 454.

97 LR BIIG7, Reg. 3803 (if.).

98 Gielge, Beschreibung, I 36.

99 AStL, HS ro84 (Stadtratsprotokoll I797), fol. 83b u. 84a. 
In den I $870 e r$ Jahren reagierte die Landesverwaltung zunächst mit wasserbaulichen Gegenmaßnahmen (»Einbau von Normalisierungsleitwerken«) und es wurde - da man darin auch eine Ursache für die Verlandung sah - I874 durch die Statthalterei das Einbringen von Schutt und Abfall in die Donau verboten (vgl. Kap. 5. Zirkulationen und Output). ${ }^{100} \mathrm{Da}$ sich infolge von niedrigen Wasserständen und Verlandungen vermehrt Abwässer und Fäkalien aus den städtischen Kanälen bei der Donaulände und im Fabrikarm ansammelten, protestierte I 876 die im Fabrikarm gelegene Schwimmschule gegen die schlechte Wasserqualität und verlangte von verschiedenen Institutionen - der Donauregulierungskommission, der Dampfschifffahrtsgesellschaft und vom Innenministerium - Baggerungsarbeiten. ${ }^{101} \mathrm{Zu}$ konkreten Maßnahmen scheint es nicht gekommen zu sein, erst als zu Beginn der I 88 oer Jahre erneut »bedenkliche sanitäre Zustände« konstatiert wurden, begannen Baggerungsarbeiten im Donauarm, um diesen zu erhalten und den Durchfluss zu erhöhen. ${ }^{102}$ I 882 entstand aus einer Anfrage der Staatseisenbahndirektion Wien an die oberösterreichische Handels- und Gewerbekammer zur Etablierung einer direkten Verbindung der Eisenbahn mit der Donau in Linz der Plan, den Fabrikarm zuzuschütten und die dadurch entstandene Fläche als »Umschlagplatz« zu verwenden. ${ }^{103}$ Linz bildete diesbezüglich keinen Sonderfall: Flussregulierungen, die auch auf Landgewinne abzielten, fanden sich in dieser Zeit in zahlreichen urbanen Gebieten, ${ }^{104}$ zudem hatten andere Donaustädte schon Schnittstellen zwischen der Eisenbahn und dem Fluss hergestellt. ${ }^{105}$ Im Frühjahr I 88 I wurde in einem Artikel in einer Linzer Zeitung auf die Umschlagplätze in Passau und Regensburg und auf ein ähnliches Projekt in Deggendorf verwiesen und eingefordert, dass »sich unsere kompetenten Behörden und hauptsächlich unsere löbliche Gemeinde-Vertretung aufraffen $[\ldots]$ und sich ein wenig um den schon lange vernachlässigten Donauquai umsehen « solle. ${ }^{106}$ Der Linzer Gemeinderat initiierte einen Diskussionsprozess, der über mehrere Jahre andauerte und zu divergierenden Entwürfen führte: Der vom "Donauverein« - der Lobbyingorganisation verschiedener Donau-Nutzer ${ }^{107}$ - beauftragte Techniker und der städtische Ingenieur plädierten für die Erhaltung des Fabrikarms, wobei der städtische Ingenieur auch einen kleinen »Hafenbahnhof « vorschlug. Ein dritter Techniker, der vom »Verein der Techniker in Oberösterreich» beauftragt worden war, erachtete eine Umgestaltung des Donauarms in zwei Hafenbecken, die mit einem engen Kanal verbunden sein sollten, als optimale Lösung. ${ }^{108}$

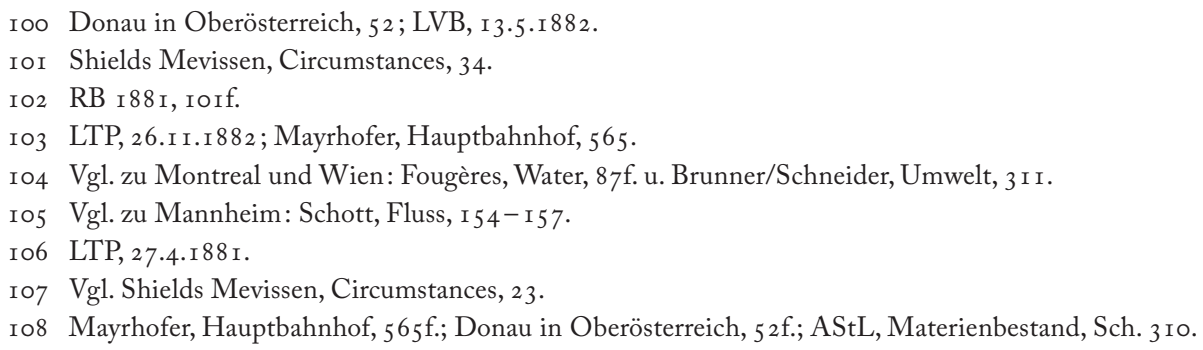




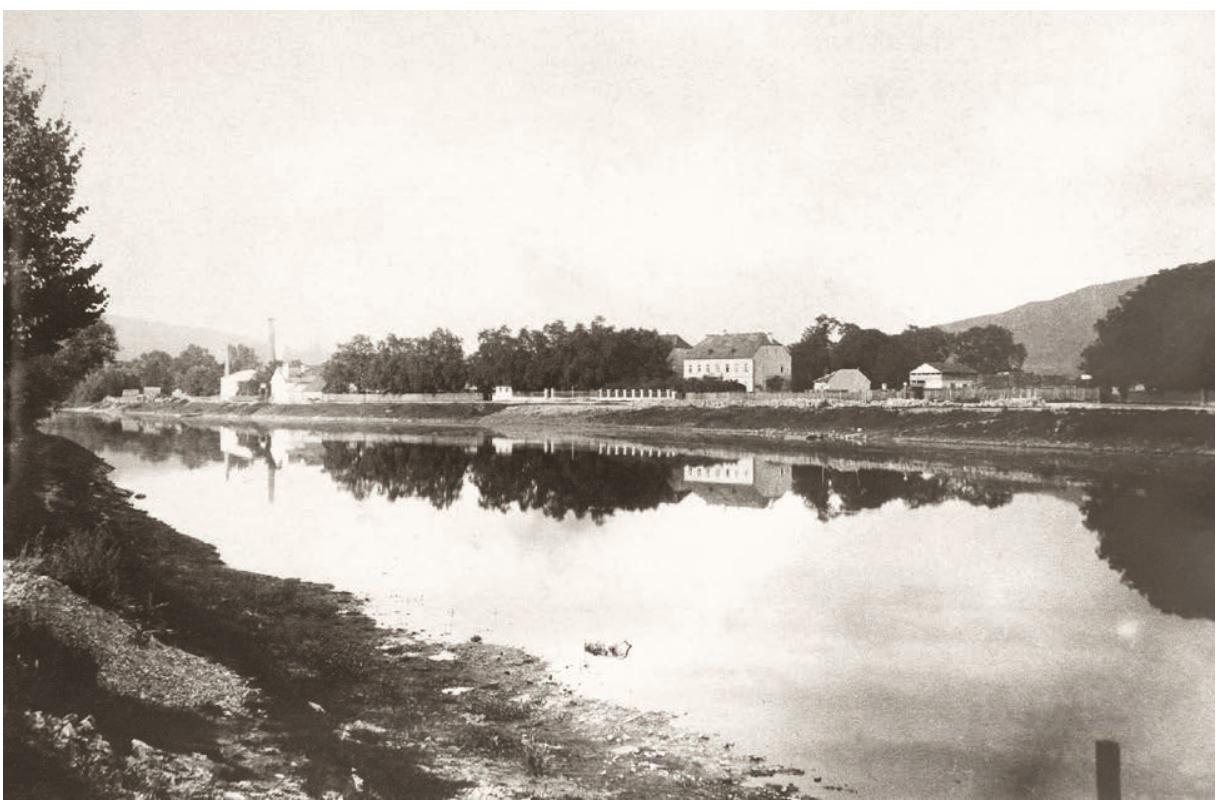

Abb. 21: Blick von der Strasserinsel auf den Fabrikarm zu Beginn der Regulierungsarbeiten, 1891

Bei der Umsetzung dieses Projektes kam es wiederum zu einer Kofinanzierung durch den Staat, der schließlich die weitgehende Zuschüttung des Fabrikarmes durchsetzte, wobei vorgesehen wurde, den untersten Teil als Winterhafen zu erhalten. ${ }^{109}$ Der Donauzugang für die Gewerbebetriebe wurde durch ein Eisenbahngleis ersetzt, I 887 begannen die Bauarbeiten zunächst mit Leitwerken und dann mit der Auffüllung des Fabrikarmes durch die Ausbaggerung des Hauptarmes, ${ }^{110}$ I 894 waren die Bauarbeiten größtenteils beendet und Gleisanschlüsse hergestellt (vgl. Abb. 2 I u. 22). ${ }^{111}$ Dass die Stadt den Umschlagplatz als Prestigeprojekt in der Städtekonkurrenz sah, zeigen die zahlreichen Diskussionen und Aktivitäten rund um die Planungen, die sogar eine "Studienreise« des Gemeinderates nach Passau, Regensburg, Heilbronn und Mannheim inkludierte. Die Neugestaltung des Umschlagplatzes zielte auch auf visuelle Bereiche ab und sah die Erhaltung der Grünflächen der Strasserinsel und die Anlage einer neuen »Promenade« mit Bäumen vor, was schließlich einen größeren Bereich als die eigentlichen Hafenanlagen einnahm. ${ }^{112}$

Schon I86 I hatte der oberösterreichische Landesbaudirektor Baumgartner auf die Möglichkeit hingewiesen, »nach dem Vorbilde am Rhein und anderen Flüssen [...]

I09 Donau in Oberösterreich, 53; vgl. RB I886, 86-88; RB I 887, I02.

I I Neweklowsky, Donau, I 94 u. 204; Donau in Oberösterreich, 53.

I I Shields Mevissen, Circumstances, 37; Lackner/Stadler, Fabriken, 25.

I 2 RB I894, I 36 - I 40; AStL, Materienbestand, Sch. 3 ro u. Sch. 3 I I. 


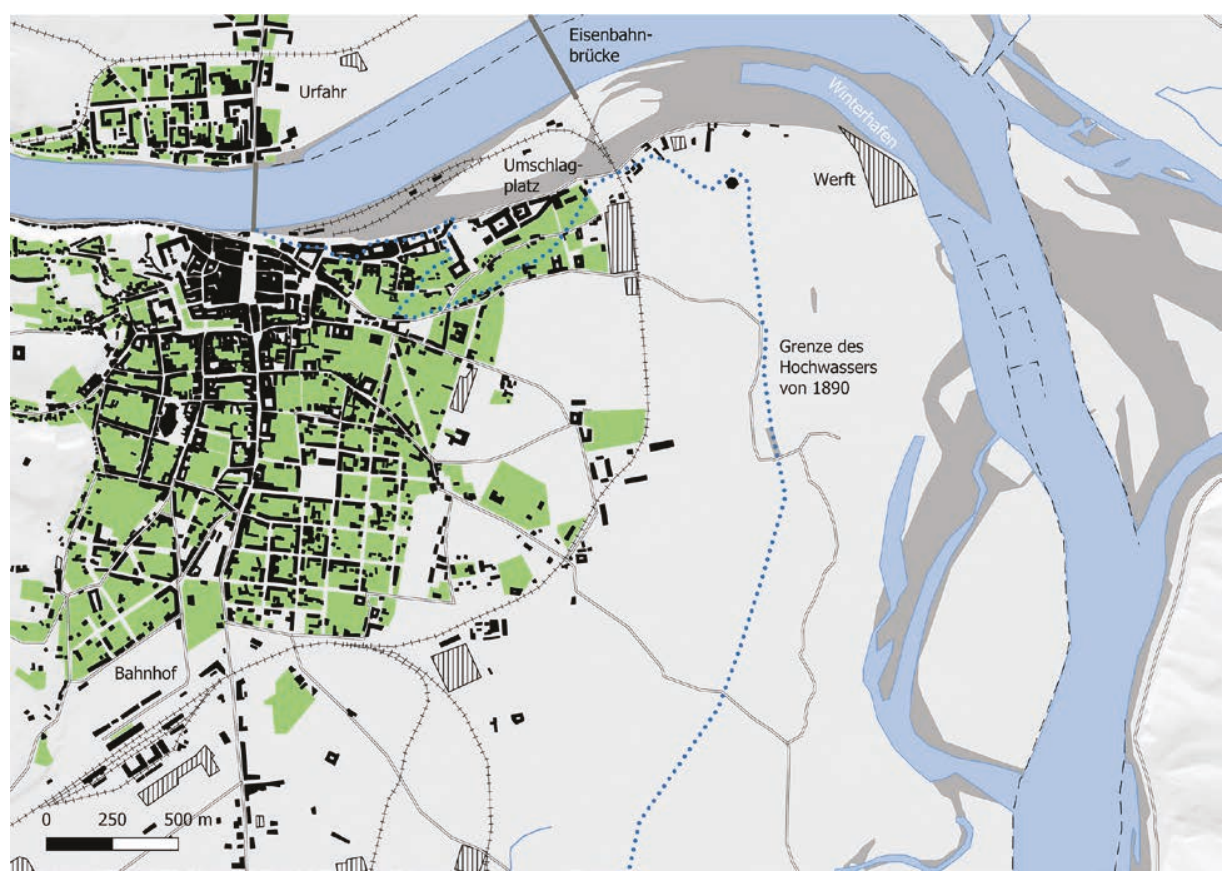

Abb. 22 : Stadt und Fluss zum Ende des 19. Jahrhunderts - dunkelgrau gefärbt ist der Verlauf der Donau in den $1820 e r$ Jahren

Winter- oder Sicherheitshäfen« zu etablieren, was aus Altarmen relativ leicht umgesetzt werden könne. ${ }^{113}$ Mit dem Bau des Umschlagplatzes sah man nun die Chance, einen Winterhafen ohne »zu grosse Kosten« zu etablieren. ${ }^{114}$ In der Praxis funktionierte dies aber nicht: Obgleich der Winterhafen weiter flussabwärts situiert wurde, waren in der Folge regelmäßige Baggerungen notwendig, um die Zufahrt freizuhalten. ${ }^{115}$ Die Kosten waren also erheblich, zudem waren die Regulierungsarbeiten nach der Bauphase der i 85 oer Jahren keineswegs abgeschlossen: Weiterhin entstanden im Linzer Raum Dämme, die die Bildung von Nebenarmen verhindern sollten, und ab den r 8 goer Jahren ging es um die Schaffung und Erhaltung einer Schifffahrtsrinne, die auch bei Niedrigwasser befahren werden konnte. ${ }^{116}$ Das war ebenso eine Reaktion auf Sedimentablagerungen und auf sinkende Wasserstände infolge von Sohlevertiefungen, was bereits in den 1870 er Jahren auftrat und sich offenbar in den I 88 oer Jahren noch

I I Allgemeine Bauzeitung 27 (I862), 83-93, hier 9I.

I 4 RB I 886, 86; AStL, Materienbestand, Sch. 3 I I.

I 5 Der Winterhafen wurde zwischen I 897 und I 900 errichtet; Neweklowsky, Donau, 205f. u. 209; Lackner/Stadler, Fabriken, 26; Donau in Oberösterreich, 86-88.

I 6 Vgl. LZ, 4.8. I 866; Donau in Oberösterreich, 54-56 u. 75f.; RB I 886, 85 ; Allgemeine Bauzeitung 62 $($ I 897$)$, I -7 . 
weiter verstärkte. ${ }^{117}$ Zudem resultierte die Verengung auf einen Flussarm - und damit eine geringe Durchflussmenge - in bestimmten Konstellationen in einer Erhöhung des Hochwasserrisikos (vgl. Kap. I r. Naturgefahr). ${ }^{118}$

\section{Das Verschwinden der urbanen Gewässer}

Da im Linzer Stadtgebiet neben der Donau nur eine geringe Anzahl anderer Gewässer bestand, hat deren Nutzung und Transformation kaum Quellen hinterlassen. ${ }^{119}$ Einer der wenigen Teiche war der Lamplwirtsteich, der sich am südlichen Ende der Oberen Vorstadt befand und vermutlich schon vor dem I 8 . Jahrhundert existierte. Der Teich ist in einem Stadtplan aus den I73oer Jahren sichtbar ${ }^{120}$ und wurde im "Josephinischen Lagebuch« als Besitz zweier nahegelegener Bauernhöfe verzeichnet, wobei man eine Größe von ca. I.80o Quadratmetern angab. ${ }^{121}$ Vermutlich diente der Lamplwirtsteich ursprünglich als Sammler für kleine, ephemere Wasserläufe vom Bauern- und Freinberg, die später versiegten, und für Niederschlagswasser. ${ }^{122}$ Zudem stellte der Lamplwirtsteich Wasser im Brandfall bereit - diese Funktion wurde in der Feuerordnung von I 808 explizit erwähnt. ${ }^{123}$ Wenngleich der »Franziszeische Kataster« den Teich nicht als produktive Fläche erfasste, ${ }^{124}$ ist eine Nutzung als Fischteich oder Eisteich zu vermuten. Nach wiederholten Räumungen wurde der Teich I 839 an den Kanal in der Langgasse angeschlossen und wahrscheinlich in den frühen I 840er Jahren zugeschüttet, ${ }^{125}$ denn I 847 suchte man im Stadtrat nach einer Lösung für Entwässerungsprobleme beim »vormaligen« Lamplwirtsteich, die nun »bei Thauwetter, oder heftigem Regen « auftraten. ${ }^{126}$

Südlich der Vorstädte befand sich der Füchselbach (auch als »Grund«, »Krum« bzw. "Breitwieserbach« bezeichnet), der - da er die Vorstädte im I8. Jahrhundert nicht

I 7 Neweklowsky, Donau, I75f.

I 8 Mayrhofer, Donaustadt, 76f.; Jungwirth et al., Donau, r 7of.; vgl. zu Wien: Brunner/Schneider, Umwelt, 3 I 2.

I 9 Vgl. als neuere Zusammenschau: Winiwarter et al., Evolution.

I 20 OÖLA, Karten- und Plänesammlung, V/3 (»Eigendtlicher GrundtRiß der Haubtstatt Lintz«, undat. [I730er Jahre]).

I 2 I Berlinger, Lamplwirtsteich, 45 ; vgl. Bohdanowicz, Vorstädte, Bd. 2, 409.

I 22 Berlinger, Lamplwirtsteich, $44 \mathrm{f}$.

I 23 Feuer-Ordnung, 29; vgl. zu den »Gemeindeteichen«: Oesterreichische Feuerwehr-Zeitung, I.9. I 865, unpag.

I 24 Bohdanowicz, Vorstädte, Bd. 2, 409 u. 423.

I25 AStL, HS I Iо2 (Stadtratsprotokoll I 82 I), fol. 3 I a; Bohdanowicz, Vorstädte, Bd. 2, 409; OÖLA, Karten- und Plänesammlung, VI/6o; AStL, Altakten, Sch. 3 I ; die ältere Literatur (Berlinger, Lamplwirtsteich folgend) geht jedoch von einem Bestehen des Teiches bis in die I86oer Jahre aus.

I 26 AStL, HS I 28 (Stadtratsprotokoll I 847), fol. 7 I steichgrundes« - vgl. AStL, HS I 29 (Sitzungsprotokolle des Gemeindeausschusses I 848), fol. 43a u. $43 \mathrm{~b}$. 
berührte - erst mit den Katastern besser sichtbar wird (vgl. Abb. I). Wenngleich der Bach relativ klein war, scheint er doch regelmäßig kleinräumige Überschwemmungen verursacht zu haben, was auch das »Josephinische Lagebuch « konstatierte. ${ }^{127}$ Ähnliches stellte der "Franziszeische Kataster« fest: Zwar verwendete man in der Oberen Vorstadt den Bach zeitweise zur Bewässerung der Wiesen, nach starken Niederschlägen verursachte der Füchselbach aber »oft bedenklichen Schaden «. ${ }^{128}$ Für die Untere Vorstadt wurde keine Nutzung angegeben, die Gemeinde monierte jedoch ebenso die Überschwemmungen, die mitunter »durch mehrere Wochen große Strecken der Oberfläche« bedeckten. »Schutzanstalten« bestanden nicht, wohl da sich die Grundbesitzer »selbst schützen« mussten und somit der erforderliche Aufwand einen etwaigen Nutzen deutlich überstieg. ${ }^{129}$ Eine Verwendung zur Abwasserentsorgung ist für den Füchselbach erst im späten I 9. Jahrhundert belegt, aber als der Bach - nach wiederholten Überschwemmungen - I 909- I9 I 3 durch die Eindeckung aus dem Stadtraum verschwand, integrierte man ihn dennoch nicht in das städtische Kanalsystem. ${ }^{130}$

Eine wichtigere Funktion nahm das Gerinne der Ludl im Wörth ein, das wie der größere Fabrikarm vermutlich durch das Hochwasser des Jahres I 572 entstanden war und bis zum Ende des I 9. Jahrhunderts zur Abwasserentsorgung genutzt wurde (vgl. Kap. 5. Zirkulationen und Output). ${ }^{131}$ Der Merian-Stich hat die Ludl in den I64oer Jahren - wohl übertrieben - als relativ breiten Seitenarm dargestellt, Bildquellen aus der ersten Hälfte des I 8. Jahrhunderts zeigen ein schmales Gerinne mit wenig Wasser, ${ }^{132}$ und ein Stadtplan aus den I78oer Jahren dokumentiert, dass die Ludl bereits zu diesem Zeitpunkt nicht mehr über einen Zufluss verfügte. ${ }^{133}$ Das graduelle Verschwinden der Ludl kann einerseits auf flussdynamische Prozesse zurückgeführt werden, andererseits kam es in den I 77oer Jahren zu einer Neugestaltung des Donauufers, das vermutlich auch zu einem Zuschütten der Ludl-Abzweigung führte (vgl. oben). Zudem hatte dieses städtische »burying of the water networks « ${ }^{134}$ einen wesentlichen hygienischen Impetus und richtete sich vor allem gegen stehende Gewässer, zu denen die Ludl ab dem i 8. Jahrhundert zu rechnen ist. ${ }^{135}$ Schon 1775 hatte die Hofkanzlei - als Betreiber der Wollzeugfabrik war sie ein Anrainer - das vollständige Zuschütten der Ludl

I 27 Bohdanowicz, Vorstädte, Bd. I, 442; vgl. Gielge, Beschreibung, I 37.

I 28 OÖLA, Franziszeischer Kataster, No. 534 (Operat 2, Linz Obere Vorstadt, Katastralschätzungs-Elaborat, undat.).

I 9 Ebd. (Operat 2, Linz Untere Vorstadt, Beantwortung Fragen Gemeinde Lustenau, 25.I. I 83 I).

I30 Pichler-Baumgartner, Wege, $257 \mathrm{f}$.

I 3 I Neweklowsky, Schiffahrt, Bd. I, 78; Kreczi, Linz, I 50; vgl. zum Sommerhochwasser von I 572 : Rohr, Naturereignisse, 247-257.

I32 Schmidt, Linz, Tafeln 8f., I 7 u. 34; OÖLA, Karten- und Plänesammlung, V/3 (»Eigendtlicher GrundtRiß der Haubtstatt Lintz«, undat. [I 73oer Jahre]).

I33 OÖLA, Karten- und Plänesammlung, V/8 (Stadtplan, I78I); vgl. auch AStL, HS 86 I (»Chronologische Beschreibung«, I 77oer Jahre), fol. 42a u. 42b.

I 34 Guillerme, Age, I 75 .

I35 Ebd., I75-i77 u. I94- I96. 


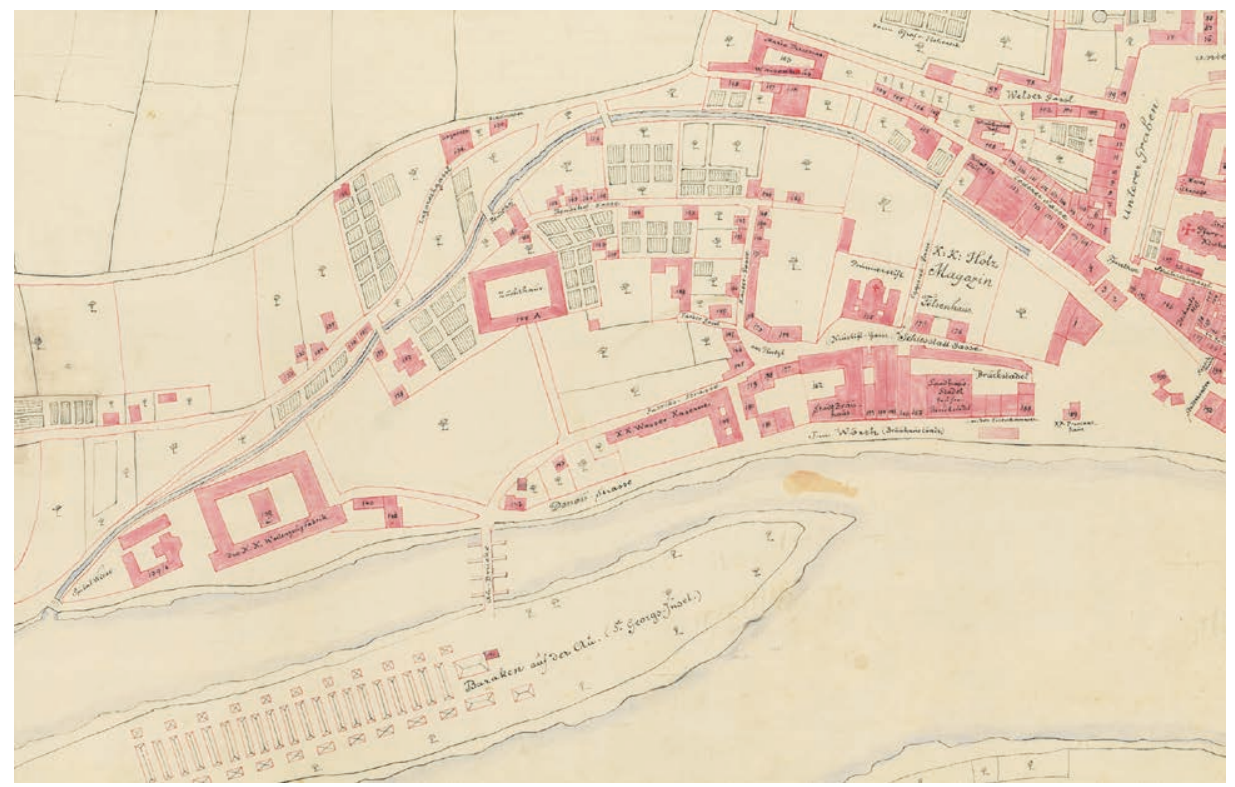

Abb. 23: Ludl und Donauarm zu Beginn der 178oer Jahre (Ausschnitt) - der Plan ist nach Süden ausgerichtet

angedacht, nachdem das Wasser im Graben »Ungemach« bereitet hatte, was aufgrund der zu erwartenden Kosten wieder verworfen wurde. ${ }^{136}$ Als i 808 die Wollzeugfabrik den Wunsch äußerte, dass »die stinkende Pfütze [...] ganz ausgetrocknet [...] und ausgeschüttet werde«, widersprach der Magistrat: Die Ludl könne man nie zuschütten, »denn wohin hätte das Wasser [... von der Lederergasse] bis zum Lazareth seinen Ablauf, die Häuser sind nach dieser Lage gebauet, und die Strassen darnach angelegt«. Der Graben solle erweitert und gereinigt werden und einen »ordentlich(e)n Ablauf» erhalten. ${ }^{137}$ Dennoch wurde rund 20 Jahre später, vermutlich auf eine Anordnung der Landesregierung hin, ein Teil der Ludl zugeschüttet. ${ }^{138}$ Trotz wiederholter Diskussionen in den I87oer und I 88oer Jahren - und zwischenzeitlicher »Räumung[en] des Grabens« durch die Stadt ${ }^{139}$ - wurde der letzte Rest der Ludl erst I 892 »saniert « und durch einen Kanal ersetzt. ${ }^{140}$ Die Heterotopie der urbanen Gewässer verschwand also nur sehr langsam und war deutlich anlassbezogen, Veränderungen wurden deutlich stärker von ökonomischen als von ideellen Faktoren induziert.

i36 LR CIIIFi u. 2, Reg. 170 (75f.).

I37 AStL, Altakten, Sch. I3.

I38 Straßmayr, Schmiedtor, I 37; AStL, Altakten, Sch. 80; vgl. OÖLA, Karten- und Plänesammlung, V/ I I.

I39 RB I 882, I 23.

I 40 Pichler-Baumgartner, Wege, 2 I4; GRP I 873, fol. I 5ob; RB I 887, I04- I08; RB I 892, 202. 


\section{Geordnete und modifizierte Umwelt}

\section{Unsaubere und saubere Vormoderne}

In der stadtgeschichtlichen Forschung ist für die Zeit vor dem I 9. Jahrhundert meistens eine prinzipiell schmutzige Stadt angenommen worden - es habe ein anderes Hygienebewusstsein gegeben und es habe Ignoranz vorgeherrscht, zudem hätten umfangreichere Infrastrukturen der Sauberkeit gefehlt. ${ }^{1}$ Analog dazu ist für das frühneuzeitliche Linz davon ausgegangen worden, »daß der Standard der Allgemeinhygiene nicht besonders hoch war ${ }^{2}$ Diese Einschätzungen sind vermutlich darauf zurückzuführen, dass eine Annäherung an die alltägliche Sauberkeit resp. Unsauberkeit schwierig ist. Als Quellen sind meistens normative Texte herangezogen worden, die relativ stereotyp - und regelmäßig (oft nach oder unmittelbar vor Epidemien) - von den Stadtbewohnern/innen verlangten, Unsauberkeiten »abzustellen« (vgl. unten). Die Linzer Ego-Dokumente bieten diesbezüglich keine Anhaltspunkte, wenn man von en passant geäußerten Bemerkungen in Reisebeschreibungen absieht. ${ }^{3}$ Auch Nachbarschaftskonflikte, etwa um eine "Mistkrippe« oder einen »Schwainstall ${ }^{4}{ }^{4}$ bilden eine schwierig zu bewertende Quelle: Es erscheint ex post weder sinnvoll noch möglich, aus Einzelfällen - aktenkundig wurden ohnehin nur Bruchteile des Umstrittenen Ideale von Sauberkeit abzuleiten, auch zu differenzieren, ob die beklagte Unsauberkeit als Belästigung oder als Bedrohung der Gesundheit (oder sogar als beides) wahrgenommen wurde. ${ }^{5}$

Bessere Einblicke in alltägliche Praktiken der Sauberkeit gewähren Rechnungsund Ausgabenbücher, die zudem nahelegen, ein komplexeres Bild zu entwerfen und nicht von der Dichotomie »unsaubere Vormoderne« versus »saubere Moderne« auszugehen: In privaten und städtischen Rechnungsbüchern sind regelmäßige häusliche Reinigungsdienste durch Dienstleister vermerkt, ${ }^{6}$ wiederholt finden sich Ausgaben für Kalk, der zur »Aussauberung « von städtischen Gebäuden verwendet wurde. ${ }^{7}$ Genauso

I Vgl. Clark, Cities, 204f. u. Lees/Lees, Cities, 283 f.; eine skeptischere Beurteilung, die auf die Forschungslücken verweist: Reith, Umweltgeschichte, IO I - Io3.

2 Mayrhofer/Katzinger, Geschichte, Bd. I, 227.

3 Vgl. Gugitz, Linz, $57 \mathrm{f}$.

4 Hier handelte es sich um einen Konflikt des Stifts Kremsmünster in der Altstadt im Jahr I 706 : LR BVII, Reg. 984 (376f.); ebd. Reg. 990 (379); ebd., Reg. 99 I (380).

5 Vgl. Lees/Hollen Lees, Cities, 63 u. Rosseaux, Städte, rogf.

6 Vgl. z.B. für das Landhaus: LR BIIA 4 , Reg. 5379 ( 177 ) u. für das Rathaus: AStL, HS 389 (Bauraittung I750), pag. IO4.

7 AStL, HS 399 (Bauraittung I760), unpag. 
zahlreich sind die Hinweise auf das Waschen der Wäsche ${ }^{8}$ oder das Auswechseln von gebrauchtem Material wie z.B. von "Bettstroh «. ${ }^{9}$ Auch die Reaktionen auf Nichtalltägliches, etwa die massenhafte Einquartierung von Soldaten bzw. Verwundeten, lassen Sauberkeits- und Hygienevorstellungen erkennen. Nach dem Erbfolgekrieg I742 meldete der Hausmeister des Kremsmünsterer Freihauses Renovierungsbedarf: Da "gefährliche« kranke Soldaten im Haus untergebracht worden seien, müsse man möglicherweise die Fußböden tauschen, zumindest aber die Böden mit Essig reinigen und den "völlig « ruinierten Pferdestall neu ausmalen. ${ }^{10}$ Sauberkeit wurde nicht nur visuell bestimmt, sondern ebenso über Gerüche. Während des Erbfolgekrieges waren auch im Linzer Schloss Soldaten einquartiert gewesen, die, wie ein ständischer Beamter später konstatierte, »starke[n] Geruch« hinterlassen hätten. Da der Geruch trotz umfangreicher Reinigungs- und Ausbesserungsarbeiten nicht verschwand, sah man schließlich davon ab, die durchreisende Kaiserin in diesen Räumlichkeiten unterzubringen. ${ }^{11}$ Schlechter Geruch wurde nicht nur als störend, sondern - infolge des Glaubens an krankheitsübertragenden Gestank (Miasmen) - genauso als gefährlich wahrgenommen. Somit zielte die Vermeidung von Schmutz auch auf die Vermeidung von schlechten Gerüchen ab. ${ }^{12}$ Die Einschätzung von gesunden resp. ungesunden Settings war subjektiv und konnte somit grundlegend divergieren: I7 I5 lehnte der zuständige Militärkommandant die Errichtung eines Soldatenlagers auf der Linzer Donauinsel $\mathrm{ab}$, weil der von den Überschwemmungen abgelagerte, stinkende Schlamm die Verbreitung von Krankheiten begünstige. ${ }^{13}$ Ein kaiserliches Mandat vom Mai I 738 ordnete hingegen die Verlegung von kranken Rekruten ins Insellager an, da dort die frische Luft "gesünder « sei. ${ }^{14}$

Vermutlich ist das Ausräuchern von Zimmern ebenso im Kontext des Geruches zu sehen: Regelmäßig bezahlten die Landstände für »Rauchwerk«, das zum »Räuchern im Landhaus« und in den ständischen Wohnungen verwendet wurde. Dass es sich nicht nur um eine religiöse Praxis handelte (vielfach tauchen Kaplane und Mesner in den Rechnungen rund um Weihnachten und Neujahr auf), zeigen die wiederholten Zahlungen an Apotheker und die Erwähnung von »Pestrauchwerk « im Jahr I 7 I $4 .{ }^{15}$

8 Vgl. z.B.: LR BIIA, Reg. 8892 (r 9); LR BIIG8, Reg. 5798 ( ( 99); LR Eıb, Reg. I79I (98); LR CIIIH4, 80I-808; OÖLA, Herrschaftsarchiv Weinberg, Sch. 643 u. Sch. 66r.

9 LR EIf, Reg. 375 ( ( 477- I49); LR BIIA40, Reg. 19694 (I08f.).

Io LR BVI2, Reg. I 246 (I87).

II LR BIIG6, Reg. 3025 (7); ebd., Reg. 3026 (7).

I2 Schott, Urbanisierung, 246; vgl. zur Miasmentheorie: Kiple, Disease, I4 U. I8f.; Leven, Ratten, I8-22 ; Reith, Umweltgeschichte, 95 - I03; Briese, Angst, Bd. I, I 43 - I 54.

I3 LR BIIA40, Reg. I97 i ( I 6 ff.).

I4 Ebd., Reg. I957 ( 35 ).

I 5 Vgl. z.B. LR BIIA 3 , Reg. 3640 (I 25); ebd., Reg. 3667 (I 29); ebd., Reg. 4232 (2 I4); LR BIIA4, Reg. 4806 (70); ebd., Reg. 54I I (I 83); LR BIIA6, Reg. 7769 (85); vgl. dazu Reith, Umweltgeschichte, 2 I u. Kellner, Pesthauch, I 29. 
Auch nach der Einquartierung der Soldaten im Kremsmünsterer Freihaus I742 räucherte man später das Haus »aus«. ${ }^{16}$

Die Herstellung und Aufrechterhaltung von Sauberkeit im öffentlichen Raum wurde im I8. Jahrhundert über ein Ineinandergreifen von privater und öffentlicher Verantwortung gelöst. ${ }^{17} \mathrm{Wie}$ in anderen Städten mahnten Dekrete regelmäßig oder anlassbezogen Sauberkeit ein, etwa bei der Pest I 7 г $3,{ }^{18}$ und dafür waren im Umfeld des Hauses die Hausbesitzer selbst zuständig. Zentrales Element der sauberen Stadt in der Vormoderne waren Pflasterungen: Zahlreiche private Flächen in Linz - meist die Innenhöfe der Häuser - waren im I 8. Jahrhundert gepflastert, was aber eher auf wohlhabende Haushalte zutraf. ${ }^{19}$ Dabei sollte eine Pflasterung nicht nur das Entstehen von Schlamm verhindern, sondern es wurde genauso als prophylaktische Maßnahme gegen aus dem Boden aufsteigende, gesundheitsschädliche Gerüche gesehen. Auch die Straßenpflasterung fiel in die Zuständigkeit der Hausbesitzer, die Stadtverwaltung trat in diesem Bereich - abgesehen von der Pflasterung einzelner Räume - nur kontrollierend und nicht aktiv auf. ${ }^{20}$ In der Praxis funktionierte dieses System nicht immer: Schon bei den vermögenden Freihäusern mussten Pflasterungen wiederholt eingemahnt werden, ${ }^{21}$ im Verlauf des I 8. Jahrhunderts scheint aber die Stadt damit begonnen zu haben, auf Kosten der Eigentümer Pflaster zu verlegen. ${ }^{22}$ Dennoch blieben die Aktivitäten der Stadt im Bereich der öffentlichen Sauberkeit bis in die zweite Hälfte des I 8. Jahrhunderts begrenzt: Für Abwässer und Abfälle hatte die Stadtverwaltung präventive räumliche Lösungen gefunden, die teilweise vermutlich schon jahrhundertealt waren (vgl. Kap. 5. Zirkulationen und Output). Das Linzer Schlachthaus befand sich im I 8. Jahrhundert - wie in vielen anderen Städten - am Fluss und stand zeitweilig sogar direkt über dem Wasser, was ein direktes Einbringen der Abfälle in die Donau ermöglichte. ${ }^{23}$ Dazu bestanden in der unmittelbaren Nähe Fleischbänke an der Stadtmauer ( 5 zur Mitte des i 8. Jahrhunderts) und einige weitere Fleischbänke für Landfleischhauer beim oberen Wassertor. ${ }^{24}$ Nur sporadisch beschäftigte die Stadt einzelne Dienstleister, um Sauberkeit im öffentlichen Raum herzustellen. Diese Aktivitäten sind in den Bauamtsrechnungen sichtbar, wenngleich bei den meisten Ausgaben

I6 $\mathrm{LR} \mathrm{BVI}_{2}$, Reg. I 246 (I87).

I7 Vgl. Brunner/Schneider, Umwelt, $272-274$ u. Cockayne, Hubbub, I 82 - I 87.

I 8 LR BIA 5 , Reg. 6424 (I 76); LR BVIII2, Reg. 99I (I08); vgl. zur pestbezogenen Sauberkeit in Regensburg: Kellner, Pesthauch, I I 4 - I 2 I.

I9 LR BVI2, Reg. I I 27 (6I-69); LR BIIG8, Reg. 50 I I (85).

20 LR BIIG8, Reg. 4996 (83); ebd., Reg. 54I4 (I46); LR BIA5, Reg. 6423 (I76).

2I LR BIA 5 , Reg. 6425 (I76f.); ebd., Reg. 6426 (I 77 ).

22 LR Eig, Reg. 352 (I 47); LR BIA 5 , Reg. 6428 (I77).

23 LR E6 (»Sint-Chronik«), 62; Kreczi, Linz, 62 u. 2 I 9 ; vgl. die bildlichen Darstellungen aus dem I 7. und I 8. Jahrhundert: Schmidt, Linz, Tafeln 8, I2, I7 u. I8.

24 AStL, HS 389 (Bauraittung I750), pag. 30-32; AStL, HS 409 (Bauraittung I770), pag. 27; Fischer, Ölbergfleischhauer, 62f.; vgl. zu Wels: Rohr, Überschwemmungen, 32 I- 323. 
für Taglöhner deren Tätigkeit nicht näher bezeichnet wurde. Bereits eine Bauamtsrechnung aus den I640er Jahren verzeichnete Taglöhner, die Straßen reinigten, und die Bezahlung »alte[r] Frauen«, die nach dem Ostermarkt die Stadt »auskehr[t]en «. ${ }^{25}$ Rund hundert Jahre später - die Bauamtsrechnungen sind erst wieder ab den I 740er Jahren überliefert - finden sich vergleichbare Einträge: Anlässlich des Oster- und Bartholomäimarktes bezahlte die Stadt I 750 »denen armen Leuthen wegen Sauberung des Blazes « insgesamt bescheidene $4 \mathrm{fl},{ }^{26}$ deutlich teurer, damit umfangreicher, waren die zahlreichen Fuhrdienste mit Kehricht und Schotter. ${ }^{27}$ Es dominierten also eher anlassbezogene Ad-hoc-Regelungen, die auf eine Herstellung von Sauberkeit in visueller Hinsicht abzielten: Vor einem kurzen Linz-Aufenthalt des Kaisers im Jahr I 732 ordnete die Landesregierung Straßenreparaturen und reinigungen an. ${ }^{28}$

Deutlich häufiger taucht das Thema der Sauberkeit in den Quellen aus dem letzten Drittel des I 8. Jahrhunderts auf: Zwar ging es einerseits immer noch um die Herstellung einer visuellen Ordnung, die auch die Umgestaltung städtischer Räume mit einschloss (vgl. Kap. 7. Geordnete und modifizierte Umwelt), andererseits verstärkten sich die hygienischen Implikationen abseits von Krisen, also im Alltag. Signifikant sind für diese Zeit das Ineinandergreifen von - wie es Lefebvre bezeichnete - "nahen« (d.h. privaten, lokal-inviduellen) und »fernen« (d.h. staatlichen oder überregional-diskursiven) Idealen von Sauberkeit (vgl. dazu Kap. I). Aus der »Ferne« kam der Diskurs über innerstädtische oder stadtnahe Friedhöfe: Bereits um die Mitte des r 8. Jahrhunderts wurde die Frage der "Vorsicht « beim Begraben der städtischen Toten intensiver diskutiert - deutlich stand hier erneut das Misstrauen gegenüber schlechten und krankmachenden Gerüchen im Vordergrund. ${ }^{29}$ In Linz war im I6. Jahrhundert ein Friedhof an der Landstraße südlich der inneren Stadt angelegt worden, der sich somit damals an der Peripherie befunden hatte, aber bis ins späte I 8 . Jahrhundert von der vorstädtischen Bebauung erreicht wurde. ${ }^{30}$ Der Linzer Friedhof liege »so nahe an der Stadt, und mitten unter den Häusern«, monierte eine I783 erschienene Satire - »Das kann ohnmöglich den [sic] Luft rein und gesund lassen. ${ }^{31} \mathrm{Im}$ Sommer I 784 ordnete, was augenscheinlich mit medizinisch-hygienischen Überlegungen zusammenhing, ein kaiserliches Mandat die Verlegung von Friedhöfen und Grüften in unbewohntes Gebiet an. ${ }^{32}$ In Linz wurde eine weit außerhalb der Vorstädte liegende, landwirtschaftlich genutzte Fläche angekauft, die man ab Herbst I786 als »allgemeinen« städtischen

\footnotetext{
25 Mayrhofer/Katzinger, Geschichte, Bd. I, 337.

26 AStL, HS 389 (Bauraittung I750), pag. I08.

27 Ebd., pag. I05.

28 LR BIIG 5, Reg. 2536 (27); LR BVII 4 u. 5, Reg. 3623 (I I 75).

29 LR EIf, Reg. 373 (I 45f.); Macher, Handbuch, Bd. I, I I I - I 29 u. I 42 - I 44; vgl. Lesky, Gesundheitswesen, I88-i 9 I u. Clark, Cities, 2 I3.

30 Mayrhofer, Linz, unpag.; Pillwein, Beschreibung, I 5 of.

3I Gimpel Insel, 3 If.

32 Luca, Landeskunde, Bd. 2, 427; vgl. Reichert, Pest, 343.
} 
Friedhof verwendete. ${ }^{33}$ Das aufgelassene Friedhofsareal wurde parzelliert und zur Bebauung versteigert, wobei man offenbar eine zehnjährige - hygienisierende - Wartefrist verlangte. ${ }^{34}$ In einer Stadtbeschreibung aus den I 8 Ioer Jahren wurden bereits die neuen »Reihen von artigen Häusern« gepriesen, wo »sonst Modergeruch den Wanderer umdunstete ${ }^{35}$

Der Geruch blieb ein Indikator für Gesundes resp. Ungesundes und zunehmend wurde die »reine« Luft zum Ideal. Dafür gibt es ab den I 78 oer Jahren Belege, auch die "Promenade« der Stände zielte auf Bewegung in frischer, »freier« Luft ab (vgl. unten). ${ }^{36}$ An vielen Orten waren schlechte Gerüche jedoch omnipräsent: In den Vorstädten gab es eine erhebliche Anzahl von Mistsammelplätzen (»Mistgruben«) und Gartenflächen, die regelmäßig mit tierischen Exkrementen bestreut (»Mistbeete«), ${ }^{37}$ aber noch nicht generell zu einem Problem erklärt wurden. I79 I musste ein Seilermeister auf der unteren Promenade seine "Mistgrube«, da sie auf landständischen Grund reichte, zwar verlegen, aber nicht gänzlich entfernen. Die visuelle Beeinträchtigung sollte mit einem Lattenzaun beseitigt werden, sodass die Mistgrube "nicht weiter « auffalle. ${ }^{38}$ Deutlich standen diese Maßnahmen im Kontext von »Verschönerungsabsichten «, wie es I 80 I bezeichnet wurde. ${ }^{39}$ Den Ständen ging es um die Herstellung eines repräsentativen Ortes beim Theater und der neu gestalteten Promenade (vgl. unten), was über Pflasterungen, die Verlegung von - die Ordnung störenden - Handwerker- und Verkaufshütten, aber auch über die Absenz resp. die Nichtsichtbarkeit von Unsauberkeit erzielt werden sollte. ${ }^{40}$ Verstärkt wurden sichtbare "Unreinheiten« und schmutzverursachende Praktiken zum Thema, ${ }^{41}$ die städtischen Aktivitäten zur Herstellung von Sauberkeit im öffentlichen Raum intensivierten sich jedoch nicht. Die Ausgaben für das Wegführen von Schutt und »Kott« blieben überschaubar, auch das geringe "Gehalt« für einen »Stadt-Butzer» deutet auf existente, aber begrenzte Ambitionen in diese Richtung, einen regelmäßigen Reinigungsdienst gab es nicht. ${ }^{42}$ Als im Jahr

33 AStL, Altakten, Sch. I 46; LZ, i r.8.r786; LR E7a u. b, Reg. Ior 9 (253); LR Eıf, Reg. 453 (i 86f.).

34 Zumindest ordnete man dies für den Urfahrer Friedhof I 788 an (vgl. LR E7a u. b, Reg. I046 [264]); die Errichtungszeitpunkte der dortigen Häuser würde für eine derartige Regelung sprechen (vgl. Kreczi, Häuserchronik, 266-270); vgl. auch die Grundbucheintragungen (Bohdanowicz, Vorstädte, Bd. 2, 863 u. 873) und die Verkaufsverträge (AStL, Altakten, Sch. I 46).

35 Heinse, Linz, I. Aufl., I I.

36 Vgl. Füssel, Tagbuch, 230 u. LR BVI2, Reg. I 495 (286f.).

37 Vgl. LR BIIA 24, Reg. I 7276 (I $29 f$.$) ; LR Erb, Reg. I 843$ (Io6f.); ebd., Reg. I 898 (i I 8); LR Erf, Reg. 375 (I 47-I 49); OÖLA; Landschaftsakten, Sch. 448, D.XV.3/No. 99.

38 LR BIIA4 I, Reg. I 9909 (82f.).

39 AStL, Altakten, Sch. 79; LR BIIA4I, Reg. 20049 (222-226).

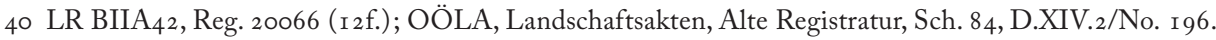

4I AStL, Altakten, Sch. 79; OÖLA, Landschaftsakten, Alte Registratur, Sch. 9I, D.XV.2/No. 64; LR

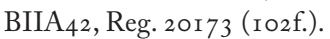

42 Vgl. AStL, HS 4 I 9 (Baurechnung I780), pag. Io8; AStL, HS 434 (Baurechnung I795/r 796), pag. 97; AStL, HS 436 (Bauamtsrechnung I8 16), pag. 65; AStL, HS ro87 (Stadtratsprotokoll r 800), fol. 239 b. 
I 800 eine Fischhändlerin beim Stadtrat um "Anweisung eines Orts zur Miststätte« ansuchte, fühlte man sich dort nicht zuständig. ${ }^{43}$ Immer noch war die Sauberkeit der Straßen eine private Zuständigkeit der Haushalte, die sogar in eine Verlassenschaftabhandlung Eingang fand: So bezahlte in den I 7 8oer Jahren eine Frau in der Altstadt für ihre Wohnung, »da ihr die Straßensäuberung obliegt«, eine geringere Miete. ${ }^{44} \mathrm{Zudem}$ setzten sich anlassbezogene Reinigungen fort: Vor dem Papstbesuch I782 ordnete die Landeshauptmannschaft die Abdeckung von Rinnsalen und Straßensäuberungen $\mathrm{an}^{45}$ und noch im beginnenden I9. Jahrhundert finden sich Reinigungsarbeiten nach Abhaltung der Märkte. ${ }^{46}$

Stärker verfolgt wurde die Lösung, Sauberkeit und Ordnung über Pflasterungen herzustellen. In der zweiten Hälfte des r 8. Jahrhunderts kam es in diesem Bereich zu einer staatlich-städtischen Kooperation: Zum Ende der I 76 oer Jahre übernahmen die Landstände Beschotterung, Ausbesserung, sporadische Reinigung und eine teilweise Pflasterung für zwei Einfallsstraßen (die Herrengasse und die Landstraße) innerhalb des Linzer Burgfrieds gegen die jährliche Zahlung von 300 fl durch die Stadt. Für die Stände war dies ein erhebliches Verlustgeschäft, das vermutlich im Verlauf der I 77oer Jahre wieder eingestellt wurde. ${ }^{47} \mathrm{Zu}$ dieser Zeit gab es aber bereits eine spezifische Erwartungshaltung, was eine »moderne « Stadt - und besonders das Entree zu dieser ausmachte. Von den Stadt- und Reisebeschreibungen wurden die städtischen Pflasterungen resp. deren Absenz ab den I 78 oer Jahren immer aufmerksamer verfolgt. ${ }^{48}$ Wenngleich die Stadt zunehmend in die Pflasterung der Stadt investierte - I 8 I 6 wurden dafür über $2.600 \mathrm{fl}$ ausgegeben ${ }^{49}$-, blieb die Verantwortung, »bis zur Mitte der Gasse« die Pflasterung zu übernehmen und zu erhalten, bei den Haushalten, was - wie im I 8. Jahrhundert - offenbar nur mäßig funktioniert hatte. ${ }^{50}$

\section{Intermediäre Sauberkeit}

Nach den Krisen des beginnenden I 9. Jahrhunderts verstärkte sich das städtische Engagement im Bereich der Sauberkeit spürbar, was möglicherweise auf die günstige wirtschaftliche Situation zurückzuführen ist, die in den frühen I82oer Jahren einsetzte und bis zur Mitte der I8 4 oer Jahren andauerte (vgl. Kap. I). Bereits I 8 I 8 hatte

43 AStL, HS ro87 (Stadtratsprotokoll I 800), fol. 260 .

$44 \mathrm{LR} \mathrm{BIIB}_{4}$, Reg. I8 89 (i I ff.).

45 LR BIIG7, Reg. 4335 (I65f.); vgl. auch OÖLA, Landschaftsakten, Sch. 448, D.XV.3/No. I I 2.

46 LR BIIA42, Reg. 20155 (87f.).

47 OÖLA, Weinberger Archivalien, Sch. 6o, No. 4; vgl. zum staatlichen Projekt der »Chaussee« vgl. EdN, s.v. Chaussee.

48 Füssel, Tagbuch, 22 I u. Hoff, Skizze, I 4; vgl. Gimpel Insel, I69.

49 AStL, HS 436 (Bauamtsrechnung I 8 I6), pag. I53 u. I 46.

50 LR BIIA42, Reg. 20066 (г 2f.); ebd., Reg. 20156 (88f.). 


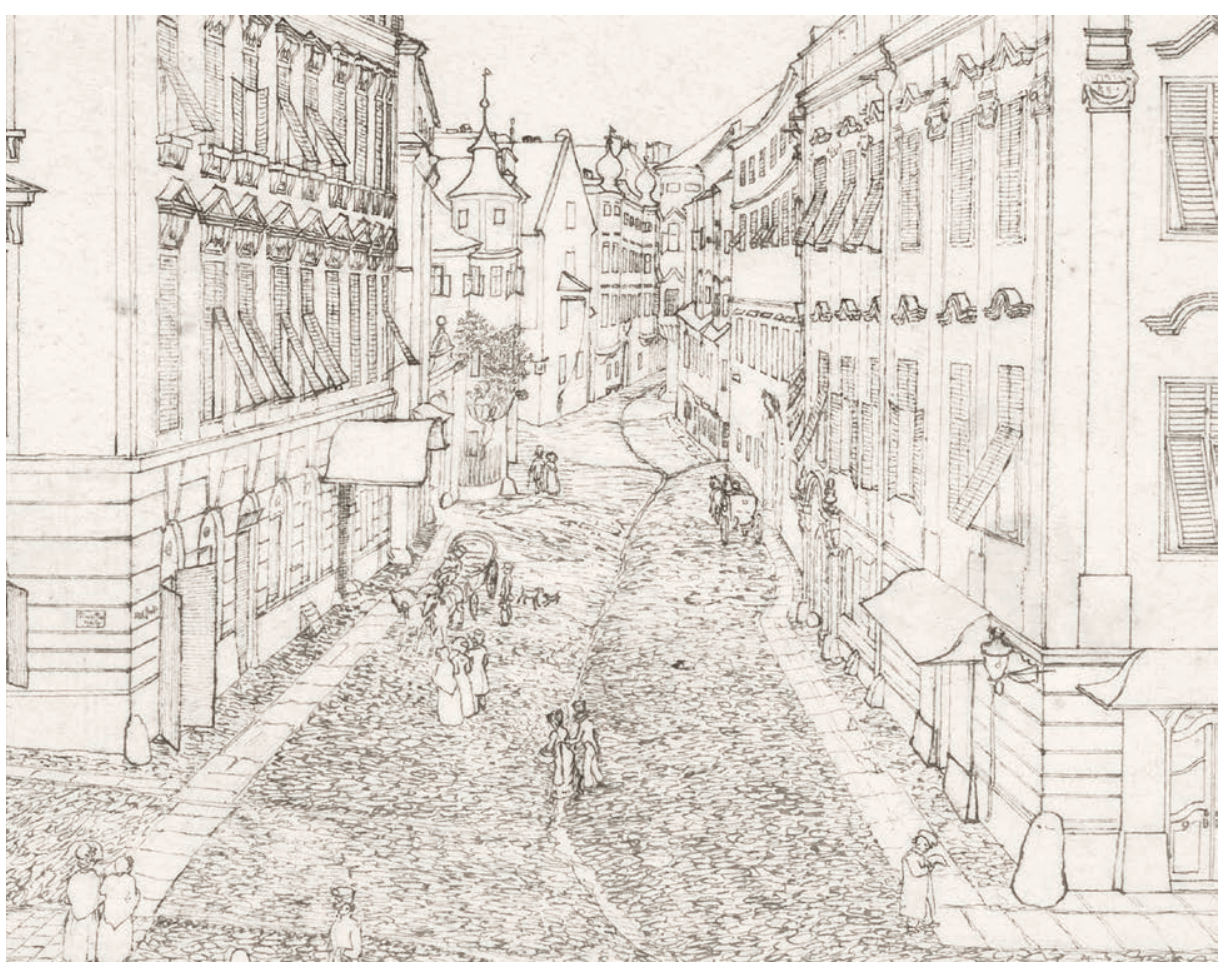

Abb. 24: Ordnung des öffentlichen Raumes in der Herrengasse, 1824 (Ausschnitt) - Straßenpflaster mit Gehsteigen und Rinnsalen

die Stadt begonnen, in den wärmeren Monaten das Bespritzen der Schotterwege und Plätze mit Wasser zu finanzieren, wofür eigentlich die Haushalte zuständig waren. ${ }^{51}$ Die Straßenbespritzung, die auf eine Reduktion der Staubentwicklung abzielte, vergab die Stadt an einen Pächter und versuchte gleichzeitig eine Refinanzierung über »freiwillige Beiträge «. ${ }^{52}$ Zwischen Anfang Mai und Ende September wurden morgens und abends die Plätze, wichtige zentrumsnahe Gassen und die Einfallsstraßen bis zum südlichen Vorstadtrand bespritzt. ${ }^{53}$ Das Bespritzen war eine defizitäre Tätigkeit: I 830 lukrierte die Stadt aus den freiwilligen Beiträgen ${ }_{2} 2$ fl I 2 kr, ${ }^{54}$ die Ausgaben für die Verpachtung lagen mit $295 \mathrm{fl}$ aber mehr als doppelt so hoch. ${ }^{55}$ Auch die städtische Straßenreinigung scheint sich in den I 82 oer Jahren intensiviert zu haben, die wie die

5 I Pillwein, Wegweiser, r67; vgl. AStL, HS ro87 (Stadtratsprotokoll i 800), fol. 23 ra.

52 Pillwein, Beschreibung, 3 r 2f.; Fink, Geschichte, 70; Heinse, Linz, 2. Aufl., 20; vgl. AStL, HS I Io I (Stadtratsprotokoll i 820), fol. r68a u. LZ/IB, I 4.6.1 822 .

$53 \mathrm{LZ} / \mathrm{IB}$, I 2.4.I822; ebd., 6.4.1829; LZ/AB, 26.3.I832; ebd., 7.4.I837.

54 AStL, HS I5 I (Oberkammeramt Empfang r 830), pag. 84.

55 AStL, HS ${ }_{52}$ (Oberkammeramt Ausgaben r 830), pag. 270. 
Straßenbespritzung teilweise verpachtet war. ${ }^{56}$ I 824 wurden dem Pächter der Fuhrdienste für die »Reinigung der Burgfriedsgässen und Strassen vom Koth u(nd) Eise» insgesamt $572 \mathrm{fl}(\mathrm{CM})$ bezahlt, ${ }^{57}$ was einer regelmäßigen Tätigkeit entsprochen haben wird. Zudem beschäftigte die Stadt zahlreiche Taglöhner für die Straßenerhaltung und für das »Strassenkoth-Abziehen und Reinigung der Wasserabläufe «, ${ }^{58}$ I 822 dachte der Stadtrat sogar über die Errichtung von »öffentlichen Abtritte[n]« am Holzplatz an der Donaulände nach. ${ }^{59}$

Parallel zur Errichtung von Kanalbauten in den I8 $20 e r$ und I 83oer Jahren (vgl. Kap. 5. Zirkulationen und Output) wurden viele der betroffenen Straßen mit einer Pflasterung versehen, wobei ein Teil der Kosten den Anrainer/innen verrechnet wurde. ${ }^{60}$ Wenig überraschend wurden die zentrumsnahen Straßen und Gassen früher gepflastert, während in peripheren Straßenzügen weiterhin Schotterstraßen bestanden und nur die Gehsteige gepflastert waren. ${ }^{61}$ Zwischen Pflasterung und Sauberkeit bestand in der Praxis natürlich ein Zusammenhang, aber auch in der Wahrnehmung war dieser Konnex tief verwurzelt. ${ }^{62}$ Ein - sonst eher kritischer - Wiener hatte bei seinem Linzaufenthalt I 825 festgestellt, dass »sich die Reinlichkeit und Zierde in der Stadt immer mehr hebt. Keine Provinzialstadt hat wie Linz, so schönes, meistenteils GranitTrottoir aufzuweisen« (vgl. Abb. 24). ${ }^{63}$ Ein Teil der Verschönerungsbestrebungen zielte auf die Beseitigung von Lagerplätzen und Verkaufsläden in zentralen Lagen ab, die als visuelle Beeinträchtigung repräsentativer Stadträume, aber genauso als Ausgangspunkt für Unsauberkeit gesehen wurden. ${ }^{64}$ Die städtischen Ausgaben für Pflasterungen und Stadtreinigung wuchsen stetig an: I 849 gab die Stadt Linz für Pflasterung rund I.700 fl (CM) und für "Säuberung" (was aber auch die Beseitigung von Schnee und Eis inkludierte) über 4. Ioo $\mathrm{fl}$ aus, im Vergleich dazu hatte man für den Bereich der Wasserversorgung nur $489 \mathrm{fl} \mathrm{I}_{2} \mathrm{kr}$ aufgewandt. ${ }^{65}$ Allein für die Fuhrdienste der Straßenreinigung wurden monatlich roo fl (CM) bezahlt, was wohl rund 300 Fuhren pro Monat entsprach. ${ }^{66}$ Dennoch blieben selbst häufig frequentierte Straßen und Plätze bis in die I 8 7oer Jahre nur teilweise gepflastert, oft wurden nur Gehsteige hergestellt. ${ }^{67}$

\footnotetext{
56 LZ/IB, 28.I.1 822.

57 AStL, HS 439 (Unterkammeramtsrechnung I 824), pag. 5 I.

58 Ebd., pag. $5 \mathrm{I}-55$.

59 AStL, HS I I03 (Stadtratsprotokoll i 822), fol. 79a.

60 Aufgrund der summarischen Buchführung ist der Anteil nicht abzuschätzen, er lag aber definitiv weit unter den entstandenen Kosten - AStL, HS 462 (Unterkameramts Contobuch pro I 848), pag. 7.

6r Pillwein, Wegweiser, r67; Pillwein, Beschreibung, 3 ro; vgl. zu Wien: Brunner/Schneider, Umwelt, 275.

62 Heinse, Linz, 2. Aufl., I7.

63 Kyselak, Skizzen, 405 .

64 AStL, Altakten, Sch. I 72 ; vgl. Pillwein, Wegweiser, 6o u. Fink, Geschichte, 72.

65 AStL, HS i 92 (Oberkammeramt Ausgaben i 849), pag. 624.

66 AStL, HS 462 (Unterkameramts Contobuch pro I 848), pag. 64; vgl. ebd., pag. 30 u. 36.

67 LTP, 2.2.1870; vgl. LZ, 2 I.4.I 867.
} 
Mit den Diskussionen um die Assanierung der Städte, die ab den I $840 e r$ Jahren von England ausgingen und wenig später auch den deutschsprachigen Raum erreichten, wurde das Beseitigen von Unsauberkeit und schlechten Gerüchen zu einer prioritären städtischen Agenda ${ }^{68}$ Dies spiegelt sich in der Gemeindeordnung von I 850 wider, die die »Reinlichkeitspolizei«, also die Überwachung der Sauberkeit, explizit als Aufgabe der Stadt sah: Diese »sorgt für Pflasterung und Erhaltung der Strassen, Gassen und Wege «. ${ }^{69}$ Bereits im Herbst I 848 war - im Gefolge der Revolution - eine eigene städtische "Sicherheitswache« durch den Gemeindeausschuss etabliert worden, die auch die Aufrechterhaltung der Sauberkeit im Stadtraum überwachen sollte. In zwei Jahren - zwischen September I 848 und August I 850 - kam es zu insgesamt $75_{2}$ Meldungen und 808 Verhaftungen, darunter waren 99 Meldungen wegen »Vergehen gegen die Straßenreinigungsordnung « und I 8 wegen $»$ schlechten Aufspritzens.$^{70}$ Dieses Überwachen und Sanktionieren ergänzte die städtischen Dienstleistungen und zeigt auch die geringere Toleranz der Mittelschichten und Eliten gegenüber Unsauberkeit und Gestank. ${ }^{71}$

Bestehende Negativwahrnehmungen von Unsauberkeit und schlechten Gerüchen verstärkte die Cholera, die ab den I $830 e r$ Jahren die westeuropäischen Städte erreichte. In Linz war die Cholera in den I 83 oer und I $840 e r$ Jahren noch nicht epidemisch aufgetreten, dies geschah erst zur Mitte der I 85 oer und I 860er Jahre. Bei diesen späteren Ausbrüchen wurde ein immer stärkerer Zusammenhang zwischen Unsauberkeit, schlechten Gerüchen und der Cholera gesehen (vgl. Kap. 5. Zirkulationen und Output). ${ }^{72}$ Dazu kam in dieser Zeit die Überhöhung der sauberen und frischen Luft: Hier gewährt Adalbert Stifter Einblicke in bürgerliche Wahrnehmungen der I85oer und I86oer Jahre. Stifter sah - wohl auch von seinen Ärzten angeregt - saubere, am besten nichtstädtische Luft und deren »Konsum « als gesundheitsfördernd an. ${ }^{73}$ Bereits im Sommer I 855 schwärmte Stifter bei seinem Aufenthalt in Lackenhäuser nahe der oberösterreichischen Grenze von »unaussprechlich herrlicher Waldluft « ${ }^{74}$ auch für seine Kirchschlagbesuche in den r 86oer Jahren bildete die Luft neben dem Wasser (vgl. Kap. 3. Wasser) ein zentrales Motiv. ${ }^{75}$ In den »Winterbriefen «, die I 865/1866 in Kirchschlag entstanden, thematisierte Stifter ebenso ausführlich die Luft, wobei Stifter in seiner Darstellung deutlich vom Diskurs über die Heilwirkung der Luft in den Schweizer Alpen beeinflusst war. ${ }^{76}$ Tagtäglich atme man - in den Städten - »viele tausend Quentchen stinkender [...] oder

68 Lees/Hollen Lees, Cities, 6I u. I I9-I23; Melosi, America, 222 ; EdN, s.v. Assanierung.

69 Gemeindeordnung I 850, LGB1. 261/1850, 274.

70 Mittmannsgruber, Stadtverwaltung, I3 I - I 33 .

7 I Lees/Hollen Lees, Cities, 60.

72 ÖB, 5.I.I 855 .

73 Vgl. Stifters sämtliche Werke, Bd. 25, 335.

74 Stifter, PRA, Bd. r 8, 266.

75 Stifters sämtliche Werke, Bd. 25, 339.

76 Stifter, PRA, Bd. 21, 56f.; in den Briefen Stifters wird das 1862 erschienene Buch »Die Schweizer 
ungesunder« Luft ein, was das Blut »vergiftet« und in einem »Heer der Krankheiten«, vor allem Tuberkulose, resultiere. ${ }^{77}$ Ungesund seien auch gasförmige »Stoffe«, die »unbrauchbar ausgeworfen wurden, als z.B. ausgeathmete Luft, Luft aus Unrath, Luft aus Schweiß, Luft aus Schleim, oder Lüfte aus chemischen Anstalten«. Die schlechte Luft »klebt« auch an und in den Städten, den Gestank aus "manchem Gäßchen« bekomme man nicht weg; er selbst habe "nach langem Siechthume« die Gesundheit erst wieder in der Höhe "gefunden ${ }^{78}{ }^{78}$ Trotz dieser euphorischen Prosa finden sich bei Stifter im Alltagsleben divergierende und situative Einschätzungen der »Bergluft«: Ende November I 866 kam Stifter die Kirchschlager Luft nicht mehr »so erquickend angenehm» vor, sie war ihm »eher zuwider «. ${ }^{79}$ Im Juni des Folgejahres vermeldete Stifter aus Kirchschlag wiederum eine "großartige heilige Ruhe« und »köstliche Luft «. ${ }^{80}$ Beim Ausbruch der Cholera in Linz I 866 betrachtete Stifter, wie vermutlich zahlreiche andere Stadtbewohner/innen, die städtische Luft überaus skeptisch. Aus seiner Sommerfrische in Lackenhäuser riet Stifter seiner in Linz zurückgebliebenen Frau zu »täglich[er] Bewegung in freier Luft, am besten außerhalb der Stadt $«{ }^{81}$ Es sei gut, so Stifter in einem Brief vom August I 866, dass sie »mehr in freier Luft « sei, »wenn sie auch nur schlechte Luft ist «. ${ }^{82}$ In der "Linzer Zeitung« vom Sommer und Herbst I 866 wurde ebenso wiederholt ein kausaler Zusammenhang zwischen schlechter Luft, etwa aus der Kanalisation (»Cloakenmiasmen «), und der Cholera hergestellt. ${ }^{83}$

Auch die Frage des Visuellen lieferte in den I 86oer Jahren Impulse zur Linzer Sauberkeitsdiskussion. Wesentlich artikulierte sich dies über den Linzer Verschönerungsverein, der im Frühjahr I 865 etabliert wurde (vgl. Kap. 8. Natur der Städter - Natur für Städter). Die Gründung des Vereins war direkt mit der Erfahrung einer alltäglichen städtischen Unsauberkeit verbunden: Man habe die Gartenbauausstellung der Landwirtschaftsgesellschaft, die I 864 beim und im Volksgarten stattgefunden hatte, nur kaum besuchen können, da das Regenwetter den Zugang »insbesondere für Damen, höchst unangenehm, d.h. schmutzig" gemacht habe. Man monierte das Fehlen eines gepflasterten Gehsteiges und damit auch die Absenz von Urbanität an einem relativ peripheren Raum. ${ }^{84}$ Die Etablierung des Verschönerungsvereins stieß offenbar einen

Alpenluft in ihren Wirkungen auf Gesunde und Kranke mit Berücksichtigung der Mineralquellen und Kurorte« I 865 zum ersten Mal erwähnt (Stifter, HKG 8/3, 360f.).

77 Stifter, HKG, Bd. 8/3, 21 5 ; hier ist ein direkter Bezug zu der Alltagswelt Stifters festzustellen, denn der mit Stifter befreundete Linzer Buchhändler Quirin Haslinger hielt sich aufgrund seiner Tuberkuloseerkrankung häufig in Kirchschlag auf (vgl. ebd., 367 f.).

78 Ebd., Bd. 8/3, 215-218.

79 Stifter, PRA, Bd. 22, 78 ; vgl. ebd., 8r.

80 Ebd., I04 u. I36f.

8I Ebd., Bd. 21, 227.

82 Ebd., 285.

83 LTP, 6. Iо. I 866.

84 LTP, I 4.4.I 865. 
breiteren Diskussionsprozess an, in dem man städtische Unsauberkeiten thematisierte und zu derer Beseitigung aufrief. Im Mai I 865 forderte ein Leserbriefschreiber, dass sich der Verschönerungsverein nicht nur der Umgebung der Stadt zuwenden, sondern sich um Linz selbst - explizit genannt wurden die staubigen Straßen - kümmern solle. ${ }^{85}$ Die »permanenten Misthaufen an dem Ablagerungsplatze hart ober der Donaubrücke«, so in einem anderen im folgenden Monat erschienenen Leserbrief, würden die Bemühungen des Verschönerungsvereins konterkarieren: Sie "gewähren kein freundliches Bild; warum werden die dort beschäftigten Arbeiter nicht angewiesen, den zusammengeführten Kehricht gleich in den Strom zu schaufeln? ${ }^{86}$ Wenige Tage später verwies ein Mitglied des Verschönerungsvereins auf den Umstand, dass man nun als »besonders schmutzig und verwahrlost bekannte Häuser« am Schullerberg renoviere, was den »besten Eindruck auf alle Vorübergehenden« machen werde. ${ }^{87}$ In der Folge beklagte man die "Kloacke« im Donauarm (vgl. Kap. 6. Fluviale und aquatische Räume) ${ }^{88}$ das nichtrepräsentative Aussehen der hölzernen »Fischhütten-Baracke» in der Stadt und anderer Baulichkeiten, das Nichtfunktionieren des "Springwasserwerk[s]« am unteren Hauptplatzbrunnen und den »massenhaft[en] [...] Unrath aller Art und Straßenkehricht« bei der Kollegienkaserne. ${ }^{89}$ Völlig ohne Auswirkungen waren diese Diskussionen offenbar nicht: Als r 866 in einem Leserbrief Unsauberkeiten in einer Urfahrer Gasse beklagt wurden, verwies der Schreiber gleichzeitig darauf, dass »vor Kurzem in der Nähe [...] eine Warnungstafel angebracht ward, auf welcher zu lesen steht, daß die Verunreinigung dieses Ortes bei Strafe verboten sei«. ${ }^{90}$ Zudem brachte der Verschönerungsverein regelmäßig Eingaben im Gemeinderat ein, dem ohnehin Vereinsmitglieder angehörten. ${ }^{91}$ Für die letzten drei Jahrzehnte des I 9. Jahrhunderts zeichnen sich im Hinblick auf die städtische Sauberkeit aber keine tiefen Brüche ab, wenngleich die städtischen Aktivitäten in diesem Bereich weiterhin zunahmen: Zum Ende der I $870 e r$ Jahre beschäftigte die Stadt im Sommer 80 und im Winter I 20 Taglöhner, ${ }^{92}$ I 879 wurden durch die Stadt insgesamt über 42.000 fl (ÖW) für »Erhaltung, Reparatur und Säuberung « der Straßen und Plätze ausgegeben. ${ }^{93}$ Nur rund 2.10o fl finanzierten die Anrainer über »Trottoirbeiträge«, der Rest kam aus allgemeinen Steuern und Abgaben. ${ }^{94}$ Die Dualität von privater und städtischer Zuständigkeit bestand über

85 LTP, 23.5.I 865.

86 LTP, 22.6.I 865 .

87 LTP, 25.6.1 865 .

88 LTP, 28.6.1 865.

89 LTP, 3I.Io.I865.

90 LTP, гі.8. 866.

91 Vgl. LTP, 20.6.1 866 u. LAB, 2 г.6.г 867.

$92 \mathrm{RB}$ I $876-1878,82$.

93 RB I 879- I 880, 102.

94 Ebd., I 2 . 
das I9. Jahrhundert hinaus, ${ }^{95}$ auch blieben Reinigungsdienste (Straßenbespritzen, Schneeräumung und Kehrichtabfuhr) an Dienstleister verpachtet, erst I 908 übernahm dies die Stadt in Eigenregie. ${ }^{96}$

Die Widersprüchlichkeit des Modernisierungsprozesses im Bereich Sauberkeit zeigt sich auch beim langwierigen Projekt eines neuen städtischen Schlachthauses. Das Schlachthaus an der Donaulände (»Schlaghaus«) wurde bis zum Ende der I 83 oer Jahre verwendet und etwas später als die Fleischbänke abgerissen. Ein Ersatz wurde zwar wiederholt diskutiert, aber nicht umgesetzt, als städtische Agenda sah man nur die Vieh- und Fleischbeschau, und so schlachteten die Fleischhauer in ihren Betrieben. ${ }^{97}$ Erst ab dem Ende der 186 oer Jahre - mit der zunehmenden Diskussion um städtische Hygiene, ${ }^{98}$ dem wiederholten Auftreten von Viehseuchen und strengeren gesetzlichen Regelungen - wurde die Neuerrichtung eines zentralen Schlachthofes intensiver überlegt. Die Zentralisierung des Schlachtens ermöglichte dabei nicht nur die Verlagerung eines Hygieneproblems in einen peripheren Raum der Stadt, sondern auch die Etablierung städtischer Kontrolle über den Zustand des Schlachtviehs und der Fleischproduktion. Zahlreiche Städte errichteten - oder planten - in den I 8 joer und I 88oer Jahren zentrale Schlachthäuser, in Linz verzögerten die Frage der Finanzierung und die laufenden Infrastrukturprojekte eine schnelle Umsetzung. Erst die Millionenanleihen der I $890 e r$ Jahre führten zu einer Realisierung des Projekts: Der Schlachthof wurde I 896- I 898 an den Gleisen des Umschlagplatzes nahe der Donau am östlichen Rand von Linz errichtet, zuvor hatte die Gemeindevertretung Schlachthöfe in Wien, Salzburg und in deutschen und Schweizer Städten besucht. ${ }^{99}$

\section{U-Topie Garten und Park}

In der inneren Stadt gab es im i 8. und r 9. Jahrhundert kaum Grünräume, die Vorstädte waren jedoch von Gärten und Feldern geprägt (vgl. Kap. 4. Energie und Biomasse). ${ }^{100}$ Diese Flächen waren als landwirtschaftlich und/oder privat genutzte Räume in der Regel nicht allgemein zugänglich. ${ }^{101}$ Neben Nutzgärten bestanden zahlreiche Ziergärten,

95 OÖLA, Musealarchiv, HS 5 I (Materialien zur Geschichte der Stadt Linz von Ignaz Fink, undat.), pag. 558-56r; LTP, 6.I.I874; LTP, 30.4.I889; LVB, I 8.2.1877.

96 Mayrhofer/Katzinger, Geschichte, Bd. 2, I 58 ; Lackner/Stadler, Fabriken, 45.

97 AStL, Altakten, Sch. I02; AStL, HS I 109 (Stadtratsprotokoll I 82 8), fol. 7 oa u. 7 ob; Kreczi, Linz, 62 u. 220; Mayrhofer/Katzinger, Geschichte, Bd. 2, I57; vgl. Puffer, Heimatstadt, I63; der Stillstand in dieser Angelegenheit hing vermutlich auch mit dem Widerstand der Fleischhauer zusammen: AStL, HS i I02 (Stadtratsprotokoll I82 I), fol. 44a, 201a u. 202b.

98 Vgl. Lesky, Schule, 589-595.

99 Lackner, Geschäft, 808-8I I u 822-824; Adam, Wiser, 3 I gf.

Ioo Vgl. EdN, s.v. Park; zu Dreseden Butenschön, Geschichte u. zu Wien Brunner/Schneider, Umwelt, 442. Ior LR CIIIHI -3 , Reg. 2 I 9 (I 2 of.); LR BIIA 35 , Reg. I 8892 (I I 6). 
in größeren Anlagen oft kombiniert oder nebeneinander, wie Pläne zeigen (vgl. Abb. I I). Die meisten vorstädtischen Freihäuser hatten derartige Ziergärten, dazu kamen eigene Gartenhäuser der städtischen Elite im suburbanen Raum. ${ }^{102}$ Das Bergschlössl am Froschberg ist das wohl bekannteste Linzer Beispiel für ein »hochbarockes Lustschlößchen« mit Garten an der städtischen Peripherie. Ende der I 7 Ioer Jahre wurde es gemeinsam mit einem Ziergarten für einen landständischen Beamten errichtet, nach dessen Tod fiel es zunächst an die Landstände und wurde später verkauft (vgl. Kap. 8. Natur der Städter - Natur für Städter). ${ }^{103}$ Auch religiöse Institutionen verfügten über umfangreiche Ziergärten, wie z.B. der Deutsche Orden, der sich zu Beginn des I 8. Jahrhunderts in der Unteren Vorstadt östlich der Landstraße angesiedelt hatte. ${ }^{104}$ Bereits während der Bauarbeiten pflanzte man Linden »in die Linien von dem Haus hinab gegen den Brunnen unnd neben dem Haus gegen den Seminaire-Garten hinüber «. ${ }^{105}$ Ausgabenrechnungen und die Korrespondenz zwischen Hausverwalter und Ordensleiter lassen Einblicke in Gartenpraktiken der I $720 e r$ Jahre zu und weisen insgesamt auf einen typischen Barockgarten hin: Die Linden wurden "ganz geleich abgemessen und geschnitten « ${ }^{106}$ und »auf Spallier-« und »Kugel-Art» gestutzt, zudem kaufte man mehrere Singvöge ${ }^{107}$ und Honig, um »die Omeissen dardurch von dem Auflauffen an die Bäumer abhalten zu khönnen «. ${ }^{108}$ Aus dem Jahr I 729 ist ein ausführliches Verzeichnis der Obst- und Lindenbäume des Gartens erhalten, in dem der damalige Verwalter Auskunft darüber gab, »wie dieselben [... im Wachsthum sich befinden«. ${ }^{109}$ Das Verzeichnis lässt das Nebeneinander von Zier- und Nutzgarten erkennen: Neben den über 200 Obstbäumen sind I30 Linden und insgesamt über 3.400 Spalierpflanzen angeführt. ${ }^{110}$

Ein Vertrag über die Vermietung des Gartens beim Freihaus Lambach aus dem Jahr I 765 dokumentiert dessen Gestaltung - "Buchs bei den Einfassungen der Beete«, dazu mit Schotter und Sand bestreute Wege - und Nutzung: Das Stift behielt sich sporadische Spaziergänge und »honettes divertiment[s] « vor. ${ }^{111}$ Auch der Garten der Patrizierfamilie Thürheim am Oberen Graben diente der Freizeitgestaltung und der Repräsentation. Der Garten war deutlich vom barocken Gartenideal geprägt, verfügte über gerade Wege und wurde teilweise auch mit Tieren (Fasanen und Nachtigallen)

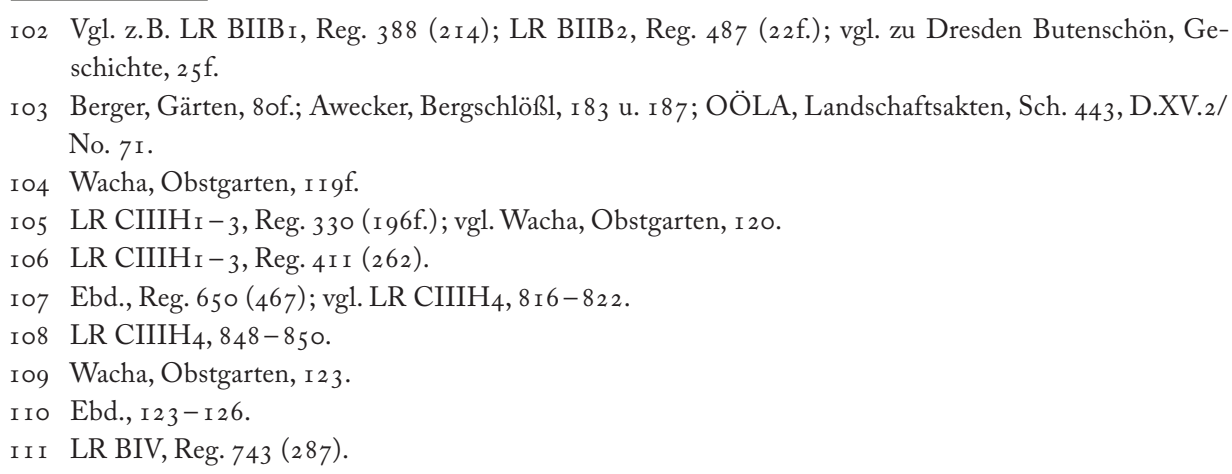


belebt. ${ }^{112}$ Die Thürheim'schen Ausgabenrechnungen des frühen I 8. Jahrhunderts deuten auf eine intensive Beschäftigung mit dem Garten hin: Es finden sich Buchbinderrechnungen für Bücher wie »Der verständige Gartenmeister«, »Die Garten Lust«, »Der kuriose Pfropf- und Oculier-Meister«, »Der wohlerfahrene Zwergbaummeister« oder »Die Garten Parterres«, ${ }^{113}$ auch Ankäufe von Titeln wie »Granat-Apfel« und »Anweisung zur Baumzucht «. ${ }^{114}$ Die Landstände unterhielten ebenso eigene Ziergärten: Bei der ständischen Reitschule (dem späteren Theater) in der Oberen Vorstadt gab es zwei »Lusthäuseln« und einen Garten, den der Syndikus nutzte und der später als »Casin[o]-Gartl« bzw. »Theatergarten« bezeichnet wurde. ${ }^{115}$ Dazu kamen die Ziergärten im Zwinger und Graben beim Landhaus und beim (ehemaligen) Minoritenkloster. ${ }^{116}$ Derartige Gärten kann man als städtische Naturnachahmung sehen, die sich als »nicht-Ort« (»U-Topie«), »als Abbild und Begriff [von], als Sehnsucht und Hoffnung» nach Natur gegen die naturferne Stadt richtete. ${ }^{117}$

Aber nicht nur städtische Institutionen und Eliten nutzten und schufen Gärten zur Freizeitgestaltung: Bereits vor dem I 9. Jahrhundert verfügten viele Gasthäuser über Gastgärten, in denen man - wie ein Linz-Besucher der I 78 oer Jahre vermerkte - »eine Menge Volks sich ergötzen « sehen konnte. ${ }^{118}$ Er selbst besuchte ein Gasthaus, »das einen schönen Garten mit einem Gartenhauß und schattichten Lauben« und »Aussicht» auf die Donau besaß. ${ }^{119}$ Zahlreicher wurden die vorstädtischen Gastgärten während des ersten Drittels des I 9. Jahrhunderts - zumindest stammen aus dieser Zeit die meisten Hinweise. ${ }^{120}$ Dazu kamen Gärten, die gegen Bezahlung eines Eintrittsgeldes besucht werden konnten, etwa der ehemalige Jesuitengarten (»Mayreder-Garten«) östlich der Landstraße oder das "Hagerstöckl« beim Kapuzinerkloster. ${ }^{121}$ Zum Ende der I 83 oer Jahre gab der Topograph Benedikt Pillwein einen Überblick zu sehenswerten Gärten in Linz: Neben den Klostergärten fand Pillwein den Garten des ehemaligen Freihauses Starhemberg in der Herrenstraße erwähnenswert, zudem die Gärten »beim Bergschlößchen, beim Alumnate, beim Niklashause (wegen der Hopfenanlage seit I833), beim Schlaferwirthe, beim ökon.[omischen] Magistratsrathe Huemer an der Kaplanhofstraße [...], beim sogenannten Hagerstöckl, [beim Gasthaus] zum römischen Kaiser,

\footnotetext{
I 2 LR BIIG8, Reg. 479I (50); ebd., Reg. 5527 (I62); ebd., Reg. 5392 (I 43).

I I 3 LR BIIG8, Reg. 4876 (64).

I 4 LR BIIG8, Reg. 5024 (87).

I 5 Depiny, Aufzeichnungen, I80; LR BIIA24, Reg. I7276 (I29f.); LR BIIA42, Reg. 20069 (I 5); vgl. Bohdanowicz, Vorstädte, Bd. 2, I го.

I 6 LR BIIA4 I, Reg. I 99 I 8 (90); OÖLA, Landschaftsakten, Alte Registratur, Sch. 96, D.XV.3/No. 2 I/4; LR BIIA42, Reg. 20137 (7of.); vgl. Bohdanowicz, Vorstädte, Bd. 2, 90 u. ro8f.

I 7 Lefebvre, Revolution, 3 I, 45, I I 7 U. I40.

I 8 Füssel, Tagbuch, 235 .

I 9 Ebd., 238.

I 20 Vgl. z.B. Heinse, Linz, I. Aufl., 93; LZ, 30.6. I 806; Pillwein, Beschreibung, 84.

I 2 I Gielge, Beschreibung, I35.
} 


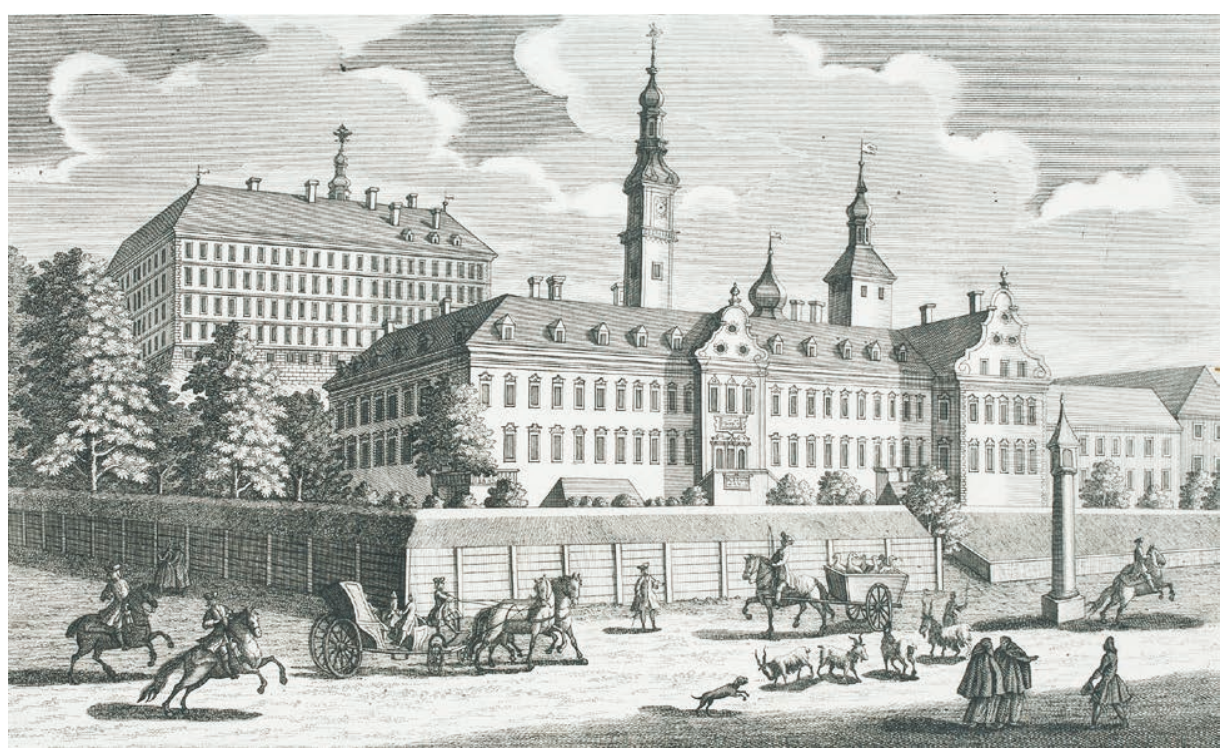

Abb. 25 : Landhaus und Schloss in den 1730er Jahren - hinter dem Wall befanden sich Gartenanlagen von Angehörigen der Stände

beim Handelsvorstande Plank am Schloßberge, beim Strafhause, der Schloßwirths- und Volksgarten, und jener des Erzherzogs Maximilian am Freinberge [...]. Wegen der mannigfaltigsten Tulpenflor wollen der kleine Garten beim Herrenwirthshause und jener des ständischen Buchhalters Pfeiffer gesehen werden. ${ }^{122}$ In dieser Zeit scheint man einen Besuch von Gartenanlagen - analog zu den Kurgärten - zunehmend mit gesundheitlichen Aspekten verbunden zu haben: I83 I kündigte ein Gastwirt in der Unteren Vorstadt die Eröffnung einer »Trink-Kur-Anstalt « an und verwies darauf, dass in seinen Gartenanlagen auch »Körperbewegung « möglich sei. ${ }^{123}$ Zur Mitte der I 86oer Jahre war Adalbert Stifter ebenso davon überzeugt, dass Spaziergänge in Gärten und die manuelle Arbeit darin als gesundheitsfördernd zu erachten seien. Stifter besuchte regelmäßig den Garten des befreundeten Lederfabrikanten Kaindl am Graben, ${ }^{124}$ in einem Brief aus dem Jahr I 864 an seinen Verleger gab Stifter sogar an, sich ein »Stück Garten« gemietet $\mathrm{zu}$ haben und »täglich in demselben« zu arbeiten. ${ }^{125}$ Diese Angabe lässt sich nicht verifizieren, sie widerspiegelt aber zumindest den Wunsch Stifters - den er bereits I 859 in einem Brief geäußert hatte -, »einen geräumigen Garten« zu besitzen. ${ }^{126}$

\footnotetext{
I 22 Pillwein, Wegweiser, 72.

I $23 \mathrm{LZ} / \mathrm{IB}, 25 \cdot 4$. I 83 I.

I 24 Stifters sämtliche Werke, Bd. 25, 335f.; vgl. Bohdanowicz, Vorstädte, Bd. I, 67 If.

I 25 Stifter, PRA, Bd. 20, 2 I 7.

I 26 Ebd., Bd. I9, 2 Io.
} 
Öffentlich zugängliche Grünanlagen entstanden in Linz erst ab den I 77oer Jahren. In dieser Zeit setzte in vielen Städten die Umwandlung zu einer, wie es Peter Clark bezeichnet hat, »open Enlightment city« ein, die nun ohne Befestigung war, aber zunehmend über Parkanlagen, Boulevards und neue semiöffentliche Gebäude (wie Theater) verfügte. ${ }^{127}$ In Wien waren in den I 76oer und I 77oer Jahren der Prater, der Augarten und weitere kaiserliche Gärten für die Öffentlichkeit zugänglich gemacht worden, zudem wurde das Festungsvorfeld (das Glacis) mit Wegen und Alleen neu gestaltet. ${ }^{128}$ Diese Transformationen trugen dem Bedeutungsgewinn neuer Freizeitaktivitäten wie dem Spazierengehen Rechnung. ${ }^{129}$ Auch in Linz wurde im Frühjahr 1772 auf einem Teil des Befestigungswalls vor der Stadtmauer eine "Promenade« angelegt. ${ }^{130}$ Diese Initiative der Landstände lässt sich mit zeitgenössischen Vorbildern (den bereits genannten und anderen) erklären; dass man für diese Umgestaltung gerade diesen Ort gewählt hatte, überrascht nicht: Einerseits befanden sich dort mit dem Landhaus und dem Redoutensaal (dem späteren Theater) landständische Prestigeobjekte, ${ }^{131}$ andererseits knüpfte der neue Grünraum an bestehende Gärten in dieser Gegend an (vgl. Abb. 25). ${ }^{132} \mathrm{Da}$ es sich beim Wall um städtischen Besitz handelte, wurde der Bereich des Oberen Grabens an die Stände verkauft bzw. übergeben, die sich im Gegenzug zur Erhaltung der Neugestaltung und der sich dort befindlichen Stadtmauern verpflichteten. ${ }^{133}$ Es erfolgte - wie in anderen Städten zu dieser Zeit - eine typische Gestaltung als Allee: Man legte eine »angenehme erhöhte Maulbeerallee « ${ }^{134}$ und Spaliere $\mathrm{an}^{135}$ und errichtete offenbar auch eine Unterstandshütte und Bänke (vgl. Abb. 26). ${ }^{136}$ Ein Landesrat "gräbt Spazierwege, und pflanzt Maulbeerbäume daran; ein anderer setzt Laternen «, verspottete eine I 782 erschienene Satire das Engagement der lokalen Elite. ${ }^{137}$ Die Pflanzung der Maulbeerbäume war utilitaristisch und stand im Kontext von merkantilen Bemühungen um die Etablierung einer inländischen Seidenzucht, die aber in Linz - trotz wiederholter Versuche - keine Bedeutung erlangte. ${ }^{138}$

I27 Clark, Cities, I79; Hajós, Stadtparks, 23 -26.

I 28 Brunner/Schneider, Umwelt, 5 rof.; Hajós, Stadtparks, I 5 f. u. 26 - 3 o.

I 9 Vgl. EdN, s.v. Spaziergang; Clark, Cities, I 88 u. Lenger, Metropolen, I7 I; Butenschön, Geschichte, $68-73$.

I30 LR BIIA 24, Reg. I7I 24 (5); vgl. Kunstdenkmäler, Bd. I, 354-356.

I3 I Kunstdenkmäler, Bd. I, 382-385; Mayrhofer/Katzinger, Geschichte, Bd. I, 372; ebd., Bd. 2, 97; Gielge, Beschreibung, I64.

I32 Vgl. Bohdanowicz, Vorstädte, Bd. 2, 67; AStL, HS 86I ( Chronologische Beschreibung«, I77oer Jahre), fol. 2 2 b u. Berger, Gärten, 92.

I33 OÖLA, Landschaftsakten, Alte Registratur, Sch. 96, D.XV.3/No. ro 1/2.

I34 Hoff, Skizze, 7 .

I35 LR BIIA 7, Reg. 97 I ( (150).

I36 LR BIIG6, Reg. 3563 (2 16).

I 37 Rabiosus, Reise, Bd. I, I 2.

I38 Kneifel, Maulbeerpflanzungen, 306-316; LR BIIA4I, Reg. 19928 (96f.); Fink, Geschichte, roo; Pillwein, Linz, Bd. 2, 30. 


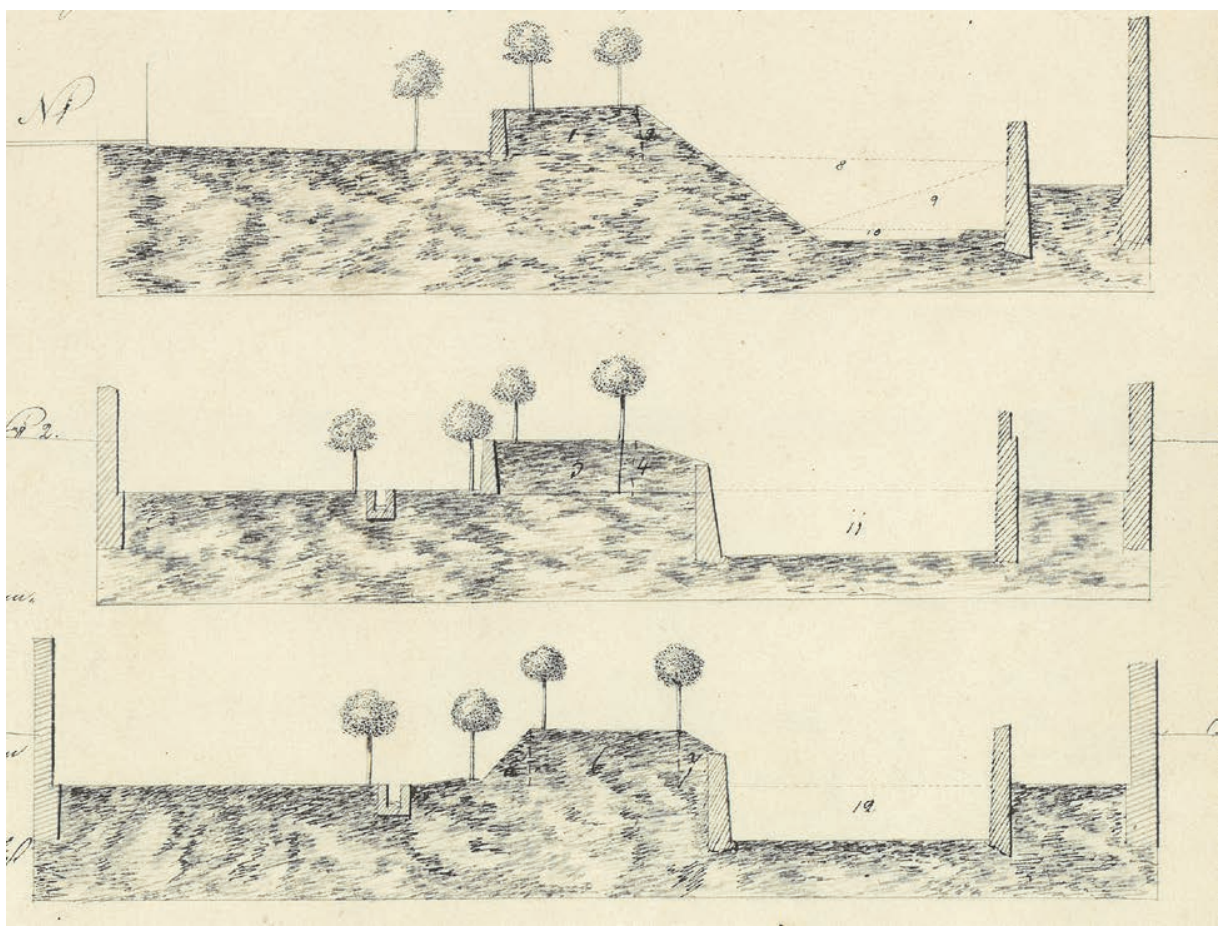

Abb. 26: Die "Promenade« am Stadtgraben als repräsentativer Grünraum, 1800 (Ausschnitt) - die Aufnahme der Querschnitte erfolgte anlässlich einer Kanalplanung

Man habe, so die ständische Selbstsicht, den Wall »zur öffentlichen Zierde und zur Promenade $[\ldots]$ aus Liebe und Achtung für das ganze Publikum hergestellt und verbessert«. ${ }^{139}$ Dass es aber eher um die Schaffung eines bürgerlichen und repräsentativen Freizeitraumes ging, zeigt der Versuch, den »unangenehme[n] Prospect gegen den Schullerberg und daselbst befindlichen zerissenen Planken und Pazenhäuße[r] « mit einer Bretterwand verschwinden zu lassen. ${ }^{140}$ In der Folge wurde die Promenade zu einer städtischen Sehenswürdigkeit: 1779 besuchte der durchreisende Kaiser nicht nur Institutionen wie die Wollzeugfabrik und die Kasernen, sondern auch die »neu angelegten Wege« am Graben und am Schlossberg, ${ }^{141}$ die Promenade wurde anlässlich von Festen illuminiert und taucht ebenso in der Publizistik des ausgehenden I8. Jahrhunderts regelmäßig auf. ${ }^{142}$

Über die alltägliche Nutzung der Promenade weiß man abgesehen von kurzen und kaum variierenden Beschreibungen der Reisepublizistik nur wenig, wenngleich ein-

I39 LR BIIA4 I, Reg. I99 2 (84f.).

I40 LR BIIG6, Reg. 3563 (2 I6).

I4I LZ, 8.I I.I779.

I42 Vgl. z.B. LR E7a u. b, Reg. 494 (I 23) u. ebd., Reg. 578 (I 42). 
zelne Berichte aus den I 79oer Jahren Einblicke gewähren und darauf hinweisen, dass auch nichtbürgerliche Schichten diesen Grünraum frequentierten: I790 lamentierte der zuständige Gärtner über wiederholte Zerstörungen an den Maulbeerbäumen und den Spalieren und »nächtliche Blätz Verunreinigung«. Probleme entstanden besonders zur Zeit der Maulbeerenreife, da dann Jugendliche die Bäume bestiegen, auch das Ernten der Maulbeerblätter schade der Entwicklung der Bäume. ${ }^{143}$ Einige Jahre später stellte man fest, dass der »Pöbel« das Buchenspalier beschädigt habe und die »im(m)er sehr zahlreichen « Kinder Löcher im Wall verursachen würden. ${ }^{144}$ Sukzessive wurden die Maulbeerbäume, die man als Hauptursache der Probleme sah, mit der Pflanzung von Buchen und Linden ersetzt; bereits zuvor waren die Maulbeerbäume stark zurückgeschnitten worden (vgl. Abb. 33). ${ }^{145}$

Der Großbrand im August I80o, der das Landhaus und andere Gebäude an der Stadtmauer zerstörte, schuf eine neue Ausgangslage (vgl. Kap. I I. Naturgefahr): Nach nur wenigen Wochen waren sich die Stände einig, am Beginn der Promenade einen neuen Zugang zur inneren Stadt zu schaffen (der - nomen est omen - zur »Theater Gasse« wurde), die Befestigung zu beseitigen und den Stadtgraben mit Material des Walles und der Brandruinen zu verfüllen, was größtenteils durch die Stände finanziert wurde. Dies war nicht nur eine pragmatische Entscheidung, sondern sie zielte auch bewusst auf eine Erweiterung dieses repräsentativen (Grün)Raumes ab, ${ }^{146}$ für den »das ganze Linzerische Publicum und selbst die Nachkommenschaft uns noch dancken wird«, wie die Stände betonten. ${ }^{147}$ Die Ausfüllung des Stadtgrabens und das Abtragen des Walles sei ein »besonderes Anliegen« des naturaffinen ständischen Syndikus Franz Xaver v. Spaun gewesen, erinnerte sich dessen Sohn Joseph v. Spaun. ${ }^{148}$ Als Syndikus hatte Spaun den »Genuss eines hübschen Gartens« bei der Reitschule, in dem, so der Sohn, der Vater für die Kinder oft »Kämpfe und gymnastische Übungen angeordnet und mitgemacht« habe und der im Sommer jeden Sonntag zum Kegeln genutzt worden sei. ${ }^{149}$ Dass die Stände bei der Neugestaltung der Promenade auf »vielen Widerspruch « gestoßen seien, wie Joseph v. Spaun konstatierte, ${ }^{150}$ ist nicht belegt und eher unwahrscheinlich, denn bereits I799 hatte die Stadt Linz den Ständen den Kauf des restlichen Teiles des Stadtgrabens (also des Unteren Grabens) angeboten. ${ }^{151}$ Ohnehin gab es zu dieser Zeit in vielen Städten keine Befesti-

I 43 OÖLA, Landschaftsakten, Alte Registratur, Sch. 85, D.XV/No. 38 ; vgl. LR BIIA4I, Reg. 19935 (IO2).

I 44 OÖLA, Landschaftsakten, Alte Registratur, Sch. 85, D.XV/No. 38 ; ebd., Sch. 92, D.XV.2/No. I 23.

I45 LR BIIA4I, Reg. 19928 (96f.); vgl. ebd., Reg. 19926 (96) u. LR BIIA4I, Reg. I 9995 (I6I).

I46 OÖLA, Landschaftsakten, Alte Registratur, Sch. 98, D.XV.3/No. 79; vgl. Awecker, Brand, 37.

I 47 OÖLA, Landschaftsakten, Alte Registratur, Sch. 96, D.XV.3/No. 2 I/4.

I48 Doku, Spaun, 53.

I49 Ebd., 4I.

I 50 Ebd., 53; vgl. Depiny, Aufzeichnungen, I 87.

I5 I LR BIIA4I, Reg. I 9998 (I63-I67); OÖLA, Landschaftsakten, Alte Registratur, Sch. 96, D.XV.3/ No. Io $1 / 2$. 
gungen mehr, auch die Stadtgräben wurden zunehmend als hygienische Bedrohung gesehen (vgl. oben). ${ }^{152}$

Die Ausweitung des Grünraumes in einen, wie es das ständische Bauamt bezeichnete, »Spaziers- oder Lust «-Garten mit insgesamt rund 8.500 Quadratmetern erfolgte erstaunlich rasch. ${ }^{153}$ Im April I80 I war der Obere Graben bis zum Landhaustor bereits zugeschüttet, der Wall abgetragen und eine ebene Fläche hergestellt, bis zum Jahresende folgte das restliche Grabenstück bis zum Schmiedtor, das nun im Besitz der Stände war. Im Laufe der nächsten Jahre verfüllte auch die Stadt - als Grundeigentümer - den restlichen Graben, wobei die dabei entstandene Fläche parzelliert und zur Bebauung verkauft bzw. zur Erweiterung des Pfarrplatzes verwendet wurde (vgl. Abb. 3). ${ }^{154}$ Bei der Neugestaltung der Promenade überlegte man zunächst eine Bepflanzung mit Kastanien, »weil diese am schnellsten gedeihen, guten Schatten und schönes Grün geben «, ${ }^{155}$ schließlich entschied man sich für Linden und Platanen, die in vier Reihen angeordnet wurden. ${ }^{156}$ Auch diese neue Anlage war noch stark von geraden Linien und formenden Pflanzenschnitten geprägt, sie offenbart, wie es Peter Clark bezeichnet hat, eine »highly controlled [...] vision of nature ${ }^{157}$ Die Promenade wurde zunehmend zu einem zentralen bürgerlichen Freizeitraum, der stark frequentiert war. Man veränderte nicht nur die Bepflanzung und die Gestaltung, ${ }^{158}$ sondern erweiterte auch die Infrastrukturen für die Nutzer/innen dieses Grünraumes: Schon I 807 hatten die Stände 40 Bänke aufstellen lassen, zudem einen Pavillon für Militärmusik und eine "Zuckerbäckerhütte «, ${ }^{159}$ in der auch Getränke erworben werden konnten. Die Hütte wurde zur Mitte der I 8 3oer Jahre durch einen »Kiosk von eleganter Form» ersetzt, in dem es zeitweise sogar »Schaustellungen bildlicher Kunstwerke« gab. ${ }^{160}$

Deutlich beobachteten und bewerteten die Stadtbeschreibungen und Reiseberichte aus den ersten Jahrzehnten des I 9. Jahrhunderts urbane Grünräume, auch lassen diese Stimmen diesbezüglich gestiegene Bedürfnisse erkennen (vgl. Kap. 8. Natur der Städter - Natur für Städter). ${ }^{161}$ Linz verfüge zwar über die Promenade und zahlreiche Gastgärten, aber »englische Gartenanlagen und Parks fürs Publikum kennt man hier nicht«,

I 52 OÖLA, Landschaftsakten, Alte Registratur, Sch. 84, D.XIV.2/r 96; vgl. zu Frankreich: Guillerme, Age, 2 IO-2I3.

I 53 OÖLA, Landschaftsakten, Alte Registratur, Sch. 98, D.XV.3/No. 79.

I 54 OÖLA, Landschaftsakten, Alte Registratur, Sch. 96, D.XV.3/No. 2 I/4; LR BIIA42, Reg. 20 I $_{2} 9$ (65); $\mathrm{RB}$ I 885 , 106.

I 55 OÖLA, Landschaftsakten, Alte Registratur, Sch. 96, D.XV.3/No. 2 I/4.

${ }_{1} 56$ LR BIIA 42, Reg. 20098 (44f.); Stauber, Ephemeriden, ${ }_{3} 4 \mathrm{ff}^{\mathrm{f}}$

I 57 OÖLA, Landschaftsakten, Sch. 582 , E.XV.8./No. 32/r; OÖLA, Landschaftsakten, Alte Registratur, Sch. 92, D.XV.2/No. I23; Clark, Cities, 325.

I 58 Vgl. OÖLA, Karten- und Plänesammlung, VI/3 1 .

I59 LR BIIA42, Reg. 20145 (77).

I60 Fink, Geschichte, I 2 of.

I6 I Mader, Reise, I4; Heinse, Linz, r. Aufl., ro u. I 5 ; Pillwein, Beschreibung, 85 u. 68f.; Kyselak, Skizzen, 406. 
wurde in einem I809 erschienenen Reisebericht angemerkt. ${ }^{162}$ Tatsächlich fehlte, wenn man von der Promenade absieht, in Linz ein dem Wiener Prater, dem Berliner Tiergarten oder dem Pariser Tivoli vergleichbares Areal. ${ }^{163}$ Erst in den I 8 2oer Jahren wurden an der südlichen Peripherie der Stadt zwei Parkanlagen etabliert: Am heutigen Schillerplatz entstand beim Militärerziehungshaus als Privatinitiative eines ranghohen $\mathrm{Mi}$ litärs ein »Vergnügungsgarten«, der aber offenbar nicht lang existierte. ${ }^{164}$ "Man wandelt zwanglos unter Blumendüften in demselben", so die zeitgenössische Beschreibung von Benedikt Pillwein. ${ }^{165}$ I 828 wurde durch den Urfahrer Kaffeehausbesitzer Bartholomä Festorazzi ein »Volksgarten« mit »acht schöne[n] Partien« auf Äckern bei der Landstraße errichtet, der im Folgejahr eröffnet wurde (zur Lage vgl. Abb. 6). Es war ein kommerzielles Projekt: Der Eintritt für die ganze Saison kostete für Erwachsene I Gulden, was ungefähr drei Taglöhnen entsprach und damit nicht gerade günstig war. ${ }^{166}$ Schon am Namen erkennt man die Nähe zum Wiener Pendant, das selbst wiederum auf der seit dem ausgehenden i 8. Jahrhundert laufenden »Volksgarten«-Diskussion basierte und unter Franz I. zwischen I 8 I9 und I 823 anstelle der gesprengten Befestigungen südwestlich der Stadt bei der Hofburg entstand ${ }^{167}$ - im Hinblick auf die Ausgestaltung bildete eher der Wiener Prater mit seinen Attraktionen und gastronomischen Angeboten ein Vorbild. ${ }^{168}$ Nach anfänglichen Erfolgen scheinen sich die Einnahmen, die Festorazzi mit seinem Garten lukrierte, reduziert zu haben: Schon I 830 unterbreitete der Kaffeehausbesitzer den Ständen ein Übernahmeangebot, schließlich gewährte die Landesverwaltung der Witwe des I 835 verstorbenen Festorazzi zwischen den Jahren I 847 und I 852 eine jährliche Subvention in der Höhe von 400 fl. ${ }^{169}$

I 850 hatte die Stadt das Angebot, den Volkgarten zu erwerben, abgelehnt, da dafür »kein Grund vorhanden « sei. ${ }^{170}$ Sieben Jahre später - zwischenzeitlich war das dortige Grundstück sogar als Standort eines neuen »allgemeinen« Krankenhauses vorgesehen gewesen (vgl. Kap. 9. Epidemie) - kaufte die Stadt Linz I 857 jedoch den Volksgarten und eröffnete ihn im folgenden Frühjahr als unentgeltlich zugänglichen Park. ${ }^{171} \mathrm{Da}-$ mit trat erstmals die Stadt als Besitzer und Unterhalter einer Grünanlage auf, was zu dieser Zeit keineswegs unüblich war: In England gab es in den I84oer Jahren einen

\footnotetext{
I62 Mader, Reise, I 5 .

I63 Vgl. EdN, s.v. Park.

I64 Kreczi, Linz, 89.

I65 Pillwein, Beschreibung, I $49 f$.

I66 LZ/IB, 24.4.1 829.

I67 Vgl. zu den Kontexten: Hajós, Stadtparks, 33-46.

I68 Kunstdenkmäler, Bd. 2, 285f.; Leonhartsberger, Freizeiträume, 73; Hajós, Stadtparks, 6rf.; im Frühjahr I 856 konnten dort z.B. eine "Wunder-Dame« und "Vorstellungen in der höheren Magie« besichtigt werden (LZ, 5.5.1856).

I69 Leonhartsberger, Freizeiträume, 73f.; OÖLA, Musealarchiv HS I78 (Geschichte der Stadt Linz von Ignaz Fink, Bd. I, undat.), pag. $775 \mathrm{f}$.

I70 GRP I 850, fol. 2 I 2a.

I7I ÖB, 20.I.I 854; Mayrhofer/Katzinger, Geschichte, Bd. 2, I 44; Fink, Geschichte, 196.
} 
breiten Diskurs zu städtischen Grünanlagen, in den I 85 oer Jahren wurden bei der Umgestaltung von Paris durch Haussmann zahlreiche Alleen angelegt und Parks an der Peripherie eingerichtet und zur gleichen Zeit entstand der Central Park in New York, der für viele nordamerikanische und europäische Städte zum Vorbild wurde. ${ }^{172}$ Diese Parks wurden zunehmend als Gegenentwürfe zu einer »düster gezeichneten Stadt«, als gesundheitsbringende »Lungen der Stadt « verstanden und als ideale Orte für bürgerliche Freizeitgestaltung gesehen, die - mit ihren zahllosen Vorschriften - auch »Bühnen des hygienischen Erziehungsprogrammes« wurden. ${ }^{173}$ Interessanterweise entstand in Linz ein »Stadtpark « rund ein Jahrzehnt früher als in anderen österreichischen Städten, was wohl auf die spezifische Genese dieses Grünraumes zurückzuführen ist: Schließlich übernahm die Stadt Linz einen bestehenden Privatpark, sie etablierte keinen neuen. ${ }^{174}$ Die substantiellen Investitionen und Veränderungen, die die Stadt seit dem Kauf vornahm, deuten darauf hin, dass man den Volksgarten tatsächlich als Linzer »Stadtpark«, also als Teil der städtischen Infrastruktur wahrnahm. ${ }^{175}$ Ab den I 86oer Jahren wurde der Volksgarten zu einem zentralen Ort städtischer Repräsentation, an dem Ausstellungen und die Volksfeste abgehalten wurden; 1877 erfolgte - aus dem ersten "Millionendarlehen« der Stadt finanziert - sogar eine Erweiterung, wodurch der Park auf die heutige Größe von etwas über 3 Hektar anwuchs. ${ }^{176}$

Nach der Promenade - dem Projekt der Stände und später der Landesregierung und dem Volksgarten entstanden erst ab den r 86oer Jahren weitere öffentlich zugängliche Grünräume in der Stadt. Möglicherweise lässt sich dies auf die omnipräsente Nutzung des grünen Um- und Hinterlandes zurückführen (vgl. Kap. 8. Natur der Städter - Natur für Städter). Die Anlage der Grünflächen bei der Donaulände (nahe der Dampfschiffstation) und beim Krankenhaus waren deutlich visuell, im Falle des Krankenhauses auch gesundheitlich (und damit dennoch symbolisch) motiviert. ${ }^{177}$ Ende der I86oer Jahre wurde durch den neu entstandenen »Verein für Naturkunde in Oesterreich ob der Enns« ein Botanischer Garten auf stadteigenem Grund in der Neustadt errichtet. ${ }^{178}$ Die Initiative dazu ging von einem botanisch interessierten Beamten aus, der den Garten einerseits als Unterrichtsobjekt für die nahen Schulen, andererseits - wie die Botanischen Gärten der Frühen Neuzeit - als Teil eines wissenschaftlichen Netzwerkes sah. ${ }^{179}$ Weitere öffentliche Grünanlagen entstanden in den

I72 Melosi, America, 37; Lees/Hollen Lees, Cities, I9I; Schott, Urbanisierung, 268f.; Benton-Short/ Short, Cities, 59-6r.

I73 Lenger, Metropolen, I 7 I.

I74 Vgl. Hajós, Stadtparks, I8f., 47-59 u. 78-80; Brunner/Schneider, Umwelt, 445 f.

I75 AStL, HS 2 I 2 (Kammeramt Ausgaben 1860), pag. ro6f.; AStL, HS 237 (Kammeramt Ausgaben I 870$)$, pag. I $28 \mathrm{f}$.

I76 RB I 876- I 878, 59; RB I 885, I06; Der Oberösterreicher I 884, I 80; Leonhartsberger, Freizeiträume, 74.

I $77 \mathrm{RB}$ I $879-\mathrm{I} 880,26$ u. 84 .

I78 Gelegen im Geviert der heutigen Mozart-, Dinghofer-, Harrach- und Fadingerstraße.

I79 Kerschner, Garten, 37-46; I 777- I788 am Froschberg und I853-I87I am Freinberg hatte es bereits 
I 88oer Jahren: Die Verwandlung der Sandgruben am Bauernberg, die der Brauerei Hatschek gehörten, in eine Parkanalage war ein Projekt des Verschönerungsvereins, ${ }^{180}$ I 884 beschloss der Gemeinderat die Begrünung des »Marktplatzes« der Neustadt (des heutigen Hessenplatzes) und ab dem Jahr I 885 war ein eigener »Stadtgärtner « angestellt, der die in städtischem Besitz stehenden Grünflächen betreute. ${ }^{181}$ Dennoch wurde in einem I 887 erschienenen Zeitungskommentar zur Linzer Luft einen Mangel an öffentlich zugänglichen Grünräumen konstatiert: Im Linzer Stadtgebiet bestünden außer der Promenade und dem Volksgarten nur Privatgärten, Grünräume wie der Frein- oder Bauernberg und die Strasserinsel seien viel zu weit vom Stadtzentrum entfernt. Die Promenade sei deutlich zu klein, denn dort »verschwindet der von den wenigen Bäumen ausgeathmete Sauerstoff ganz gegenüber den Ausdünstungen und Rauchmengen, welche den dicht herum stehenden Häusern und den im Verhältnisse zur Fläche zahlreichen Passanten entstammen«. Die zunehmende Verbauung verschlechtere die Luft und besonders in der Neustadt fehle eine größere Parkanlage, wie sie in Städten wie Wien oder München bestehe oder in Planung sei. ${ }^{182}$ Tatsächlich blieb öffentlich zugängliches, städtisches Grün bis zum Ende des I 9. Jahrhunderts auf die oben genannten Grünräume und die Begrünung des Umschlagplatzes beschränkt, auch der I 888 beschlossene "Generalregulierungsplan« war von einer weitgehenden Absenz von innerstädtischen Grünflächen gekennzeichnet. ${ }^{183}$

\section{Beleuchtung: Urbane Emanzipation von der Natur}

Wie auch die Sauberkeit und die Wasserinfrastruktur blieb die Straßenbeleuchtung lange Zeit eine Agenda, die durch die Hausbesitzer übernommen werden musste. Im Rahmen der Feuerordnungen wurde regelmäßig die private Zuständigkeit für die Außenbeleuchtung festgehalten, die mit Öllampen und Kienspänen erfolgte. ${ }^{184}$ Die Verwendung von Kerzen blieb, da relativ teuer, meist auf den innerhäuslichen Einsatz beschränkt, bei Dienstleistungen, die Kerzenlicht erforderten (z.B. Senkgrubenräumungen), wurden die Kerzen gesondert abgerechnet. ${ }^{185}$

Ab dem Ende des I 7. Jahrhunderts kam es - ausgehend von größeren Städten wie Paris, London, Amsterdam oder Wien - zu einer Expansion der bislang rudimentären Straßenbeleuchtung: Einerseits ging es um Repräsentation, um die »Eroberung der

Botanische Gärten gegeben, die aber nur begrenzt zugänglich waren - vgl. Promitzer/Speta, Naturgeschichte, 60 u. LZ, I5.3.1 856 .

I 80 Berger, Gärten, 88; Leonhartsberger, Freizeiträume, 66; vgl. Linz a./d. Donau, I 38.

I8 I RB I 885 , I08f.

182 LTP, г 2.6.1 887 .

I8 3 Mayrhofer/Katzinger, Geschichte, Bd. 2, I 44 .

I 84 Kutschera, Straßenbeleuchtung, 348.

I 85 Vgl. LR BIIG 3 , Reg. I 505 (3f.) u. LR BVI2, Reg. I 198 (I 22 - I67). 
Nacht«, also um das Urbane, andererseits war die Forderung einer umfangreicheren Beleuchtung auch mit Sicherheitsüberlegungen verbunden; das Licht sollte kriminelles und deviantes Verhalten verhindern und die Brandbekämpfung verbessern. ${ }^{186}$ Als »Vorläufer« einer dauerhaften Beleuchtung in Linz kann man die »Illuminationen« des I 8. Jahrhunderts sehen, die vor allem mit kaiserlichen Besuchen und anderen herrscherbezogenen Feierlichkeiten verbunden waren und die aus Laternen im öffentlichen Raum oder Leuchten auf Fensterbrettern bestanden. ${ }^{187}$ I 724 wurden die Linzer Freihäuser von der Landesregierung wegen einer kaiserlichen Geburt zu "gewöhnlicher Beleuchtung" aufgefordert, ${ }^{188}$ bei der Erbhuldigung für Kaiser Karl VI. im Jahr 1732 hatten die Stände immerhin 300 Laternen benötigt, ${ }^{189}$ auch anlässlich der Kaiserkrönung von Joseph II. I764 gab es eine umfangreiche »öffentliche« und private Beleuchtung. ${ }^{190} \mathrm{Im}$ ausgehenden I 8. Jahrhundert gehörten diese temporären Beleuchtungen bereits zum Standardrepertoire städtischer Festlichkeit und schlossen nun auch andere Anlässe mit ein, wie z.B. die Eroberung Belgrads im Herbst I789, bei der sogar im Ursulinenkloster »jedes Fenster mit zwei Kerzen« beleuchtet wurde. ${ }^{191}$ Die Beleuchtungen weisen eine erstaunliche Kontinuität auf: Sie wurden bis ins letzte Drittel des I9. Jahrhunderts regelmäßig durchgeführt ${ }^{192}$ und noch I 865 hat man »die innige Theilnahme der Stadtbevölkerung « an einer habsburgischen Geburt durch die Beleuchtung des Rathauses »kundgegeben «. ${ }^{193}$ Zunehmend erhielten die Beleuchtungen aber einen bürgerlichen Charakter: Die revolutionären Ereignisse feierten Stadtbewohner/innen im März I 848 mit einer Beleuchtung, wobei »manche Fenster, die man zu beleuchten vergessen hatte, [...] eingeworfen « wurden, ${ }^{194}$ genauso kam es anlässlich des ersten Jahrestages der Verfassung von I 86 I zu einer Beleuchtung ${ }^{195}$ und auch beim Fest zum hundertsten Geburtstag von Friedrich Schiller, »erglänzte« I 859 »die Facade des Rathhauses« - nunmehr - »im Gaslichte«. 196

Interessanterweise entstand in Linz bereits um I 70o ein »Entwurff yber die nächtliche beleuchtung der statt«, was wohl eine ständische Initiative bildete. Es seien zur Beleuchtung der öffentlichen Räume, so die Überlegung, »wenigstens 72 laternen« not-

I 86 Koslofsky, Empire, I 30- I 44; Rosseaux, Städte, I 2of.; vgl. als Überblicke: Reith, Umweltgeschichte, 65 u. EdN, s.v. Straßenbeleuchtung.

I 87 Kutschera, Straßenbeleuchtung, 348; vgl. Koslofsky, Empire, I 30.

I 88 LR CIIIHI-3, Reg. 658 (473).

I 89 LR BIIG 5 , Reg. 254I (29).

I90 LR E7a u. b, Reg. IO2 (3 If.).

I 9 I LR Eib, Reg. I8 I6 (102).

I 92 Vgl. z.B. LZ, 27.9.I790; ebd., I 8.8.I809; ebd., 8.10.1830; Fink, Geschichte, 43, I 57 u. I 78f.; Stifter, PRA, Bd. I 8, 2 ro.

I93 Der Oberösterreicher I 884, I76.

I $94 \mathrm{LR} \mathrm{BVI}_{3}$, Reg. I 7 I 9 (I Io-I43).

I95 LAB, 26.2.I862; diesmal sei die Beleuchtung »eine gänzlich freiwillige, ohne Nöthigung« gewesen, bemerkte man süffisant.

I 96 Fink, Geschichte, 207. 
wendig, über die man - vermutlich aufgrund der regelmäßigen Illuminationen - bereits verfüge. Somit würden nur »das öell und unterhaltung deren hierzu benöthigten leuth« Kosten verursachen. Eine Laterne benötige pro Woche ein halbes Pfund "paumöell«, was jährlich insgesamt $468 \mathrm{fl}$ koste - verwende man »leinöell«, würden die Kosten auf 3 I 2 fl sinken. Diesen Betrag könne man über einen Zuschlag auf die städtische »hausnuzungs-steur«, auf die "gwerb steur« und über Abgaben der Freihäuser abdecken; den Rest könnten staatliche Stellen in Linz beisteuern und auch die Arbeitskosten finanzieren. ${ }^{197}$ Es ist anzunehmen, dass die Kosten die Umsetzung dieses Vorschlages verhinderten, denn erst in den I 76oer Jahren entstand eine ständige Beleuchtung öffentlicher Räume. In der städtischen Bauamtsrechnung für das Jahr I 764 sind Ausgaben für roo Laternen, die mit Leinöl betrieben wurden, in der Höhe von 208 fl 55 kr verzeichnet möglicherweise stand dies im Zusammenhang mit der bereits erwähnten Illumination anlässlich der Kaiserkrönung in diesem Jahr. Zumindest ab dem Jahr i 766 wurden die damals rund i o Lampen von den Linzer Seifensiedern betrieben, die als Leuchtmittel Unschlitt verwendeten und dafür einen Aufschlag auf Kerzen und Seife von I Pfennig pro Pfund verlangen durften. ${ }^{198} \mathrm{Sehr}$ hell leuchtete diese öffentlich-unternehmerische Straßenbeleuchtung vermutlich nicht, wie eine I 783 erschienene Satire andeutet: Was »du für [leuchtende] Käfer ansiehst, sind unsere Laternen«. Zwar brennen diese nur bis zehn Uhr Abends und "nicht vielmehr als die Johannes-Käfer; deswegen können wir aber doch sagen, daß wir Laternen haben «. ${ }^{199}$ Die Seifensieder stellten, nachdem sie mehrfach über zu hohe Ausgaben geklagt hatten - I772 waren angeblich I.762 fl und I788 2.I80 fl aufgewandt worden - die Beleuchtung im Herbst I 790 ein. ${ }^{200}$ Daraufhin etablierte die Stadt Linz selbst einen »Illuminazionsfond «, der - wie es bereits zu Beginn des Jahrhunderts angedacht war - durch einen Zuschlag auf den Hausertrag dotiert wurde. Die Durchführung der Beleuchtung wurde einem Pächter auf acht Jahre übergeben, der gegen Bezahlung bei einzelnen Institutionen (wie den Ständen) auch "private « Laternen betrieb, die weiterhin leuchten mussten. ${ }^{201}$ Die durch die Straßenbeleuchtung für die Hausbesitzer entstehenden Kosten waren nicht unerheblich; größere Häuser wie das Kremsmünsterer Altstadthaus mussten in den I 79oer Jahren jährlich über ro $f$ bezahlen, ${ }^{202}$ für andere Häuser sind $6 \mathrm{fl} \mathrm{belegt.}{ }^{203}$ Dementsprechend

I $97 \mathrm{LR} \mathrm{BIIG}_{3}$, Reg. $5_{5} 85$ (38f.).

I98 AStL, Altakten, Sch. I9I ; Kutschera, Straßenbeleuchtung, 348-35 I; Luca, Landeskunde, Bd. I, 30 I ; LR BVIII2, Reg. $\mathrm{IOO}_{3}$ (III).

I99 Gimpel Insel, r 45f.; vgl. zur Brenndauer (im Winter neun Stunden, im Sommer vier Stunden) und den Defiziten: AStL, Altakten, Sch. I9I.

200 AStL, Altakten, Sch. I 9 I ; vgl. Kutschera, Straßenbeleuchtung, 35 I - 353.

20 I LR BIIA4I, Reg. I986 I (5 I); ebd., Reg. 19924 (94); LR E7a u. b, Reg. I 283 (3 16); LR BIIA 35, Reg. I 8902 (I 24-I 27); OÖLA, Landschaftsakten, Sch. 448, D.XV.3/No. I I3; LZ, I 7.9.1790; inspiriert war dies wohl durch die Wiener Lösung eines "Beleuchtungsguldens« (Csendes/Opll, Wien, Bd. 3, 73).

$202 \mathrm{LR} \mathrm{BVI}_{3}$, Reg. I53 I (ro).

203 AStL, HS ro84 (Stadtratsprotokoll i 797), fol. 3a; vgl. zu Wien: Koslofsky, Empire, I39f. 
war die Höhe der Zahlungen umstritten: Im Linzer Gemeinderat konstatierte man im Mai 1796 - in einer Teuerungsphase -, dass die Bevölkerung die "Beleuchtungssteuer" als »drückend« empfinde, dennoch gab sich der Bürgermeister von der Sinnhaftigkeit der Beleuchtung und der Angemessenheit der Zahlungen überzeugt. ${ }^{204}$ Aber auch die neue Beleuchtung (mit vermutlich 200 Leinöllaternen ${ }^{205}$ ) scheint in der Praxis nicht reibungslos funktioniert zu haben: 1795 konstatierte ein Bericht der Landstände, dass die Laternen verschmutzt seien und meist nach Mitternacht ausgehen würden. In der Früh zünde man sie "zum Schein« wieder an, insgesamt sei der Pächter »sehr nachlässig «. ${ }^{206}$ Speziell die Regelung, dass die Beleuchtung während einer mondhellen Nacht unterbleiben könne, lud zu Konflikten ein. ${ }^{207}$ Nachdem der erste Pachtvertrag 1798 ausgelaufen war, vergab man die Durchführung der Beleuchtung einem Konsortium aus dem Umfeld des Stadtrates, wobei man die bestehenden Vertragsbestimmungen übernahm und erneut eine achtjährige Laufzeit festsetzte, diesem Pächter folgten weitere, wobei die Klagen über eine mangelhafte Beleuchtung fortdauerten. ${ }^{208}$ Probleme der Beleuchtung resultierten aus ihrer chronischen Unterfinanzierung: Die Pachtbeträge (d.h. Entschädigungen für den Pächter) waren knapp bemessen - wenn die Preise für Leinöl anstiegen oder mehr Öl verbraucht wurde, dann blieb dem Pächter nur eine temporäre Reduktion der Beleuchtung, die zu Protesten führte. Dass daraus finanzielle Probleme für den Pächter entstehen konnten, zeigt das Beispiel des ersten Pächters der Straßenbeleuchtung. Dieser war weiterhin für die Beleuchtung der ständischen Gebäude zuständig, er flüchtete aber, nachdem erhebliche Schulden entstanden waren, im Frühjahr I 800 »über die Dächer der benachbarten Häuser«. ${ }^{209}$ Danach - da »man mit der Verpachtung der Beleuchtung nicht zufrieden sein kann« - entschlossen sich die Stände dazu, die Beleuchtung wieder selbst zu übernehmen. ${ }^{210}$ I 8 I o waren dies 70 Lampen, die immerhin jährliche Ausgaben von I. 353 fl $27 \mathrm{kr}$ verursachten. ${ }^{211}$

Dass in der Folge die Anzahl der Laternen und damit auch die Beleuchtungskosten stetig anstiegen (vgl. Tab. 29), ist als Hinweis darauf zu sehen, dass die öffentliche Beleuchtung in den ersten Jahrzehnten des I9. Jahrhunderts als konstitutives Element für eine "moderne« Stadt unstrittig geworden war. Immer stärker betont wurde zu dieser Zeit die Verbesserung von Sicherheit durch die Beleuchtung: Benedikt Pillwein zählte die Straßenbeleuchtung in seiner I 824 veröffentlichten Topographie zu den

\footnotetext{
204 AStL, HS ro83 (Stadtratsprotokoll I 796), pag. 67f.; vgl. Koslofsky, Empire, I 52 - I 54 .

205 AStL, HS Io83 (Stadtratsprotokoll I 796), pag. 445.

206 LR BIIA4 I, Reg. I 9954 ( ( 20).

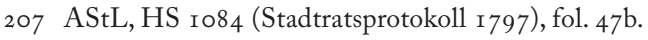

208 OÖLA, Landschaftsakten, Alte Registratur, Sch. 75, D.XIII/No. 6o; AStL, HS ro87 (Stadtratsprotokoll i 8oo), fol. $289 \mathrm{~b}$.

209 LR BIIA4 I, Reg. I 9879 (6If.); ebd., Reg. I 9882 (63f.).

2 Io Ebd., Reg. I9883 (64).

2 I I Ebd., Reg. I 9890 (68f.).
} 
"Anstalten zur öffentlichen Sicherheit und Bequemlichkeit«, ${ }^{212}$ auch bei der Einführung einer ständigen Beleuchtung der Donaubrücke, die ab den I82oer Jahren auf Anordnung der Landesregierung erfolgte, argumentierte man mit Sicherheit. ${ }^{213}$ I 825 äußerte ein Linz-Besucher den Wunsch, dass - aufgrund des dortigen »Pöbel[s] « - die Promenade »besser beleuchtet « werden solle. ${ }^{214}$ Die städtischen Aufwendungen für die Beleuchtung - wenngleich sie über die Beleuchtungssteuer refinanziert wurde ${ }^{215}$ - waren substantiell und durchaus vergleichbar mit Ausgaben für andere infrastrukturelle Bereiche, mitunter übertrafen sie diese aber deutlich (vgl. Kap. 5. Zirkulationen und Output). I850 war die Zuständigkeit der Gemeinde für die Beleuchtung bereits explizit in der Gemeindeordnung vorgesehen - dies schloss den Transformationsprozess von der privaten zur öffentlichen Straßenbeleuchtung ab. ${ }^{216}$

Tab. 29: Entwicklung der "öffentlichen« Straßenbeleuchtung, 1760 bis 1900

\begin{tabular}{lcll}
\hline & $\begin{array}{c}\text { Öllampen (ab 1850 inkl. } \\
\text { Argandlampen) }\end{array}$ & $\begin{array}{c}\text { Argand- (bis 1839) resp. } \\
\text { Gaslampen (ab 1860) }\end{array}$ & Kosten in fl (gerundet) \\
\hline 1760 & 100 & & \\
1785 & 112 & & Pacht 2.220 \\
$1790 e r$ & 200 & & Pacht 2.910 \\
1807 & & 22 & Pacht 13.300 (WW) \\
1817 & 279 & 22 & Pacht 2.452 (CM), gesamt 4.059 (CM) \\
1830 & 306 & & 5.187 (CM) \\
1839 & 298 & & 4.810 (CM) \\
1840 & & 374 & 14.576 (ÖW) \\
1850 & $371(1851)$ & 591 & 19.920 (ÖW) \\
1860 & 135 & 995 & \\
1886 & 134 & & \\
1900 & 112 & & \\
\hline
\end{tabular}

Quelle: AStL, Altakten, Sch. 191; Fink, Geschichte, 70; AStL, HS 128 (Kammeramtsrechnung 1807), fol. 84a; LZ/IB, 17.5.1830; AStL, HS 152 (Oberkammeramt Ausgaben 1830), pag. 253f.; AStL, HS 171 (Kammeramt Empfang 1840), pag. 54; AStL, HS 192 (Oberkammeramt Ausgaben 1849), pag. 429 u. 624; Kutschera, Straßenbeleuchtung, 354; LTP, 7.8 .1887 ; RB 1900, 281

2 I 2 Pillwein, Beschreibung, 309 u. 3 I 5.

2 I 3 AStL, Altakten, Sch. I9I; die Kosten wurden mit Urfahr geteilt: AStL, HS I Ior (Stadtratsprotokoll I 820 ), fol. 377 a u. 377b; Kutschera, Straßenbeleuchtung, 354; AStL, HS I 5 I (Oberkammeramt Empfang I 830), pag. 70; vgl. Koslofsky, Empire, I33, I 44 u. I 57 - I 59.

2 I 4 Kyselak, Skizzen, 406.

2 I 5 Die Steuer wurde über den Hauswert festgesetzt: vgl. Bohdanowicz, Vorstädte, Bd. 2, 922 ; AStL, HS 435 (Baurechnung I 808), pag. 68; LR BVI 3 , Reg. I657 (55-7I).

2 I 6 Gemeindeordnung I 850, LGB1. 261/1850, 274. 
Ab den I 82 oer Jahren waren in zahlreichen englischen Städten Unternehmen entstanden, die Gas für die Straßenbeleuchtung und Privatkunden produzierten. ${ }^{217}$ In Wien fanden Beleuchtungsversuche mit Gas zwar schon im ersten Jahrzehnt des r 9. Jahrhunderts statt, aber erst ab den I 84 oer Jahren wurde Gas in größerem Ausmaß für die Wiener Straßenbeleuchtung verwendet. ${ }^{218}$ Die Gasproduktion und beleuchtung erlebte in zahlreichen westeuropäischen Städten ab der Mitte des r 9. Jahrhunderts einen Boom, ${ }^{219}$ in Linz wurde am Ende der I 85 oer Jahre das erste Gaswerk errichtet. Zunächst hatte die Stadt versucht, selbst das Gaswerk zu erbauen, aber dafür keinen Kredit erhalten. Schließlich wählte man aus drei Angeboten die "Allgemeine Oesterreichische Gas-Gesellschaft « aus Triest und schloss mit dem Unternehmen I 857 einen Vertrag, der auf 35 Jahre ein Monopol für die Beleuchtung und die Gasversorgung einräumte. ${ }^{220}$ Im April I 858 gab es bereits 230 Gaslaternen, daneben bestanden aber weiterhin die Öllampen, die mit Rübsamenöl, ab I 863 mit Petroleum und ab I868 direkt durch die Stadt betrieben wurden. Mit der Einführung des Gaslichts waren die Beleuchtungskosten stark angestiegen (vgl. Tab. 29), wenngleich man I 856 noch damit gerechnet hatte, dass "nur unerhebliche Mehrauslagen« entstehen würden: ${ }^{221}$ Die knapp 20.000 fl, die man für die Straßenbeleuchtung im Jahr I 880 aufwandte, entsprachen immerhin knapp 4 Prozent der damaligen städtischen Gesamtausgaben. ${ }^{222}$ Aber erst mit der Gasbeleuchtung, die sukzessive erweitert wurde, genügte Linz den Ansprüchen, die während der zweiten Hälfte des I 9. Jahrhunderts an eine Mittelstadt gestellt wurden. ${ }^{223}$ Mit dem Auftreten der elektrischen Beleuchtung in den I88oer Jahren veränderten sich diese Ansprüche erneut: ${ }^{224}$ I 883 war die Frage einer elektrischen Beleuchtung erstmals im Linzer Gemeinderat thematisiert worden, ${ }^{225}$ und als I 89 I der Bahnhof erstmals elektrisch beleuchtet wurde, betonte man, dass dies eigentlich »schon längst zum Bedürfnisse geworden« sei. ${ }^{226}$ Dennoch begann die Ära der elektrischen Straßenbeleuchtung in Linz erst im Jahr I905 - gebremst hatte die monopolistische Gasgesellschaft. ${ }^{227}$

2 I 7 Schott, Urbanisierung, 283.

2 I 8 Brunner/Schneider, Umwelt, I 57- r6o; Csendes/Opll, Wien, Bd. 3, 73; vgl. zum Beleuchtungsversuch des Polytechnischen Instituts: LZ, 9. 2.18 I6.

2 I 9 Schott, Urbanisierung, 285-287.

220 AStL, Altakten, Sch. I92; vgl. ÖB, I I.7.I 856; LAB, 20. I I. I 856; erst I 9 I 3 wurde das Linzer Gaswerk zu einem städtischen Betrieb: Lackner/Stadler, Fabriken, 54-57 u. 489.

22 I ÖB, I 2.7.I 856.

222 RB I 879-i 880, I02 u. I Io; Kutschera, Straßenbeleuchtung, 355 f.

223 Vgl. LAB, 8.I I.I 856.

224 Schott, Urbanisierung, 289 f.; Lees/Hollen Lees, Cities, I93f.; vgl. für Wien Brunner/Schneider, Umwelt, I 56 u. für Salzburg LTP, i 7.2. I 888.

225 Lackner/Stadler, Fabriken, $23 \mathrm{f}$.

226 LTP, i 9. Iо. 890.

227 Lackner/Stadler, Fabriken, 5 6f. u. 429; Kutschera, Straßenbeleuchtung, 363 u. 365 f. 


\section{Natur der Städter - Natur für Städter}

\section{Irrationale und rationale Natur, untersuchte und gesammelte Natur}

Für den Blick auf die Natur und den Umgang mit ihr bildete das I 8. Jahrhundert eine Übergangszeit. Empirisch-rationale Beobachtungen gewannen an Bedeutung, kritisierten und modifizierten ältere Wissensbestände und erreichten eine breitere Öffentlichkeit. ${ }^{1}$ Diese Veränderungen, die nicht unbedingt linear verliefen, sollen anhand von drei Beispielen nachgezeichnet werden: der Wahrnehmung von Wetterphänomenen, des 1777 beim Bergschlössl etablierten Botanischen Gartens und des naturwissenschaftlich induzierten Sammelns seit der Mitte des I 8. Jahrhunderts.

Das unvollständige Wissen zu vielen meteorischen Phänomenen resultierte im Alltag in religiösen und metaphysischen Deutungen und Praktiken. ${ }^{2}$ Einzelne Einblicke in diese Bereiche liefern die jährlichen Tätigkeitsberichte der Linzer Jesuiten (»Litterae annuae«): I70I wurde am Kalvarienberg bei St. Margarethen auf Initiative eines Jesuitenpaters ein Holzkreuz errichtet, das - neben anderem - ebenso gegen Gewitter und Hagelschlag schützen sollte, was auch eine der beiden Inschriften (»a fulgure et tempestate, ab omni malo libera nos«) erbat. ${ }^{3}$ Dies war vermutlich mit der Verehrung des Heiligen Donatus verbunden, der nicht nur von den Linzer Jesuiten als Beschützer vor Unwettern angesehen resp. inszeniert wurde. Ab den I 7 Ioer Jahren gibt es Hinweise auf Donatus-Feierlichkeiten in Linz, bei denen mehrere tausend - mit den Donatus-Reliquien geweihte - Heiligenbilder verteilt wurden, die auch gegen Feuer helfen sollten. ${ }^{4}$ Im Herbst I 7 I 3 , der einem kalten Frühjahr und einem niederschlagsreichen Sommer folgte und in Teuerungen resultierte (vgl. Kap. 2. Kontexte: Linz I 700 bis I 900), organisierten die Jesuiten eine Prozession auf den Kalvarienberg, um für eine Wetterbesserung zu beten, die dann tatsächlich eingetreten zu sein scheint. ${ }^{5}$ $\mathrm{Ab}$ den I72oer Jahren sollte mit den Reliquien des jesuitischen Ordensgründers Ignatius von Loyola geweihtes Wasser gegen verschiedene Bedrohungen, unter anderem gegen Viehseuchen helfen. Bis in die I75oer Jahre wurde dieses Wundermittel in großen Mengen unter die Bevölkerung gebracht, die offenbar auch einen Schutz gegen Zauber, Hagel und andere Unwetterereignisse erhoffte. ${ }^{6}$ Daneben finden sich

\footnotetext{
I Vgl. Sommer/Müller-Wille/Reinhardt, Handbuch, 278-28I; Hochadel, Wissenschaft, I4-28; EdN, s.v. Naturwissenschaft u. Williams, Ideas, 7 If. u. 79-82.

2 Vgl. EdN, s.v. Meteore, Meteorologie u. Wetterbeobachtung.

3 Dies ist durchaus als zeittypische Formel zu erachten, die oft bei Kirchenglocken verwendet und mitunter durch "grandine« (Hagel) ergänzt wurde; LR CIIIC 3 , Reg. 37 (I I).

4 Ebd., Reg. 203 (85); ebd., Reg. 209 (88f.).

5 Ebd., Reg. 228 (96).

6 Ebd., Reg. 422 (I77); ebd., Reg. 560 (237f.); ebd., Reg. 745 (3 18); ebd., Reg. 755 (323).
} 
genauso rationalere Deutungen und Praktiken: I740 wurden für die Jesuitenkirche große Glasfenster angekauft, von denen man sich neben besseren Lichtverhältnissen auch eine höhere Widerstandsfähigkeit gegen Hagel versprach. ${ }^{7}$ Blitzeinschläge in der Stadt oder starke Gewitter im Umland wurden in Chroniken und der Korrespondenz aus der ersten Hälfte des I8. Jahrhunderts eher unter dem Aspekt der Schäden oder der direkten Gefährdung thematisiert, während metaphysische oder religiöse Interpretationen meist fehlen. ${ }^{8}$

Eine weit verbreitete semireligiöse Praktik gegen Gewitter bildete das Wetterläuten, das aber in den Quellen nur selten dokumentiert wurde. ${ }^{9}$ In den Archivalien des Deutschen Ordens findet sich eine Zahlung für »Hilfe im Läuten« anlässlich der zahlreichen Gewitter des Sommers I 72 8, ${ }^{10}$ I 73 I verlangte ein Vertreter der Stände, dass der Mesner der Landhauskirche bei heranziehenden Gewittern »mit sämtlichen Glocken» läuten solle. ${ }^{11}$ Die Verbote des Wetterläutens standen im Kontext der Aufklärung: ${ }^{12}$ In den österreichischen Ländern wurde das Glockenläuten bei Gewitter im November I 783 untersagt, ${ }^{13}$ nachdem bereits in den frühen I770er Jahren das Wetterschießen verboten worden war. ${ }^{14}$ Dass sich gerade im Jahr I783 die Diskussion um diese Praktiken intensivierte, ist kein Zufall, war doch der Sommer dieses Jahres in Mittel- und Westeuropa durch eine ungewöhnliche Gewitterhäufigkeit geprägt. ${ }^{15}$ In der oberhalb von Linz gelegen Pöstlingbergkirche sei - so ein im Juli I 783 in der "Linzer Zeitung « veröffentlichtes »Schreiben« - »aus Besorgniß [..., dass] die Gewitter über die Stadt hergetrieben werden «, das Wetterläuten bereits verboten. ${ }^{16}$ Dazu betonte die aufgeklärte Publizistik die Nützlichkeit von Blitzableitern, ${ }^{17}$ so auch in der "Linzer Zeitung « ${ }^{18}$ in der aber gleichzeitig darauf verwiesen wurde, dass man »Hier Lands [...] die Blitzleiter blos aus der Zeitung « kenne. ${ }^{19}$ Auch von staatlicher Seite wurde die Etablierung von Blitzableitern propagiert und initiiert, was man als Wirken einer »fernen Ordnung« verstehen kann, deren Diffusion dieser Innovation aber ungleichzeitig

\footnotetext{
7 Ebd., Reg. 575 (247).

8 Vgl. z.B. LR Eıb, Reg. I399 (37); ebd., Reg. I 4 I 6 (39); ebd., Reg. I 478 (47); LR BIIAI7, Reg. I 5 I 38 (96f.); LR BIIG6, Reg. 3024 (7).

9 Vgl. dazu die mikrogeschichtliche Annäherung Norbert Schindlers für Salzburg: Schindler, Konflikte.

ro $\mathrm{LR} \mathrm{CIIIH}_{4}, 886-893$.

I I LR BIIG 5 , Reg. 2507 (3).

I 2 EdN, s.v. Blitzableiter; Reith, Umweltgeschichte, I 5 .

I3 LZ, I 9.I 2.I783; ebd., 26. I 2.I783; vgl. Hochadel, Wissenschaft, I 47f.; Brunner/Schneider, Umwelt, 304 u. Schindler, Konflikte, ro7- i io.

I 4 Luca, Landeskunde, Bd. 2, 70; vgl. ebd., I65.

I5 Hochadel, Nebula, 45-47; diese Wetterphänomene gelten als Folgewirkung des Laki-Ausbruchs (vgl. ebd., $55-57)$.

I6 $\mathrm{LZ}, 30.7 \cdot 1783$.

I7 Hochadel, Nebula, 53 f.

I $8 \mathrm{LZ}, 2.8 .1783$.

I $9 \mathrm{LZ}, 30.7 \cdot 1783$.
} 
verlief. Das größte staatliche Gebäude in Linz, die Wollzeugfabrik, verfügte vermutlich ab dem Sommer I 784 über einen »Wetter Ableiter «, ${ }^{20}$ das ständische Theater ab dem Frühjahr $1805,{ }^{21}$ für die Wasserkaserne und das Brauhaus, die in städtischem Besitz waren, wurden erst I 807 Ausgaben für Blitzableiter verzeichnet. ${ }^{22}$ In den ersten Jahrzehnten des I 9. Jahrhunderts scheint der Blitzableiter in Linz bereits stärker verbreitet gewesen zu sein. Eine I 8 I 2 erschienene Stadtbeschreibung konstatierte »viele Häuser« mit Blitzableiter, besonders in den Vorstädten: „Der Aufseher des [physikalischen] Musäums Herr P[ater]. Hösel, ist dafür bekannt, sehr wirksame Wetterableitungen anzulegen. ${ }^{23}$ Zwar seien Gewitter in Linz selten, so in einer Reisebeschreibung aus dem Folgejahrzehnt, es bestehe aber kein Mangel an »Wetterableitern «. ${ }^{24}$ Gleichzeitig ist von einem teilweisen Fortbestehen älterer Praktiken auszugehen: In den r8zoer Jahren kam es auf Bitte von zwei Bauern in einer Linzer Kirche zu »Bethstunden zur Erflehung eines günstigen Aerndte-Wetters ${ }^{25}$ und noch in den letzten Jahrzehnten des I 9. Jahrhunderts finden sich Belege für das Wetterläuten. Eine Linzer Zeitung war I 872 davon überzeugt, dass alles »eher abgestellt werden kann, als das leidige >Wetterläuten` auf dem Lande«. Falls »heute Jemand beim >Wetterläuten erschlagen wird, so wird morgen wieder 'wettergeläutet‘, wenn es auch noch so sinnlos und gefährlich ist «. ${ }^{26}$ Das Gewitterläuten, so räumte man im »Linzer Diözesanblatt« I 892 ein, habe sich trotz der Verbote »theilweise auch in der Diöcese Linz, bis auf heute erhalten «. ${ }^{27}$

Begleitet wurden diese Veränderungen von einem zunehmenden wissenschaftlichen Interesse an der Meteorologie, das sich ebenso in Linz manifestierte. ${ }^{28}$ Wenngleich einzelne Wetteraufzeichnungen für Linz auch für die Zeit vor dem I 8. Jahrhundert überliefert sind (z.B. im frühen I7. Jahrhundert vom Astronomen und Mathematiker Johannes Kepler), setzten regelmäßige Beobachtungen, nun mit Instrumentenmessungen, erst nach den 175 oer Jahren ein. ${ }^{29}$ Für diese Zeit gibt es auch zahlreiche Hinweise auf den Besitz und die Verfügbarkeit von Thermometern und Barometern in Linz: ${ }^{30}$ Es

20 LR CIIIG, Reg. I 209 (324f.).

2 I LR BIIA42, Reg. 20128 (64f.).

22 AStL, HS I 28 (Kammeramtsrechnung I 807), fol. 50a; vgl. Reith, Umweltgeschichte, 88f. u. Hochadel, Wissenschaft, I $45-\mathrm{I} 67$.

23 Heinse, Linz, r. Aufl., r6.

24 Schultes, Donau-Fahrten, I rof.

25 LZ/IB, 4.4.I 834.

26 LTP, 28.5.1872.

27 Linzer Diözesanblatt 38 (1892), I43; vgl. zu den Widerständen und Kontinuitäten in Salzburg: Schindler, Konflikte, I I 2 - i I 7 .

28 Vgl. EdN, s.v. Wetterbeobachtung u. Klima; Hochadel, Wissenschaft, ro5- Io7.

29 Lauscher et al., Witterung, I 5-34; vgl. zu Wien Brunner/Schneider, Umwelt, 302 u. allgemein White/ Pfister/Mauelshagen, Handbook, 83-89.

30 Erstaunlicherweise wurde in den Rechnungen des Deutschen Ordens bereits 1724 der Ankauf eines »doppelten« Barometers verzeichnet - $\mathrm{LR} \mathrm{CIIIH}_{4}, 85$ I -856 . 
sind Temperaturmessungen aus den Jahren I 760 und I 767 überliefert, ${ }^{31}$ I 763 verstarb ein Barometermacher aus Como in Linz, ${ }^{32}$ zwei Barometermacher - vermutlich aus dem Mailänder Raum - wurden in den I 78 oer und I 79oer Jahren Linzer Bürger, ${ }^{33}$ im Freihaus des Stifts Lambach gab es I 777 - laut Inventar - im Schlafzimmer ein Thermometer und zwei "gewöhnliche Barometer mit dicken Röhren neben dem Fenster «. ${ }^{34}$ In den I 79oer Jahren und im beginnenden I 9. Jahrhundert finden sich regelmäßig Anzeigen von Thermometer- oder Barometerhändlern in der "Linzer Zeitung «. ${ }^{35}$

Somit ist es wenig überraschend, dass Witterung und Wetter bei den Linzer Topographen ab dem frühen I 9. Jahrhundert selbstverständliche Themen waren, auch im Kataster der I 8 2oer Jahre sind meteorologische Einschätzungen weitaus präsenter als im rund 40 Jahre zuvor entstandenen »Josephinischen Lagebuch» (vgl. Kap. 2. Kontexte: Linz I 700 bis I 900). Gottlob Heinrich Heinse konnte in seiner in den I 8 Ioer Jahren entstandenen Stadtbeschreibung bereits auf die »vieljährigen Beobachtungen eines thätigen Meteorologen« verweisen und veröffentlichte Durchschnittstemperaturen aus »einer Reihe von I9 Jahren «. ${ }^{36} \mathrm{Ob}$ es sich dabei um den Linzer Geistlichen Franz de Paula Haslinger ( 7765 - I 833) handelte, ist unklar, aber eher unwahrscheinlich, da Haslinger ab i 806 in Linz wohnte, ${ }^{37}$ vermutlich im Karmeliterkloster an der Landstraße. ${ }^{38}$ Haslinger hinterließ umfangreiche Wetterbeobachtungen, für die Jahre I 796 bis I 833 täglich erfolgten und stets nach dem gleichen Schema aufgebaut sind (vgl. Abb. 27). ${ }^{39}$ Bereits im ersten (überlieferten) Heft aus dem Jahr I 796 gibt es neben den meteorologischen Beobachtungen (»Witterung« als erste Spalte) und zahlreichen weiteren täglichen Aufzeichnungen (z.B. "Spaziergang« oder »Beichtende«) auch jährliche Zusammenfassungen zum Wetter (»Bemerkungen über die Jahreszeiten«) und zur »Fruchtbarkeit «. ${ }^{40}$

Haslinger war ein genauer und nüchterner Betrachter des Wetters und seiner Auswirkungen: Ab April 1796 finden sich drei Temperaturwerte pro Tag, die bis auf wenige Lücken (v.a. März bis August I797, Juni I 806 bis Dezember I 808, Mai I 809 bis

3I Lauscher et al., Witterung, 32 u. 63-69 (Originale in OÖLA, Herrschaftsarchiv Schwertberg, Akten, No. I90).

32 LR BIIB I, Reg. 367 (209).

33 Lauscher et al., Witterung, 3 If.

34 LR BIV, Reg. 770 (302-307).

35 LR E7a u. b, Reg. 1377 (342); ebd., Reg. 598 (394); LR E7e-g, Reg. 245 (60).

36 Heinse, Linz, I. Aufl., If.

$37 \mathrm{HTb}$ I 806, 4.6.

38 Zumindest in den $1820 e r$ Jahren - vgl. LR Eıi, Reg. 58 I 3 (9If.).

39 Vgl. Haslinger, Tagebücher, unpag. (Vorwort); Pillwein, Beschreibung, 233; Zotl, Geschichte, 45 ; Temperaturangaben und kurze Wetterbeschreibungen sind ediert in: Haslinger, Tagebücher; das Original in 38 Heften (Stiftsbibliothek St. Florian, Handschriftensammlung, XI ${ }_{5} 6{ }_{5} \mathrm{~B}$ ) zitiere ich in der Folge als $\mathrm{HTb}$ - da unpaginiert - mit dem jeweiligen Datum des Eintrages resp. der Rubrik der Jahreszusammenfassungen (Jahreszeiten, Fruchtbarkeit oder Begebenheiten).

$40 \mathrm{HTb}$ i 796, passim. 
Jänner I8 1о) durchgängig bis zum Ende der Aufzeichnungen mit Februar I833 - vermutlich von Haslinger selbst - notiert wurden. Dies weist deutlich Anklänge an die überregionalen meteorologischen Netzwerke auf, die seit dem frühen I 8. Jahrhundert in Westeuropa entstanden waren und zur Standardisierung von Wetterbeobachtungen beitrugen. ${ }^{41}$ Hinweise darauf, dass Haslinger Teil dieser Korrespondenznetze war, finden sich in den Tagebüchern aber nicht. Es fehlen ebenso religiöse oder metaphysische Deutungen, Blitzeinschläge hielt der Pfarrer Haslinger sachlich und ohne weitere Bewertung ebenso wie das epidemische Auftreten der Pocken in den Jahren I 799 und I 805 fest, ${ }^{42}$ nur anlässlich der guten Ernte des Jahres i 8 I 8 (nach den Missernten und der Teuerung der Vorjahre - vgl. Kap. Io. Versorgungskrise) und der I 83 I in Linz nicht aufgetretenen Cholera (vgl. Kap. 9. Epidemie) wurde »Gott innigster Dank « ausgesprochen. ${ }^{43}$

Ein wesentlicher Impetus Haslingers und anderer Beobachter war der Wunsch, Regeln des Wettergeschehens zu identifizieren und auf dieser Basis eine empirisch fundierte Wetterprognostik entwickeln zu können. ${ }^{44}$ Ein derartiger Prognoseversuch findet sich in der "Linzer Zeitung « nach dem überdurchschnittlich kühlen und niederschlagsreichen Frühjahr und Sommer I 8 $6^{45}$ für den Herbst I 8 I6 und das Frühjahr I 8 17: "Der Oktober wird sich dießmal meistens durch trockne und angenehme Herbstwitterung auszeichnen. Mit dem Anfang Novembers ist zwar etwas vermischte Witterung zu erwarten, es wird aber die trockene bis gegen den 20 . noch vorherrschen. Bis dahin ist wenig oder nichts von Kalte zu fürchten. Vom 20 bis 29. Nov. vermischt und kalt, aber mehr trocken als feucht. In diesem Zeitraum wird sich der erste Schnee sehen lassen. [...] Zwischen dem 8. und I4. März ist nach und nach Thauwetter zu erwarten, wobei es aber mehr trocken als naß seyn wird. « ${ }^{46}$ Tatsächlich war der Herbst nicht so niederschlagsreich wie der vorangegangene Sommer, die ersten beiden Monate des Jahres I 8 I 7 waren überdurchschnittlich warm, die folgenden Monate aber relativ kalt und der April überdurchschnittlich kalt. ${ }^{47}$ Somit spiegelte eine derartige Wetterprognose wohl eher ein Wunschdenken wider, wie auch die »Vermuthliche Witterung «, die im April I 8 I 7 veröffentlicht wurde: »Es läßt sich also hoffen, daß ein fruchtreicher Sommer der niedergedrückten Menschheit wieder aufhelfen werde. ${ }^{48}$ Fortlaufende und standardisierte Wetterbeobachtungen setzten in Linz aber erst ab der Mitte des I 9. Jahrhunderts ein. ${ }^{49}$ Zeitweilig war Adalbert Stifter ebenso ein all-

4I EdN, s.v. Wetterbeobachtung.

42 HTb г 8 г 2, 22.8. u. 3 г.8.; HTb I 799, Fruchtbarkeit; HTb I 805, Fruchtbarkeit.

$43 \mathrm{HTb}$ г 8 18, Fruchtbarkeit; HTb I 83 г, Fruchtbarkeit.

$44 \mathrm{EdN}$, s.v. Klima, Meteorologie u. Wetterbeobachtung.

45 Lauscher et al., Witterung, 74f.; vgl. Kap. Io. Versorgungskrise.

46 LZ, iт.Iо.I8I6.

47 Vgl. HISTALP u. Kap. Io. Versorgungskrise.

$48 \mathrm{LZ}, 4.4 .18 \mathrm{I} 7$.

49 Lauscher et al., Witterung, 87-89; Topitz, Geschichte, 540; Schwab/Schwarz/Wenzel, Beobachtungen, I4; Zotl, Geschichte, 54 f. 
Abb. 27: Die Aufzeichnungen von Franz de Paula Haslinger aus dem Dezember 1809

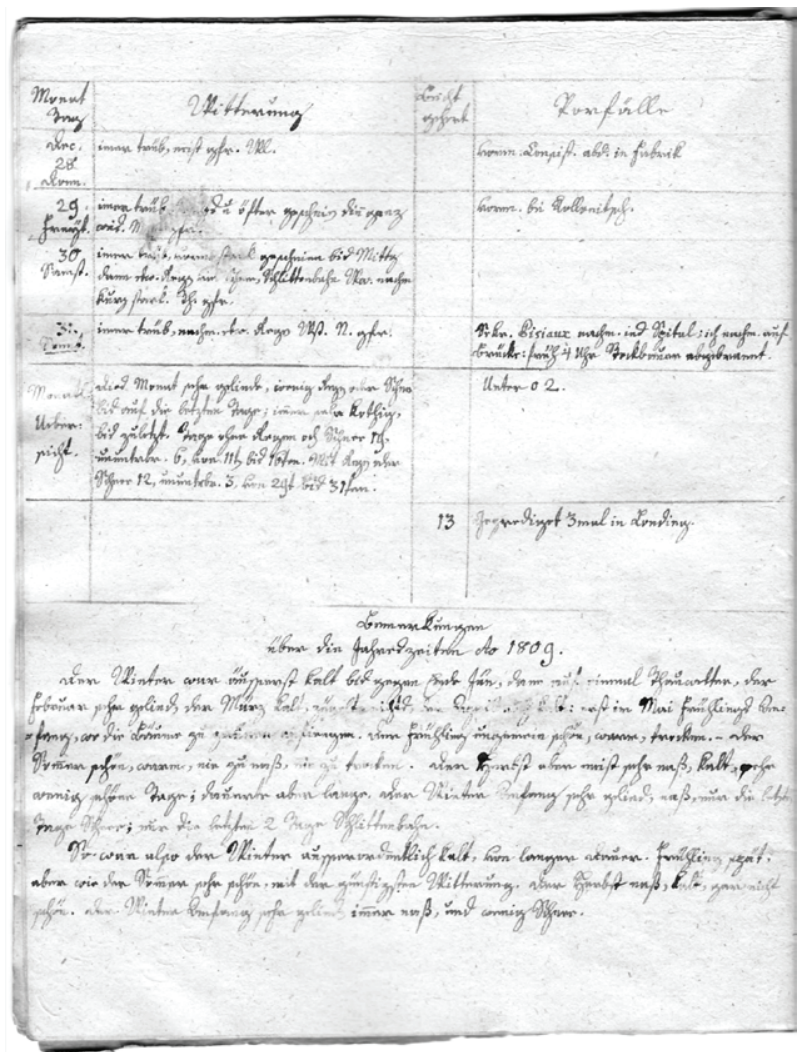

täglicher Wetterbeobachter, ${ }^{50}$ der auch aus der Ferne diese Beschäftigung seiner Frau übertrug, ${ }^{51}$ und seine Temperaturmessungen - auf einem »8ogradigen " Thermometer außen am Fenster »in der Sonne« (!) abgelesen - in den »Winterbrief« zur »Wärme« einbrachte. ${ }^{52}$

Der Bedeutungsgewinn der Naturbeobachtung und der Naturwissenschaften im I 8. Jahrhundert manifestierte sich auch im zunehmend systematischen Sammeln und Untersuchen von Natur. ${ }^{53}$ Ein Beispiel dafür bilden die Botanischen Gärten, die zwar vielerorts schon im I6. und I7. Jahrhundert entstanden waren, aber im Verlauf des I 8. Jahrhunderts als Forschungseinrichtungen und als - wie es Marianne Klemun bezeichnet hat - „Verschub-Bahnhöfe von Samen und Nutzpflanzen im weltweiten Kul-

50 Stifter, PRA, Bd. 17, 227 ; ebd., Bd. 21, 7I ; HKG 8/3, 368.

5I Am r8.10.1865 in einem Brief an Amalie Stifter aus Kirchschlag: „Schreibe ja die Grade gut auf, und vergiß in deiner Geschäftigkeit nicht auf das Beobachten.« - Stifter, PRA, Bd. 2 I, 42.

52 Stifter, HKG, Bd. 8/3, 207.

53 Vgl. EdN, s.v. Empirismus u. Naturwissenschaft. 
turpflanzentransfer « nochmals an Bedeutung gewannen. ${ }^{54}$ Dass im Jahr I 777 an der Peripherie von Linz ein »ökonomisch-botanischer Garten« etabliert wurde, ${ }^{55}$ stand deutlich im Kontext der Wiener Botanischen Gärten, die zur Mitte des I 8. Jahrhunderts angelegt worden waren. ${ }^{56}$ Gründer des Linzer Gartens war der Geistliche (und ehemalige Jesuit) Ignaz Schiffermüller, der I777 Direktor des Nordischen Stiftes (»Collegium Nordicum«) - eines elitären religiösen Internats - wurde. Schiffermüller war bereits in Wien an einer ähnlichen Institution, dem jesuitischen »Collegium Theresianum «, als Lehrer tätig gewesen. ${ }^{57}$ Der neue Botanische Garten wurde beim Bergschlössl am Froschberg angelegt, das damals schon über eine barocke Gartenanlage und landwirtschaftlich genutzte Flächen verfügte. Ursprünglich war das Bergschlössl eine villa suburbana mit Garten gewesen, die später als ständische Sommerwohnung fungierte und in den frühen I77oer Jahren vielleicht auch für Anbauversuche der ständischen »Agricultur-Societät« genutzt wurde. ${ }^{58}$ I 773 pachtete das Collegium den Besitz und erwarb ihn einige Jahre später. Als Schiffermüller I 777 dort einen Botanischen Garten anlegen ließ, bestand nur im mehrere Kilometer entfernten (und jenseits der Donau gelegenen) Schloss Auhof ein kleiner Botanischer Garten, der im Besitz der Adelsfamilie Starhemberg war. ${ }^{59}$

Der »ökonomisch-botanische Garten« Schiffermüllers knüpfte nicht nur mit seinem Namen an den Garten des Wiener Theresianums an, er zielte ebenso auf den praktischen Unterricht für die Zöglinge des Internats ab: Der Garten war nach dem jeweiligen Nutzen der Pflanzen resp. nach deren Zusammengehörigkeit (in Anlehnung an den schwedischen Botaniker Carl v. Linné) aufgebaut, gleichzeitig ging es aber auch darum, einen ästhetisch ansprechenden und romantischen Naturraum zur Freizeitgestaltung zu schaffen. ${ }^{60}$ Er habe die vorgefundene »Wildnis« des BergschlösslGrundes, erinnerte sich Schiffermüller in seiner zu Beginn des I 9. Jahrhunderts entstandenen "Lebensbeschreibung ${ }^{61}{ }^{61} \mathrm{zu}$ einem "Garten $\mathrm{zu}[\mathrm{r}]$ manigfältigen Unterhaltung der Stiftsjugend « umgestalten lassen, eine Allee »zu einem Spaziergang [...] nach der schönsten Aussicht« angelegt, die »beiderseits mit abwechselnden, in- und ausländischen Bäumen und Gestreicharten nach ihren Verwandtschaften« bepflanzt

54 Klemun, Garten; Sommer/Müller-Wille/Reinhardt, Handbuch, 236-24I.

55 Promitzer/Speta, Naturgeschichte, 47.

56 Klemun, Exotik, 305-308.

57 Promitzer/Speta, Naturgeschichte, 47, 5 If. u. 64.

58 Zumindest wurde dies im Jahr I 773 überlegt - LR BIIA 3 8, Reg. I93 I 9 (88); vgl. zu den landwirtschaftlichen Flächen und deren Nutzung: Awecker, Bergschlößl, r96f. u. 206f.; auch Kap. 4. Energie und Biomasse.

59 Awecker, Bergschlöß1, I 97-200; Promitzer/Speta, Naturgeschichte, 5 I ; vgl. Heinse, Linz, I. Aufl., Io6f. u. LZ/IB, 25.3.1 822 .

6o Promitzer/Speta, Naturgeschichte, 52 u. 55 f.

6I Die "Jahre in Linz« sind ediert (Promitzer/Speta, Naturgeschichte, 62-66), das Original befindet sich im OÖLA (OÖLA, Musealarchiv, HS i 97). 
wurde, wobei man die Gewächse mit »angehefteten sistematischen lateinischen, deutschen und französischen Namen« versah. Dazu kam I784 ein Beet »mit den verschiedenen klassifizirten Pflanzen [...], die den Menschen mit Saamen oder Blätter oder mit Wurzel zur Nahrung oder als Gewürz oder als Stoff zur Bekleidung oder Stofffarben, zu den Speisen dienen«. Im Bergschlössl selbst gab es eine Sammlung ausgestopfter heimischer Vögel "zur Ergötzung des Auges [...] in einer ihnen bekannten Eigenschaften anpassenden Bewegung «, im Garten befanden sich steinerne Becken mit heimischen Fischen ${ }^{62}$ und im Gartenhaus waren Decke und Wände »mit Gegenständen der Naturgeschichte ganz nach der Natur bemalet «, dass man sich, so ein Besucher in den I 78 oer Jahren, "auf einmal nach beyden Indien versetzet « fühle. ${ }^{63}$ Schiffermüller verfügte über zahlreiche lokale und überregionale Vernetzungen: Er war ein ehemaliger Schulkollege des Lyzeumprofessors Franz Xaver Racher (vgl. unten) und des Landeshauptmannes Christoph Wilhelm Thürheim, auch zahlreiche naturwissenschaftlich interessierte Reisende besichtigten den Garten und die umfangreiche Insektensammlung Schiffermüllers, ${ }^{64}$ wie z.B. der Berliner Verleger und Publizist Friedrich Nicolai ${ }^{65}$ oder der bayerische Botaniker Franz de Paula Schrank, der sogar mehrere Wochen in Linz blieb. ${ }^{66}$ Dennoch wurde der Botanische Garten - im Gefolge der Aufösung des Nordischen Stifts - bereits I788 aufgelassen; ${ }^{67}$ das Bergschlössl und die dazugehörigen Gründe wurden versteigert, wobei ein Teil der landwirtschaftlich genutzten Flächen parzelliert und bebaut wurde. ${ }^{68}$

Einzelne Hinweise auf das Sammeln von - und somit die intensivere Beschäftigung mit - Naturobjekten und naturwissenschaftlichen Geräten gibt es für die erste Hälfte des r 8. Jahrhunderts ${ }^{69}$ für die Zeit danach mehren sich diese jedoch deutlich. ${ }^{70}$ Wesentliche Impulse gingen von den Jesuiten aus, die seit dem ausgehenden I 7. Jahrhundert gemeinsam mit den Ständen eine höhere Schule (»Lyzeum«) betrieben. ${ }^{71}$ Das Jesuitenkolleg besaß bereits zu Beginn des I 8. Jahrhunderts physikalische Instrumente, deren Anzahl seit der Mitte des Jahrhunderts deutlich zunahm. Augenscheinlich hing das mit Joseph Walcher zusammen, der am Lyzeum als Lehrer tätig war und später in Wien als Wasserbauer bekannt wurde. ${ }^{72}$ Vermutlich war auch das "physikalisch-

62 Promitzer/Speta, Naturgeschichte, 64 .

63 Schrank/Moll, Briefe, 5 ; vgl. ebd., 7- i 8.

64 Promitzer/Speta, Naturgeschichte, $54-58$.

65 Nicolai, Beschreibung, 5 I 4 .

66 Schrank/Moll, Briefe, I- I 8.

67 In Wien war dies mit dem »Collegium« und dessen Garten I 784 passiert - Klemun, Exotik, 328.

68 Awecker, Bergschlößl, 204f.; Promitzer/Speta, Naturgeschichte, 59 f. u. 66; vgl. LZ/IB, г 0.5.I 830.

69 LR BIIA 3 o, Reg. I 8478 (Iо6-I I3); LR E7a u. b, Reg. 33 (I I).

70 Vgl. dazu allgemein: Sommer/Müller-Wille/Reinhardt, Handbuch, 235 f. u. Hochadel, Wissenschaft, 3oof.

7I Stauber, Ephemeriden, 48; Kunstdenkmäler, Bd. I, i I 5 u. I I 9.

72 Kunstdenkmäler, Bd. I, I I 7; LR CIIIC 3 , Reg. 728 (3 Io); Pillwein, Linz, Bd. I, 32. 
mathematische Kabinett«, das ab 1756 für Unterrichtszwecke genutzt wurde, ebenso eine Initiative Walchers. ${ }^{73}$ Dafür gab es ein regionales Vorbild: Im rund 30 Kilometer von Linz entfernten Stift Kremsmünster bestand ab I747 eine »mathematische Stube« mit Messgeräten und ab I748 wurde dort der "Mathematische Turm» (die Sternwarte) errichtet. ${ }^{74}$ Aus dem jesuitischen »Kabinett «, das I759 einen eigenen Saal erhielt und für Besucher geöffnet wurde, ${ }^{75}$ entstand nach der Aufhebung des Jesuitenordens I773 ein semiöffentliches »Museum Physicum«, das zunächst noch im Kolleg verblieb, dann - gemeinsam mit der Jesuitenbibliothek - ins Schloss übersiedelte und ab I784 im aufgehobenen Kloster Baumgartenberg (heute Klosterhof) untergebracht wurde. ${ }^{76}$ Finanziert wurde das Museum durch die Landstände, die Leitung blieb beim Lyzeumprofessor (und Ex-Jesuiten) Franz Xaver Racher. ${ }^{77}$ Die zeitgenössische Beurteilung des Museums divergierte: Franz de Paula Schrank gab sich bei seinem LinzBesuch beeindruckt und empfahl eine Besichtigung der zahlreichen "Maschinen « ${ }^{78}$ Eine I $_{7} 8$ erschienene Satire kommentierte die Sammlung und die dortigen Experimente spöttisch: »ich versteh nichts von diesen Instrumenten, und Experimenten; ich bewundere nur so, wie es auch andere Zuseher bewundern, wenn er [Racher] auf dem Feuer zuwege bringt, daß ein blauer Dunst in die Höhe steigt «. ${ }^{79}$ Im Frühjahr I 784 ließ Racher einen Wasserstoffballon im großen Landhaussaal steigen und kündigte dabei einen größeren Folgeversuch im Freien an. ${ }^{80}$ Dies war möglicherweise auch ein Versuch, das schmale Budget der Sammlung, das von den Ständen zur Verfügung gestellt wurde, auszuweiten. ${ }^{81}$ Der zweite Ballonstart beim Bergschlössl im September I784 war ein lokales Großereignis mit »zahlreiche[r] Gegenwart des hohen und niederen Adels« und "Zulauf des Volkes«: Zwei 6o Zentimeter große Ballone, der erste »durchsichtig mit goldenen Blumen« und der zweite aus »roth[en] und grünen $\mathrm{Ku}-$ gelschnitten zusammengesetzt, und wechselweis mit goldenen Rösgen[,] Adlern und Blumensträussen geziert«, stiegen auf eine Höhe von über 400 Metern und lieferten damit ein "hierorts niemals gesehene[s] Schauspiel « angewandter Naturwissenschaft. ${ }^{82}$ Die Prekarität der Sammlung scheint aber dennoch weiter bestanden zu haben: Nur

73 Pillwein, Wegweiser, Ir 8; vereinzelt wird auch 1764 als Gründungsdatum des Kabinetts angegeben Promitzer/Speta, Naturgeschichte, 58; vgl. zu Augsburg und anderen deutschen Schulen: Hochadel, Wissenschaft, I $20-139$.

74 Schwab/Schwarz/Wenzel, Beobachtungen, 8- ro.

$75 \mathrm{LR} \mathrm{CIIIC}_{3}$, Reg. 80r (344).

76 Kunstdenkmäler, Bd. I, I 17f.; Pillwein, Wegweiser, I 18; Gielge, Beschreibung, r65; LR BIIG6, Reg. 3792 (273).

77 LR CIIIDI-3, Reg. 3 I9 $(23$ I-236).

78 Schrank/Moll, Briefe, 2; vgl. zu den elektrischen Maschinen: Hochadel, Wissenschaft, 73-85.

79 Gimpel Insel, гог.

8o LR E/a u. b, Reg. 72 I ( I77); vgl. EdN, s.v. Ballonfahrt; Csendes/Opll, Wien, Bd. 2, 33 u. Hochadel, Wissenschaft, 298-300.

8I LR BIIA7, Reg. I0340 (243f.).

82 LZ, I 7.9.1 784 (Zitat); ebd., I0.9.I 784; Awecker, Bergschlöß1, 203f.; Kutschera, Luftfahrt, 43 of. 
punktuell wurde der Ankauf neuer Geräte durch die Stände bewilligt, wenngleich I 795 die erhebliche Summe von 400 fl für eine Elektrisiermaschine, die vermutlich aus Krumau stammte, aufgewandt wurde. ${ }^{83}$ Berichte aus den I 8 Ioer Jahren konstatieren »eine Menge mathematischer und physikalischer Instrumente «, aber Geldmangel und insgesamt "wenig bemerkenswerthes «. ${ }^{84}$ In den I 8 3oer Jahre verfügte das "physikalische Museum « immerhin über sieben Zimmer und ein Labor und bestand aus rund 500 Objekten, darunter - neben der Elektrisiermaschine - „viele « Thermometer und Barometer, Uhren, Luftpumpen, Hohlspiegel, Waagen und zahlreiche weitere Objekte aus dem Nachlass Rachers. ${ }^{85}$

Die Errichtung eines neuen, umfassenden - und wohl auch repräsentativeren - Museums wurde von den Linzer Eliten ab den i 83oer Jahren angestrebt: I 833 kam es zur Gründung des »Vereines des vaterländischen Museums für Österreich ob der Enns mit Inbegriff von Salzburg«, der bereits im ersten Jahr seines Bestehens über 700 Mitglieder zählte. ${ }^{86}$ Wesentlich ging diese Initiative von den Florianer Chorherren und von Anton v. Spaun aus, der ab den I 82 oer Jahren Mitglied des Landtages und später ständischer Syndikus war. Spaun verfügte über zahlreiche regionale und überregionale Kontakte zu künstlerisch und wissenschaftlich Interessierten, ${ }^{87}$ er war - wie sich sein Bruder Joseph v. Spaun in den I86oer Jahren erinnerte - vom naturaffinen Vater ${ }^{88}$ und von den häufigen Landaufenthalten, auf denen die Geschwister »in den Wald [gingen,] um Blumen und Käfer zu suchen«, und »jedem Eichhörnchen nach[jagten]«, geprägt worden. ${ }^{89}$ Zunächst sammelte man bei diesem Museumsprojekt explizit auch »Natur«: Es gehe um »alle Gegenstände, welche sich auf die Geschichte und Natur von [Ober] Oesterreich beziehen und sich zur Aufbewahrung in einem Museum eignen «, ist in einer Beschreibung aus den I 84 oer Jahren zu lesen. ${ }^{90} \mathrm{Zu}$ diesem Zeitpunkt befand sich die Sammlung - unter anderem Fossilien, Tierpräparate und Mineralien in mehreren Zimmern eines Gebäudes hinter dem ständischen Theater, ${ }^{91}$ sie war also noch nicht mit einer umfangreicheren Zurschaustellung verbunden. ${ }^{92}$ Wenngleich es bereits in den I 85 oer Jahren Pläne für einen eigenen Museumsbau gegeben hatte, kam es erst wieder in den I 8 joer Jahren zu konkreteren Planungen. Konzeptionelle

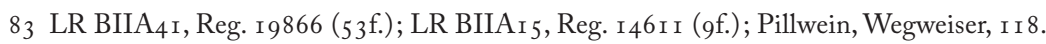

84 Heinse, Linz, r. Aufl., 4If.; vgl. Sartori, Reise, 4I 9.

85 Vgl. die Auflistung in: Pillwein, Beschreibung, 225-227; LR BVI 3 , Reg. I684 (88f.).

86 Heinse, Linz, 2. Aufl., 32; Fink, Geschichte, 92 ; Mayrhofer/Katzinger, Geschichte, Bd. 2, 92 -94; Wimmer, Geschicke, if.

87 Ebner/Ebner/Weißengruber, Literatur, I95; Fink, Geschichte, 92; OÖLA, Nachlass Familien Dierzer v.

Traunthal-Fossel, Sch. I (»Familien Chronick«, I890), pag. 3 If.

88 Franz Xaver v. Spaun - vgl. Kap. 7. Geordnete und modifizierte Umwelt.

89 Doku, Spaun, 62.

90 Kohl, Reise, $26 \mathrm{f}$.

9I Wimmer, Geschicke, rf.

92 Kunstdenkmäler, Bd. 2, 2 I gf.; vgl. Koch, Donaureise, 7 u. Wimmer, Geschicke, ${ }_{5}$ f. 
Konflikte und die Unklarheit der Finanzierung verzögerten die Umsetzung deutlich. ${ }^{93}$ Schließlich wurde ein repräsentativer Neubau ab I 884 errichtet und als »FranciscoCarolinum« (benannt nach dem den Verein protektionierenden Erzherzog Franz Carl) im Mai r 895 - in Anwesenheit des Kaisers - eröffnet. ${ }^{94}$

\section{Naturraum Um- und Hinterland}

Städter nutzten, veränderten oder schufen nicht nur Grünräume in der Stadt, sondern auch solche im Um- und Hinterland. Dabei wirkten diese Nutzungen - etwa über Naturvorstellungen - wesentlich auf die Stadt zurück. ${ }^{95}$ Nimmt man die Erwähnung in Quellen als Indikator, dann kam es in den letzten Jahrzehnten des I 8. Jahrhunderts zu einem deutlichen Anstieg der Freizeitnutzung von stadtnaher Natur, was als Ausdruck neuer Möglichkeiten und Ambitionen des expandierenden Bürgertums gedeutet wird. ${ }^{96}$

Für die erste Hälfte des i 8. Jahrhunderts sind Hinweise auf die Freizeitnutzung des Linzer Um- und Hinterlandes rar und verstreut und sie betreffen - nicht überraschend - eher Angehörige der städtischen Oberschichten. I 720 richtete der Verwalter der Linzer Niederlassung des Deutschen Ordens brieflich Grüße von drei adeligen Frauen aus, die »aus der Statt heraus spazieren gefahren « waren $;^{97}$ die Ausgabenrechnungen des Patrizierhaushaltes Thürheim dokumentieren für die I 7 I oer Jahre Fahrten - vermutlich zur Jagd - in den westlich von Linz gelegenen Kürnberger Wald und eine Fahrt nach Kirchschlag. ${ }^{98}$ Die Reiseberichte dieser Zeit, die in nicht überaus großer Zahl vorliegen, fokussierten meist nur den unmittelbaren Stadtraum, nur vereinzelt wurde das Linzer Um- und Hinterland thematisiert (und besucht). ${ }^{99}$ Ein kaiserlicher Gesandter, der auf der Donau nach Wien unterwegs war und Ende November 1698 in Linz kurz Halt machte, verwies darauf, dass im Sommer ins südöstlich von Linz gelegene Zizlau »viel von Linz herauß [...] komen hier die guete Fisch zu essen ${ }^{100}$ Es ist aber davon auszugehen, dass in der ersten Hälfte des I 8. Jahrhunderts im Linzer Um- und Hinterland einzelne Infrastrukturen der Naturnutzung bestanden. Am stadtnahen Freinberg besaß das »Jägermayrhäusl« - vermutlich ein altes Forsthaus - schon vor den I 740er Jahren ein Ausschankrecht, ${ }^{101}$ in einem Häuserverzeich-

\footnotetext{
$93 \mathrm{LR} \mathrm{BVI}_{3}$, Reg. I 749 ( I $_{5}$ 6); Wimmer, Geschicke, 5 - I 2.

94 Kunstdenkmäler, Bd. 2, 2 I 9f.; RB I 884, 23f.; RB I 895, 309 u. 3 I If.; Wimmer, Geschicke, 2 u. 38.

95 Hays, Role, $78-80$; Williams, Nature, 8o-82; Culver, Confluences, 56 If. u. 568.

96 Clark, Cities, I93.

97 LR CIIIHI -3 , Reg. 396 (25 of.).

98 LR BIIG8, Reg. 4999 (84).

99 Willebrand, Berichte, 349.

Io० Pillich, Donaureise, 509.

Iо I LR BVIII 2 , Reg. 885 (73f.); Benesch, Freinberg, Io6.
} 
nis aus dem Jahr I 77 I wurde der Jägermayr bereits als »Gastgebergütl« bezeichnet. ${ }^{102}$ Ab der Mitte des I 8. Jahrhunderts wurde zudem das ca. I 2 Kilometer nördlich von Linz und 700 Meter höher gelegene Kirchschlag zu einem Kur- und Ausflugsort der städtischen Elite. Einerseits suchte man die dortige Heilquelle auf (vgl. Kap. 3. Wasser), andererseits wurde auch die Luft zu einem Besuchsmotiv: »Die Lufft ist da so gesund «, versprach man in einer zeitgenössischen Werbeschrift. ${ }^{103}$

In den Reiseberichten, deren Zahl im letzten Drittel des i 8. Jahrhunderts und zu Beginn des r 9. Jahrhunderts deutlich anstieg, war das Lob des grünen Umlandes omnipräsent. Dass man die »Gegend « bei der Stadt als »ungemein angenehm « empfand, ${ }^{104}$ hing möglicherweise mit den topogenen Erfahrungen der nach Linz kommenden Reisenden zusammen: Wenn man donauaufwärts oder über den Landweg von Süden Linz erreichte, dann war man zumindest für mehrere Stunden in flacher, relativ unspektakulärer Landschaft unterwegs gewesen, donauabwärts kam man aus der Enge des Donaudurchbruches in »ein ungemein schönes Amp[h]itheater «, ${ }^{105}$ bei einer Annäherung aus dem Norden lag Linz weit unterhalb in einer »reizende[n] Ebene«, die sich bis zu den Bergen erstreckte, die das Alpenvorland begrenzten. ${ }^{106}$ Die Donau war ein wichtiges visuelles Element der »herrlichen Gegend «, ${ }^{107}$ sie gab »dieser schönen Landschaft noch mehr Pracht, Leben und Mannichfaltigkeit«. ${ }^{108}$ Als Mary Wollstonecraft Shelley im September I 842 von Budweis mit der Pferdeeisenbahn nach Linz kam, erlebte sie "glorious sunset « oberhalb von Linz und war von der Aussicht beeindruckt: "The prospect was extensive; varied by the lines of wooded hills and majestic mountains [...]. The Danube wound through the varied plain below [...] giving that life and sublimity to the landscape «. ${ }^{109}$ Ähnlich euphorisch waren viele Stadtbeschreibungen und Reisehandbücher: Man pries »lachende Hügel«, »Felder, Wiesen und Gruppen von Bäumen im manchfaltigsten Grün «, ${ }^{110}$ »alles dieses gewähret dem forschenden Auge einen so ergreifenden Anblick«. ${ }^{111}$ Das Umland bilde »die schönsten Parks«, wurde in einem in den I 8 2oer Jahren erschienenen »Handbuch für Reisende auf der Donau« konstatiert: Die Hügel im Norden, die Auen im Osten und Süden, die »Felsenwände und Nadelwälder« im Westen bieten »Abwechslung von Spaziergängen«, deshalb müsse man »die Linzer entschuldigen, wenn sie keine Parks oder öffentliche Gärten im englischen

\footnotetext{
I02 Bohdanowicz, Vorstädte, Bd. 2, 740; Benesch, Freinberg, I39.

I03 Mayer, Vorbericht, 5 .

I04 Burney, Tagebuch, I4I.

I05 Risbeck, Briefe, I77.

ro6 Hoff, Skizze, 9f.; vgl. Gober, Linz, I 55 - I 57.

I07 Füssel, Tagbuch, 24I.

Io8 Risbeck, Briefe, I77.

ro9 Wollstonecraft Shelley, Rambles, i gf.

I 10 Heinse, Linz, I. Aufl., 5 .

I I Pillwein, Beschreibung, 85 .
} 
Style in der Nähe ihrer Stadt anlegten «. ${ }^{112}$ Diese Sichtweise findet sich auch in einem Tagebucheintrag aus dem Frühjahr I 848: Die Umgebung des Freinbergs gleiche »einer englischen Park-Anlage«, die für das »Vergnügen für die Linzer in dem vollkommensten Zustande sei. $^{113}$

$\mathrm{Ab}$ dem beginnenden i 9. Jahrhundert weitete sich der Diskurs über Naturräume im Um- und Hinterland von Linz aus, was wohl mit einer intensiveren Nutzung dieser Räume korrespondierte. Für Wien lässt sich zu dieser Zeit Vergleichbares beobachten: In der ersten Hälfte des r 9. Jahrhunderts wurden die städtische Peripherie und der Wienerwald zu Naherholungsgebieten, die bald auch über entsprechende Infrastrukturen verfügten. ${ }^{114}$ Alltägliche Freizeitbeschäftigungen der Linzer seien, so ist in einem I 8 I I erschienenen Reisebericht zu lesen, eine "Spazierfahrt nach Ebersberg« (Ebelsberg) oder zum Jägermayr am Freinberg, eine "Excursion nach der Zizelau « oder ein »Spaziergange auf den Pöstlingberg [, wo man] sich bey vollem Glase und gedecktem Tische Vergnügen holt «. ${ }^{115}$ Viele "gardens and taverns in the vicinity are resorted to by the inhabitants as places of recreation« stellte John Murray in seinem einflussreichen, erstmals I 837 erschienenen »Handbook for travellers in southern Germany» fest. ${ }^{116}$ Franz Xaver v. Spaun, zwischen 1796 und I 804 ständischer Syndikus in Linz, unternahm weite »Spaziergänge«, und er ging - so sein Sohn Joseph v. Spaun - mit seinen Kindern an den Wochenenden »oft in einen Wald, wo er [...] mit uns spielte [,] und [er] ordnete Wettläufe und Springübungen an«. ${ }^{117}$

Bis in den Vormärz hatte sich ein Kanon des Besuchens herausgebildet, der spezifischer Orte und Routen - ältere und neuere - umfasste und auch die diesbezüglichen Infrastrukturen mit einschloss. Aufgrund der Nähe zum Stadtzentrum wurden der Freinberg und das dortige Gasthaus »Jägermayr « häufig frequentiert. ${ }^{118}$ "Wenn nicht der Jägermeyr ein so gutes Bier hätte, u. auf dem Schloßberg ein passabler Wein zu haben wäre, so müßte ich mich auf der Promenade aufhängen, mit der Überschrift: Aus Schmerz über die entflohene Linzer-Seele«, schrieb Franz Schubert im Juli I 825 an seinen Freund Joseph v. Spaun. ${ }^{119}$ Vor allem die Aussicht vom Freinberg auf Linz und die Donau wurde zu einem typischen und prägenden Sujet, das sich in zahlreichen Bildern und Photographien widerspiegelt (vgl. Abb. $30 \mathrm{u}$. das Titelbild). ${ }^{120}$ Man habe den »best point of view« von »Jägermeyer's Garden«, war Murrays »Handbook« über-

\footnotetext{
I 2 Schultes, Donau-Fahrten, I I 5 .

I 3 Záloha, Tagebücher, I 29.

I I 4 Brunner/Schneider, Umwelt, 346 u. 507.

I 5 Sartori, Reise, 424 .

I 6 Murray, Handbook, I23f.

I 7 Doku, Spaun, 35 u. 4I; vgl. Depiny, Aufzeichnungen, I 75- I 77 .

I 8 Heinse, Linz, I. Aufl., 4; Benesch, Freinberg, I 4 If.; vgl. Bohdanowicz, Vorstädte, Bd. 2 , I6 2 I.

I 9 Franz Schubert an Josef v. Spaun, 2 I.7.I 825 - Deutsch, Schubert, I I 3.

I 20 Benesch, Freinberg, I Io- I I 2 ; Záloha, Tagebücher, I 28f.; u. Deinhardstein, Skizzen, I 88.
} 
zeugt $;^{121}$ die "Aussicht « von dort »rührte [...] mein Herz«, bekannte ein Linz-Besucher des Jahres I 82 9. ${ }^{122}$ Nördlich der Donau waren der bereits erwähnte Pöstlingberg und die dörfliche Ansiedlung St. Magdalena populäre Nahausflugsziele. St. Magdalena, etwas erhöht am Abhang des Mühlviertler Hochlandes gelegen, konnte »am romantischen Gehwege« der Donau entlang »durch lachende Felder« erreicht werden. ${ }^{123}$ Auch in dem sonst relativ nüchternen "Franziszeischen Kataster fand man überschwängliches Lob für die »herrliche Aussicht« von St. Magdalena und »das diesseitige schöne[,] einem Garten gleichende Donautal, durch welches die Städter teils zu Fuß teils auf der neugebauten [Pferde] Eisenbahn fahrend lustwandeln $« .{ }^{124}$ Beim Pöstlingberg waren ebenso die land- und forstwirtschaftlich genutzten Grünräume und der Ausblick auf das Donautal und die fernen Berge im Süden Hauptanziehungspunkte. ${ }^{125}$

St. Peter und Zizlau, ein von der Landwirtschaft und von Auen geprägtes Gebiet südöstlich der Stadt, wurde von den Stadt- und Reisebeschreibungen des frühen I 9. Jahrhunderts bereits zu den »Erholungsorten « gezählt, ${ }^{126}$ wobei die Ärmlichkeit dieses peripheren Gebietes eher als Bestandteil eines ursprünglichen Landlebens romantisch erfahren und gedeutet wurde. ${ }^{127}$ Mit dem I 836 erfolgten Anschluss an die Pferdeeisenbahn, der auf die Güterbeförderung zur Donau abzielte, verstärkte sich der städtische Besuch von Zizlau deutlich. ${ }^{128}$ An den Wochenenden fuhren zahlreiche Personenwagen nach Zizlau: Gegen Ende der i $830 e r$ Jahre wurden an manchen Tagen angeblich »über 3000 Personen « befördert. ${ }^{129}$ Die Anzeige des Pächters eines Zizlauer Gasthaues aus dem Jahr I 838 sparte nicht mit lobenden Adjektiven: Zizlau liege »am reizenden Ufer der majestätischen Donau«, sei »mit schattigen Auen und herrlichen Wiesen« umgeben und weise eine »wahrhaft entzückende Aussicht der am entgegengesetzten Donau-Ufer im mahlerischen Farbenglanze prangenden Steyregger Waldgebirge « auf. ${ }^{130}$ Die Pferdeeisenbahn weitete den Radius der bürgerlichen Freizeitaktivitäten aus: Mit ihr konnte man, wie Murrays »Handbook« I 837 betonte, den »fine view« in St. Magdalena in nur zwanzig Minuten erreichen. ${ }^{131}$

\footnotetext{
I 2 I Murray, Handbook, I23-I25.

I 22 Krickel, Fußreise, I 91.

I 3 Pillwein, Beschreibung, 343; vgl. Heinse, Linz, I. Aufl., ro8.

I 24 Bohdanowicz, Katzbach, 243; vgl. Koch, Donaureise, rof. u. I 3 f u. OÖLA, Musealarchiv HS I 78 (Geschichte der Stadt Linz von Ignaz Fink, Bd. I, undat.), pag. 804.

I 5 Vgl. Pillwein, Beschreibung, 340-342; Deinhardstein, Skizzen, I 88- I 90 u. Koch, Reise, 4I.

I 26 Pillwein, Beschreibung, 354.

I 27 Kyselak, Skizzen, 408.

I 28 Fink, Geschichte, I 8 .

I 29 Heinse, Linz, 2. Aufl., 66.

I30 LZ/IB, 29.6.1838.

I3 I Murray, Handbook, I23-I25.
} 
Diese Ausflugsorte bestanden in der zweiten Hälfte des I 9. Jahrhunderts fort, wie Reiseführer und Ego-Dokumente nahelegen. ${ }^{132}$ Der Freinberg rückte in den Fokus des Verschönerungsvereins (vgl. unten), die »Spazier-Fahrten« in die Zizlau an Sonnund Feiertagen überstanden den Anschluss an die Westbahn (vgl. Abb. 28), ${ }^{133}$ auch St. Magdalena und der Pöstlingberg blieben wichtige lokale Ausflugsziele, was ein I864 erschienenes Leporello (»Panorama vom Pöstlingberg«) unterstreicht. ${ }^{134}$ Der Pöstlingberg wurde in den I $890 e r$ Jahren, was im Kontext der Errichtung von stadtnahen Zahnradbahnen (z.B. der Gaisberg- oder Kahlenbergbahn) ab den I 87 oer Jahren zu sehen ist, zudem durch eine elektrische Bergbahn erschlossen. Die Bahn, die von einem Linzer Techniker initiiert wurde, sah man als wichtiges symbolisches und touristisches Projekt für Linz, das der Urfahrer und der Linzer Gemeinderat zwar unterstützten, aber nicht finanzierten. ${ }^{135}$

Gleichzeitig weitete sich das Hinterland der Städter in der zweiten Hälfte des I9. Jahrhunderts deutlich aus. In Kirchschlag, das laut Stifter in den I840er Jahren noch ein »vereinsamter Ort « war, ${ }^{136}$ verbrachten vermögende Linzer ab der Mitte des 1 9. Jahrhunderts zunehmend ihre Sommerfrische, ${ }^{137}$ zudem wurde es von zahlreichen Tagesgästen besucht. ${ }^{138}$ Bis in die r 88 oer Jahre war »eine ganze Colonie netter Villen [... von] Linzer Familien, die hier gerne ihren Sommeraufenthalt nehmen« entstanden. ${ }^{139}$ Nahe Kirchschlag - und (zu Fuß) von Linz rund zweieinhalb Stunden entfernt - wurde auch der 927 Meter hohe Lichtenberg zu einem neuen Ausflugsziel von Linzer/innen. ${ }^{140}$ Erneut bildete neben der prekär bewirtschafteten Natur die Aussicht auf das Donautal und das nördliche Alpenvorland den Hauptanziehungspunkt. Linzer Geschäftsleute - unzweifelhaft häufige Besucher des Linzer Hinterlandes und auch generell alpinistisch interessiert ${ }^{141}$ - riefen im Frühjahr I 856 zur Errichtung einer Aussichtswarte am Lichtenberg auf, da aufgrund der Bewaldung »die volle Rundsicht fehlt«. Dazu wurden über Zeitungen »Freunde der Natur, schöner Aussichten, und unseres schönen Landes« zur finanziellen Unterstützung aufgefordert. ${ }^{142}$ Das Aufbringen der finanziellen Mittel dauerte nicht lange - bereits im Sommer i 856 konnte die

I32 Linz und seine Umgebung, I6, 2 I-25; Linz a./d. Donau, I33; Schröckinger-Neudenberg, Reisegefährte, 24; Der Oberösterreicher I 883, I 75; Commenda, Linz, 238; Stifter, PRA, Bd. 20, 275 ; ebd., Bd. 2 I, I I 5 .

I33 LAB, I6.8. I 856 .

I34 LAB, 9.r.r 864; vgl. Doku, Fossel, i 8f.

I 35 Rausch, Urbański, 333-338; vgl. LVB, I 3.r. 895 .

I 36 Haslinger, Ehrenbuch, I 2 of.

I 37 Stifter, PRA, Bd. 2 I, 4I-43.

I3 8 Ebd., Bd. 22, I 4 O.

I39 Linz a./d. Donau, I6 I.

I 40 Ebd., I6rf.; Linz und seine Umgebung, $26 f$.

I4 I Zumindest einer der damaligen Protagonisten (Johann Pollak) war an der Gründung des »Oesterreichischen Alpenvereins« im Oktober 1862 beteiligt - vgl. Linz a./d. Donau, unpag.

I 42 LAB, I o.4.I 856. 
Abb. 28: Der auf den Gütertransport abzielende Eisenbahnanschluss der Zizlau wurde auch für "Spazier-Fahrten « aus Linz genutzt, 1856

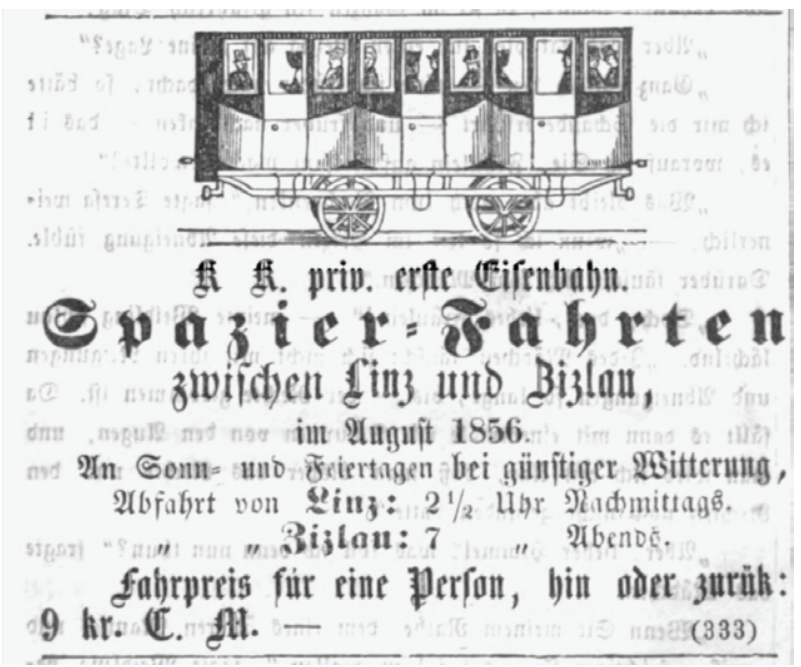

"Gisela-Warte« (aus taktischen oder patriotisch-emotionalen Gründen benannt nach der damals geborenen Kaisertochter Gisela) eröffnet werden. ${ }^{143}$ Dass die Warte ein Projekt von gut vernetzten bürgerlichen Angehörigen des Linzer Establishments war, verdeutlicht die weitere Geschichte des Bauwerks: I 866 wurde die Warte durch den Verschönerungsverein übernommen ${ }^{144}$ und ging zum Ende der I $870 e r$ Jahre an den »Oesterreichischen Alpenverein«, der I 874 eine eigene Linzer Sektion erhalten hatte, über. ${ }^{145}$ Mit den Eisenbahnanschlüssen - im Falle von Linz ab dem Ende der I 85 oer Jahre - erweiterte sich der »Aktionsradius« der naturbesuchenden Städter deutlich aus und damit die touristische Infrastruktur im Hinterland. ${ }^{146}$ "Die Eisenbahn hat es dem Städter ermöglicht, selbst für einen Tag billig und schnell einen weiteren Ausflug zu machen«, man könne - so ein Beitrag in der »Linzer Zeitung « I 866 - z. B. mit der Westbahn nach Attnang-Puchheim oder nach Straßwalchen fahren und dann weiter an den Mond- oder Attersee. ${ }^{147}$ Als man anlässlich der Hauptversammlung des Alpenvereins im Jahr I 887 betonte, dass man in Linz "an der Schwelle der Alpenwelt « stehe, bezog man dies zwar auf das nahe Alpenvorland, aber vielleicht ebenso auf die mittlerweile problemlos erreichbaren Alpen. ${ }^{148}$ Auch für die Pöstlingbergbahn wurde - zumindest in einem Vorschlag des Jahres I 895 - eine Verbindung mit dem Lichtenberg, also eine touristische Erschließung des weiter entfernten Hinterlandes,

\footnotetext{
I43 LAB, 2 I.8.I 856; vgl. LTP, I 8.7. I 896.

I $44 \mathrm{LAB}$, I 2.5.I $866 ; \mathrm{LZ}$, I 4.4. I 866.

I 45 Linz a./d. Donau, unpag.

I46 Vgl. zu Wien: Brunner/Schneider, Umwelt, $546 \mathrm{f}$.

I $47 \mathrm{LZ}, \mathrm{r} 8.5 .1866$.

I 48 Linz a./d. Donau, VI.
} 
überlegt. ${ }^{149}$ Viele Stadtbewohner/innen blieben jedoch in den stadtnahen Grünräumen: »Der Freinberg war das äußerste Ziel der damaligen Linzer«, erinnerte sich ein Linzer an seine Kindheit in den r 89oer Jahren. »Ein Ausflug war nur ein mehr oder weniger bedeutender Umweg ins Wirtshaus. Höchstens einmal im Jahr ging man [...] auf den Pöstlingberg 'wallfahrten« ${ }^{150}$

\section{Verschönerung durch Natur}

Prominent auf der ersten Seite platziert wurde im April I 865 über eine Linzer Tageszeitung die bevorstehende Gründung eines »Verschönerungs-Verein[s] für Linz« angekündigt. Zahlreiche deutsche Städte hätten bereits »Lokalvereine, welche dahin wirken, die Umgebungen durch Anlage und Erhaltung von Wegen, Spaziergängen, Baumpflanzungen u. dgl. zu verschönern und überhaupt den Sinn für das Schöne zu heben«. In Linz gebe es einen »Mangel guter, beschatteter Zugänge zum Freinberge, zum Pöstlingberge, nach Magdalena u.s.w.«. ${ }^{151}$ Wenngleich es somit um die Verbesserung von schon bestehenden stadtnahen Ausflugszielen ging, hing die Vereinsgründung auch wesentlich mit einer Unzufriedenheit an visuellen Aspekten der Stadt bzw. mit wahrgenommenen Defiziten städtischer Sauberkeit zusammen (vgl. Kap. 7. Geordnete und modifizierte Umwelt). Es war eine bürgerliche Initiative, die von Zeitungsredakteuren und einem Gemeinderat, der zudem Mitglied in der oberösterreichischen Landwirtschaftsgesellschaft war, ausging. ${ }^{152}$ Die Gründung sah man auch als Positionierung in der Konkurrenz um touristische Besucher/innen, wie I 866 auf der ersten Generalversammlung betont wurde: Durch den Eisenbahnanschluss habe der Stadtbesuch »bedeutend« abgenommen; viele Reisende, die nach Salzburg, Gmunden und Ischl unterwegs seien, würden »im Fluge in der unmittelbaren Nähe der Stadt Linz« vorbeifahren. Die Aufgabe des Verschönerungsvereins und der Stadt Linz sei es, den Tourismus zu befördern, dazu müsse die Stadt selbst "freundlicheres Aussehen gewinnen «. ${ }^{153} \mathrm{Zu}$ Beginn des Jahres I 866 hatte der Verschönerungsverein bereits 642 Mitglieder, was in einem Budget von I.284 fl (plus Spenden) resultierte, und bis zum Ende des I9. Jahrhunderts stieg die Zahl der Mitglieder auf knapp über r.ooo an. ${ }^{154}$ Indes scheint der Verein selbst nur von wenigen Akteuren getragen worden zu sein: Bei der Generalversammlung des Jahres I 866 waren nur 26, zwei Jahre später sogar nur r 6 Vereinsmitglieder anwesend. ${ }^{155}$ Erste Projekte des Vereines bildeten die

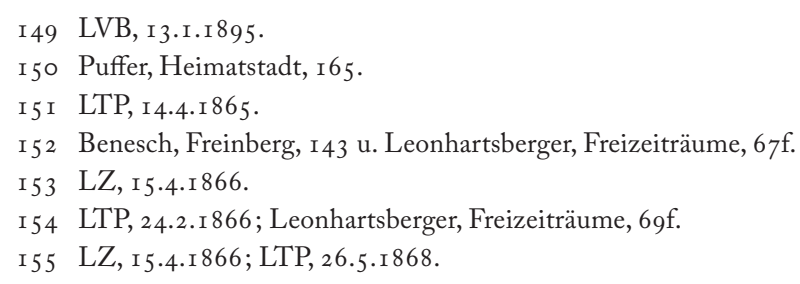


Neuerrichtung eines Fußweges zum Freinberg (und über denselben zur Donau) und die Aufstellung von Bänken beim Volksgarten, ${ }^{156}$ wobei der Fußweg - das ermöglichten die personellen Überschneidungen zwischen Verein und Gemeinderat - teilweise durch die Stadt Linz finanziert wurde, ${ }^{157}$ und I 87 I pachtete der Verein am Freinberg oberhalb des Jägermayr eine kleine Waldfläche. ${ }^{158}$ Einerseits waren die Vereinsaktivitäten eine Reaktion auf das Anwachsen der Stadt und den damit verbundenen Verlust von stadtnahen Grünräumen (und auch auf analoge Initiativen in anderen österreichischen Städten), andererseits kreierten und gestalteten Angehörige der städtischen Elite Infrastrukturen und Naturräume zur eigenen Nutzung: Nicht nur Bürgermeister Karl Wiser, lange im Vorstand des Verschönerungsvereins tätig, war als regelmäßiger Spaziergänger und Besucher des Freinberges bekannt. ${ }^{159}$ Aber auch eine tatsächliche »Verschönerung" der Stadt, also eine Beseitigung von in visueller Hinsicht Störendem, war Teil der Agenda: I 866 sah man im Verschönerungsverein durch »die vielen Schweinställe und den abfließenden Unrath« an der städtischen Peripherie den »Spaziergang auf den Jägermayrberg gefährdet «. ${ }^{160}$ I 87 I dachte man diesbezüglich darüber nach, mit finanziellen Anreizen die Hausbesitzer zu überzeugen, »ihre Gartenzäune u. dgl. in besseren, gefälligeren Stand zu setzen «. ${ }^{161}$ Somit beteiligten sich derartige Initiativen am Diskurs zum Bild einer »modernen«, zeitgemäßen Stadt, und sie beeinflussten - über die Verbindung von Hygiene mit Visualität - vermutlich auch die Wahrnehmung von Umweltproblemen.

Während der I 87oer und I 88oer Jahre wurden weiterhin zusätzliche Wege angelegt (resp. ausgebaut), Bänke aufgestellt und zahlreiche Bäume gepflanzt. Diese Pflanzungen erfolgten meist in Form von Alleen, oft in Kooperation mit der Stadt, mitunter kofinanziert durch Linzer Institutionen oder Privatpersonen. ${ }^{162}$ Zudem beteiligte sich der Verschönerungsverein an der »Schaffung eines Naturparkes« am Bauernberg, der aus den Flächen des Linzer Brauunternehmers Hatschek entstehen sollte. ${ }^{163}$ Nachdem man in den I $890 e r$ Jahren konstatiert hatte, dass die geringe Humusschicht den Baumbestand geschädigt habe, initiierte der Verschönerungsverein eine Umgestaltung der Promenade. Insgesamt wurden rund I. Ioo Tonnen Ackererde angeschüttet und zahlreiche Neupflanzungen vorgenommen, die in einem deutlichen Gegensatz zu der vorigen Alleegestaltung standen (vgl. Abb. 29). ${ }^{164}$

\footnotetext{
I56 LTP, I 5.6.1865; Linz und seine Umgebung, I 5 .

I57 LAB, 30.1 I.I 865; LZ, 24.2.1866.

I 58 Leonhartsberger, Freizeiträume, 62.

I59 Adam, Wiser, $329 f$.

I60 Benesch, Freinberg, I 96.

I6 I Ebd., I 85; vgl. ebd., I96.

I62 AStL, Alte Registratur, Sch. I 44; Leonhartsberger, Freizeiträume, 62f. u. 7 If.; RB I 879- I 880, 84.

I63 RB I 885, I07.

I64 RB I 895, 208-2 го; RB I 896, I74ff.
} 
Der Freinberg blieb jedoch deutlich im Fokus des Vereins: Bereits I 873 war auf der Spitze des Freinberges (auch als Kalvarien- resp. Galgenberg bezeichnet) ein hölzerner Aussichtsturm errichtet worden, I 883 hatte der Verein - kofinanziert durch die Linzer Sparkasse - das gepachtete Waldstück erworben und es explizit zum »Stadtwäldchen« erklärt. Obgleich man es als »spezielles Schutzobjekt « deklarierte, erfolgten zahlreiche Umgestaltungen. ${ }^{165}$ Nachdem der reparaturbedürftige Aussichtsturm I 883 abgerissen worden war, wurde Ende der I $880 e r$ Jahre durch den Verein ein steinerner Neubau errichtet, den man - als sich eine Koinzidenz mit dem Jubiläum der Kaiserkrönung ergab - im Sommer I 889 als »Franz-Josefs-Warte« eröffnete, welche als wichtiger Teil der stadttouristischen Infrastruktur verstanden wurde. ${ }^{166}$ Tatsächlich zählte man im Jahr I 889 über 7.000 zahlende Turmbesucher - die Mehrzahl wird jedoch aus Linz gekommen sein: I 89 I standen 8.220 einheimische 990 fremden Besuchern gegenüber. ${ }^{167}$ Ein touristisches Produkt war auch das I 893 vom Verschönerungsverein herausgegebene Faltpanorama, das die Aussicht von der Warte am Freinberg dokumentierte und benannte (vgl. Abb. 30). ${ }^{168}$

Zum Ende der I $890 e r$ Jahre erweiterte der Verein den Besitz beim Stadtwäldchen auf rund 6 Hektar. "Abgesehen von der herrlichen Luft im Stadtwalde sei die Aussicht dort so schön $u$. abwechselnd wie es bei wenigen Landeshauptstädten der Fall sein dürfte«, argumentierte man auf der Generalversammlung im Herbst i 899. Dabei zielte man jedoch nicht auf die Schaffung eines Naturraumes ab, sondern war eher an einem »Park mit schönen Fahrwegen u. ebensolchen Promenade-Wegen« interessiert. ${ }^{169}$ Die Divergenzen um die Errichtung einer Straße durch das Stadtwäldchen im Frühjahr I 900 geben Einblick in die Naturbilder bürgerlicher Stadtbewohner/innen. Die Vereinsleitung plädierte für die Straße: Es müssten für die Besucher »harmonische moderne Fahrwege « angelegt werden, ohnehin habe man die Planung an Gelände und Natur angepasst. Der Widerstand sei eher eine prinzipielle "Animosität gegen jede Neuanlage, wo ein alter Baum weichen müsze; wir haben dieß bei der PromenadeErneuerung u. Volksgarten-Erweiterung erlebt«. Tatsächlich äußerte ein Beamter »Bedenken wegen etwaiger Beseitigung schöner alter Bäume, bisheriger Waldwege u. wünscht die Schonung aller Bäume, [man solle] lieber einen alten Straszenzug erweitern u. verbeßern ${ }^{170}$ Ein Arzt forderte, das Wäldchen »intakt« zu lassen, er wünsche sich »im Walde vollkommene Ruhe, ganz staubfreie Luft «. ${ }^{171}$ Ein anderes Vereinsmitglied befürchtete ebenso Beeinträchtigungen durch den Straßenstaub und deklarierte sein Auftreten gegen die Straße als »Schutz [... der] Einheimischen«, denn diese

I65 Leonhartsberger, Freizeiträume, 62; Benesch, Freinberg, I 24; RB I 889, 205.

I66 Benesch, Freinberg, I 29 u. I70-I 74; vgl. RB I 889, I63.

I67 RB I889, 205; RB I89I, I8I.

I68 Vgl. RB I 892, I 84 .

I69 Benesch, Freinberg, I 92 ; Leonhartsberger, Freizeiträume, 62-65; RB I 900, 20 I.

I 70 Benesch, Freinberg, I 25 ; vgl. LTP, 9.5. 1900.

I 7 I Benesch, Freinberg, I 25 . 


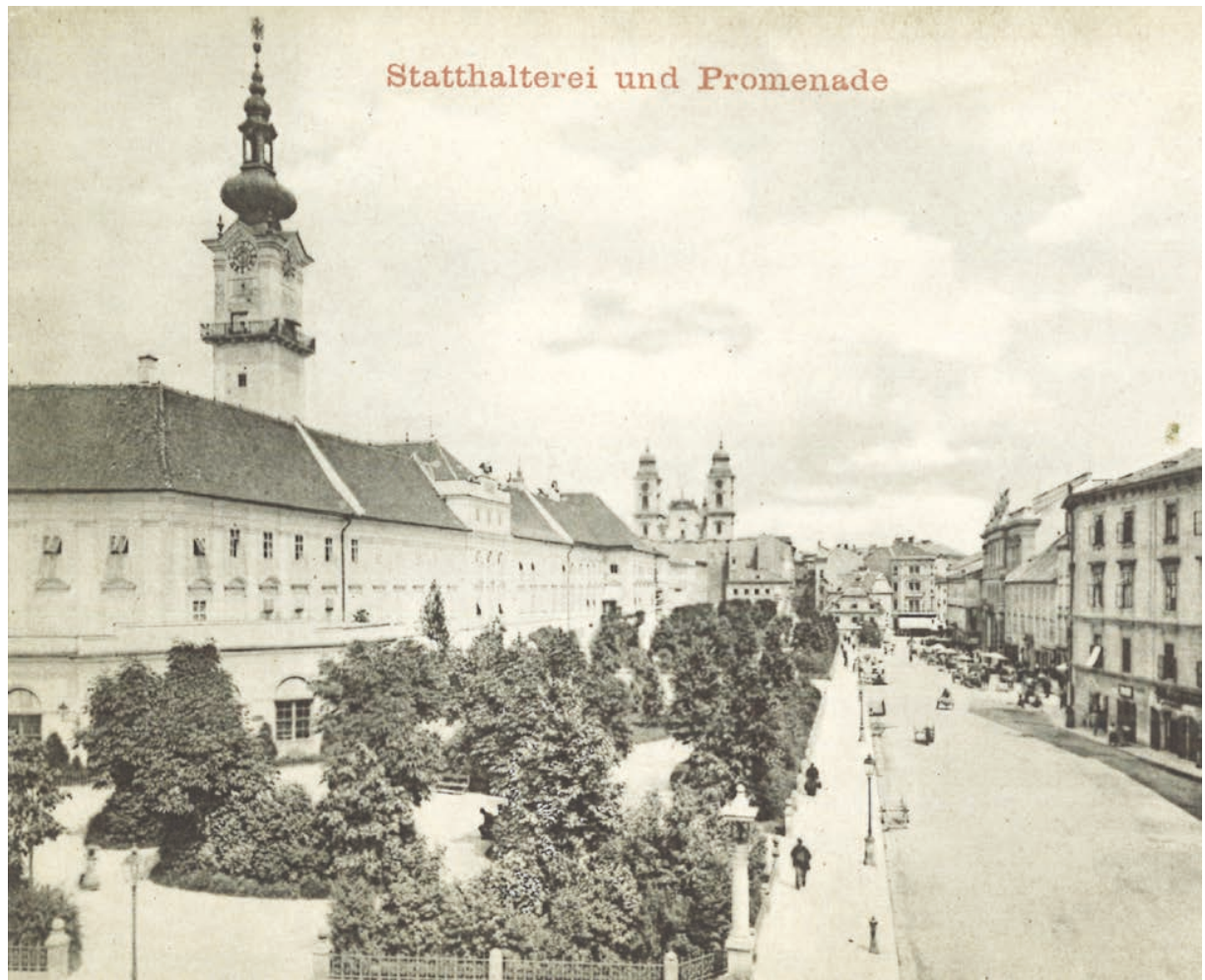

Abb. 29: Die Promenade nach der durch den Verschönerungsverein initiierten Umgestaltung in den 189oer Jahren - der Alleecharakter ist verschwunden, um 1900

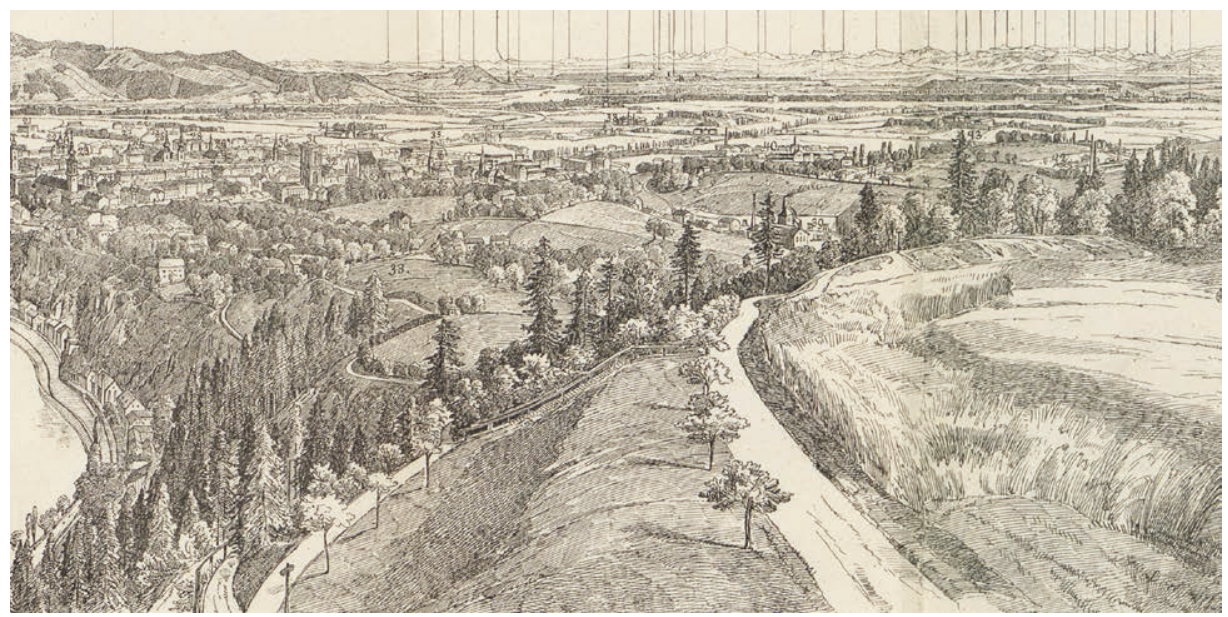

Abb. 30 : Ideale Natur mit Infrastruktur - Blick auf Linz (im Hintergrund links), das "Stadtwäldchen “ (rechts) und die Wege des Verschönerungsvereins von der »Franz-Josefs-Warte« am Freinberg aus, 1893 (Ausschnitt) 
würden ohnehin »nicht fahren, sondern zu Fuss den Stadtwald besuchen «. ${ }^{172}$ Über das "praktische u. schöne« Straßenprojekt und dessen touristischen Relevanz bestand schließlich aber Konsens - es wurde "per majora angenommen. ${ }^{173}$

I72 Ebd., I25.

I73 Ebd., I25f. 


\section{Epidemie}

\section{Die letzte Pest}

In der Forschung gilt Pest als spezifische Infektionskrankheit, die durch das (in den I $890 e r$ Jahren entdeckte) Bakterium Yersinia pestis ausgelöst wird - sie kann somit als Impact der Natur auf die Gesellschaft gesehen werden. In den europäischen Städten trat die Pest regelmäßig bis ins ausgehende I 7. Jahrhundert epidemisch auf, zur letzten Pestepidemie im Alpenraum kam es I 7 I 3/I 7 I 4. Prinzipiell kann zwischen der weniger letalen Beulenpest und der hochansteckenden Lungenpest, die in einer hohen Mortalität resultierte, unterschieden werden. Die "retrospektive Diagnose« ist aber schwierig, da eventuell auch andere Infektionskrankheiten als »Pest « tituliert wurden oder Epidemien eine Mischung verschiedener Krankheiten bildeten. Insgesamt waren Epidemien im I 8. Jahrhundert nicht ausschlaggebend für die hohe städtische Mortalität, sondern eher endemisch auftretende Infektionskrankheiten. ${ }^{1}$ Die Pest trat auch im Linzer Raum - nach den Epidemien von r678/1679 und r683/r684 - in den Jahren I7 I 3/ I 7 I 4 zum letzten Mal auf. ${ }^{2}$ Linz selbst war kaum betroffen - vermutlich gab es nur einzelne pestbezogene Todesfälle -, in Urfahr starben aber insgesamt 60 Menschen an der Pest. ${ }^{3}$ Es war somit keine schwere Epidemie, auch nicht in Wien, wenngleich es dort mehrere tausend Tote gegeben hatte. ${ }^{4} \mathrm{Zu}$ dieser Zeit bestanden es bereits verschiedene Gegenmaßnahmen und Infrastrukturen, die beim - oder kurz vor dem - Auftreten der Pest aktiviert wurden. Seit dem I6. Jahrhundert hatte sich eine Reihe von Praktiken herausgebildet, die eine Mischung aus präventiven und reaktiven Maßnahmen darstellten: Man intensivierte die Kontrollen an den Landesgrenzen und verhängte Quarantäne in Verdachtsfällen. Beim Auftreten von Pestsymptomen wurden die Betroffenen isoliert und geordnet betreut, die Wohnungen gesperrt, der Warenaustausch und das öffentliche Leben partiell beschränkt, z. B. Messen, Märkte oder der Schulunterricht temporär abgesagt. ${ }^{5}$

Dies wurde größtenteils auch bei der Epidemie I7I3/I7I 4 in Linz und Urfahr umgesetzt. Linz verfügte seit dem I6. Jahrhundert über ein Pestlazarett, das in den r640er Jahren in ein Haus an der städtischen Peripherie im Wörth bei der Ludl verlegt

I Reith, Umweltgeschichte, 93f. u. 97- Ior ; EdN, s.v. Pest; Leven, Ratten, I If.; Schott, Urbanisierung, I 78 f.; vgl. zu Wien: Weigl, Wandel, r63 u. I68 u. Reichert, Pest.

2 Mayrhofer/Katzinger, Geschichte, Bd. I, 28 f. u. 3 I 2 ; Pillwein, Linz, Bd. I, 2 oof.

3 LR Era, Reg. I25 (3of.); ebd., Reg. I26 (3I); in Regensburg war die Pest mit mehr als 7.00o Toten deutlich stärker aufgetreten: Kellner, Pesthauch, ro8 - i io.

4 Weigl, Wandel, 229 u. 364.

5 EdN, s.v. Pest; Reith, Umweltgeschichte, 2 I ; vgl. Kellner, Pesthauch, 89- I04. 
worden war und - außerhalb der Pestjahre - als Krankenhaus genutzt wurde. ${ }^{6}$ Die Stadt finanzierte für diese Institution auch einen Bader, der im beginnenden I 8. Jahrhundert immerhin I62 fl erhielt, also wohl über das ganze Jahr hinweg beschäftigt war. ${ }^{7}$ Linz verfügte zu dieser Zeit offenbar nicht über einen eigenen Stadtarzt, aber die Landstände finanzierten Ärzte (»Landschaftsphysici«) und verfügten ab r 666 über ein ärztliches Gremium (»Collegium Medicum»), das eng mit der Hauptstadt Wien verbunden war. ${ }^{8}$ Vermutlich gab es damals drei für die Stadt zuständige Ärzte und einen (handwerklichen) Chirurgen, die die Stadtbevölkerung behandelten und auch für die Kontrolle von Apotheken sowie die allgemeine Aufsicht über den Gesundheitszustand der Menschen zuständig waren. ${ }^{9}$

Bereits Ende März I 7 I 3 wurde der Staat über die kaiserliche Sanitäts-Hofkommission aktiv und delegierte einen ständischen Arzt an die niederösterreichische Grenze, um vor Ort Informationen über die Situation einzuholen. Zugleich wurde eine Visitation der oberösterreichischen Apotheken angeordnet, die vermutlich auf eine Erfassung (und Kontrolle) der Medikamente abzielte, im April befahl der Wiener Hof eine "genauer Bewachtung « der oberösterreichischen Grenzen. ${ }^{10}$ Der erst im Sommer vorliegende Bericht der ständischen Ärzte war kalmierend: Die Apotheken seien gut auf die Seuche vorbereitet, man solle aber gegen Bader, Barbiere und Händler auftreten, die unberechtigt dubiose Arzneien anböten. ${ }^{11}$ Ein weiterer Bericht aus dem August I7 I3 liefert Einblicke in ländliche Praktiken des Umgangs mit der Seuche, illustriert aber auch die Ratlosigkeit der akademischen Medizin: Die Medikamente würden nicht helfen, da sie zu spät eingenommen würden. Der "gemaine Mann und d(e)ß Paurn Volckh« würden »allezeit denen Marckhtschreiern und Paadern mehr Credit alß denen Medicis beylegen«, auch verbrenne man nur selten die Hinterlassenschaft von Seuchenopfern oder missachte beim Verbrennen basale Vorsichtsmaßnahmen. Als Prophylaxe empfahlen die Ärzte kleine hölzerne Behältnisse, die mit »guten« Riechstoffen angefüllt und um den Hals getragen werden sollten. ${ }^{12}$

Nachdem aufgrund der Pest bereits beim Ostermarkt der Handel mit einzelnen Waren (Fellen, Wolle und Altkleidung) beschränkt worden war, dachte die Obrigkeit

6 AStL, Altakten, Sch. I67; im I9. Jahrhundert war das heute nicht mehr bestehende Gebäude Gebärund Findelanstalt (Lederergasse 33, Konskr.-No. 366 - Kreczi, Häuserchronik, I43); vg1. zu Regensburg: Kellner, Pesthauch, 98 u. allgemein zu den Pestlazaretten: Scheutz, Pestspitäler, 259-265; Abb. I6 zeigt Pläne aus den $1840 e r$ Jahren.

7 AStL, HS 63 (Kammeramtsrechnung I 700), 96a u. b; vgl. LR BIIG 4, Reg. 24I6 (I4I-2 II).

$8 \mathrm{LR} \mathrm{BIIG}_{4}$, Reg. 2215 (5f.); Stauber, Ephemeriden, 75; LR BIIA 5 , Reg. 6580 (13 I).

9 LR BIIA 4, Reg. 5 I 36 ( I 28); vgl. dazu die Regelungen für die Steiermark in den I 740er Jahren - Macher, Handbuch, Bd. I, 50 u. 54 .

Io OÖLA, Landschaftsakten, Sch. I 220, J.III.2/No. 20.

I I OÖLA, Landschaftsakten, Sch. I 220, J.III.2/No. 2 I.

I2 OÖLA, Landschaftsakten, Sch. I220, J.III.2/No. 21; vgl. LR BIIA4O, Reg. 19793 (I64); vgl. Kellner, Pesthauch, 94 f. u. I 23 - I 29. 
anlässlich des im August stattfindenden Bartholomäusmarktes über einen Ausschluss von Händlern und Besuchern aus von der Pest betroffenen Gebieten (Regensburg und Innviertel) und von jüdischen Händlern aus Böhmen und Mähren nach. ${ }^{13}$ Auf Anordnung der Wiener Sanitäts-Hofkommission wurde der Bartholomäusmarkt schließlich abgesagt, wobei aber dennoch der Verkauf in Gewölben für einzelne auswärtige Händler und die Abhaltung der »Zahlwoche« erlaubt wurden. Zudem wurden Quarantäneregelungen (»Kontumaz«) vor der Stadt und an den Landesgrenzen in Kraft gesetzt. ${ }^{14}$ Die vermutlich in den I76oer Jahren entstandene "Seyringer-Chronik" beschreibt diese ersten Maßnahmen: Die Zugänge zur Stadt und zu den Vorstädten wurden »mit Pallisaden [...] und nötiger Wacht um und um besetzt«, die "verstorbenen Personen genau visitiert, die mit verdächtigen Zeichen befunden[,] in dem Lazarett begraben, die Häuser gesperrt, die noch gesunden Armen in die Donauinsel übersetzt, denen Armen in [Urfahr .... Brot und Almosen ausgeteilt, zu Abwendung dieses Übels öffentliche Andachten angestellt «. ${ }^{15}$ Die ersten Pestfälle traten Ende September I 7 3 in Urfahr auf und ab Ende Oktober gab es Pestkranke in der Linzer Vorstadt, die ins Lazarett im Wörth gebracht und dort behandelt wurden. Insgesamt waren es in Linz zu dieser Zeit wohl unter zehn Betroffene. Zudem bestanden, vermutlich in der Nähe des Lazarettes, ein Quarantänehaus und der Pestfriedhof. ${ }^{16}$ Die konkreten Aktivitäten der Stadt sind schwer abzuschätzen, da weder Stadtratsprotokolle noch die städtischen Ausgabenrechnungen aus dieser Zeit vorhanden sind. In den I $720 e r$ Jahren, als sich die Stadt Linz zu ihren Schulden äußerte, wurden jedoch 7.000 fl »Kontagionsunkosten « angegeben. ${ }^{17}$

Für Anfang November lässt sich ein gewisser Optimismus in den Berichten der ständischen Ärzte erkennen, da keine neuen Pestfälle in Linz aufgetreten waren. ${ }^{18}$ Doch dann kam es zu weiteren Erkrankungen, zuerst in einem Haus (vermutlich an der Landstraße), das bereits wegen eines Pestfalles gesperrt worden war, und zu einem Todesfall in der westlichen Vorstadt. Zu diesem Zeitpunkt befanden sich 25 Personen, darunter 5 Kinder, in Quarantäne. ${ }^{19}$ Mitte November gab es in Linz keine neuen Erkrankungen, von den sich in Quarantäne befindlichen Menschen wies niemand mehr Symptome der Pest auf, im Lazarett waren von vier oder fünf Erkrankten bereits drei

I3 OÖLA, Weinberger Archivalien, Sch. 58, No. I: Bei den jüdischen Händlern "gibts allerhandt bedenckhen wegen der disen Volkh angeartheten Vnsauberkheit, Wuecher, und geiz«, so die Landstände in einem Bericht an den Kaiserhof - vgl. zu den antijüdischen Stereotypen und den Kontexten: Stöger, Märkte, r64f. u. 237 f.

${ }_{4}$ OÖLA, Landschaftsakten, Sch. I 220, J.III.2/No. 24; LR BIIA4, Reg. 4697 (52); LR BIIG3, Reg. 2 I 40 (1 95); LR E6 (»Seyringer-Chronik«), ıo8f.

I5 LR E6 (»Seyringer-Chronik«), ro8f.

I6 OÖLA, Weinberger Archivalien, Sch. 58, No. I; OÖLA, Landschaftsakten, Sch. I 220, J.III.2/No. 22.

$17 \mathrm{LR} \mathrm{BIIG}_{4}$, Reg. 2397 (I25-I33).

I 8 OÖLA, Weinberger Archivalien, Sch. 58 , No. I - Berichte liegen für November und Dezember I 7 I 3 vor.

I9 Ebd.; vgl. LR BIIA 39 , Reg. 19457 (I 2 I). 
rekonvaleszent. ${ }^{20}$ Schließlich scheinen in Linz die letzten mit der Pest zusammenhängenden Erkrankungs- und Todesfälle im Dezember aufgetreten zu sein, die staatliche Überwachung des Gesundheitszustandes (durch die ständischen Ärzte) wurde aber weiterhin aufrechterhalten. ${ }^{21}$ Im Spätherbst, zum Höhepunkt der Seuche, begann eine öffentliche Sammlung für die Errichtung einer Steinsäule am Hauptplatz, die der Dreifaltigkeit, der Mutter Gottes und dem Kaiser huldigte und um Abwehr von Pest, Feuer und Krieg bat (»ob pestem, ignes, bella amota«), als Kofinanziers traten die Stadt und die Landstände auf. Angeblich hatte man ein derartiges Denkmal, das als Bewältigungsstrategie gedeutet werden kann, bereits nach dem Seuchenjahr I679 und der erfolglosen Belagerung von Wien r683 versprochen. ${ }^{22}$ Die Steinsäule wurde I 7 I 7-I723 als »Dreifaltigkeitssäule« errichtet, und sie orientierte sich in gestalterischer und symbolischer Hinsicht wesentlich an der Pestsäule am Wiener Graben. ${ }^{23}$

Die Ortschaft Urfahr, die zu dieser Zeit vermutlich rund tausend Einwohner/innen hatte, ${ }^{24}$ erlebte einen vergleichsweise schweren Ausbruch der Pest. Akten und eine Chronik der Urfahrer Kapuziner, die die Pestkranken betreuten, dokumentieren den Verlauf der Seuche vor Ort, und sie ermöglichen auch eine von der obrigkeitlichen Sicht abweichende Perspektive. Nach den ersten der Pest zugeschriebenen Todesfällen Mitte Oktober ordnete die Landesregierung die Unterbrechung der Brücke durch das Abtragen eines Jochs an und isolierte Urfahr damit von Linz. Zwar war auch in Urfahr das ständische »Consilium« für die Seuchenbekämpfung zuständig, nunmehr aber nur noch über Anordnungen aus der Ferne präsent. ${ }^{25}$ Die Chronik der Kapuziner dokumentiert den behelfsmäßigen Charakter der Krankenbetreuung und ein Gefühl des Alleingelassenseins: Da es kein Lazarett in Urfahr gab, betreute schließlich der Vikar des Klosters mit einem Laienbruder die Pestkranken, deren Verpflegung zuerst über Spenden und später aus Klostervorräten erfolgte. Beide Pfleger waren selbst vier Wochen lang krank, ab November war ein weiterer Geistlicher tätig. ${ }^{26}$ Die Unterstützung durch die Landstände war begrenzt: Als Anfang November die Gemeinde Urfahr um Medikamente, Geld und Getreide ansuchte, wurden nur Medikamente geschickt, für das Weitere, richtete man aus, seien die jeweiligen Grundherrschaften zuständig. ${ }^{27}$ Schließlich gab es durch die Stände (300 fl), den Linzer Dechanten ( Ioo fl) die »Stadt [Linz] und Bürgerschaft « finanzielle Unterstützung, aber erst nachdem - wie die »Sey-

\footnotetext{
20 OÖLA, Weinberger Archivalien, Sch. 58, No. I.

2 I Ebd.

22 Kunstdenkmäler, Bd. I, I 55 u. I58; LR BIIA4, Reg. 47 I 4 (55); vgl. AStL, Altakten, Sch. I 46.

23 Pillwein, Beschreibung, 70; vgl. Mauelshagen, Pestepidemien, 244 u. 248; Csendes/Opll, Wien, Bd. 2, 274 f.

24 Klein, Ortslexikon, i if.

25 LR Era, Reg. I 25 (3of.); ebd., Reg. 175 (66f.); ebd., Reg. I 77 (67f.); ebd., Reg. I 84 (7 I); ebd., Reg. I 86 (78); ebd., Reg. I 88 (79); ebd., Reg. I 89 (79).

26 LR Eia, Reg. 25 (3of.); LR Erf, Reg. 198 (82).

27 LR BIIA4, Reg. 47 I I (55).
} 
ringer-Chronik« vermerkt - »die armen Leute im Urfahr an dem Rand der Donau mit ausgespannten Armen knieend, so viel sie rufen können, um Gottes und die fünf Wunden Christi willen um Hilf gebeten« hatten. Zu Beginn des Jahres I 7 I 4 war die Brücke zwischen Linz und Urfahr offenbar schon wieder passierbar und Mitte Jänner Urfahr wieder frei zugänglich. ${ }^{28} \mathrm{Nach}$ dem Abklingen der Pest wurden vom »Consilium« die Vernichtung des Gewandes der Krankenwärter des Kapuzinerklosters und deren 4otägige Quarantäne angeordnet. ${ }^{29}$ Dass diese Maßnahmen auch tatsächlich erfolgten, zeigen die überlieferten Refundierungen für vernichtete Textilien. ${ }^{30}$

Im März I 7 I4 fand der Ostermarkt wieder regulär statt, wenngleich keine Waren oder Personen aus - dem noch immer wegen der Pest gesperrten - Regensburg zugelassen waren, ${ }^{31}$ und vom Bartholomäusmarkt wurden pauschal Juden mit "giftfangenden Waren « ausgeschlossen. ${ }^{32}$ Insgesamt bleibt ein ambivalentes Fazit: Einerseits war die Eindämmung der Epidemie durch Quarantänemaßnahmen offenbar durchaus erfolgreich, andererseits resultierten die Pestpraktiken in einem ungleich verteilten Risiko und in selektiver Hilfeleistung, sie basierten auf autoritärem Handeln und einer Begrenzung individueller Freiheiten. ${ }^{33}$

\section{Epidemien und medizinische Infrastruktur: Konnex und Koevolution}

In der Forschung ist die Frage nach der Rolle von Epidemien für steigende Ambitionen der Hygiene und für die Ausweitung versorgender resp. medizinischer Infrastruktur unterschiedlich beantwortet worden. ${ }^{34}$ Pest und Cholera hat man teilweise als »Schrittmacher» oder "Ansporn « für Veränderungen gesehen, ${ }^{35}$ teilweise hat man eher auf den koevolutiven Charakter dieser Prozesse und weitreichendere Kausalitäten verwiesen. ${ }^{36}$ Betrachtet man das Beispiel Linz, dann scheinen die Pest und andere epidemisch auftretende Krankheiten maßgeblich den Umgang mit ansteckenden Krankheiten geprägt und auch erheblichen Einfluss auf medizinische Infrastrukturen gehabt zu haben: Eines der beiden städtischen Siechenhäuser - das Siechenhaus Straßfelden an der Land-

28 LR E6 (»Seyringer-Chronik«), ıo9.

29 LR Eıa, Reg. I 25 (3of.); LR Eıf, Reg. I98 (82); LR Eıf, Reg. I 99 (82).

30 LR BIIA4, Reg. 4802 (69); LR Era, Reg. I 27 (3 If.); vgl. LR BIIA4, Reg. 4760 (63); vgl. zu dieser Praxis: Kellner, Pesthauch, 94 f.

3 I LR BIA 5, Reg. 5437 (54); vgl. zu Regensburg: Kellner, Pesthauch, Io2f.

$32 \mathrm{LR} \mathrm{BIIG}_{3}$, Reg. 2 I 56 (202).

$33 \mathrm{LR} \mathrm{BIIG}_{4}$, Reg. 2255 (25); vgl. Macher, Handbuch, Bd. I, 49 u. Reichert, Pest, 34If.

34 Vgl. als Überblick: EdN, s.v. Mortalität u. Epidemie; zudem auch die Kap. 3. Wasser u. Kap. 5. Zirkulationen und Output.

35 Reith, Umweltgeschichte, 2 I u. 96f.; EdN, s.v. Umwelt; Hardy, Ärzte, 63-87; vgl. Lesky, Gesundheitswesen, I6-25; Weigl, Wandel, I $92 f$; Evans, Epidemics, I 44f.

36 Vgl. für die Cholera: Hamlin, Health, r 86f., 2 r 8f. u. 294f. u. Hamlin, Cholera; zusammenfassend: Pichler-Baumgartner, Wege, ro8- i 10. 
straße - war ursprünglich ein Pestlazarett gewesen, das zwischen dem Beginn des I 7 . und der Mitte des I8. Jahrhunderts über eine Stiftung 20 Insassen versorgte und danach (bis I 789) als Ordenskrankenhaus fungierte (vgl. unten). Im Wörth - an der östlichen Burgfriedsgrenze - war in den I640er Jahren durch die Stadt ein Pestlazarett geschaffen worden, das auch als Krankenhaus genutzt wurde. ${ }^{37}$ Gleichzeitig zeichnet sich ein Erfahren und Wahrnehmen der Pest als temporäre, nichtalltägliche Bedrohung $\mathrm{ab}$, mit deren Verschwinden auch die medizinischen und hygienischen Ambitionen wieder abnahmen. So dachten z. B. die Stände r 7 I 8 darüber nach, die Anzahl der Ärzte aus finanziellen Gründen zu reduzieren. ${ }^{38}$ Dennoch wurde - gerade im Kontext der Pest - während des i 8. Jahrhunderts ein grundsätzlicher und latenter Überwachungszustand aufrechterhalten. ${ }^{39}$ Zwischen 1728 und der Mitte des I 9. Jahrhunderts bestand in Ungarn ein ständiger "Pestkordon«, der die westlichen Teile der Habsburgermonarchie schützen sollte, ${ }^{40}$ auch die - vermutlich selbst aus dem Pestkontext stammende Wiener Sanitäts-Hofkommission existierte weiter. ${ }^{41}$ Vor Ort wurden die Häufung von Infektionskrankheiten oder der Ausbruch von Viehseuchen genau registriert, wie die Korrespondenz der Linzer Patrizierfamilie Thürheim nahelegt. ${ }^{42}$

Im I 8. Jahrhundert führten die "ansteckende[n] Krankheiten « eher in Kombination mit anderen Krisen zu einer Übersterblichkeit (vgl. Tab. 30 und Kap. Io. Versorgungskrise). ${ }^{43}$ Ein Beispiel dafür ist das epidemieartige Szenario bei der Belagerung von Linz im Winter I74I/I742: Mehrere hundert Verwundete wurden in städtischen Institutionen und Privathäusern untergebracht, zahlreiche verstorbene Soldaten hatte man in situ, in den Gärten begraben, dazu kam eine Lebensmittelknappheit. ${ }^{44}$ Dies resultierte, obwohl die fremden Soldaten Linz im Jänner I 742 verlassen hatten, in einer überdurchschnittlich hohen (zivilen) Sterblichkeit, die bis ins Jahr I743 andauerte. Und auch die hohe Sterblichkeit der Jahre I762/I 763 fiel mit einer Zeit starker militärischer Präsenz in Linz zusammen sie erhöhte offenbar die Vulnerabilität der Zivilgesellschaft (vgl. Tab. 30).

Für Linz ist ab Mitte des i8. Jahrhunderts eine Expansion der medizinischen Infrastrukturen zu beobachten, die von »oben« (durch die Stände bzw. den Staat) resp. von »außen« (durch die Neuansiedlung von Krankenpflegeorden) ausging. Ab I745 bestand für Frauen das Krankenhaus der Elisabethinen und ab I 757 für Männer das

37 Kreczi, Häuserchronik, I92, 262f. u. 301 ; Mayrhofer/Katzinger, Geschichte, Bd. I, 36r ; Knörlein, Geschichte, Io; LR BIIG 5 , Reg. 276 I (I I 7 ).

$38 \mathrm{LR} \mathrm{BIIG}_{4}$, Reg. 2237 (19).

39 Pfister, Bevölkerungsgeschichte, 42.

40 Lesky, Gesundheitswesen, I6- I8; Reichert, Pest, 35 2f.; Briese, Angst, Bd. I, 242-244; vgl. zu den Kordons und ihren Auswirkungen: Mauelshagen, Pestepidemien, 26If.

4I Lesky, Gesundheitswesen, 40-47; Macher, Handbuch, Bd. I, 55 u. LR BVI2, Reg. I 248 - I 250 (I 88 f.).

42 LR BIIG $_{4}$, Reg. 2490 (246f.); LR BIIG 5 , Reg. 2664 (85).

43 Pillwein, Wegweiser, 39.

44 LR Eic, Reg. 297 (I09- I I ); ebd., Reg. 2974 (I I If.); LR CIIIC 3 , Reg. 6 Iо (257); LR BIIA40, Reg. I 9799 (I66f.); LR BVI2, Reg. I 246 (I 87 ). 
Tab. 30 : Sterbefälle in der Pfarre Linz, 1710-1715, 1730-1744 und 1758-1767

\begin{tabular}{lcc}
\hline Jahr & Anzahl & pro 1.00o Einwohner \\
\hline 1713 & 423 & 33,05 \\
1714 & 409 & 31,71 \\
1715 & 559 & 43,00 \\
Mittelwert 1710-1719 & & 35,20 \\
1736 & 517 & 34,24 \\
1737 & 525 & 34,54 \\
Mittelwert 1730-1739 & & 35,51 \\
1740 & 618 & 39,87 \\
1741 & 916 & 58,72 \\
1742 & 1.259 & 80,19 \\
1743 & 860 & 54,43 \\
Mittelwert 1735-1744 & & 45,33 \\
1761 & 618 & 39,87 \\
1762 & 916 & 58,72 \\
1763 & 1.259 & 80,19 \\
1764 & 860 & 54,43 \\
Mittelwert 1758-1767 & & 41,35 \\
\hline
\end{tabular}

Quelle: Eigene Berechnungen basierend auf Datenbank Sterbefälle; Benedikt Pillwein gab für die Jahre 1713-1715, 1736/1737 und 1772 "ansteckende Krankheiten « an (Pillwein, Wegweiser, 39)

Krankenhaus der Barmherzigen Brüder; beide waren der Aufsicht der Landschaftsärzte unterstellt. ${ }^{45}$ Gegen die Etablierung der Krankenhäuser hatte es Widerstände der Stadt gegeben, die die Ansiedlung neuer religiöser Institutionen und vor allem deren Steuerbefreiung (in Form der Freihäuser) zu verhindern versuchte. Unterstützung fanden die Orden, die auf die Defizite der vor Ort bestehenden medizinischen Infrastrukturen hinwiesen, durch die Landstände und den Staat. ${ }^{46}$ Beide Ordenskrankenhäuser verfügten aber nur über geringe Kapazitäten: Bei den Elisabethinen gab es I749 I 2 Betten, I78I I 8 Betten, bei den Barmherzigen Brüdern waren es I757 Io Betten und in den 178 oer Jahren 2 I Betten. ${ }^{47}$ Insgesamt war diese Expansionsphase von einer Absenz von Epidemien gekennzeichnet, auch sind die neuen Krankenhäuser nicht als Resultat von Epidemien zu sehen, sondern eher als eine Entwicklung,

45 Ardelt, Elisabethinen, 95, I05 u. I I i vgl. zu Wien: Csendes/Opll, Wien, Bd. 2, 3 I - 33 .

46 LR Eık, Reg. 6r 20 (г); ebd., Reg. 6г 2 I (г); ebd., Reg. 6r 24 (2); ebd., Reg. 6r 34 (9); ebd., Reg. 6I 45 (г3); LR Erd, Reg. 3253 (r6f.); LR BIX2, Reg. 436 (r 89f.); vgl. Mayrhofer/Katzinger, Geschichte, Bd. 2, 44 .

47 Ardelt, Elisabethinen, i 8 u. Losch, Tod, I4; vgl. LR Eık, Reg. 6220 (36f.). 
die sich parallel dazu in anderen österreichischen Städten zu dieser Zeit vollzog und wesentlich durch staatliche Initiativen und neue staatliche Normen in diesem Bereich begünstigt wurde. ${ }^{48}$

Eine zweite Expansionsphase in den I77oer und I 78 oer Jahren vollzog sich ebenso ohne Epidemien und ging erneut vom Wiener Hof aus: Das sehr umfangreiche »Generalsanitätsnormativum» (auch »Haupt-Sanitätsnormativ«), das in allen Erbländern gültig war, schuf I 770 permanente Sanitätskommissionen, die den Landesregierungen (also dem Staat) direkt unterstellt waren, mahnte »Vorsichten« - also präventives Handeln - gegenüber epidemischen Krankheiten ein und sah eine Berichtspflicht sowie eine Aufsicht über die im Medizinwesen tätigen Akteure vor. ${ }^{49}$ Ein im Gefolge dieser Anordnungen erstellter Bericht zur »Medizinal-Pfuscherei« gibt einen Überblick zu alltäglichen medizinischen Infrastrukturen im Linzer Raum: Namentlich genannt wurden u.a. der Bader im Linzer Lazarett, der auch innere Krankheiten behandelte, ein Bader bei den Kalvarienwänd, der ambulante Krankenbehandlung durchführte und Medikamente anbot, ein Ex-Jesuit, der Heilwässer und Pulver erzeugte, ein Bauer, der auch in Linz Operationen durchführte, drei Frauen, die Medikamente verkauften oder medizinische Dienstleistungen übernahmen, und »Wälsche Kraxentrager«, die mit medizinischen Produkten hausierten. ${ }^{50}$ In den I77oer Jahren schuf die Wollzeugfabrik - ein staatseigener Betrieb - ebenso eine neue Lösung für die medizinische Betreuung der Beschäftigten. $\mathrm{Ab}$ I 773 erhielten ein Arzt und ein Chirurg Jahresbesoldungen für die Behandlung der Fabriksangehörigen, ${ }^{51}$ später - möglicherweise seit den I 79oer Jahren - wurden dafür die Krankenhäuser der Elisabethinen und der Barmherzigen Brüder bezahlt. ${ }^{52}$

Die verstärkten medizinischen Diskurse manifestierten sich auch in der Gründung des Wiener "Allgemeinen Krankenhauses« und des "Josephinums«, die beide Projekte von Joseph II. und dessen Reformpolitik darstellten. ${ }^{53}$ I 784 meldete sich der Linzer Beamte und Schriftsteller Anton Cremeri mit einer - unter einem Pseudonym erschienenen - publizistischen Kritik an den Linzer Ordenskrankenhäusern zu Wort: Die Orden hätten damit ein "Monopolium « auf die städtische Krankenbetreuung, ${ }^{54}$ was eigentlich eine »öffentliche Angelegenheit des Staates« sei. ${ }^{55}$ Es bestehe keine Kontrolle über die Ordenskrankenhäuser, die teuer und ineffizient seien und wiederholt Kranke - da »kein Platz« gewesen sei - abgewiesen hätten. Cremeri forderte die

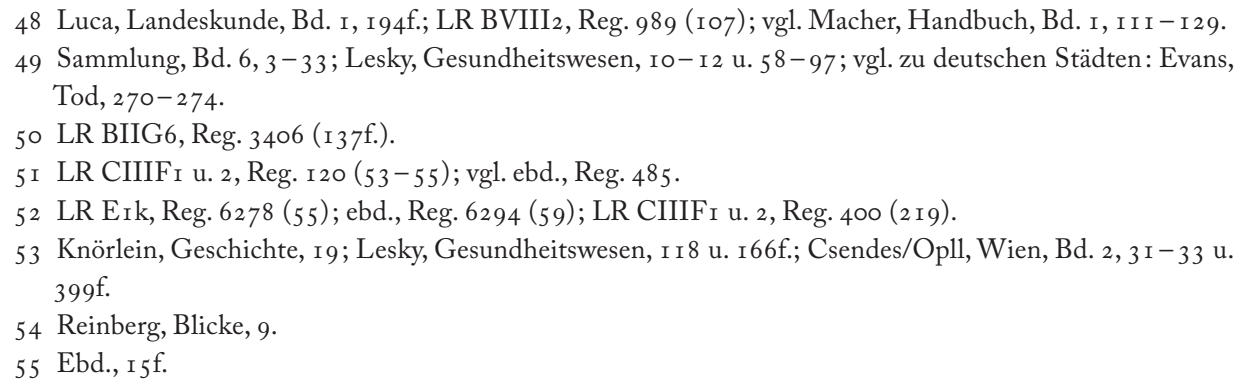


Auflassung der Ordenskrankenhäuser und die Schaffung einer säkularen und öffentlichen Lösung - ohnehin finanziere die Bevölkerung diese Krankenhäuser durch die Sammlungen und die Zuschüsse der Stadt. ${ }^{56}$ Eine ähnliche Einschätzung wurde in einer I 783 erschienenen Satire formuliert: Die Elisabethinen »meinen es gut«, sie führten ihr Krankenhaus aber relativ ineffizient. Es sei erstaunlich, welche Summen die Barmherzigen Brüder »durch Stiftungen und durch Sammeln [...] zusamm bringen «, dennoch würden sie unbemittelte Kranke oft nicht aufnehmen. ${ }^{57}$ Von den drei Ärzten in der Stadt, so die Satire weiter, vernachlässigten zwei ihre Krankendienste, einer besuche nur »aus Gefälligkeit oder alter Bekanntschaft«, nur der dritte Arzt sei "noch ohne Unterschiede thätig «. ${ }^{58}$

Tab. 31: Behandlungen und Todesfälle in den beiden Linzer Ordenskrankenhäusern, $1771-1854$

\begin{tabular}{|c|c|c|c|c|c|}
\hline & $\begin{array}{l}\text { Barmherz. Br.: } \\
\text { Kranke }\end{array}$ & $\begin{array}{l}\text { Barmherz. Br.: } \\
\text { Verstorbene }\end{array}$ & $\begin{array}{l}\text { Elisabeth.: } \\
\text { Kranke }\end{array}$ & $\begin{array}{l}\text { Elisabeth.: } \\
\text { Verstorbene }\end{array}$ & Quelle \\
\hline 1771 & 462 & 48 & 147 & 8 & LR E7a u. b, Reg. 139 (42) \\
\hline 1775 & 311 & 20 & 145 & 11 & LR E7a u. b, Reg. 198 (56) \\
\hline 1777 & 228 & 19 & 114 & 4 & LR E7a u. b, Reg. 266 (71) \\
\hline 1779 & 285 & 38 & 128 & 13 & LR E7a u. b, Reg. 398 (102) \\
\hline 1781 & 303 & 31 & 137 & 6 & LR E7a u. b, Reg. 523 (130) \\
\hline 1783 & 319 & 34 & 162 & 6 & LR E7a u. b, Reg. 705 (172) \\
\hline 1785 & 369 & - & 206 & - & LR E7a u. b, Reg. 898 (224) \\
\hline 1788 & 421 & 51 & 230 & 18 & LR E7a u. b, Reg. 1052 (265) \\
\hline 1798 & 653 & 80 & 405 & 27 & LR E7a u. b, Reg. 1502 (373) \\
\hline 1800 & 959 & 95 & 434 & 35 & LR E7e-g, Reg. 10 (2) \\
\hline 1804 & 965 & 111 & 380 & 32 & LR E7e-g, Reg. 639 (161) \\
\hline 1810 & 691 & 119 & 401 & 65 & LR E7e-g, Reg. 1745 (423) \\
\hline 1815 & $536^{a}$ & $78^{\mathrm{a}}$ & 399 & 49 & $\begin{array}{l}\text { LR E7h-j, Reg. } 2460 \text { (5) u. ebd., } \\
\text { Reg. } 2467(6)\end{array}$ \\
\hline 1838 & 1.121 & 122 & 673 & 79 & Koch, Reise, 18. \\
\hline 1842 & 1.514 & 93 & 688 & 85 & Koch, Reise, 18. \\
\hline 1850 & $\begin{array}{c}1.681 \\
\text { (plus } 783^{b} \text { ) }\end{array}$ & 123 & 1.010 & 81 & $\begin{array}{l}\text { Knörlein, Geschichte, unpag. } \\
\text { [nach 50] }\end{array}$ \\
\hline 1854 & $\begin{array}{c}1.604 \\
\text { (plus } 943^{b} \text { ) }\end{array}$ & 116 & 1.215 & 108 & $\begin{array}{l}\text { Knörlein, Geschichte, unpag. } \\
\text { [nach 50] }\end{array}$ \\
\hline
\end{tabular}

a November 1814 bis Oktober 1815

b Barmherzige Schwestern

56 Ebd., r6-i 9, 22-24, 42-44 u. 66f.

57 Gimpel Insel, 33 ; vgl. Füssel, Tagbuch, 230.

58 Gimpel Insel, I36f. 
Auch die Landesbehörden scheinen zu dieser Zeit gegen die Ordenskrankenhäuser agitiert zu haben, Joseph II. entschied sich jedoch nach einem Linz-Besuch I 786 für eine Beibehaltung dieser Institutionen, die in der Folge sogar ausgebaut wurden. ${ }^{59}$ Die Barmherzigen Brüder erhielten I 789 das aufgelassene Karmelitinnenkloster in der Herrenstraße, in dem sie ein Krankenhaus mit 4I Betten einrichteten und das vermutlich als »allgemeines Krankenhaus« (für Männer) nach Wiener Vorbild gesehen wurde. ${ }^{60}$ Auch das weibliche Pendant, die Elisabethinen, expandierte: I 790 gab es 30 und I $827 /$ I 828 bereits 50 Betten $;^{61}$ dementsprechend stieg die Zahl der Behandlungen in beiden Institutionen deutlich an (vgl. Tab. 3 I). Finanziert wurden die Krankenhäuser - 1803 gaben die Barmherzigen Brüder jährliche Kosten von rund 9.300 fl an - weiterhin über die Stiftungen, öffentliche Gelder, die Sammlungen der Orden und bürgerliches Fundraising. ${ }^{62}$ Als I 82 I die staatliche Unterstützung der Ordenskrankenhäuser wegfiel, schloss zunächst die Stadt Linz die Budgetlücke, forderte aber bald von allen Patienten »Verpflegsgebühren«, die aufgrund von Widerständen I 833 wieder aufgehoben wurden. ${ }^{63}$

Bei ansteckenden Krankheiten bildeten die Ordenskrankenhäuser eine zentrale Infrastruktur, die die Vulnerabilität der Stadt zwar reduzierte, aber schnell an ihre Kapazitäten stieß. ${ }^{64}$ An reaktiven Praktiken bestand weiterhin das Desinfizieren von Wohnungen und das Vernichten von möglicherweise infizierten Gegenständen, ${ }^{65}$ auch die Isolation von Kranken, ${ }^{66}$ dazu kamen ab dem beginnenden I 9. Jahrhundert Armenspeisungen »wegen zu befürchtender Epidemie«. ${ }^{67}$ Als neue präventive - und von staatlicher Seite forcierte - Maßnahme etablierte sich das durch den Staat forcierte Impfen: Dies betraf die regelmäßig epidemisch auftretenden Infektionskrankheit Pocken (auch "Blattern«), die in einzelnen Jahren zu einem massiven Anstieg der Kindersterblichkeit führte und gegen die zum Ende des 18. Jahrhunderts eine Impfung entwickelt wurde. ${ }^{68}$ In Linz ordneten die Landesbehörden die Pockenimpfung bei Kindern ab I 800 regelmäßig an und bezahlten wiederholt Impfprämien für die »flei-

59 Ardelt, Elisabethinen, I I 2 ; AStL, Altakten, Sch. I 66.

6o LR EId, Reg. 3820 (I 4 ); LR Erk, Reg. 6268 (52); ebd., Reg. 6270 (53); ebd., Reg. 6297 (60); vgl. Heinse, Linz, r. Aufl., 30 .

6I Ardelt, Elisabethinen, i 8.

62 LR Erk, Reg. 6297 (60); LZ, r9.4.I 8 I6.

63 LR Eri, Reg. 609r (r92f.); ebd., Reg. 6094 (193).

64 LR BIIA4I, Reg. 19865 (53); LR EIk, Reg. 628I (56).

65 LR BIIB 2, Reg. 704 (I I 4f.); LR BIIB 4, Reg. I 760 (98); vgl. Macher, Handbuch, Bd. I, 520.

66 Vgl. zum Militärspital: Knörlein, Geschichte, r4; Pillwein, Beschreibung, 265; LR E7a u. b, Reg. 1433 (354); LR BIIG7, Reg. 4345 (I69).

$67 \mathrm{LR} \mathrm{BVIII}_{2}$, Reg. I I 47 (I 5 I).

68 Clark, Cities, I I If.; EdN, s.v. Pocken; Kiple, Disease, 9- I9; vgl. zu Wien und Österreich allgemein: Pammer, Blattern, I73-176; Weigl, Wandel, 231-235; Weigl, Existenzsicherung, 80-82; Lesky, Gesundheitswesen, I4 I - I 54; Lesky, Schule, 28 -3 I. 
ßigsten Aerzte und Wundärzte«. ${ }^{69}$ Der einjährige Sohn des damaligen ständischen Syndikus erhielt bereits I798 eine Pockenimpfung. Geschehen sei dies, so dessen Bruder Joseph v. Spaun, auf Veranlassung des Vaters, der sich durch den »Schrei der Entrüstung [...] von allen uns bekannten alten Frauen«, die in der Impfung »eine offene Auflehnung gegen Gott « sahen, offenbar nicht beeindrucken ließ. ${ }^{70} \mathrm{~B}$ is in den Vormärz gab es staatlich dotierte »Impfpreise«, ${ }^{71}$ im Frühjahr I 829 wurde - aufgrund zahlreicher Krankheitsfälle - in Linz sogar eine »Gemeinde-Impfung« gegen Pocken angeordnet und die Namen von Impfverweigerern im »Intelligenzblatt« veröffentlicht. ${ }^{72}$ Parallel zur Expansion der städtischen medizinischen Infrastruktur war auch die Erwartungshaltung der Stadtbevölkerung angestiegen: In den I $820 e r$ und I 83 oer Jahren finanzierte die Stadt Linz 2 Ärzte, I Chirurgen und 3 Hebammen, ${ }^{73}$ insgesamt gab es damals in Linz I4 Ärzte, 8- ro Chirurgen ${ }^{74}$ und ca. 8o Betten in den beiden Krankenhäusern ${ }^{75}$ - dies sei »noch immer zu wenig«, konstatierte der Topograph Benedikt Pillwein I $837 .^{76}$

\section{Ferne und nahe Cholera}

Die Cholera, eine bakterielle Infektionskrankheit, erreichte im Herbst I 830 Moskau und im Verlauf des Jahres I 83 I weite Teile Zentral- und Westeuropas. Erreger und Übertragungswege der Cholera blieben bis ins ausgehende I9. Jahrhundert unklar: Analog zur Pest vermutete man zunächst eine »kontagiöse« Übertragung, also eine Ansteckung von Mensch zu Mensch, zunehmend gewannen miasmatische Überlegungen, die von einer krankmachenden Verunreinigung von Luft und Boden ausgingen, an Bedeutung. Erst in den I 88oer Jahren wurde als Krankheitserreger das Bakterium Vibrio cholerae, das gut im Wasser überlebt, identifiziert. ${ }^{77}$ In den I 83 oer Jahren existierte - vor allem basierend auf den Erfahrungen mit der Pest und den rezenteren Typhusepidemien - bereits ein Bündel an präventiven und reaktiven Maßnahmen, die auf die lokale Aufsicht durch die »vom Staate aufgestellten Fisiker« und die Vermeidung von »Sanitätgebrechen«, also besonders von Schmutz und schädlicher »Ausdünstung«,

69 LR E7e-g, Reg. 570 (138); Pillwein, Wegweiser, I47; Fink, Geschichte, 64f.; vgl. zu Niederösterreich:

Pammer, Blattern, I76- I 83 .

70 Doku, Spaun, I I 3 f.

7 I LZ, 2I.I.I 828; LZ, 23.8.I830.

$72 \mathrm{LZ/IB}, 2 \cdot 3.1829$; ebd., 23.3.1829.

73 LR E7h-j, Reg. 6438 (759); AStL, HS I 5 I (Oberkammeramt Empfang I 830), pag. I $74 f$.

74 Tafeln zur Statistik 7 (I 834), unpag.; Schematismus I 835, 4I $4 \mathrm{f}$.

75 Pillwein, Beschreibung, 262 ; Losch, Tod, I 4.

76 Pillwein, Wegweiser, 99.

77 EdN, s.v. Cholera; Kiple, Disease, 642-649; Evans, Tod, 294-296; Schott, Urbanisierung, 223 f. 
abzielten. ${ }^{78}$ Im November I 830 versuchte der habsburgische Staat - man handelte analog zur Pest - zunächst mit Sperren und Quarantänemaßnahmen durch »MilitärCordons« und mit der "Durchräucherung« von Briefen die weitere Ausbreitung der Cholera zu verhindern. Gleichzeitig wurde die Medizinische Fakultät in Wien aufgefordert, Informationen zur Krankheit zu sammeln. ${ }^{79}$

In Linz konnte man die herannahende Cholera über die Zeitungen verfolgen: Die »Linzer Zeitung" berichtete ab November 1830 über die Ausbrüche in Russland und Polen und später in Ungarn und Galizien. ${ }^{80}$ In dieser Zeitung begann im Jänner I 83 I eine Diskussion über die »besten« Vorbeugemaßnahmen gegen Cholera: $\mathrm{Zu}$ empfehlen seien - damit gab man durchaus damaliges State-of-the-Art-Wissen wieder ${ }^{81}$ - Reinlichkeit, gute, gesunde Nahrung, Lüftung der Wohnungen und Mäßigkeit ${ }^{82}$ und auch »keine Furcht ${ }^{83}{ }^{83}$ Mit der »furchtbare[n] Annäherung « ${ }^{84}$ der Krankheit an Wien tauchten im Frühsommer i 83 I die ersten Publikationen zur Cholera in den Linzer Buchhandlungen auf, 85 im August wurden im Linzer "Amtsblatt» »Verhaltungsregeln zur Bewahrung der Gesundheit« und ein »Kurzer Unterricht [...] gegen die morgenländische Brechruhr « veröffentlicht. ${ }^{86}$ Bis in den Sommer etablierte der Staat auch in Linz ein engmaschiges Monitoring: Wie bei den vorangegangenen Pestepidemien musste die Landessanitätskommission regelmäßig Statusberichte nach Wien schicken, zudem bereitete man Gebäude für Verdachts- und Erkrankungsfälle vor, korrespondierte mit auswärtigen Herrschaften und ließ Listen von »als gefährlich anerkannten « Orten zirkulieren. ${ }^{87} \mathrm{Im}$ September - mittlerweile waren in Wien über hundert Cholerafälle aufgetreten und der Kaiser war (demonstrativ) aus Baden in die Stadt zurückgekehrt ${ }^{88}$ - betonte man im Linzer »Intelligenzblatt«, dass die Sterblichkeit in Linz derzeit »keineswegs ungewöhnlich oder bedenklich « sei, ${ }^{89}$ dennoch begannen in der Stadt und in vielen anderen Teilen Oberösterreichs präventive Sammlungen, die Geld- oder Sachspenden (meist Textilien) umfassten und die Resilienz

78 Vgl. das »Epidemie-Normale« für die Steiermark aus dem Frühjahr I 830-Macher, Handbuch, Bd. 2, 343358.

79 LZ, 5.Ir.I830; ebd., I 2.Ir.I830; Macher, Handbuch, Bd. 2, 396 u. 578; vgl. Weigl, Wandel, 237f.; Evans, Epidemics, I $40-$ I $_{4} 2$; Briese, Angst, Bd. I, $246 f$. u. 25 of.

80 LZ, 5 .I I.I 830; ebd., I 2.I I.I 830 ; ebd., 28.I.I 83 I ; ebd., I 3.6.I 83 I; vgl. dazu auch: Briese, Angst, Bd. 2, I623.

8I Vgl. EdN, s.v. Cholera u. Evans, Tod, 3 I 8 - 320.

82 LZ, 28.I.I83 I; vgl. AStL, Altakten, Sch. 242.

83 LZ, I.7.I831; vgl. die gedruckten Anordnungen und »Ermahnungs-Worte« in: OÖLA, Landesregierungsarchiv Präsidium, Sch. I 49.

84 LZ/IB, 2 I.IO.I83 I.

85 LZ/IB, ro.6.183 I; ebd., I I.7.I83 I; ebd., I5.7.I83 I.

86 LZ/AB, 5.8.183 1 ; ebd., 19.8.183 I.

87 OÖLA, Landesregierungsarchiv Präsidium, Sch. 499.

$88 \mathrm{LZ}, \mathrm{I} 9.9 .183 \mathrm{I}$.

$89 \mathrm{LZ} / \mathrm{IB}$, r6.9.1 $83 \mathrm{I}$. 
gegen die Krankheit erhöhen sollten, zudem wurden »Bürger-Ausschüsse« etabliert, die als Anlaufstelle beim Ausbruch einer Epidemie dienen sollten. ${ }^{90}$ Gefährdet waren in Linz vor allem die insgesamt rund 3.700 Arbeiter/innen, die mit der Errichtung der Maximilianischen Befestigungstürme beschäftigt waren. Sie standen auch im Fokus der obrigkeitlichen Bemühungen, einen Ausbruch der Cholera zu verhindern: Zuerst wurde der Verkauf von Obst - das man als möglichen Verursacher der Cholera ansah - verboten und eine Überwachung der Verpflegung angeordnet. Anfang August erkrankten einige Frauen an der Ruhr (Dysenterie), die dann ins Militärspital gebracht wurden, die betroffene Baustelle wurde durch Ärzte regelmäßig besucht, man verbesserte die Abortanlagen und richtete eine ärztliche Versorgung für andere Baustellen ein. Als neue Ruhrerkrankungen im Folgemonat auftraten, wurden die Bauarbeiten teilweise eingestellt, zu einem Ausbruch der Cholera kam es aber nicht. ${ }^{91}$ Nachdem die Cholera im Oktober I83 I Oberösterreich erreicht hatte, wurden in Linz drei temporäre Choleraspitäler (und ein zusätzliches in Urfahr) geschaffen ${ }^{92}$ und zumindest im Karmeliterorden - dies ist als eine weitere Analogie zur Pest zu sehen - betete man gegen die Ausbreitung der Cholera, ${ }^{93}$ die nun zunehmend auch öffentlich thematisiert wurde. ${ }^{94}$ Es waren »die Leute nicht wenig beängstiget«, notierte der Linzer Geistliche Franz Haslinger in seinem Rückblick auf das Jahr I83 I. »Eine Menge Schriften von Ärzten kamen heraus [...], welche sich oft einander geradezu widersprechen « - man kenne einfach »Natur und Heilungsart « der Cholera nicht. ${ }^{95}$ In den lebensgeschichtlichen Erinnerungen des Linzers Joseph v. Spaun, der die Cholera in Wien erlebte, blieb diese Epidemie erstaunlich blass, es findet sich dazu nur ein Satz: Der Sommer I 832 sei »wie der vorangegangene Herbst [...] durch die Cholera verdüstert» worden. ${ }^{96}$ Auch Adalbert Stifter, der in den I 86oer Jahren auf die Cholera mit panischer Angst reagierte (vgl. unten), betonte in der Retrospektive, dass er früher »in Wien, ohne sie [die Cholera] zu beachten, fort gelebt « habe. ${ }^{97}$

Wenngleich es Todesfälle in Wels gab, trat die Cholera in Oberösterreich nirgends epidemisch auf. Seit dem Beginn des Jahres I 832 scheint es zu keinen neuen Choleraerkrankungen gekommen zu sein, auch wurde die unterbrochene Eilverbindung der Post zwischen Linz und Wien im Februar wieder aufgenommen. ${ }^{98}$ Man sollte die Absenz der Cholera in Linz jedoch nicht als Wirkung eines erfolgreichen kollektiven oder individuellen Krisenmanagements interpretieren, sondern eher als (glückliche)

90 AStL, Altakten, Sch. 242 ; LZ, I6.9.183 I; ebd., 30.9.1831; ebd., 2.I.I 832.

91 Hillbrand, Türme, I I 4 - I 7 ; vgl. OÖLA, Landesregierungsarchiv Präsidium, Sch. I 5 O.

92 Fink, Geschichte, 4I u. gof.

93 LR EId, Reg. 4057 (I56).

94 Etwa bei einer Ansprache des Linzer Theaterpächters - vgl. LZ, 7. I0.I 83 I.

$95 \mathrm{HTb}$ i 83 I, Begebenheiten.

96 Doku, Spaun, 265.

97 Stifter, PRA, Bd. 21, 272.

98 LZ, I4.IO.I83 I; ebd., 2.I.I832; ebd., 3.2.1832; ebd., I3.2.I832. 
Koinzidenz: Man hatte in Linz nichts anderes als in Wien gemacht - dort erkrankten trotz umfangreicher obrigkeitlicher Maßnahmen und erheblicher Ausgaben zwischen August I 83 I und Herbst I 832 ca. 7.400 Menschen an der Cholera, ca. 4.200 starben. ${ }^{99}$ Auch in anderen Großstädten wie London und Paris verursachte die Cholera den Tod von tausenden Menschen und sie stieß - da die angewandten Maßnahmen der Seuchenbekämpfung weitgehend wirkungslos blieben und damit die Vulnerabilität der Städte deutlich hervortrat - einen Diskussionsprozess über Defizite der städtischen Hygiene und der medizinischen Infrastruktur an. ${ }^{100}$ Im Februar I 849 wiederholte die »k.k. Sanitäts-Commission« anlässlich eines erneuten Choleraausbruches in Wien ${ }^{101}$ ihre »Belehrung über die Vorsichts-Maßregeln gegen die Cholera«, die auch in Linzer Zeitungen publiziert wurde: Immer noch empfahl man, neben einer ärztlichen Behandlung, »Mäßigkeit im Essen und Trinken«, aber auch »Bewegung in einer freien Luft«. Zudem hälfen gegen die Cholera »Reinlichkeit«, sauberes Wasser, ordentlich geräumte Senkgruben und geruchsfreie Kanäle. ${ }^{102}$ In Linz richtete der Magistrat im März I 849 in einem Haus an der Peripherie prophylaktisch ein temporäres »Cholera Spital« ein, ${ }^{103}$ Cholerafälle traten in Linz damals aber offenbar keine auf. Wenngleich die Zahl des medizinischen Personals und der Krankenhausbetten in Linz weiter anstieg, wurden die wahrgenommenen Defizite in diesem Bereich zur Mitte des I 9. Jahrhunderts immer deutlicher artikuliert. ${ }^{104} \mathrm{Im}$ Mittelpunkt stand die Forderung nach einem »allgemeinen« Krankenhaus, das ein bürgerliches Projekt bildete: Bereits in den frühen I 84 oer Jahren hatten Linzer Apotheker eine Stiftung für die »Errichtung eines städtischen Krankenhauses« in Leben gerufen, ${ }^{105}$ I 848 hatte der provisorische Gemeindevorstand (und spätere Bürgermeister) Reinhold Körner einen Krankenhausneubau als wichtiges städtisches Projekt definiert, ab dem Jahr I 850 gab es Sammlungsaufrufe und Charityveranstaltungen, eine "Commission« des Gemeinderates wurde eingerichtet, die I 852 das Münchner Krankenhaus (erbaut I 808- I 8 I 3) besuchte. Ein Hindernis stellte - einmal mehr - die Finanzierung des Neubaus dar, für den in den I 85 oer Jahren Kosten von rund $200.000 \mathrm{fl}(\mathrm{CM})$ angenommen wurden. Den I 852 eingerichteten "Baufonds« dotierte man aus umgewidmetem, ursprünglich für ein Arbeitshaus vorgesehenem Geld, zudem konnten wenige Jahre später $53.000 \mathrm{fl}$ aus der Staatslotterie lukriert werden. Dennoch blieb eine Kofinanzierung durch das

99 Dies exkludiert die 80.000- I00.000 Menschen, die Wien wegen der Cholera verlassen hatten - Weigl, Wandel, 237 f.; Birkner, Stadt, 4I, 48 u. 85-89.

Ioo Lees/Hollen Lees, Cities, I I 9 - I 23 ; Schott, Urbanisierung, 224f.; Hamlin, Health, I 7 , 2 If., 85 f., I 20 I 26 u. r 86f.; vgl. auch Kap. 3. Wasser, Kap 5. Zirkulationen und Output u. Kap. 7. Geordnete und modifizierte Umwelt.

Ior Vgl. Birkner, Stadt, I 25.

IO2 ÖB, 20.2.1 849 .

Io3 AStL, HS 192 (Oberkammeramt Ausgaben I849), pag. 575.

I04 Vgl. Fink, Geschichte, roof. u. Koch, Reise, I6.

I05 Damals wurden aber offenbar nur 400 fl gesammelt - AStL, Altakten, Sch. r 66. 
Land unumgänglich, aber die Statthalterei bremste und stellte I 855 fest, dass in Linz ohnehin die Ordenskrankenhäuser bestünden, die man vergrößern oder adaptieren könne. Wolle man ein eigenes Krankenhaus, dann solle man dies über ein Darlehen oder über Sammlungen finanzieren. ${ }^{106}$ Der Arzt und Gemeinderat Anton Knörlein betonte in seinem im gleichen Jahr erschienenen Aufsatz zur Geschichte der medizinischen Infrastrukturen in Linz, der durchaus als Werbeschrift für das Krankenhausprojekt gelesen werden kann, dass der »Aufbau einer zeitgemässen allgemeinen Krankenanstalt« als prioritär anzusehen sei. Bald würden »ein lebhafterer Verkehr und eine vermehrte Bevölkerung [...] das Unzureichende der vorhandenen Krankenanstalten um so mehr empfinden«, vielleicht werde man es später - bei steigenden Preisen bereuen, dass man nicht gehandelt habe. ${ }^{107}$ Besonders bei epidemisch auftretenden Krankheiten hätten sich die Kapazitäten der bestehenden Krankenhäuser bereits als »weit« zu gering gezeigt. Wiederholt mussten, so Knörlein, »viele Kranke abgewiesen werden [... oder konnten] erst nach mehreren Tagen Verweilens unter den ungünstigsten häuslichen Verhältnissen in verschlimmertem, ja oft hoffnungslos gewordenen Zustande aufgenommen werden «. ${ }^{108}$

Auf diese Diskussion traf der erste Ausbruch der Cholera in Linz - er blieb mit rund 900 Erkrankten und mindestens 480 (zivilen) Todesfällen auch der größte. ${ }^{109}$ In Wien war die Cholera bereits im Herbst I 854 aufgetreten, ${ }^{110}$ in Linz starben im Frühling des Folgejahres die ersten Menschen an der Cholera, Ende Juni nahm die Anzahl der Cholerafälle zu und im August brach die Cholera dann epidemisch aus. ${ }^{111}$ Die ersten Choleratoten gab es in der Unteren Vorstadt nahe der Landstraße, danach breitete sich die Seuche über die beiden Vorstädte bis in die peripheren Teile von Linz und nach Urfahr aus und verschwand Ende September wieder. ${ }^{112}$ Relativ stark - und vermutlich überproportional ${ }^{113}$ - von der Cholera betroffen war die südlich von Linz gelegene, gewerblich geprägte Ortschaft Kleinmünchen, in der sich die

Io6 Stadler, Armee-Spital, 86f.; Marx, Ende, 739; vgl. Knörlein, Geschichte, 3 f. u. 40-46.

I07 Knörlein, Geschichte, 46.

ro8 Ebd., 39.

ro9 Diese Zahlen exkludieren die Todesfälle in Kleinmünchen, Urfahr und in den Kasernen, die - so ein zeitgenössischer Bericht - »auch zahlreich« gewesen sein sollen (Fink, Geschichte, I9I) - LAB, 29.9. I 855 ; Schiedermayr, Sanitätsverhältnisse, 8 ; Pichler-Baumgartner, Wege, I I 2 ; vgl. dazu auch den umfangreichen Bericht des Stadtarztes Adam Haller (OÖLA, Archiv der Statthalterei, Präsidium, Sch. $369)$.

I Iо ÖB, 29.8.I 854; ebd., I 4.I I.I 854; die Cholera der Jahre I 854/I 855 forderte in Wien insgesamt rund 5.000 Tote (Birkner, Stadt, I 25 ).

I I I OÖLA, Archiv der Statthalterei, Präsidium, Sch. 369; LR EId, Reg. 4 I64 (I 74f.).

I 2 Schiedermayr, Sanitätsverhältnisse, II; LAB, I0.7.I855; ebd., I6.7.I855; ebd., 31.7.I855; ebd., I.IO.I 855 .

I 3 Vgl. zur sozial-räumlichen Ungleichverteilung des Cholerarisikos in Wien: Weigl, Wandel, 240-242 u. allgemein Lees/Hollen Lees, Cities, 62 . 
Sterblichkeit mehr als verdoppelte. ${ }^{114}$ Ende August versuchte eine überregionale, in Linz erscheinende Zeitung zu kalmieren: Zwar seien die Cholerafälle nun zahlreicher geworden, in Kleinmünchen und am »Ursprungspunkte« in der Unteren Vorstadt gebe es aber kaum noch Erkrankungen. „Dieser wahre Sachverhalt möge die Gemüther jener beruhigen, die durch Uebertreibungen alarmirt werden. Gerüchten vom Aussterben ganzer Häuser, von der Absperrung von Straßen, von Häufung von Todten u. dgl. können höchstens jene Glauben beimessen, die überhaupt von Furcht bemeistert, der Vorsorge der Staatsbehörde, der Gemeindevorstehung und der Sanitätsorgane mißtrauen. ${ }^{115}$ Ohnehin seien die Ärzte und die beiden Krankenhäuser in der Betreuung der Erkrankten überaus engagiert, es bestehe eine umfangreiche Aufsicht über die Lebensmittelversorgung und die städtische Hygiene, auch desinfiziere die Stadtgemeinde öffentliche Gebäude und schaffe wiederholt den »Unrath « weg. ${ }^{116} \mathrm{Zu}$ diesen Maßnahmen kamen, wie schon r 83 r, Geld- und Sachspenden und Suppenspeisungen, zudem wurden Choleraspitäler in Linz, Urfahr und in Kleinmünchen zur Isolation und Pflege der Kranken eingerichtet. ${ }^{117}$ Dass auch die Krankenhäuser maßgeblich zur Behandlung der Cholerakranken genutzt wurden, zeigen städtische Zahlungen und kaiserliche Ehrungen für deren Ärzte und Funktionsträger, die nach dem Ende der Epidemie erfolgten. ${ }^{118}$

Die individuellen Reaktionen der Stadtbewohner/innen zielten offenbar mehrheitlich auf - mehrheitlich bereits in den I8zoer Jahren formulierte - Prophylaxe- und Vorsichtsmaßnahmen (vgl. Abb. 3 I) und auf einen temporären Rückzug aus dem öffentlichen Leben, ein Meiden von Menschenansammlungen ab. Viele seien »vor der Seuche aufs Land « geflohen, so eine Linzer Tageszeitung rückblickend im Oktober I 855. Am Höhepunkt der Epidemie, Ende August, seien nur noch "Leichenträger, Speisgänge, Todtenglöcklein die gewöhnlichen Begegnisse und Erscheinungen des Tages und der Nacht gewesen, ${ }^{119}$ alles sei "ganz still geworden ${ }^{120}$ In einem anderen zeitgenössischen Bericht wurde konstatiert, dass sich »die größere Masse in ihrer gewöhnlichen Lebensweise und ihren Vergnügungen nicht stören ließ«, auch habe sich die Auslastung der Dampfschiffe kaum reduziert. ${ }^{121}$ Im August wurde der alljährliche Bartholomäusmarkt abgehalten, er war aber deutlich geringer frequentiert als in den vorangegangenen Jahren. ${ }^{122}$ Am Höhepunkt der Choleraepidemie griff man auf ein

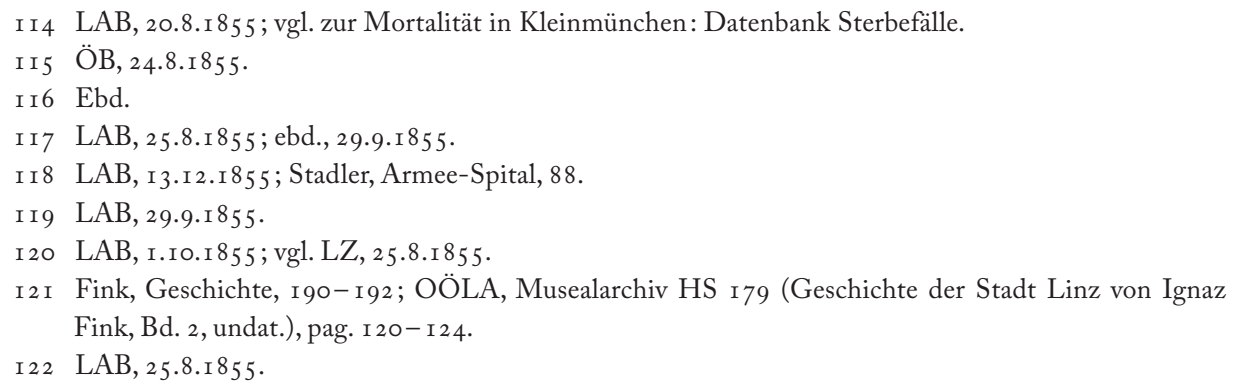


Abb. 31: Individuelle Seuchenprophylaxe in Zeiten der Cholera Annonce in einer Linzer Zeitung für »Retiraden-Pulver«, 1855
Befonbere Bead)tung zur 3eit ber (5holera=(5pibemie verbient bag

\section{Retiraben=Pullder,}

weldes bei einfadjer 2 (nwwenbung in ben \&borten unb Sinchenaus:

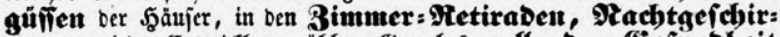
ren 2c. jede (Entwidłlung üblen (Berud)ę, alle Der Gefiutbbeit

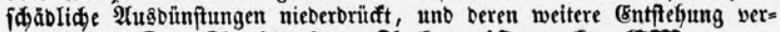
hinbert. - Der \$reis cines \$afets ift $18 \mathrm{er}$. (SD2.

Inwenoung: \&ür einen गiađttopf genügt cine Quantität gleiđ einem (56)

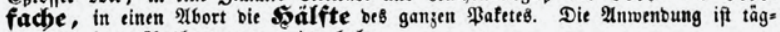

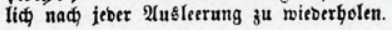

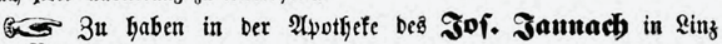
an ber ßromenabe.

$108-1$

tradiertes Element der Pestabwehr zurück: Ab dem r 9. August gab es Betstunden in den Pfarrkirchen, zudem auch Gebete im Karmeliterkloster. ${ }^{123}$ Mit dem Ende der Choleraerkrankungen scheint eine Rückkehr zum Alltagsleben relativ schnell erfolgt zu sein, wie eine Zeitung bereits am I. Oktober berichtete: Am regen Besuch der Promenade und der Linzer Naherholungsgebiete erkenne man, dass nun »wieder Heiterkeit und Geselligkeit aufzuleben « beginne. ${ }^{124}$ Die zwei Wochen später erfolgte »feierliche Prozession« mit »Tausende[n] von Andächtigen« von der Stadtpfarrkirche zur Dreifaltigkeitssäule - »zum Danke für die glückliche Abwendung der Cholera-Epidemie« - trug deutliche Züge der Pestbewältigung. ${ }^{125}$ Trotz der wieder eingetretenen Normalität wirkte die Cholera in den Diskussionen fort: Immerhin war seit der Pest I 7 I 3 »der Todesengel mit keinem so verheerenden Schritte durch die Straßen unserer Landeshauptstadt « gezogen wie in den letzten Wochen, wurde in einem Zeitungsartikel Ende September I 855 betont. ${ }^{126}$ Deutlich habe man "gerade« während der Epidemie, wohl, da die Choleraspitäler bald ihre Kapazitätsgrenzen erreicht hatten, ${ }^{127}$ »das Bedürfnis« eines »allgemeine[n] Linzer-Krankenhaus[es] « verspürt. ${ }^{128}$ Und tatsächlich erhielten die - ins Stocken geratenen - Krankenhausplanungen nach der Cholera einen neuen Schub. I856 wurde das Krankenhaus zu einer von der Gemeinde und dem Land Oberösterreich gemeinsam finanzierten Landesanstalt; als Bauplatz war zunächst der Volksgarten vorgesehen, dann - da die als ideal erachtete freie Lage aufgrund des Bahnhofsbaus nicht mehr gegeben sein werde - entschied man sich für ein Grundstück an der östlichen Peripherie, das aber erst I 859 angekauft wurde. Erneut verzögerte die Frage der Finanzierung (und wohl auch die Absenz von Epidemien) den Baubeginn: Im Jänner I 863 erklärte der Landtag das Krankenhaus zum städti-

I23 Fink, Geschichte, I9I; LR EId, Reg. 4I64 (I74f.).

I 24 LAB, I.IO.I 855 .

I 25 LAB, I 5 .IO.I 855 ; vgl. Pfister, Bevölkerungsgeschichte, 4 I.

I $26 \mathrm{LAB}, 29 \cdot 9 \cdot 1855$.

I 27 Stadler, Armee-Spital, 88.

I 28 LAB, I.IO.I 855 . 
schen Projekt, die Stadt kaufte den Baugrund an und begann noch im gleichen Jahr, finanziert durch einen Kredit von über 70.00o fl, mit der Errichtung des Krankenhauses, das sich maßgeblich, wenngleich kleiner dimensioniert (nun mit roo Betten), am Zürcher Spital orientierte. Das Krankenhaus war im Herbst I 865 weitgehend fertiggestellt und wurde zunächst für Verwundete des Preußisch-Österreichischen Krieges verwendet, erst im Oktober I 868 startete der reguläre Betrieb. I 874 erhielt das Krankenhaus das Öffentlichkeitsrecht und expandierte stark: I 888 verfügte es über I 83 Betten und 1908 bereits über 345 Betten. ${ }^{129}$

Beim Herannahen der nächsten Choleraepidemie zur Mitte der I 86oer Jahre bestand an der Krankheit deutlich mehr mediales Interesse. Zunächst handelte es sich noch um die Cholera in der Ferne: Regelmäßig - und deutlich dichter als in den I 85 oer Jahren wurde ab dem Sommer I 865 in den Linzer Zeitungen über das erneute Auftreten der Cholera in Europa, aber auch in Nordafrika, Russland oder Indien berichtet. ${ }^{130}$ Dazu kamen Beiträge, die Präventivmaßnahmen und mögliche Übertragungswege diskutierten. Im August I 865 wurde in zwei Leitartikeln in der Linzer »Tagespost « zwar darauf verwiesen, ${ }^{131}$ dass die Ursachen und Übertragungswege der Cholera noch unbekannt seien - man kategorisierte aber den "Eindringling" etwas diffus als »kontagiöse und miasmatische akute Krankheit«, die durch »Choleragift» hervorgerufen werde. Effektive Gegenmaßnahmen bildeten die Quarantäne von Erkrankten sowie die Desinfektion von Krankenzimmern und den dortigen Aborten, da sich die Krankheit über die »Darmausleerungen« der Erkrankten - konkret über »die Luft« oder durch Senkgruben verunreinigtes Wasser - weiterverbreite. Diese Artikel verbanden das Thematisieren der Cholera deutlich mit dem Plädoyer für eine Modernisierung der städtischen Abwasserinfrastruktur. ${ }^{132} \mathrm{Im}$ September wurden aus der "Wiener Zeitung « die »zweckmäßigen Verhaltungsmaßregeln« gegen die Cholera übernommen, die neben anderem »frisches reines Wasser« und »Reinlichkeit« empfahlen. Zwar kümmere sich die Obrigkeit um die Reinigung der Kanäle, »aber es liegt im Interesse jedes Einzelnen selbst darauf zu sehen, daß der Abort, den er benutzt, rein gehalten, mit gut schließendem Deckel versehen sei und daß täglich größere Mengen von Wasser hineingegossen werden «. ${ }^{133}$ Derartige Empfehlungen zielten auf das Vermeiden schlechter (krankmachender) Gerüche $a b$, wobei aber genauso zur präventiven Desinfektion der privaten Aborte mit Eisensulfat - hier folgte man dem Wiener Magistrat - geraten wurde, ${ }^{134}$ von der man sich ein Abtöten »des spezifischen Cholerakeims oder Ferments« erhoffte. ${ }^{135}$ Obwohl

\footnotetext{
I 29 Stadler, Armee-Spital, 86 u. 88-90; vgl. Mittmannsgruber, Stadtverwaltung, 225-228; Mayrhofer/ Katzinger, Geschichte, Bd. 2, I37- I 39; LAB, 2 I.2.1 862.

I30 Vgl. z.B. LAB, 4. Iо. I 865 .

I3 I LTP, I 5.8.I 865 ; ebd., 24.8.I 865 .

I32 LTP, I 5.8.1865; vgl. Evans, Tod, 307-3 I 4 u. Kap. 5. Zirkulationen und Output.

I33 LTP, I3.9.1 865 .

I34 LTP, I4.9.1865; vgl. ebd., 7.9. I 866.

I35 LTP, I3.9.1866; LZ, I 4.8.1866.
} 
sich ab dem Frühjahr I 866 aufgrund des Preußisch-Österreichischen Krieges viele Soldaten in Linz aufhielten und später zahlreiche Verwundete nach Linz kamen, ${ }^{136}$ brach die Cholera erst im Spätsommer r 866 aus: Ende August war eine Frau, die mit dem Schiff von Wien nach Linz unterwegs gewesen waren, während der Fahrt verstorben. Da man von einem Cholerafall ausging, desinfizierte man das Schiff und ordnete eine Quarantäne an. ${ }^{137}$ Die obrigkeitsnahe »Linzer Zeitung « trat zu diesem Zeitpunkt eher beschwichtigend auf: Von der Choleraerkrankung und dem Tod des Ennser Bürgermeisters habe man nur aus dem »Wiener Tagblatt« erfahren können, so die Kritik einer anderen Linzer Tageszeitung. ${ }^{138}$ Auch der Linzer Gemeinderat war Anfang September bemüht, »Beängstigung und Aufregung im Publikum« zu vermeiden. Derzeit sei nur allgemeine »Vorsicht« angebracht, anderes sei »vorläufig verfrüht «. ${ }^{139}$ Wenig später begann die Stadt präventiv mit der Desinfektion »mehrerer öffentlicher CummunalGebäude« und ordnete dies auch für einige Gastbetriebe an. ${ }^{140}$ Tatsächlich trat die Cholera zwischen September und Ende November I 866 nur auf Donauschiffen und an der südlichen und südöstlichen Peripherie der Stadt auf. Erneut war - wie schon I 855 die Ortschaft Kleinmünchen stark betroffen, in der die überwiegende Mehrheit der Choleratoten gewohnt oder gearbeitet hatte. ${ }^{141}$ Der Ausbruch von 1866 blieb mit vermutlich 35 Toten (im Stadtgebiet von Linz) sehr klein, ${ }^{142}$ in Wien hatte die Cholera analog zu I 854/I 855 - ca. 3.000 Tote gefordert. ${ }^{143}$ Ein Linzer Arzt beurteilte Anfang der I $890 e r$ Jahre die r 866 gegen die Cholera ergriffenen Maßnahmen als ambivalent: Cordone hätten sich als nutzlos erwiesen, die medizinische Behandlung habe sich auf den Einsatz von »Hausmitteln« beschränkt, nur die "gewissenhafte Handhabe der öffentlichen und privaten Gesundheitspflege « und auch die Lebensmittelüberwachung seien effektive Maßnahmen gewesen. ${ }^{144}$ Die deutlich geringere Anzahl der Todesfälle spricht insgesamt für eine Erhöhung der Resilienz.

Über die Korrespondenz von Adalbert Stifter ergibt sich die seltene Möglichkeit, eine Binnenperspektive zum Choleraausbruch von I 866 einzunehmen, die die Wechselwirkung zwischen privater Ebene und ferner resp. intermediärer (städtischer) Ordnung zeigt. Zwar kann Stifter nicht unbedingt als repräsentativ für eine allgemeine städtisch-bürgerliche Wahrnehmung gelten, da dessen Gesundheitszustand zu diesem Zeitpunkt schlecht war und er dementsprechend ansteckende Krankheiten panisch

I 36 Der Oberösterreicher I 884, I 8 I - I 83; vgl. LAB, 29.9. I 866 u. GRP I 866, fol. 65 b; die Militärpräsenz verringerte sich erst im November I 886: vgl. Der Oberösterreicher I 885, I $93 \mathrm{f}$.

I 37 LTP, 30.8. I 866 .

I 38 LTP, 7.9. I 866.

I39 GRP i 866, fol. $96 \mathrm{~b}$.

I $40 \mathrm{LAB}, \mathrm{I} 5 \cdot 9 \cdot \mathrm{I} 866$.

I 4 I LAB, 29.9.I866; ebd., 23.I I.I 866; ebd., 30.I I.I 866; LZ, I0.5.I 867; vgl. Stifter, PRA, Bd. 22, $72 f$.

I 42 Dies berücksichtigt also die Toten in Kleinmünchen nicht: Schiedermayr, Sanitätsverhältnisse, 8.

I43 Brunner/Schneider, Umwelt, I 95 ; Birkner, Stadt, I 25.

I 44 Pochmann, Cholerapilz-Maßregeln, $3 \mathrm{f}$. 
fürchtete. ${ }^{145}$ Eine »rathlose Angst « vor der Cholera empfanden aber wohl viele seiner Zeitgenossen/innen. ${ }^{146}$ Stifter hatte Linz bereits vor dem Auftreten der ersten Cholerafälle verlassen: Zunächst hielt er sich in Kirchschlag ${ }^{147}$ und dann in Lackenhäuser am Rande des Böhmerwaldes auf und verfolgte von dort - über die »Linzer Zeitung« die Annäherung der Cholera an und deren Verlauf in Linz. ${ }^{148}$ Wenn die Cholera nicht wäre, so Stifter in einem Brief an seine Frau aus dem August r 866, dann »wäre ich rüstig und fröhlich; aber diese Schlange [...] quält mich in meinem jezigen Zustande beständig«. Breche die Cholera in Linz aus, dann müsse sie, Amalia Stifter, »sogleich« die Stadt verlassen. ${ }^{149}$ Als Stifter Anfang September über die ersten Choleratodesfälle in Linz Kenntnis erhielt, äußerte er brieflich erhebliche Zweifel an den ergriffenen Maßnahmen: Es sei fraglich, ob man wirklich alles »desinficirt« habe - seit über »50 Jahre[n] « sei man mit der Cholera konfrontiert, dennoch habe man bislang nur mit "Flickwerk«, »Saumseligkeit und [...] Verschlendern« reagiert - der »Einzelne« bleibe bei der Cholera »auf sich gewiesen «. ${ }^{150}$ Tatsächlich kam Amalia Stifter, wohl auf Ersuchen ihres Mannes, wenig später nach Lackenhäuser und blieb dort bis Ende Oktober. ${ }^{151}$ Vermutlich über eine Rückkehr nach Linz nachdenkend, kontaktierte Adalbert Stifter im Oktober mehrere Linzer Freunde und Bekannte, die er über die Situation in Linz befragte, da die Informationen in der "Linzer Zeitung« spärlich blieben, die Gerüchte »aber anders [...] sprechen « würden. ${ }^{152}$ Die aus Linz eingetroffenen Einschätzungen divergierten: In einem Brief wurde vermutet, dass die Cholera »bald verschwinden « werde, ${ }^{153}$ in einem anderen wurde konstatiert, dass sich die Cholera »stetig [...] ausbreite ${ }^{154}{ }^{15 m}$ Herbst habe ihn »die Cholerafurcht lächerlich heftig« ergriffen, schrieb Stifter seinem Arzt Ende November und er erkundigte sich gleichzeitig nach der aktuellen Lage in Linz. ${ }^{155}$ Schließlich kam Stifter erst wieder Anfang Dezember ins »cholerafrei[e] « Linz, nachdem er vor dem Wintereinbruch in Lackenhäuser - mit einem Zwischenaufenthalt in Kirchschlag - geflüchtet war. ${ }^{156}$

Zum letzten Mal trat die Cholera in Linz I873 auf und verursachte zumindest 72 der rund I.700 Todesfälle in diesem Jahr. ${ }^{157}$ Auf die heranziehende Cholera reagierte man im Gemeinderat im November I 872 ähnlich wie in den vorangegangenen

I 45 Dallinger, Hunger, 3 I 7 ; Stifter, PRA, Bd. 2 I, I 39 u. 3 I 3 f.

I 46 LZ, 3.8.1 866; diese Korrespondenz findet sich teilweise auch in: Briese, Angst, Bd. 3, 287-293.

I47 Stifter, PRA, Bd. 21, 253 u. 26r.

I 48 Ebd., 285 f. u. 3 I I ; Stifter, PRA, Bd. 22 , I 2.

I49 Ebd., Bd. 2I, $272 \mathrm{f}$.

I50 Ebd., 297.

I5 I Ebd., 313; ebd., Bd. 22, 3.

I5 2 Ebd., Bd. 2I, 3II-3I4.

I53 Ebd., Bd. 24, I 16.

I 54 Ebd., ir $6 f$.

I 55 Ebd., Bd. 22, $72 \mathrm{f}$.

I56 Ebd., I 2, 78, 8I u. 84.

I 57 Schiedermayr, Sanitätsverhältnisse, 8; vgl. Datenbank Sterbefälle u. RB I 898, nach 352. 
Jahrzehnten, wenngleich nun auch die Hausbesitzer zur regelmäßigen Reinigung und Desinfektion der Kanäle und Senkgruben (mit Eisensulfat und Chlorkalk mit Schwefelsäure) aufgefordert wurden und das neue Krankenhaus als Choleraspital herangezogen werden konnte. ${ }^{158}$ In der Praxis wurde aber, wie ein Gemeinderat im Herbst i 873 betonte, die "Aufforderung zur Desinfektion in den meisten Privathäusern entweder gar nicht oder nur in mangelhafter Weise befolgt«. Trotz einiger Widerstände (strittig war der Zwang) beschloss man, Desinfektionen auf Kosten der säumigen Hausbesitzer durch die Stadt zu übernehmen. ${ }^{159}$ Dabei zielte zu dieser Zeit eine »Desinfection« offenbar immer noch stark darauf ab, »Gestank« und »Ausdünstungen [...] durch andere Stoffe unschädlich « zu machen, ${ }^{160}$ auch die - bereits bei der Epidemie der I $830 e r$ Jahre geäußerte - Empfehlung der »Reinlichkeit des Hauses und des Körpers« blieb Bestandteil der publizistischen Empfehlungen zur Abwehr der Cholera. ${ }^{161}$

Die Cholera hatte die Aufmerksamkeit von anderen Infektionskrankheiten abgezogen: Linz wies um I870 - im Vergleich mit anderen österreichischen Städten - eine erhöhte Mortalität auf, die sich nicht auf epidemisch, sondern auf endemisch auftretende Infektionskrankheiten zurückführen lässt. ${ }^{162}$ Zwischen den Jahren I 873 und I 880 wurde Tuberkulose als Ursache für rund 23 Prozent der Sterbefälle festgestellt, während es bei Typhus - der in Linz in der zweiten Hälfte des I 9. Jahrhunderts nicht epidemisch auftrat - nur I,7 Prozent waren. ${ }^{163}$ Beide Krankheiten blieben über die Jahrhundertwende hinaus in Linz präsent, wenngleich die Typhusmorbidität und mortalität mit der Etablierung der neuen Wasserinfrastruktur deutlich sanken. ${ }^{164}$ Insgesamt hatte die Cholera in Linz zwar keine großen Auswirkungen auf die städtische Mortalität, dafür aber seit den I 85 oer Jahren auf den Diskurs zur medizinischen Infrastruktur und ab den I 86oer Jahren auf den Diskurs zur Modernisierung der Wasserinfrastruktur. Als man im Herbst I 892 erneut »Vorkehrungen« gegen die Cholera traf, gab sich der Linzer Bürgermeister davon überzeugt, dass die Kombination von städtischer Sauberkeitsaufsicht, transportablem »Desinfections-Apparat nach dem System Thurnfield« und der modernen Infrastruktur - die »von dem ernsten Streben der Landeshauptstadt nach gründlicher Assanierung« zeuge - die Resilienz der Stadt erhöht habe. ${ }^{165}$

I 58 GRP I 872 , fol. 3 I 3 b-3i 4 b.

I59 GRP I873, fol. 292a-293b; ähnlich zehn Jahre später: RB I 883, I09.

I60 LVB, 31.7.I 873 .

I6 I LTP, 23.8.1873.

I62 Schiedermayr, Sanitätsverhältnisse, 6-8.

I63 Pichler-Baumgartner, Wege, i rof.

I64 Statistische Monatschrift 20 (I 894), 98; RB I 897, I 97; Pichler-Baumgartner, Wege, I I 3 f.

I65 RB I892, I98-20I. 


\section{Versorgungskrise}

\section{Rekurrente Krisen type ancien}

Missernten, aber auch politische Ereignisse führten bis ins I 9. Jahrhundert regelmäßig $\mathrm{zu}$ Versorgungskrisen, in denen sich Grundnahrungsmittel verknappten und verteuerten. Diese Krisen - in Anlehnung an die französische Forschung mit der Beifügung type ancien versehen - resultierten in Übersterblichkeit, die durch Hunger und den Ausbruch von epidemischen Krankheiten verursacht wurde. ${ }^{1}$ Lebensmittelteuerungen infolge von Missernten bildeten einen Impact der Natur auf die Gesellschaft: Temperatur- und Niederschlagsanomalien resp. Wetterextreme führten zu geringeren Erträgen, einem geringeren Nährwert und schließlich zu steigenden Preisen. Eine besonders negative Konstellation für das Hauptnahrungsmittel Getreide waren ein langer und niederschlagsreicher Winter, Kälte im Frühling, ein niederschlagsreicher und kalter Sommer und lange Regenphasen in der Erntezeit (September/Oktober). Aus derartigen Witterungsverhältnissen entwickelte sich zumeist ein »Katastrophenjahr « mit massiven Ernteausfällen und Preissteigerungen. ${ }^{2}$ Die Getreideversorgung von Linz erfolgte einerseits aus der Region (die Stadt lag am Rande eines Getreideanbaugebietes), andererseits über die Donau (vgl. Kap. 4. Energie und Biomasse). Somit war Linz tendenziell von in der Region auftretenden Missernten schwächer betroffen und lag auch bei überregionalen Krisen und Verknappungen günstiger.

Die ersten Jahre des I 8. Jahrhunderts bildeten einen Ausläufer der Teuerungsphase der I69oer Jahre, ${ }^{3}$ aber nur für I704 ist eine erhöhte Mortalität festzustellen. ${ }^{4}$ Für die Jahre I 7 I 2 - I 7 I 5 sind aufgrund von Ernteausfällen (und möglicherweise auch aufgrund der Pest I7 I3/I7I4) wiederholte Nahrungsknappheit und Teuerungen belegt; tatsächlich war in Linz die Mortalität im Jahr I 7 I 5 höher als in den Seuchenjahren I 7 I 3/ I 7 I 4 (vgl. Tab. 30). Wie schon in den I6goer Jahren wurde als Gegenmaßnahme durch die Landstände Getreide (Roggen und Hafer) in Oberungarn angekauft und auch für Passau bestimmte Getreidefuhren auf der Donau abgefangen. Das Getreide wurde zu einem niedrigeren Preis vor Ort - teilweise als Mehl den Bäckern - verkauft bzw. gegen spätere Rückerstattung (in natura) verteilt. Damit wurden Linz und andere Gebiete Oberösterreichs (explizit genannt ist das Mühlviertel) versorgt, was für die Stände zwar ein erheb-

I Collet/Krämer, Germany; EdN, s.v. Ernährung u. Hungerkrisen und -revolten; Krämer, Menschen, I 28 I3 I ; Pfister, Bevölkerungsgeschichte, 37f.; Mauelshagen, Klimageschichte, 94f.; Abel, Massenarmut, ${ }_{27} 9 \mathrm{f}$.

2 Krämer, Vulnerabilität; Pfister/Brázdil, Vulnerability, I I 8 - I 2 I ; vgl. Mauelshagen, Klimageschichte, 85 89 .

3 LR Eıb, Reg. I370 (33); ebd., Reg. I 378 (34); ebd., Reg. I38 I (34); vgl. zu den Krisen der I69oer Jahre Kumpfmüller, Hungersnot, roof., Collet/Krämer, Germany, ro6 u. Abel, Massenarmut, I 58 - I67.

4 Die Mortalität lag ungefähr ein Drittel über dem mehrjährigen Durchschnitt (Datenbank Sterbefälle). 
liches Verlustgeschäft darstellte, die Krise jedoch erheblich abschwächen konnte. ${ }^{5}$ Für die folgenden Jahrzehnte gibt es Hinweise auf einzelne schlechte Ernten (besonders für das Jahr I 724), aber es trat in Linz offenbar keine Versorgungskrise auf. ${ }^{6}$ Teuerung und Mangel begleiteten den Erbfolgekrieg der I 740er Jahre: ${ }^{7}$ Im Jänner I 742 wurde eine Nahrungsknappheit durch die Belagerung von Linz bewusst herbeigeführt und diese führte angeblich sogar dazu, wie die Hauschronik des Karmeliterklosters vermerkte, dass die eingeschlossenen Soldaten Pferde- und Katzenfleisch aßen. Das begleitende epidemische Auftreten von Infektionskrankheiten ließ die allgemeine Sterblichkeit ansteigen und diese bis ins Jahr I744 überdurchschnittlich hoch bleiben. ${ }^{8}$

Eine signifikant erhöhte Mortalität lässt sich - abgesehen von der wohl krankheitsbedingten Übersterblichkeit I 762/ I 763 (vgl. oben) - erst wieder für die Jahre I 77 I und I 772 feststellen. ${ }^{9}$ Dabei handelte es sich um die Auswirkungen einer Teuerungs- und Hungerkrise, die große Teile Zentral- und Nordeuropas zwischen den Jahren I 770 und I 773 betraf. Diese Krise wurde durch eine Serie von Missernten ausgelöst, wobei eine negative Witterungskonstellation in manchen Gegenden Europas schon I769 eingesetzt hatte. ${ }^{10}$ In Böhmen waren weite Teile des Jahres I 769 überdurchschnittlich niederschlagsreich und kalt gewesen, zudem kam es im Winter zu Überschwemmungen und dann blieb der Schnee lange liegen. Daraus ergaben sich erhebliche Ernteausfälle beim Getreide. ${ }^{11}$ Betrachtet man die für diese Zeit für den Linzer Raum zur Verfügung stehenden Klimadaten, dann deuten diese für das Jahr i769 auf einen kalten Mai und Oktober und auf einen sehr niederschlagsreichen Juni hin. Das Frühjahr I 770 war bis in den Mai überdurchschnittlich kalt, ebenso waren die Monate Juni und Juli kühl, wobei der Juni wiederum sehr niederschlagsreich ausfiel. Auf einen normalen Winter I770/I77 I folgten ein sehr kaltes Frühjahr mit spätem Schneefall, ein niederschlagsreicher Sommer und ein sehr kalter November. Im Gegensatz dazu war I772 bis auf den Mai ein überdurchschnittlich warmes und eher trockenes Jahr. ${ }^{12}$ I 770 und I 77 I traten in vielen Teilen des Habsburgerreiches Missernten auf und vor allem in Mähren, Böhmen, Tirol, Nieder-

5 Kumpfmüller, Hungersnot, roo- 106; vgl. LR BIIA 3 , Reg. 3709 (I 25) u. 3716 (I 37 ); LR BIIA4, Reg. 4702 (53); ebd., Reg. 4783 (66).

$6 \mathrm{LR} \mathrm{BIIG}_{4}$, Reg. 2343 (70); LR Erb, Reg. 1579 (6r).

7 Vgl. zu den Getreidepreisen: OÖLA, Landschaftsakten, Sch. 879, G.XIX.D/No. 8.

8 LR EIc, Reg. 2970 (Io8f.); vgl. LR CIIIC 3 , Reg. 608 (256); LR Era, Reg. 298 (64); ebd., Reg. 30 I (65f.); Datenbank Sterbefälle; vgl. zum planmäßigen Aushungern von Linz Thürheim, Feldmarschall, I $77 \mathrm{f}$.

9 Vgl. Datenbank Sterbefälle - wenngleich Benedikt Pillwein im frühen I9. Jahrhundert für die Jahre I 764 und I 769 »Unfruchtbarkeit« und Teuerung notierte (Pillwein, Wegweiser, 30 u. 39).

ıo Vgl. Abel, Massenarmut, 200-257; vgl. zusammenfassend: Collet/Krämer, Germany, ro6 - ro9 u. Collet, Katastrophe, $57-86$.

I I Pfister/Brázdil, Vulnerability, i 2 If.

I2 Kumpfmüller, Hungersnot, I I I Casty et al., Temperature; »durchschnittlich« bezieht sich auf den Durchschnitt I 90 - - 960 der HISTALP-Daten - vgl. zu den Datensätzen Kap. 2. Kontexte: Linz I 700 bis 1900 . 
und Oberösterreich stiegen bereits seit dem Jahr I770 die Getreidepreise stark an (vgl. Tab. 32$).{ }^{13}$ Besonders gravierend waren Böhmen und deutsche Territorien betroffen. ${ }^{14}$

Tab. 32: Getreidepreise in Linz, 1767-1771 und 1786

\begin{tabular}{|c|c|c|c|c|}
\hline pro Metzen & Weizen & Roggen & Gerste & Hafer \\
\hline 1767 & $2 \mathrm{fl} 58 \mathrm{kr}$ & $2 \mathrm{fl} 16 \mathrm{kr}$ & $1 \mathrm{fl} 36 \mathrm{kr}$ & $51 \mathrm{kr}$ \\
\hline 1768 & $2 \mathrm{fl} 20 \mathrm{kr}$ & $1 \mathrm{fl} 55 \mathrm{kr}$ & $1 \mathrm{fl} 27 \mathrm{kr}$ & $57 \mathrm{kr}$ \\
\hline 1769 & $2 \mathrm{fl} 45 \mathrm{kr}$ & $2 \mathrm{fl} 17 \mathrm{kr}$ & $1 \mathrm{fl} 44 \mathrm{kr}$ & $1 \mathrm{fl} 9 \mathrm{kr}$ \\
\hline $9 / 1770$ bis $8 / 1771$ & $4 \mathrm{fl} 17 \mathrm{kr}$ & $3 \mathrm{fl} 23 \mathrm{kr}$ & $2 \mathrm{fl} 40 \mathrm{kr}$ & $1 \mathrm{fl} 25 \mathrm{kr}$ \\
\hline $1 / 1786$ & $2 \mathrm{fl} 30 \mathrm{kr}$ bis $3 \mathrm{fl} 15 \mathrm{kr}$ & $2 \mathrm{fl}$ bis $2 \mathrm{fl} 6 \mathrm{kr}$ & & $45 \mathrm{kr}$ bis $51 \mathrm{kr}$ \\
\hline $5 / 1786$ & $2 \mathrm{fl} \mathrm{bis} 3 \mathrm{fl} 3 \mathrm{kr}$ & $1 \mathrm{fl} 45 \mathrm{kr}$ bis $1 \mathrm{fl} 48 \mathrm{kr}$ & & \\
\hline $8 / 1786$ & $1 \mathrm{fl} 45 \mathrm{kr}$ bis $2 \mathrm{fl} 57 \mathrm{kr}$ & $1 \mathrm{fl} 45 \mathrm{kr}$ bis $1 \mathrm{fl} 48 \mathrm{kr}$ & & \\
\hline
\end{tabular}

Quellen: OÖLA, Landschaftsakten, Sch. 879, G.XIX.D/No. 8 (für 1767-1771); LZ, 6.1.1786; ebd., LZ, 12.5.1786; ebd., 4.8.1786 (für 1786); vgl. Kumpfmüller, Hungersnot, 106. Zwar wurden die Angaben für 1767-1771 mit „Getrayd Preise in Öe.[sterreich] ob der Ennß« tituliert, es handelt sich aber vermutlich - dies zeigt der Vergleich mit Angaben in anderen Quellen (LR E1b, Reg. 1790 u. LR BIIB2, Reg. 520) - um Preise, die die Landschaft in Linz für Getreideankäufe bezahlte.

Eine erste Reaktion im obrigkeitlichen »Teuerungskanon« zielte auf die »Vermehrung der verfügbaren Getreidemenge« ab, ${ }^{15}$ die über Verbote für die Ausfuhr von Getreide und Mautbefreiungen für Einfuhr erzielt werden sollte, was in Oberösterreich im September I77 I angeordnet wurde. ${ }^{16}$ Dies war keine Innovation des späten I 8. Jahrhunderts, sondern auch schon zuvor regelmäßig praktiziert worden. Dahinter stand die Hoffnung, dass vorhandenes Getreide lokal angeboten wurde, was aber - da die meisten Territorien so handelten - dazu führte, dass überregionale Transfers von Getreide unmöglich oder zumindest erschwert wurden. ${ }^{17} \mathrm{Zudem}$ versuchten die Obrigkeiten Druck zu erzeugen, um gelagertes Getreide auf den Markt zu bringen: Demonstrativ wurden Lagerbestände erfasst und deren Verkauf angeordnet. Für Linz sind Requirierungen oder Zwangsverkäufe nicht belegt: Erst im Februar I772 wurden die Bauern in »ausgemessenen Bezirken « rund um Linz dazu aufgefordert, ihre »Erzeugnisse» in der Stadt anzubieten, der Zwischenhandel (»Vorkauf«) wurde bei Konfiszierungsstrafe verboten. ${ }^{18}$ Interessant ist, dass es zu dieser Zeit in Linz keinen öffentlichen Getreide-

I 3 Kumpfmüller, Hungersnot, 3of., 106 u. I I i OÖLA, Landschaftsakten, Sch. 93 I, G.XXIII.2/No. 59; Brunner/Schneider, Umwelt, 305.

I 4 Abel, Massenarmut, 203-206; Pfister/Brázdil, Vulnerability, I 22 ; Weber, Kurmainz, 9I.

I 5 Weber, Kurmainz, 96.

I6 Kumpfmüller, Hungersnot, 36; OÖLA, Landschaftsakten, Sch. 930, G.XXIII.2/No. 43; vgl. Luca, Landeskunde, Bd. 2, 49 f. u. Awecker, Bruckamt, $20 \mathrm{ff}$.

I7 Kumpfmüller, Hungersnot, I6, I 9-2 I u. 42f.; vgl. Abel, Massenarmut, 226-23 I u. Collet, Katastrophe, I 47 - I 5 I u. 3 rof.

I 8 Luca, Landeskunde, Bd. 2, 55 ; Kumpfmüller, Hungersnot, r6-28; vgl. zu Böhmen: Pfister/Brázdil, Vul- 
speicher gab, der als Puffer fungieren konnte. Es waren zwar große Getreidemengen im städtischen Brauhaus vorhanden (im Jahr I726 I 2.000 Metzen Gerste), ${ }^{19}$ die, wenngleich es sich um vermalzte Gerste handelte, prinzipiell als Nahrungsmittel oder als Zusatz für Brot genutzt werden konnte - für eine derartige Verwendung gibt es jedoch keine Belege. Dass es nur in wenigen Städten öffentliche Getreidespeicher gab, hatte vor allem finanzielle Gründe. In Tirol, das von Getreideimporten aus Bayern abhängig war, erwog die Hofkammer während der I 76oer Jahre wiederholt die Errichtung eines Getreidespeichers, was aber aufgrund der Kosten verworfen wurde. Ohnehin funktionierte die Getreideversorgung in normalen Jahren problemlos. ${ }^{20}$ In Wien bestand ab den I $720 e r$ Jahren ein Getreidemagazin, das als Puffer bei Verknappungen und Preissteigerungen fungieren sollte. Dies war ein staatliches Projekt, das defizitär war, aber offenbar die Krise der I 77oer Jahre etwas abmilderte. Auch in Wien zeigten sich die Probleme der Lagerhaltung: Die Kosten waren hoch, der Nutzen war bei normalen Ernten nicht gegeben, zudem war das eingelagerte Getreide gegenüber der frischen Ernte meist im Nachteil (im Hinblick auf Preis und Qualität). ${ }^{21}$ Eine weitere Maßnahme stellten obrigkeitlich festgelegte regionale Höchstpreise dar, die stabilisierend wirken sollten, ${ }^{22}$ aber zunehmend - wie die Ausfuhrsperren - als kontraproduktiv eingestuft wurden. ${ }^{23}$ Für Oberösterreich ist eine Preisfestsetzung für Getreide jedoch erst für den Mai I 77 I belegt. ${ }^{24}$

Obrigkeitliche Kernstrategie war das massenhafte Aufkaufen von Getreide in Überschussgebieten. ${ }^{25}$ Dies verursachte eine erhebliche Konkurrenz um Getreide und wirkte preistreibend. Klar im Vorteil waren Territorien, die im Hinblick auf den Transport günstig lagen oder über den Binnenmarkt - im Falle der habsburgischen Länder aus Ungarn - versorgt werden konnten. ${ }^{26}$ Auch in Oberösterreich setzte man - wie in Wien - auf Getreideankäufe in Ungarn, was die Stände »wegen ausserordentlich sich hierlands geäusserten Misswachs deren Körnern « schon I 770 gemacht hatten. ${ }^{27}$ Im Folgejahr warteten die Stände offenbar noch ab, erst im Frühjahr schloss man mit einem Weinhändler aus Mauthausen einen Liefervertrag über 30.000 Metzen ungarisches Getreide ab, wobei diese Lieferung für ganz Oberösterreich vorgesehen

\footnotetext{
nerability, I 26
}

I9 LR BIIG4, Reg. 2397 (I25-I33).

20 Kumpfmüller, Hungersnot, 9 If.

2 I Ebd., 5 I-53; vgl. zu den Getreidespeichern und zu deren Problemen in der Praxis: Collet, Katastrophe, I69- I 82 .

22 Weber, Kurmainz, 96.

23 Kumpfmüller, Hungersnot, 22 u. $45 \mathrm{f}$.

24 Luca, Landeskunde, Bd. 2, 39.

$25 \mathrm{Vgl}$. Abel, Massenarmut, 2 I6-226 u. Collet, Katastrophe, I $82-$ I 89.

26 Kumpfmüller, Hungersnot, 3of. u. 42-46; Abel, Massenarmut, 232 f.; vgl. für Wien: Brunner/Schneider, Umwelt, $305 \mathrm{f}$.

27 OÖLA, Landschaftsakten, Sch. 93 I, G.XXIII.2/No. 59; vgl. Kumpfmüller, Hungersnot, 54-6o. 
war und in Teillieferungen bis zum Ende des Jahres erfolgte. ${ }^{28}$ Im Mai I 77I organisierten die Linzer Bäcker, die möglicherweise schon zuvor regelmäßig Getreide in größeren Mengen aus Oberungarn bezogen hatten, eine Getreidelieferung: Belegt ist ein Liefervertrag zwischen einem Linzer Schiffmeister und einem Konsortium von Linzer Bäckern über die Lieferung von 3.00o Metzen (ca. I 30 Tonnen) Getreide. Der erste Teil dieser Lieferung wurde im Juli I 77 I in Wien, ein zweiter Teil im September in Stockerau beschlagnahmt und das Getreide - gegen spätere Entschädigung - der oberösterreichischen Landschaft übergeben, also nach Linz weitertransportiert. ${ }^{29}$ Ein weiterer, ähnlich dimensionierter Transport wurde nicht beschlagnahmt. ${ }^{30}$

Im Verlauf des Jahres I77 I passierte auch ein Getreidetransport der Wiener Hofkammer mit rund 3.000 Metzen, der für das tirolerische Schwaz bestimmt war, Linz. Aufgrund des hohen Preises - pro Metzen hätte der Weizen $5 \mathrm{fl}$ und der Roggen $4 \mathrm{fl}$ 56 kr gekostet - wurde das Getreide in Schwaz aber nicht angenommen, der Transport drehte bereits in Rosenheim um und kehrte nach Linz zurück. Dort stellte man fest, dass ein Teil der Ladung verdorben war, einen Teil verkaufte man, wobei dafür - da die Stände nicht Eigentümer des Getreides gewesen waren - ex post eine Ablöse bezahlt werden musste. ${ }^{31}$ Nachdem die Ernte des Jahres I 77 I in Oberösterreich noch schlechter als die des Vorjahres ausgefallen war, beschlossen die Landstände im September I771, 60.000 Metzen Roggen in Ungarn anzukaufen, und schickten dazu einen Abgeordneten nach Ungarn, der aber keinen Vertrag abschließen konnte, da niemand vor Anfang April Preise festlegen wollte. ${ }^{32}$ Somit ersuchte man um staatliche Hilfe und bekam »Aerialgetreide« zugesagt. Dafür und für zusätzlich durch die Stände angekauftes Getreide wurden mit Linzer Schiffmeistern Transportverträge abgeschlossen - dies kostete $250.000 \mathrm{fl}$, davon entfielen auf den Transport 70.000 fl. Hatte das Getreide in Ungarn pro Metzen noch 2 bis $2 \frac{1}{2} \mathrm{fl}$ gekostet, so hatte sich das Getreide bis Linz auf über 4 fl verteuert. ${ }^{33}$ Abgegeben hat man das Getreide aber unter diesem Preis. ${ }^{34}$

Der Wassertransport war zwar deutlich billiger als der Landtransport, er barg aber dennoch Probleme: Der Höhepunkt der Getreideknappheit trat im Winter I 77 I auf und fiel mit einem niedrigen Wasserstand der Donau zusammen, auch waren bei deutlich gestiegener Nachfrage die Transportkapazitäten begrenzt oder Schiffmeister bereits mit Verträgen gebunden. ${ }^{35}$ Ein Linzer Schiffmeister konnte I77 I keine Transporte für die Landstände durchführen, da er für das Militär Getreide beförderte.

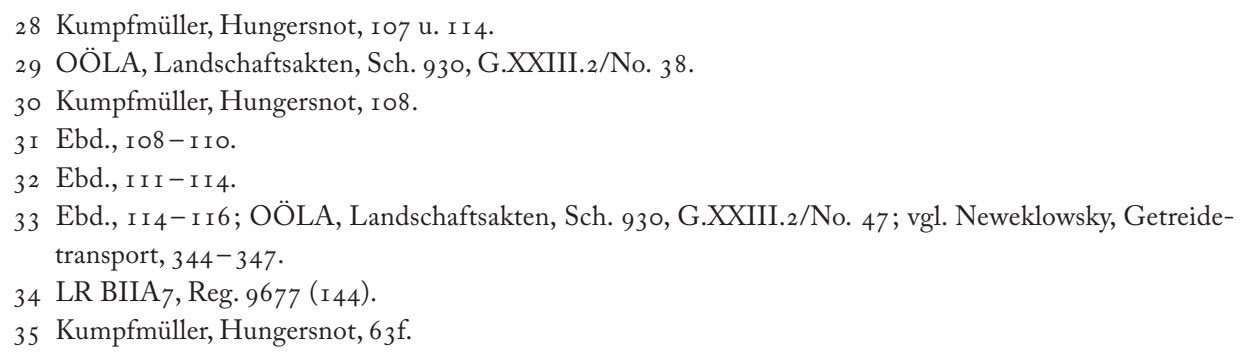


Mitte Juni I 772 mussten die für Linz bestimmten Schiffszüge wegen eines zu hohen Wasserstandes temporär einen Halt einlegen, ein Schiffszug erlitt eine Havarie und verlor Teile seiner Ladung. ${ }^{36}$ Zudem waren Schiffszüge schon bei normalen Bedingungen rund zwei Monate von Pest bis Linz unterwegs. ${ }^{37}$ Im August I 772 scheint sich eine normale Getreideernte abgezeichnet zu haben. Da man einen erneuten Preisanstieg befürchtete und das Mühlviertel und das Machland unterversorgt erschienen, suchten die Landstände um eine Lieferung von 30.000 Metzen staatlichem Getreide an. ${ }^{38} \mathrm{Im}$ Jänner I773 wurde zudem, vermutlich aufgrund der günstigen Preisentwicklung, ein Liefervertrag mit einem Linzer Gastwirt über 20.000 Metzen Roggen und 3.000 Metzen Gerste abgeschlossen. Als die Transporte aber im Mai Linz erreichten, waren die Getreidepreise vor Ort niedriger als die Kosten für das Importgetreide, das dann mit erheblichem Verlust verkauft wurde. ${ }^{39}$ Damit - und mit der guten Ernte des Jahres I773 - war die Knappheit im Linzer Raum offenbar überwunden, die Ausfuhrbeschränkungen blieben aber bis I 773 resp. I775. ${ }^{40}$ Rückblickend waren die Landstände davon überzeugt, dass die Getreideimporte die Krise abgeschwächt hätten: Ohne diese Intervention wären die Preise möglicherweise auf $8 \mathrm{fl}$ für Weizen bzw. $6 \mathrm{fl}$ für Roggen angestiegen. Die Mengen und der finanzielle Aufwand sind jedenfalls beeindruckend: I77I/I 772 hatten die Landstände insgesamt 19.550 Metzen Weizen und 84.849 Metzen Roggen für 408.00o fl angekauft, I 773 waren es 25.000 Metzen Roggen und 5.000 Metzen Gerste für ro8.000 fl. Daraus ergab sich, da man das Getreide unter dem Selbstkostenpreis abgegeben hatte (Weizen um 3 fl $45 \mathrm{kr}$ und Roggen um $3 \mathrm{fl} 30 \mathrm{kr}$ ), ein Verlust von I I 2.000 fl, dessen Abdeckung über den Verkauf des noch vorhandenen Getreides und eine Extrasteuer versucht wurde. ${ }^{41}$

Tab. 33: Sterbefälle in der Pfarre Linz, 1765-1774

\begin{tabular}{lrc}
\hline Jahr & Anzahl & pro 1.00o Einwohner \\
\hline 1770 & 661 & 33,05 \\
1771 & 966 & 48,29 \\
1772 & 1.211 & 60,52 \\
1773 & 701 & 35,02 \\
Mittelwert 1765-1774 & & 39,21 \\
\hline
\end{tabular}

Quelle: Eigene Berechnungen basierend auf Datenbank Sterbefälle

36 Neweklowsky, Getreidetransport, 344 u. 347.

37 LR CIIIG, Reg. I 23 (292).

38 OÖLA, Landschaftsakten, Sch. 93 I, G.XXIII.2/No. 58; Kumpfmüller, Hungersnot, 6 If.

39 Kumpfmüller, Hungersnot, I I 8- I 20; OÖLA, Landschaftsakten, Sch. 93 I, G.XXIII.2/No. $72-75$.

40 Kumpfmüller, Hungersnot, 4of.

4 I Kumpfmüller, Hungersnot, I 20- I 23. 
Dass Linz über die Donau an die ungarischen Getreidegebiete gut angebunden war und dadurch selbst in der Krise günstiger lag, ${ }^{42}$ zeigen die gravierenden Versorgungsprobleme in Böhmen und Tirol; ${ }^{43}$ auch Salzburg war vom Getreideimport weitgehend abgeschnitten und auf den Goodwill der Nachbarländer angewiesen gewesen. ${ }^{44}$ In Linz kam es zwar zu einer überdurchschnittlich hohen Mortalität in den Jahren I 77 I und I 772 - was vermutlich mit dem verstärkten Auftreten von Infektionskrankheiten zusammenhing -, sie blieb aber deutlich unter den Werten, die für andere Teile Europas angenommen wurden, und 1773 war die Sterbeziffer wieder auf ein normales Niveau gesunken (vgl. Tab. 33). ${ }^{45}$ Da die Linzer Stadtratsprotokolle erst ab den letzten Jahren des I 8. Jahrhunderts überliefert sind, ist das Handeln der städtischen Obrigkeit kaum greifbar: Die städtischen Rechnungsbücher dokumentieren für das Jahr I 772 zwar überdurchschnittliche Ausgaben (vgl. Tab. 6, darunter erhebliche Aufwendungen für die Armenunterstützung), sie beinhalten aber keine weiteren Informationen zum städtischen Agieren in der Teuerungskrise. ${ }^{46}$ Auch gibt es nur wenige Hinweise auf Auswirkungen und individuelle Handlungen vor Ort. Von den Chroniken wurde die Versorgungskrise der frühen I 77oer Jahre nicht thematisiert oder nur gestreift, ${ }^{47}$ ebenso wenig gibt es Anhaltspunkte für Unruhen oder sozialen Protest, sondern lediglich Ansuchen um Lohnerhöhungen. ${ }^{48}$ Ein direktes "Lernen« aus dieser gravierenden Krise lässt sich im Linzer Fall nicht feststellen: Zwar wurde die Absenz von Handelsbeschränkungen nun - von staatlicher Seite - verstärkt als Ideal gesehen und auch auf eine ständige Bevorratung mit Getreide gedrängt, die Praxis veränderte sich aber nicht. ${ }^{49}$ Nach der Vorstellung des Wiener Hofes wäre es zukünftig Aufgabe der Landstände gewesen, für ganz Oberösterreich 40.000 Metzen (rund I.800 Tonnen) Getreide als Vorrat bereitzuhalten. Dies wiesen die Stände im Frühjahr I 773 zurück: Man könne diese Menge nicht aus der heimischen Produktion beziehen, auch ergäben sich bei hohen Preisen - und bei überregionalen Importen - enorme Kosten. Dieses Projekt wurde nicht umgesetzt, aber zum Ende der I 78 oer Jahre - im Kontext einer Missernte - erneut diskutiert und schließlich wieder verworfen, denn das Grundproblem - teures Lagergetreide, das nach dem Abklingen der Teuerung auf günstiges

42 Vgl. Collet/Krämer, Germany, ro2; vgl. das andere Setting in Regensburg: Collet, Katastrophe, 309-329.

43 Pfister/Brázdil, Vulnerability, г 22- I 26; Kumpfmüller, Hungersnot, 91-94; vgl. die Einschätzung von

Roman Sandgruber: Sandgruber, Lebensstandard, 275.

44 Kumpfmüller, Hungersnot, $39 \mathrm{f}$.

45 LR BIIG6, Reg. 3470 ( 1 95); LR BIIA7, Reg. 9722 (I 52 ); LR BIIG7, Reg. 4097 (87); Ardelt, Elisabethinen, I I I ; vgl. Abel, Massenarmut, 252 - 254 u. Pfister/Brázdil, Vulnerability, I 26.

46 Vgl. AStL, HS 92 (Stadtkammeramtsrechnung I772), pag. 308f. u. AStL, HS 93 (Stadtkammeramtsrechnung 1773), pag. I87f.; vgl. zur städtischen Politik in Regensburg: Collet, Katastrophe, 3 I4-3 18.

47 Vgl. LR E6; LR CIIIC 4 ; LR Erd; Pillwein, Wegweiser, 30 u. 39.

48 LR BIIA25, Reg. 17806 (ro2 - Io6); vgl. zu sozialem Protest und Unruhen: Collet, Katastrophe, r IoI I 6 U. 2 I 8 -23 I.

49 Kumpfmüller, Hungersnot, I7 u. I24; vgl. zum Lernen und zum »Erinnern und Vergessen«: Collet, Katastrophe, $366-396$. 
frisches Getreide traf - ließ sich nicht lösen. ${ }^{50}$ Auch die Kartoffel, die in manchen von der Versorgungskrise der I 77oer Jahre stark betroffenen Gebieten als Pufferungsstrategie nun verstärkt angebaut wurde, entwickelte sich erst im Vormärz zum Grundbestandteil der Ernährung im Linzer Raum (vgl. Kap. 4. Energie und Biomasse). ${ }^{51}$

\section{Das langsame Auslaufen der Versorgungskrisen}

In den letzten Jahrzehnten des i 8. Jahrhunderts waren die Erträge der landwirtschaftlichen Produktion in der Region angestiegen und die überregionale Versorgung hatte sich weiter verbessert. Teuerungen und Nahrungsknappheit verschwanden zwar nicht, blieben aber bis zu den Napoleonischen Kriegen deutlich weniger gravierend als die Krise der I 77oer Jahre. ${ }^{52}$ Erst mit dem Näherrücken der kriegerischen Auseinandersetzungen an Linz stiegen die Lebensmittelpreise und die Sterblichkeit an (vgl. Grafiken I u. 3 sowie Tab. 34), ${ }^{53}$ was durch klimatisch induzierte Missernten verstärkt wurde. Franz Haslinger, der ab I 806 in Linz und zuvor im nördlichen Hinterland von Linz Pfarrer war, ${ }^{54}$ dokumentierte für die Jahre I797, I 798 und I 805 schlechte Ernten ${ }^{55}$ und für I 803 eine Missernte beim Getreide: „Seit gar vielen Jahren war kein solcher Miswachs. " ${ }^{56}$ Dies resultierte in einer Teuerungsphase, die im Kern von I 803 bis I 807 andauerte (vgl. Grafik 3): Verglichen mit I 800 hatten sich die Preise für Weizen und Gerste bis 1806 beinahe verdreifacht. ${ }^{57}$ Auf diese Teuerungen reagierten die Stadt und die Landstände wie in den I77oer Jahren mit Getreideimporten aus Ungarn, die die Preise senken sollten. Dazu wurde Brot verbilligt angeboten oder als "Armenbrot « gratis verteilt. ${ }^{58} \mathrm{Im}$ Winter I 803/1 804 waren dies in der Stadt über 9 Tonnen Brot ${ }^{59}$ und in zwei Sommermonaten des Jahres I 805 rund 4 Tonnen. ${ }^{60}$ Da die Preise hoch blieben, gaben ein Linzer und ein Urfahrer Schiffmeister im Frühsommer I 805 Getreide (»einige tausend Metzen Korn«) verbilligt ab bzw. ließen es verbacken; dazu kamen ähnliche Aktionen von anderen Stadtbewohner/innen und staatlich finanzierte Getreideimporte. ${ }^{61}$ Trotz der wiederholten Verordnung gegen den Vorkauf von Getreide, einer

50 Kumpfmüller, Hungersnot, I 24- I 26; vgl. ebd., 66-7 1 .

5 I Pfister/Brázdil, Vulnerability, I 26; kritisch dazu: Collet/Krämer, Germany, rogf.

52 Vgl. LR E7a u. b, Reg. 837 (207); LR Eıb, Reg. 1837 (I o6); ebd., Reg. 1952 (I 25 ).

53 Vgl. LR Erb, Reg. 2084 (I 44); ebd., Reg. 2 I 28 (I5 I); ebd., Reg. 2 I 32 (I52); ebd., Reg. 2 I76 (I58f.);

ebd., Reg. 2197 (I6If.); OÖLA, Neuerwerbungen, Sch. 76/No. 6.

54 Haslinger, Tagebücher, unpag. (Vorwort); vgl. Kap. 8. Natur der Städter - Natur für Städter.

$55 \mathrm{HTb}$ I 797, Fruchtbarkeit; HTb I798, Fruchtbarkeit; HTb I 805, Fruchtbarkeit.

$56 \mathrm{HTb}_{1803}$, Fruchtbarkeit.

57 Schweiger, Stadt, I36f., I 40 u. I60; LR Eır, Reg. 2136 (I 5 2); LZ, 7.2.1803; ebd., I 2.I 2.1803.

$58 \mathrm{HTb}$ 1803, Fruchtbarkeit; LZ, I6.1 2.1803; ebd., 29.6.1804; ebd., 20.7.1804; ebd., 27.8.1804.

59 LZ, 29.6.1804.

60 LZ, 23.8.1805; vgl. LR CIIIDI -3, Reg. 224 (160f.).

6r HTb I 805, Fruchtbarkeit; vgl. LZ, 24.6.1805; ebd., 8.7.1805; ebd., 19.7.1805. 
obrigkeitlichen »Bewirtschaftung der Getreidevorräte (also Verkaufszwänge) und der Abgabe von verbilligtem Getreide dauerte diese Teuerungsphase bis ins Jahr I $807 .{ }^{62}$ Der Einmarsch der Franzosen in Linz im Mai I 809 verursachte - trotz guter Ernten der Jahre I 808 und I 809 - eine erneute Teuerung, eine Nahrungsmittelknappheit und ein verstärktes Auftreten von Infektionskrankheiten. ${ }^{63}$ Diese Konstellation resultierte in der höchsten Mortalität während des I 9. Jahrhunderts, die sogar die Sterblichkeit der Jahre I77I und I772 deutlich überstieg (vgl. Tab. 34). ${ }^{64}$ Aber auch die folgenden Jahre waren durch hohe Preise geprägt, einen Höhepunkt erlebte die sozioökonomische Dauerkrise des frühen I 9. Jahrhunderts mit der Geldentwertung des Jahres I 8 I I ${ }^{65}$ Erst die guten Ernten der Jahre I 8 I 2 und I 8 I 3 führten zu sinkenden Preisen, die aber infolge der unterdurchschnittlich ausfallenden Getreideernten der Jahre I 8 I 4 und I 8 I 5 wieder deutlich anstiegen und zur nächsten Teuerungskrise überleiteten. ${ }^{66}$

Die Teuerungen und Knappheiten im Kontext der Napoleonischen Kriege und des "Jahres ohne Sommer« I 8 I 6 können als Transitionsphase und turning point der Versorgungskrisen in Zentraleuropa gesehen werden. ${ }^{67}$ Sie waren nur noch teilweise vom Muster type ancien gekennzeichnet, bei denen klimatisch induzierte Missernten zu Teuerungen und einer Übersterblichkeit führten. Die Mortalität der Jahre I 8 I 6 und I 8 I 7 lag in Linz sogar deutlich unter dem Schnitt der I 8 roer Jahre, die höchste Sterblichkeit wies in diesem Zeitraum - typhusbedingt - das Jahr I 8 I 4 auf (vgl. Tab. 34). ${ }^{68}$

Die Witterung des Jahres I 8 I6 fiel, was eine Auswirkung niedriger Sonnenaktivität (des "Dalton-Minimum«) und des Ausbruchs des indonesischen Vulkans Tambora im April I 8 I 5 war, in weiten Teilen Zentral- und Westeuropas überdurchschnittlich kalt und niederschlagsreich aus. Der Winter I 8 I 5/ I8 6 dauerte lange und war schneereich, Frühjahr und Sommer waren kalt und verregnet, der Wintereinbruch kam früh. Durchschnittlich lagen die Temperaturen in Europa bis zu 3 Grad Celsius (für die Monate Juni, Juli, August und November) unter den Durchschnittswerten des Referenzzeitraumes r 90 I - 1960. ${ }^{69}$ Für Linz zeigen die Klimadaten eine geringere Abkühlung: Der Jänner I 8 I 6 war etwas über 2 Grad wärmer, der (meteorologische) Frühling nur o,5 Grad und der Sommer wie der Herbst rund I Grad kühler. Die Niederschläge scheinen nur

62 HTb I 808, Fruchtbarkeit u. HTb I 809, Fruchtbarkeit; vgl. LZ, 24.5 .I 805 ; ebd., I.7.I 805 ; LR Erb, Reg. 2197 (I6If.); LR E7e-g, Reg. 1009 (247); ebd., Reg. 1072 (26r).

63 Ruhr und Typhus - vgl. RB I 899, nach 352.

64 Schweiger, Stadt, I78f. u. I 89; vgl. LR Erb, Reg. 2236 (I67); ebd., Reg. 2255 (I69).

65 HTb I 8 Iо, Fruchtbarkeit u. HTb I 8 I I , Fruchtbarkeit; vgl. Sandgruber, Ökonomie, 222 f.

66 HTb I 8 Iо-I8 15, Fruchtbarkeit; vgl. OÖLA, Neuerwerbungen, Sch. 76/No. 6.

67 Vgl. als Übersicht: EdN, s.v. Jahre ohne Sommer; zudem Collet/Krämer, Germany, Io9-I I I ; u. Abel, Massenarmut, $3 \mathrm{I} 7-326$.

$68 \mathrm{HTb}$ г 8 I 4, Fruchtbarkeit; RB г 899, nach 352; vgl. Collet/Krämer, Germany, I Io u. Behringer, Tambora, II 9 - I22.

69 Pfister, Wetternachhersage, I 53 - I 55 u. 297; vgl. Krämer, Menschen, 37-39 u. 276-284; White/Pfister/ Mauelshagen, Handbook, 55 I - 56r, Behringer, Tambora, 40-56. 
Tab. 34: Sterbefälle in den Linzer Pfarren, 1800-1819

\begin{tabular}{lrc}
\hline Jahr & Anzahl & pro 1.00o Einwohner \\
\hline 1800 & 961 & 47,70 \\
1801 & 915 & 45,41 \\
1802 & 736 & 36,47 \\
1803 & 869 & 43,00 \\
1804 & 860 & 42,49 \\
1805 & 1.083 & 53,43 \\
1806 & 1.280 & 63,05 \\
1807 & 823 & 40,48 \\
1808 & 911 & 44,74 \\
1809 & 1.498 & 73,47 \\
1810 & 1.116 & 54,65 \\
1811 & 894 & 43,72 \\
1812 & 829 & 40,48 \\
1813 & 845 & 41,20 \\
1814 & 1.147 & 55,84 \\
1815 & 860 & 41,81 \\
1816 & 863 & 41,89 \\
1817 & 776 & 37,62 \\
Mittelwert 1800-1809 & & 49,03 \\
Mittelwert 1810-1819 & & 44,42 \\
\hline
\end{tabular}

Quelle: Eigene Berechnungen basierend auf Datenbank Sterbefälle

im Juni und September überdurchschnittlich gewesen zu sein. ${ }^{70}$ "Im Ganzen war die herrschende Witterung die trübe«, charakterisierte ein Pater aus dem südlich von Linz gelegenen Stift Kremsmünster das Jahr I 8 I 6, »in den Sommermonathen Juni, Juli, Aug., und Sept. gab es 68 Tage, an welchen es regnete «. ${ }^{71}$ Der Linzer Geistliche Franz Haslinger verzeichnete in seinem Tagebuch ebenso fast 70 Tage mit Regen zwischen Juni und September, ${ }^{72}$ einen lange andauernden Winter, der erst im April endete, und einen kühlen, trüben Sommer mit zahlreichen Gewittern und nur einzelnen schönen Tagen. ${ }^{73}$ Möglicherweise sei diese "ganz ungewöhnliche Witterung", so die »Linzer Zeitung" im Juli I 8 I6, das Resultat von »irgend einem ausserordentlichen Naturereigniß, vielleicht

70 HISTALP (Temperatur) und Casty et al., Temperature (Niederschlag); vgl. Lauscher et al., Witterung, 74f. u. Reith, Umweltgeschichte, I I.

7I LZ, 6.I.I8I7.

72 Haslinger, Tagebücher, 237-242.

73 HTb г 8 16, Jahreszeiten; vgl. LZ, 8.7.1816 u. ebd., г2.8.18 16. 
einem großen Erdbeben oder ungewöhnlichen Ausbruch eines Vulkans «. ${ }^{74}$ Der Herbst und der Winter I 8 I 6 waren in Linz zwar mild, aber »nas« und »trüb «. ${ }^{75}$

Diese Witterungskonstellation führte zu Ernteausfällen in der Landwirtschaft, besonders war das Getreide betroffen, und bald stiegen die Lebensmittelpreise stark an. ${ }^{76}$ Das Getreide "misrieth fast überall«, notierte Haslinger. ${ }^{77}$ Mitte Juni waren noch optimistische Meldungen in der »Linzer Zeitung« erschienen: Die Roggenernte finde zwar zu einem etwas späteren Zeitpunkt statt, sie sei aber »weit ergiebiger, als man erwartet hatte«, und auch für die anderen Getreidesorten sei ein guter Ertrag anzunehmen. Ähnliches lasse sich aus den Berichten aus Ungarn schließen, die Preise würden - in Erwartung einer guten Ernte - bereits sinken. ${ }^{78}$ Tatsächlich stiegen die Getreidepreise in Linz seit Juni deutlich an (vgl. Tab. 35). Im September erwartete man in Deutschland eine gute Ernte und hoffte auf sinkende Getreidepreise, da »kein wirklicher Mangel an Fruchtvorräthen « herrsche. ${ }^{79}$ Ähnliches konstatierte man in den Folgemonaten - die Getreidepreise in Linz stiegen aber weiterhin an. ${ }^{80}$

Tab. 35: Getreide- und Brotpreise in Linz, 1816

\begin{tabular}{|c|c|c|c|c|c|}
\hline & $\begin{array}{l}\text { Metzen } \\
\text { Weizen }\end{array}$ & $\begin{array}{l}\text { Metzen } \\
\text { Roggen }\end{array}$ & $\begin{array}{l}\text { Metzen } \\
\text { Gerste }\end{array}$ & $\begin{array}{l}\text { Gewicht des } \\
\text { "6-kr«-Brotlaibes }\end{array}$ & Quelleb \\
\hline Jänner u. Februar & $18 \mathrm{fl} 27 \mathrm{kr}$ & $17 \mathrm{fl} 12 \mathrm{kr}$ & $8 \mathrm{fl} 33 \mathrm{kr}$ & 13 Lot & LZ/AB, 5.1.1816 \\
\hline März & $19 \mathrm{fl} 3 \mathrm{kr}$ & $17 \mathrm{fl} 15 \mathrm{kr}$ & $9 \mathrm{fl} 15 \mathrm{kr}$ & 12 Lot 2 Q & LZ/AB, 4.3.1816 \\
\hline April & $18 \mathrm{fl} 12 \mathrm{kr}$ & $16 \mathrm{fl} 42 \mathrm{kr}$ & $9 \mathrm{fl} 9 \mathrm{kr}$ & 13 Lot & LZ/AB, 5.4.1816 \\
\hline Mai & $18 \mathrm{fl} 24 \mathrm{kr}$ & $16 \mathrm{fl} 39 \mathrm{kr}$ & $9 \mathrm{fl} 18 \mathrm{kr}$ & 13 Lot & LZ/AB, 3.5.1816 \\
\hline Juni & $20 \mathrm{fl} 18 \mathrm{kr}$ & $17 \mathrm{fl} 30 \mathrm{kr}$ & $10 \mathrm{fl}$ & 12 Lot 10 & $L Z / A B, 7.6 .1816$ \\
\hline Juli & $22 \mathrm{fl} 24 \mathrm{kr}$ & $18 \mathrm{fl} 9 \mathrm{kr}$ & $11 \mathrm{fl} 15 \mathrm{kr}$ & 11 Lot & $L Z / A B, 5 \cdot 7 \cdot 1816$ \\
\hline August & $22 \mathrm{fl} 33 \mathrm{kr}$ & $17 \mathrm{fl} 21 \mathrm{kr}$ & $11 \mathrm{fl}$ & 11 Lot 10 & LZ/AB, 5.8.1816 \\
\hline September & $34 \mathrm{fl} 48 \mathrm{kr}$ & $26 \mathrm{fl} 51 \mathrm{kr}$ & $15 \mathrm{fl} 54 \mathrm{kr}$ & 7 Lot 2 Q & LZ/AB, 16.9.1816 \\
\hline Oktober & $34 \mathrm{fl} 30 \mathrm{kr}$ & $27 \mathrm{fl} 6 \mathrm{kr}$ & $15 \mathrm{fl} 30 \mathrm{kr}$ & 7 Lot 2 Q & $L Z / A B, 4.10 .1816$ \\
\hline November & $35 \mathrm{fl} 18 \mathrm{kr}$ & $30 \mathrm{fl} 48 \mathrm{kr}$ & $16 \mathrm{fl} 57 \mathrm{kr}$ & 7 Lot 30 & $L Z / A B, 1.11 .1816$ \\
\hline \multirow[t]{2}{*}{ Dezember } & $37 \mathrm{fl} 42 \mathrm{kr}$ & $34 \mathrm{fl}$ & $19 \mathrm{fl} 27 \mathrm{kr}$ & 7 Lot & LZ/AB, 6.12 .1816 \\
\hline & 22 bis $35 \mathrm{fl}$ & 18 bis $33 \mathrm{fl}$ & bis $20 \mathrm{fl}$ & & HTb 1816, Fruchtbarkeit \\
\hline
\end{tabular}

a 1 Lot $=17,5$ Gramm $=4$ Q (Quentchen - vgl. Kap. Währungen und Maßeinheiten)

b Preise in WW laut "Mehl- und Brodsatzung", damit korrespondieren die durchschnittlichen Preise auf den nächsten Wochenmärkten in Eferding oder Wels (vgl. LZ/AB, 27.12.1816, 316)

74 LZ, I9.7.I8 16, 238; vgl. zu den zeitgenössischen Deutungen: Krämer, Menschen, 23.

$75 \mathrm{HTb}$ I 8 I6, Jahreszeiten; Haslinger, Tagebücher, 242- 245.

76 Vgl. Pfister, Wetternachhersage, I 55; Abel, Massenarmut, 3 I 7-32 I.

$77 \mathrm{HTb}$ I 8 16 , Fruchtbarkeit.

$78 \mathrm{LZ}$, I5.7.18 86.

$79 \mathrm{LZ}, 6.9 .18 \mathrm{I} 6$.

80 LZ, 29.II.I8I6. 
Tab. 36: Getreide- und Brotpreise in Linz, 1817

\begin{tabular}{|c|c|c|c|c|c|}
\hline & $\begin{array}{l}\text { Metzen } \\
\text { Weizen }\end{array}$ & $\begin{array}{l}\text { Metzen } \\
\text { Roggen }\end{array}$ & $\begin{array}{l}\text { Metzen } \\
\text { Gerste }\end{array}$ & $\begin{array}{l}\text { Gewicht des } \\
\text { "6-kr«-Brotlaibes }\end{array}$ & Quelle \\
\hline Jänner & $38 \mathrm{fl} 39 \mathrm{kr}$ & $33 \mathrm{fl} 12 \mathrm{kr}$ & $19 \mathrm{fl} 42 \mathrm{kr}$ & 7 Lot & LZ/AB, 30.12 .1816 \\
\hline Februar & $39 \mathrm{fl} 3 \mathrm{kr}$ & $33 \mathrm{fl} 39 \mathrm{kr}$ & $20 \mathrm{fl} 33 \mathrm{kr}$ & 7 Lot & LZ/AB, 31.1.1817 \\
\hline März & $37 \mathrm{fl} 48 \mathrm{kr}$ & $32 \mathrm{fl} 21 \mathrm{kr}$ & $20 \mathrm{fl} 51 \mathrm{kr}$ & 7 Lot 1 O & LZ/AB, 28.2.1817 \\
\hline April & $36 \mathrm{fl} 45 \mathrm{kr}$ & $29 \mathrm{fl} 33 \mathrm{kr}$ & $20 \mathrm{fl} 6 \mathrm{kr}$ & 7 Lot 30 & LZ/AB, 31.3.1817 \\
\hline Mai & $37 \mathrm{fl} 39 \mathrm{kr}$ & $29 \mathrm{fl} 48 \mathrm{kr}$ & $20 \mathrm{fl} 45 \mathrm{kr}$ & 7 Lot 3 O & LZ/AB, 2.5.1817 \\
\hline Juni & $41 \mathrm{fl} 42 \mathrm{kr}$ & $33 \mathrm{fl} 24 \mathrm{kr}$ & $23 \mathrm{fl} 24 \mathrm{kr}$ & 6 Lot 4 O & LZ/AB, 30.5.1817 \\
\hline Juli & $40 \mathrm{fl} 24 \mathrm{kr}$ & $33 \mathrm{fl} 12 \mathrm{kr}$ & $24 \mathrm{fl} 33 \mathrm{kr}$ & 7 Lot & $\mathrm{LZ} / \mathrm{AB}, 4.7 .1817$ \\
\hline Julia & $33 \mathrm{fl} 45 \mathrm{kr}$ & $29 \mathrm{fl} 9 \mathrm{kr}$ & $20 \mathrm{fl} 24 \mathrm{kr}$ & 8 Lot 2 O & LZ/AB, 18.7.1817 \\
\hline August ${ }^{b}$ & $34 \mathrm{fl} 6 \mathrm{kr}$ & $24 \mathrm{fl} 3 \mathrm{kr}$ & $19 \mathrm{fl} 54 \mathrm{kr}$ & 8 Lot 30 & LZ/AB, 1.8.1817 \\
\hline August ${ }^{a}$ & $27 \mathrm{fl} 6 \mathrm{kr}$ & $20 \mathrm{fl}$ & $18 \mathrm{fl} 39 \mathrm{kr}$ & 10 Lot 2 Q & LZ/AB, 18.8.1817 \\
\hline September & $20 \mathrm{fl} 45 \mathrm{kr}$ & $18 \mathrm{fl} 12 \mathrm{kr}$ & $14 \mathrm{fl} 42 \mathrm{kr}$ & 12 Lot 2 O & LZ/AB, 1.9.1817 \\
\hline Oktober & $20 \mathrm{fl} 36 \mathrm{kr}$ & $18 \mathrm{fl} 9 \mathrm{kr}$ & $13 \mathrm{fl} 27 \mathrm{kr}$ & 13 Lot & LZ/AB, 3.10.1817 \\
\hline November & $18 \mathrm{fl} 48 \mathrm{kr}$ & $16 \mathrm{fl} 21 \mathrm{kr}$ & $13 \mathrm{fl} 6 \mathrm{kr}$ & 13 Lot 3 O & LZ/AB, 31.10.1817 \\
\hline \multirow[t]{2}{*}{ Dezember } & $19 \mathrm{fl} 48 \mathrm{kr}$ & $16 \mathrm{fl} 48 \mathrm{kr}$ & $13 \mathrm{fl} 6 \mathrm{kr}$ & 13 Lot 30 & LZ/AB, 1.12.1817 \\
\hline & 18 bis $40 \mathrm{fl}$ & 16 bis $33 \mathrm{fl}$ & 12 bis $20 \mathrm{fl}$ & & HTb 1817, Fruchtbarkeit \\
\hline
\end{tabular}

a zweite Monatshälfte

b erste Monatshälfte

Auf diesen Preisanstieg reagierte man in dieser überregionalen Krise mit ähnlichen Maßnahmen wie bei den Teuerungen zuvor: Es kam zu staatlich organisierten Getreideimporten, zur verbilligten Abgabe von Brot, Getreide und Brennholz, zudem zu öffentlichen Speisungen (vor allem durch Suppenküchen) und zum Propagieren von Ersatznahrung (besonders der Kartoffel). Das nun omnipräsente Ideal des Wirtschaftsliberalismus führte aber dazu, dass nur einzelne Territorien die Ausfuhr und den Handel mit Getreide untersagten und beschränkten. ${ }^{81}$ Neu in dieser Krise waren das Engagement bürgerlicher Initiativen, eine deutlich intensivere kommunikative Vernetzung und eine verbesserte Marktintegration. ${ }^{82}$ Auch in Linz wurde die Armenunterstützung ausgeweitet, Brot verteilt resp. subventioniert, der Geistliche Haslinger notierte zwar »sehr groß[e] « Not und »Unzufriedenheit«, es gibt aber keine Hinweise auf Unruhen - in Linz scheint eine größere Krise ausgeblieben zu sein. ${ }^{83}$ Die Witterung des Jahres i 8 I 7 war deutlich günstiger: Zwar führte das Abschmelzen der großen

8I Collet/Krämer, Germany, i io; Collet, Katastrophe, I48; Abel, Massenarmut, 327-342.

82 Collet/Krämer, Germany, I I I; LR CIIIG, Reg. r665 (507f.); vgl. die Meldungen über in Triest und Livorno angekommenes Getreide LZ, 4. Iо. 8 I6.

83 HTb i 8 I 7, Begebenheiten; vgl. zur Schweiz: Krämer, Menschen, 337-342 u. als Synopsis: Behringer, Tambora. 
Schneemengen im Frühjahr I 8 I 7 mancherorts - aber nicht in Linz - zu Überschwemmungen, insgesamt war dieses Jahr jedoch deutlich wärmer und niederschlagsärmer. ${ }^{84}$ Laut Haslingers Aufzeichnungen war der Winter I8I6/I8I7 »ausserordentlich gelinde«, der April jedoch kalt und mit einzelnen Schneefällen, was »bange Besorgnisse» ausgelöst habe, »weil ohnedies der Mangel und die Theuerung so ungeheuer groß und trückend war«. Die warme Witterung des Mai gab wieder »frohe Hoffnungen«, der Sommer - der »nie zu naß« und »allzeit gleich wieder schön« war - und die warme und trockene Erntezeit führten zu einer relativ guten Getreideernte im Linzer Raum. ${ }^{85}$ Die Getreidepreise stiegen aber noch bis in den Juni an und sanken nur langsam ab erst im November I8 77 wurde wieder das Preisniveau vom Beginn des Jahres I 8 i 6 erreicht (vgl. Tab. 36). ${ }^{86}$ Der guten Ernte des Jahres I 8 I 7, für die in der Linzer Ignatiuskirche ein Dankesfest abgehalten worden war, ${ }^{87}$ folgte I 8 I 8 ein »ungemein fruchtbares, sehr gesegnetes Jahr« mit niedrigen Preisen. »Gott sey Dank dafür!«, notierte der sonst relativ nüchterne Beobachter Haslinger in seinem Tagebuch. ${ }^{88}$ Es begann eine relativ günstige Phase, die bis in die I 84oer Jahre andauerte (vgl. Grafik 4), ${ }^{89}$ auch das Jahr I 830, das vielerorts von Missernten und Teuerungen geprägt war, ${ }^{90}$ blieb im Linzer Raum ohne »besondere Theuerung ${ }^{91}{ }^{91}$

Ihr Ende fand diese Phase mit den hungry forties, die den letzten Ausläufer der Kombination von Missernten und daraus resultierenden überregionalen Versorgungskrisen darstellten. ${ }^{92}$ In Linz war nach einem Sommer mit stark unterdurchschnittlichem Niederschlag (was auch den Wiener Raum betroffen hatte) bereits I 842 eine Preissteigerung bei Getreide und Hülsenfrüchten eingetreten. ${ }^{93}$ Die Preise für Getreide blieben in den Folgejahren hoch und stiegen durch die schlechten Ergebnisse der Getreideernte des Jahres I 845 und die im Sommer des gleichen Jahres auftretende Kartoffelfäule weiter an. ${ }^{94}$ Die verminderte Ernte der Kartoffeln - in Österreich war sie rund ein Drittel geringer - verschlechterte die Ernährungssituation erheblich, da

84 HISTALP (Temperatur) u. Casty et al., Temperature (Niederschlag); vgl. Behringer, Tambora, I I 3 - I I 5 . $85 \mathrm{HTb}$ г 8 I7, Jahreszeiten u. Fruchtbarkeit; vgl. auch OÖLA, Musealarchiv HS I 78 (Geschichte der Stadt Linz von Ignaz Fink, Bd. I, undat.), pag. 553.

86 Vgl. zu den verfrühten Meldungen eines Sinkens der Getreidepreise: LZ, 24.2.I8I7; ebd., 3 I.3.I8 I7; ebd., 4.7.I8I 7; ebd., 7.7.18 I 7; vgl. allgemein: Behringer, Tambora, I65- I68.

87 Fink, Geschichte, 32.

$88 \mathrm{HTb}$ г 8 18, Fruchtbarkeit.

89 HTb r819-1832, Fruchtbarkeit; vgl. zu Wien: Csendes/Opll, Wien, Bd. 3, r29f. u. allgemein: Abel, Massenarmut, $344 \mathrm{f}$.

90 Vgl. HTb i 830, Jahreszeiten; HISTALP; Pfister, Wetternachhersage, , 104 u. 297; allgemein: Abel, Massenarmut, $353 \mathrm{f}$.

9г $\mathrm{HTb}$ i 830, Fruchtbarkeit.

92 Collet/Krämer, Germany, i i if.

93 Marx, Ende, I 90 u. I94; vgl. Casty et al., Temperature.

94 Marx, Ende, 274f. u. 369 ; vgl. LR BVI 3 , Reg. I 7 I I (Io6). 


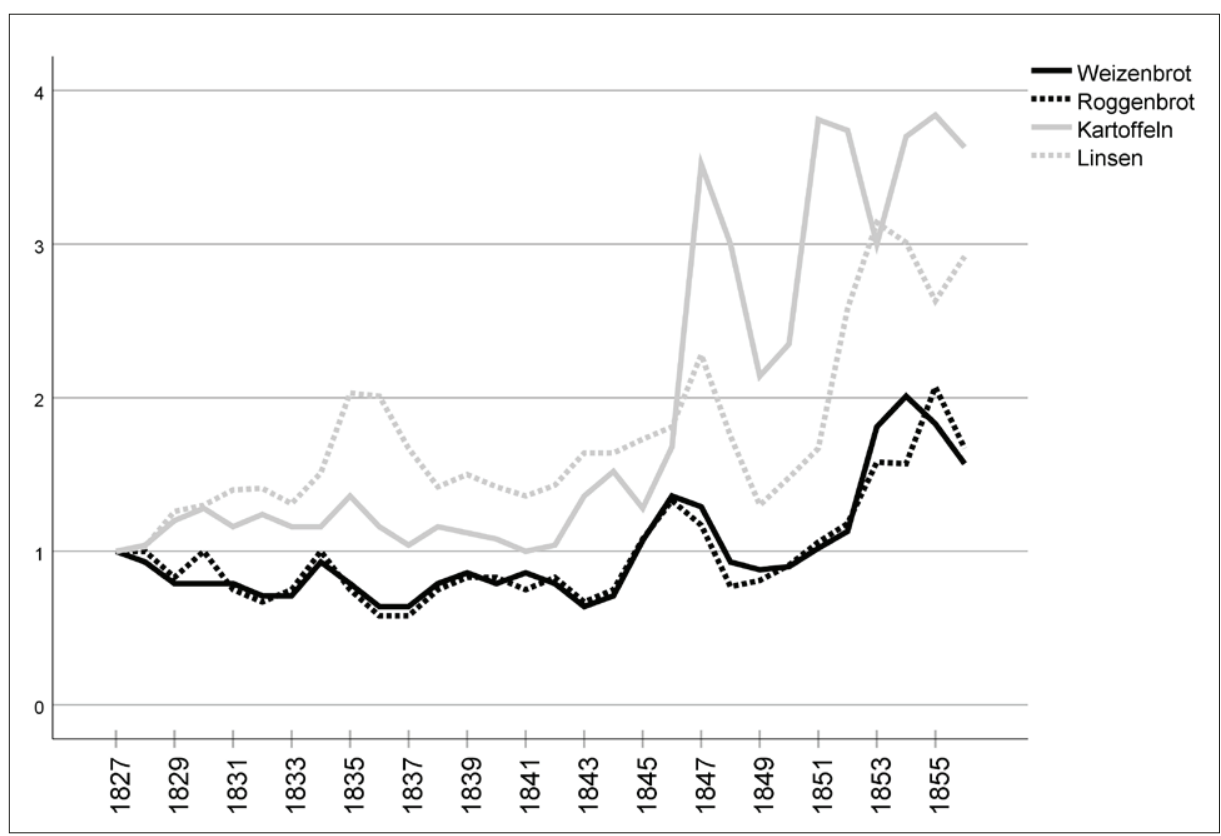

Grafik 4: Lebensmittelpreise in Oberösterreich, 1827-1856. Quelle: Eigene Berechnung und Darstellung basierend auf Cvrcek, Wages; $1827=1$

die Kartoffel nach der Krise 1816/1817 an Bedeutung gewonnen hatte. ${ }^{95}$ Im Linzer Raum war die Teuerung im Jahr I 845 noch begrenzt, auch scheint die Kartoffelernte noch nicht von der Fäule betroffen gewesen zu sein, dennoch stiegen die Getreidepreise - wohl, da die Getreidelieferungen aus Ungarn deutlich geringer gewesen waren - bis ins Frühjahr I 846 deutlich an. ${ }^{96}$ In diesem Jahr trat die Kartoffelfäule erstmals in Oberösterreich stark auf, zudem fiel die ungarische Getreideernte unterdurchschnittlich aus, was zu einer allgemeinen Teuerung führte. ${ }^{97}$ Ihren Höhepunkt erreichten die Lebensmittelpreise im Frühjahr und Sommer I 847 - verglichen mit den Preisen des Jahres 1838 war 1847 in Linz der Weizen ca. 8o Prozent, der Roggen ca. 6o Prozent und Linsen 25 Prozent teurer (vgl. Grafik 3 u. 4). ${ }^{98}$

Zunächst scheinen von staatlicher Seite kaum Maßnahmen gegen die Teuerungen ergriffen worden zu sein, möglicherweise da die Ernte des Jahres I 846 vielerorts gut ausfiel und man die Versorgung über Getreideimporte als ausreichend erachtete. Erst

95 Collet/Krämer, Germany, I I I ; vgl. zum Kartoffelanbau und -konsum in Salzburg, der vor allem seit den I 8 I oer Jahren zunahm: Schuhladen, Einführung, 3 I6-338.

96 Marx, Teuerung, i ro; Marx, Ende, 504-506.

97 Marx, Teuerung, ro6f.

98 Marx, Ende, 737; Abel, Massenarmut, 363f.; Hecht, Handeln, I35; vgl. zu Wien: Marx, Teuerung, I I 2 - I I 7 . 
mit dem Teuerungsschub im Frühjahr I 847 kehrten einzelne deutsche Territorien zu den »alten« Reaktionen zurück und setzten Vorverkaufs- und Zwischenhandelsverbote, Zollerleichterungen für Einfuhr von Getreide und Verbote des Schnapsbrennens aus Getreide oder Kartoffeln in Kraft und initiierten finanzielle Unterstützungen resp. staatlich subventionierte Getreideankäufe. Der unbeschränkte Getreidehandel wurde aber von staatlicher Seite, anders als in früheren Versorgungskrisen, nicht grundsätzlich infrage gestellt - es bestanden nur temporäre Exportverbote. ${ }^{99}$ Zwischen Mai und November I 847 war auch in Oberösterreich die Ausfuhr von Getreide, Hülsenfrüchten und Kartoffeln verboten, ${ }^{100}$ in Linz wurde erneut die Armenversorgung ausgeweitet, preisreduziertes Brot - teilweise über eine bürgerliche »Privatwohlthätigkeits-Anstalt« - angeboten und Notstandsbauten als Arbeitsbeschaffungsmaßnahme initiiert. ${ }^{101}$

Die Folgen dieser Krise waren vermutlich weniger existenzbedrohender Hunger, sondern soziale Probleme und eine Erhöhung des Armutsrisikos, ${ }^{102}$ denn immer noch musste in Unterschichtshaushalten der Großteil der Einnahmen für Lebensmittel ausgegeben werden. ${ }^{103}$ Eine weitere Auswirkung waren soziale Proteste, die unregulierte Märkte für die Teuerungen verantwortlich machten. ${ }^{104}$ Erstaunlicherweise wurden in den Linzer Ego-Dokumenten Versorgungskrisen - nicht nur die der I $840 e r$ Jahre anders als z. B. das "politische« I 848 oder die Franzosenkriege kaum thematisiert. Der Hunger fand nur in Chroniken Erwähnung, aber auch nicht sehr ausführlich. Für Linz geben lediglich einzelne Polizeiberichte, die das habsburgische Innenministerium summarisch über die Situation vor Ort informierten und die für die Jahre I 845 und I 847 überliefert sind, Einblick in sozioökonomische Auswirkungen und Wahrnehmungen der damaligen Teuerungskrise. Schon I 845 meldete der Linzer Polizeidirektor nach Wien, dass man in der Stadtbevölkerung ein obrigkeitliches Vorgehen gegen die Teuerung erwarte, besonders ein Ausfuhrverbot für Getreide. Es sei »Meinung der Masse«, so der Bericht, dass die Teuerungen mit dem Zurückhalten des regionalen Getreides und mit dem Export nach Bayern zusammenhingen, die Schuld also bei den Händlern zu suchen sei. Derzeit gebe es keinen Anstieg der Kriminalität, auch keine Unruhe in der Bevölkerung. ${ }^{105}$ Deutlich zugespitzt hatte sich die Lage im Jahr I 847: In seinem Bericht konstatierte der Linzer Polizeidirektor einen breiten »Unmut« in den Unterschichten; es habe »Drohbriefe« an den Magistrat gegeben, die die obrigkeitliche Untätigkeit kritisiert hätten und die »in den Gassen verstreut« worden

99 Abel, Massenarmut, 377-380; Hecht, Handeln, I 36 - I 4I; Schanbacher, Vulnerabilität, I 2 of.

I00 LZ, I0.5.I847, 296; ebd., 29.1 I. I 847 .

Ior Marx, Ende, 738; LZ, 9.6.I 847; ebd., 29.I 2.1848; AStL, HS I I 29 (Sitzungsprotokolle des Gemeindeausschusses I 848), fol. I 5a, 74a u. 74b; vgl. Abel, Massenarmut, 38 I - 384 .

I02 Abel, Massenarmut, $370-377$ u. $384-387$.

I03 Sandgruber, Anfänge, 324.

I04 Vgl. Hecht, Handeln, I35.

I05 Marx, Ende, 504-506. 
seien. Deutliche Kritik wurde gegenüber dem Einzelhandel, den Getreidehändlern (»Kornwucherer«) und Großeinkäufern wie den Klöstern geäußert. Die Bevölkerung, so der Bericht, wünsche mehrheitlich ein Ausfuhrverbot für Getreide, man verfolge die Maßnahmen in Bayern deutlich, die »weit energischer« seien. Es habe zwar eine reiche Obsternte gegeben, die Getreidepreise seien nach der Ernte aber nur zeitweilig gesunken, vermutlich werde es drei bis vier sehr gute Ernten benötigen, um auf das Preisniveau von I $838 \mathrm{zu}$ kommen. Breite Aufmerksamkeit habe zum Ende des Jahres I 847 der »erschütternde Fall« einer möglicherweise an Unterernährung verstorbenen alten Frau erzeugt. ${ }^{106}$ Tatsächlich ist für das Jahr I 848 eine leicht erhöhte Sterblichkeit festzustellen, ${ }^{107}$ die aber unter den Werten zahlreicher Jahre in den I 83 oern blieb und relativ genau der Mortalität der Jahre I 8 I 5 und I 8 I 6 entsprach. ${ }^{108}$ Somit können diese Jahre als letztes - und durch verbesserte Marktintegration abgeschwächtes - Auftreten des Krisenmusters type ancien gesehen werden, denn in der Folge traten deutlich andere Formen der Lebensmittelteuerung und knappheit auf. ${ }^{109}$ Die politischen und gesellschaftlichen Folgewirkungen der Teuerungen reichten aber weit über das Jahr I 848 hinaus. ${ }^{110}$

Io6 Ebd., 736-739; LR CIIIDI-3, Reg. 295 (2 I 2-2 I4); ebd., Reg. 296 (2 I4-2 I6); erstaunlicherweise wurde dieser Fall erst fast ein Jahr später in einer Randnotiz der "Linzer Zeitung« thematisiert - LZ, 29.I 2.I 848.

I07 4I,65 Sterbefälle pro r.ooo Einwohner (Datenbank Sterbefälle).

I08 Vgl. Abel, Massenarmut, $387 f$.

Io9 Meist im Gefolge von wirtschaftlichen und politischen Krisen - vgl. Collet/Krämer, Germany, I I ff. u. Clark, Cities, 256.

I Io Vgl. Rumpler/Urbanitsch, Habsburgermonarchie, Bd. 8, 22 - 50 u. I I3-I 43; ebd., Bd. 9, I 42 I - I 429. 


\section{Naturgefahr}

\section{Hochwasser zwischen Alltag und Extremereignis}

Infolge der Lage an der Donau, die als Gebirgsfluss gilt, war Linz regelmäßig von Hochwasserereignissen betroffen, wenngleich die Lage der Stadt - leicht erhöht und flussabwärts großflächige Überflutungsräume - im Hinblick auf das Überflutungsrisiko als prinzipiell günstig zu erachten ist (vgl. Kap. 2. Kontexte: Linz I 700 bis I 900). Somit resultierte nicht jedes Hochwasser in Überschwemmungen und diese Extreme tangierten nur einzelne Teile des städtischen und vorstädtischen Gebietes. Für die Zeit vor den regelmäßigen Pegelmessungen - in Linz setzte dies zu Beginn der I 82 oer Jahre ein $^{1}$ - können Überschwemmungsereignisse über Meldungen zu Schäden, Dauer und zur räumlichen Ausdehnung abgeschätzt werden. Bei der Erforschung historischer Überschwemmungsereignisse kann in Anlehnung an die Überlegungen von Pfister, Rohr und anderen eine vierteilige Abstufung vorgenommen werden: leichte Überschwemmungen, die schnell und mit geringen Mitteln zu behebende Schäden verursachten (I), leichte bis mittlere Überschwemmungen, die flussnahe Landwirtschaft und Infrastruktur stärker und länger betrafen und höhere Reparaturkosten erforderten (2), mittelschwere Überschwemmungen, bei denen »lebenswichtige Infrastrukturanlagen « in größerem Ausmaß zerstört wurden, was signifikante lokale Hilfe (etwa durch die Stadt) notwendig machte (3), sowie schwere Überschwemmungen, die in einem "Zusammenbruch der Versorgung mit lebenswichtigen Gütern und Dienstleistungen« resultierten und die ohne überregionale Hilfe nicht bewältigt werden konnten (4). ${ }^{2}$

Nicht alle Extremniederschläge führten zu Überschwemmungen, denn die fluviale Dynamik der Donau war komplexer. Häufig wurden Überschwemmungen in den Sommermonaten durch Überregnung (meist Juni bis August) verursacht, zudem traten regelmäßig Überschwemmungen durch Schmelzwasser nach Warmlufteinbrüchen im Frühjahr auf (meist Jänner bis März), auch im Gefolge von Eisstößen, d.h. wenn die zugefrorene Donau auftaute und sich die Eisschollen flussabwärts schoben, die dann in rasch auftretenden, kleinräumigen Überflutungen resultieren konnten (meist Ende Dezember bis März). Hohe Wasserstände der Donau im Linzer Raum hingen vor allem mit dem Inn und anderen Flüssen im bayerischen Alpenvorland (Lech und Isar) zusammen, die eher zu Sommerhochwasser tendierten. ${ }^{3}$ Allgemein kam es bei

I Rosenauer, Donau, 86; Neweklowsky, Donau, I 77 .

2 Pfister, Wetternachhersage, 2 I9; Rohr, Naturereignisse, 204; Brázdil/Kundzewicz/Benito, Hydrology, $748 \mathrm{f}$.

3 Pfister, Wetternachhersage, 21 Iff; Rohr, Naturereignisse, 20I-203 u. 208-2 I3; Brázdil/Kundzewicz/ Benito, Hydrology, 753 f.; Böhm/Wetzel, Flood, 792 ; vgl. zur Donau: Neweklowsky, Donau, I 79 f. u. Jungwirth et al., Donau, I 42 - I 46 . 
der Donau im i 8. Jahrhundert - klimatisch bedingt - zu einer »intensivere[n] Hochwasserphase«, die zwischen I 768 und I789 noch zunahm. ${ }^{4}$

Tab. 37: Ausgewählte Maximalpegelstände der Donau bei Linz, 1784-1899

\begin{tabular}{llc}
\hline Jahr & Tag & Pegel in $\mathbf{c m}^{\text {a }}$ \\
\hline 1784 & 28.2. & 458 \\
1786 & 28.6. & 541 \\
1786 & 20.8. & 525 \\
1787 & 30.10. & 574 \\
1789 & 31.1. & 469 \\
1815 & 10.8. & 461 \\
1819 & 24.12. & 485 \\
1824 & 5.11. & 506 \\
1830 & 1.3. & 453 \\
1840 & 31.7. & 474 \\
1845 & 1.4. & 503 \\
1862 & 3.2. & 595 \\
1883 & 3.1. & 482 \\
1890 & 4.9. & 470 \\
1897 & 2.8. & 515 \\
1899 & 16.9. & 607 \\
\hline
\end{tabular}

Quelle: Donau in Oberösterreich, 22-25

a die Zentimeterangaben beziehen sich auf den Pegel zu Beginn des 20. Jahrhunderts; in die Tabelle aufgenommen wurden nur Pegel über 450 Zentimeter; ab dem Jahr 1821 handelt es sich um tatsächlich gemessene Pegel vgl. dazu die Hochwassermarken 1786-1862 in OÖLA, Karten- und Plänesammlung, XIV/16

Die Angaben zu Hochwasser und Überschwemmungen im Linzer Raum während des I 8. und der ersten Hälfte des i 9. Jahrhunderts - vor allem für die ersten Jahrzehnte des I 8. Jahrhunderts - sind fragmentarisch und teilweise widersprüchlich. Grundsätzlich finden sich Hinweise auf leichte bis mittlere Überschwemmungen (Typ 2) für fast jedes Jahrzehnt bis in die I73oer Jahre, danach scheinen bis in die I 78 oer Jahre die Überschwemmungen sehr viel seltener gewesen zu sein: Übereinstimmend - also in verschiedenen Quellen - genannt wurden die Jahre I 705 (Juli), I 7 I6 (März?), I723, I 728, I730 (Juli?), I736 (Juli), I738 (Mai), I76 I (August), I 784 (Februar/März) und I 789 (Jänner/Februar). ${ }^{5}$ Danach traten erst wieder in den I 8 Ioer und I 82 oer Jahren leichte bis mittlere Überschwemmungen auf: im Sommer I 8 I 5, zum Jahreswechsel

4 Hohensinner, Strom, 47f.; Jungwirth et al., Donau, I42 u. I46; vgl. Hohensinner, Hochwässer, 8- Io.

5 Pillwein nennt auch die Jahre I 7 I I und I740 (Pillwein, Beschreibung, I 5 u. I I 7); Neweklowsky, Donau, I88-ı90; LR Eıg, Reg. 370 (I 52); LR E7a u. b, Reg. 724 (I 77f.); ebd., Reg. Io6o (267); vgl. zur 
I 8 I9/I820, im November I 824 und im Februar/März I830, wobei das Hochwasser von 1824 den höchsten Maximalpegel erreichte (vgl. Tab. 37). Zu größeren Überschwemmungen kam es erneut zum Beginn der Jahre I 845 und r 862 (vgl. unten). ${ }^{6}$

Mittelschwere Überschwemmungen (Typ 3) waren überaus selten: Hier zu nennen sind das Ende Oktober/Anfang November I 787 aufgetretene Hochwasser, das aber deutlich weniger Schäden als in Wien verursachte, und die drei Sommerhochwasser des Jahres I786, die die gesamte obere Donau betrafen. ${ }^{7}$ In Linz begann am Abend des 25. Juni I 786 - infolge von Schneeschmelze und Regenfällen - der Wasserstand der Donau stark anzusteigen, sodass das Wasser am nächsten Tag die donauseitigen Stadttore erreichte und den unteren Teil des Hauptplatzes überschwemmte. Die Brücke wurde am gleichen Tag weggerissen, bald standen alle »an dem Flusse liegende Häuser [...] im Wasser«, so ein Bericht der »Linzer Zeitung«, »von einigen sah man nur die Tächer noch ausstehen, so daß die unglücklichen Einwohner sich und ihre nöthigste Geräthschaften durch die Fenster und Tächer auf Zillen und von Brettern gemachten Flößen retten « mussten. ${ }^{8}$ Erst am 28. Juni fiel der Pegel ab, ${ }^{9}$ Anfang Juli hatte sich die »Wuth des wild brausenden Stromes [...] endlich gelegt « und der Fluss war wieder ins Bett zurückgekehrt. Angeblich war in Linz ein Schaden von $50.000 \mathrm{fl}$ entstanden, ein Todesopfer hatte man - wobei unklar bleibt, ob es sich dabei um einen Stadtbewohner handelte - nach dem Sinken des Wassers nahe der Donau gefunden. ${ }^{10}$ Aber bereits wenige Tage später trat die Donau - nach starken Regenfällen - erneut über die Ufer und verursachte schwere Schäden in Urfahr, ${ }^{11}$ am Ende des Monats stand die Donau noch immer »weit über ihr Gestad « ${ }^{12}$ und in der letzten Augustwoche kam es in Linz nochmals zu Überflutungen. ${ }^{13}$ Nach diesen außergewöhnlichen Hochwasserereignissen wurde die Donauinsel als Lagerplatz des Militärs aufgegeben, die landwirtschaftliche Nutzung dauerte jedoch fort und im I 9. Jahrhundert scheint die Insel auch bewohnt gewesen zu sein (vgl. Kap. 7. Geordnete und modifizierte Umwelt).

Infolge der Regelmäßigkeit der kleinen und mittleren Überschwemmungen entwickelten die Linzer Stadtbewohner/innen eine - wie es Christian Rohr in Anlehnung an Greg Bankoffs Überlegungen zum Umgang mit Naturgefahren bezeichnet hat -

\footnotetext{
Donau bei Wien: vgl. Hohensinner, Hochwässer, 29-4I u. Strömmer, Klima-Geschichte, ro3, I r rf., I 25, I 28f., I35f. u. 209-2 I2.

6 Neweklowsky, Donau, I9of.; LZ, I4.8.I8 8 5 ; LR EId, Reg. 4028 (I 50); ebd., Reg. 3967 (I40); OÖLA, Landschaftsakten, Sch. 860, G.XVI/No. I I ; vgl. zu Wien Strömmer, Klima-Geschichte, 269 f. u. 286.

7 Neweklowsky, Donau, I 8 gf.; vgl. Hohensinner et al., Changes, I 59 f.; Strömmer, Klima-Geschichte, $220-$ 222 ; Hübner, Angedenken.

8 LR E 7a u. b, Reg. 970 (239f.); Hübner, Angedenken, 43; vgl. Hohensinner, Hochwässer, 35.

9 LR E7a u. b, Reg. 970 (239f.).

Io Ebd., Reg. 972 (24If.).

I I Neweklowsky, Donau, I 89f.; Klimadaten geben für den gesamten Monat Juli um rund ein Drittel mehr

Niederschlag an: Casty et al., Temperature.

I2 LZ, 2 I.7.1786; LR E7a u. b, Reg. 973 (242f.).

I3 LZ, 2 I.8.I 786 ; ebd., 25.8.1786.
} 
„Überschwemmungskultur«, sie lebten mit der Bedrohung durch den Fluss und trafen Vorsorge- resp. Gegenmaßnahmen. ${ }^{14}$ Eine wichtige Strategie zur Verminderung der Vulnerabilität durch Hochwasser bildete das Situieren der Siedlungsräume: In Linz waren die tiefer gelegenen donaunahen Gebiete im Wörth, in Lustenau und Zizlau nur dünn besiedelt, auf den weiträumigen, flussabwärts gelegenen Überflutungsflächen bestanden Auwälder und eher extensive Landwirtschaft. Der Siedlungskern befand sich auf den Hügeln bzw. den Niederterrassen einige Meter über der Donau, Risikolagen wurden gemieden. In einem Bericht aus dem Jahr I 8 I 2 wurde konstatiert, dass es im Donautal oberhalb von Linz (Kalvarienwänd) und in weiten Teilen von Zizlau und St. Peter zwar wiederholt zu Überschwemmungen komme, die betroffenen Häuser seien aber »im(m)er nur im unteren Geschoße mit Wasser gefüllt worden, und dem reißenden Strom, bis auf wenige, nicht ausgesezt sind, wo ihr Gefahr des Lebens drohen könnte«. Zudem hätten die Häuser »ihren Rücken frey«, was den Bewohner/ innen ermögliche, sich im Bedarfsfall »selbst retten« oder schnell Hilfe erhalten zu können. ${ }^{15}$ Nach einer ähnlichen Logik und wohl in der Erwartung, dass nur seltene Extremereignisse gefährlich sein würden, kam es im I 8. und I 9. Jahrhundert sogar zur Errichtung von einzelnen Häusern unmittelbar an der Donau: Anstelle des bei den Sommerüberschwemmungen I 786 stark beschädigten Theaterhauses wurde z. B. I 790 ein Haus gebaut, von dem der Besitzer versprach, »daß es bey großen Wassergüssen, wo andere viel weiter von der Donau entlegene Häuser« betroffen seien, selbst nicht überflutet werde. ${ }^{16}$ Dieses Risiko war aber - wie viele andere - in sozialer Hinsicht ungleich verteilt: In Urfahr erreichte das Hochwasser von I786 vermutlich vor allem Angehörige der Unterschichten (»größtentheils arme Weber aus der Fabrik«), die nahe an der Donau wohnten. ${ }^{17}$

Eine Anpassung an die Bedrohung erfolgte auch durch bauliche Maßnahmen: Die Häuser konnten mit hohen und kleinen Fenstern im Untergeschoss und ohne Keller errichtet werden (wenngleich es offenbar sogar im donaunahen Wörth Keller gab), ${ }^{18}$ dazu wurden Schutzbauten gegen Überschwemmungen errichtet. ${ }^{19}$ Diese Wasserbauten erfolgten in Linz vor der Mitte des I 9. Jahrhunderts aber nur sehr punktuell und zielten eher fast ausschließlich auf den Uferschutz ab (vgl. Kap. 6. Fluviale und aquatische Räume). Eine weitere Präventivmaßnahme stellte das ständige Bereithalten von Bauholz dar, um die durch Hochwasser oder Eisstöße beschädigte Brücke schnell reparieren zu können, ${ }^{20}$ auch wurde die anfällige Schiffmühle im Winter und

\footnotetext{
I 4 Rohr, Naturereignisse, 59 f., 2 I 5 u. 279 f.

I 5 AStL, Altakten, Sch. I 90.

I6 LZ/IB, 22.7.I8 I 4; vgl. Kreczi, Häuserchronik, I 52.

I 7 LR E7a u. b, Reg. 973 (242f.).

I 8 Sogar die exponiert gelegene Wollzeugfabrik verfügte über einen Keller - AStL, Altakten, Sch. I 3

I 9 EdN, s.v. Überschwemmung; Rohr, Naturereignisse, 354-368 u. $375 \mathrm{f}$.

20 Awecker, Bruckamt, I 8 I u. I 84; AStL, Altakten, Sch. 44; vgl. Rohr, Naturereignisse, $368-370$.
} 
bei Gefahr umgehängt. ${ }^{21}$ Dazu kamen obrigkeitliche Anordnungen im Rahmen der "Polizey«, die - analog zu anderen Bereichen öffentlicher Sicherheit und Ordnung ab dem Beginn des r 9. Jahrhunderts zunahmen, aber dennoch kaum Präventivmaßnahmen vorsahen. Das kann einerseits durch die Regelmäßigkeit und Kurzfristigkeit der Hochwasserereignisse erklärt werden, was die Motivation, etwas zu ändern, begrenzte, ${ }^{22}$ andererseits ging es in der damaligen Logik noch klar um eine "private« und nicht eine öffentliche Zuständigkeit. Die im Jänner I 8 I 2 für Eisstöße und Hochwasser obrigkeitlich verfügten Maßnahmen, die vermutlich auf eine staatliche Initiative zurückgingen, zielten insgesamt nur auf die Erhaltung des Donauüberganges bzw. auf eine öffentliche Ankündigung der »Gefahr« ab: Es wurde die Sperre der Brücke in der Nacht angeordnet, zudem sollten Schiffleute Boote und das städtische Bauamt Stege und zusätzliche Beleuchtung bereithalten. ${ }^{23}$ In der Praxis blieb das Ergreifen von präventiven und reaktiven Gegenmaßnahmen somit weitgehend in privater Verantwortung. Falls ein Hochwasser entstehe, so der Linzer Magistrat I 82 I, sollten die Bewohner/innen ihre Besitztümer in obere Stockwerke bringen und »sich in ein anderes Locale umsehen«. Falls dies nicht möglich sei, solle man sich beim Magistrat melden. ${ }^{24}$ Derartige städtische Angebote finden sich in der "Linzer Zeitung « bereits für die ausgehenden I 79oer Jahre, wobei in Urfahr Besitztümer im dortigen Pfarrhof und Möbel im Garten (!) des Richters deponiert werden konnten. ${ }^{25}$

Derartige Adaptionsversuche und reaktive Ad-hoc-Strategien scheinen im Linzer Fall prinzipiell relativ gut funktioniert zu haben, außer bei Extremereignissen wie den großen Überschwemmungen des Sommers I786, denen die »Linzer Zeitung“ attestierte, dass man sich seit "Mannsgedenken [...] keiner so großen Uiberschwemmung zu erinnern« vermochte. ${ }^{26}$ Gerade bei ungewöhnlich schnell ansteigendem Wasserpegel barg diese Praxis erhebliche Gefahren: Die Überschwemmung im Juni I 786 war eine rasche ("gähliche ${ }^{27}$, bei der Schiffknechte sogar - vermutlich von der Donauinsel - den sicherlich hochwassererfahrenen »Auhütter" samt seiner Familie retten mussten. ${ }^{28}$ Auch musste man, als das Wasser schon seit Tagen anstieg, mit Zillen Bewohnern des Wörths zur Hilfe kommen. ${ }^{29}$ Diese waren also, trotz der sich zuspitzenden Situation, in den Häusern geblieben. Die Rückkehr zur Normalität des Alltags erfolgte scheinbar schnell, da Überflutungen - wie auch Brände und Epidemien - »sharp

2 I Awecker, Bruckamt, I99; Neweklowsky, Schiffmühlen, 55.

22 Im Hinblick auf die Bedrohung durch Überschwemmungen ist für die Stadt Montreal ein bewusstes

Vergessen (»hazards amnesia«) konstatiert worden - vgl. Boone, Ecology, I 38.

23 AStL, Altakten, Sch. 190; vgl. zur Praxis: LR E7e-g, Reg. I 899 (46I); ebd., Reg. 1908 (463).

24 AStL, Altakten, Sch. I90.

25 LZ, 28.I.I799; ebd., I.2.I799.

26 LR E 7 a u. b, Reg. 970 (239f.).

27 Ebd., Reg. 970 (239f.); LZ, 7.7.1786.

$28 \mathrm{LZ}, 3 \cdot 7 \cdot 1786$.

29 LR E7a u. b, Reg. 970 (239f.). 
boundaries between the affected and protected « verursachten. ${ }^{30}$ Bereits am 2. Juli I 786 , somit unmittelbar nach der ersten und kurz vor der zweiten Überschwemmung, wurde die Kirche am jenseits der Donau gelegenen Pöstlingberg feierlich eingeweiht. ${ }^{31}$

Nach einer schwereren Überschwemmung - hier besteht eine Analogie zu Großbränden und Epidemien - erfolgte eine Unterstützung für die vom Hochwasser Betroffenen durch Sach- und Geldspenden, die überwiegend durch die Gesellschaft bereitgestellt wurden. Auch politisch-administrative Funktionsträger oder Mitglieder des Kaiserhofes spendeten immer als Individuen, während die Obrigkeiten selbst nur die Verteilung dieser Hilfsleistungen übernahmen. Bereits unmittelbar nach dem Sommerhochwasser des Jahres I786 kam es zu bürgerlichen Wohltätigkeitsaktivitäten (über Theaterstücke, Konzerte und Publikationen), ${ }^{32}$ auch die Überschwemmungen infolge eines Eisstoßes im Februar 1799 führten zu überregionalen Sammlungen, die bis ins Frühjahr andauerten. ${ }^{33}$ Ähnlich wurde bei der großen Überschwemmung in Wien I830 gehandelt: Auch die "Linzer Zeitung" rief zu Sach- und Geldspenden auf. ${ }^{34}$ Derartige Hilfsaktionen waren eng an die Medialität derartiger Ereignisse gebunden, d.h. an eine Bekanntmachung über Zeitungen und andere Publikationen. Die zeitgenössische Berichterstattung über entfernte Überschwemmungen oder Eisstöße lässt sich dabei auch als Hinweis auf das genaue Beobachten extremer Naturereignisse lesen und kann auch - wie die Hochwassermarken (die aber ebenso praktischen Nutzen hatten - vgl. unten) - als Teil einer mentalen Bewältigung gesehen werden. ${ }^{35}$ Lorenz Hübners Buch "Zum traurigen Angedenken der Ueberschwemmungen einiger Gegenden Oberdeutschlands im Junius I786«, in dem Hübner auch auf der Basis der »Linzer Zeitung « die Situation im Linzer Raum thematisierte, ${ }^{36}$ war bereits Anfang September I 786 erhältlich. ${ }^{37}$ Es gehe, so Hübner einleitend, nicht nur darum, aus dem Ereignis zu lernen, sondern ebenso aus derartigen Beschreibungen »Trost zu ziehen ${ }^{38}{ }^{38}$

30 Boone, Ecology, 146 .

3I LZ, 3.7.1786.

32 Etwa die Broschüre des Linzer Beamten Anton Cremeri, die zum »Besten der durch das grosse Wasser verunglückten Bürger« aufgelegt wurde (Cremeri, Selbstgespräch).

33 LZ, 7.7.I786; ebd., I4.7.I786; Mayrhofer/Katzinger, Geschichte, Bd. 2, 90; LR E7a u. b, Reg. I 520 (377f.); ebd., Reg. I56I (387); vgl. LZ, 7.1.1820; ebd., I 9.5.1830; ebd., 22.3.1830.

34 LZ, 22.3.1830 u. ebd., 19.5.I830; vgl. zum Hochwasser: Hohensinner, Hochwässer, 39 u. Strömmer, Klima-Geschichte, 297-300.

35 Vgl. z.B. LR E7a u. b, Reg. 36 ( (13); ebd., Reg. 63 (20); vgl. zu den Hochwassermarken und -tafeln: Rohr, Naturereignisse, 386-39r.

36 Hübner, Angedenken, 44-47.

$37 \mathrm{LZ}, 8.9 .1786$.

38 Hübner, Angedenken, unpag. [2]; ähnlich hatte Hübner in seiner Beschreibung der Überschwemmung von I 784 argumentiert: "Juvat meminisse laborum« (Hübner, Ueberschwemmungs-Geschichte, unpag. [3f.]). 
Aufgrund ihrer Regelmäßigkeit seien religiöse Deutungsmuster bei Überschwemmungen »selten« gewesen, so die Einschätzung von Christian Rohr für das Mittelalter und das I6. Jahrhundert, Hinweise auf religiöse Praktiken bei oder nach Hochwasserereignissen gebe es hingegen häufiger. ${ }^{39}$ Mitunter erinnern die religiösen Gegenmaßnahmen an seuchenbezogene Praktiken (vgl. Kap. 9. Epidemie). Am Höhepunkt des ersten Sommerhochwassers I 786 wurden Betstunden in der Ignatiuskirche abgehalten, woran man »das Publikum zuvor durch den Trommelschlag öffentlich erinnert[e] «. ${ }^{40}$ Die Dreifaltigkeitssäule am Linzer Hauptplatz wurde I 7 I 7- I 723 nicht nur aufgrund der eher glimpflich verlaufenen Pest errichtet, so der Topograph Benedikt Pillwein ein Jahrhundert später, sondern auch »wegen gedrohten türkischen Einfall, [...] Wassernot und Rebellion «. ${ }^{41}$ Vermutlich bezog sich dies auf die große Überschwemmung des Frühjahrs I7 16, die Ober- und Niederösterreich betroffen hatte. ${ }^{42} \mathrm{Nach}$ dem Rückgang der von einem Eisstoß verursachten Überschwemmung im Februar/März I 784 erfolgten die Säuberung der Stadt und ein Dankgottesdienst ${ }^{43}$ und noch I 830 fanden Dankgottesdienste "für die Abwendung der Gefahren beim letzten Eisstoß « statt. ${ }^{44}$ Für das I 8. Jahrhundert finden sich kaum religiöse Deutungen von Überschwemmungen: Selbst die Klosterchroniken notierten die regelmäßigen Hochwasserereignisse nur knapp und beschrieben eher die Schäden, ${ }^{45}$ nur der Linzer Beamte Anton Cremeri verband in seinem »Selbstgespräch" das sommerliche Extremhochwasser des Jahres I 786 mit »Vorsehung « und einer »straffenden Gottheit «. ${ }^{46}$ Anders deutete dieses Hochwasser der donaunah aufgewachsene Publizist Lorenz Hübner, der zuvor bereits eine »Gräuliche Überschwemmungs-Geschichte« über das große Hochwasser I784 aus Zeitungs- und Zeugenberichten kompiliert hatte, ${ }^{47}$ und begründete es weitgehend rational-aufgeklärt: Zwar finden sich in der Einleitung religiöse Untertöne (»ewigen Fürsehung«), was bei einem Ex-Jesuiten nicht überraschen sollte, Hübner schrieb aber noch auf der gleichen Seite vom »schrecklichsten Naturübel« und von natürlichen "Begebenheiten ${ }^{48}{ }^{48}$ Sein abschließendes Nachdenken über die Ursachen der Überschwemmungen titulierte er als »Physikalische Bemerkung«: Vermutlich seien neben heftigen Regenfällen Erdbeben, die »Erdgewölbe« einstürzen und un-

39 Rohr, Naturereignisse, $39 \mathrm{I}-397$.

$40 \mathrm{LZ}$, 30.6.I786; vgl. Cremeri, Selbstgespräch, I 5 .

4I Pillwein, Beschreibung, 70; vgl. AStL, Altakten, Sch. I46.

42 Hohensinner, Hochwässer, 39.

43 LR E7a u. b, Reg. 724 (I77f.).

$44 \mathrm{LZ}, 22 \cdot 3 \cdot 1830$.

45 Vgl. dazu das donaunahe Kapuzinerkloster: LR Era.

46 Cremeri, Selbstgespräch, 7 f. - »die Hand des Herrn [ist] über euch gekommen, euch für eure Sünden zu straffen« (ebd., 5).

47 Hübner, Ueberschwemmungs-Geschichte.

48 Hübner, Angedenken, unpag. [2]. 
terirdisches Wasser hervortreten ließen, als »Mitursache« zu erachten. ${ }^{49}$ Der Bericht eines landständischen Beamten zur Überschwemmung im Dezember I 8 I 9 stellt das Ereignis nüchtern-kausal dar: "Durch das nach der Hälfte des Monats Dezember I 8 I 9. plötzlich eingetrettene, außerordentliche Thauwetter, und dadurch verursachte schnelle Schmelzen des früher häufig gefallenen Schnees [...] erreichte die Donau eine Höhe von mehr als I 5 Schuh über dem gewöhnlichen Wasserstand. Zwey Schuh höher, als im Jahre (г) 8 I 5 «. ${ }^{50}$ Ein Wiener, der I 830 Linz besucht hatte, sah in einem »Wolkenbruch«, der »an der Gränze von Tyrol« niedergegangen war, die Ursache, dass die Donau bei Linz »ungeheuer geschwellt und weit aus den Ufern getrieben « war. ${ }^{51}$

Von obrigkeitlicher, vor allem staatlicher Seite begann man sich im beginnenden I 9. Jahrhundert stärker für Hochwasserereignisse zu interessieren. Bei der I 8 I 2 erfolgten Zusammenstellung von präventiven und reaktiven Maßnahmen bezog man sich auf die »seit 30 bis 40 Jahren gemachte Erfahrung und Beobachtung bey Eisgänge und Hochwässer« der Flüsse Donau und Traun. ${ }^{52}$ Die regelmäßige Messung des Donaupegels begann in Linz I $82 \mathrm{I}^{53}$ - dies ist ebenso als staatliche Maßnahme im Kontext des Wasserbaus und der Beobachtung von Extremereignissen zu sehen. ${ }^{54}$ Eine I 826 gedruckte "Instruktion« zeigt bereits ausdifferenziertere Praktiken, die auf hydrologische Extreme reagierten: Bei bevorstehenden Eisstößen sollten Signalschüsse abgegeben, auch die Gefährdung durch Trommelschlag oder Ausrufen publik gemacht werden, Menschen potentiell gefährdete Gebäude räumen und - wenn keine anderweitige Unterkunftsmöglichkeit bestehe - in Ersatzquartieren untergebracht werden. Stege für Fußgänger/innen sollten in einzelnen Teilen der Stadt errichtet werden und Schiffleute mit Wasserfahrzeugen für Rettung von Menschen und Besitz bereitstehen, wobei der Magistrat im Bedarfsfall »diese Dienstleistung « zu bezahlen habe. Nach der Überschwemmung sollte die Polizey-Direktion den Bauzustand der betroffenen Häuser überprüfen und die Wohnungen seien "gut«, auch die Gassen, Straßen und Plätze »sorgfältig« zu reinigen. Relativ neu war der Passus zum Umgang mit überschwemmten Brunnen - er stand im Kontext von Überlegungen zur Sauberkeit von Wasser (vgl. Kap. 3. Wasser): Es sollte aus diesen Brunnen so lange kein Wasser getrunken werden, bis dieser »von Sachverständigen untersucht, und für unschädlich erkennt worden ist. Die Brunnen selbst sind, wenn es nothwendig oder räthlich gefunden wird, zu räumen, oder ihr Wasser ist durch andere [...] Mittel, zu reinigen. « Auch die Seuchenprophylaxe war nun Bestandteil des Normenkatalogs: Nach Überschwemmungen sei der

\footnotetext{
49 Ebd., 50-52.

50 OÖLA, Landschaftsakten, Sch. 860, G.XVI/No. I I.

5 I Deinhardstein, Skizzen, I 89.

52 AStL, Altakten, Sch. I 90.

53 Neweklowsky, Donau, I77.

54 Dies erfolgte auch anderorts im Verlauf der i 82oer Jahre: zur Moldau bei Prag vgl. Brázdil/Kundzewicz/ Benito, Hydrology, 755 u. zu Lech und Isar Böhm/Wetzel, Flood, 788.
} 
Gesundheitszustand der »Menschen und Thiere« durch die obrigkeitlichen Behörden genau zu beobachten. ${ }^{55}$

\section{Absenz und Rückkehr des Hochwassers}

Der Maximalpegel des Hochwassers von I 824 wurde erst wieder I 845 erreicht und im Frühjahr I 862 kam es - nach beinahe einem Jahrzehnt ohne signifikantes Hochwasser - zu einem Pegelstand, der vermutlich mit den Extremereignissen der Jahre I786 und I 787 vergleichbar ist (vgl. Tab. 37). ${ }^{56}$ Das Hochwasser von I 862 war das erste, das nach dem Donau-Umbau im Linzer Raum auftrat. Eine der Intentionen der Regulierung und der Verwandlung der Donau in »ein einziges Rinnsal« war - neben der Beseitigung von Schifffahrtshindernissen und Landgewinnen - eine Verringerung der Anfälligkeit für Hochwasser und Eisstöße gewesen (vgl. Kap. 6. Fluviale und aquatische Räume). ${ }^{57}$ Bei den Planungen der Regulierung in den I 85 oer Jahren hatte man offenbar auch historische Hochwassermarken berücksichtigt, darunter den Maximalpegel des Hochwassers vom Herbst I $787 .{ }^{58}$ An den Extremereignissen der I78oer Jahre, die zum Beginn der Regulierungsarbeiten bereits über 6o Jahre zurücklagen, orientierte sich die Umgestaltung des Flusses aber verständlicherweise nicht. ${ }^{59}$ Tatsächlich traten nach der Regulierung bei kleinerem Sommerhochwasser seltener Überschwemmungen auf, die Flussverkürzungen und begradigungen bewirkten aber eine schnellere Ausbreitung der Wassermassen und konnten, vor allem nach langen, niederschlagsreichen Wintern, die von Tauwetter unterbrochen wurden, gravierende Überschwemmungen verursachen. ${ }^{60}$ Auch Eisstöße gab es nach der Regulierung der oberösterreichischen Donau nicht mehr, dennoch konnten Eisstöße auf dem Inn und der bayerischen Donau zu Überschwemmungen in Oberösterreich führen. ${ }^{61}$

Nach einem relativ kalten, aber niederschlagsarmen Winter setzte im Jänner I 862 Tauwetter ein, das auf dem Inn einen Eisstoß verursachte, der am 3 I. Jänner in Linz ankam ; ${ }^{62}$ dazu kamen überaus starke Niederschläge. ${ }^{63}$ Am r. Februar war das Wasser schon bis zum Hauptplatz und in Urfahr, in der donaunahen Lederergasse und im Wörth bis zum ersten Stockwerk der dortigen Bebauung angestiegen. Ihren Höchst-

55 AStL, Altakten, Sch. I90.

56 Neweklowsky, Donau, I 9of.; LTP, 24.9.1 899; vgl. zur Wiener Donau: Hohensinner, Hochwässer, 39-4I.

57 Allgemeine Bauzeitung 27 (1862), 83-93, hier 83 u. 9 r.

58 Donau in Oberösterreich, Beilage V; vgl. Allgemeine Bauzeitung 62 (I 897), 2f. u. OÖLA, Karten- und Plänesammlung, XIV/r6.

59 Allgemeine Bauzeitung 62 (1897), 3 ; Donau in Oberösterreich, 54.

60 Jungwirth et al., Donau, 162 u. Cioc, Rhine, 36 .

6r Neweklowsky, Donau, I 93.

62 LAB, 30.1.1862; ebd., 31.I.1862; ebd., 8.2.1862.

63 Bezogen auf den Mittelwert I 90 I - I 960; eigene Berechnung auf der Basis HISTALP. 
stand erreichte die Donau am 3. Februar und überflutete dann die untere Badgasse, die Fabrikstraße und die Paradies- und Prunerstiftgasse, am Hauptplatz stand das Wasser bereits bis zur Dreifaltigkeitssäule. Danach sank die Wasserhöhe relativ schnell und nach einigen Tagen wies die Donau wieder einen normalen Wasserstand auf. ${ }^{64}$ Bezogen auf die Auswirkungen und die Reaktionen unterschied sich diese Überschwemmung wenig von den Hochwasserereignissen der I 78 oer Jahre und der ersten Jahrzehnte des I 9. Jahrhunderts $:^{65}$ Immer noch wurden relativ kurzfristig die "nöthigsten Vorsichten getroffen «, Stege errichtet und Teile der Brücke abmontiert, ${ }^{66}$ auch die Betroffenheit war nach wie vor ungleich verteilt. Adalbert Stifter, der nahe der Brücke unmittelbar an der Donau wohnte, berichtete in einem Brief an einen Wiener Freund relativ unaufgeregt über die gerade überstandene Überschwemmung. Stifter und dessen Frau übersiedelten für drei Tage in ein höhergelegenes Gasthaus, Stifter selbst habe die Wohnung im zweiten Stock »öfter« mit einem Boot aufgesucht und den Wassermassen zugesehen. Im Haus hatte das Wasser nur das Erdgeschoss und den Keller überflutet, der aber bereits geräumt worden war - es gab somit »keinen Schaden «. ${ }^{67}$ In den tiefer gelegenen Teilen von Linz sah die Situation anders aus: »Hunderte von Familien« wurden obdachlos, zahlreiche Häuser und Teile der Uferbefestigung waren beschädigt und einige Kanäle eingestürzt, zwei Häuser in der unteren Badgasse mussten später abgerissen werden. ${ }^{68}$ Die in Linz stationierten Pioniere leisteten Hilfsdienste bei der Evakuierung der »von der ungeahnten Schnelligkeit der steigenden Fluthen« Eingeschlossenen, neben Menschen brachte man auch »Vieh und viele andere Fahrnisse in Sicherheit. ${ }^{69}$ Zwei Pioniere fanden bei einer derartigen Aktion den Tod, als ein mit insgesamt neun Menschen besetztes Boot kenterte. ${ }^{70}$ Aufgrund der prekären Lage der vom Hochwasser Betroffenen kam es rasch zu Hilfeleistungen der Stadt (vor allem durch Suppenspeisungen), dazu wurde in den Zeitungen zu Spenden aufgerufen und Benefizveranstaltungen organisiert: Es müsse »das ganze Volk helfen«, insistierte eine Linzer Zeitung. ${ }^{71}$ Tatsächlich wurden bis Mitte Februar 7.750 fl (ÖW) gesammelt, dazu kam eine Spende des Kaisers in der Höhe von I.500 fl für die städtischen Armen - die entstandenen Schäden schätzte man auf rund roo.00o fl. ${ }^{72}$

Deutlich zeigen die Reaktionen, dass dieses Extremereignis unerwartet kam: »Gott dem Allerhöchstem hat es gefallen, unser Land mit einer Ueberschwemmung

$64 \mathrm{LAB}, 4.2 .1862$; vgl. Fink, Geschichte, 2 I 7.

65 Vgl. zur great flood des Jahres I 866 in Manchester: Platt, Shock, 2 I 4-224.

66 LAB, I3.2.I 862; GRP I 862, fol. I6b u. I7a; vgl. Fink, Geschichte, 2 I 7.

67 Stifter, PRA, Bd. 20, 55 .

68 LAB, 4.2.I862; vgl. Fink, Geschichte, 2 I $8 f$.

69 LAB, 4.2.I862; vgl. OÖLA, Nachlass Familien Dierzer v. Traunthal-Fossel, Sch. I (»Familien Chronick«, I 890$)$, pag. $72-74$.

70 GRP I 862, fol. I 8b; LAB, I 5.3.1862.

7I LAB, 4.2.I862; ebd., 8.2.1862; GRP I 862, fol. 19a.

72 LAB, I4.2.1 862 ; ebd., 5.3.1862. 
heimzusuchen, wie sie in diesem Jahrhunderte noch nie in so furchtbarer Weise stattgefunden hat «, betonte der Linzer Statthalter in seinem Spendenaufruf. ${ }^{73}$ Der Linzer Bürgermeister sah die Überschwemmung, etwas pragmatischer, als eine der »Kalamitäten [, die] von Zeit zu Zeit über Land und Leute hereinbrechen« - man müsse sich »mit ruhiger Ergebung diesem Verhängnisse fügen« und den »Trost [...] darin finden, daß es nicht noch schlimmer gekommen ist «. ${ }^{74}$ Von staatlicher Seite reagierte man mit neuen Schutzbauten an der Donau, da - wie zu Beginn des 20. Jahrhunderts rückblickend festgestellt wurde - »die Fluten wiederholt in bereits verlassen gewesene Seitenarme« vorgedrungen waren und »Kulturboden« bedroht hätten. ${ }^{75}$ Die Prämissen der Regulierung hinterfragte man aber nicht - die fluviale Dynamik der Folgejahrzehnte schien den Wasserbauern recht zu geben: Nach dem großen Hochwasserereignis von I 862 kam es in Linz nur im Februar I 876, im Jänner I 883 und im September I 890 zu mittelgroßen Überschwemmungen (vgl. Tab. 37). ${ }^{76}$ I 886 gab man sich im Linzer Gemeinderat (anlässlich der projektierten Zuschüttung des Fabrikarms - vgl. Kap. 6. Fluviale und aquatische Räume) davon überzeugt, dass Überschwemmungen nun »seltener eintreten « würden. ${ }^{77}$ Somit kamen die großen Überschwemmungen im Sommer I 897 und im September I 899 zwar nicht überraschend, denn über Telegramme informierte man sich über die Pegelstände und gab diese weiter, das Ausmaß der Schäden war aber unerwartet. Selbst die technischen Experten titulierten die Ereignisse wenige Jahre später - vielleicht auch entschuldigend - als »Elementarkatastrophen ${ }^{78}$

Das vom 30. Juli bis 5. August I 897 andauernde Hochwasser, das die Niederterrassen überschwemmte, sei eine »in ihrer Grösse und Ausdehnung seit Menschengedenken noch nie dagewesene Hochwasser-Katastrophe " gewesen, stellte die Stadtverwaltung rückblickend fest. ${ }^{79}$ Dabei lag der Maximalpegel dieses Hochwassers interessanterweise nur leicht über denen der Jahre I 824 und I 845 , aber deutlich unter dem des Jahres I862. Ein überaus niederschlagsreicher Juli hatte die Überschwemmung ausgelöst: Verglichen mit dem Durchschnitt der Jahre I90 I - i 960 fiel in diesem Monat doppelt so viel Regen. ${ }^{80}$ Nach beinahe einer Woche Dauerregen in Oberösterreich

73 LAB, 8.2.I 862 ; die eingegangenen Spenden bildeten die Grundlage für den I 868 gegründeten »Innudationsfond « - AStL, Materienbestand, Sch. I 82.

$74 \mathrm{LAB}, \mathrm{I} 3.2 .1862$.

75 Donau in Oberösterreich, 46.

76 LTP, го.r.1 883; RB I 890, I73- I 75 ; vgl. zur Donau bei Wien: Hohensinner, Hochwässer, 42 - 44.

$77 \mathrm{RB}$ I $886,85-88$.

78 AStL, Materienbestand, Sch. I 82 ; Donau in Oberösterreich, 63; vgl. Hochwasserkatastrophe, $3 \mathrm{f}$.

79 RB I 897, I65; LTP, 5.8.1 897; vgl. Allgemeine Bauzeitung 68 (1903), 7 O.

80 Eigene Berechnung auf der Basis HISTALP; Streitt/Schiller/Stadler, Eisenbahnbrücke, rozf.; für den Wiener Raum wurde dieses Ereignis als 3o-jähriges Hochwasser klassifiziert (Hohensinner, Hochwässer, 43), Christian Rohr sah für Linz einen »Hochwasserquotienten« 70 bis 80 (Streitt/Schiller/Stadler, Eisenbahnbrücke, I03). 
und Salzburg stieg der Pegel der Donau ab dem 29. Juli stark an, ${ }^{81}$ bald waren die Donauauen, Felder und Wiesen bei Katzbach überschwemmt, die Regenfälle dauerten aber weiter an. ${ }^{82}$ Kleinmünchen und Zizlau waren vom Hochwasser der Traun betroffen, großräumig wurden Verkehrswege unterbrochen und der Damm für den im Entstehen begriffenen Winterhafen zerstört. ${ }^{83}$ In Linz reagierte man mit den üblichen Maßnahmen: Man errichtete Notstege, setzte Bereitschaftsdienste ein und forderte Unterstützung bei den Pionieren an. Einer zwischenzeitlichen Wetterbesserung folgte wiederum Regen, der den Donaupegel weiter ansteigen ließ. Erneut hatten sich nicht alle Bewohner in den gefährdeten Gebieten in Sicherheit gebracht: Der Pächter auf der überaus exponiert gelegenen, früheren Strasserinsel war geblieben, »um Vieh und andere Habseligkeiten zu bergen«; im »letzten Augenblicke« forderte er über das Telefon Hilfe an und wurde aus dem steigenden Wasser gerettet. ${ }^{84}$ Für Nichtbetroffene bildete das Hochwasser ein eindrucksvolles Ereignis: "Tausende von Menschen waren abends an der Donau um die Ueberschwemmung zu besichtigen und um 9 Uhr wurde den nach Hunderten zählenden, dort angesammelten Menschen« mit der zeitweiligen elektrischen Beleuchtung der Wasserfläche »ein Schauspiel geboten, wie man es hier nicht so leicht zu sehen bekommt «. ${ }^{85}$

Die Schäden waren erheblich: Für Linz stellte man eine Summe von I 6.499 fl, für die Vorstädte I 2 I.264 fl fest, wobei dieser hohe Wert vor allem auf die Zerstörungen bei der unmittelbar an der Donau gelegenen Dampfsäge zurückzuführen ist, die Holz im Wert von 75.000 $\mathrm{fl}$ verloren hatte. ${ }^{86} \mathrm{Im}$ Hinblick auf die entstandenen Schäden mussten die Bewohner/innen - wie im Jahrhundert zuvor - »auf den Sonnenschein der Nächstenliebe [...] hoffen«, denn Stadt und Staat gaben nur Almosen. ${ }^{87}$ Indes war man sich noch immer sicher, dass die Donauregulierung Schlimmeres verhindert habe, da diese das Flussbett »um circa 80 Centimeter [vertieft hatte] und damit nicht allein eine Erniedrigung des mittleren Standes der Donau, sondern auch einen rascheren Abfluss verursachte«. In der Gegend der Ludl sei »der Einfluss der Regulierung am deutlichsten kennbar und jedem klar, welcher sich noch an die Ludl bei früheren, wenn auch kleineren Ueberschwemmungen erinnert «. ${ }^{88}$ Man müsse in Zukunft »der Regulierung der Flüsse [...] und den Wasserschutzbauten überhaupt erhöhte Sorgfalt zuwenden « - hätte man an der Traun umfangreichere Bauten ausgeführt, dann "würden viele im Hochwasser untergegangene Millionen Jahre hindurch erspart worden sein«. Als eine Ursache für die außergewöhnliche Überschwemmung sah man - und

8I LTP, 29.7.1897; ebd., 30.7.1897.

82 LTP, 3 I.7.I 897 .

83 LTP, г.8.1 897 .

84 LTP, 3.8.1897.

85 Ebd.

86 RB I 897, I66f.; LTP, 3.8. 1897; AStL, Materienbestand, Sch. I 82.

87 AStL, Materienbestand, Sch. I82; LTP, 6.8.1897; vgl. ebd., I0.8.1897.

88 LTP, 3.8.1897. 
damit folgte man einer breiteren überregionalen Diskussion - die »fortschreitenden Entwaldungen « in den Bergen. ${ }^{89}$

Noch gravierender war die Überschwemmung im September r 899: Deren Maximalpegel lag fast einen Meter über dem Hochwasser von I897 und auch höher als im Jahr I862. Erneut hatten überdurchschnittlich große Niederschlagsmengen und hochwasserführende Zubringer im Linzer Raum zu einer Überschwemmung durch Donau und Traun geführt. ${ }^{90}$ Am Höhepunkt des Hochwassers, dem r6. September, passierten vermutlich 8.500 Kubikmeter Wasser pro Sekunde - d.h. fünfeinhalbmal so viel wie bei »Mittelwasser« (vgl. Kap. 2. Kontexte: Linz I 700 bis I 900) - die Stadt Linz. ${ }^{91}$ Nachdem der Donaupegel ab dem I 2. September stark angestiegen war, wurden Feuerwehrleute und die städtische Sicherheitswache alarmiert und das Militär um Hilfsleistung ersucht, das aber zu diesem Zeitpunkt wegen eines Manövers mehrheitlich absent war - schließlich kamen Pioniere aus Prag zu Hilfe (vgl. Abb. 32 ). ${ }^{92} \mathrm{Als}$ am I4. September das Wasser nochmals anstieg, wurde die Donaubrücke zeitweise für den Verkehr gesperrt und den Bewohnern der Ludlgegend und von Lustenau »empfohlen«, ihre Häuser zu räumen. ${ }^{93}$ "Doch die meisten thaten dies nicht, sondern wollten erst räumen, als das Wasser einzudringen begann: dann war es nicht mehr möglich, so rasch als nothwendig Hilfe zu bringen, da die Flut zu rasch stieg. «" "Es hat's nicht noth«, soll sich ein Hausbewohner in Lustenau gerechtfertigt haben, bevor das Wasser dann stark anstieg. ${ }^{95}$ Auch die zur Hilfe gerufenen Pioniere berichteten von vereinzelten Widerständen gegen die Evakuierungen. ${ }^{96}$ Die unterhalb der Niederterrasse liegenden Häuser wurden völlig überschwemmt, an der Brückenbaustelle traten erneut schwere Schäden auf. ${ }^{97}$ Abgesehen von einem »Wäschermädchen « in Urfahr, das vom Wasser mitgerissen wurde (dessen Schicksal die Zeitungen aber nicht weiter thematisierten), scheint es im Linzer Raum - wie schon bei den meisten Hochwasserereignissen des Jahrhunderts - keine Todesfälle gegeben zu haben. ${ }^{98}$ Bereits am Tag nach dem Höchststand der Donau konnte man Bilder der Überschwemmung »in den Auslagen mehrerer hiesiger Buch- und Papierhandlungen« sehen, die ein »Heer von

89 LTP, 6.8.1897; LVB, 20.8.1897; vgl. Hochwasserkatastrophe, I 55.

90 LTP, го.9.1 899; ebd., I 3.9.1899; ebd., I 4.9.1899; ebd., I 9.9.I899; Hochwasserkatastrophe, 9f., 28 f. u. 33-37; für den Wiener Raum wurde dieses Ereignis als roo-jähriges Hochwasser klassifiziert (Hohensinner, Hochwässer, 44), Christian Rohr konstatierte für Linz ebenso einen »Hochwasserquotienten« Ioo (Streitt/Schiller/Stadler, Eisenbahnbrücke, Io3).

9I Rosenauer, Donau, $83-87$.

92 LTP, I 4.9.I899; ebd., I6.9.1899; ebd., I 9.9.1 899.

93 LTP, I6.9.1899; AStL, Materienbestand, Sch. I 82.

94 LTP, г 9.9.1899.

95 LTP, 22.9.1899.

96 AStL, Materienbestand, Sch. I 82.

97 AStL, Materienbestand, Sch. I92; LTP, r6.9.I 899; ebd., I7.9.1899; vgl. Streitt/Schiller/Stadler, Eisenbahnbrücke, IO4f.

98 LTP, г6.9. I 899. 


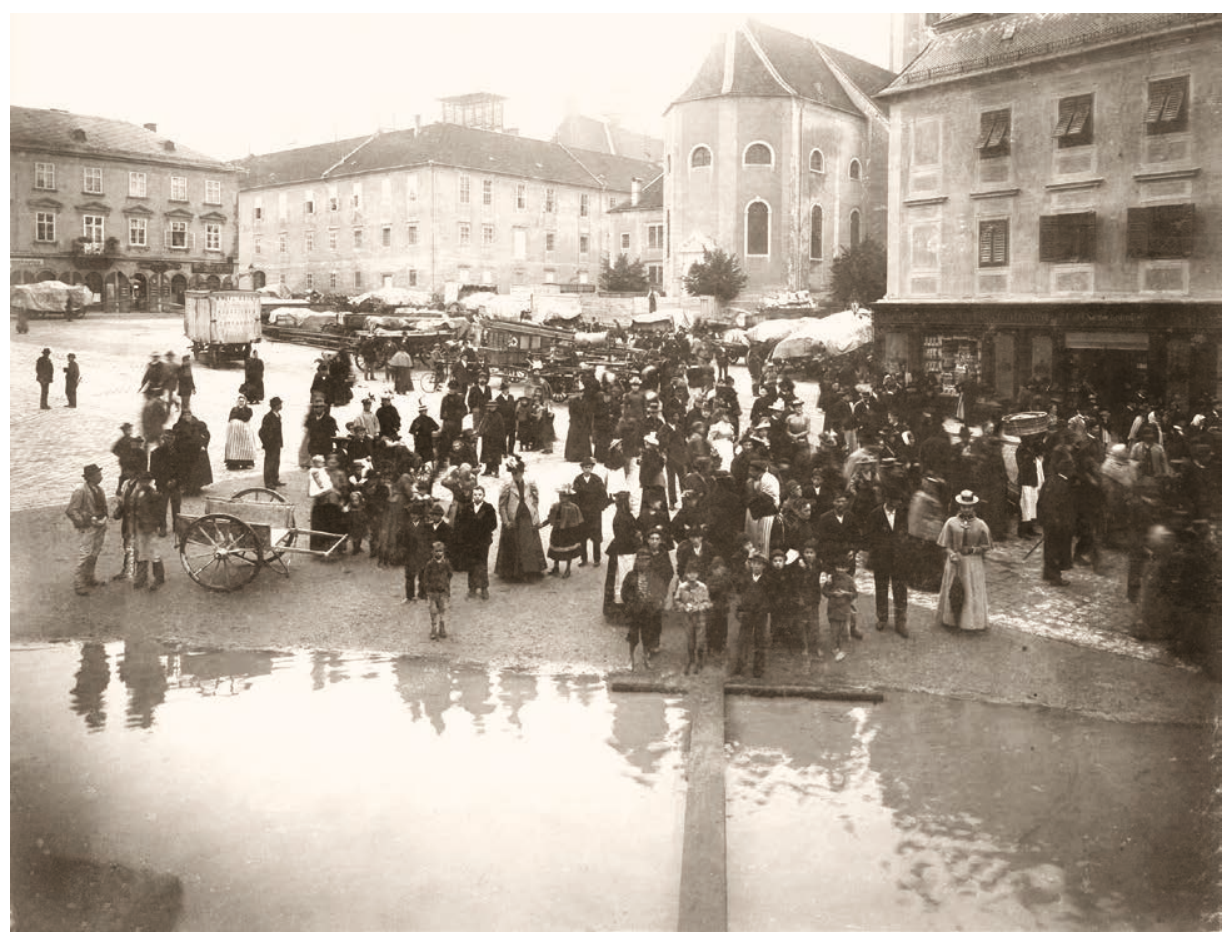

Abb. 32: Alltag bei der Jahrhundertüberschwemmung - Schaulustige und evakuierter Besitz am Pfarrplatz, September 1899

Berufs- und Amateurphotographen angefertigt hatte. ${ }^{99}$ Erneut liefen Sammlungen an, der Kaiser, die Landesregierung und die Statthalterei gewährten finanzielle Unterstützung für die Betroffenen, ebenso die »Allgemeine Sparkasse« und die Stadt Linz, die zudem »Speisemarken« ausgab und Holz und Kohle »zur Ausheizung« der nassen Wohnungen bereitstellte. ${ }^{100}$

Hauptsächlich dominierte eine Deutung als extreme »Wechselwirkung atmosphärischer Erscheinungen « ${ }^{101}$ in den Linzer Zeitungen wurden aber auch mögliche anthropogene Ursachen thematisiert: Den neuen Eisenbahndamm, der zur im Bau befindlichen zweiten Brücke führte und bei der Überschwemmung zerstört worden war, erachtete man als gefährlich, als "Sorge vieler Linzer Bewohner «. ${ }^{102}$ Bei den Wasserbauten an der unteren Traun seien schwere Fehler begangen worden: Die "Niederwasserwerke« hätten eine »Absenkung des Wasserspiegels« verhindert, stetige »Klagen

99 LTP, I7.9. I 899.

Iо० RB I899, I63-г66; LTP, г6.9.I 899; ebd., I7.9.I 899; ebd., I 9.9.I899 u. 8; ebd., 22.9. I 899.

Io I Hochwasserkatastrophe, I 55- I62 (Zitat ebd., I 55).

IO2 LTP, r 9.9. I 899. 
und Warnungen« vor Ort seien von den Ingenieuren »kühl lächelnd« abgetan worden, "pochend auf Erfahrungen, die irgend wo an einem Wasser ganz anderen Charakters als unsere Traun ist, gesammelt wurden «. ${ }^{103}$ Derartige Einschätzungen, »entbehren [...] jeder Berechtigung «, ${ }^{104}$ stellte man pauschal in den staatlichen »Beiträgen zur Hydrographie Österreich « fest, man argumentierte interessanterweise historisch und zeichnete ein Bild rekurrenter Überschwemmungen, die erst durch die Donauregulierungen seit der Mitte des I9. Jahrhunderts verschwunden waren. ${ }^{105}$ »Hochwasserkatastrophen«, also »Elementarereignisse, hervorgerufen durch Naturgewalten«, könne man aber »heute noch « nicht »siegreich [...] bekämpfen «. ${ }^{106}$ Dennoch - möglicherweise nahm dies auch Bezug auf kritische Einwürfe - ordnete die Landesregierung eine Überprüfung der Baumaßnahmen $a^{107}$ und bestimmte das Hochwasser des Jahres I 899 zur "Richtschnur « der Wasserbauten an der Donau - es war aber kleiner als das Hochwasser des Sommers I $954 .^{108}$

\section{Feuer als kollektives Risiko}

Feuer war - durch die Beleuchtung, durch Heizen und Kochen, durch Prozesswärme für Handwerker (Bäcker, Brauer, Hafner, Metallhandwerker) - omnipräsent in der Stadt und bildete dadurch ein latentes Risiko. Verstärkt wurde dies durch dichte Bebauung, die Verwendung von Holz als Baumaterial, das Fehlen einer institutionalisierten Brandbekämpfung und ausreichender resp. effektiver Löschmittel vor Ort. Diese Konstellation führte zu häufigen, kleinen, räumlich begrenzten Bränden und periodisch zu Großbränden, die über mehrere Tage andauern konnten, erhebliche Teile einer Stadt betrafen und somit ein kollektives Risiko darstellten. ${ }^{109}$ Die Forschung hat für den Verlauf der Frühen Neuzeit einen deutlichen Rückgang großer Brände (fire gap) konstatiert, der sich im deutschen Raum bis in die erste Hälfte des I 8. Jahrhunderts vollzogen hatte, große Brände traten aber auch noch danach auf. ${ }^{110}$ Bei größeren Bränden gab es - wie bei anderen Naturgefahren (Überschwemmungen, Seuchen) - teilweise eine religiöse Deutung, die Feuer als göttliche Bestrafung begriff und teilweise bis

I03 LTP, 22.9. I 899; vgl. dazu die Rechtfertigung der Techniker: Allgemeine Bauzeitung 65 (I 900), 46- 52.

I04 Hochwasserkatastrophe, 156.

I05 Ebd., I56-i6o.

Io6 Ebd., i6o.

I07 LTP, 20.9.1899.

ro8 Neweklowsky, Donau, I78 u. I92; vgl. Streitt/Schiller/Stadler, Eisenbahnbrücke, ro9 u. Rosenauer, Donau, $83-87$.

I09 Garrioch, Fire; Bankoff/Lübken/Sand, Cities, 9-13; Reith, Umweltgeschichte, 9of.; Mauelshagen, Klimageschichte, I 26 - I 29 ; EdN, s.v. Stadtbrand, Feuer u. Feuerwehr.

I Io Garrioch, Fire, 204f.; Zwierlein, Prometheus, 82-93; Mauelshagen, Klimageschichte, I 24 - I 26. 
ins I8. Jahrhundert nachwirkte, mit der Aufklärung aber zunehmend verschwand. ${ }^{111}$ Bedeutender waren rationale Deutungen und darauf basierende Praktiken, die auf eine Reduktion des Brandrisikos bzw. auf ein effektives Bekämpfen von Bränden abzielten. Normative, schriftlich festgehaltene Vorgaben der Obrigkeiten bestanden in manchen Städten seit dem Spätmittelalter, häufiger im Rahmen der »Feuerpolicey« in eigenen, regelmäßig publizierten »Feuerordnungen« ab dem I 7. Jahrhundert. Diese sahen das verpflichtende Bereithalten von Löschmitteln durch die Hausbesitzer vor, zudem eine obrigkeitliche Feuerbeschau und Wachtdienste, auch umrissen sie Verhaltensregeln und Zuständigkeiten im Brandfall. ${ }^{112}$

In Linz sind schon für das Spätmittelalter eine obrigkeitliche Feuerbeschau und weitere Präventivbestimmungen belegbar, die das Brandrisiko reduzieren sollten. Dazu kamen ab dem beginnenden r6. Jahrhundert Bauvorschriften, die - im innerstädtischen Bereich -Grabendächer und Feuermauern vorschrieben. ${ }^{113}$ Diese Normen wurden sukzessive ausgeweitet und regelmäßig publiziert, manchmal anlassbezogen direkt nach Brandereignissen. Die Feuerordnung des Jahres I672, die I723, I 749 und I755 in weitgehend identischer Form neu verlautbart wurde, sah - wie bei der Sauberkeit eine prinzipiell private Verantwortung vor, die durch eine begrenzte obrigkeitliche Aufsicht ergänzt wurde: Der Hausbesitzer (resp. die Hausmeister der Freihäuser) seien verantwortlich, dass sich die Rauchfänge in gutem Zustand befänden und regelmäßig geputzt würden, man solle gut auf offenes Feuer achten, zudem die Lagerung von brandgefährlichem Material möglichst reduzieren und dieses eher in gemauerten Gewölben resp. das Holz in den Höfen unterbringen. An Geräten sollten zwei lange Leitern (die das Löschen über die Dächer ermöglichten), Laternen, Haken, Handspritzen und zumindest ein gefüllter Wasserbottich auf dem Dachboden resp. im Winter in der Wohnung bereitgehalten werden. Eine »Visitation«, also eine Überprüfung der Feuerstellen, Rauchfänge und Löschutensilien erfolge zu Advent und bei den beiden Märkten durch den Magistrat und die Landstände. Vor starken Winden - die Brände auslösen konnten - warnten die Stadt- und Nachtwachen, eine ständige Feuerwache gab es auf dem Pfarrturm, die mit Glocke und »verruffen« (auch durch Trompetensignal), zudem bei Tag mit roter Fahne und bei Nacht mit Laternen den Brand signalisierte. Im jeweils betroffenen Viertel müssten dann die Bewohner/innen »einer dem anderen [...] zulauffen, und zum Retten zugehen«, für das Löschen waren die Bediensteten des städtischen Bauamts verantwortlich, für einzelne Handwerker (Maurer, Zimmerer, Schlosser, Schmiede, Pumpenmacher) waren Beistandsplichten vorgesehen, auch der Brunnmeister (als Verantwortlicher für die Wasserinfrastruktur), Rauchfangkehrer,

I I Zwierlein, Prometheus, I 20-I35.

I 2 Reith, Umweltgeschichte, 68; Allemeyer, Fewersnoth, 37-42; Zwierlein, Prometheus, I 55-I 72; vgl. Suter, Wasser, 88-9r (zu Zürich); Ebner/Weigl, Wasser, 48f. (zu Salzburg); Körner, Stadtzerstörung, Bd. I, I 76- i 78 (zu Wien).

I I 3 Grüll, Brandverhütung, 355f. u. 36 If.; vgl. Reith, Umweltgeschichte, 68 u. Clark, Cities, I I of. 
Fasszieher (für Transportdienste) und Bader (mit Bottichen) sollten sich am Brandort einfinden. ${ }^{114}$

Diese Vorschriften und Praktiken weiteten sich im Verlauf des I 8. Jahrhunderts aus: Es bestanden Feuerwachen am Pfarrturm und am Landhausturm, später auch am Schmiedtorturm $;^{115}$ dazu ab der Mitte des Jahrhunderts zahlreiche weitere staatlich induzierte Verordnungen, die die Brandgefahr mindern sollten. ${ }^{116}$ Die normativen Vorgaben spiegeln sich in Ausgabenrechnungen und anderen Dokumenten wider, die - zumindest für größere Häuser - auf eine regelmäßige Inanspruchnahme von Rauchfangkehrern hindeuten. Meist erhielt der Rauchfangkehrer eine jährliche »Bestallung«, die nicht gerade günstig war: Für das Haus in der Altstadt bezahlte das Stift Kremsmünster im Jahr I $7458 \mathrm{fl}$, für das in der Landstraße $4 \mathrm{fl}$, was damals rund 30 resp. I 5 Arbeitstagen für einen Taglöhner entsprach. ${ }^{117}$ Billiger war es, wie in den landständischen Häusern zu Beginn des r 8. Jahrhunderts praktiziert, wenn die Öfen von Taglöhnerinnen (»Weibern«) gekehrt wurden. Nach I 7 I 7 beschäftigten die Landstände aber aus Gründen der Feuersicherheit, wie man betonte, Rauchfangkehrer. ${ }^{118}$

Es gibt Hinweise auf regelmäßige Begehungen durch die zuständigen Obrigkeiten, ${ }^{119}$ auch ein Verzeichnis, das um I 700 funktionstüchtiges Feuerlöschgerät und bestehende feuersichere Bauten notierte (vgl. Tab. 38), deutet auf einen gewissen obrigkeitlichen Druck hin und zeigt erhebliche Infrastrukturen der Brandprävention, die ebenso in Inventaren und Hausbeschreibungen präsent sind. ${ }^{120}$ Eine zentrale Innovation der frühneuzeitlichen Brandbekämpfung bildeten Feuerspritzen, die ab dem späten I7. Jahrhundert auch mit Schläuchen ausgestattet waren und im frühen i 8. Jahrhundert bereits einen relativ hohen technischen Stand erreicht hatten. ${ }^{121}$ In Oberösterreich sind Feuerspritzen ab der zweiten Hälfte des I 7. Jahrhunderts belegbar, ${ }^{122}$ in den Akten der Landstände tauchen sie regelmäßig ab den I 7 roer Jahren auf, ${ }^{123}$ zur Mitte des I 8. Jahrhunderts verfügte das Landhaus bereits über eine »neue große« Feuerspritze mit einem rund 6,5 Meter langen Lederschlauch und fünf »kleinere[n] Feuerspritzen. ${ }^{124}$ Besonders bei größeren Gebäuden war man - verständlicherweise - für Brände sensibilisiert: Für den großen Neubau des Deutschen Ordens wurde I724 eine »neue

I 4 AStL, Altakten, Sch. I 88; vgl. Grüll, Brandverhütung, 368-372.

I 5 Kreczi, Linz, 6r ; LR BIIA23, Reg. I7084 (I 44); ähnlich in Wien: Körner, Stadtzerstörung, Bd. I, I 79 resp. in Wels: Winkler, Stadtbrände, $73-78$.

I 6 Grüll, Brandverhütung, 364 f. u. 379; AStL, Altakten, Sch. I90.

I 7 Vgl. für Kremsmünster: LR BVI 4 , Reg. I 824 (247-249); ebd., Reg. I833 (263f.); vgl. für den Deutschen Orden: LR CIIIHI -3 , Reg. 296 (I64-I69); $\mathrm{LR} \mathrm{CIIIH}_{4}, 789$.

II 8 LR BIIA4, Reg. 5274 (I 57 ).

II 9 LR Eib, Reg. I75 I (89).

I20 LR BIIA4I, Reg. I98 I 5 ( I - I6); LR BIIG6, Reg. 3466 (I64- I69).

I 2 I Bankoff/Lübken/Sand, Cities, 25-28; vgl. EdN, s.v. Feuerwehr.

I 22 Grüll, Brandverhütung, 366.

I 23 LR BIIA4, Reg. 4525 (23f.); ebd., Reg. 475 I (6I); LR BIIA23, Reg. I699I (58).

I 24 LR BIIA4I, Reg. I9815 (I-I6). 
kupferne Feuerspritzen mit doppelt- und mössingenen Stiffeln, Wechsel unnd Pumpen« samt Schlauch und Holztrage angekauft. ${ }^{125}$

Tab. 38: Feuerlöschgeräte und Feuerschutzbauten in Stadt und Vorstädten, um 1700

\begin{tabular}{lcl}
\hline Art & Gesamtzahl & Anmerkung \\
\hline Feuerlaternen & 562 & davon im Rathaus 5 \\
große Wasserbottiche & 443 & dito 6 \\
kleine Wasserbottiche & 318 & $\begin{array}{l}\text { dito 6, davon je 1 bei oberem und unterem Rohr- } \\
\text { brunnen und beim oberen und unteren Graben }\end{array}$ \\
Fässer & 25 & v.a. bei Brunnen und am Graben \\
Messingspritzen & 6 & jeweils 1 in den Stadtvierteln 1-3 und 3 im \\
& & Rathaus \\
kleine oder mittlere Holzspritzen & 665 & darunter 15 im Rathaus \\
Ledereimer & 1.902 & dito 187 \\
große Leitern & 234 & dito 6 \\
mittlere und kleine Leitern & 609 & \\
$\begin{array}{l}\text { Feuerhaken } \\
\text { Wasserschäffer (i.e. tragbare hölzerne }\end{array}$ & 1.382 & alle Größen \\
$\begin{array}{l}\text { Behältnisse) } \\
\text { Feuermauern (mit Ziegeln oder Schindeln } \\
\text { gedeckt) }\end{array}$ & 306 & \\
$\begin{array}{l}\text { Dachboden (mit Ziegeln oder Estrich } \\
\text { belegt) }\end{array}$ & 347 & unbelegt waren 41 \\
\hline
\end{tabular}

Quelle: LR BIIG3, Reg. 1586 (40f.)

Im I 8. Jahrhundert wurden bei Neubauten oder Umbauten größerer Gebäude häufig prophylaktische Maßnahmen getroffen, etwa der Einbau von Feuermauern, der Ersatz von Holz- durch Steintreppen, die Verwendung von Ziegeln als Dachdeckung und in Zwischendecken oder die Errichtung von gemauerten Holzlagen. ${ }^{126}$ Für »normale« Häuser, speziell an der Peripherie, wird man Derartiges aber nicht annehmen können. Dass ein grundsätzliches Bewusstsein über das alltägliche und omnipräsente Risiko eines Brandes existierte, legt die Beobachtung von Brandereignissen und Blitzeinschlägen - dokumentiert z.B. in der Klosterchronik der Ursulinen - nahe. ${ }^{127}$ Ein regelmäßiges Rauchfangkehren und einen vorsichtigen Umgang mit Asche forderten teilweise

I 25 LR CIIIHi - 3, Reg. 692 (505f.); ebd., Reg. 732 (542f.).

I 26 Ebd., Reg. 2 I 9 (I 2of.); ebd., Reg. 479 (3 I ff.); LR CIIIC 3 , Reg. 537 (226f.); ebd., Reg. 826 (356); LR EIc, Reg. 2883 (92); LR BIIA4, Reg. $50{ }_{4} 4$ (ro4).

I 27 LR Erb, Reg. I442 (42); ebd., Reg. I444 (43); ebd., Reg. I399 (37); ebd., Reg. I4I6 (39); ebd., Reg. I 478 (47). 
auch Mietverträge. ${ }^{128}$ Ein Bewusstsein über die Gefahr des alltäglichen Feuergebrauches zeichnet sich möglicherweise in räumlichen Lösungen ab: Das Stadtbräuhaus lag im dünn besiedelten Wörth bei der Donau, und zahlreiche Backhäuser befanden sich im Donautal entlang der Straße nach St. Margarethen - vielleicht waren aber auch andere Umstände (z.B. niedrige Grundstückspreise und eine günstige Lage für den Transport) dafür verantwortlich. ${ }^{129}$ Außerhalb der Stadt wurden, angeblich bereits im Mittelalter, Schmiede vor dem daraufhin so benannten Schmiedtor angesiedelt, ${ }^{130} \mathrm{zu}$ dem könnte man Straßennamen in peripheren Vorstadtbereichen wie »Hafnergasse«, »Hafnerwinkl« und »Glockengießergasse « als Indiz für eine einstmalige Verlagerung von feuergefährlichen (und rauchverursachenden) Gewerben sehen. Ein Adressverzeichnis aus dem Jahr I 825 dokumentiert an diesen Orten zwar einzelne feuernutzende Gewerbetreibende, jedoch genauso Bäcker, Hafner und Metallhandwerker in dichter besiedelten Stadt- und Vorstadtgebieten. ${ }^{131}$

Mit Beunruhigung beobachtete man eher nichtalltägliche Objekte: I7I 7 begann eine längere Diskussion um das Pulverlager, das sich in einem Turm der Stadtbefestigung an der Unteren Donaulände befand. Wiederholt ersuchten die Stadt Linz und Anrainer/innen um die Verlagerung des Pulverlagers - zwar war die Stadt bereit, die entstehenden Kosten zu übernehmen, aber offenbar konnte keine Einigung mit der als neuem Lagerort vorgesehenen Stadt Wels erreicht werden. ${ }^{132}$ Nachdem Anfang Juli I73 I ein Blitzschlag in der unmittelbaren Nähe des Pulverturmes ein kleineres Feuer verursacht hatte, intensivierte sich erneut die Debatte über die Absiedlung und resultierte diesmal in der kaiserlichen Anordnung, das Pulverlager in der Stadtbefestigung aufzulassen und an einem Ort außerhalb der Stadt zu errichten. ${ }^{133} \mathrm{Zu}$ diesem Zeitpunkt hatten die Landstände das Pulver aber bereits aus Linz abtransportieren lassen nach Enns gingen immerhin rund 36 Tonnen Pulver. ${ }^{134}$ Auch bei Großereignissen wie den Märkten war man sich der Brandgefahr bewusst, die von den eng stehenden hölzernen Ständen, den Waren, der offenen Beleuchtung und den zahlreichen Besuchern ausging. Als Präventivmaßnahmen wurden Aufsichtsdienste eingerichtet, zudem Wasser und Löschgerät bereitgehalten. ${ }^{135}$ Ebenso erachtete man den - als sorglos eingeschätzten - Umgang von Soldaten mit Feuer als Risiko: Tatsächlich gab es zahlreiche Kleinbrände in den Linzer Militärunterkünften, die aber, da das sommerliche Soldatenlager auf der Donauinsel und die Wasserkaserne im nur spärlich bebauten

I 28 OÖLA, Landschaftsakten, Sch. 442, D.XV.2/No. 32 .

I 29 Kreczi, Häuserchronik, I77; Bohdanowicz, Vorstädte, Bd. 2, I 556.

I30 Mayrhofer/Katzinger, Geschichte, Bd. I, 69.

I3 I Verzeichniß I 825.

I32 LR BIIA4, Reg. 4986 (Io0); LR CIIIG, Reg. 693 (I6I); LR CIIIG, Reg. 695 (I 77).

I33 LR BIIA 7 , Reg. I 5 I 38 (96f.); LR Eıb, Reg. I 557 (56); LR Eıg, Reg. 376 (I53); LR BIIG 5 , Reg. 2506 (2f.); ebd., Reg. 2507 (3); ebd., Reg. 2509 (4); vgl. OÖLA, Karten- und Plänesammlung, VI/2.

I34 LR BIIG 5 , Reg. 25 I3 (5).

I35 Grüll, Brandverhütung, 366 . 
Wörth situiert wurden, mit Ausnahme des Brandes der Wasserkaserne I 755 und des als Militärspital genutzten - Schlosses I 800 nicht auf andere Gebäude übergriffen. ${ }^{136}$

Die alltägliche Nutzung von Feuer in einer mehrere tausend Einwohner zählenden Stadt bildete ein erhebliches Grundrisiko, das sich in regelmäßigen Kleinbränden artikulierte und in ungünstigen Konstellationen zu einem Großbrand werden konnte. ${ }^{137}$ Im I8. Jahrhundert gab es jedoch in Linz - abgesehen von den Bränden bei der Belagerung während des Erbfolgekrieges Anfang I742 - keinen Großbrand. ${ }^{138}$ Dies kann man als relativ erfolgreiches Reagieren auf isolierte Kleinbrände interpretieren oder als Zufall. Für letztere Deutung sprächen der Großbrand des Jahres I80o (vgl. unten) und auch der Brand von I755, der als Beinahegroßbrand zu sehen ist. Der im Mai 1755 in der Wasserkaserne ausgebrochene Brand konnte erst nach vier bis fünf Stunden eingedämmt werden, er zerstörte oder beschädigte insgesamt rund 6o Häuser und verursachte einen Gesamtschaden von 70.000 fl. Aufgrund des erheblichen Funkenfluges bereitete man sich im ca. 800 Meter entfernten Ursulinenkloster bereits auf einen Großbrand vor, räumte die Möbel in den Keller und stellte (für das Schindeldach) Wasserbehälter und Leitern bereit. ${ }^{139}$ Eine Übersicht zu den Brandereignissen im Linz des i 8. Jahrhunderts zu erstellen, ist schwierig, da Vorarbeiten fehlen: Der Linzer Beamte und Topograph Benedikt Pillwein listete im Vormärz lediglich Brände für die Jahre I732 (mindestens 4 Häuser nahe dem Ursulinenkloster), I742 ( 89 Häuser in den südlichen Vorstädten), I 745 (unklar - nur bei Pillwein genannt) und I755 (rund 6o Häuser beim Brand der Wasserkaserne) auf, ${ }^{140}$ die Chroniken des I 8. Jahrhunderts erwähnen hingegen nur den Brand von I 755 als größeres Ereignis. ${ }^{141}$ Aus diesen - und anderen kleineren Bränden oder Beinahebränden - lassen sich verschiedene Aspekte des Brandrisikos und der Praxis der Brandbekämpfung erkennen: Fast ausschließlich scheint Feuer im häuslich-alltäglichen Bereich - worunter man auch Institutionen wie das Militär und Arbeitsplätze von Dienstleistern zählen kann durch heiße Asche, Kamin- oder Küchenbrände ausgebrochen zu sein. ${ }^{142}$

I 36 LR Eic, Reg. 2964 (Io6); LR BIIG 5, Reg. 2639 (7 I); LR BIIG7, Reg. 3803 (If.); LR EId, Reg. 3870 (I22); LR Eib, Reg. 2 I 7 I U. 2 I 72 (I58).

I37 Unter Großbrand soll im Folgenden ein Brand verstanden werden, der länger als einen Tag dauerte und/oder erhebliche Schäden verursachte. Leider unterblieb bei Zwierlein diesbezüglich ein Definitionsversuch (vgl. Zwierlein, Prometheus, 8 I - 87).

I 38 Pillwein, Wegweiser, 27 f.; vgl. Zwierlein, Prometheus, $82-84$.

I39 AStL, HS 86 (»Chronologische Beschreibung«, I 77oer Jahre), fol. 59a u. 59b; LR CIIIC 3 , Reg. 749 (32 I); LR Eı a, Reg. 476 (95); LR Eıа, Reg. I roo (206); LR Eıb, Reg. I 739 (86f.).

I 40 Pillwein, Wegweiser, 26 u. 38 ; Pillwein, Linz, Bd. I, 2 I 8 ; gelegentlich ist auch ein Brand I7 I 2 erwähnt (AStL, Altakten, Sch. I 88), der auch für die Inschrift »ignes« auf der Dreifaltigkeitssäule verantwortlich sein soll (Kunstdenkmäler, Bd. I, I 58 ).

I4I AStL, HS 86 I (»Chronologische Beschreibung«, I77oer Jahre), fol. 59a u. 59b u. LR E6 (»SeyringerChronik«), 98 .

I42 LR BIIA 5 , Reg. 7 IOO9 (224); LR CIIIC 3 , Reg. 835 (36I). 
Die Brandbekämpfung zielte, wenn man das Feuer am Brandherd nicht mehr löschen konnte, auf das Absichern und Evakuieren der Nachbarhäuser und auf das Anlegen von Feuerschneisen ab. Wie in den Feuerordnungen vorgesehen, übernahmen dies oftmals die Handwerker oder Rauchfangkehrer, so etwa bei einem kleineren Feuer am Landhausturm im September I 740. ${ }^{143}$ Beim Brand eines Gasthauses nahe der Landstraße im November I 732 halfen die Anrainer mit, aber auch zwölf Soldaten waren auf dem Schindeldach des Ursulinenklosters damit beschäftigt, eine weitere Ausbreitung des Feuers zu verhindern. ${ }^{144}$ Bei einem kleineren Brand in der Oberen Badgasse im Juli I793 wurde Taglöhnern, Soldaten und Bewohnern/innen, darunter sogar einigen aus Urfahr, für ihre Hilfe öffentlich gedankt. ${ }^{145}$ Für derartige Hilfeleistungen wurden offenbar nur bei Transportdiensten, die Besitztümer in Sicherheit brachten, Zahlungen verlangt, mitunter bezahlten aber Hausbesitzer - eher bei erfolgreich gelöschten Kleinbränden - Prämien. ${ }^{146}$ Dem Ansuchen von fünf Rauchfangkehrergesellen um »Remuneration « für die Hilfeleistung beim Brand von I 755 wurde durch die Landstände beschieden, dass Derartiges eigentlich ein Pflichtdienst sei, wobei dann doch je 2 fl gewährt wurden. ${ }^{147}$ Bei diesem Brand war auch der Karmeliterprior als "geistliche[r] Feuerlöscher" aufgetreten, wie es eine Linzer Satire aus den I $780 e r$ Jahren maliziös bezeichnete, ${ }^{148}$ und hatte sich dem Feuer mit einer Monstranz entgegengestellt. ${ }^{149}$ Einem Brand im Jahr I 732 begegnete man ähnlich: Ein Geistlicher ging, so der damalige Landeshauptmann in einem Brief, "mit den hochw(ürdigsten)-Guett hinaus und hat den Seegen gegeben, worauf die Brunst balt nachgelassen «. ${ }^{150}$

Nach den Bränden feierten nicht oder wenig Betroffene - ähnlich wie bei Überschwemmungen und Seuchen (vgl. oben u. Kap. 9. Epidemie) - Dankgottesdienste, ${ }^{151}$ Geschädigte erhielten finanzielle und materielle Hilfe über Sammlungen und Steuernachlässe. ${ }^{152}$ Für Oberösterreich sind »Brandbriefe«, die durch lokale Obrigkeiten ausgestellt wurden und Betroffene zur Sammlung von Spenden autorisierten, schon für das I6. Jahrhundert belegt. Ab I 750 wurden diese Sammlungen von staatlicher Seite legitimiert, I76 I eingestellt und I786 wieder eingeführt. Ebenso bestanden Steuerbefreiungen nach Großbränden, die in der Regel drei steuerfreie Jahre einräumten. ${ }^{153}$

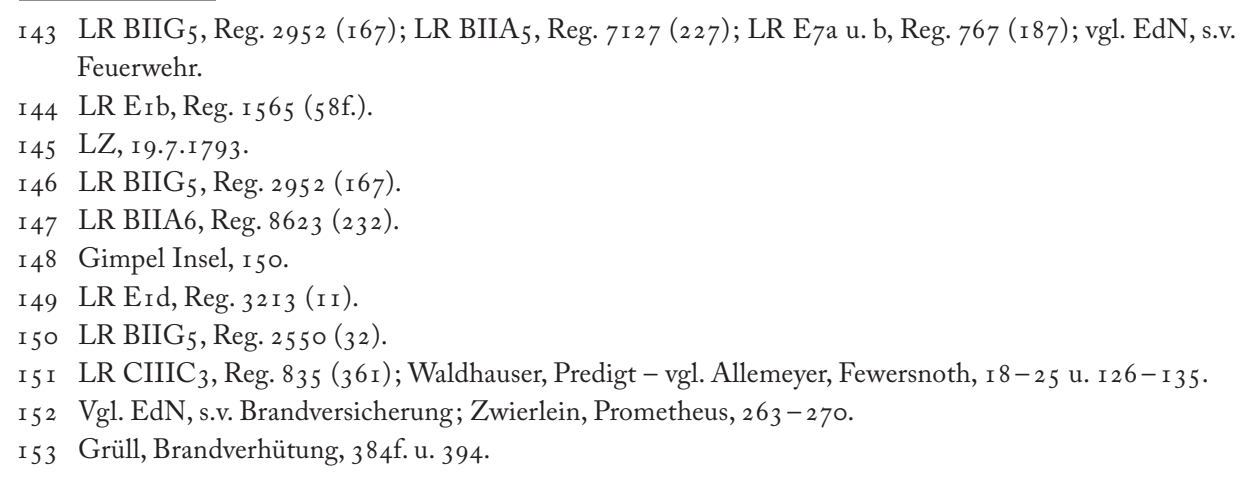


Direkte finanzielle Hilfe durch Staat oder Stadt (als "Brandsteuer« resp. "Beihülfe« bezeichnet) gab es nur punktuell und in begrenztem Ausmaß. ${ }^{154}$ Nach den Zerstörungen im Erbfolgekrieg Anfang I742, die wesentlich durch Brandlegungen österreichischer Truppen verursacht wurden, ${ }^{155}$ erhielten die Betroffenen zwar einen dreijährigen Steuererlass, aber erst nach wiederholten Eingaben im April I 744 3.000 fl als »Brandsteuer« durch die Landstände. Weitere Eingaben führten zur Auszahlung von zusätzlichen, kleineren Beträgen, im Herbst I746 gewährte der Kaiserhof schließlich eine Steuerbefreiung von sechs Jahren und eine »Brandsteuer« von fast $6.000 \mathrm{fl}$ - insgesamt betrugen aber allein die Brandschäden vermutlich über 90.000 fl. ${ }^{156}$ I 750 wurde ein erneutes Ansuchen einer weiteren Steuerbefreiung auf drei Jahre für die abgebrannten Häuser offenbar nicht mehr bewilligt. ${ }^{157}$ Ein weiterer Effekt, der vermutlich nicht allzu lange andauerte, war ein erhöhtes Risikobewusstsein nach unmittelbar erlebten Feuerausbrüchen: Nach einem Dachbrand durch Funkenflug I 7 I 2 dachte man im Jesuitenkolleg über brandhemmende Baumaßnahmen nach, ${ }^{158}$ nach dem Brand der nahegelegenen Wasserkaserne I755 kaufte die Wollzeugfabrik acht Häuser und ein Wiesengrundstück, angeblich wegen der »größere[n] Sicherheit vor Feuersgefahr«, an. ${ }^{159}$

Auf obrigkeitlichen Druck hin waren die zahlreichen und relativ ausdifferenzierten Maßnahmen, die das Brandrisiko reduzieren und die Brandbekämpfung effektiver gestalten sollten, im ausgehenden I 8. Jahrhundert noch erweitert worden, speziell die Feuerbeschau scheint regelmäßig und konsequent von der Stadt durchgeführt worden $\mathrm{zu}$ sein. ${ }^{160}$ Gleichzeitig bestand offensichtlich ein Bewusstsein über die Defizite der bestehenden Brandbekämpfung, was zwei I783 erschienene Satiren deutlich artikulierten: Wenn in Linz ein Feuer ausbreche, "so laufen die Leute wie zu einer Illumination zu, um sich recht satt zu sehen, wie schön es brennt «, anstatt zu helfen. Die Feuerwächter am Turm würden zu spät alarmieren, dann vergehe zu viel Zeit, bis die feuerlöschenden Handwerker sich zusammenfänden, zudem "müssen die Kutscher auch erst ihre Pferde anlegen «, um die Feuerspritzen transportieren zu können. ${ }^{161}$

I 54 Pillwein, Linz, Bd. I, 256.

I 5 Pillwein, Wegweiser, 28; irgendwann war man der »erfolglosen Beschießung müde« und versprach »den Panduren und Warasdinern zweihundert Ducaten zur Belohnung [...], wenn es ihnen gelänge, alle Vorstädte gleichzeitig in Brand zu stecken«, was diese dann auch schafften (Thürheim, Feldmarschall, I77).

I56 LR BIIA36, Reg. I 9227 (2 I 9f.); LR BIIA6, Reg. 77 I9 (76f.); ebd., Reg. 7743 (8I); ebd., Reg. 7753 (82 - vgl. ebd., Reg. 7753 u. 7786); ebd., Reg. 7997 (I 2 I); LR BIIAI4, Reg. I 4408 (I 53); ebd., Reg. I 44 I 0 (I 54); ebd., Reg. I 44 I 9 (I 56 f.).

I 57 LR BIIA6, Reg. 8324 (I 79).

I 58 LR CIIIC $_{3}$, Reg. 2 I 4 (90).

I59 Pillwein, Beschreibung, 286; vgl. Gielge, Beschreibung, I67.

I60 Vgl. AStL, Altakten, Sch. I90; LR BIIA24, Reg. I73 I 2 (I86); LR B V, Reg. 838 (4I4); LR BIIG7, Reg. 4335 (I65f.); LR BIIA4I, Reg. I 9908 (8If.).

I6 I Gimpel Insel, I47. 
Nach dem Eintreffen aller am Brandort »halten die Feuerspritzen ihre Auferstehung«, die - angeblich nach jedem Einsatz teilweise zerlegt - erst wieder "zusammenkommen müssen «. ${ }^{162}$ Dazu kämen Defekte und Bedienungsfehler der Spritzen - bei einem Brand hätten sogar »Räthe von der Landesstelle Wasser tragen« müssen. ${ }^{163}$ Als ähnlich ineffizient wurde in der zweiten Satire der Ablauf und die Hilfsmittel der Brandbekämpfung beurteilt: Bei einem abendlichen Feueralarm in der Vorstadt habe es Verzögerungen gegeben, da die »besoffenen Thorsteher» das bereits geschlossene Landhaustor nicht gleich öffneten. ${ }^{164}$ Es sei zwar die "gröste Feuerspritze« - gemeint war wohl die landständische - mitgenommen worden, man habe aber unterwegs "zwey Räder" verloren, auch sei die Spritze nicht mit Wasser gefüllt worden. ${ }^{165}$ Mit dem Verweis auf einen (real nicht existierenden) »Befehl« zur Feuerordnung, dass »allezeit 3 Tage vor einer entstehenden Feuersbrunst die Spritzen gut befeuchtet, und alle übrigen gehörigen Instrumenten brauchbar hergestellt werden«, sprach man in ironischer Weise implizit ein Grundproblem städtischer Brandereignisse an: Man wusste nicht, wann und wo es brennen würde. ${ }^{166}$

Der Großbrand im August I 800 war das Resultat des Aufeinandertreffens von unzureichenden Maßnahmen resp. Möglichkeiten der Brandbekämpfung und einer spezifischen, brandfördernden Witterungskonstellation, er war also sozionatural bedingt. ${ }^{167}$ Wie das gesamte Frühjahr war der August I 800 überdurchschnittlich niederschlagsarm, zudem deutlich wärmer. ${ }^{168}$ Diese Anomalie konstatierten auch die Zeitgenossen nach dem Brand: Es hätten eine starke »Som(me)rhitze« und extreme Trockenheit geherrscht. ${ }^{169}$ Bereits am I3. August war ein kleines Feuer im hölzernen Gartenhaus beim Schloss ausgebrochen, das aber schnell gelöscht werden konnte. Noch am gleichen Tag verfasste der Schlosspfleger einen Bericht an die Landstände, in dem er die Gefahr betonte, die im Brandfall bei Trockenheit und entsprechender Windrichtung vom nahegelegenen hölzernen Wehrgang, der das Schloss mit dem ständischen Landhaus verband, ausgehe. Zwei Tage später, am Abend des I 5 . August, brannte es erneut im (oder beim) Gartenhaus: Die Ursache dafür ist nicht klar, in einem Bericht an den

\footnotetext{
I62 Ebd., I48.

I63 Ebd., I $48 f$.

I64 Rabiosus, Reise, Bd. 3, 24.

I65 Ebd., 25.

I66 Ebd., 26.

I67 Mauelshagen, Klimageschichte, I 27- I 29; Zwierlein, Prometheus, rogf.; Körner, Stadtzerstörung, Bd. I, 247 u. 279-28I ; vgl. zur Trockenheit und zum starken Föhnwind beim Brand der Stadt Salzburg Ende April/Anfang Mai r 8 1 8: Marx, Flammen, 47f. u. 55-57.

I68 Casty et al., Temperature; Der Sommer war "äußerst dürr und trocken, [...] im August außerordentlich heiße Tage«, notierte der Pfarrer Franz Haslinger - HTb i 80o, Jahreszeiten; vgl. zu Temperatur und Niederschlägen des Sommers I 800 im nördlichen Linzer Hinterland: Haslinger, Tagebücher, 57-59.

I69 OÖLA, Landschaftsakten, Alte Registratur, Sch. 98, D.XV.3/No. 82; LR CIIIG, Reg. I453 (4I7); Waldhauser, Predigt, 8.
} 


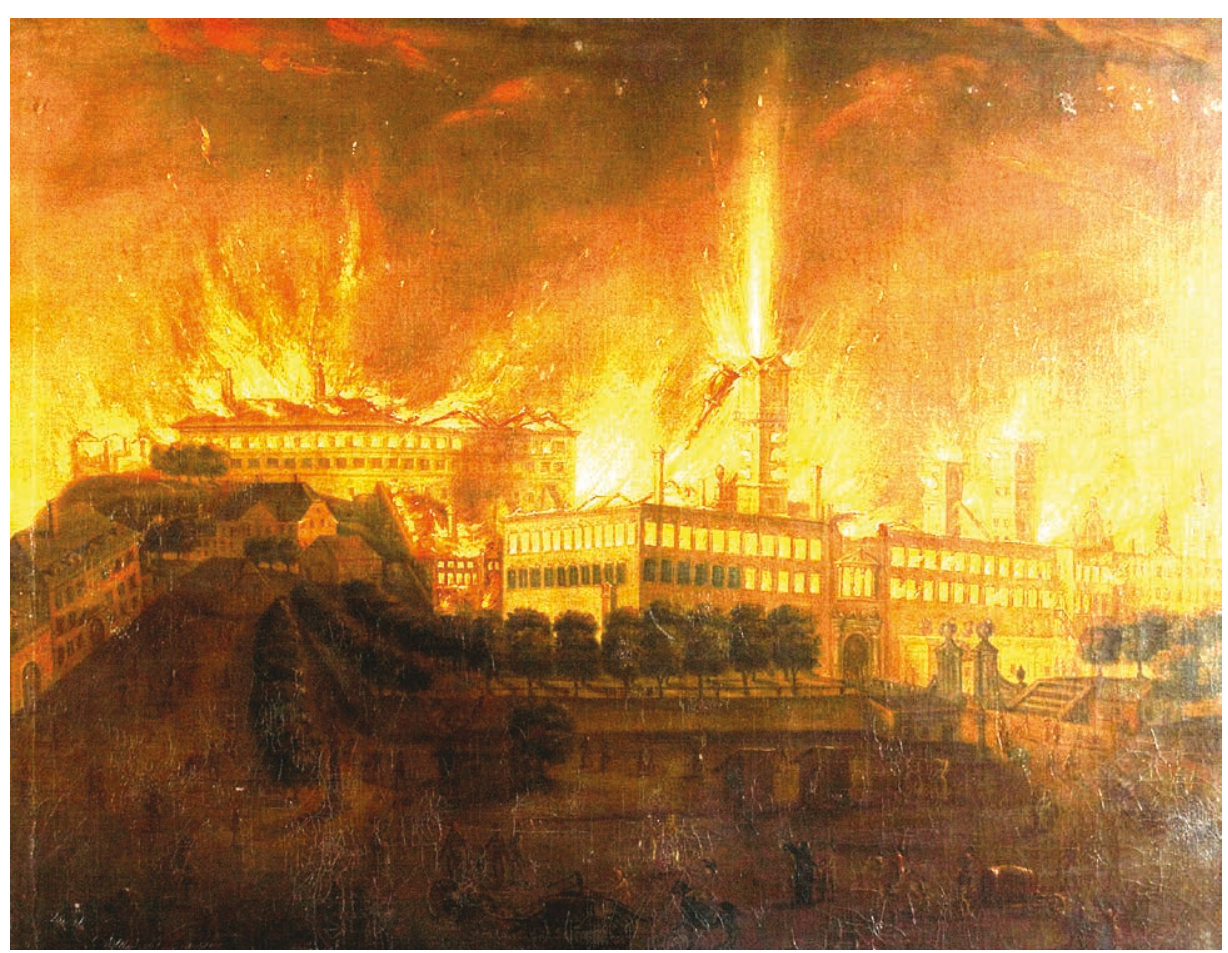

Abb. 33: Der Großbrand vom August 1800 auf einem Gemälde von Thomas Dialer (Ausschnitt) - links das Schloss und rechts das Landhaus, im Vordergrund des (aufgehellten) Bildes sind einige hölzerne Markthütten und Löschbehelfe zu sehen

Wiener Hofkriegsrat am nächsten Tag teilte man mit, dass das Feuer »der Sage nach« durch einen Böller entstanden sei. Diese Aussage sollte man vielleicht als eine strategische erachten, denn wenige Tage zuvor hatte der Schlosspfleger einen Zusammenhang zwischen dem ersten Brand und den im damals als Militärspital fungierenden Schloss untergebrachten - und wohl rauchenden - Soldaten hergestellt. Das kleine Feuer verbreitete sich schnell über den hölzernen Verbindungsgang Richtung Süden und Südosten aus und bald brannten zahlreiche Häuser im südwestlichen Teil der dicht verbauten inneren Stadt (vgl. Abb. 33). ${ }^{170}$

Der damals elfährige Joseph v. Spaun, der als Sohn des landständischen Syndikus Franz Xaver v. Spaun im Landhaus wohnte, erinnerte sich an den Brand als einschneidendes Kindheitserlebnis und gibt einen Einblick in das Handeln während eines Großbrandes. Als er mit seinen zwei kleineren Brüdern und einem ständischen Beamten von einem Spaziergang zurückkam, sah er das brennende Schloss und eine, dieses

I70 OÖLA, Landschaftsakten, Alte Registratur, Sch. 98, D.XV.3/No. 82; vgl. LR CIIIG, Reg. I 453 (4I7) u. Awecker, Brand, $26 f$. 
Ereignis aus der Ferne bestaunende, "grosse Menschenmenge«. Trotzdem das Feuer das Landhaus schon fast erreicht hatte, führte der Beamte die Kinder in das Gebäude, "wahrscheinlich[,] um etwas von seinen Sachen zu retten«. Von dort sahen die Kinder, wie in einem brennenden Nebengebäude an der Nordwestseite des Landhauses der dort wohnende ständische Diener ums Leben kam. Aber erst nachdem man ein paar Gegenstände »in der unsinnigsten weise« zusammengesammelt hatte, entschloss man sich zum Verlassen der Wohnung, was durch den starken Rauch und eine beinahe zugefallene Tür fast gescheitert wäre. Zu diesem Zeitpunkt war selbst Spauns Mutter mit den beiden kleinsten Geschwistern - noch in einem anderen Teil der Wohnung und versuchte mit »ein paar Männer[n] «, wertvollere Besitztümer in einem Keller des Landhauses in Sicherheit zu bringen. ${ }^{171}$ Spauns Vater war zwar ebenso im Landhaus, er kümmerte sich jedoch um die Löschversuche und die Evakuierung des ständischen Archivs und der Kasse und forderte nur über einen Boten seine Familie zum Verlassen des Gebäudes auf: Man solle nicht in das Elternhaus der Mutter am Hauptplatz, sondern zu einem Freund der Familie, dem Direktor der Wollzeugfabrik, flüchten. ${ }^{172}$ Zwar war relativ schnell Feueralarm gegeben worden, auch kam regionale Hilfe, das Feuer brannte aber bis zum I6. August weiter und konnte erst beim Schmiedtor und am Hofberg, vermutlich durch die Anlage von Feuerschneisen, gestoppt werden. ${ }^{173}$

Es war ein »schauerliches Feuermeer am nächtlichen Himmel und über das ganze Firmament wälzten sich die glühenden Massen«, erinnerte sich Joseph v. Spaun. Omnipräsent waren das ständige Läuten der »Feuerglocken«, das Schlagen der »Trommeln«, das Gedränge und »Geschrei der Leute« - das alles resultierte für Spaun in einem »fürchterlichen[,] nie zu vergessenden Eindruck«. ${ }^{174}$ Es habe Menschen gegeben, so wurde in einer wenige Wochen nach dem Brand gehaltenen Predigt moniert, »die dem allgemeinen Elende mit Kälte und Gleichgültigkeit zusahen; andere, die Arm in Arm lustwandelten, und in dem fürchterlichen Schauspiele Unterhaltung zu finden schienen ${ }^{175}$ Spauns Mutter betete »die ganze Nacht«, erst am nächsten Tag sah die Familie den Vater wieder, der lakonisch verkündete, dass man nun »Bettler-allein« sei, da alle Besitztümer verbrannt seien. ${ }^{176}$ Das Feuer scheint in den nachfolgenden Tagen, zuletzt in der Nacht zum i 9. August, in den Ruinen vereinzelt erneut aufgeflammt zu sein, was die Landstände als Nachlässigkeit der Stadt kritisierten. ${ }^{177}$ Insgesamt war ein

I7 I Doku, Spaun, 42; vgl. Depiny, Aufzeichnungen, I 80- I 82.

I72 Doku, Spaun, 43 f.

I73 Awecker, Brand, 26-30; Waldhauser, Predigt, 20; Mader, Reise, I3.

I74 Doku, Spaun, 43.

I75 Waldhauser, Predigt, 16.

I76 Doku, Spaun, 44; Spaun meldete dem Magistrat einen Schaden von rund 5.000 fl (»Geld, Praetiosen, Kleydung, Wesch, Better, und Zim[m]ereinrichtungen«) und äußerte den Wunsch, dass - bei einer etwaigen Vergütung seiner Schäden - das Geld an seine drei Dienstbotinnen ausgezahlt werden solle (AStL, Altakten, Sch. I 89).

I77 AStL, Altakten, Sch. 189; vgl. Awecker, Brand, 3I u. LR BIIA4I, Reg. 20009 (I 78 f.). 
Schaden von rund $300.000 \mathrm{fl}$ entstanden: Das Schloss, das Landhaus und 58 Häuser waren weitgehend abgebrannt, bei I 9 weiteren Häusern wurden die Dächer beschädigt, auch verbrannten einzelne der für den Markt aufgestellten Verkaufshütten samt Inhalt. ${ }^{178}$ Offenbar gab es - außer dem bereits erwähnten Todesfall beim Landhaus keine weiteren Opfer, da sich der Brand relativ langsam ausgebreitet hatte. ${ }^{179}$ Selbst im Schloss war niemand gestorben: Die Kranken hätten sich alle »verloffen«, so ein Bericht vom I6. August. ${ }^{180}$

Dieser Brand war deutlich ein Feuer vormoderner Prägung, das durch Wassermangel und punktuelle, unkoordinierte Löscharbeiten gekennzeichnet war: Die meisten Bewohner/innen hatten - wie auch der Großteil der Familie Spaun - versucht, eigene Besitztümer zu retten, statt zu löschen, ${ }^{181}$ »alles« hatte »den Kopf verloren«, so Spaun rückblickend. ${ }^{182}$ In Linz hatte sich die dichte Bauweise der inneren Stadt als erheblich brandfördernd erwiesen, zudem hatte sie die Löschversuche behindert: Beim Landhaus, dem Verbreitungspunkt des Feuers unterhalb des Schlosses, konnte man, wie das Bauamt i 8 I o feststellte, nur »von zwey kürzeren freyen Seiten [...] mit Rettungsmittel bey dem unglücklichen Feuer zu Hilfe kom(m)en«. ${ }^{183}$ Dennoch war der Brand, wie der des Jahres I755, nur eine Beinahekatastrophe: Es kam, vermutlich lediglich aufgrund des Umstandes, dass es nur leicht windig war, zu keinem Totalbrand der Stadt. ${ }^{184}$ Auch die Bewältigung des Ereignisses trägt vormoderne Züge: Es wurde eine Spendensammlung (»Brandsteuersammlung «) bewilligt, die vermutlich rund so Prozent der entstandenen Schäden abdeckte, ${ }^{185}$ und auf Antrag erhielten Betroffene partielle Steuerbefreiungen, auch wurde die Abgabe auf in die Stadt gebrachtes Baumaterial temporär aufgehoben. ${ }^{186}$ Die meisten Brandopfer waren auf die Solidarität ihres näheren Umfeldes angewiesen: Zwar bekam der Vater von Joseph v. Spaun eine Prämie von r.ooo Gulden für seinen Einsatz bei der Rettung des Archives und der Kassen, Spauns Mutter lieh sich aber bereits unmittelbar nach dem Brand Geld, zudem erhielt die Familie bald durch "Freunde und Beamte Sachspenden und schließlich eine anonym zugesandte Kiste mit Kleidung und Stoffen. ${ }^{187}$ Der Linzer Adelige Heinrich Kheven-

I78 Awecker, Brand, 27-3 I; Mayrhofer/Katzinger, Geschichte, Bd. 2, 58.

I79 Dies war bei mittleren Bränden nicht unüblich: Körner, Stadtzerstörung, Bd. I, 25 If. u. 284; anders beim Brand der Stadt Salzburg im April r 8 18, der zwölf Todesopfer forderte (Marx, Flammen, $64-70)$.

I80 LR CIIIG, Reg. I 453 (4I7).

I 8 I LR Erb, Reg. 2008 (I 32); Waldhauser, Predigt, 8; vgl. Körner, Stadtzerstörung, Bd. I, 25 of. u. Marx, Flammen, 53 f.

I 82 Doku, Spaun, 44; vgl. Marx, Flammen, 65-67.

I 83 OÖLA, Landschaftsakten, Alte Registratur, Sch. 84, D.XIV.2/No. I 96.

I 84 Für den I 5. und I6. August I 800 notierte Haslinger, der sich damals im nördlichen Linzer Hinterland aufhielt, nur leichten Wind aus Ost resp. West - Haslinger, Tagebücher, 59.

I 85 AStL, Altakten, Sch. I 89; OÖLA, Musealarchiv, Sch. 4/No. I 5 ; vgl. Awecker, Brand, 36.

I 86 AStL, HS ro87 (Stadtratsprotokoll i 8oo), fol. 259 a u. 30rb.

I 87 Doku, Spaun, 44f. 
hüller hatte ebenso »theils durch den Raub der Flammen, theils durch jenen böser Menschen« den größten Teil seiner Besitztümer verloren - auch ihm halfen "gutte Freunde, in der ersten Noth « mit einer Unterkunft, »Leibswäsch, und Kleidung «. ${ }^{188}$

Die vorhandenen Archivalien deuten nicht darauf hin, dass in den Wochen und Monaten nach dem Brand in Stadtrat und Stadtverwaltung eine breitere Diskussion über Brandprävention und risiko geführt wurde - der Brand führte aber erneut zu einem Bündel an kleineren Ad-hoc-Maßnahmen, die die omnipräsente Brandgefahr in der Stadt vermindern sollten: Man reduzierte die Anzahl der hölzernen Verkaufshütten, ordnete an, die Neubauten feuersicherer zu machen, und verlegte die Salpeterproduktion aus dem Schloss an die Peripherie. ${ }^{189}$ Folgenreicher waren die Auswirkungen im Umfeld des Landhauses: Anstelle des abgebrannten Aufschlagamtes wurde neben dem Landhaus eine neue Gasse angelegt, die einen besseren Zugang zur inneren Stadt ermöglichte. Dies zielte einerseits auf die Reduktion der Brandgefahr ab, andererseits ging es genauso um eine Aufwertung der Promenade und des dortigen landständischen Besitzes. ${ }^{190}$ Gleichzeitig begann man, die Stadtbefestigung abzutragen, den Wall mit Brandschutt aufzuschütten, und schuf auf den neu gewonnenen Flächen einen repräsentativen Grünraum für die Linzer Ober- und Mittelschichten (vgl. Kap. 7 . Geordnete und modifizierte Umwelt). Ex post - und wohl nur von Nichtbetroffenen wurde der Brand aus diesem Blickwinkel als »Gelegenheit« und "glückliche Krisis» für Linz bezeichnet. ${ }^{191}$ Nun sei Linz, schrieb ein Besucher über seinen Aufenthalt im Jahr I 807, "wie ein Phönix schöner aus der Asche wieder emporgestiegen «. ${ }^{192}$ »Wie gut es doch ist, wenn zuweilen eine Feuersbrunst das alte Rumpelwerk einer Stadt ausbrennt «, wurde noch in einem in den I 8 2oer Jahren erschienenen Reisehandbuch konstatiert. $^{193}$

\section{Feuer als städtisch-bürgerliche Aufgabe}

Die Feuerordnung, die durch den Magistrat Linz im Sommer I 807 veröffentlicht wurde, kann man nicht als unmittelbare Nachwirkung des Brandes von I 800 werten, sie basierte weitgehend auf der Josephinischen Feuerordnung von I786 und ergänzte

I 88 OÖLA, Neuerwerbungen, HS 74 (»Bau-Rechnung« Kremsmünsterer Haus, I 804), unpag.

I89 AStL, HS 1087 (Stadtratsprotokoll I 800), fol. 257a-266b; LR BIIA 4I, Reg. 20025 ( 198 ); LR E7e-g, Reg. 95 (2 If.); LR BVI 3 , Reg. I56I ( 7 ff.); LR CIIIG, Reg. I484 (43of.); eine »soziale Entmischung» (Körner, Stadtzerstörung, Bd. I, I4I) durch den Wiederaufbau nach dem Brand kann im Linzer Fall nicht festgestellt werden.

I90 LR BIIA I5, Reg. I 4628 ( 19 f.); OÖLA, Landschaftsakten, Alte Registratur, Sch. 84, D.XIV.2/ I 96.

I 9 I Mader, Reise, I I ; Heinse, Linz, I. Aufl., ıо; vgl. dazu die Überlegung von »fire as risk and as a catalyst of change« (Bankoff/Lübken/Sand, Cities, 9 u. 226-228).

I92 Mader, Reise, I3.

I93 Schultes, Donau-Fahrten, 88f. 
sie um die vonseiten des aufgeklärten Staates erdachten Neuerungen. ${ }^{194}$ Wie bisher zielte man auf eine Reduktion der Feuergefahr über Bauvorschriften ab: Die »Veranlassung zu Feuersbrünsten lieget grösentheils [...] in der gefährlichen Bauart«, stellte man einleitend fest - wenngleich beigefügt wurde, dass genauso »mancherley Unvorsichtigkeiten, oder endlich [...] Sorglosigkeit und Vernachlässigung« Ursache für Brände seien. ${ }^{195}$ Vor allem ging es um die bereits lange postulierte Substitution von Holz durch Ziegel - zumindest für Neubauten war nun eine Ziegeldeckung vorgeschrieben. Dazu kam die Wiederholung von älteren Vorschriften, die erneut u.a. das regelmäßige Kehren durch Rauchfangkehrer, das Bereithalten von Löschgerät durch die Haushalte und die »Dienstbereitschaft « der Stadtbewohner verlangten. ${ }^{196}$ Eine Neuerung stellten die I 4 »öffentlichen Feuerlösch-Rüstungsdepot[s]« (inkl. Urfahr und St. Margarethen) dar, in denen Löschgerät, Feuerspritzen und Fuhrwerke aufbewahrt wurden. ${ }^{197} \mathrm{Zudem}$ wurden bei I 8 "öffentlichen Wasserstätten und Schöpfplätzen« in der Stadt und in den Vorstädten (dies betraf v.a. Brunnen und an der Peripherie einige Teiche) Bottiche zum Wasserschöpfen aufgestellt, dauernde Feuerwachen bestanden auf den Türmen der Pfarrkirche, des Schmiedtors und des Landhauses. ${ }^{198}$ Die Einrichtung einer bezahlten Bereitschaftsfeuerwehr, die z.B. in Paris oder Wien zu diesem Zeitpunkt schon gab, unterblieb jedoch. ${ }^{199}$ Die Feuerordnung sah erneut Dienstpflichten für Handwerker vor, stellte aber explizit Belohnungen in Bargeld in Aussicht. ${ }^{200}$ Diese Dienstpflicht scheint sich noch im beginnenden I9. Jahrhundert ausgeweitet zu haben - die Feuerordnung des Jahres I 8 I 6 ordnete bereits eine verpflichtende Bereitstellung von Pferden an. ${ }^{201}$

In den I 8 oer Jahren setzte in Linz im Rahmen der staatlich-städtischen Reformen (vgl. z.B. Kap. 7. Geordnete und modifizierte Umwelt) auch eine Neuregelung der Feuerbekämpfung und prävention ein: Seit dem Sommer I 82 I gab es eine ständige "Nachtwache zur Feuer-Reserve", die aus einem Maurer, einem Zimmermann, einem Rauchfangkehrer und einem Taglöhner bestand und unter Aufsicht des Stadtwachtmeisters stand, ${ }^{202} \mathrm{im}$ Jahr I 830 wurden durch die Stadt für die "Feuerlöschanstalten « insgesamt $727 \mathrm{fl} \mathrm{I} 4 \mathrm{kr}(\mathrm{CM})$ ausgegeben und I $840298 \mathrm{fl} 40 \mathrm{kr}^{203}$ Dieser Feuerwach-

I 94 Vgl. Handbuch, Bd. I, 323-34I; Handbuch, Bd. I 2, 329-337; Winkler, Stadtbrände, 65 f.

I 95 Feuer-Ordnung, I.

I 96 Ebd., 2-i 9 .

I 97 Ebd., 23-25.

I 98 Ebd., $28 \mathrm{f}$.

I 99 EdN, s.v. Feuerwehr; Körner, Stadtzerstörung, Bd. I, I 79 u. I 84 .

200 Feuer-Ordnung, 78f.; die Bezahlung der Belohnungen übernahmen die Hauseigentümer, so bezahlte z.B. die Stadt als Eigentümer I 807 einem Feldwebel für »Entdeckung« eines Feuers in der Wasserkaserne 5 fl, einem Rauchfangkehrer für ein gelöschtes Feuer im Rathaus 5 fl-AStL, HS I 28 (Kammeramtsrechnung I 807), fol. 86a; vgl. LZ/IB, I 4.8.i 8 I 5 .

20 I AStL, Altakten, Sch. i 90.

202 Pillwein, Beschreibung, 3 I 4 - in den Stadtratsprotokollen fand sich zu dieser Innovation aber nichts.

203 AStL, HS i 7 I (Kammeramt Empfang I 840), pag. I 46 u. 237 ; AStL, HS I 52 (Oberkammeramt Ausgaben I 830 ), pag. 244 . 
dienst beseitigte aber die private Verantwortung für die Brandbekämpfung nicht, sondern ergänzte nur die bestehende Lösch- und Brandbekämpfungspflicht der Handwerker und der Bewohner/innen durch einen Bereitschaftsdienst. Dennoch zeigen sich deutlich Versuche der Stadt, die Brandprävention und bekämpfung auszuweiten: Die Anzahl der Feuerlöschdepots wurde erhöht, ${ }^{204}$ zudem geriet die Schwierigkeit, im Brandfall ausreichende Mengen von Wasser zu beziehen, in den Blick. Um den Wassermangel am Schullerberg, der »vorzüglich bei einer Feuersbrunst fühlbar seyn würde ${ }^{205} \mathrm{zu}$ beseitigen, wurde in den frühen I 83 oer Jahren eine kleine städtische Wasserleitung mit Auslaufbrunnen angelegt (vgl. Kap. 3. Wasser). Zudem kann man eine abnehmende Toleranz gegenüber tradierten Praktiken und Bauweisen erkennen: Hausbesitzern wurde der nachträgliche Einbau von Eisentüren auf Dachböden ${ }^{206}$ oder das Abtragen von hölzernen Bauten in Höfen (Holzlagen, Schuppen) vorgeschrieben. ${ }^{207}$ Als I 822 das Militärbackhaus bei einer Feuerbeschau beanstandet wurde, wandte man vonseiten des Linzer Militärs ein, dass »die Brod Erzeugung durch 40 Jahre betrieben worden wäre, ohne [...] ein Bedenken«, der Wiener Hofkriegsrat ordnete jedoch an, die Auflagen umzusetzen. ${ }^{208}$ Feuergefährliche Settings, vor allem die Schindeldächer, bestanden aber in peripheren Teilen der Stadt bis ins 20. Jahrhundert.

Als Innovation im Bereich der Risikobewältigung traten im frühen I 9. Jahrhundert Versicherungen auf: Feuerkassen und versicherungen gab es, z.B. in Hamburg und London, zwar schon seit dem ausgehenden I 7. Jahrhundert, sie erlebten im deutschsprachigen Raum aber erst ab der Mitte des I 8. Jahrhunderts einen Boom. ${ }^{209}$ Auch in Oberösterreich wurde durch die Stände die Etablierung einer »Feuersocietät«, also einer territorialen Brandkasse in den I 76oer und I 77oer Jahren und erneut gegen Ende des I 8. Jahrhunderts diskutiert, aber nicht umgesetzt. Zumindest gab es in einzelnen Herrschaften verpflichtende Brandkassen. ${ }^{210}$ In Linz bestand erst ab den I 82 oer Jahren die Möglichkeit, eine Feuerversicherung abzuschließen, die meist durch Filialen bereits existierender Versicherungsgesellschaften, wie der »Salzburger Brandassekuranz« ( $\mathrm{ab}$ I 82 I) , der "Elementar-Versicherungs-Anstalt « (eine Filiale der Triester »Azienda Assicuratrice«, ab I 825) oder der »Österreichischen Brandversicherungsgesellschaft» (Wien, ab I 825), angeboten wurden. ${ }^{211}$ Obwohl die Versicherungsprämien moderat waren - r 830 zahlte die Stadt als zweijährige Prämie für ein Haus am Graben I fl

\footnotetext{
204 LR Eri, Reg. 58 I 9 (94); LR CIIIG, Reg. 1986 (643f.).

205 LZ/IB, 22.I 2.1828.

206 LR EId, Reg. 3979 (I 43).

$207 \mathrm{LR} \mathrm{BVI}_{3}$, Reg. 1696 (94).

208 LR CIIIG, Reg. 1774 (555).

209 EdN, s.v. Brandversicherung; Zwierlein, Prometheus, 199-242 u. 370-376.

2 1o Grüll, Brandverhütung, 395-398 u. 386f.; vgl. zu Salzburg: Marx, Flammen, 356-358.

21 I Fink, Geschichte, I04; Pillwein, Wegweiser, I48; vgl. LZ, 3.6.1822; ebd., 9.5.1823; LZ/ IB, I5.II.I824; ebd., 4.8.I826.
} 
$25 \mathrm{kr}^{212}$-, verbreitete sich die Feuerversicherung in Linz offenbar nur langsam: Ende I 832 waren in der inneren Stadt »nur«, wie der »Franziszeische Kataster» betonte, 34 Häuser von insgesamt 200 Häusern bei der »n: ö: wechselseitigen Feuerschaden Assekuranz« versichert, ${ }^{213}$ in der nördlich der Donau gelegenen Gemeinde Pöstlingberg waren von 98 Häusern 46 Häuser »im einheimischen gegenseitigen Privat-Vereine«, 5 bei der niederösterreichischen und I Haus bei der Triester Versicherung, ${ }^{214}$ in St. Peter I I Häuser in privaten Kassen und nur I Haus bei der niederösterreichischen Assekuranz versichert. ${ }^{215}$ Brandgefährliche Betriebsobjekte wie Gießereien waren vermutlich mehrheitlich von den Versicherungen ausgeschlossen, zudem war kein Versicherungsschutz durch kriegerisch induzierte Brände vorgesehen. ${ }^{216}$ Somit blieben die private reziproke - Unterstützung vor Ort, das regionale und überregionale Sammeln von monetären und materiellen Spenden weiterhin zentral für die durch Brände Betroffenen. ${ }^{217}$

„Die Feuerlöschanstalten in Linz [...] entbehren der im Löschgeschäfte abgerichteten Feuerwärter «, stellte ein Wiener Publizist in seiner I846 erschienenen Reisebeschreibung fest. Bei einem Brand "greifen [...] alle eben Hinzukommenden an, wodurch Geschrei und Unordnung entstehen. Statt die Straße, wo das Haus in Feuer gerieth, abzusperren, läßt man Jeden zu, der löschen hilft. Dies kann auch so lange nicht verhindert werden, bis nicht eine eigene Feuerwartmannschaft hergestellt wird. ${ }^{218}$ Diese Beobachtung artikulierte die ab den I $840 e r$ Jahren im deutschsprachigen Raum verstärkt auftretenden Diskussionen um die Etablierung einer ständigen Feuerwehr. Vorbilder dafür bildeten die in der napoleonischen Zeit reorganisierte französische Feuerwehr und die in größeren Städten bestehenden Feuerlöschdienste, die vor allem für die Bedienung der Feuerspritzen vorgesehen waren. ${ }^{219}$ Zahlreiche kleinere und mittlere Städte etablierten in der Folge "freiwillige Feuerwehr-Corps«, die als liberal-bürgerliche Lösung im Rahmen der kommunalen Selbstverwaltung zu sehen sind und oft von lokalen Turnvereinen organisiert wurden. In Berlin bestand hingegen ab i 85 I eine kasernierte Berufsfeuerwehr, die als Teil der Polizei, aber auch

2 I 2 AStL, HS I 5 I (Oberkammeramt Empfang i 830), pag. 223.

2 I 3 OÖLA, Franziszeischer Kataster, No. 534 (Operat I u. 2, Braune Mappe, Linz-Stadt, Katastralschätzungs-Elaborat, I 8.12.1832).

2 I 4 Bohdanowicz, Pöstlingberg, 2 I 9 u. 232.

2 I 5 Bohdanowicz, St. Peter, 233 - zu diesen privaten Feuerkassen ist derzeit noch nichts bekannt.

2 I6 Vgl. die Statuten der landständischen »Feuerschaden-Versicherungs-Anstalt« (undat., um I848) AStL, Altakten, Sch. I 90; beim Salzburger Stadtbrand von I 8 I 8 wurden nur ıo Prozent der Schäden durch die Versicherungen abgedeckt: Marx, Flammen, $36 \mathrm{I}$.

2 I 7 LZ, 26.7.I830; ebd., 20.6.I842; LTP, 2.7.I867; Allemeyer, Fewersnoth, 26f.; vgl. zur Spendenaktion für Salzburg: Marx, Flammen, I09- I 3 I.

2 I 8 Koch, Reise, 6; I 849 gab es in Wien jedoch auch erst 46 ständig besoldete Feuerwehrleute (Csendes/ Opll, Wien, Bd. 3, 68f.).

2 I 9 Vgl. als rezente Überblicke: EdN, s.v. Feuerwehr; Briese, Sicherheit, 9- I 2, 30-37 u. I Iff.; Schamberger/Leupold, Brandschutzgeschichte, 62-64. 
als Hilfstruppe gegen Unruhen in Reaktionszeit gedacht war. ${ }^{220}$ Breites mediales Echo generierte im Frühjahr I 847 der Brand im Karlsruher Theater, der durch eine freiwillige Feuerwehrmannschaft aus dem nahegelegenen Durlach gelöscht wurde. Dort hatte man im vorangegangenen Jahr eine moderne Feuerspritze aus der Produktion des Heidelberger Fabrikanten Carl Metz angekauft, der ausgebildetes und geübtes Personal für die Bedienung der Spritze empfahl. Das griff man in Durlach auf, nahm aber zudem weitere Personen ins "Corps« auf, die andere Aufgaben im Brandfall (z.B. Steiger oder »Vorpompiers «) hatten. ${ }^{221}$ Möglicherweise wird man die zeitnah erfolgte demonstrative Probe der städtischen Feuerspritze in Linz und den Ankauf einer neuen Spritze in diesem Kontext sehen können. ${ }^{222}$

In Linz lud der Gemeinderat im Herbst I 850 "zur Bildung einer bleibenden Feuerwehr ein, bestehend aus Männern, die sich verpflichten, bei den Löschanstalten voranzugehen ${ }^{223}$ Dieser Versuch, eine freiwillige Feuerwehr zu gründen, ging maßgeblich vom Gemeinderat und späteren Bürgermeister Vinzenz Fink aus, der als Buchhändler vermutlich über die publizistische Feuerwehrdebatte Bescheid wusste. Die Brandbekämpfung »nach einem erprobtem Systeme« sei, so der gedruckte Aufruf im Dezember I 850, effektiver als »das Zusammenwirken von Hunderten«. Eine geübte Feuerwehrtruppe lösche in jedem Fall besser als die Hausbewohner selbst: »Es ist nämlich eine bekannte Erscheinung bei Bränden, daß die besonnensten und muthigsten Menschen, in deren Wohnungen oder Nähe derselben ein Feuer ausbricht, häufig ganz rathlos und verzagt werden, und dann ganz unthätig sind, oder die verkehrtesten und unzweckmäßigsten Maßregeln ergreifen. « ${ }^{224}$ Wenngleich sich 23 Männer fanden, darunter auch der Gürtler und Gießer Johann Rosenbauer, ein eigenes »Reglement « geschaffen wurde und der Bürgermeister als »Löschdirektor« fungierte, blieb diese erste Linzer Feuerwehr ohne größere Folgewirkung. Das Löschen von Bränden war wie in der Frühen Neuzeit (dies wurde in der Feuerlöschordnung des Jahres I 85 I mit Strafandrohung erneut festgeschrieben) Aufgabe der Bewohner/innen und der Handwerker, wenngleich nun mit Beteiligung der Feuerwehrleute und unter Anleitung der im Vormärz etablierten städtischen »Feuer-Commissäre ${ }^{225}$ Die städtischen Ausgaben für das Feuerlöschwesen deuten in diesem Bereich aber auf begrenzte Ambitionen hin: Wenngleich man I 855 eine moderne Feuerspritze für 2.000 fl kaufte, ${ }^{226}$ wurden

220 Briese, Sicherheit, I I, 84f. u. 254f.; Schamberger/Leupold, Brandschutzgeschichte, 77-79.

22 I Briese, Sicherheit, I 23- I32; Schamberger/Leupold, Brandschutzgeschichte, 73-76.

222 AStL, HS i 28 (Stadtratsprotokoll i 847), fol. 9oa-9ra u. I53a.

223 Wiener Zeitung, 24.I 2.I 850 ; in den Gemeinderatsprotokollen aus diesem Jahr fand sich diesbezüglich kein Beschluss.

224 AStL, Altakten, Sch. I 88; OÖLA, Musealarchiv, HS 5 I (Materialien zur Geschichte der Stadt Linz von Ignaz Fink, undat.), pag. 575-577.

225 Ebd.; vgl. Carrington/Reiter, Linz, gf. u. Mittmannsgruber, Stadtverwaltung, 249.

226 GRP I 855, fol. 202b u. 203 a. 
I 860 nur 27 I fl 52 kr (ÖW) ausgegeben - für die Gasbeleuchtung hatte man im gleichen Jahr hingegen das mehr als Vierzigfache bezahlt. ${ }^{227}$

Mit dem Ende des Neoabsolutismus und der neuen Gemeindeautonomie scheinen sich die Diskussionen über Feuerwehren im österreichischen Raum in der ersten Hälfte der I 86oer Jahre erneut intensiviert zu haben: Bis zur Mitte des Jahrzehnts wurden in zahlreichen Mittel- und Kleinstädten Feuerwehren gegründet, z.B. I 862 in Krems, I 863 in Wels und I 865 in Salzburg. ${ }^{228}$ Auf dem Turnertreffen des Jahres I 864, das in Linz stattfand, wurden Statuten für eine "Turnerfeuerwehr» entworfen ${ }^{229}$ und ab dem Sommer des Jahres I 865 erschien die "Oesterreichische Feuerwehr-Zeitung", die aus dem Umfeld eines Wiener Versicherungsunternehmens stammte. Gleich in der ersten Ausgabe der Zeitung wurden im Leitartikel Feuerwehren als notwendiger Bestandteil einer autonomen (und modernen) Gemeinde präsentiert - sie seien »der Hort und Schirm, unter dem das Eigenthum sicher geborgen ruht «. ${ }^{230}$ Bildreich schilderte die »Feuerwehr-Zeitung" den Brand in Bad Ischl im Juli I 865, bei dem eine Abordnung Gmundner Turner »kaltblütig in Mitte der gräßlichen Verwirrung, nur den Anordnungen ihres Anführers folgend, das Feuer regelrecht bekämpften und das Weitergreifen desselben verhinderten «. ${ }^{231}$ Im Herbst folgte eine »Anleitung zur Gründung freiwilliger Feuerwehren«, die wesentlich auf die Kremser Turner-Feuerwehr Bezug nahm. ${ }^{232} \mathrm{Zu}$ dieser Zeit diskutierte man auch im Linzer Gemeinderat die Schaffung einer städtischen Feuerwehr, was diesmal deutlich durch Mitglieder des - I862 gegründeten - Turnvereins lanciert wurde. ${ }^{233}$ Im Sommer I 866 erfolgte die Gründung einer freiwilligen Feuerwehr in Linz, die anfangs etwas über 6o Mitglieder aufwies. ${ }^{234}$ Bislang, so die »Linzer Zeitung« im Juli I 866 (und damit gab man den oben erwähnten Leitartikel der ersten Ausgabe der „Oesterreichischen Feuerwehr-Zeitung « in weiten Teilen wortgleich wieder), sei das Feuerwehrwesen von »allen Gemeinde-Angelegenheiten [...] auf das stiefmütterlichste behandelt« worden, man habe sich auf den Ankauf von Löschgerät und die Aufstellung der »Feuer-Commissäre« beschränkt. Eine »wohlorganisirte Feuerwehr«, die mit »geübten Hände[n]« und einer erfahrenen »Lei-

227 AStL, HS 2 I 2 (Kammeramt Ausgaben r 860), pag. 70 u. I38.

228 Winkler, Stadtbrände, 92 f.; Carrington/Reiter, Linz, Io; Marx, Flammen, 37 I ; LTP, 3.3. I 865; Oesterreichische Feuerwehr-Zeitung, I 5.I I.I865, unpag.

229 AStL, Altakten, Sch. I 88; Polesny, Turnen, I 37; Schneider, Entwicklung, 37f.; vgl. zu den Turnerfeuerwehren im deutschsprachigen Raum: ebd., I6- i 9 u. 40-45.

230 Oesterreichische Feuerwehr-Zeitung, I 5.8.1 865, unpag.

23 I Ebd.; vgl. Schneider, Entwicklung, 62.

232 Oesterreichische Feuerwehr-Zeitung, I.9. I 865, unpag.

233 Polesny, Turnen, I26f. u. I32; LAB, I 5.r.I864; ebd., 8.7.I865; ebd., 24.I.r 866; ebd., I 8.3.I862; Oesterreichische Feuerwehr-Zeitung, I.2.I 866, unpag.; GRP i 866, fol. 32b-34a; Rumpler/Urbanitsch, Habsburgermonarchie, Bd. 8, 24 If.; vgl. zu den Diskursen der I 85 oer und I 86oer Jahre: Schamberger/ Leupold, Brandschutzgeschichte, $80-83$.

234 AStL, Materienbestand, Sch. 646 u. Sch. 647; vgl. Carrington/Reiter, Linz, I I u. I 3; LZ, I 7.7. I 866. 
tung" effektiv löschen könne, habe gefehlt. ${ }^{235}$ Wenig später stellte die gleiche Zeitung einer - wohl demonstrativen - Übung der neuen Feuerwehr aber kein gutes Zeugnis aus; deutlich sei die mangelnde Übung der Mannschaft zutage getreten. ${ }^{236}$ Die Feuerwehrgründung war ein deutlicher Ausdruck der neuen bürgerlichen Autonomie, sie wurde auch bewusst als »Gemeinde-Anstalt « tituliert: »Mich treibt der echte Bürgersinn«, betonte ein »Lied der Linzer Feuerwehr «. ${ }^{237}$ Nachdem die Feuerspritzen in der Stadt durch die neue Feuerwehr »als ungenügend « bewertet worden waren, ${ }^{238}$ erfolgte deren Ersatz - kofinanziert durch die "Allgemeine Sparkasse - durch modernes Gerät aus der Produktion von Carl Metz, was sich vermutlich auf die regen überregionalen Kontakte des Gürtlers (und Turners) Johann Rosenbauer zurückführen lässt, der bald ein eigenes Geschäft für Feuerwehrausrüstungsgegenstände eröffnete und später auch als Feuerwehrkommandant fungierte. ${ }^{239}$ Die Kontakte und das Engagement Rosenbauers manifestierten sich auch in der Abhaltung des "deutschen Feuerwehrtages" in Linz I 870, der damals zum ersten Mal in Österreich stattfand. ${ }^{240}$

Mitgliederzahl und Ausrüstung der Linzer Feuerwehr expandierten bis zum Beginn der I 87oer Jahre deutlich: Insgesamt rund 300 Mann verfügten über I Mannschafts- und 4 Wasserwagen, 3 Schiebeleitern und 38 weitere Leitern, 6 Saugspritzen, I Druckspritze und I kleine Spritze sowie über mehr als r.ooo Meter Schläuche. ${ }^{241}$ Mit diesen Investitionen stiegen die Ausgaben der Stadt Linz für die »Feuerlöschanstalten « ebenso signifikant an: Sie betrugen im Jahr I870 I.522 fl $23 \mathrm{kr}^{242}$ und I 880 bereits $3.523 \mathrm{fl} 87 \mathrm{kr}^{243}$ Auch in den letzten zwei Jahrzehnten des I 9. Jahrhunderts wuchs die Linzer Feuerwehr: I88 I wurde ein eigener Feuerlöschzug am Schullerberg eingerichtet, ${ }^{244}$ I 889 sponserte die »Allgemeine Sparkasse« eine Dampfspritze im Wert von 6.000 fl, ${ }^{245}$ I 890 besaß die Feuerwehr 2.400 Meter Schläuche, ${ }^{246}$ dazu hatte der Feuerwächter am Stadtpfarrturm eine elektrische Klingelanlage, mit der Feuer-

\footnotetext{
235 LZ, I5.7.I866; Oesterreichische Feuerwehr-Zeitung, I 5.8.1 865, unpag.

$236 \mathrm{LZ}, 29 \cdot 9 \cdot 1866$.

237 AStL, Materienbestand, Sch. 647; LZ, 6.I.I 867.

238 LZ, I 4.I I.I 866.

239 GRP г 866, fol. го3a, г04a, г29a u. I29b; LZ, 20.3.1867; AStL, Materienbestand, Sch. 647; vgl. zum Heidelberger Carl Metz: Schamberger/Leupold, Brandschutzgeschichte, $67 \mathrm{f}$.

240 Oesterreichische Feuerwehr-Zeitung, 22.I.I87I ; Schneider, Entwicklung, 87f.; vgl. Schamberger/ Leupold, Brandschutzgeschichte, $80-83$.

24I Feuerwehr-Kalender, 3 I u. 64 f.

242 AStL, HS 237 (Kammeramt Ausgaben i 870), pag. I7 r.

243 Wobei aber rund ein Drittel dieser Summe für die Entlohnung der Feuerwächter auf den Türmen aufgewendet wurde - RB I879-1880, ro9.

244 RB I 896, 273; dieser Zug wurde, wie der 1875 in St. Margarethen etablierte, I 899 in die Linzer Feuerwehr eingegliedert (Carrington/Reiter, Linz, 35 u. 37).

245 RB I889, I03; vgl. zu den Dampfspritzen des ausgehenden I9. Jahrhunderts: Schamberger/Leupold, Brandschutzgeschichte, $88 f$.

246 RB I $890,80$.
} 
alarm gegeben werden konnte, und ab 1898 bestand sogar eine ständige Bereitschaft von 8 Mann in der Feuerwehrzentrale in der Lederergasse. ${ }^{247}$ Ein zentrales Element der Feuerbekämpfung, das Wasser, wurde aber nur langsam in adäquater Menge verfügbar: zunächst für Teile der Stadt durch die Teilwasserleitungen der I $870 e r$ und I 88 oer Jahre, flächendeckend - und mit höherem Wasserdruck - erst durch die »Allgemeine Wasserleitung « ab den I $890 e r$ Jahren, die I 895 bereits 237 Hydranten aufwies (vgl. Kap. 3. Wasser). ${ }^{248}$

Betrachtet man die Linzer Feuerordnung, die I90 i in Kraft trat, so wird deutlich, dass neben der Innovation Feuerwehr zahlreiche vormoderne Praktiken der Brandprävention und bekämpfung fortdauerten: Es finden sich die Aufforderung zu allgemeiner »strengste[r] Wachsamkeit«, Feuerwachen auf den städtischen Türmen, ${ }^{249}$ für die Haushalte die Verpflichtung zum Kehren der Rauchfänge, zur Feuerbeschau und falls kein Hydrant beim Haus vorhanden war - zum Bereithalten von Löschgerät und Wasser. Noch immer war eine prinzipielle Hilfeleistung durch die Bewohner/innen auf Verlangen verpflichtend, auch die Brunnen mussten einer Nutzung offenstehen. Neben den für die moderne Infrastruktur Zuständigen (Wasser, Gas- und Elektrowerksarbeiter) mussten im Brandfall weiterhin die Rauchfangkehrer erscheinen, ebenso wie die Fasszieher und Fiaker, die die Pferdebespannung für die Dampfspritze stellten resp. Fuhrdienste leisteten. ${ }^{250}$

Nach dem Großbrand des Sommers I 800 trat in Linz im I9. Jahrhundert kein vergleichbares Brandereignis ein, ${ }^{251}$ obwohl Bevölkerung und gewerblich-industrielle Aktivitäten deutlich zugenommen hatten. ${ }^{252}$ Diese Absenz von Großbränden der "trefflich organisierten und opferwilligen freiwilligen Feuerwehr« zuzuschreiben, ${ }^{253}$ würde zu kurz greifen, sie ist eher als ein komplexeres Zusammenwirken von sozionaturalen Konstellationen zu sehen, an der der Zufall wohl auch einen erheblichen Anteil hatte. ${ }^{254}$ Ebenso sollte nicht übersehen werden, dass einzelne "vormoderne« Brandrisiken (z.B. Wassermangel oder Schindeldächer) bis ins 20. Jahrhundert fortbestanden.

247 Ebd., 81; Carrington/Reiter, Linz, 27.

248 RB I879-1880, 80 u. RB I 895, 203.

249 Ab I 895 gab es sogar eine Feuerwache auf der Franz-Josefs-Warte am Freinberg - Carrington/Reiter, Linz, I4f.

250 AStL, Altakten, Sch. I90; vgl. RB I 900, 92-95; die Linzer Feuerwehr wurde erst 1933 zu einer Berufsfeuerwehr (Carrington/Reiter, Linz, I63).

25 I Pillwein, Wegweiser, 38 ; RB I879- I880, 45.

252 Vgl. zum Brandrisiko: Zwierlein, Prometheus, I I 2 - I 18.

$253 \mathrm{RB}$ I $876-\mathrm{I} 878,38$.

254 Vgl. zum Brand von 1842 in Hamburg, das über eine relativ umfangreiche und gut ausgestattete Feuerwehr verfügte: Bankoff/Lübken/Sand, Cities, 2 I 4-228. 


\section{Logiken und Akteure des Existenten und des Wandels}

Im frühen I 8. Jahrhundert - dem Ausgangspunkt dieser Studie - zeigten sich die Mensch-Umwelt-Interaktionen in der Mittelstadt Linz wesentlich durch dezentrale und individuelle Praktiken bestimmt, die in einem engen Konnex mit naturräumlichen Konstellationen standen. Es gab z.B. bei gewerblichem Abwasser oder bei feuergefährlichen Tätigkeiten räumliche Lösungen, die Belastungen oder Gefährdungen verhindern oder reduzieren sollten. Ohnehin verlangte die Topographie der Stadt eine Anpassung der Bewohner/innen: Hügellagen tendierten zu Wasserarmut und in den flachen Teilen von Linz bildete das geringe Gefälle ein Hindernis für die Entwässerung. Andere Bereiche des städtischen Metabolismus waren ebenso naturräumlich geprägt: Bereits im I8. Jahrhundert kam das Linzer Brennholz kaum noch aus dem Gebiet der Stadt oder aus dem unmittelbaren Umland, es wurde aus dem Hinterland bezogen. Dafür war die Lage am Fluss günstig, obgleich flussabwärts (mit Wien) ein Großabnehmer für Konkurrenz sorgte. Wasserkraft und tierische Antriebskraft wurden in der Stadt und im stadtnahen Bereich verwendet, wobei die Wasserkraftnutzung vor allem an der Traun und kaum an der Donau anzutreffen war, was als Anpassung an die fluviale Dynamik der beiden Flüsse und an die topographischen Gegebenheiten zu werten ist. In den Vorstädten gab es auf den fruchtbaren Schwemmböden eine intensive landwirtschaftliche und gartenbauliche Nutzung, sogar von kleinsten Flächen. Die Nutzgärten an der urbanen Peripherie waren wichtig für die Versorgung der Stadt, sie bildeten zudem Subsistenz und Zuverdienst für Angehörige der Unterschichten.

Ausschlaggebend für die Entstehung einer Ansiedlung im Linzer Raum war vermutlich die Lage an der Donau - sie prägte auch danach wesentlich das städtische Leben. Man kann durchaus von einer Koexistenz und symbiotischen Beziehung mit der Donau sprechen: Der Fluss war für die Versorgung entscheidend, an den Fluss, dessen Naturraum und fluviale Dynamik passten sich die Stadtbewohner/innen an. Potentielle Überflutungsräume wurden als Dauersiedlungsfläche gemieden und extensiv bewirtschaftet, wobei man die Auen vielfältig, aber ebenso angepasst nutzte. Der bis in die I 860er Jahre bestehende hölzerne Donauübergang ist ebenso als angepasste Lösung zu betrachten, die über Jahrhunderte hinweg gut funktionierte. Zwar wurde die Holzbrücke regelmäßig durch Hochwasser und Eisstöße beschädigt oder zerstört, Reparaturen waren aber relativ schnell und einfach umzusetzen. Derart gewachsene, angepasste und multifunktionale Praktiken lassen sich auch in anderen Bereichen städtischer Umwelt erkennen, z.B. bei Wasserinfrastruktur, Sauberkeit oder individueller Versorgung. Grundlegend war hier eine private Zuständigkeit und Verantwortung der Stadtbewohner/innen, die Stadtverwaltung selbst verhielt sich zumeist reaktiv. Bis ins 19. Jahrhundert hinein wurden bestehende Lösungen eher erweitert und nur selten komplett verändert oder ersetzt. 
Vieles scheint einer ökonomischen Logik geschuldet gewesen zu sein: Brunnen benötigten außer menschlicher Arbeitskraft keinen weiteren Energieinput, verglichen mit Wasserleitungen waren sie billiger zu errichten und instand zu halten. Bei der Abwasser- und Fäkalentsorgung bildeten die omnipräsenten Sicker- und Senkgruben ebenso günstige wie technisch einfache Lösungen, die nicht zwingend - wenn sie dicht waren und durch Dienstleister regelmäßig entleert wurden - in Hygieneproblemen resultieren mussten. Abwasserkanäle waren hingegen teuer und nicht unbedingt zweckmäßig, da kaum ein konstanter Wasserfluss zum Durchspülen vorhanden war. Und deutlich wirkte bei derartiger Infrastruktur der finanzielle Aufwand begrenzend. Sparsamkeit bildete einen Grundzug des vormodernen Lebens, und auch die städtische Verwaltung versuchte Kosten zu reduzieren und finanzielle Risiken auszulagern; so waren z.B. die Donaubrücke oder die Straßenbeleuchtung zeitweilig einem Pächter übergeben. Ebenso zeigt der Bereich der Material- und Dingnutzung das Wirtschaften im Kontext einer sparsamen economy of makeshifts: Aufgrund relativ hoher Materialpreise waren Praktiken des Weiternutzens, Reparierens und Wiederverwendens Teil der Alltagsroutine und ökonomie.

Zahlreiche Umweltelemente und Umweltprobleme wurden differenziert wahrgenommen: In Bezug auf Wasser unterschied man deutlich zwischen Trink- und Brauchwasser und man reflektierte teilweise über gesunde oder ungesunde Eigenschaften des Wassers. Es ist kein prinzipielles Negieren von Unsauberkeit zu konstatieren; besonders bei Gestank sorgte die Angst vor krankmachenden Miasmen für ein Suchen nach Lösungen. Die größtenteils private Zuständigkeit konnte in der Praxis jedoch Probleme verursachen, das Engagement der Stadtverwaltung und politik blieb aber begrenzt und anlassbezogen.

Naturinduzierte Krisen stellten in der Regel nur kurzfristige Beeinflussungen des städtischen Alltags dar. Obgleich die Impacts sehr verschieden waren, lassen sich dennoch Ähnlichkeiten im Hinblick auf Wahrnehmungen und den Umgang mit diesen Ereignissen feststellen. Bei der im frühen i 8. Jahrhundert zuletzt aufgetretenen Pest basierten die Gegenmaßnahmen bereits auf relativ großem Erfahrungswissen und staatlichem Druck, was ein erfolgreiches Eindämmen der Krankheit ermöglichte. Die meisten Maßnahmen waren jedoch reaktiv und blieben es in der Folgezeit auch, wenngleich sich die Vulnerabilität im Hinblick auf Epidemien durch den Ausbau der medizinischen Infrastruktur reduzierte. Versorgungskrisen traten bis in die erste Hälfte des I9. Jahrhunderts regelmäßig auf - diesen Impacts begegnete man ähnlich: Die Stadtverwaltung wurde kaum aktiv, nur die territoriale Herrschaft traf einzelne Gegenmaßnahmen. Meist wurden Getreideimporte organisiert, die preisdämpfend wirken sollten. Es kam aber zu keinen Prophylaxemaßnahmen, da eine umfangreichere Lagerhaltung von Getreide komplex und teuer war und die Nahrungsmittelversorgung in Normaljahren problemlos funktionierte. Die ebenso regelmäßig auftretenden Überschwemmungen führten zu einem Leben mit diesem Impact und zu einer Anpassung daran, was gleichzeitig die Vulnerabilität reduzierte. Fluviale Ext- 
remereignisse waren eher selten: Sie verursachten zwar erhebliche Schäden, forderten aber kaum Todesopfer, da die Vorwarnzeit meist ausreichend für Evakuierungen war. Der Umgang mit und die Bewältigung von derartigen Krisen lag prinzipiell in der Eigenverantwortung der Stadtbewohner/innen - Betroffene konnten jedoch mit gesellschaftlicher Solidarität rechnen, die finanzielle und materielle Hilfe umfasste. Das Risiko des Feuers war nicht vorhersehbar - dennoch gab es ebenso Anpassungstendenzen: Auf städtischer Ebene versuchte man das Brandrisiko durch Regelwerke (Feuerordnungen, Bauvorschriften) und räumliche Lösungen zu reduzieren. Die regelmäßige Inanspruchnahme von Rauchfangkehrern und eine ständige Feuerwache auf Türmen zielten ebenso auf eine Verringerung der Brandgefahr ab, zudem sind individuelle Prophylaxemaßnahmen belegbar. Für das Bekämpfen des Feuers waren einzelne Handwerker und die Anwohner selbst zuständig, wobei man statt auf das Löschen meist nur auf das Eindämmen des Brandes abzielte. Ein Brand blieb bei einer entsprechenden Konstellation ein nicht zu beherrschendes sozionaturales Ereignis: Aus einem kleinen Brand konnte bei Trockenheit und Wind rasch ein Großfeuer entstehen, wie das Beispiel des Jahres I80o zeigt. Analog zu anderen Extremereignissen war auch bei Bränden mit umfangreicher und teilweise überregionaler gesellschaftlicher Solidarität zu rechnen.

Bis ins ausgehende I 9. Jahrhundert veränderten sich diese Praktiken und Lösungen erheblich. Dabei lassen sich für Linz zwei Phasen verstärkten Wandels feststellen: erstens eine Phase, die von den letzten Jahrzehnten des I 8. Jahrhunderts bis in die I84oer Jahre andauerte und durch die politischen und ökonomischen Krisen der Franzosenkriege unterbrochen wurde; zweitens die (auch in der allgemeinen Forschung stärker rezipierten) Veränderungen des letzten Drittels des I 9. Jahrhunderts. Ein wichtiger Impetus für Transformation war der kulturelle Wandel: Bedürfnisse, Wahrnehmungen, Wissensbestände und Technologien erlebten eine signifikante Transformation. Die Toleranz gegenüber Unsauberkeit, besonders gegenüber schlechten Gerüchen, reduzierte sich, dazu kamen - ab den I 77oer Jahren und dann vor allem ab den r $820 e r$ Jahren - Bestrebungen, die visuelle Qualität der Stadt zu verbessern, was auch die Frage der öffentlichen Sauberkeit tangierte. Diese Bereiche wurden ein häufiges mediales Thema und ab den I 84 oer Jahren gingen auch von der Stadtverwaltung vermehrt Impulse aus, die auf die Herstellung und Aufrechterhaltung von Sauberkeit abzielten. Neue Vorstellungen von Hygiene begannen zudem Praktiken des Weiternutzens und Wiederverwertens zu verändern. Erste öffentlich nutzbare Grünräume entstanden in Linz ab den letzten Jahrzehnten des i 8. Jahrhunderts: Wie in zahlreichen anderen Städten wurden Teile der Festungsanlagen begrünt, was wesentlich von Angehörigen der Oberschichten ausging, die an der Schaffung und Umgestaltung neuer, repräsentativer und semiöffentlicher (Freizeit)Räume interessiert waren. Mit dem Aufstieg des Bürgertums intensivierte sich im I9. Jahrhundert das Bedürfnis nach öffentlich zugänglichen Grünräumen, gleichzeitig gewann die Nutzung des Umlandes als grünes Nahausflugsziel an Bedeutung. 
Die im s 8. Jahrhundert von den Eliten begonnenen Diskussionen um die Qualität von Wasser setzten sich im I9. Jahrhundert fort und intensivierten sich im Kontext der Cholera ab den i $840 e r$ Jahren. Zwar waren die tatsächlichen Übertragungswege dieser Infektionskrankheit unklar; man vermutete aber zunehmend einen Zusammenhang zwischen der Cholera, kontaminiertem Boden und verunreinigtem Trinkwasser. Diese Wahrnehmungen gingen der Umsetzung neuer infrastruktureller Lösungen, die ab dem Ende der I 86oer Jahre beschlossen wurden, somit deutlich voran. Wenngleich die Diskussion, in Linz eine zentrale Kanalisierung zu errichten, letztendlich von außen angestoßen wurde, bestand vor Ort schon eine latente Bereitschaft zur Veränderung. Dies ist auch in einen breiteren Kontext zu stellen: Andere österreichische Städte errichteten zu dieser Zeit bereits eine moderne Wasserinfrastruktur. Das medizinische Wissen und die medizinische Infrastruktur weiteten sich sukzessive aus: In Linz wurde diese Entwicklung einerseits von der territorialen Herrschaft, andererseits von Ordensspitälern getragen, die ab der Mitte des I 8. Jahrhunderts entstanden; dazu kamen aus der »Ferne« Impulse des aufgeklärten Staates und der regelmäßig auftretenden Choleraepidemien. Die Stadt trat im medizinischen Bereich spät als eigenständiger Akteur auf: Dies fiel erst in die zweite Hälfte des I 9. Jahrhunderts und damit in den Kontext der kommunalen Leistungsentfaltung. Für den Bereich des technischen Wissens war die Expansion des Ingenieurswesens zentral; es bildete die Basis für die Neuerrichtung von Infrastruktur und den Donau-Umbau ab der Mitte des i 9. Jahrhunderts. Dazu kam neues technisches Gerät: Feuerspritzen bildeten z.B. eine Innovation der Brandbekämpfung im I 8. Jahrhundert, und sie brachten auch Diskussionen um die Notwendigkeit einer professionellen Bedienung mit sich.

Naturwahrnehmungen wurden im Verlauf des i 8. Jahrhunderts zunehmend durch empirische Beobachtungen geprägt, was sich in einer stärkeren Präsenz von Messgeräten manifestierte. Generell verloren religiöse und metaphysische Deutungen an Relevanz, während eine systematisch-wissenschaftliche Auseinandersetzung mit der Natur - mit dem Bürgertum als neuem Träger - im Verlauf des I 9. Jahrhunderts zum Mainstream wurde. Es intensivierten sich die Orientierung an und der Vergleich mit anderen Städten: Dies lässt sich schon im I8. Jahrhundert bei der Frage der Straßenbeleuchtung beobachten, deutlich verstärkte sich diese Entwicklung im Verlauf des r 9. Jahrhunderts. Wiederholt wurden Zwänge des Schritthaltens und eine Sorge, den Anschluss an Entwicklungen zu verpassen, artikuliert; in diesem Kontext von einer Positionierung im Städtewettbewerb zu sprechen, ist vermutlich nicht übertrieben. Eine stärkere überregionale Vergleichbarkeit ergab sich über die Expansion der Druckpublizistik und über die zunehmende Verfügbarkeit statistischer Kennzahlen. Deutlich zeichnet sich für Linz das Vorbild Wien ab (z.B. in Bezug auf die Wasserversorgung), aber auch kleinere Städte fungierten mitunter als Referenzpunkte (vgl. die Feuerwehrdiskussionen und gründungen).

Signifikanter Wandel ergab sich in institutioneller Hinsicht: Zunächst war der Staat (resp. die territoriale Herrschaft) ein zentraler Akteur aus der »Ferne«, was beim Do- 
nau-Umbau, der selbst außerösterreichische Vorbilder hatte, deutlich zutage trat. Bis ins I 9. Jahrhundert erfolgten - abgesehen von kleineren Maßnahmen zur Ufersicherung - kaum Wasserbauten durch Private oder durch die Stadt. Der Staat bildete auch in anderen Umweltbereichen einen wichtigen Zwischenakteur: Über Bauordnungen und andere Normen wurde die Modernisierung von Infrastrukturen gefordert (und damit gefördert); die Pflasterungen und Kanäle des Vormärz wurden durch den Staat kofinanziert. Auch im Bereich der Naturrisiken wurden die normativen Auflagen des Staates ab dem beginnenden I 9. Jahrhundert zahlreicher. Parallel dazu begann die Stadt, in einzelnen Bereichen als Akteur des Wandels aufzutreten: Ein Beispiel dafür ist die (die bescheidene private Außenbeleuchtung ergänzende) Straßenbeleuchtung, die im I 8. Jahrhundert über Verpachtungen betrieben, schließlich zum Ende des Jahrhunderts von der Stadt selbst übernommen und durch eine Gebühr für Hausbesitzer finanziert wurde. Schon in den I82oer Jahren wurde die städtische Beleuchtung bereits als unverzichtbarer Teil einer sicheren, modernen Stadt wahrgenommen. Später setzte diese Entwicklung bei der Brandbekämpfung, der Sauberkeit oder der Wasserinfrastruktur ein. Flankiert wurde diese städtische Leistungsentfaltung durch den Aufstieg des Bürgertums und die Artikulation bürgerlicher Bedürfnisse. Im Verlauf des I 9. Jahrhunderts reduzierte sich die private Verantwortung sukzessive und wurde durch städtische, über Gebühren finanzierte Lösungen ersetzt. Auch bei Naturrisiken erfolgte ein Übergang vom individuellen Risiko zu kollektiven und städtisch-öffentlichen Antworten: In Versorgungskrisen trat organisierte, bürgerliche Hilfe ab dem beginnenden I 9. Jahrhundert stärker in Erscheinung, bei Überschwemmungen und Feuer war dies deutlich später der Fall - hier war zunächst noch der Staat (über Normen) ein wichtiger Akteur. Die Entfaltung der bürgerlichen Selbstverwaltung der Städte ab den I 86oer Jahren ermöglichte und initiierte die größeren Infrastrukturprojekte; in anderen Bereichen trat die Stadt als Akteur nur zögerlich auf: In Linz erwarb die Stadt zur Mitte des I 9. Jahrhunderts eine bestehende (kommerziell genutzte) Parkanlage, bis zur Jahrhundertwende entstanden aber kaum weitere stadteigene Grünräume. Dafür wurden ab den I86oer Jahren über eine Kooperation zwischen Stadtverwaltung und Bildungsbürgertum Grünräume an der Peripherie und im unmittelbaren Umland zur Freizeitgestaltung umgestaltet.

Die Industrialisierung brachte einen materiellen und energetischen Wandel mit sich, der auch die städtische Umwelt erheblich tangierte. Der Werkstoff Eisen ermöglichte neue Infrastruktur (z.B. Wasserleitungen und Brücken), die Nutzung fossiler Energie modifizierte Versorgung und Hinterlandbeziehungen der Stadt. Dazu veränderten sich die finanziellen Rahmenbedingungen - zum einen für die Stadtbewohner/innen, zum anderen für die Stadt selbst: Die tiefgreifenden infrastrukturellen Modifizierungen benötigten nicht nur sozialen und politischen Konsens, sondern auch steigende Steuereinnahmen und potente Kreditgeber, die im Linzer Raum erst ab der Mitte des I9. Jahrhunderts auftraten.

Die meisten Transformationen erweisen sich in der Rückschau als mehrdimensional - sie ergaben sich aus einer Konstellation von verschiedenen Faktoren, die sich 
teilweise überschnitten und zusammenwirkten. Ein Beispiel dafür ist die Linzer Wasserinfrastruktur: Frühe, begrenzte Veränderungen ergaben sich aus einem Mangel an Löschwasser und dem Bedürfnis nach repräsentativen Brunnen. Über eine Modernisierung der Wasserversorgung und Abwasserentsorgung begannen die politischen Eliten in Linz in der zweiten Hälfte des I9. Jahrhunderts zu diskutieren, was im Kontext von Hygienisierung, Assanierung und Gemeindeautonomie zu sehen ist. Zunächst sollten (analog zu anderen Städten) kommerzielle Unternehmen eine neue Wasserleitung errichten, was aber mehrfach scheiterte. Schließlich entschloss sich die Stadtpolitik dazu, das Projekt selbst über langfristige Kredite, Gebühren und Steuern zu finanzieren. Dagegen protestierten einzelne bürgerliche Akteure, die die finanzielle Belastung ablehnten und die »Wasserfrage« als nicht drängend erachteten. Dies führte $\mathrm{zu}$ erheblichen Verzögerungen, und erst in den I88oer Jahren wurde das Wasserleitungsprojekt konsensfähig, was wohl auch mit der Umsetzung vergleichbarer Infrastrukturbauten in anderen Städten zu dieser Zeit zusammenhing. Anders als bei der Wasserversorgung war die Modernisierung der Kanalisierung, die von Anfang an als städtisch finanzierte Lösung konzipiert wurde, unumstritten. Sie wurde in der öffentlichen Diskussion als gesundheitsfördernde Investition gesehen. Ermöglicht wurden beide Projekte auch durch neue Materialien und neues technisches Wissen.

Diese Konstellationen und Entwicklungen führten zu vielfältigen, intendierten und unintendierten Modifikationen städtischer Umwelt. Eine Lösung (wie Auswirkung) war die Externalisierung von problematischem Output: Durch die expandierende Nutzung von fossiler Energie stieg die Belastung durch Emissionen an, die moderne Schwemmkanalisation mündete in die Donau und auch für andere Abfälle diente der Fluss als Entsorger, was eine pragmatische und kaum hinterfragte Lösung bildete. Es kam zu einem veränderten Zugriff auf das Linzer Hinterland: Die Nachfrage nach Brennholz reduzierte sich, die Versorgung mit Ressourcen und Lebensmitteln wurde zunehmend überregional, zudem weitete sich die Nutzung des Hinterlandes als Freizeit- und Erholungsraum aus. Die Produktivitätssteigerungen der regionalen Landwirtschaft und eine bessere Integration in die überregionale Versorgung ließen Versorgungs- und Teuerungskrisen ab dem beginnenden I9. Jahrhundert verschwinden, wenngleich dieser Prozess in sozialer Hinsicht ungleichmäßig verlief. Die bessere Marktintegration ermöglichte zudem die Überbauung von landwirtschaftlich genutzten Gründen in den Vorstädten und Vororten. Die Expansion von medizinischer Infrastruktur und medizinischem Wissen erhöhte die Resilienz der Stadt im Hinblick auf Epidemien, wobei sich diesbezüglich die Grenzen bei der Cholera deutlich zeigten: Zunächst reagierte man analog zur Pest, was - obgleich die Cholera in Linz nur im Jahr I 855 schwerer auftrat - weitgehend scheiterte. Die Cholera fungierte jedoch deutlich als Movens für die Hygienediskussion und den Ausbau der medizinischen Infrastruktur, sie überdeckte aber die Problematik anderer, endemisch auftretender Infektionskrankheiten. Neues Wissen war mitunter nicht vollständig, was unintendierte Konsequenzen verursachen konnte: Durch den Donau-Umbau beschleunigte sich die 
Fließgeschwindigkeit, auch verschwanden Überflutungsräume. Diese Modifikationen des Flusses resultierten in einem veränderten Impact von extremen Hochwasserereignissen, die zudem partiell unerwartet auftraten; der Glaube an eine erfolgreiche Regulierung wurde dadurch aber nicht erschüttert. Auch die neue Donaubrücke veränderte die Strömungsverhältnisse, wodurch es zu Verlandungen im Donauarm und dadurch zu Problemen der Abwasserentsorgung kam. Die Antwort auf diese Probleme war ingenieurstechnischer Natur: Es wurden neue Dämme errichtet und bestehende erhöht, man schüttete den Donauarm großflächig zu und verlegte den Abwasserkanal.

Den Transformationen standen Kontinuitäten in einer Vielzahl von Bereichen gegenüber: Partiell dauerten vormoderne Praktiken lange fort und auch neue Infrastrukturen wiesen Pfadabhängigkeiten auf. Brunnen und Senkgruben blieben in peripheren Bereichen über das I 9. Jahrhundert hinaus in Verwendung; sie wurden nur bei offensichtlichen Problemen infrage gestellt. Persistent war die Vorstellung des krankmachenden Gestanks, was weiterhin zu out-of-sight-out-of-mind-Lösungen führte (z.B. bei Abwasser oder Abfall). Im energetischen Bereich ergab sich eine mittelfristige $\mathrm{Pa}-$ rallelität: Als kalorischer Energieträger verlor das Brennholz nur langsam an Bedeutung, vor allem in den Privathaushalten erfolgte der Übergang zur fossilen Energie deutlich später. Auch die Wasserkraft- und Pferdenutzung verschwand nicht: Es handelte sich um angepasste Lösungen, die im Verlauf des I9. Jahrhunderts teilweise sogar ausgebaut wurden und deutliche ökonomische Vorteile aufwiesen. Erhebliche Kontinuitäten gab es beim Recycling von Materialien und beim Weiternutzen von Objekten, ebenso behielten Pfandleihe und Reparieren ihre Relevanz. Der vormoderne Grundzug des Sparens, der auch den Umgang mit Objekten und Ressourcen prägte, wirkte bis ins 20. Jahrhundert fort - der Konsum von Gebrauchtem verschwand aber zunehmend aus der Alltagsökonomie. Deutlich zeichnen sich trotz der zahlreichen Veränderungen das Fortdauern einer solidarischen Gesellschaft und die weitgehende Absenz staatlicher oder städtischer Hilfe bei Extremereignissen ab. Erst in den letzten Jahrzehnten des I9. Jahrhunderts entstand eine städtische Feuerwehr, die ein bürgerliches Projekt darstellte. Daneben existierten aber immer noch vormoderne Elemente: private Löschpflichten, die Feuerwachen auf den Türmen, zudem vormoderne Brandrisiken und Brandbekämpfungsprobleme, besonders an der Peripherie der Stadt.

Es wurde versucht, die Alltäglichkeit städtischer Umwelt und deren Wandel anhand der Fokalpunkte Metabolismus, Urbanisierung von Natur und sozionaturale Krisen zu rekonstruieren, was es ermöglichte, parallele und reziproke, aber auch divergierende Entwicklungen zu identifizieren. Insgesamt zeichnet sich ab, dass es im Falle der Stadt Linz nicht gerechtfertigt erscheint, eine Dauerkrise städtischer Umwelt im Modernisierungsprozess anzunehmen. Es ergaben sich vielmehr neue Settings, neue Arrangements und Praktiken auf der einen Seite und Kontinuitäten auf der anderen Seite, wobei sich insgesamt keine linearen Wandlungsprozesse und kaum tiefere Brüche erkennen lassen. Die Wechselwirkungen zwischen den verschiedenen Akteursebenen, wie es Henri Lefebvre bezeichnet hat, sind als vielschichtig und mitunter situativ einzu- 
schätzen. Im Hinblick auf die Akteure erwiesen sich jedoch besonders Angehörige der Unterschichten (d.h. der Mehrheitsbevölkerung der Städte) als Blackbox - sie sollten, wenngleich die Quellenlage diesbezüglich nicht einfach ist, von der Forschung mehr Aufmerksamkeit erhalten. Gleiches gilt für die durch die städtische Umweltgeschichte bislang nur wenig genutzten Ego-Dokumente, die eine wichtige Zugangsmöglichkeit zu den vielschichtigen alltäglichen Praktiken und Wahrnehmungen abseits der Mainstreamüberlieferung ermöglichen. Als weitere Forschungsdesiderate können derzeit Kleinstädte gelten, zudem urban fringes, die sich im Zeitverlauf deutlich verschoben und veränderten, und auch die Frage nach Imitation und »Städtevergleich« im Kontext der städtischen Umwelt. Sinnvoll erscheint ebenso eine Ausweitung des Betrachtungszeitraumes: Das I 7. Jahrhundert ist für viele Bereiche städtischer Umwelt (vor allem in systemischer Hinsicht) wenig erforscht, auch wäre die Verbindung einer langfristigen Perspektive mit den Entwicklungslinien der jüngeren Vergangenheit wichtig. Zuletzt möchte ich der (städtischen) Umweltgeschichte eine stärkere wirtschafts- und sozialgeschichtliche Einbettung anraten, wobei die Stadtgeschichte von einer Berücksichtigung umwelthistorischer Ansätze (und Erkenntnisse) genauso profitieren würde. Der common ground ist jedenfalls breiter als wechselseitig angenommen. 


\section{Literatur- und Quellenverzeichnis}

\section{Archivalien und ungedruckte Quellen}

\section{Archiv der Stadt Linz (AStL)}

Altakten: Sch. I3 3 3 I 42, 44, 52, 79, 80, 83, I0 I, I02, I46, I65-I67, I 7 I - I 73, I 88- I 92,242

Alte Registratur: Sch. I 44 u. I75

Gemeinderatsprotokolle: Jahrgänge I 850, I 855, I 862, I866- I 870, I 872 - I 875

Handschriften: 63, 69, 70, 92, 93, I I I , I 2 I I, I 28 , I 29, I 33, I 5 I, I 5 2, I 7 I I I 72, I 9 I, I 92 2, 2 I 2 , 236 , 237, 389, 399, 409, 4 I 9, 434-436, 439, 462, 48 5, 50 I, 859, 86 I, I083, I084, I087, I IO I - I IO3, I I 08 , I I 09, I I 28 , I I 29

Materienbestand: Sch. I 82, I 92, 2 I3, 3 I0, 3 I I , 646, 647

\section{Dokumentation lebensgeschichtlicher Aufzeichnungen (Institut für Wirtschafts- und} Sozialgeschichte der Universität Wien)

Doku, Fossel = Annemarie Fossel, Mädchenjahre in Linz (I 855- I877) (Typoskript I 985)

Doku, Hartung = Gottfried Hartung, Tagebuchaufzeichnungen, I 879- I896 (Manuskript)

Doku, Hirnschrodt $=$ Karl Hirnschrodt, Erinnerungen aus meinem Leben (undatiertes Manuskript, um I 9 15)

Doku, Spaun = Joseph von Spaun, Etwas über unsere Voreltern und Verwandten/Einiges über mein Leben für meine Kinder, I864 (Typoskript r 98 I)

\section{Oberösterreichisches Landesarchiv (OÖLA)}

Archiv der Statthalterei, Präsidium: Sch. 369

Franziszeischer Kataster: No. 534 u. I090

Herrschaftsarchiv Weinberg: Sch. 643, 66 I, 829

Josephinisches Lagebuch: HS I $90-192$

Karten- und Plänesammlung: V/3, V/8, V/I I, V/43, VI/2, VI/I 8, VI/20, VI/23, VI/25, VI/26, $\mathrm{VI} /{ }_{2} 7, \mathrm{VI} / 28, \mathrm{VI} / 3$ I $, \mathrm{VI} / 49, \mathrm{VI} / 60, \mathrm{VI} / 64, \mathrm{VII} / \mathrm{s} 8, \mathrm{XIV} / 5, \mathrm{XIV} / 6, \mathrm{XIV} / 7, \mathrm{XIV} / \mathrm{I}$ I, $\mathrm{XIV} / \mathrm{s} 2$,

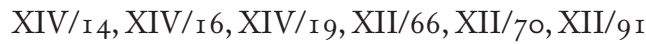

Landesregierungsarchiv, Präsidium: Sch. I 49 u. I 50

Landschaftsakten: Sch. 2 I 4, 442, 443, 446-448, 576, 582, 583, 860, 879, 930, 93 I, 954, I 220

Landschaftsakten, Alte Registratur: Sch. 75, 84, 85, 90-92, 95, 96, 98

Musealarchiv: Sch. 4; HS 5 I, I78, I79 u. 43 I

Nachlass Familien Dierzer v. Traunthal-Fossel: Sch. I

Neuerwerbungen: Sch. 76 u. HS 74

Weinberger Archivalien: Sch. 58 u. 60

Österreichische Nationalbibliothek

Kartensammlung: AB 52 A 3 u. K III Ior 834 


\section{Österreichisches Staatsarchiv (Wien)}

Finanz- und Hofkammerarchiv: Sonderbestände, Sammlungen und Selekte, Karten- und Plansammlung, G 045/I u. 2, F-365/I-4, F-370/I u. 3

\section{Privatsammlung Paul Stöger (Linz)}

ohne Signatur, »Zur feierlichen Eröffnung der Wasserleitung am Schullerberge den 28. November I 875"(Abschrift 3.I 2.I 875)

\section{Stiftsbibliothek St. Florian}

Handschriftensammlung: XI ${ }_{56}{ }_{5} \mathrm{~B}$

\section{Wiener Stadt- und Landesarchiv}

Alte Registratur: A2 I69/I763 u. A 3 I75/I763

Hauptarchiv: A8.2

\section{Datenbanken}

Casty et al., Temperature $=$ Carlo Casty et al., European Alps Temperature and Precipitation Reconstructions. IGBP PAGES/World Data Center for Paleoclimatology. Data Contribution Series \# 2005-070. NOAA/NCDC Paleoclimatology Program, Boulder/CO 2005, ftp:// ftp.ncdc.noaa.gov/pub/data/paleo/historical/europe/alps [r.8.20I 8].

Datenbank Sterbefälle = Datenbank Sterbefälle in Oberösterreich. Betaversion 07.10.2017, www.statistik-ooe.at [I 5.I2.2018].

HISTALP = HISTALP - Historical Instrumental Climatological Surface Time Series of the Greater Alpine Region, www.zamg.ac.at/histalp/dataset/station.php [29.8.2018].

\section{Periodika}

Allgemeine Bauzeitung (Wien): I $836 \mathrm{ff}$.

Der Oberösterreicher. Geschäfts-, Haus- und Volks-Kalender [...] (Linz): I 882 - I884

Linzer Zeitung [LZ] (bis I 788 unter dem Titel »Linzerische [Montags resp. Freytags] ordinari Zeitung «); mit Amtsblatt [LZ/AB] und Intelligenzblatt [LZ/AB]: I 779ff.

Linzer Abendbote: Zeitschrift für Stadt und Land [LAB]: I $855 \mathrm{ff}$.

[Linzer] Tages-Post [LTP]: I $865 \mathrm{ff}$.

Linzer Volksblatt für Stadt und Land [LVB]: I $870 f f$.

Oesterreichische Feuerwehr-Zeitung (Wien): I 865- I 867

Österreichisches Bürgerblatt für Verstand, Herz und gute Laune [ÖB] (Linz): I 8 I 9 - I 857

Statistische Monatschrift (Wien): I (I 875) u. 20 (I 894)

Tafeln zur Statistik (Wien): 7 (I 834 ), I6 (I 843), I 7 (I 844), I 8/I 9 (I 845 - I 846), NF 3 (I 855 I 857 )

Wiener Zeitung: I 837 u. I $85^{\circ}$ 


\section{Gedruckte Quellen und Literatur}

Abel, Massenarmut = Wilhelm Abel, Massenarmut und Hungerkrisen im vorindustriellen Europa. Versuch einer Synopsis, Hamburg/Berlin 1974.

Adam, Wiser = Ingrid Adam, Dr. Carl Wiser, ein großer Linzer Bürgermeister, in: HistJbL I $964,259-346$.

Albrecht, Need = Jonas Albrecht, The Need for Wheat. The Pre-industrial Expansion of Vienna's Grain Supply, I800-I840, Linz 20I8, https://www.jku.at/institut-fuer-sozial-und-wirt schaftsgeschichte/forschung/working-papers/ [ I 5.6.2019].

Allemeyer, Fewersnoth $=$ Marie Luisa Allemeyer, Fewersnoth und Flammenschwert. Stadtbrände in der frühen Neuzeit, Göttingen 2007.

Altmüller, Eingemeindungen = Rudolf Altmüller, Die Linzer Eingemeindungen. Ein Beitrag zur Entwicklungsgeschichte der Landeshauptstadt Linz, Linz s.a. [1965].

Ardelt, Elisabethinen $=$ Rudolf Ardelt, Geschichte des Konventes und Krankenhauses der Elisabethinen zu Linz, in: HistJbL I 978, 95- r 46.

Aschauer, Eisenbahnbrücke = Franz Aschauer, Die erste »Eisenbahnbrücke« über die oberösterreichische Donau, in: Oberösterreichische Heimatblätter I5 (2/3) I 96 I, I63-I64.

Auer et al., Klimatographie = Ingeborg Auer et al., Klimatographie und Klimaatlas von Oberösterreich. 3 Bde., Linz/Wien 1998.

Awecker, Bergschlöß1 = Hertha Awecker, Das Bergschlößl, in: HistJbL I 95 8, I 8 I - 227.

Awecker, Bevölkerung = Hertha Awecker, Die Bevölkerung der Stadt Linz im Jahre I 750, in: HistJbL i 957, 197-240.

Awecker, Brand = Hertha Awecker, Der Brand von Linz im Jahre I 800, in: JbL I 95 I, 26-40.

Awecker, Bruckamt $=$ Hertha Awecker, Das Bruckamt der Stadt Linz, in: JbL I953, I67-2 I 4 .

Bahr, Selbstbildnis = Hermann Bahr, Selbstbildnis, hg. v. Gottfried Schnödl, Weimar 20 I . [Berlin 1923]

Bai/Schandl, Ecology = Xuemei Bai/Heinz Schandl, Urban ecology and industrial ecology, in: Ian Douglas et al., Hg., The Routledge Handbook of Urban Ecology, London/New York $2011,26-37$.

Bankoff/Lübken/Sand, Cities = Greg Bankoff/Uwe Lübken/Jordan Sand, Hg., Flammable Cities. Urban Conflagration and the Making of the Modern World, Madison 2012.

Barles, Approach = Sabine Barles, A Metabolic Approach to the City. Igth and 2oth Century Paris, in: Dieter Schott/Bill Luckin/Geneviève Massard-Guilbaud, Hg., Resources of the City. Contributions to an Environmental History of Modern Europe, Aldershot 2005, 28 - 47 .

Barles, Metabolism = Sabine Barles, Urban Metabolism, in: Sebastian Haumann/Martin Knoll/ Detlev Mares, Hg., Concepts of Urban-Environmental History, Bielefeld 2020, ro9- I 24.

Barles, Umwelt $=$ Sabine Barles, Umwelt und Städtebautechniken - Der Pariser Boden im I 9. Jahrhundert, in: Christoph Bernhardt, Hg., Environmental Problems in European Cities of the I 9 th and 2oth Century. Umweltprobleme in europäischen Städten des 19. und 20. Jahrhunderts, Münster u.a. 200I, 53-65.

Barles/Knoll, Transitions = Sabine Barles/Martin Knoll, Long-Term Transitions, Urban Imprint and the Construction of Hinterlands, in: Tim Soens et al., Hg., Urbanizing Nature. Actors and Agency (Dis)Connecting Cities and Nature since I 500, New York 201 9, 29-49. 
Bartholomämarkt $=$ Der Bartholomämarkt oder auf Linz will ich ewig denken. Ein Lustspiel in zwey Aufzügen, Linz I 784 .

Bauer, Bauch $=$ Thomas Bauer, Im Bauch der Stadt. Kanalisation und Hygiene in Frankfurt am Main I6.- I 9. Jahrhundert, Frankfurt am Main 1998.

Begemann/Giuriato, Stifter-Handbuch = Christian Begemann/Davide Giuriato, Hg., StifterHandbuch. Leben - Werk - Wirkung, Stuttgart 2017.

Behringer, Tambora $=$ Wolfgang Behringer, Tambora und das Jahr ohne Sommer. Wie ein Vulkan die Welt in die Krise stürzte, München 2015.

Behringer, Topographie $=$ Wolfgang Behringer, Topographie und Topik. Das Bild der europäischen Stadt in ihrer Umwelt, in: Dieter Schott/Michael Toyka-Seid, Hg., Die europäische Stadt und ihre Umwelt, Darmstadt 2008, I 23- I 44.

Benesch, Freinberg = Alfred Benesch, Am Freinberg. Eine kurze Natur- und Kulturgeschichte »Hortigrafie« des zentralen Linzer Frei- und Grünraumes, in: Berichte für Ökologie und Naturschutz der Stadt Linz 2009/2, 99-2 I 3.

Benton-Short/Short, Cities = Lisa Benton-Short/John R. Short, Cities and Nature, London/ New York 2008.

Berger, Gärten = Eva Berger, Historische Gärten Österreichs. Garten- und Parkanlagen von der Renaissance bis um I930. Bd. 2, Wien/Köln/Weimar 2003.

Berlinger, Lamplwirtsteich $=$ Rudolf Berlinger, Der einstige Lamplwirtsteich in Linz, in: Heimatgaue I4 (I933), 44-45.

Bernhardt, Umweltprobleme = Christoph Bernhardt, Umweltprobleme in der neueren europäischen Stadtgeschichte, in: ders., Hg., Environmental Problems in European Cities of the I 9 th and 2oth Century. Umweltprobleme in europäischen Städten des I 9. und 20. Jahrhunderts, Münster u.a. 2001, 5-23.

Birkner, Stadt = Othmar Birkner, Die bedrohte Stadt. Cholera in Wien, Wien 2002.

Bohdanowicz, Katzbach $=$ Franz Xaver Bohdanowicz, Die Linzer Vororte. Dargestellt nach dem »Josephinischen Lagebuch« und »Francisceischen Kataster». Gemeinde Katzbach, Linz I 958/1959.

Bohdanowicz, Kleinmünchen $=$ Franz Xaver Bohdanowicz, Die Linzer Vororte. Dargestellt nach dem »Josephinischen Lagebuch« und »Francisceischen Kataster«. Gemeinde Kleinmünchen, Linz i 960 .

Bohdanowicz, Pöstlingberg $=$ Franz Xaver Bohdanowicz, Die Linzer Vororte. Dargestellt nach dem »Josephinischen Lagebuch» und »Francisceischen Kataster». Gemeinde Pöstlingberg, Linz $1957 /$ I 958 .

Bohdanowicz, St. Peter = Franz Xaver Bohdanowicz, Die Linzer Vororte. Dargestellt nach dem »Josephinischen Lagebuch« und »Francisceischen Kataster«. Gemeinde St. Peter bei Zizlau, Linz 1959 .

Bohdanowicz, Urfahr = Franz Xaver Bohdanowicz, Die Linzer Vororte. Dargestellt nach dem »Josephinischen Lagebuch« und »Francisceischen Kataster«. Gemeinde Urfahr, Linz I 957.

Bohdanowicz, Vorstädte $=$ Franz Xaver Bohdanowicz, Die Linzer Vorstädte. Dargestellt nach dem »Josephinischen Lagebuch» und »Francisceischen Kataster». 2 Bde., Linz s.a. [1952] u. I 955 / 956 .

Böhm et al., Webseite = Reinhard Böhm et al., Eine neue Webseite mit instrumentellen Qua- 
litäts-Klimadaten für den Großraum Alpen zurück bis I76o, in: Wiener Mitteilungen 2 I 6 (2009), 7-20.

Böhm/Wetzel, Flood = Oliver Böhm/Karl-Friedrich Wetzel, Flood History of the Danube Tributaries Lech and Isar in the Alpine Foreland of Germany, in: Hydrological Sciences Journal 5I (2006), 784-798

Boone, Ecology $=$ Christopher G. Boone, The Political Ecology of Floods in the Late Nineteenth Century, in: Stéphane Castonguay/Michèle Dagenais, Hg., Metropolitan Natures. Environmental Histories of Montreal, Pittsburgh 20 I I, I33- I 47.

Brázdil/Kundzewicz/Benito, Hydrology = Rudolf Brázdil/Zbigniew Kundzewicz/Gerardo Benito, Historical Hydrology for Studying Flood Risk in Europe, in: Hydrological Sciences Journal 5 I (2006), $739-764$.

Brenner, Governance $=$ Neil Brenner, Urban Governance and the Production of New State Spaces in Western Europe, I960-2000, in: Review of International Political Economy I I (2004), $447-488$.

Briese, Angst = Olaf Briese, Angst in den Zeiten der Cholera. 4 Bde., Berlin/Boston 2003.

Briese, Sicherheit $=$ Olaf Briese, Für des Staates Sicherheit. Das Löschwesen im I 9. Jahrhundert und die Gründung der ersten Berufsfeuerwehr Deutschlands in Berlin I 85 I, Berlin 2018.

Brimblecombe, Smoke $=$ Peter Brimblecombe, The Big Smoke. A History of Air Pollution in London since Medieval Times, London/New York 1987.

Broich, London $=$ John Broich, London. Water and the Making of the Modern City, Pittsburgh 2013.

Brosch, Flurnamen $=$ Franz Brosch, Flurnamen sprechen, in: JbL I 949, 306-340.

Brown, Crisis = John C. Brown, Coping with Crisis? The Diffusion of Waterworks in Late Nineteenth-Century German Towns, in: The Journal of Economic History 48/2 (I988), 307-318.

Brüggemeier, Umweltprobleme $=$ Franz-Josef Brüggemeier, Umweltprobleme und Zonenplanung in Deutschland. Der Aufstieg und die Herrschaft eines Konzepts, in: Christoph Bernhardt, Hg., Environmental Problems in European Cities of the I 9 th and 2oth Century. Umweltprobleme in europäischen Städten des I 9. und 20. Jahrhunderts, Münster u.a. 200I, I $43-$ I 64 .

Brunner/Schneider, Umwelt = Karl Brunner/Petra Schneider, Hg., Umwelt Stadt. Geschichte des Natur- und Lebensraumes Wien, Wien u.a. 2005.

Burney, Tagebuch $=$ Carl Burney's [...] Tagebuch seiner Musikalischen Reisen [...], Bd. 2, Hamburg I 773 .

Butenschön, Geschichte $=$ Sylvia Butenschön, Geschichte des Dresdner Stadtgrüns, Berlin 2007 .

Carrington/Reiter, Linz = Manfred Carrington/Andreas Reiter, Linz. Streiflichter zur Stadtgeschichte, Bd. 2. Die Feuerwehren der Stadt I 85 I- I 945, Linz 20 Io.

Castonguay, Agriculture = Stéphane Castonguay, Agriculture on the Montreal Plain, I $850-$ I 950 . Urban Market and Metropolitan Hinterland, in: Stéphane Castonguay/Michèle Dagenais, Hg., Metropolitan Natures. Environmental Histories of Montreal, Pittsburgh 20 I I, I 8 7- 2 I 0.

Cavert, Smoke = William M. Cavert, The Smoke of London. Energy and Environment in the Early Modern City, Cambridge u.a. 2016.

Charpy, Scope $=$ Manuel Charpy, The Scope and Structure of the Nineteenth-Century Secondhand Trade in the Parisian Clothes market, in: Laurence Fontaine, Hg., Alternative Exchan- 
ges. Second-hand Circulations from the Sixteenth Century to the Present, New York/Oxford 2008, I $27-$ I 5 I.

Charruadas/Deligne, Cities = Paulo Charruadas/Chloé Deligne, Cities Hiding the Forests. Wood Supply, Hinterlands and Urban Agency in the Southern Low Countries, Thirteenth to Eighteenth Centuries, in: Tim Soens et al., Hg., Urbanizing Nature. Actors and Agency (Dis)Connecting Cities and Nature since I 500, New York 2019, I I 2 - I 34.

Cioc, Rhine = Mark Cioc, The Rhine. An Eco-Biography, I 8 I 5 - 20oo, Seattle/London 2002.

Clark, Cities = Peter Clark, European Cities and Towns. 400-2000, Oxford u.a. 2009 .

Cockayne, Hubbub = Emily Cockayne, Hubbub. Filth, Noise \& Stench in England, I600- I 770, New Haven/London 2007.

Collet, Katastrophe $=$ Dominik Collet, Die doppelte Katastrophe. Klima und Kultur in der europäischen Hungerkrise I770-I772, Göttingen 2019.

Collet, Vulnerabilität = Dominik Collet, »Vulnerabilität « als Brückenkonzept der Hungerforschung, in: ders./Thore Lassen/Ansgar Schanbacher, Hg., Handeln in Hungerkrisen. Neue Perspektiven auf soziale und klimatische Vulnerabilität, Göttingen 20 12, I3-25.

Collet/Krämer, Germany = Dominik Collet/Daniel Krämer, Germany, Switzerland and Austria, in: Guido Alfani/Cormac Ó Gráda, Hg., Famine in European History, Cambridge u.a. 2or 7 , IOI-I I 8 .

Commenda, Linz = Hans Commenda, Linz vor hundert Jahren, in: HistJbL i 964, 227-257.

Cremeri, Selbstgespräch = Anton Cremeri, Selbstgespräch eines Bürgers im Urfahr, als er am 28. Juny I786 in der Domkirche zu Linz das Zeichen zum öffentlichen Gebet geben hörte [...], Linz s.a. [ I786].

Cronon, Metropolis = William Cronon, Nature's Metropolis. Chicago and the Great West, New York/London I 991.

Csendes/Opll, Wien = Peter Csendes/Ferdinand Opll, Hg., Wien. Geschichte einer Stadt. 3 Bde., Wien/Köln/Weimar 200 I- 2006.

Culver, Confluences = Lawrence Culver, Confluences of nature and culture. Cities in environmental history, in: Andrew C. Isenberg, Hg., The Handbook of Environmental History, Oxford u.a. 2014, 554-570.

Cvrcek, Wages = Tomas Cvrcek, Wages, prices, and living standards in the Habsburg Empire, I 827-r 910, in: Journal of Economic History 73 (2013), I-37.

Dagenais, Source $=$ Michèle Dagenais, At the Source of a New Urbanity. Water Networks and Power Relations in the Second Half of the Nineteenth Century, in: Stéphane Castonguay/ Michèle Dagenais, Hg., Metropolitan Natures. Environmental Histories of Montreal, Pittsburgh 20 I I, IOI-II4.

Dallinger, Hunger = Petra-Maria Dallinger, $» I c h$ hatte Hunger und dann einen sehr guten Witikonachmittag«. Adalbert Stifters letzte Jahre, Versuche des Maßhaltens, in: Katharina Manojlovic/Kerstin Putz, Hg., Im Rausch des Schreibens. Von Musil bis Bachmann, Wien 201 7 , $306-32 \mathrm{I}$.

Dampfmaschinen $=$ Die Dampfmaschinen der österreichischen Monarchie. Nach der im Jahre I 863 vorgenommenen Zählung [...], Wien I 864 .

Deinhardstein, Skizzen = Johann Ludwig Deinhardstein, Skizzen einer Reise [...], Wien I83 I.

Depiny, Aufzeichnungen $=$ Adalbert Depiny, Aufzeichnungen aus Alt-Linz. Aus den Lebenserinnerungen des Joseph Freiherrn von Spaun, in: Heimatgaue 6 (I925), I 73 - I 89. 
Deutsch, Schubert = Otto Erich Deutsch, Franz Schubert. Briefe und Schriften, 4. Aufl., Wien I 954 .

Doblhamer, Stadtplanung = Gerhard Doblhamer, Die Stadtplanung in Oberösterreich von 1850 bis I 938, Wien/New York I 972.

Dobraszczyk, Sewers = Paul Dobraszczyk, Sewers, Wood Engraving and the Sublime: Picturing London's Main Drainage System in the Illustrated London News, I859-62, in: Victorian Periodicals Review 38 (2005), 349-378.

Donau in Oberösterreich $=$ Die Donau in Oberösterreich. Geschichtliche Darstellung der Regulierungsarbeiten zur Ausbildung ihrer Fahrrinne [...], Groß-Lichterfelde r 909.

Doris, Urmappe $=$ https://doris.ooe.gv.at/themen/basiskarten/urmappe.aspx [2.8.2018] .

Douglas, Analysis = Ian Douglas, The analysis of cities as ecosystems, in: ders. et al., Hg., The Routledge Handbook of Urban Ecology, London/New York 20 I I, I 7-2 5.

Douglas, Geomorphology = Ian Douglas, Urban Geomorphology, in: ders. et al., Hg., The Routledge Handbook of Urban Ecology, London/New York 201 I, I 59- I63.

Douglas, Hydrology = Ian Douglas, Urban Hydrology, in: ders. et al., Hg., The Routledge Handbook of Urban Ecology, London/New York 20 I I, I 48 - I 58.

Douglas, Introduction = Ian Douglas, Introduction, in: ders. et al., Hg., The Routledge Handbook of Urban Ecology, London/New York 20 I , 3-6.

Ebner/Ebner/Weißengruber, Literatur = Helga Ebner/Jakob Ebner/Rainer Weißengruber, Literatur in Linz. Eine Literaturgeschichte, Linz r 99 I.

Ebner/Weigl, Wasser = Romana Ebner/Herbert Weigl, Das Salzburger Wasser. Geschichte der Wasserversorgung der Stadt Salzburg, Salzburg 2014.

Eichwalder, Wohnverhältnisse = Reinhard Eichwalder, Wohnverhältnisse in den größeren Städten Österreichs in der zweiten Hälfte des i 9. und zu Beginn des 20. Jahrhunderts, Geschichte und Ergebnisse der zentralen amtlichen Statistik in Österreich I829-1979, Bd. I, Wien I 979, 559-574.

Einig et al., Governance = Klaus Einig et al., Urban Governance, in: Informationen zur Raumentwicklung 9/10 (2005), I-IX.

Enzyklopädie der Neuzeit = Friedrich Jäger, Hg., Enzyklopädie der Neuzeit. I 2 Bde., Stuttgart 2005-20I 2. [zitiert nach: https://referenceworks.brillonline.com/entries/enzyklopaedie-derneuzeit]

Evans, Epidemics = Richard Evans, Epidemics and Revolutions: Cholera in Nineteenth-Century Europe, in: Past and Present I 20 (I988), I 23 - I 46.

Evans, Tod $=$ Richard J. Evans, Tod in Hamburg. Stadt, Gesellschaft und Politik in den CholeraJahren r 830-i9io, Reinbek bei Hamburg I 990.

Fennetaux, Economics = Ariane Fennetaux, Sentimental Economics. Recycling Textiles in Eighteenth-Century Britain, in: Ariane Fennetaux/Amelie Junqua/Sophie Vasset, Hg., The Afterlife of Used Things. Recycling in the Long Eighteenth Century, New York/London 2015 , I 22-I4I.

Feuer-Ordnung $=$ Feuer-Ordnung der K. K. Hauptstadt Linz, in Oesterreich ob der Enns, Linz I 808 .

Feuerwehr-Kalender $=$ Oberösterreichischer Feuerwehr-Kalender [...] I873, Linz s.a. [1872]. Fink, Geschichte = Josef Fink, Geschichte von Linz. 2 Bde., Linz s.a. [ca. I 885]. [die drei Fort- 
setzungen finden sich in »Der Oberösterreicher. Geschäfts-, Haus- und Volks-Kalender [...] « für die Jahre I 883-85 - vgl. Periodika

Fischer, Ölbergfleischhauer $=$ Adolf Fischer, Die Ölbergfleischhauer und das Ölbergschlachthaus in Linz, in: Heimatgaue Io/I (1929), 62-63.

Födermayr, Pflug $=$ Florian Födermayr, Vom Pflug ins Parlament. Lebenserinnerungen eines oberösterreichischen Bauern, Braunau am Inn I 954.

Foltz, Statistik $=$ Carl Foltz, Statistik der Bodenproduktion von Oberösterreich [...],Wien I 878 . Fontaine/Schlumbohm, Household = Laurence Fontaine/Jürgen Schlumbohm, Household strategies for survival: An introduction, in: International Review of Social History 45 (2000), I- I 7 .

Fougères, Water = Dany Fougères, Surface Water in the Early Nineteenth Century, in: Stéphane Castonguay/Michèle Dagenais, Hg., Metropolitan Natures. Environmental Histories of Montreal, Pittsburgh 20 i I, 85 - ioo.

Fouquet, Bauen = Gerhard Fouquet, Bauen für die Stadt. Finanzen, Organisation und Arbeit in kommunalen Baubetrieben des Spätmittelalters. Eine vergleichende Studie vornehmlich zwischen den Städten Basel und Marburg, Köln/Weimar/Wien I 999.

Freytag/Piereth, Holzversorgung $=$ Nils Freytag/Wolfgang Piereth, Städtische Holzversorgung im I8. und 19. Jahrhundert. Dimensionen und Perspektiven eines Forschungsfeldes, in: Wolfram Siemann/Nils Freytag/Wolfgang Piereth, Hg., Städtische Holzversorgung. Machtpolitik, Armenfürsorge und Umweltkonflikte in Bayern und Österreich (I750- I 850), München $2002, \mathrm{I}-8$.

Frioux, Crossroads $=$ Stéphane Frioux, At a Green Crossroads: Recent Theses in Urban Environmental History in Europe and North America, in: Urban History, 39 (201 2), 529-539.

Fuchs, Produktion = Maria Fuchs, Produktion - Transport - Konsum : Eine sozial-ökologische Analyse der Ressourcenversorgung von Linz I83 I bis I 875, unveröffentlichte Masterarbeit, Universität Klagenfurt, 2014 .

Füssel, Tagbuch $=$ [Johann Michael Füssel], Unser Tagbuch oder Erfahrungen und Bemerkungen eines Hofmeisters und seiner Zöglinge [...], Bd. 3, Erlangen r 79 r.

Gandy, Wasser = Matthew Gandy, Das Wasser, die Moderne und der Niedergang der bakteriologischen Stadt, in: Leviathan 33/4 (2005), 522-543.

Garrioch, Fire = David Garrioch, Towards a Fire History of European Cities (Late Middle Ages to Late Nineteenth Century), in: Urban History 46 (2019), 202-224.

Geschichte und Ergebnisse = Geschichte und Ergebnisse der zentralen amtlichen Statistik in Österreich I829- I979. Bd. 2 Tabellenanhang, Wien 1979.

Gewerbe-Adressen-Buch I 853 = Handels- und Gewerbe-Adressen-Buch für Österreich ob der Enns, Linz I 853 .

Gielge, Beschreibung = Ignaz Gielge, Topographisch-historische Beschreibung aller Städte, Märkte, Schlösser, Pfarren, und anderer merkwürdigen Oerter des Landes Oesterreich ob der Enns. [...], Bd. 2, Wels I 8 I 4.

Gierlinger et al., Feeding $=$ Sylvia Gierlinger et al., Feeding and Cleaning the City. The Role of the Urban Waterscape in Provision and Disposal in Vienna during the Industrial Transformation, in: Water History 5 (2013), 2 I 9-239.

Gierlinger, Food = Sylvia Gierlinger, Food and Feed Supply and Waste Disposal in the In- 
dustrialising City of Vienna (I830-I9I3). A Special Focus on Urban Nitrogen Flows, in: Regional Environmental Change I5 (2015), 31 7 - 327 .

Gimpel Insel = Die Gimpel Insel oder der Stiefbruder des Linnäus, s.1. [Wien] I 783.

Gingrich/Haidvog1/Krausmann, Danube = Simone Gingrich/Gertrud Haidvog1/Fridolin Krausmann, The Danube and Vienna: Urban Resource Use, Transport and Land Use r 80o- r 9ro, in: Regional Environmental Change I 2 (2012), 283-294.

Ginsburg, Rags = Madeleine Ginsburg, Rags to Riches. The Second-hand Clothes Trade I 700I 978 , in: Costume I 4 ( I 980), I 2 I - I 35 .

Gober, Linz = Elisabeth Gober, Linz und seine Donaulandschaft in den Reisebeschreibungen der ersten Hälfte des I 9. Jahrhunderts, in: HistJbL I 972, I 52 - I 90.

Goddard/Sheail, Reform = N. Goddard/ J. Sheail, Victorian Sanitary Reform: Where Were the Innovators?, in: Christoph Bernhardt, Hg., Environmental Problems in European Cities of the I 9 th and 2oth Century. Umweltprobleme in europäischen Städten des I 9. und 20. Jahrhunderts, Münster u.a. 2001, 87-103.

Gray, Sewage $=$ Marion W. Gray, Urban Sewage and Green Meadows: Berlin's Expansion to the South r 870-1920, in: Central European History 47 (2014), 275-306.

Grubauer, Betrachtungen = Math.[ias] Grubauer, Betrachtungen über die Denkschrift des Gemeinderathes der Landeshauptstadt Linz in Betreff der Aufnahme eines Anleihens von Einer Million Gulden, Linz I 874 .

Grüll, Brandverhütung = Georg Grüll, Zur Geschichte der Brandverhütung und Schadensversicherung in Oberösterreich, in: Jahrbuch des Oberösterreichischen Musealvereines I I I (1966), 355-398.

Grüll, Ingenieure = Georg Grüll, Die Ingenieure Knittel im Rahmen der o.-ö. Mappierungen im I7. und I 8. Jahrhundert, in: Mitteilungen des oberösterreichischen Landesarchivs 2 (I952), $43-76$.

Grünn, Wäschergewerbe = Helene Grünn, Volkskundliches vom Wäschergewerbe um Linz, in: JbL i 954, 58 I -662 .

Gubitzer, Brunnenbaukunst $=$ Gabriele Gubitzer, Brunnenbaukunst in Linz, in: Kunstjahrbuch der Stadt Linz 1980, Linz I98 I, 5-7.

Gugitz, Gimpelinsel = Gustav Gugitz, Die Gimpelinsel. Eine Satire auf Linz im Jahre I783, in: JbL i 954, 3 I I -335 .

Gugitz, Linz = Gustav Gugitz, Linz im Urteil der Reisebeschreibungen und Lebenserinnerungen. Versuch einer Bibliographie, in: JbL I 953, 43- roo.

Guillerme, Age = André E. Guillerme, The Age of Water. The Urban Environment in the North of France, A.D. 300- I800, College Station i 988.

Guillerme, Geschichte = André Guillerme, Zur Geschichte industrieller Altlasten in Frankreich, in: Christoph Bernhardt, Hg., Environmental Problems in European Cities of the I 9 th and 2oth Century. Umweltprobleme in europäischen Städten des I9. und 20. Jahrhunderts, Münster u.a. 200I, 4I-5I.

Haidvogl et al., Wasser = Gertrud Haidvogl et al., Wasser Stadt Wien. Eine Umweltgeschichte, Wien 2019.

Hajós, Stadtparks = Géza Hajós, Hg., Stadtparks in der österreichischen Monarchie I 765 - I 9 I 8. Studien zur bürgerlichen Entwicklung des urbanen Grüns in Österreich, Ungarn, Kroatien, Slowenien und Krakau aus europäischer Perspektive, Wien/Köln/Weimar 2007. 
Halliday, Stink = Stephen Halliday, The Great Stink of London. Sir Joseph Bazalgette and the Cleansing of the Victorian Capital, Sutton r 999.

Hamlin, Cholera $=$ Christopher Hamlin, »Cholera forcing . The Myth of the Good Epidemic and the Coming of Good Water, in: American Journal of Public Health 99 (2009), I 946 - i 954 .

Hamlin, Health $=$ Christopher Hamlin, Public Health and Social Justice in the Age of Chadwick: Britain, I $800-$ I 854 , Cambridge u.a. I 997.

Handbuch = Handbuch aller unter der Regierung des Kaisers Joseph des II. für die K.K. Erbländer ergangenen Verordnungen und Gesetze [...]. I 8 Bde., Wien I 785- I 790.

Hanley, Sanitation = Susan B. Hanley, Urban Sanitation in Preindustrial Japan, in: The Journal of Interdisciplinary History i 8/ I ( I987), I - 26.

Hardy, Ärzte = Anne I. Hardy, Ärzte, Ingenieure und städtische Gesundheit. Medizinische Theorien in der Hygienebewegung des I 9. Jahrhunderts, Frankfurt/Main u.a. 2005.

Haslinger, Ehrenbuch = Franz Haslinger, Literarisches Ehrenbuch der Donaustadt Linz. Stadt und Umgebung in der Schau älterer und neuerer Dichter, Gelehrter und Reiseschriftsteller. Vom Humanismus bis zur Gegenwart. 2. Auf., Linz I 956.

Haslinger, Stadtplan = Karl Haslinger, Der Stadtplan als Bestandteil eines Organisationssystems der Verwaltung am Beispiel der Großstadt Linz, in: Naturkundliches Jahrbuch der Stadt Linz 28 (1982), 3 I - I 79 .

Haslinger, Tagebücher $=$ Die Tagebücher Franz de Paula Haslingers I 796- I 833. Wetterbeobachtungen und Temperaturmessungen. Bearb. von Georg Wacha, Linz i 962/64.

Hausmülldeponie Hollaberergraben = Altlast $\mathrm{O}_{5} \mathrm{I}$ »Hausmülldeponie Hollaberergraben , hg. vom Umweltbundesamt, Wien 2009, https://www.altlasten.gv.at/dam/jcr:24076760-8 Ie 449ef-a232-5bfaogd99086/O5 I.pdf [23.4.2019].

Hays, Role $=$ Samuel Hays, The Role of Urbanization in Environmental History, in: Explorations in Environmental History. Essays by Samuel Hays, Pittsburgh I998, 69- Ioo.

Heinse, Linz, r. Aufl. = Gottlob Heinrich Heinse, Linz und seine Umgebungen [...], Linz I 8 I 2 .

Heinse, Linz, 2. Aufl. = Gottlob Heinrich Heinse, Linz und seine Umgebungen. [...] Zweyte umgearbeitete und vermehrte Auflage, Linz I 838.

Heller, Wasserversorgung = Josef F. Heller, Die Wasserversorgung der Landeshauptstadt Linz. Eine Denkschrift anlässlich der Vollendung der allgemeinen Wasserleitung im Auftrage des Gemeinderathes [...], Linz I 894 .

Hermann-Bahr-Buch $=$ Das Hermann-Bahr-Buch, Berlin I 9 I 3 .

Heynen/Kaika/Swyngedouw, Ecology = Nik Heynen/Maria Kaika/Erik Swyngedouw, Urban Political Ecology. Politicizing the Production of Urban Natures, in: dies., Hg., In the Nature of Cities. Urban Political Ecology and the Politics of Urban Metabolism, London/New York 2006, I- 20 .

Hillbrand, Türme = Erich Hillbrand, Die Türme von Linz. Erzherzog Maximilians Festungssystem für die Monarchie, in: HistJbL I 984, I I - 2 I 3 .

Historischer Umweltatlas Münster $=$ Historischer Umweltatlas Münster, hg. vom Oberstadtdirektor der Stadt Münster - Umweltamt in Verbindung mit der Projektgruppe Stadtjubiläum, Münster/New York I 993 .

Hochadel, Nebula = Oliver Hochadel, »In nebula nebulorum«. The Dry Fog of the Summer of 
I 783 and the Introduction of Lightning Rods in the German Empire, in: Transactions of the American Philosophical Society New Series 99/5 (2009), 45-70.

Hochadel, Wissenschaft = Oliver Hochadel, Öffentliche Wissenschaft. Elektrizität in der deutschen Aufklärung, Göttingen 2003.

Hochwasserkatastrophe = Die Hochwasserkatastrophe des Jahres I 899 im österreichischen Donaugebiete Österreich, Wien I 900 .

Hoff, Skizze $=$ Heinrich-Georg Hoff, Skizze von Linz, s.l. [Leipzig] I 787 .

Hoffmann, Bauernland = Alfred Hoffmann, Hg., Bauernland Oberösterreich. Entwicklungsgeschichte seiner Land- und Forstwirtschaft. Trauner, Linz I 974.

Hoffmann, Footprint = Richard C. Hoffmann, Footprint Metaphor and Metabolic Realities: Environmental Impacts of Medieval European Cities, in: Paolo Squatriti, Hg., Natures Past. The Environment and Human History, Ann Arbor 2007, 288-325.

Hoffmann/Meixner, Wirtschaftsgeschichte = Alfred Hoffmann/Erich Maria Meixner, Wirtschaftsgeschichte des Landes Oberösterreich. 2 Bde., Salzburg 1952.

Hofmann, Beiträge $=$ Viktor Hofmann, Beiträge zur neueren österreichischen Wirtschaftsgeschichte. Die Wollenzeugfabrik zu Linz an der Donau, Wien r 9 I 9.

Hohensinner et al., Changes = Severin Hohensinner et al., Changes in Water and Land: The Reconstructed Viennese Riverscape from I 500 to the Present, in: Water History 5/2 (2013), I $45-\mathrm{I} 72$.

Hohensinner et al., Steps = Severin Hohensinner et al., Two Steps back, One Step forward: Reconstructing the Dynamic Danube Riverscape under Human influence in Vienna, in: Water History 5/2 (20I3), I 2 I - I 43 .

Hohensinner, Fahrzeuge $=$ Severin Hohensinner, Wie viele Fahrzeuge liegen in den Schottermassen begraben?« Die Schifffahrt auf der unregulierten Donau, in: Verena Winiwarter/ Martin Schmid, Hg., Umwelt Donau. Eine andere Geschichte [...], St. Pölten 20 го, ro4 - I I 7.

Hohensinner, Hochwässer = Severin Hohensinner, Historische Hochwässer der Wiener Donau und ihrer Zubringer, Wien 2015.

Hohensinner, Strom $=$ Severin Hohensinner, $»$ Sobald jedoch der Strom einen anderen Lauf nimmt ...«. Der Wandel der Donau vom i 8. zum 20. Jahrhundert, in: Verena Winiwarter/ Martin Schmid, Hg., Umwelt Donau. Eine andere Geschichte [...], St. Pölten 2010, 38 - 55. Huang/Lee, Metabolism = Shu-Li Huang/Chun-Lin Lee, Urban Metabolism Analysis, in: Ian Douglas et al., Hg., The Routledge Handbook of Urban Ecology, London/New York 20 I I, $52 \mathrm{I}-527$.

Hübner, Angedenken = L[orenz] H[übner], Zum traurigen Angedenken der Ueberschwemmungen einiger Gegenden Oberdeutschlands im Junius I 786, s.1. [Salzburg] s.a. [I 786].

Hübner, Ueberschwemmungs-Geschichte = L[orenz] H[übner], Gräuliche Ueberschwemmungs-Geschichte von den Monaten Hornung und März des Jahres MDCCLXXXIV [...], München/Salzburg s.a. [I784].

Hye, Geschichte $=$ Franz-Heinz Hye, Geschichte der Trinkwasserversorgung der Landeshauptstadt Innsbruck, Innsbruck 1993.

Illi, Schîssgruob = Martin Illi, Von der Schîssgruob zur modernen Stadtentwässerung, Zürich 1987 .

Imhof, Gaswerk = Philipp Imhof, Das Linzer Gaswerk. Zum 8ojährigen Bestand, in: JbL I 937, $58-70$. 
Isenberg, Nature $=$ Andrew C. Isenberg, Introduction. New Directions in Urban Environmental History, in: ders., Hg., The Nature of Cities, Rochester 2006, XI-XIX.

Janik, Böden = Christoph Vinzenz Janik, Die Böden des Linzer Raumes, Linz I 96 I.

Janssens/Soens, Water = Ellen Janssens/Tim Soens, Urbanizing Water: Looking beyond the

Transition to Water Modernity in the Cities of the Southern Low Countries, Thirteenth to Nineteenth Centuries, in: Tim Soens et al., Hg., Urbanizing Nature. Actors and Agency (Dis)Connecting Cities and Nature since I 500, New York 2019, 89- I I I.

Jenner, Monopoly = Mark S. R. Jenner, Monopoly, Markets and Public Health: Pollution and Commerce in the History of London water I 780- I830, in: ders./Patrick Wallis, Hg., Medicine and the Market in England and its Colonies, c. I 450-c. I 850, Basingstoke 2007, 2 I6-237.

Johann, Holzversorgung = Elisabeth Johann, Die Holzversorgung Klagenfurts im Übergang vom i 8. zum i 9. Jahrhundert, in: Wolfram Siemann/Nils Freytag/Wolfgang Piereth, Hg., Städtische Holzversorgung. Machtpolitik, Armenfürsorge und Umweltkonflikte in Bayern und Österreich (I750-I850), München 2002, 79-105.

John, Bevölkerung = Michael John, Bevölkerung in der Stadt. »Einheimische« und »Fremde« in Linz ( I 9. und 20. Jahrhundert), Linz 2000.

John/Stadler, Bevölkerungsentwicklung = Michael John/Gerhard A. Stadler, Zu Bevölkerungsentwicklung und Stadtwachstum in Linz I 840-1880, in: HistJbL i 987, 99- I 44.

John/Stadler, Wirtschaftsraum = Michael John/Gerhard A. Stadler, Der Wirtschaftsraum Linz im I 9. und frühen 20. Jahrhundert. Perspektiven einer regionalen ökonomischen Entwicklung, in: Linzer Wirtschaftschronik. Hg. v. Gesellschaft für Wirtschaftsdokumentationen Ges.m.b.H., Wien s.a. [ca. I 990], 95- I 54 .

Jørgensen, Sanitation = Dolly Jørgensen, Cooperative Sanitation. Managing Streets and Gutters in Late Medieval England and Scandinavia, in: Technology and Culture 49 (2008), 547-567.

Jungwirth et al., Donau = Mathias Jungwirth et al., Österreichs Donau. Landschaft - Fisch Geschichte, Wien 2014.

Kander/Malanima/Warde, Power = Astrid Kander/Paolo Malanima/Paul Warde, Power to the People. Energy in Europe over the Last Five Centuries, Princeton 2013.

Kellner, Pesthauch = Katharina Kellner, Pesthauch über Regensburg. Seuchenbekämpfung und Hygiene im I 8. Jahrhundert, Regensburg 2005.

Kerschner, Garten = Theodor Kerschner, Der alte botanische Garten und der Verein für Naturkunde, in: JbL 1952, 37-68.

Kim/Barles, Energy = Eunhye Kim/Sabine Barles, The Energy Consumption of Paris and Its Supply Areas from the Eighteenth Century to the Present, in: Regional Environmental Change I 2 (2012), 295-310.

Kiple, Disease $=$ Kenneth F. Kiple, Hg., The Cambridge World History of Human Disease, Cambridge u.a. I993.

Király, Donau = Edit Király, »Die Donau ist die Form«. Strom-Diskurse in Texten und Bildern des I 9. Jahrhunderts, Wien/Köln/Weimar 2017.

Kitzmantel, Finanzpolitik = Michael Kitzmantel, Die Finanzpolitik der Landeshauptstadt Linz, in: Fritz Mayrhofer/Walter Schuster, Hg., Linz im 20. Jahrhundert. Beiträge, Linz 20 го, 2 I I -367 .

Klein, Ortslexikon $=$ Kurt Klein, Historisches Ortslexikon. Statistische Dokumentation zur Bevölkerungs- und Siedlungsgeschichte. Oberösterreich I. Teil, Wien 20 I 6. 
Klemun, Exotik = Marianne Klemun, Exotik, Nutzen, Wissenschaft. Praktiken der Pflanzenaneignung im »Ökonomisch-Botanischen Garten« der Theresianischen Akademie, in: Franz M. Eybl, Hg., Strukturwandel kultureller Praxis. Beiträge zu einer kulturwissenschaftlichen Sicht des theresianischen Zeitalters, Wien 2002, 303-333.

Klemun, Garten = Marianne Klemun, Der Botanische Garten, in: Europäische Geschichte Online (EGO), hg. vom Leibniz-Institut für Europäische Geschichte (IEG) Mainz [20 I 5], urn :nbn:de:o159-201506222 I [15.12.2018].

Kneifel, Maulbeerpflanzungen $=$ Herbert Kneifel, Maulbeerpflanzungen in Enns im 19. Jahrhundert, in: Oberösterreichische Heimatblätter 4I (I 987), 306-3 I 7 .

Knoll, Bodenhaftung = Martin Knoll, Nil sub sole novum oder neue Bodenhaftung? Der material turn und die Geschichtswissenschaft, in: Neue Politische Literatur 59 (2014), I 9I - 207.

Knoll, Luft = Martin Knoll, »Dicke Luft und lachende Fluren.« Überlegungen zur Umweltgeschichte der europäischen Stadt, in: Clio Online - Themenportal Europäische Geschichte [2008], www.europa.clio-online.de/essay/id/artikel-3467 [I 5.I 2.2018].

Knoll, Natur = Martin Knoll, Die Natur der menschlichen Welt. Siedlung, Territorium und Umwelt in der historisch-topografischen Literatur der Frühen Neuzeit, Bielefeld 2013.

Knoll, Wald = Martin Knoll, Wald und Holz als verknappte Ressourcen. Anmerkungen zur städtischen Brennholzversorgung im I 8. und I 9. Jahrhundert am Regensburger Beispiel, in: Bernd Herrmann, Hg., Beiträge zum Göttinger Umwelthistorischen Kolloquium 2004-2006, Göttingen 2007, I 89-2 I I.

Knoll/Lübken/Schott, Introduction = Martin Knoll/Uwe Lübken/Dieter Schott, Introduction, in: dies., Hg., Rivers Lost, Rivers Regained. Rethinking City-River Relations, Pittsburgh 20I $7,3-22$.

Knörlein, Geschichte = Anton Knörlein, Kurzgefasste Geschichte der Heilanstalten und des Medicinalwesens in Linz, in: Jahrbuch des Oberösterreichischen Musealvereines I 5 ( 1855 ), I -5 O.

Koch, Donaureise = Matthias Koch, Die Donaureise von Linz bis Wien [...], 2. Aufl., Wien I84I.

Koch, Reise = Matthias Koch, Reise in Oberösterreich und Salzburg, auf der Route von Linz nach Salzburg, Fusch, Gastein und Isch1 [...], Wien I 846.

Kohl, Reise = J. G. Kohl, Reise von Linz nach Wien, Dresden/Leipzig I842.

Körner, Stadtzerstörung = Martin Körner, Hg., Stadtzerstörung und Wiederaufbau. Zerstörung durch Erdbeben, Feuer und Wasser [...]. 3 Bde., Bern/Stuttgart/Wien I 999.

Koslofsky, Empire = Craig Koslofsky, Evening's Empire. A History of the Night in Early Modern Europe, Cambridge 20 I .

Krackowizer, Landeshauptstadt $=$ Ferdinand Krackowizer, Die Landeshauptstadt Linz. Ein Führer für Einheimische und Fremde, Linz I 874.

Krämer, Menschen = Daniel Krämer, »Menschen grasten nun mit dem Vieh.« Die letzte grosse Hungerkrise der Schweiz I 816/17, Basel 2015.

Krämer, Vulnerabilität $=$ Daniel Krämer, Vulnerabilität und die konzeptionellen Strukturen des Hungers. Eine methodische Annäherung, in: Dominik Collet/Thore Lassen/Ansgar Schanbacher, Hg., Handeln in Hungerkrisen. Neue Perspektiven auf soziale und klimatische Vulnerabilität, Göttingen 201 2, 45-65.

Krausmann, City = Fridolin Krausmann, A City and Its Hinterland: Vienna's Energy Meta- 
bolism I 800-2006, in: Simron Jit Singh et al., Hg., Long Term Socio Ecological Research. Studies in Society-Nature Interactions across Spatial and Temporal Scales, Dordrecht u.a. $2013,247-268$.

Kreczi, Häuserchronik = Hanns Kreczi, Linzer Häuserchronik, Linz I 94 I .

Kreczi, Linz = Hanns Kreczi, Linz. Stadt an der Donau, Linz I 95 I.

Kreuzer, Stadtumbau = Bernd Kreuzer, Stadtumbau für den Verkehr: Linz auf dem Weg zur autogerechten Stadt, in: Fritz Mayrhofer/Walter Schuster, Hg., Linz im 20. Jahrhundert. Beiträge, Linz 2010, 5 I9-6 I8.

Krickel, Fußreise = Adalbert Joseph Krickel, Fußreise durch den größten Theil der österreichischen Staaten [...], Bd. 3, Wien I83 I.

Kucera, Ausgaben $=$ Josef Kucera, Ausgaben und deren Finanzierung г 86 I bis г 89 г, in: BanikSchweitzer et al., Hg., Wien in der liberalen Ära. Festgabe des Wiener Stadt- und Landesarchivs anläßlich des I 4. Österreichischen Historikertages, Wien I 978, 44-6r.

Kumpfmüller, Hungersnot = Josef Kumpfmüller, Die Hungersnot von I 770 bis I 772 in Österreich, unveröffentlichte Dissertation, Universität Wien, I 969.

Kunstdenkmäler = Die profanen Bau- und Kunstdenkmäler der Stadt Linz. 3 Bde., Wien I 977 I999.

Kutschera, Luftfahrt = Richard Kutschera, Luftfahrt und Flugwesen in Linz, in: HistJbL I 962, $429-484$.

Kutschera, Straßenbeleuchtung = Richard Kutschera, 200 Jahre öffentliche Straßenbeleuchtung in Linz, in: HistJbL 1 964, 347-403.

Kyselak, Skizzen = Joseph Kyselak, Skizzen einer Fußreise durch Österreich. Hg. von Gabriele Goffriller und mit einem Vorwort von Gabriele Goffriller und Chico Klein, Salzburg/Wien 2009 [zuerst Wien I 829].

Lackner, Geschäft = Helmut Lackner, Ein »blutiges Geschäft« - Zur Geschichte kommunaler Vieh- und Schlachthöfe. Ein Beitrag zur historischen Städtetechnik am Beispiel Österreich, in: HistJbL $2003,805-828$.

Lackner/Stadler, Fabriken $=$ Helmut Lackner/Gerhard A. Stadler, Fabriken in der Stadt. Eine Industriegeschichte der Stadt Linz, Linz i 990.

Lauscher et al., Witterung = Friedrich Lauscher et al., Hg., Witterung und Klima von Linz, Wien 1959 .

Lees $/$ Hollen Lees, Europe $=$ Andrew Lees/Lynn Hollen Lees, Europe: $1800-2000$, in: Peter Clark, Hg., The Oxford Handbook of Cities in World History, Oxford 2016, 464-482.

Lees/Hollen Lees, Cities = Andrew Lees/Lynn Hollen Lees, Cities and the Making of Modern Europe. I750-I914, Cambridge u.a. 2007.

Lefebvre, Alltagsleben = Henri Lefebvre, Das Alltagsleben in der modernen Welt, Frankfurt am Main 1972 [zuerst Paris I 968].

Lefebvre, Kritik = Henri Lefebvre, Kritik des Alltagslebens. 3 Bde., München I 974f. [zuerst Paris I 958 u. I96I].

Lefebvre, Revolution $=$ Henri Lefebvre, Die Revolution der Städte, Frankfurt am Main 1976 [zuerst Paris I 970].

Leide1/Franz, Flußlandschaften = Gerhard Leidel/Monika Ruth Franz, Altbayerische Flußland schaften an Donau, Lech, Isar und Inn. Handgezeichnete Karten des I6. bis I 8. Jahrhunderts aus dem Bayerischen Hauptstaatsarchiv, Weißenhorn 1998. 
Lemire, Clothing = Beverly Lemire, The Secondhand Clothing Trade in Europe and beyond. Stages of Development and Enterprise in a Changing Material World, c. I60o-1850, in: Textile Io/2 (2012), I44-I63.

Lengauer, Massenwohnbau = Ursula Lengauer, Massenwohnbau. Alltagsgeschichte der Baukultur am Beispiel des Arbeiterwohnbaus der franzisko-josephinischen Zeit im Linzer Raum, in: HistJbL I 996, 73-267.

Lenger, Metropolen $=$ Friedrich Lenger, Metropolen der Moderne. Eine europäische Stadtgeschichte seit I 850 , München 2013 .

Leonhartsberger, Freizeiträume $=$ Andrea Leonhartsberger, Freizeiträume und Freizeitaktivitäten des Linzer Bürgertums in der franzisko-josephinischen Epoche, unveröffentlichte Dissertation, Universität Wien, I 994.

Lesky, Gesundheitswesen = Erna Lesky, Österreichisches Gesundheitswesen im Zeitalter des aufgeklärten Absolutismus, Wien I 959.

Lesky, Schule = Erna Lesky, Die Wiener medizinische Schule im I9. Jahrhundert, Graz/Köln I 965 .

Leven, Ratten $=$ Karl-Heinz Leven, Von Ratten und Menschen - Pest, Geschichte und das Problem der retrospektiven Diagnose, in: Mischa Meier, Hg., Pest. Die Geschichte eines Menschheitstraumas, Stuttgart 2005, I I -32 .

Linner, Salubritäts-Verhältnisse = Rudolf Linner, Die Salubritäts-Verhältnisse der Stadt Linz vom technischen Standpunkte, Linz I 868.

Linz a./d. Donau = Linz a./d. Donau und seine Umgebungen. Festgabe der Section Linz des Deutschen und Oesterreichischen Alpenvereines [...], Linz I 887.

Linz und seine Umgebung = Linz und seine Umgebung. Ein Führer für Einheimische und Fremde. Mit einer Karte, Linz I 866.

Linzer Regesten [LR] = Linzer Regesten, hg. vom Archiv der Stadt Linz. I99 Bde., Linz I 952 - I 993 .

Losch et al., Tod = Hermine Losch et al., Tod in Armut. $\mathrm{Zu}$ den Totenbüchern des Barmherzigen Brüderspitals in Linz von I757- I850, in: HistJbL I 982 , I I-73.

Lotz-Heumann, Repräsentationen = Ute Lotz-Heumann, Repräsentationen von Heilwassern und -quellen in der Frühen Neuzeit: Badeorte, lutherische Wunderquellen und katholische Wallfahrten, in: Matthias Pohlig et al., Hg., Säkularisierungen in der Frühen Neuzeit: Methodische Probleme und empirische Fallstudien, Berlin 2008, 277-330.

Lübken, Cities = Uwe Lübken, Cities and Rivers, in : Sebastian Haumann/Martin Knoll/Detlev Mares, Hg. , Concepts of Urban-Environmental History, Bielefeld 2020, I 55- I65.

Luca, Landeskunde = Ignaz De Luca, Landeskunde von Oesterreich ob der Enns. 3 Bde., Linz I 786 u. Linz/Wien I79r/92.

Lüdtke, Alltagsgeschichte $=$ Alf Lüdtke, Alltagsgeschichte: Aneignung und Akteure. Oder - es hat noch kaum begonnen!, in: WerkstattGeschichte I7 (I 997), 83-92.

Lüdtke, Einleitung = Alf Lüdtke, Einleitung. Was ist und wer treibt Alltagsgeschichte?, in: ders., Hg., Alltagsgeschichte. Zur Rekonstruktion historischer Erfahrungen und Lebensweisen, Frankfurt/Main u.a. I 989, 9-47.

Macher, Handbuch = Mathias Macher, Handbuch der kaiserl. königl. Sanität-Gesetze und Verordnungen mit besonderer Beziehung auf die innerösterreichischen Provinzen. 2 Bde., Graz u.a. $1846 / 47$. 
Macher, Hygienisierung = Heribert Macher, Hygienisierung in Graz zwischen $\mathrm{I} 860$ und $\mathrm{\text {I }}$ г $\mathrm{o}$. Ursache und Wirkung unter besonderer Berücksichtigung der städtischen Wasserversorgung beziehungsweise Abwasserbeseitigung, in: Pro Civitate Austriae. Informationen zur Stadtgeschichtsforschung in Österreich NF 20 (2015), 5-23.

Mader, Reise $=\mathrm{J}[$ oseph] Eduard Mader, Reise von Böhmisch-Krumau durch das Oberennsische Salzkammergut nach Salzburg und Berchtesgaden. Im Herbste I 807, Prag I 809.

Mapire, Franziszeischer Kataster $=$ Franziszeischer Kataster [undat., I 82 oer Jahre]. Mapire. Historical Maps Online, https://mapire.eu/de/map/cadastral [22.2.2019].

Marckhgott, Mitbürger $=$ Gerhart Marckhgott, Fremde Mitbürger. Die Anfänge d. israelitischen Kultusgemeinde Linz-Urfahr I849- I 877, in: HistJbL I 984, 285-309.

Martens, Reise $=$ Georg v. Martens, Reise nach Venedig. Bd. I, Ulm I 824 .

Marx, Ende = Julius Marx, Das Ende des Wohlfahrtsstaates. Ein Beitrag zur Vorgeschichte des Jahres I 848, unveröffentlichte Dissertation, Universität Wien, I 925.

Marx, Flammen = Erich Marx, Hg. »Die Flammen lodern wütend «. Der große Stadtbrand in Salzburg I 8 18, Salzburg 2018.

Marx, Teuerung = Julius Marx, Die Teuerung der Jahre I 846 und I 847, in: Jahrbuch des Vereines für Geschichte der Stadt Wien, Neue Folge I ( I 939), I03- I 28.

Massard-Guilbaud, Einspruch = Geneviève Massard-Guilbaud, Einspruch! Stadtbürger und Umweltverschmutzung im Frankreich des I 9. Jahrhunderts, in: Christoph Bernhardt, Hg., Environmental Problems in European Cities of the r 9 th and 2oth Century. Umweltprobleme in europäischen Städten des I9. und 20. Jahrhunderts, Münster u.a. 200 I, 68-85.

Massard-Guilbaud/Thorsheim, Cities = Geneviève Massard-Guilbaud/Peter Thorsheim, Cities, Environments, and European History, in: Journal of Urban History 33 (2007), 69 I - 70 I.

Mathieu, Inselstadt $=$ Christian Mathieu, Inselstadt Venedig. Umweltgeschichte eines Mythos in der Frühen Neuzeit, Köln/Weimar/Wien 2007.

Mauelshagen, Klimageschichte $=$ Franz Mauelshagen, Klimageschichte der Neuzeit I $500-$ I 900 , Darmstadt 2010.

Mauelshagen, Pestepidemien = Franz Mauelshagen, Pestepidemien im Europa der Frühen Neuzeit (1500-1800), in: Mischa Meier, Hg., Pest. Die Geschichte eines Menschheitstraumas, Stuttgart 2005, 237-265.

Mayer, Vorbericht $=$ Johann Georg Mayer, Nothwendiger Vorbericht Von der Beschaffenheit und Gebrauch Des Kirchschlager Baads In Ober-Oesterreich, Linz I 753.

Mayr, Reiseführer = René Mayr, Ein stadtmorphologischer Reiseführer ... zur Morphogenese von Linz, unveröffentlichte Diplomarbeit, TU Wien, 20 I I.

Mayrhofer, Donaustadt = Franz Mayrhofer, Die Donaustadt Linz. Eine geographische Betrachtung, in: Jahrbuch des oberösterreichischen Musealvereins 88 (I939), 59-2 Io. [= Dissertation, Universität Innsbruck, I932]

Mayrhofer, Hauptbahnhof = Fritz Mayrhofer, Ein Hauptbahnhof an der Donau?, in: Jahrbuch des Oberösterreichischen Musealvereines I 49 (2004), 56 I- 568.

Mayrhofer, Linz = Fritz Mayrhofer, Linz, in: Österreichischer Städteatlas. 2. Lieferung, hg. v. Wiener Stadt- u. Landesarchiv u. Ludwig-Boltzmann-Inst. für Stadtgeschichtsforschung, Wien 1985 .

Mayrhofer/Katzinger, Geschichte = Fritz Mayrhofer/Willibald Katzinger, Geschichte der Stadt Linz. 2 Bde., Linz I 990. 
Meiß1, Hochquellenleitungen $=$ Gerhard Meiß1, Hochquellenleitungen und Unratsschiffe. Zur Geschichte der Wiener Wasserver- und -entsorgung vor I9 14, in: Sylvia Hahn/Reinhold Reith, Hg., Umwelt-Geschichte. Arbeitsfelder - Forschungsansätze - Perspektiven, Wien und München 200I, I57-I79.

Melosi, America = Martin V. Melosi, Effluent America. Cities, Industry, Energy and the Environment, Pittsburgh $200 \mathrm{I}$.

Melosi, City = Martin. V. Melosi, The Sanitary City. Urban Infrastructure in America from Colonial Times to the Present. Baltimore und London 2000.

Melosi, Garbage = Martin V. Melosi, Garbage in the Cities. Refuse, Reform, and the Environment, Pittsburgh 2005 .

Melosi, Humans = Martin V. Melosi, Humans, Cities, and Nature: How Do Cities Fit in the Material World?, in: Journal of Urban History 36 (2010), 3-2 I.

Melosi, Place = Martin V. Melosi, The Place of the City in Environmental History, in: Environmental History Review I7/I (I 993), I-23.

Miodunka, Longue Durée $=$ Piotr Miodunka, The Longue Durée in Polish Towns: Agriculture from the Sixteenth to the Nineteenth Century, in: Erich Landsteiner/Tim Soens, Hg., Farming the City. The Resilience and Decline of Urban Agriculture in European History. Resilienz und Niedergang der städtischen Landwirtschaft in der europäischen Geschichte, Innsbruck/Wien 2020, 75-94.

Mittmannsgruber, Stadtverwaltung = Wieland Mittmannsgruber, Die Linzer Stadtverwaltung I 848-I9I 8. Organisation, Aufgaben und Bedienstete vom Beginn der Gemeindeautonomie bis zum Ende der Monarchie unter Einschluss der Entwicklung der Gemeindeselbstverwaltung, in: HistJbL 2001, 99-289.

Moore/Rodger, Cities = James Moore/Richard Rodger, Who Really Ran the Cities? Municipal Knowledge and Policy Networks in British Local Government, I832-19I4, in: Robert Beachy/Ralf Roth, Hg., Who Ran the Cities? City Elites and Power Structures in Europe and North America, I750-I940, Aldershot 2007, 37-69.

Mühlpeck/Sandgruber/Woitek, Index = Vera Mühlpeck/Roman Sandgruber/Hannelore Woitek, Index der Verbraucherpreise von I 800 bis I 9I 4. Eine Rückberechnung für Wien und den Gebietsstand des heutigen Österreichs, in: Geschichte und Ergebnisse der zentralen amtlichen Statistik in Österreich I829- I979, Bd. I, Wien I979, 649-688.

Müller, Brunnen = Albert Müller, Brunnen in Linz, in: Kunstjahrbuch der Stadt Linz I980, Linz I98 I, 8-45.

Murray, Handbook = John Murray, A Handbook for Travellers in Southern Germany [...], London u.a. I 837 .

Neweklowsky, Donau = Ernst Neweklowsky, Die Donau bei Linz und ihre Regelung, in: Naturkundliches Jahrbuch der Stadt Linz I (1955), I 7 I - 226.

Neweklowsky, Donauschiffahrt $=$ Ernst Neweklowsky, Linz und die Donauschiffahrt, in: JbL I 937, I 78 - I 95 .

Neweklowsky, Getreidetransport $=$ Ernst Neweklowsky, Ein Getreidetransport von Ungarn nach Linz im Jahre I 772, in: Oberösterreichische Heimatblätter 3 (I 949), 344-347.

Neweklowsky, Schiffahrt = Ernst Neweklowsky, Die Schiffahrt und Flößerei im Raum der oberen Donau und ihrer Nebenflüsse. 3 Bde., Linz I 95 2- 1964. 
Neweklowsky, Schiffmühlen = Ernst Neweklowsky, Die Linzer Schiffmühlen, in: HistJbL I 955 , $53-58$.

Nicolai, Beschreibung $=$ Friedrich Nicolai, Beschreibung einer Reise durch Deutschland und die Schweiz im Jahre I78 I [...]. Bd. 2, Berlin/Stettin I 783 .

Oberegger, Weg = Elmar Oberegger, Der eiserne Weg nach Böhmen. Von der Pferde-Eisenbahn zur Summerauer Bahn, in: Anita Kuisle, Hg., Kohle und Dampf. Oberösterreichische Landesausstellung Ampflwang 2006, Linz 2006, 247-258.

Otruba/Kropf, Industrietopographie $=$ Gustav Otruba/Rudolf Kropf, Industrietopographie, in: Oberösterreichische Heimatblätter 25/3 U. 4 (I97 I), 98 - I 25.

Pammer, Blattern = Michael Pammer, Warum verschwanden die Blattern?, in: Sonia Horn/Rudolf Kropf, Hg., Gesundheit und Hygiene im pannonischen Raum vom ausgehenden Mittelalter bis ins 20. Jahrhundert, Eisenstadt 2007, I 73 - 193.

Pfeffer, Fabriksbau = Franz Pfeffer, Ein Fabriksbau der Barockzeit, in: Oberösterreichische Heimatblätter 4 (I 950), 33-43.

Pfeffer, Kirchschlag = Franz Pfeffer, Kirchschlag. Das Bergdorf am Breitenstein, in: Oberösterreichische Heimatblätter I 5 ( I96I), $201-252$.

Pfeffer, Naturfreude $=$ Franz Pfeffer, Die Naturfreude des Städters. Ihre Entwicklung im alten und neuen Linz, in: JbL I 937, 204-22 I.

Pfeisinger, Industrie = Gerhard Pfeisinger, $»$ Industrie und gute Policey«. Bemerkungen zu Staat, Ordnung und Wohlfahrt im ausgehenden I 8. Jahrhundert, in: HistJbL I 99 I, I I - 28.

Pfister et al., Syndrom = Christian Pfister et al., »Das I95oer Syndrom«. Zusammenfassung und Synthese, in: Christian Pfister, Hg., Das r 95oer Syndrom. Der Weg in die Konsumgesellschaft. 2. Aufl., Bern/Stuttgart/Wien I 996, 2 I - 47.

Pfister, Bevölkerungsgeschichte $=$ Christian Pfister, Bevölkerungsgeschichte und historische Demographie. I 500-1800. 2. Aufl., München 2007.

Pfister, Wetternachhersage $=$ Christian Pfister, Wetternachhersage. 500 Jahre Klimavariationen und Naturkatastrophen ( 496 - I 995), Bern u.a. I999.

Pfister/Brázdil, Vulnerability = Christian Pfister/Rudolf Brázdil, Social Vulnerability to Climate in the "Little Ice Age«. An Example from Central Europe in the Early I 77os, in: Climate of the Past 2 (2006), I I 5- I 29.

Pichler-Baumgartner, Effect $=$ Luisa Pichler-Baumgartner, The Overrated Effect of Cholera and Typhoid Fever on Sanitary Reform: The Case of Linz, in: Environment \& Society Portal, Arcadia (Spring 2017), No. 6. Rachel Carson Center for Environment and Society, https:// doi.org/I0.5 282/rcc/7746 [20.2.2019].

Pichler-Baumgartner, Weg = Luisa Pichler-Baumgartner, Der Weg zu einer modernen Wasserinfrastruktur. Eine sozial- und umweltgeschichtliche Perspektive auf die Stadt Linz (ca. I 860- I 920), unveröffentlichte Dissertation, Universität Salzburg, 20I7 [Druckfassung mit gleichem Titel Linz 2020].

Pillich, Donaureise $=$ Walter Pillich, Die Donaureise des kaiserlichen Gesandten Ferdinand Bonaventura Graf Harrach im Jahre I698, in: HistJbL I 962, 502 - 5 I 4.

Pillwein, Beschreibung = Benedikt Pillwein, Beschreibung der Provinzial-Hauptstadt Linz und ihrer nächsten Umgebung [...], Linz I 824 .

Pillwein, Linz = Benedict Pillwein, Linz, Einst und Jetzt, von den ältesten Zeiten bis auf die neuesten Tage. 2 Bde., Linz I 846. 
Pillwein, Wegweiser = Benedikt Pillwein, Neuester Wegweiser durch Linz und seine nächste Umgebung [...], Linz I 837 .

Platt, Shock = Harold L. Platt, Shock Cities. The Environmental Transformation and Reform of Manchester and Chicago, Chicago/London 2005.

Pochmann, Cholerapilz-Maßregeln = Emanuel Pochmann, Die Cholerapilz-Maßregeln von Prof. Robert Koch mit ihren Irrthümern und Gefahren und das Cholera-Elend in Hamburg [...], Linz I 892 .

Polesny, Turnen $=$ Herbert Polesny, Turnen in Linz. Aus Anlaß der vor I 25 Jahren erfolgten Gründung des »Linzer Turnvereines«, in: HistJbL г 986, г 2 I - I67.

Pribram, Materialien = Alfred F. Pribram, Materialien zur Geschichte der Preise und Löhne in Österreich, Wien 1938.

Promitzer/Speta, Naturgeschichte $=$ Christian Promitzer/Franz Speta, Naturgeschichte im josephinischen Linz. Ignaz Schiffermüller und der »ökonomisch-botanische Garten« beim Bergschlössl, in: HistJbL i 989, 45-66.

Puffer, Heimatstadt $=$ Emil Puffer, So sah ich meine Heimatstadt. Aus den Erinnerungen des Linzer Primars Dr. Fritz Reiß, in: HistJbL i 987 , I 45 - I 80.

Rabiosus, Reise, Bd. I = Anselmus Rabiosus, Reise nach dem Kürbislande im Jahre I779 [...], s.1. [Wien] I782.

Rabiosus, Reise, Bd. 3 = Anselmus Rabiosus, Reise nach dem Kürbislande im Jahre I 78 I. Dritter Theil, Krammerstetten/Leipzig I 783 .

Radkau, Natur = Joachim Radkau, Natur und Macht. Eine Weltgeschichte der Umwelt, München 2000.

Radkau, Rätsel = Joachim Radkau, Das Rätsel der städtischen Brennholzversorgung im »hölzernen Zeitalter«, in: Dieter Schott, Hg., Energie und Stadt in Europa. Von der vorindustriellen »Holznot« bis zur Ölkrise der I 97oer Jahre, Stuttgart I997, 43-75.

Rafetseder, Variationen = Hermann Rafetseder, Variationen Linzer Kommunalwirtschaft im 20. Jahrhundert, in: Fritz Mayrhofer/Walter Schuster, Hg., Linz im 20. Jahrhundert. Beiträge, Linz 2010, 369-518.

Rafetseder, Verstaatlichung = Hermann Rafetseder, Von der »Verstaatlichung «ur »Entstaatlichung« am Beispiel der Linzer Industrie, in: Fritz Mayrhofer/Walter Schuster, Hg., Linz im 20. Jahrhundert. Beiträge, Linz 2010, 927 - 1008.

Rausch, Urbański = Wilhelm Rausch, Josef Urbański. Dem geistigen Vater der Pöstlingbergbahn zur Ehrenrettung, in: HistJbL i 958, 33 I-358.

Rechenschaftsbericht $[\mathrm{RB}]=$ Rechenschaftsbericht des Gemeinderathes der Landeshauptstadt Linz über seine Thätigkeit [...], Linz I 879- г 90 г.

Reichert, Pest $=$ Ramon Reichert, Auf die Pest antwortet die Ordnung. Zur Genealogie der Regierungsmentalität I 700-I800, in: Österreichische Zeitschrift für Geschichtswissenschaft 7 (1996), 327-357.

Reinberg, Blicke = Kaspar Reinberg [i.e. Anton Cremeri], Blicke und Wahrheiten auf und über die Krankenhäuser der barmherzigen Brüder und Elisabethinerinnen [...], Frankfurt/Leizpig I 784 .

Reiseabentheuer $=$ Reiseabentheuer des Hans-Jörgels von Gumpoldskirchen, auf einer Luftfahrt von Wien nach Gratz und zurück über Leoben [...], Wien I 84r. 
Reith et al., Haushalten = Reinhold Reith et al., Hg., Haushalten und Konsumieren. Die Ausgabenbücher der Salzburger Kaufmannsfamilie Spängler von I 733 bis I 785, Salzburg 2016.

Reith, Umweltgeschichte $=$ Reinhold Reith, Umweltgeschichte der Frühen Neuzeit, München $201 \mathrm{II}$.

Richter, Reise $=[$ Joseph Richter], Reise von Wien nach Paris. In Briefen an einen Freund, Wien I78 I.

Risbeck, Briefe $=$ K. R. [i.e. Johann Kaspar Risbeck], Briefe eines reisenden Franzosen über Deutschland an seinen Bruder zu Paris, Bd. I, s.l. I784.

Rohr, Naturereignisse $=$ Christian Rohr, Extreme Naturereignisse im Ostalpenraum. Naturerfahrung im Spätmittelalter und am Beginn der Neuzeit, Köln/Wien/Weimar 2007.

Rohr, Überschwemmungen = Christian Rohr, Überschwemmungen an der Traun zwischen Alltag und Katastrophe. Die Welser Traunbrücke im Spiegel der Bruckamtsrechnungen des I 5 . und I6. Jahrhunderts, in: Jahrbuch des Musealvereines Wels 33 (200I-3), $28 \mathrm{I}-327$.

Rosen/Tarr, Importance $=$ Christine M. Rosen/Joel A. Tarr, The Importance of an Urban Perspective in Environmental History, in: Journal of Urban History 20/3 (I 994), 299-3 10.

Rosenauer, Donau = Franz Rosenauer, Die Donau bei Linz. Hundert Jahre Stromregelungsarbeiten; in: JbL I 937, 76-87.

Rosseaux, Städte = Ulrich Rosseaux, Städte in der Frühen Neuzeit, Darmstadt 2006.

Rottleuthner, Gewichte $=$ Wilhelm Rottleuthner, Alte lokale und nichtmetrische Gewichte und Maße und ihre Größen nach metrischem System. Ein Beitrag in Übersichten und Tabellen, Innsbruck 1985 .

Rumpler/Urbanitsch, Habsburgermonarchie = Helmut Rumpler/Peter Urbanitsch, Hg., Die Habsburgermonarchie I 848-i 9 1 8 . Bde. 8 u. 9, Wien 2006/2010.

Sablonier, Wasser = Roger Sablonier, Wasser und Wasserversorgung in der Stadt Zürich vom I 4 . zum I 8. Jahrhundert, in: Zürcher Taschenbuch I 985 , Zürich I984, I- 28.

Sammlung $=$ Sammlung aller k.k. Verordnungen und Gesetze vom Jahre I740 bis I 780 [...]. Bd. 6, Wien 1786.

Sandgruber, Anfänge = Roman Sandgruber, Die Anfänge der Konsumgesellschaft. Konsumgüterverbrauch, Lebensstandard und Alltagskultur in Österreich im I8. und I 9. Jahrhundert, Wien 1982.

Sandgruber, Grenzen = Roman Sandgruber, Die Grenzen der Stadt, in: Fritz Mayrhofer/Walter Schuster, Hg., Linz im 20. Jahrhundert. Beiträge, Linz 2010, 57-91.

Sandgruber, Lebensstandard = Roman Sandgruber, Lebensstandard und Ernährung in Oberösterreich im I8. und I9. Jahrhundert, in: Österreich in Geschichte und Literatur 2 I (I977), 273-294.

Sandgruber, Ökonomie = Roman Sandgruber, Ökonomie und Politik. Österreichische Wirtschaftsgeschichte vom Mittelalter bis zur Gegenwart, Wien I 995 .

Sartori, Reise $=$ Franz Sartori, Neueste Reise durch Oesterreich ob und unter der Ens [...]. Bd. I, Wien I 8 I I.

Schadler, Karte = Josef Schadler, Geologische Karte von Linz und Umgebung, Linz I 966.

Schaller, Linz = Martin Schaller, Linz im Blick von außen. Beschreibungen der Stadt von britischen Reisenden um die Mitte des I 9. Jahrhunderts, in: Jahrbuch des Adalbert-StifterInstituts des Landes Oberösterreich 25 (2018), I 47-I 57. 
Schamberger/Leupold, Brandschutzgeschichte $=$ Rolf Schamberger/Daniel Leupold, Brandschutzgeschichte, Stuttgart 2015.

Schematismus I 835 = Kaiserlich Königlicher Schematismus des Erzherzogthums Oesterreich ob der Enns für das Jahr I 835, Linz s.a. [1834].

Scheutz, Persistenz = Martin Scheutz, Die Persistenz schlechter Luft und der Charme der Peripherie. Krankenhäuser in der österreichischen Stadt der Neuzeit, in: Lukas Morscher/Walter Schuster/Martin Scheutz, Hg., Orte der Stadt im Wandel vom Mittelalter bis zur Gegenwart, Innsbruck 2013, 473-508.

Schiedermayr, Sanitätsverhältnisse = Carl Schiedermayr, Die Sanitätsverhältnisse der Landeshauptstadt Linz und der eventuelle Einfluss einer Wasserleitung auf dieselben. Vortrag des Referenten im oberösterr. Landes-Sanitätsrathe, gehalten in der Sitzung des Landes-Sanitätsrathes am 6. April I 88 I, Linz I 882.

Schindler, Konflikte $=$ Norbert Schindler, Die Konflikte um das Salzburger Wetterläutverbot von 1785 . Zum pragmatischen Gebrauch der Mikrogeschichte, in: Ewald Hieb1/Ernst Langthaler, Hg., Im Kleinen das Große suchen. Mikrogeschichte in Theorie und Praxis. Festschrift für Hanns Haas zum 7o. Geburtstag, Innsbruck/Wien/Bozen 20 1 2, Io6- I 20.

Schmid, Stadt $=$ Christian Schmid, Stadt, Raum und Gesellschaft. Henri Lefebvre und die Theorie der Produktion des Raumes, Stuttgart 2005.

Schmidt, Linz = Justus Schmidt, Linz in alten Ansichten, Salzburg I 965 .

Schneider, Entwicklung = Günter Schneider, Die Entwicklung des niederösterreichischen Feuerwehrwesens bis I 870 und die Einflüsse aus Deutschland, Tulln I 993.

Schott, Cities = Dieter Schott, Energizing European Cities: From Wood Provision to Solar Panels - Providing Energy for Urban Demand, I 80o-200o, in: Tim Soens et al., Hg., Urbanizing Nature. Actors and Agency (Dis)Connecting Cities and Nature Since I 500, New York 2019, I35-156.

Schott, Energie = Dieter Schott, Energie und Stadt in Europa. Von der vorindustriellen »Holznot« bis zur Ölkrise der r 97oer Jahre. Einführung, in: ders., Hg., Energie und Stadt in Europa. Von der vorindustriellen »Holznot« bis zur Ölkrise der I 97oer Jahre, Stuttgart I 997, 7-42.

Schott, Fluss = Dieter Schott, Stadt und Fluss: Flüsse als städtische Umwelten im r 9. und 2o. Jahrhundert, in: Bernd Herrmann, Hg., Beiträge zum Göttinger Umwelthistorischen Kolloquium 2004-2006, Göttingen 2007, I4I- I62.

Schott, Modernität $=$ Dieter Schott, Symbolische Modernität und die elektrische Vernetzung der Stadt, oder: Stadtentwicklung als Drahtseilakt, in: Heidemarie Uhl, Hg., Kultur - Urbanität - Moderne. Differenzierungen der Moderne in Zentraleuropa um I 900, Wien I 999, $287-320$.

Schott, Resources $=$ Dieter Schott, Resources of the City: Towards a European Urban Environmental History, in: ders./Bill Luckin/Geneviève Massard-Guilbaud, Hg., Resources of the City. Contributions to an Environmental History of Modern Europe, Aldershot 2005, I - 27.

Schott, Stadt = Dieter Schott, Die europäische Stadt und ihre Umwelt. Einleitende Bemerkungen, in: ders./Michael Toyka-Seid, Hg., Die europäische Stadt und ihre Umwelt, Darmstadt $2008,7-26$.

Schott, Urbanisierung = Dieter Schott, Europäische Urbanisierung $($ гоoo-2000). Eine umwelthistorische Einführung, Köln/Weimar/Wien 20 I 4. 
Schrank/Moll, Briefe $=$ Franz de Paula Schrank/Karl Maria Ehrenbert v. Moll, Naturhistorische Briefe über Oestreich, Salzburg, Passau und Berchtesgaden, Bd. r, Salzburg I 785.

Schreinzer, Methode $=$ Edmund Schreinzer, Clarks Methode der Härtebestimmung des Wassers, angewendet auf Linzer Trinkquellen, in: Jahres-Bericht der kaiserl. königl. Ober-Realschule in Linz für das Schul-Jahr I 8 53/54, 9- I 4 .

Schröckinger-Neudenberg, Reisegefährte = Julius v. Schröckinger-Neudenberg, Reisegefährte durch Ober-Österreichs Gebirgsland. Ein Wegweiser in Linz und seiner Umgebung [...], Linz I 84I.

Schuhladen, Einführung = Hans Schuhladen, Zur Einführung der Kartoffel im Salzburgischen . Ein Beispiel lenkender Sorge um die Bevölkerung durch Vertreter der Volksaufklärung, in: Ingolf Bauer/Edgar Harvolk/Wolfgang A. Mayer, Hg., Forschungen zur historischen Volkskultur. Festschrift für Torsten Gebhard zum 80. Geburtstag, München I 989, 309-338.

Schultes, Donau-Fahrten = J. A. Schultes, Donau-Fahrten. Ein Handbuch für Reisende auf der Donau, Bd. 2, Stuttgart/Tübingen I 827 .

Schultes, Stifter $=$ Lothar Schultes, Adalbert Stifter als Zeichner und Maler. In: Jahrbuch des Oberösterreichischen Musealvereines I 52 (2007), 237-300.

Schwab/Schwarz/Wenzel, Beobachtungen = Franz Schwab/Thiemo Schwarz/Gallus Wenzel, Ueber die bisher in Oberösterreich angestellten meteorologischen und geophysikalischen Beobachtungen [...], Linz I 896.

Schweiger, Stadt $=$ Anneliese Schweiger, Die Stadt Linz in den Napoleonischen Kriegen. Die französischen Besetzungen der Stadt in den Jahren I800, I805 und I 809 und deren wirtschaftliche Auswirkungen, in: HistJbL r 980, ro9- 98.

Scott, Seeing = James C. Scott, Seeing Like a State. How Certain Schemes to Improve the Human Condition Have Failed, New Haven/Conn. u.a. I 998.

Seelinger, Grundlagen = Franz Seelinger, Grundlagen der Linzer Stadtplanung, Linz i 968.

Shields Mevissen, Circumstances $=$ Robert Shields Mevissen, Meandering Circumstances, Fluid Associations: Shaping Riverine Transformations in the Late Habsburg Monarchy, in: Austrian History Yearbook 49 (2018), 23-40.

Silló-Menzel, Oxenweg = Ágnes Silló-Menzel, Der europäische Oxenweg damals und heute. Ein historischer Reiseführer, Aichach 2015.

Sima, Pferdeeisenbahn = Johannes Sima, Die Pferdeeisenbahn Budweis - Linz - Gmunden . Ein Beispiel der Technikgeschichte aus der Sicht des Denkmalschutzes, unveröffentlichte Dissertation, TU Wien, 2008.

Soens, Agriculture $=$ Tim Soens, Urban Agriculture and Urban Food Provisioning in Pre- 1850 Europe: Towards a Research Agenda, in: Erich Landsteiner/Tim Soens, Hg., Farming the City. The Resilience and Decline of Urban Agriculture in European History. Resilienz und Niedergang der städtischen Landwirtschaft in der europäischen Geschichte, Innsbruck/ Wien $2020, \mathrm{I}_{3}-28$.

Soens et al., Cities = Tim Soens et al., Introduction: Did Cities Change Nature? A Long-Term Perspective, in: ders. et al., Hg., Urbanizing Nature. Actors and Agency (Dis)Connecting Cities and Nature Since I 500, New York 201 9, 3-25.

Sommer/Müller-Wille/Reinhardt, Handbuch = Marianne Sommer/Staffan Müller-Wille/ Carsten Reinhardt, Hg., Handbuch Wissenschaftsgeschichte, Stuttgart 2017.

Sonnlechner/Winiwarter, Verbrauch = Christoph Sonnlechner/Verena Winiwarter, Räumlich 
konzentrierter Verbrauch von Holz. Das Beispiel der Saline Hallein und der Stadt Salzburg vom I6. bis zum i 9. Jahrhundert, in: Wolfram Siemann/Nils Freytag/Wolfgang Piereth, Hg., Städtische Holzversorgung. Machtpolitik, Armenfürsorge und Umweltkonflikte in Bayern und Österreich (I 750- I 850), München 2002, 55-77.

Stadler, Armee-Spital = Gerhard A. Stadler, Vom Armee-Spital zum modernen Krankenhaus. Ein Abriß der Baugeschichte des Allgemeinen Öffentlichen Krankenhauses in Linz, in: HistJbL I 989, 85- Iо2.

Stadler, Wasserversorgung = Rudolf Stadler, Die Wasserversorgung der Stadt Wien in ihrer Vergangenheit und Gegenwart [...], Wien I 873 .

Starke, Kohlenbergbau = Karl Starke, Kohlenbergbau im oberösterreichischen Hausruck. Frühzeit I 760-1860, Wien/Zürich I 988.

Statistischer Bericht I $872=$ Statistischer Bericht der Handels- und Gewerbekammer Oberösterreichs zu Linz [...], über die gesammte Produktion ihres Bezirkes nach den Ergebnissen des Jahres I 870 , Linz I 872 .

Statistischer Bericht I 876 = Statistischer Bericht der Handels- und Gewerbekammer Oberösterreichs zu Linz über die gesammten wirthschaftlichen Verhältnisse Oberösterreichs [...], Linz 1876.

Statistischer Bericht $1882=$ Statistischer Bericht über die gesammten [sic] wirthschaftlichen Verhältnisse Oberösterreichs in den Jahren I 876- I880 [...]. 3. Bde., Linz I 882.

Stauber, Ephemeriden $=$ Franz X. Stauber, Historische Ephemeriden über die Wirksamkeit der Stände von Österreich ob der Enns, Linz I 884.

Steege et al., History = Paul Steege et al., The History of Everyday Life: A Second Chapter, in: The Journal of Modern History 80 (2008), 358-378.

Stifter, $\mathrm{HKG}=$ Adalbert Stifter Werke und Briefe. Historisch-kritische Gesamtausgabe. Bd. 8/3, Stuttgart 2012.

Stifter, PRA = Adalbert Stifters sämtliche Werke. Bde. I7-24, Reichenberg/Prag I 916- I939. Stifters sämtliche Werke, Bd. 25 = Adalbert Stifters sämtliche Werke, Bd. 25 , Hildesheim 1979. Stöger, Konsumieren = Georg Stöger, Zwischen Konsumieren und Produzieren: Dinge und ihre

Nutzer*innen im I 8. Jahrhundert, in: Österreichische Zeitschrift für Geschichtswissenschaften 30/I (2019), I 24- I43.

Stöger, Markets = Georg Stöger, Urban Markets for Used Textiles. Examples from EighteenthCentury Central Europe, in: Bruno Blondé/Jon Stobart, Hg., Selling Textiles in the Long Eighteenth Century. Comparative Perspectives from Western Europe, Basingstoke 2014, $210-225$.

Stöger, Märkte = Georg Stöger, Sekundäre Märkte ? Zum Wiener und Salzburger Gebrauchtwarenhandel im I 7. und I 8. Jahrhundert, Wien/München 20I I.

Stöger, Re-use = Georg Stöger, Re-use and Recycling in Western European Cities, in: Tim Soens et al., Hg., Urbanizing Nature. Actors and Agency (Dis)Connecting Cities and Nature Since I 500 , London u.a. 2019, I 57-176.

Stöger, Sustainability = Georg Stöger, Premodern Sustainability? The Secondhand and Repair Trade in Urban Europe, in: Ruth Oldenziel/Helmuth Trischler, Hg., Cycling and Recycling. Histories of Sustainable Practices, New York/Oxford 2016, I 47- I67.

Stöger/Reith, Recycling = Georg Stöger/Reinhold Reith, Western European Recycling in a 
Long-Term Perspective. Reconsidering Caesuras and Continuities, in: Jahrbuch für Wirtschaftsgeschichte 2015/1, 267-290.

Stöger/Reith, Tobakier = Georg Stöger/Reinhold Reith, Für ein silberne Tobakier zu vergoldten . Eine Annäherung an die Dinge im Haushalt, in: Reinhold Reith et al., Hg., Haushalten und Konsumieren. Die Ausgabenbücher der Salzburger Kaufmannsfamilie Spängler von I 733 bis I 785 , Salzburg 20I6, I35-I 5 I.

Štorm, Occultist $=$ František Štorm, Master's Hammer. The Jilemnice Occultist, Praha I 993.

Strasser, Waste = Susan Strasser, Waste and Want. A Social History of Trash. New York I 999.

Straßmayr, Schmiedtor = Eduard Straßmayr, Das Linzer Schmiedtor, in: Jahrbuch des oberösterreichischen Musealvereines 82 (I 928 ), I $29-$ I 42 .

Streitt/Schiller/Stadler, Eisenbahnbrücke = Ute Streitt/Elisabeth Schiller/Gerhard A. Stadler, Hg., Die Linzer Eisenbahnbrücke. Von der Neuen Brücke zur Alten Dame, Weitra 20 I6.

Strömmer, Klima-Geschichte $=$ Elisabeth Strömmer, Klima-Geschichte. Methoden der Rekonstruktion und historische Perspektive. Ostösterreich I 700 bis I 830, Wien 2003.

Suter, Wasser = Elisabeth Suter, Wasser und Brunnen im alten Zürich. Zur Geschichte der Wasserversorgung der Stadt vom Mittelalter bis ins I 9. Jahrhundert, Zürich I 98 I.

Swyngedouw, Urbanization = Erik Swyngedouw, Metabolic Urbanization. The Making of Cyborg Cities, in: Nik Heynen/Maria Kaika/Erik Swyngedouw, Hg., In the Nature of Cities. Urban Political Ecology and the Politics of Urban Metabolism, London/New York 2006, $2 \mathrm{I}-4 \mathrm{O}$.

Swyngedouw/Kaika, Environment = Erik Swyngedouw/Maria Kaika, The Environment of the City ... or the Urbanization of Nature, in: Gary Bridge/Sophie Watson, Hg., A Companion to the City, Oxford 2000, $567-580$.

Tarr, History = Joel Tarr, Urban History and Environmental History in the United States: Complementary and Overlapping Fields, in: Christoph Bernhardt, Hg., Environmental Problems in European Cities in the I 9 th and 20 th Century. Umweltprobleme in europäischen Städten des I 9. und 20. Jahrhunderts, Münster u. a. 200I, 25-39.

Tarr, Metabolism = Joel A. Tarr, The Metabolism of the Industrial City. The Case of Pittsburgh, in: Journal of Urban History 28/5 (2002), 5 I I -545.

Tarr, Search = Joel A. Tarr, The Search for the Ultimate Sink. Urban Pollution in Historical Perspective, Akron I 996.

Tello/Ostos, Water = Enric Tello/Joan Ramon Ostos, Water Consumption in Barcelona and Its Regional Environmental Imprint. A Long-Term History ( 7 I 7-2008), in: Regional Environmental Change I2 (2012), 347-36r.

Thiel, Papiererzeugung = Viktor Thiel, Papiererzeugung und Papierhandel vornehmlich in den deutschen Landen von den ältesten Zeiten bis zum Beginn des I 9. Jahrhunderts. Ein Entwurf, in: Archivalische Zeitschrift 4I (1932), ro6-I 5 I.

Thünen, Staat = Johann Heinrich v. Thünen, Der isolirte Staat in Beziehung auf Landwirthschaft und Nationalökonomie [...], Hamburg I 826 .

Thürheim, Feldmarschall $=$ Andreas Joseph v. Thürheim, Feldmarschall Ludwig Andreas Graf von Khevenhüller-Frankenburg [...], Wien I 878 .

Tomory, Water = Leslie Tomory, London's Water Supply before $\mathrm{r} 800$ and the Roots of the Networked City, in: Technology and Culture 56 (2015), 704-737. 
Topitz, Geschichte $=$ Alois Topitz, Zur Geschichte der Linzer Klimastationen, in: JbL I 952 , $539-544$.

Tweraser, Gemeinderat $=$ Kurt Tweraser, Der Linzer Gemeinderat I880-I9I4. Glanz und Elend bürgerlicher Herrschaft, in: HistJbL I 979, 293-34I.

Tweraser, Parteiensystem $=$ Kurt Tweraser, Das politische Parteiensystem im Linzer Gemeinderat, in: Fritz Mayrhofer/Walter Schuster, Hg., Linz im 20. Jahrhundert. Beiträge, Linz 2010, 93-2 10.

Uekötter, Umweltgeschichte $=$ Frank Uekötter, Umweltgeschichte im I 9. und 20. Jahrhundert, München 2007 .

Van Lieshout, Droughts = Carry Van Lieshout, Droughts and Dragons: Geography, Rainfall, and Eighteenth-Century London's Water Systems, in: Technology and Culture 57 (2016), $780-805$.

Veichtlbauer, Strombaukunst = Ortrun Veichtlbauer, Von der Strombaukunst zur Stauseenkette. Die Regulierung der Donau; in: Verena Winiwarter/Martin Schmid, Hg., Umwelt Donau. Eine andere Geschichte [...], St. Pölten 2010, 57-73.

Verzeichniß I 825 = Kaiserlich-Königlicher Schematismus des Erzherzogthums Oesterr. ob der Enns auf das Jahr I 825. 2. Teil, Linz s.a. [1824].

Wacha, Fische $=$ Georg Wacha, Fische und Fischhandel im alten Linz, in: Naturkundliches Jahrbuch der Stadt Linz 2 (I 956), 6 I - I I 7 .

Wacha, Obstgarten = Georg Wacha, Ein Linzer Obstgarten Anno I729, in: Naturkundliches Jahrbuch der Stadt Linz I (I 955), i I 9- I 26.

Wacha, Sparkasse = Georg Wacha, Die »Allgemeine Sparkasse« und Linz I 849- I 9 I 4, in: HistJbL 200I, 29I-33I.

Waldhauser, Predigt = Johann Evangelist Waldhauser, Predigt am zwölften Sonntage nach Pfingsten bey Gelegenheit der grossen Feuersbrunst, die am I 5ten August I 800 die Hälfte der Stadt in Asche legte [...], Linz s.a. [180o].

Weber, Urbanisierung = Heike Weber, Urbanisierung und Umwelt: Ein Plädoyer für den Blick auf Materialitäten, Ressourcen und urbane »Metabolismen«, in: Informationen zur modernen Stadtgeschichte 201 2/2, 28-35.

Weigl, Existenzsicherung = Andreas Weigl, Von der Existenzsicherung zur Wohlstandsgesellschaft. Überlebensbedingungen und Lebenschancen in Wien und Niederösterreich von der Mitte des r 9. Jahrhunderts bis zur Gegenwart, Wien/Köln/Weimar 2020.

Weigl, Wandel = Andreas Weigl, Demographischer Wandel und Modernisierung in Wien, Wien 2000.

Westermann, Forschungsaufgaben = Ekkehard Westermann, Forschungsaufgaben des internationalen Ochsenhandels aus mitteleuropäischer Sicht, in: ders., Hg., Internationaler Ochsen-

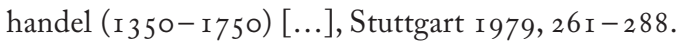

White/Pfister/Mauelshagen, Handbook = Sam White/Christian Pfister/Franz Mauelshagen, Hg., The Palgrave Handbook of Climate History, London 2018.

Willebrand, Berichte $=$ Des Herrn Johann Peter Willebrand [...] Historische Berichte und Practische Anmerkungen auf Reisen in Deutschland und andern Ländern, Leipzig I 769.

Williams, Ideas = Raymond Williams, Ideas of Nature, in: ders., Problems in Materialism and Culture. Selected Essays, London/New York i 980, 67-85. 
Wimmer, Geschicke = Julius Wimmer, Die Geschicke des Oberösterreichischen Musealvereines durch neunzig Jahre [...], Linz I 923 .

Winckler, Übersicht = Johann Winckler, Übersicht des Schiffs- und Waarenverkehrs auf der Oberen Donau zu Wien, Linz und Engelhartszell in den Jahren I 849- I 869, Wien I 870.

Winiwarter et al., Evolution = Verena Winiwarter et al., The Long-Term Evolution of Urban Waters and Their Nineteenth Century Transformation in European Cities. A Comparative Environmental History, in: Water History 8/3 (2016), 209-233.

Winiwarter/Knoll, Umweltgeschichte = Verena Winiwarter and Martin Knoll, Umweltgeschichte. Eine Einführung, Köln/Weimar/Wien 2007.

Winiwarter/Schmid/Dressel, Danube = Verena Winiwarter/Martin Schmid/Gert Dressel, Looking at Half a Millennium of Co-Existence. The Danube in Vienna as a socio-natural site, in: Water History 5 (2013), Ior - I I 9.

Winkler, Stadtbrände = Claudia Winkler, »Wohltätig ist des Feuers Macht, wenn sie der Mensch bezähmt, bewacht«. Stadtbrände und Feuerordnungen in Wels vor Gründung der Freiwilligen Feuerwehr, unveröffentlichte Diplomarbeit, Universität Salzburg, 2008.

Wollstonecraft Shelley, Rambles = Mary Wollstonecraft Shelley, Rambles in Germany and Italy in I 840 , I 842 , and I 843 . Bd. 2 , London I 844 .

Woodward, Swords = Donald Woodward, »Swords into Ploughshares«. Recycling in Pre-Industrial England, in: The Economic History Review 38/2 (I 985), I 75 - I 9 I.

Záloha, Geschichte = Jirí Záloha, Zur Geschichte der Holzausfuhr aus Böhmen nach Österreich in der 2. Hälfte des i 9. Jahrhunderts [...], in: Jahrbuch des Oberösterreichischen Musealvereines I 20 (I 975), 257-269.

Záloha, Tagebücher = Jirí Záloha, Aus den Tagebüchern des Ing. Josef Langweil, in: HistJbL I 979, I23-I37.

Zöhrer, Linz = Ferdinand Zöhrer, Linz a/d. Donau. Culturhistorisch und topographisch geschildert, Zürich I 89г.

Zotl, Geschichte = Gottfried Zotl, Die Geschichte der Linzer Luft, unveröffentlichte Diplomarbeit, Universität Linz, I 993.

Zumbrägel, Holzströme = Christian Zumbrägel, Die vorindustriellen Holzströme Wiens. Ein sozionaturales großtechnisches System?, in: Technikgeschichte 8 I (2014), 335-362.

Zwierlein, Prometheus = Cornel Zwierlein, Der gezähmte Prometheus. Feuer und Sicherheit zwischen Früher Neuzeit und Moderne, Göttingen 20 I I. 


\section{Anhang}

\section{Verzeichnis der Tabellen und Grafiken}

Tabelle r: Temperaturextreme in narrativen Quellen und in Klimarekonstruktionen, I70oI 850

Tabelle 2: Einwohnerzahlen für die Stadt Linz und die Vorstädte, r 700- I 900

Tabelle 3: Kinder- und Säuglingssterblichkeit, I 807-18 16

Tabelle 4: Linzer Taglöhne in Rindfleisch, I 700- I 900

Tabelle 5: Gewerbetreibende in Linz, I 822 und 1875

Tabelle 6: Städtische Ausgaben, I 700- r 900

Tabelle 7: Etablierung von städtischer Infrastruktur im I 9. Jahrhundert

Tabelle 8: Etablierung zentraler Wasserversorgung in Österreich

Tabelle 9: Holzeinfuhr nach Linz I 834 gemäß Verzehrsteuer

Tabelle ıо: Waldfächen in Linz und den Vorstädten, I 78 oer bis I $870 e r$ Jahre

Tabelle I I : Brennholzerträge im Linzer Raum (gerundet), I 78 oer und I $820 e r$ Jahre

Tabelle r 2: Über die Donau in Linz angekommenes Brennmaterial, I 849- I 868

Tabelle 1 3: Pro-Kopf-Verbrauch von Brennholz und Kohle in Linz, I 834- 1905

Tabelle I4: Preisentwicklung von Brennholz und Kohle in Linz, I 876 - 1899

Tabelle 15: Pferde in Linz, I83 I - I900

Tabelle r6: Einfuhr von Lebensmitteln gemäß Verzehrsteuer, I 83 oer und I 85 oer Jahre

Tabelle I7: Linzer Fleisch- und Getreidekonsum pro Kopf, I 834-1905

Tabelle ı 8: Landwirtschaftlich genutzte Flächen in Linz, I 78 oer bis I 87 oer Jahre

Tabelle 19: Ernteerträge im Linzer Raum (gerundet), Ende der I 78 oer Jahre

Tabelle 20: Erzeugung und Verbrauch von Getreide pro Kopf/Jahr in Oberösterreich, I 77oer Jahre bis I 9 Io

Tabelle 2 I: Über die Donau in Linz angekommene Lebensmittel, I 849- I868

Tabelle 22: Ausgewählte Einnahmen und Ausgaben des städtischen Brückenamtes, I7I 3 und I7 6

Tabelle 23: Preise für ein einfaches neues Leinenhemd, I 865- I 894

Tabelle 24: Akteure auf sekundären Märkten in Oberösterreich und Linz, I859-1900

Tabelle 25: Pfandleihanstalt der »Allgemeinen Sparkasse« in Linz, I 849- I 875

Tabelle 26: Zahlungen der Stadt Linz an den »Nachtarbeiter « Paul Wallinger, I 8 I 6

Tabelle 27: Kanalbauten in Linz, I82 I - I 840

Tabelle 28: Donauregulierungen im Linzer Raum, I 850- I 860

Tabelle 29: Entwicklung der »öffentlichen« Straßenbeleuchtung, I760 bis I 900

Tabelle 30: Sterbefälle in der Pfarre Linz, I 7 Io- I 7 I 5, I 730- I 744 und I 758- I 767

Tabelle 3 I: Behandlungen und Todesfälle in den beiden Linzer Ordenskrankenhäusern, I 77 I I 854

Tabelle 32: Getreidepreise in Linz, I767-r 77 I und 1786

Tabelle 33: Sterbefälle in der Pfarre Linz, I765-1774 
Tabelle 34: Sterbefälle in den Linzer Pfarren, I 800- I 8 I 9

Tabelle 35 : Getreide- und Brotpreise in Linz, I 8 I 6

Tabelle 36: Getreide- und Brotpreise in Linz, I 8 I 7

Tabelle 37: Ausgewählte Maximalpegelstände der Donau bei Linz, I 784- I 899

Tabelle 38 : Feuerlöschgeräte und Feuerschutzbauten in Stadt und Vorstädten, um I 700

Grafik I : Sterbefälle in Linz pro r.ooo Einwohner, I 700- I 900 (eigene Darstellung)

Grafik 2: Sterbefälle in Linz, Urfahr und Kleinmünchen, I70o- I 900 (eigene Darstellung)

Grafik 3: Preisentwicklung für Ernährung und Getränke, I 80o - г 9oo (eigene Darstellung)

Grafik 4: Lebensmittelpreise in Oberösterreich, r 827- 1856 (eigene Darstellung)

\section{Abbildungsnachweis}

Abbildung r : Der Großraum von Linz zur Mitte der r 8 2oer Jahre (eigene Darstellung)

Abbildung 2: Stadt und Vorstädte in den I73oer Jahren (eigene Darstellung)

Abbildung 3: Stadt und Vorstädte in den I 8 2oer Jahren (eigene Darstellung)

Abbildung 4: Stadt und Vorstädte um r 900 (eigene Darstellung)

Abbildung 5: Geologie des Linzer Raumes (eigene Darstellung)

Abbildung 6: Ausgewählte lokale Toponyme und Baulichkeiten (eigene Darstellung)

Abbildung 7: Der Großraum von Linz um r 900 (eigene Darstellung)

Abbildung 8: Wasserleitung des Schlosses, Plan von r 848 (OÖLA, Karten- und Plänesammlung, VI/25)

Abbildung 9: Die »Allgemeine Wasserleitung«, Plan von I 899 (Rechenschaftsbericht des Gemeinderathes der Landeshauptstadt Linz I 899)

Abbildung ro: Johann Adam Klein, Linzer Schiffmühle, Zeichnung von i 8 I 5 (Kunstsammlungen der Stadt Nürnberg, Inventar-Nr. Norica I I 4 )

Abbildung i : : Gartenanlage von Franz Joseph Weber, Plan von I775 (OÖLA, Karten- und Plänesammlung, XII/9I)

Abbildung I 2: [Vorname unbekannt] Hartenstein, Das Urfahrer Platzl, Aquarell von I 820 (Privatbesitz)

Abbildung I 3 : Zeitungsanzeige, I 842 (Linzer Zeitung/Intelligenzblatt, I 8.7. I 842)

Abbildung I 4: Zeitungsanzeigen, i 887 u. I880 (Linzer Volksblatt, 7. Io. 877 u. [Linzer] TagesPost, 22.2.1880)

Abbildung I 5 : Kanalisationsprojekt im Stadtgraben, Plan von i 800 (OÖLA, Karten- und Plänesammlung, VI/26)

Abbildung r6: Das Lazarett im Wörth, Plan von r 840 (OÖLA, Karten- und Plänesammlung, $\mathrm{XII} / 66)$

Abbildung I7: Bestehende und geplante Kanäle, Plan von i88 I (eigene Darstellung basierend auf Rechenschaftsbericht des Gemeinderathes der Landeshauptstadt Linz i 88 I)

Abbildung I 8: Belagerung von Linz I 74 I/42, undatiertes und unsigniertes Gemälde (Nordico Stadtmuseum Linz, G 38 r; Reproduktion: Thomas Hackl)

Abbildung r 9: Adalbert Stifter [zugeschrieben], Die Strasserau bei Linz, Gemälde um r 850 (Wikimedia Commons) 
Abbildung 20: Die hölzerne Donaubrücke, otographie um I 865 (Nordico Stadtmuseum Linz, NWA-oo $0_{2}$; Reproduktion: Thomas Hackl)

Abbildung 21: Strasserinsel und Fabrikarm, Photographie um r89 I (Nordico Stadtmuseum Linz, NA-0 5 I025; Reproduktion: Thomas Hackl)

Abbildung 22: Stadt und Fluss zum Ende des I 9. Jahrhunderts (eigene Darstellung)

Abbildung 23: Christian Schanz, Plan der Stadt Linz, I 78 r (OÖLA Plansammlung, V/8)

Abbildung 24: Joseph Kenner u. Moritz von Schwind, Herrengasse, Zeichnung von I 824 (Nordico Stadtmuseum Linz, T i 4. I45; Reproduktion: Thomas Hackl)

Abbildung 25: Landhaus und Schloss, undatierter und unsignierter Druck (Nordico Stadtmuseum Linz, Gr 3.225 ; Reproduktion: Thomas Hackl)

Abbildung 26: "Promenade«, Plan von I 800 (OÖLA Karten- und Plänesammlung, VI/26)

Abbildung 27: Franz de Paula Haslinger, Tagebuch von I809 (Stiftsbibliothek St. Florian, Handschriftensammlung, XI $\left.{ }_{5} 65 \mathrm{~B}\right)$

Abbildung 28: Zeitungsanzeige, I 856 (Linzer Abendbote, I6.8.1 856)

Abbildung 29: Ansichtskarte, um I 900 (Privatbesitz)

Abbildung 30: Alfred Baumgartner, Faltpanorama von Linz, I 893 (Privatbesitz)

Abbildung 3 I: Zeitungsanzeige, I 855 (Linzer Abendbote, 20.8.1855)

Abbildung 32: Pfarrplatz während der Überschwemmung, Photographie von I 899 (Nordico Stadtmuseum Linz, NWT-o03708; Reproduktion: Thomas Hackl)

Abbildung 33: Thomas Dialer, Ansicht des brennenden Landhauses und der Schlosskaserne, Gemälde von 1800 (Nordico Stadtmuseum Linz, G r68; Reproduktion: Thomas Hackl)

\section{Währungen und Maßeinheiten}

\section{Geld}

Grundsätzliche Recheneinheit war im I 8. und I9. Jahrhundert der Gulden (fl), wobei bis I 858 I Gulden 6o Kreuzern (kr) oder 240 Pfennigen (pf/d) entsprach. Nach dem Staatsbankrott von I 8 I I galt zwischen I 8 I 2 und I 8 I 9 die "Wiener Währung " $(\mathrm{fl} / \mathrm{kr}$ WW), I 8 I 9 bis I 858 die »Conventionsmünze« (fl/kr CM), wobei $250 \mathrm{fl} \mathrm{WW}$ roo $\mathrm{fl}$ CM entsprachen. I 858 bis Ende I 899 galt die »Österreichische Währung « (fl ÖW, zu ıoo kr ÖW), ı 5 fl ÖW entsprachen dann ıoo fl CM. ${ }^{1}$

I Mühlpeck/Sandgruber/Woitek, Index, 673; die I 892 eingeführte Goldwährung (Kronen/Heller) tangiert den durch dieses Buch behandelten Zeitraum nicht mehr, da sie erst ab Jänner I 900 alleiniges Zahlungsmittel wurde. 


\section{Gewichte 2}

\begin{tabular}{ll}
\hline 1 Lot $=4$ Quentchen & 0,0175 Kilogramm \\
1 (Wiener) Pfund & 0,56 Kilogramm \\
1 Zentner $=100$ Pfund & 56 Kilogramm \\
1 Zollzentner & 50 Kilogramm \\
1 Meterzentner & 100 Kilogramm \\
\hline
\end{tabular}

Längen-, Flächen- und Hohlmaße $e^{3}$

\begin{tabular}{ll}
\hline bis ca. $1760: 1$ (Wiener) Klafter $=6$ Fuß/Schuh $=72$ Zoll & 1,872 Meter \\
danach: 1 Wiener Klafter = 6 Fuß/Schuh $=72$ Zoll & 1,896 Meter \\
bis ca. $1760: 1$ altes Niederösterreichisches Joch & 5.434 Quadratmeter \\
danach: 1 Niederösterreichisches Joch $=1.600$ Quadratklafter & $5.754,64$ Quadratmeter = 0,575 Hektar \\
1 Kubikklafter & 6,82 Kubikmeter \\
\hline
\end{tabular}

\section{Getreidemaße ${ }^{4}$}

vor 1756: 1 Niederösterreichischer Metzen

61 Liter

danach: 1 Niederösterreichischer Metzen

61,49 Liter

1 Mut $=30$ Metzen

\section{Brennholz}

Schwierig ist die Umrechnung der Brennholzmaße, denn es gab eine »oft willkürliche Verwendung gleicher Namen für recht verschiedene Größen«. ${ }^{5}$ Selten war offenbar der Kubikklafter, häufiger der »Wiener Waldklafter« mit einer Tiefe von 36 Zoll (= 3 Werkschuh $=93,6$ Zentimeter $), 30$ Zoll $\left(=2 \frac{1}{2}\right.$ Werkschuh $=78$ Zentimeter $)$ oder 24 Zoll (= 2 Werkschuh $=62,4$ Zentimeter $).{ }^{6}$ Bei 36-zölligem Holz würde sich pro Klafter ein Gewicht von I,8 Tonnen für Buche und I,2 Tonnen für Fichte ergeben. ${ }^{7}$

2 Sandgruber, Ökonomie, 585 ; Rottleuthner, Gewichte, I I u. I 7 .

3 Sandgruber, Ökonomie, 58 f f.; Rottleuthner, Gewichte, ${ }_{2} 5$ f., 30 u. 43 f.

4 Sandgruber, Ökonomie, 584 ; in meiner Umrechung wurden als Näherungswert 46 Kilogramm pro Metzen angenommen - vgl. Sandgruber, Ökonomie, 585; Donau in Oberösterreich, 3of.; LR CIIIG, Reg. 233 I $(783)$.

5 Mühlpeck/Sandgruber/Woitek, Index, 67 If.

6 AStL, Altakten, Sch. 42, Sch 52 u. Sch. Ior; OÖLA, Musealarchiv, Sch. 4/No. I8; LR BIIA 37 , Reg. I 9274 (I 28 - I 42); Luca, Landeskunde, Bd. 2, I I 3 ; Bohdanowicz, Urfahr, 224; Bohdanowicz, Vorstädte, Bd. I, 4I ; Bohdanowicz, Kleinmünchen, 454.

7 Sandgruber, Ökonomie, 585 ; Rottleuthner, Gewichte, 98 u. I03. 


\section{Hinweise zu den kartographischen Darstellungen}

Alle historischen Karten und Pläne wurden mit QGIS 3.ro georeferenziert und umgezeichnet, dabei wurden zahlreiche andere Quellen zur Beurteilung der Plausibilität einbezogen. ${ }^{8}$ In den Umzeichnungen (Vektorisierungen) sind Gebäude schwarz eingefärbt, Nutz- und Ziergärten sowie Parks hellgrün, Waldflächen dunkelgrün, Gewässer hellblau, Brücken braun (für um r 900 dunkelgrau) und Siedlungen außerhalb von Linz hellgrau. Davon Abweichendes resp. Zusätzliches wird im Folgenden oder in der jeweiligen Bildunterschrift angeführt.

\section{Darstellung der 1730 er Jahre (Abb. 2)}

Basis dieser Darstellung ist ein detailreicher, großformatiger Plan der Stadt und der Vorstädte, den vermutlich der landständische Ingenieur Franz Anton Knittel in der zweiten Hälfte der I 73oer Jahre anfertigte. ${ }^{9}$ Nutz- und Ziergärten sind in diesem Plan mit bemerkenswerter Akribie erfasst, zudem die beiden stadtnahen Waldstücke. Der Vergleich mit späteren Karten ${ }^{10}$ deutet auf eine weitgehend realitätsnahe Wiedergabe hin, wenngleich die Georeferenzierung einige Aufnahmefehler bzw. Vereinfachungen erkennen ließ, die - sofern vertretbar - korrigiert wurden. Auch die Gartenflächen wurden offenbar nicht durchgängig ausgewiesen und somit sollte man zumindest in dieser Hinsicht der Karte (und den Umzeichnungen) mit leichter Skepsis begegnen. Eine ähnliche Karte, bei der Knittel als Urheber genannt wird, zeigt die Belagerung im Winter I 74I/I 742 und wählt einen größeren Ausschnitt, enthält aber weniger Details. ${ }^{11}$ Diese Karte wurde für Ergänzungen in Randbereichen verwendet (links und rechts unten und für Urfahr), ebenso - da sie eine plausiblere Variante präsentiert - für die Umzeichnung von Donau und Donauinsel. Schwarz schraffiert dargestellt ist die Stadtbefestigung am Oberen und Unteren Graben, grau das temporäre Soldatenlager auf der Donauinsel.

\section{Darstellung der 1820 er Jahre (Abb. 1 u. 3)}

Basis dieser Darstellungen sind die im Rahmen des »Franziszeischen Katasters« zur Mitte der I 8 2oer Jahre entstandenen kartographischen Erfassungen der Katastralgemeinden, die die Nutzung der einzelnen Parzellen auswiesen. ${ }^{12}$ Als Bildhintergrund dient die Schummerung des Landes Oberösterreich, wobei zuvor kontemporäre Ele-

\footnotetext{
8 Vgl. dazu die prinzipiellen methodischen Überlegungen in Haidvogl et al., Wasser, 430-433.

9 OÖLA, Karten- und Plänesammlung, V/33; Grüll, Ingenieure u. Mayrhofer, Linz. ro Vgl. OÖLA, Karten- und Plänesammlung, V/8 und die Katasterkarten.

I I Österreichische Nationalbibliothek, Kartensammlung, FKB C.34.c.5.

I 2 Doris, Urmappe.
} 
mente (z.B. Brücken, Straßen und Uferverbauungen) geglättet wurden. ${ }^{13}$ Der angegebene Verlauf von Donau und Traun sollte aus der Perspektive des Katasters verstanden werden: Als »Fluss« wurde mitunter auch Land (z.B. Schotterbänke oder temporär überflutete Uferbereiche) bezeichnet, sehr wahrscheinlich sind zudem Vereinfachungen bei Mäandern und kleineren Seitenarmen, was teilweise an den Rändern der Einzelkarten zu sehen ist. In der Umzeichnung sind Stadt und Vorstädte (inkl. Urfahr) im Hinblick auf die Bebauung und Flächennutzung möglichst genau dargestellt worden, die Streubesiedlung der Vororte und die Ortschaften diesseits und jenseits der Donau wurden hingegen vereinfacht. Bachläufe im weiteren Umkreis wurden nur erfasst, sofern sie für Stadt und Vorstädte von Relevanz waren und sie dementsprechend im Text genannt werden. Im Gebiet zwischen Donau und Traun (also auf Linzer Seite) wurden Waldparzellen vollständig vektorisiert, jenseits der beiden Flüsse aber nur größere Flächen in den Auen, zwischen dem Pöstlingberg und Haselgraben (im Nordwesten), am Pfenningberg (nördlich von Steyregg) und am Schiltenberg (im Südosten bei Ebelsberg).

\section{Darstellung um 1900 (Abb. 4, 7 U. 22)}

Basis dieser Darstellungen ist ein Stadtplan des städtischen Bauamts aus dem Jahr I 898, ${ }^{14}$ der in Außenbereichen durch eine spätere Version dieses Plans aus dem Jahr I 926 ergänzt wurde, was vor allem Ortschaften und Bachläufe im Linzer Großraum betrifft. ${ }^{15}$ Bildhintergrund ist die modifizierte Schummerung des Landes Oberösterreich (vgl. oben). Der Verlauf der Donau und die Situierung der Wasserbauwerke (schwarze, gestrichelte Linie) basiert auf Planbeilagen einer zeitgenössischen Publikation. ${ }^{16}$ Die Traun und deren Nebenläufe wurden auf der Basis des Plans von 1926 vereinfacht dargestellt. Die Maximalausbreitung der Überschwemmung im September I 890 (dunkelblaue Punkte) ist einem zeitgenössischen Plan entnommen. ${ }^{17}$ Für die Umzeichnung der Stadt und Vorstädte gilt das Gleiche wie für die Darstellungen der I 82 oer Jahre, die Bebauung in Urfahr wurde einem Bauamtsplan aus dem Jahr I 9 Io entnommen. ${ }^{18}$ Der Bauamtsplan von I 898 enthält zwar eine Kennzeichnung von öffentlichen und privaten Parkanlagen, weist aber Garten- und Waldparzellen nicht aus. Es wurde versucht, die Gärten für Linz und Urfahr über einen Stadtplan aus dem Jahr r 903 zu ergänzen. ${ }^{19}$ Da diese Karte augenscheinlich vereinfacht, sind diese

I3 Land Oberösterreich, Abteilung Geoinformation und Liegenschaft (2013) - online unter: https://www. land-oberoesterreich.gv.at/I $22436 . h t m[2.10 .2020]$.

I4 Österreichische Nationalbibliothek, Kartensammlung, K III Ior 834.

I5 AStL, Plansammlung, LI- I926 I/D (online unter: »Open Data Österreich« - data.gv.at).

I6 Donau in Oberösterreich, Tafel V.

I7 AStL, Materienbestand, Sch. I82.

I 8 AStL, Plansammlung, LI-ı 9 Iо-ı I/D (online unter: „Open Data Österreich«-data.gv.at).

I9 OÖLA, Karten- und Plänesammlung, V/43. 
Umzeichnungen mit größerer Unsicherheit verbunden und sollten somit nicht direkt mit den für die I 82 oer Jahre ausgewiesenen Flächen verglichen werden. Ausgewählte Waldparzellen im Linzer Raum wurden (analog zu den I 82 oer Jahren) auf der Basis des Plans von I926 dargestellt. Eisenbahntrassen und wichtige Straßenverbindungen stammen aus den Plänen des Bauamts, zudem sind größere stadtnahe Gewerbebetriebe - z.B. Fabriken, Brauereien und die Schiffswerft - erfasst (schraffierte Flächen).

\section{Abkürzungen}

\begin{tabular}{|c|c|}
\hline Abb. & Abbildung \\
\hline AStL & Archiv der Stadt Linz \\
\hline Bd./Bde. & Band/Bände \\
\hline $\mathrm{CM}$ & „Conventionsmünze« (vg1. Maßeinheiten) \\
\hline Doku & $\begin{array}{l}\text { Dokumentation lebensgeschichtlicher Aufzeichnungen (vgl. Archiva- } \\
\text { lien) }\end{array}$ \\
\hline $\mathrm{EdN}$ & Enzyklopädie der Neuzeit \\
\hline $\mathrm{f} / \mathrm{fl}$ & florenus, Gulden (vgl. Maßeinheiten) \\
\hline fol. & folio, Blatt (gegebenenfalls: $\mathrm{a}=$ recto, Vorderseite, $\mathrm{b}=$ verso, Rückseite) \\
\hline gr. & Groschen ( 1 Groschen $=3$ Kreuzer $=$ I 2 Pfennig) \\
\hline GRP & Gemeinderatsprotokolle der Stadt Linz (AStL - vgl. Archivalien) \\
\hline HistJbL & Historisches Jahrbuch der Stadt Linz \\
\hline HS & Handschrift(en) \\
\hline $\mathrm{HTb}$ & Stiftsbibliothek St. Florian, Handschriftensammlung, XI ${ }_{56}{ }_{5} \mathrm{~B}$ \\
\hline i.e. & id est, das ist, das heißt \\
\hline $\mathrm{JbL}$ & Jahrbuch der Stadt Linz \\
\hline Konskr.-No. & Konskriptionsnummer (Häusernummerierung) \\
\hline $\mathrm{kr} / \mathrm{cr} / \mathrm{xr}$ & Kreuzer (vgl. Maßeinheiten) \\
\hline LAB & Linzer Abendbote: Zeitschrift für Stadt und Land (vgl. Periodika) \\
\hline LGB1. & Landesgesetzblätter für Oberösterreich (nach dem Muster No./Jahr) \\
\hline LR & Linzer Regesten (vg1. Gedruckte Quellen und Literatur) \\
\hline LTP & [Linzer] Tages-Post (vgl. Periodika) \\
\hline LVB & Linzer Volksblatt für Stadt und Land (vgl. Periodika) \\
\hline $\mathrm{LZ}$ & Linzer Zeitung (vgl. Periodika) \\
\hline $\mathrm{LZ} / \mathrm{AB}$ & Amtsblatt der Linzer Zeitung (vgl. Periodika) \\
\hline $\mathrm{LZ} / \mathrm{IB}$ & Intelligenzblatt der Linzer Zeitung (vgl. Periodika) \\
\hline No. & Nummer(n) \\
\hline ÖB & Österreichisches Bürgerblatt [...] (vgl. Periodika) \\
\hline OÖLA & Oberösterreichisches Landesarchiv \\
\hline ÖW & »Österreichische Währung« (vgl. Maßeinheiten) \\
\hline pag. & pagina, Seite (bei Handschriften) \\
\hline
\end{tabular}


pf

$\mathrm{RB}$

Reg.

s.a.

Sch.

s.1.

s.v.

Stifter, HKG
Pfennig (vgl. Maßeinheiten)

Rechenschaftsbericht des Gemeinderathes der Landeshauptstadt

Linz

Regest (vgl. LR/Linzer Regesten)

ohne Jahresangabe

Schachtel

ohne Ortsangabe

sub voce, unter dem Begriff (vgl. EdN)

Stifter, PRA Adalbert Stifters sämtliche Werke

Tab.

Tabelle

WW

»Wiener Währung« (vgl. Maßeinheiten)

undat.

undatiert

unpag.

unpaginiert 
Publikation im Sinne der CC-Lizenz BY 4.0 


\section{DIE MITTELSTADT IM FOKUS VON WISSENSCHAFT, GESELLSCHAFT UND POLITIK}

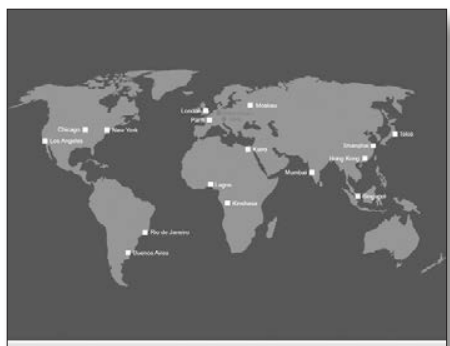

Aushandlungen städtischer Größe

Mittelstadt leben, erzählen, vermarkten

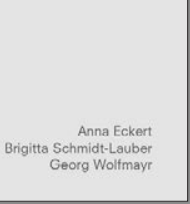

Anna Eckert | Brigitta SchmidtLauber | Georg Wolfmayr Aushandlungen städtischer Größe

Mittelstadt leben, erzählen, vermarkten

Ethnographie des Alltags, Band 6

2020. 271 Seiten, gebunden

$€ 45,00 \mathrm{D} \mid € 47,00 \mathrm{~A}$

ISBN 978-3-205-23202-5

E-Book $€ 37,99 \mathrm{D} \mid € 39,10 \mathrm{~A}$

Wissenschaftlich wie gesellschaftlich hat das Thema Stadt anhaltend Konjunktur. Bei genauerem Blick sind es allerdings fast ausschließlich Großstädte bzw. Metropolen der nördlichen Hemisphäre, die im Fokus von Wissenschaft, Gesellschaft und Politik stehen und als paradigmatische Beispiele urbanen Lebens fungieren. Kleinere Städte kommen demgegenüber weniger und schon gar nicht als Beispiele für Urbanität in den Sinn. Der vorliegende Band korrigiert diese Schieflage und bietet als Ergebnis eines ethnographischen Forschungsprojektes umfassende Einblicke in Aushandlungen städtischer Größe - exemplarisch am Beispiel der Städte Hildesheim in Niedersachsen und Wels in Oberösterreich.

Vandenhoeck \& Ruprecht Verlage 


\section{UMWELT UND GESELLSCHAFT}

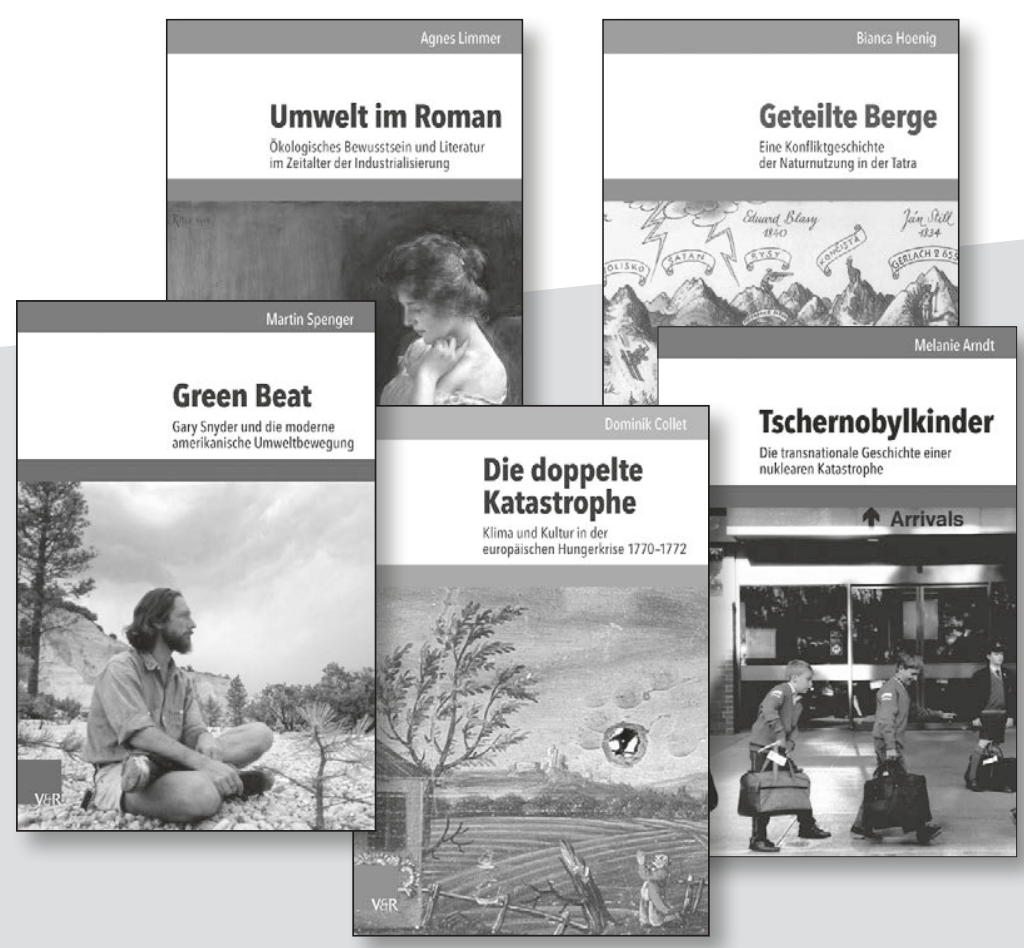

Mehr Infos zu allen Bänden: vdn.hk/umwelt-gesellschaft

"Umwelt und Gesellschaft" ist die deutschsprachige Buchreihe des Rachel Carson Centers in München. Sie wird von Christof Mauch und Helmuth Trischler herausgegeben und versammelt herausragende Beiträge zum Verhältnis von Umwelt und Gesellschaft in der Geschichte. Sie umfasst insbesondere Monographien, steht jedoch auch für ambitionierte Aufsatzsammlungen offen.

V\&R Vandenhoeck \& Ruprecht Verlage

www.vandenhoeck-ruprecht-verlage.com 